DOC.20041109.0006

QA: QA

ANL-WIS-MD-000010 REV 03

November 2004

\title{
Dissolved Concentration Limits of Radioactive Elements
}

Prepared for:

U.S. Department of Energy

Office of Civilian Radioactive Waste Management

Office of Repository Development

1551 Hillshire Drive

Las Vegas, Nevada 89134-6321

Prepared by:

Bechtel SAIC Company, LLC

1180 Town Center Drive

Las Vegas, Nevada 89144

Under Contract Number

DE-AC28-01RW12101 


\section{DISCLAIMER}

This report was prepared as an account of work sponsored by an agency of the United States Government. Neither the United States Government nor any agency thereof, nor any of their employees, nor any of their contractors, subcontractors or their employees, makes any warranty, express or implied, or assumes any legal liability or responsibility for the accuracy, completeness, or any third party's use or the results of such use of any information, apparatus, product, or process disclosed, or represents that its use would not infringe privately owned rights. Reference herein to any specific commercial product, process, or service by trade name, trademark, manufacturer, or otherwise, does not necessarily constitute or imply its endorsement, recommendation, or favoring by the United States Government or any agency thereof or its contractors or subcontractors. The views and opinions of authors expressed herein do not necessarily state or reflect those of the United States Government or any agency thereof. 
QA: QA

Dissolved Concentration Limits of Radioactive Elements

ANL-WIS-MD-000010 REV 03

November 2004 


\begin{tabular}{|l|l|l|}
\hline \multirow{2}{*}{ OCRWM } & MOdel Signature Page/Change History & Page iii \\
\cline { 3 - 3 } & & 1. Total Pages: 242 \\
\hline
\end{tabular}

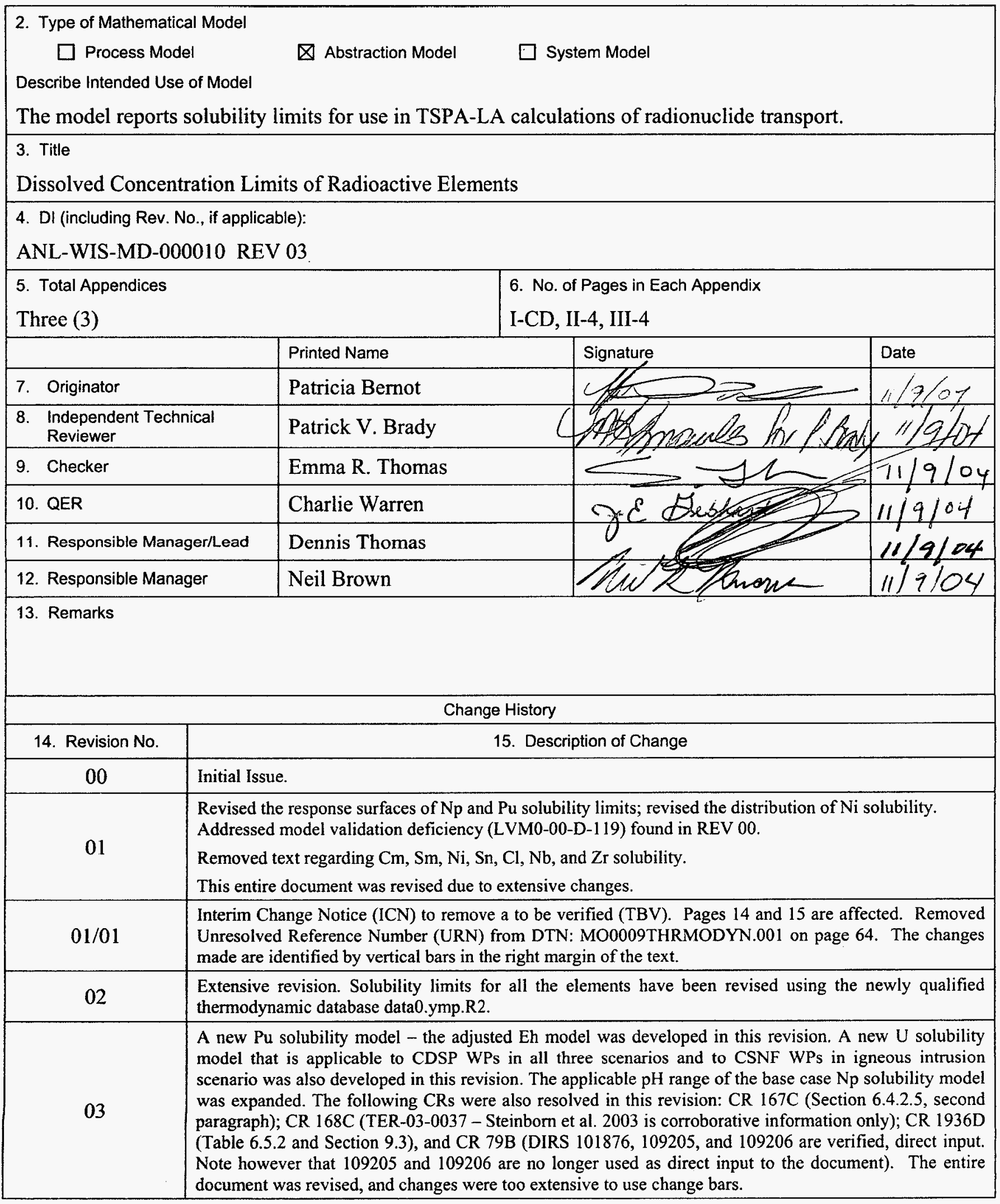


This model report was developed through the contributions of the following individuals, listed in alphabetical order:

- Steve Alcorn, ISSI. Contributing author to the final REV03.

- Patricia Bernot, BSC. Lead author on REV 03 starting from REV03C. Major contributor to final REV03 and responsible for incorporation of Regulatory Integration Team comments and items in the RIT Action Item Database.

- Patrick Brady, Sandia National Laboratories. Contributing author to prior revision of this report (Rev 02).

- Yueting Chen, BSC. Lead author of prior revision of this report (REV 02) and REV03 up to REV03B and major contributor to the final REV03.

- Paul Cloke, IDT. Contributing author of prior revision of this report (REV 02).

- Bill Downs, Frankie Friend and Associates Inc. Contributing author to the final REV03.

- Susan LeStrange, BSC. Contributing author to the final REV03.

- F. Joe Pearson, IDT. Major contributing author of prior revision of this report (REV 02) and major contributor to the final REV03 and responsible for incorporation of Regulatory Integration Team comments and items in the RIT Action Item Database.

- Terry Steinborn, IDT. Contributing author of prior revision of this report (REV 02).

- Emma Thomas, BSC. Major contributing author of prior revision of this report (REV 02). 


\section{EXECUTIVE SUMMARY}

The purpose of this study is to evaluate dissolved concentration limits (also referred to as solubility limits) of elements with radioactive isotopes under probable repository conditions, based on geochemical modeling calculations using geochemical modeling tools, thermodynamic databases, field measurements, and laboratory experiments. The scope of this modeling activity is to predict dissolved concentrations or solubility limits for 14 elements with radioactive isotopes (actinium, americium, carbon, cesium, iodine, lead, neptunium, plutonium, protactinium, radium, strontium, technetium, thorium, and uranium) important to calculated dose. Model outputs for uranium, plutonium, neptunium, thorium, americium, and protactinium are in the form of tabulated functions with $\mathrm{pH}$ and $\log f \mathrm{CO}_{2}$ as independent variables, plus one or more uncertainty terms. The solubility limits for the remaining elements are either in the form of distributions or single values. The output data from this report are fundamental inputs for Total System Performance Assessment for the License Application (TSPA-LA) to determine the estimated release of these elements from waste packages and the engineered barrier system.

Consistent modeling approaches and environmental conditions were used to develop solubility models for all of the actinides. These models cover broad ranges of environmental conditions so that they are applicable to both waste packages and the invert. Uncertainties from thermodynamic data, water chemistry, temperature variation, and activity coefficients have been quantified or otherwise addressed. 
INTENTIONALLY LEFT BLANK 


\section{CONTENTS}

Page

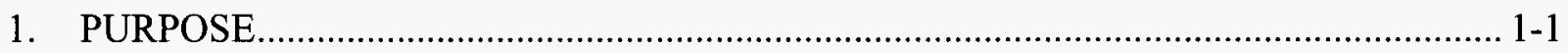

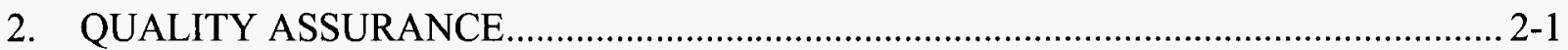

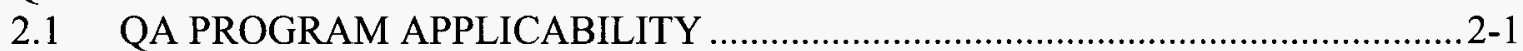

2.2 ELECTRONIC MANAGEMENT OF DATA ................................................... $2-1$

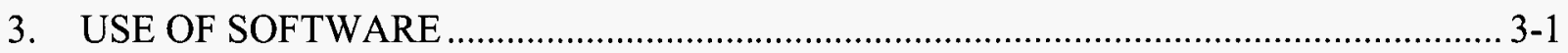

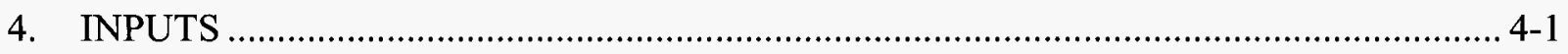

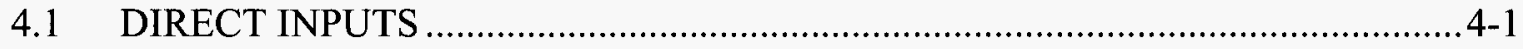

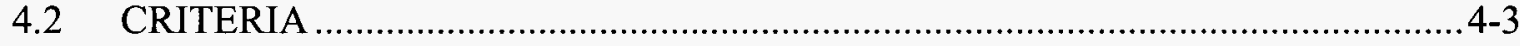

4.3 CODES, STANDARDS, AND REGULATIONS .............................................. $4-4$

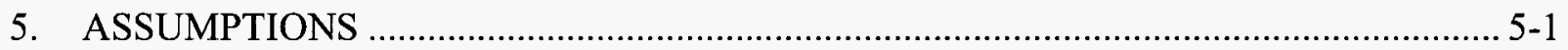

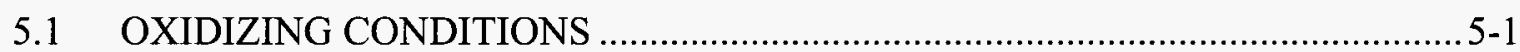

5.2 INVENTORY VALUES ……................................................................. $5-1$

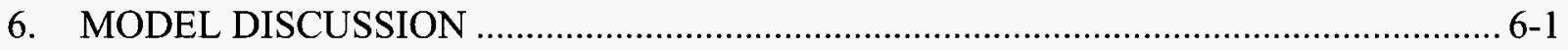

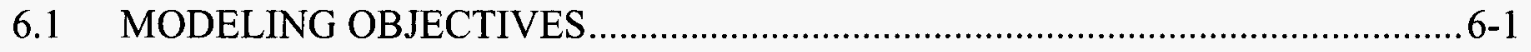

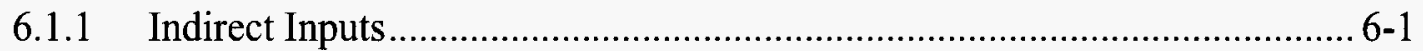

6.2 FEATURES, EVENTS, AND PROCESSES INCLUDED IN MODEL ................6-4

6.3 TECHNICAL ISSUES IN SOLUBILITY EVALUATION .................................. $6-4$

6.3.1 The Definition of Solubility ..................................................................... 6-4

6.3.2 Identification of the Controlling Solid................................................... 6-5

6.3.3 Treatment of Variation and Uncertainty.............................................. 6-8

6.4 CHEMICAL CONDITIONS FOR SOLUBILITY CALCULATIONS ….............6-24

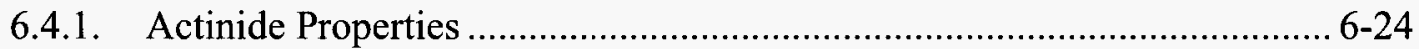

6.4.2 Site-Specific Chemical Conditions.................................................... 6-25

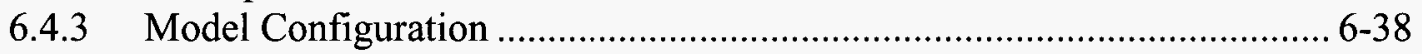

6.4.4 Valid Ranges of Solubility Models .................................................. 6-42

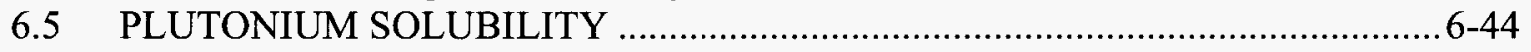

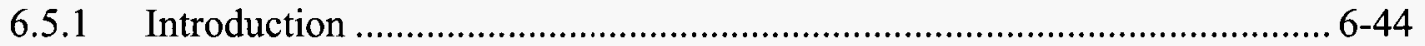

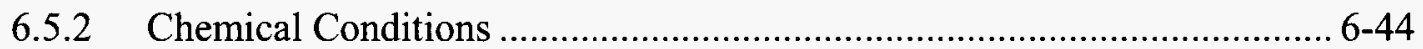

6.5.3 The Adjusted-Eh Pu-Solubility Model (Base-Case Pu-Solubility Model). 6-44

6.5.4 Logic Basis for Eh-Adjusted Pu-Solubility Model................................... 6-57

6.5.5 Effect of Mineral Aging on the Model ............................................... 6-68

6.5.6 Relationship of $\mathrm{PuO}_{2+\mathrm{x}}$ to Plutonium Solubility ................................... 6-69

6.5.7 Effects of Small Eh Change on Other Elements.................................... 6-72

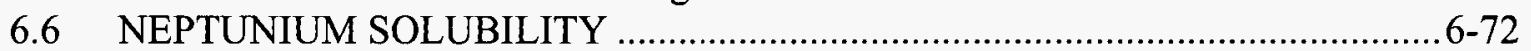

6.6.1 Conceptual Models ....................................................................... 6-72

6.6.2 Chemical Conditions ..................................................................... 6-73

6.6.3 Base-Case Neptunium Solubility Model: $\mathrm{Np}_{2} \mathrm{O}_{5}-\mathrm{NaNpO}_{2} \mathrm{CO}_{3}$ Model ..... 6-73

6.6.4 Alternative Neptunium Solubility Model I: $\mathrm{NpO}_{2}$ Model ...................... 6-84 


\section{CONTENTS (Continued)}

6.6.5 Alternative Neptunium Solubility Models II: Secondary Phase Model .... 6-90

6.7 URANIUM SOLUBILITY. 6-101

6.7.1 Introduction 6-101

6.7.2 Factors Considered in Selecting Controlling Solids............................ 6-102

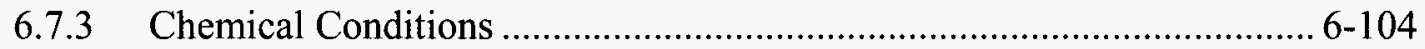

6.7.4 Results: Speciation and Solubility .................................................. 6-106

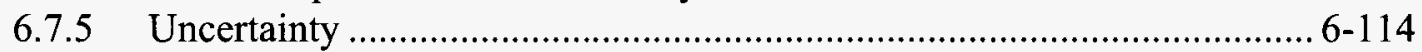

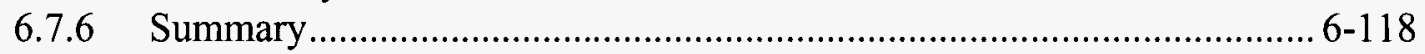

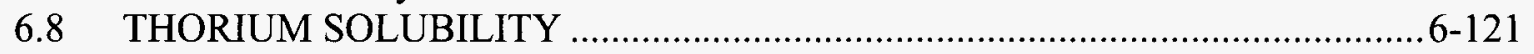

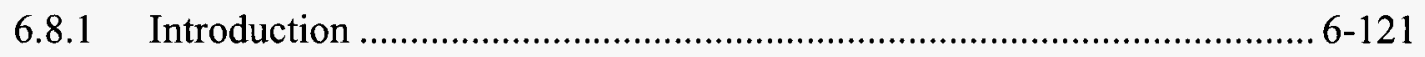

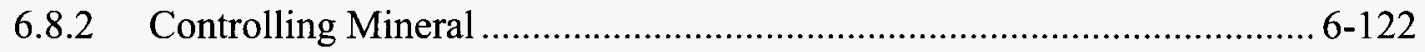

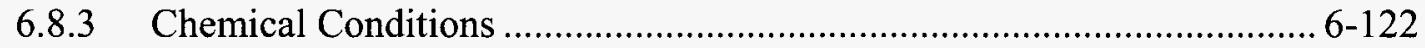

6.8.4 Thorium Solubility Model Results ..................................................... 6-122

6.8.5 Alternative Uncertainty Terms ......................................................... 6-131

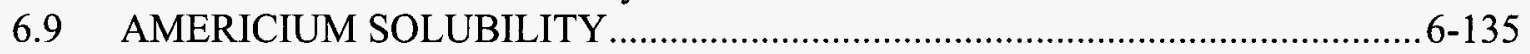

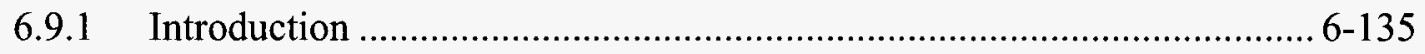

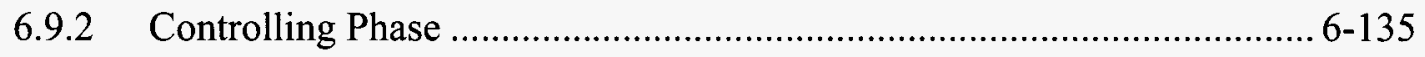

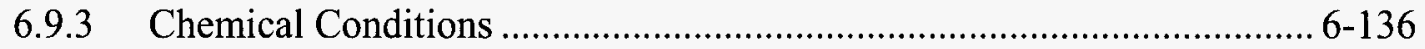

6.9.4 Americium Solubility Model Results ..................................................... 6-136

6.9.5 Alternative Conceptual Model.......................................................... 6-143

6.9.6 Alternative Uncertainty Terms ................................................... 6-143

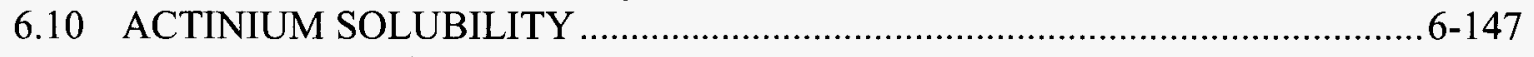

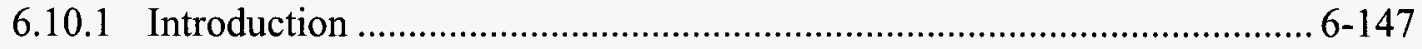

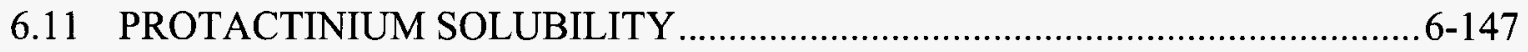

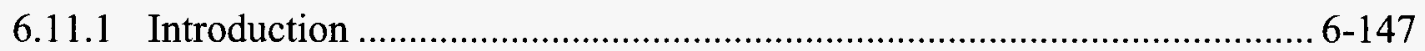

6.11.2 Solubility Development ............................................................... 6-149

6.11.3 Chemical Conditions ................................................................ 6-149

6.11.4 Protactinium Solubility Model ................................................ 6-149

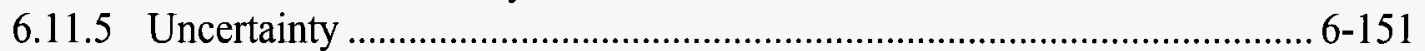

6.11.6 Alternative Protactinium Solubility Model ........................................... 6-153

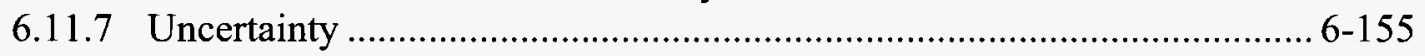

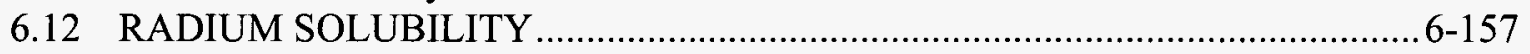

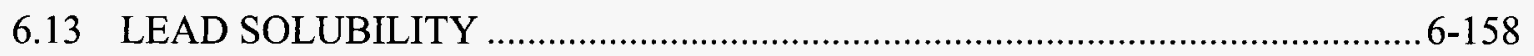

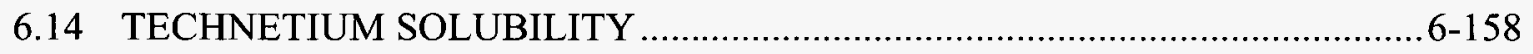

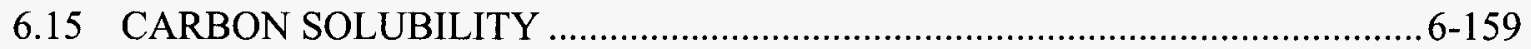

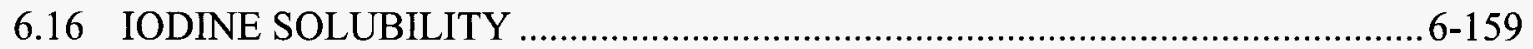

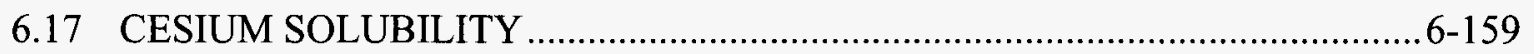

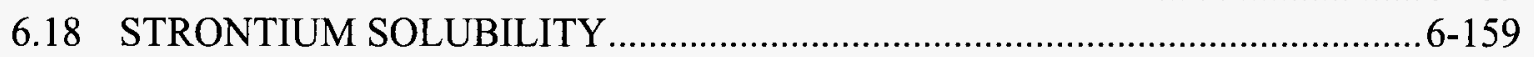

6.19 CONSIDERATION OF ALTERNATIVE CONCEPTUAL MODELS ..............6-159

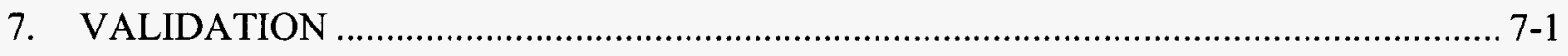

7.1 CONFIDENCE BUILDING DURING MODEL DEVELOPMENT TO ESTABLISH SCIENTIFIC BASIS AND ACCURACY FOR INTENDED USE ......................... $7-1$ 


\section{CONTENTS (Continued)}

Page

7.2 CONFIDENCE-BUILDING AFTER MODEL DEVELOPMENT TO SUPPORT THE SCIENTIFIC BASIS OF THE MODEL

7.2.1 $\mathrm{Pu}$ and $\mathrm{Np}$ Independent Technical Review.

7.2.2 Validation of the Adjusted-Eh Pu-Solubility Model .................................... 7-5

7.2.3 Validation of $\mathrm{Np}_{2} \mathrm{O}_{5}-\mathrm{NaNpO}_{2} \mathrm{CO}_{3}$ Solubility Model................................ 7-7

7.2.4 Validation of Uranium Solubility Model............................................... 7-8

7.2.5 Validation of Thorium Solubility Model...................................................... 7-9

7.2.6 Validation of Americium Solubility Model................................................ 7-10

7.2.7 Validation of Actinium Solubility Model............................................... 7-10

7.2.8 Validation of Protactinium Solubility Model ......................................... 7-10

7.2.9 Validation of Radium Solubility Model .................................................. 7-11

7.2.10 Validation of Lead Solubility Model....................................................... 7-11

7.2.11 Validation of Technetium, Carbon, Iodine, Cesium, and Strontium Solubility Models ...................................................................................... 7-11

7.3 VALIDATION SUMMARY …................................................................ $7-11$

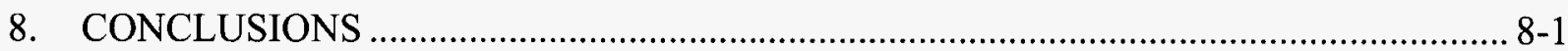

8.1 MODEL OUTPUT ................................................................................ $8-1$

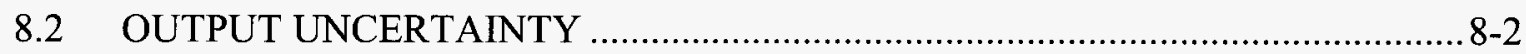

8.3 YUCCA MOUNTAIN REVIEW PLAN ACCEPTANCE CRITERIA ....................8-7

8.4 RESTRICTIONS .............................................................................................. $8-12$

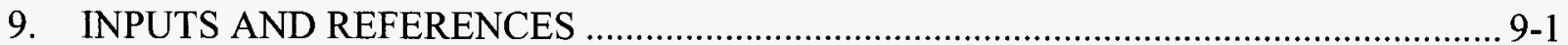

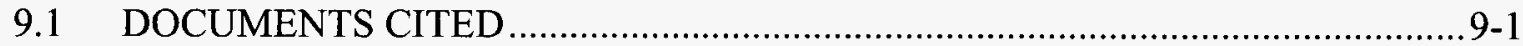

9.2 CODES, STANDARDS, REGULATIONS, AND PROCEDURES ...................... 9-10

9.3 SOURCE AND CORROBORATIVE DATA, LISTED BY DATA TRACKING

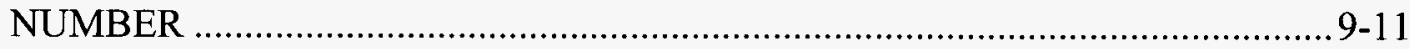

9.4 OUTPUT DATA, LISTED BY DATA TRACKING NUMBER ....................... $9-12$

9.5 SOFTWARE CODES .....................................................................................

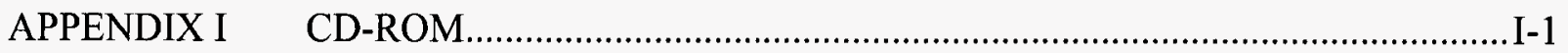

APPENDIX II $\quad$ LIST OF COMPUTER FILES......................................................... II-1

APPENDIX III EVALUATION OF DISSOLVED CONCENTRATION LIMITS OF NEPTUNIUM AND PLUTUTONIUM ............................................. III 1 
INTENTIONALLY LEFT BLANK 


\section{FIGURES}

Page

6.3-1. Total Uranium Concentration and Speciation Diagram in moles $\mathrm{U} / \mathrm{kg} \mathrm{H}_{2} \mathrm{O}$ Calculated at $f \mathrm{CO}_{2}=10^{-3.0}$ bars

6.3-2. Uranium Speciation Diagram in Percent Total Uranium Calculated at $f \mathrm{CO}_{2}=$ $10^{-3.0}$ bars

6.3-3. Comparison of Activity Coefficients of Anions Calculated from Mean Salt (MS)

Data and the B-dot and Truesdell-Jones (T-J) Equations ...

6.3-4. Comparison of Activity Coefficients of Cations Calculated from Mean Salt (MS)

Data and the B-dot and Truesdell-Jones (T-J) Equations ..................................... 6-23

6.4-1. Sensitivity to Variation in the Total Concentration of the Base-Case Water ............ 6-29

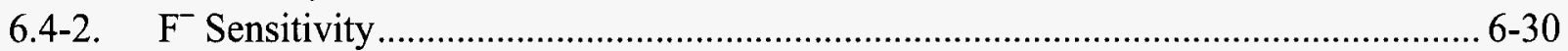

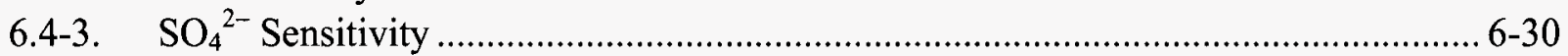

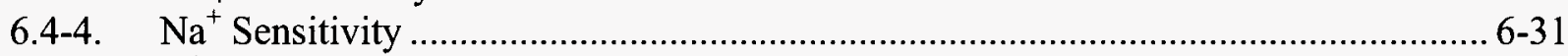

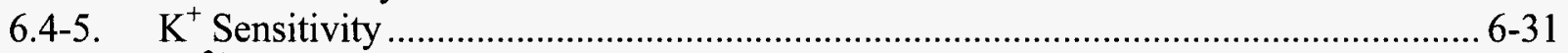

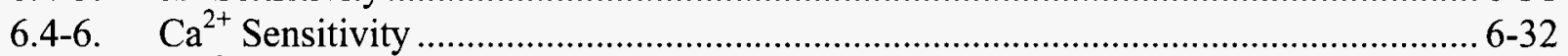

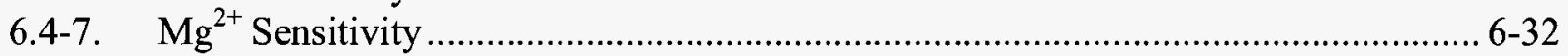

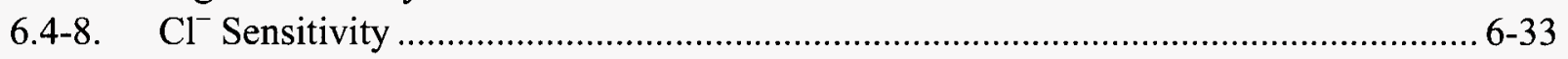

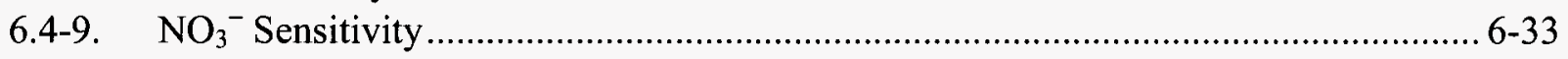

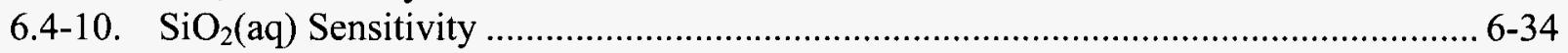

6.4-11. Effect of $\left(\mathrm{UO}_{2}\right)_{3}\left(\mathrm{PO}_{4}\right)_{2} \cdot 4 \mathrm{H}_{2} \mathrm{O}$ Saturation on Uranium Solubility ............................ 6-34

6.4-12. Total $\mathrm{Th}$ Concentration and Speciation Diagram at $\log f \mathrm{CO}_{2}$ (bars) $=-3.0$ in

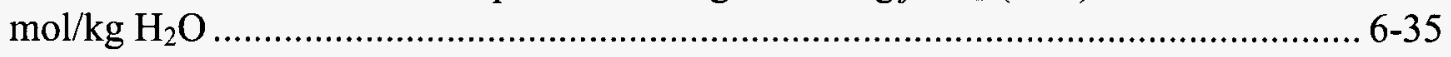

6.4-13. Th Speciation Diagram at $\log f \mathrm{CO}_{2}$ (bars) $=-3.0$ in Percent Total Dissolved Th ..... 6-36

6.4-14. Total $\mathrm{Pu}$ Concentration and Speciation Diagram at $\log f \mathrm{CO}_{2}$ (bars) $=-3.0$ in

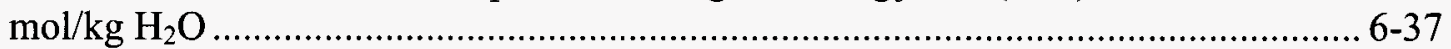

6.4-15. Pu Speciation Diagram at $\log f \mathrm{CO}_{2}$ (bars) $=-3.0$ in Percent Total Pu.................... 6-37

6.5-1. Dual Equilibrium Among Dissolved $\mathrm{Pu}, \mathrm{Pu}$ Precipitates, and Pu Colloids ............... 6-46

6.5-2. Molal Concentrations of Total $\mathrm{Pu}$ and $\mathrm{Pu}$ Aqueous Complex Species in at

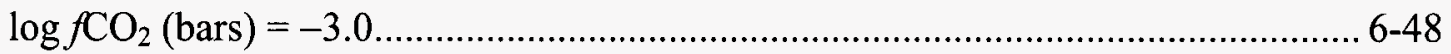

6.5-3. Relative Concentrations of Pu Aqueous Complex Species as Percent of Total

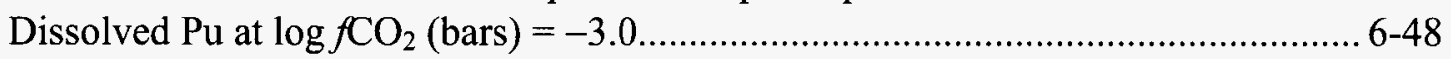

6.5-4. Molal Concentrations of Total $\mathrm{Pu}$ and $\mathrm{Pu}$ Aqueous Complex Species in at $\log f \mathrm{CO}_{2}$ (bars) $=-5.0$

6.5-5. Relative Concentrations of Pu Aqueous Complex Species as Percent of Total

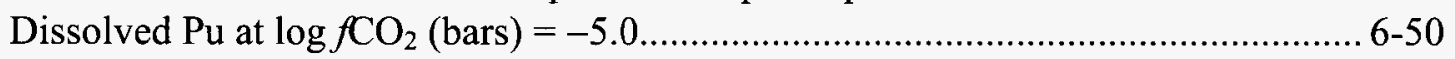

6.5-6. Comparison of Experimental Data with the Predictions of Plutonium-Solubility Model

6.5-7. $\mathrm{PuO}_{2}$ (hyd,aged) Solubility Modeled With the Theoretical $f \mathrm{O}_{2}$ as a Function of $\mathrm{pH}$

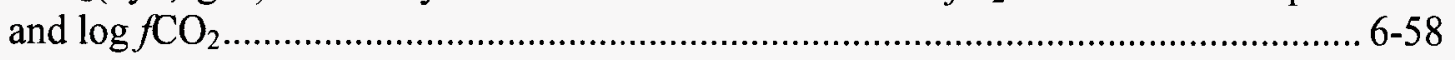

6.5-8. Comparison of the Theoretical $f \mathrm{CO}_{2}, \mathrm{PuO}_{2}$ (hyd,aged) Model with Pu Solubility Measurements

6.5-9. Pu-Oxidation States Distribution in Pu-Solubility Experiments .............................. 6-60

6.5-10. Pu-Oxidation States Distribution in Pu-Solubility Experiments .............................. 6-61 


\section{FIGURES (Continued)}

6.5-11. Pu Oxidation States Distribution Given by the Simple $\mathrm{PuO}_{2}$ (hyd,aged) Model ........ 6-61

6.5-12. Eh-pH Measurements at Yucca Mountain ............................................................ 6-63

6.5-13. Pu Oxidation States Distribution Given by the Eh Model ...................................... 6-65

6.5-14. Pu Solubility Given by the Eh model ................................................................ 6-66

6.5-15. Measured Eh in Rai 1984 Experiments and the Empirical-Eh Relation Given by Baas Becking et al. 1960 [DIRS 168371] .......................................................... 6-67

6.5-16. Modeled Results with Eh-Adjusted $(E h=1.10-0.0592 \mathrm{pH})$ and Experimental Results.

6.5-17. Comparison of Solubilities Between Crystalline $\mathrm{PuO}_{2}$ (c) and $\mathrm{PuO}_{2}$ (hyd,aged)........ 6-69

6.6-1. $\mathrm{Np}_{2} \mathrm{O}_{5}$ Solubility Modeled as a Function of $\mathrm{pH}$ and $\log f \mathrm{CO}_{2} \ldots \ldots \ldots \ldots \ldots \ldots \ldots \ldots \ldots \ldots \ldots \ldots . . . . .6-76$

6.6-2. Molal Concentrations of Total $\mathrm{Np}$ and of $\mathrm{Np}$ Aqueous Complex Species in at $\log f \mathrm{CO}_{2}$ (bars) $=-3.0$

6.6-3. Relative Concentrations of $\mathrm{Np}$ Aqueous Complex Species as Percent of Total Dissolved $\mathrm{Np}$ at $\log f \mathrm{CO}_{2}$ (bars) $=-3.0$

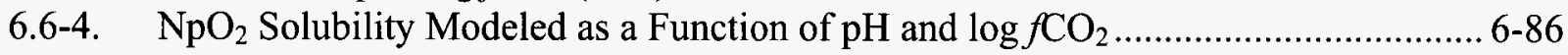

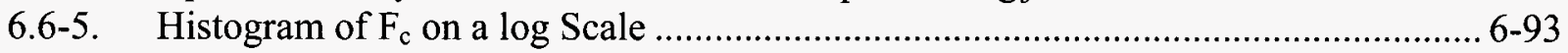

6.6-6. $\quad F_{c}$ Values of Neptunium in the ANL High-Drip Tests as a Function of Time ........... 6-96

6.6-7. $\quad F_{c}$ Values of Neptunium in the ANL Low-Drip Tests as a Function of Time ............ 6-97

6.6-8. Comparison of Secondary Phase Neptunium Solubility Model (Without Inventory Adjustment) with PNNL and ANL Measurements and Calculated $\mathrm{Np}_{2} \mathrm{O}_{5}$

Solubility.

6.7-1. Uranium Solubility in CSNF Packages Breached Under Nominal and Seismic Scenarios Modeled as a Function of $\mathrm{pH}$ and $f \mathrm{CO}_{2}$

6.7-2. Uranium Solubility in CSNF Packages Breached by a Hypothetical Igneous Event, Codisposal Packages Under any Breach Scenario and Waters in the Invert Modeled as a Function of $\mathrm{pH}$ and $f \mathrm{CO}_{2}$

6.7-3. Total Uranium Concentration and Speciation Diagram in mol U/ $/ \mathrm{kg} \mathrm{H}_{2} \mathrm{O}$ Calculated at $f \mathrm{CO}_{2}=10^{-3.0}$ bars

6.7-4. Uranium Speciation Diagram in Percent Total Uranium Calculated at $f \mathrm{CO}_{2}=$ $10^{-3.0}$ bars

6.7-5. Effect of Fluoride on Solubilities of Schoepite and Na-Boltwoodite at $\log f \mathrm{CO}_{2}=$ -3.0 bars

6.8-1. $\quad \mathrm{ThO}_{2}(\mathrm{am})$ Solubility Modeled as a Function of $f \mathrm{CO}_{2}$ and $\mathrm{pH}$............................... 6-126

6.8-2. Total Th Concentration and Speciation Diagram at $\log f \mathrm{CO}_{2}$ (bars) $=-3.0$ in $\mathrm{mol} / \mathrm{kg} \mathrm{H} \mathrm{H}_{2} \mathrm{O}$

6.8-3. Th-Speciation Diagram at $\log f \mathrm{CO}_{2}$ (bars) $=-3.0$ in Percent Total Dissolved Th ... 6-127

6.8-4. $\mathrm{ThO}_{2}$ (am) Solubility at $\log f \mathrm{CO}_{2}=-3.0$ bars as a Function of $\mathrm{pH}$ and $\mathrm{F}^{-}$ Concentrations

6.8-5. $\mathrm{ThO}_{2}(\mathrm{am})$ Solubility at $\log f \mathrm{CO}_{2}=-3.0$ bars as a Function of $\mathrm{pH}$ and $\mathrm{F}^{-}$ Concentrations

6.9-1. Total Am Concentration and Speciation Diagram in mol Am/ $\mathrm{kg} \mathrm{H}_{2} \mathrm{O}$ at $\log f \mathrm{CO}_{2}$ (bars) $=-3.0$. 


\section{FIGURES (Continued)}

6.9-2. Am Speciation Diagram in Percent Total Am at $\log f \mathrm{CO}_{2}$ (bars) $=-3.0$

6.9-3. AmOHCO $\mathrm{Al}_{3}$ Solubility Modeled as a Function of $f \mathrm{CO}_{2}$ and $\mathrm{pH}$.

6.9-4. Sensitivity of Americium Solubility at $\log f \mathrm{CO}_{2}=-3.0$ bars to Variations of Fluoride Concentrations.

6.9-5. Sensitivity of Americium Solubility at $\log f \mathrm{CO}_{2}=-3.0$ bars to Variations of Alternative Fluoride Concentrations

6.11-1. Correlation Between $\mathrm{z}^{2} / \mathrm{r}$ and $\log \mathrm{K}\left(25^{\circ} \mathrm{C}\right)$ for the Formation of the Monohydroxyl Complex of Selected Ions

6.11-2. Differences Between $\mathrm{Np}_{2} \mathrm{O}_{5}$ and $\mathrm{ThO}_{2}(\mathrm{am})$ Solubilities $(\log \mathrm{mg} / \mathrm{L})$ as Functions of $\mathrm{pH}$ and $f \mathrm{CO}_{2}$

6.11-3. Differences Between $\mathrm{Np}_{2} \mathrm{O}_{5}$ and $\mathrm{ThO}_{2}(\mathrm{am})$ Solubilities $(\log \mathrm{mg} / \mathrm{L})$ as Functions of $\mathrm{pH}$ and $f \mathrm{CO}_{2}$

7-1. Comparison of Experimental Data with the Predictions of Plutonium Solubility Model. $7-6$

7-2. Comparison of $\mathrm{Np}_{2} \mathrm{O}_{5}$ Neptunium Solubility Model with PNNL and ANL Measurements 
INTENTIONALLY LEFT BLANK 


\section{TABLES}

Page

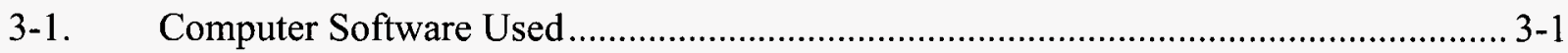

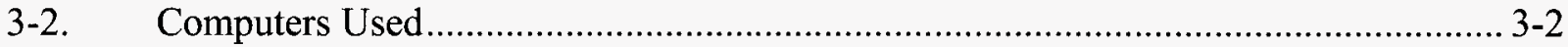

4-1. Direct Inputs for Solubility Models ................................................................ 4-2

4-2. Chemical Composition of Reference Water (J-13 Well Water) ................................ 4-3

4-3. Applicable Project Requirements Criteria ............................................................ 4-4

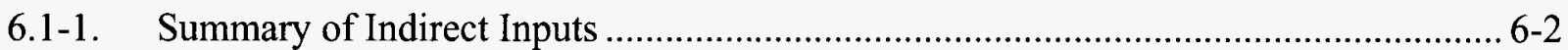

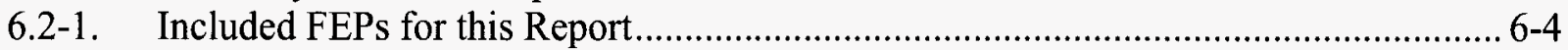

6.3-1. Solid Phases of Four-Valent Actinides Included in Project Thermodynamic

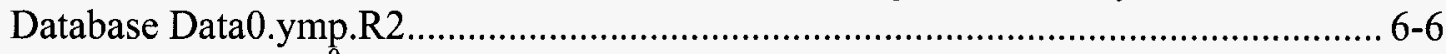

6.3-2. Comparison of $\Delta_{\mathrm{f}} \mathrm{G}^{0}$ Values for Aqueous Major Species .................................... 6-10

6.3-3. Fluoride Concentrations from In-Package Chemistry Abstraction Report used

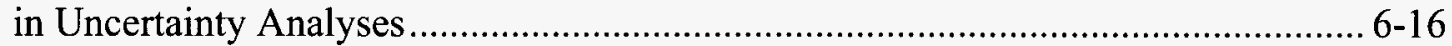

6.3-4. Differences in Solubility of Solids Modeled at $25^{\circ} \mathrm{C}$ and $100^{\circ} \mathrm{C}$.......................... 6-17

6.3-5. Comparison of Ion Activity Coefficients Based on Mean Salt Data and Calculated from the B-dot Equation .................................................................................. 6-22

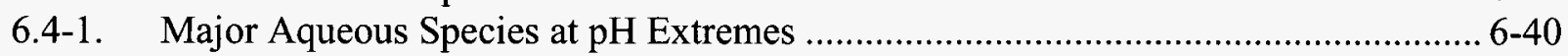

6.4-2. Summary of EQ3NR Model Configuration ................................................... 6-42

6.5-1. Calculated Pu Solubility (the Adjusted-Eh Model) $(\log [\mathrm{Pu}] \mathrm{mg} / \mathrm{L}) \ldots \ldots \ldots \ldots \ldots \ldots \ldots . . . . . . . . .6-47$

6.5-2. Pore Size of Filters Used in Experiments .......................................................... 6-52

6.5-3. The Effect of Variations in Fluoride Concentration on Plutonium Solubility ........... 6-54

6.5-4. The Multiplication Factor, $(\mathrm{N})$, used to modify $\mathrm{F}^{-}$Uncertainty Terms for

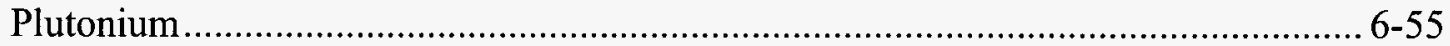

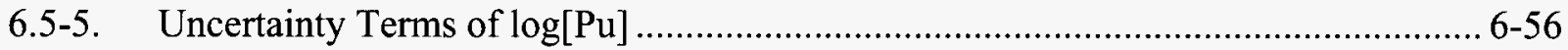

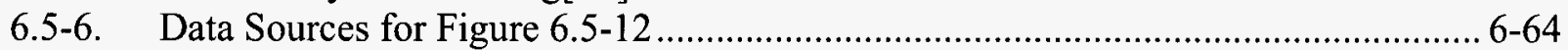

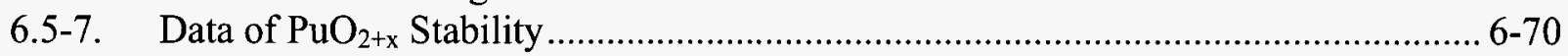

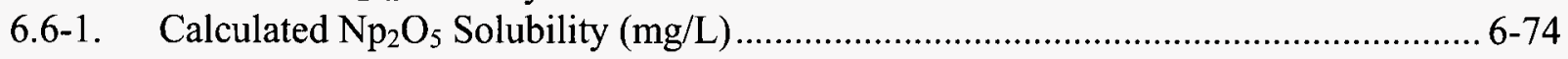

6.6-2. Calculated $\mathrm{Np}$ Solubility Using $\mathrm{NaNpO}_{2} \mathrm{CO}_{3} \cdot$ as the Controlling Phase ([Np]

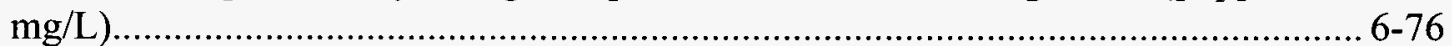

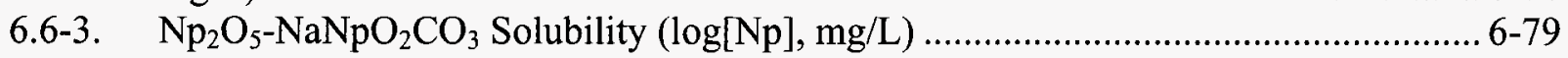

6.6-4. The Effects of Variations in Fluoride Concentration on Np Solubility .................... 6-81

6.6-5. Uncertainty Terms of $\log [\mathrm{Np}]$ of $\mathrm{Np}_{2} \mathrm{O}_{5} / \mathrm{NaNpO}_{2} \mathrm{CO}_{3}$ Model ................................ 6-82

6.6-6. Multiplication Factor $(\mathrm{N})$ used to modify $\mathrm{F}^{-}$Uncertainty Term for Neptunium ........ 6-83

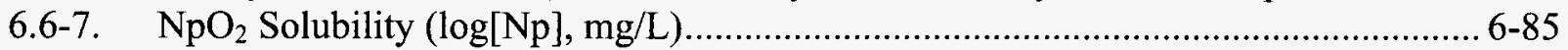

6.6-8. The Effects of Variations in Fluoride Concentration on $\mathrm{NpO}_{2}$ Solubility ................ 6-87

6.6-9. Uncertainty Terms of $\log [\mathrm{Np}]$ of $\mathrm{NpO}_{2}$ Model............................................... 6-88

6.6-10. Multiplication Factor $(\mathrm{N})$ used to Modify $\mathrm{F}^{-}$Uncertainty Terms ............................ 6-89

6.6-11. Calculated Mole Ratio of ${ }^{237} \mathrm{~Np}$ to ${ }^{238} \mathrm{U}$ in the Fuels Used in ANL Experiments....... 6-92

6.6-12. Statistics of $F_{c}$ of Neptunium from High and Low Drip Tests ................................ 6-94

6.6-13. Neptunium-Uranium Ratios in Spent Fuel and Its Solution ................................. 6-94 


\section{TABLES (Continued)}

6.6-14. Statistics of $F_{c}$ of Neptunium from the Subset of High and Low Drip Tests $(t \geq$ 2yr.).

6.6-15. Secondary Phase Neptunium Solubility Model $(\log [\mathrm{Np}](\mathrm{mg} / \mathrm{L}))$

6.6-16. Uncertainty Terms of $\log [\mathrm{Np}]$ of the Secondary Phase Neptunium Solubility Model

6.7-1. Phases Observed During 10-Year Degradation of $\mathrm{UO}_{2}$ by Dripping Water of J-13 Composition and Corresponding Phases in Modeling Database, Data0.ymp.R2 .... 6-103

6.7-2. Silica Phases for which Data are Given in Thermodynamic Database, Data0.ymp.R2

6.7-3. Calculated Uranium Solubility as $\log [\mathrm{U}](\mathrm{mg} / \mathrm{L})$ within CSNF Waste Packages Breached Under Nominal Conditions or by Seismic Activity.

6.7-4. $\quad \mathrm{pH}$ Values at Which Control of $U$ Concentrations Gives Way from Schoepite to $\mathrm{Na}$-boltwoodite and From Na-boltwoodite to $\mathrm{Na}_{4} \mathrm{UO}_{2}\left(\mathrm{CO}_{3}\right)_{3}$ at various $f \mathrm{CO}_{2}$ Values

6.7-5. Calculated Uranium Solubility as $\log [\mathrm{U}](\mathrm{mg} / \mathrm{L})$ within Codisposal Waste Packages Breached under any Scenario, CSNF Waste Packages Breached by a Hypothetical Igneous Intrusion and in the Invert.

6.7-6. Calculated Uranium Solubility as Log [U] (mg/L) within Codisposal Waste Packages Breached under any Scenario, CSNF Waste Packages Breached by a Hypothetical Igneous Intrusion and in the Invert

6.7-7. Range of $\mathrm{pH}$ Values at Which Schoepite Saturation Gives Way to Na-

Boltwoodite Saturation Based on Uncertainties in the log K Values of the Solids .. 6-115

6.7-8. Increases in Solubilities of Schoepite and Na-boltwoodite with Additional $\mathrm{F}^{-}$at Various $\mathrm{pH}$ Values

6.7-9. Normalized $\mathrm{pH}$ Dependence, $\mathrm{N}(\mathrm{pH})$, of c-Parameter of Fluoride Uncertainty Factor $\varepsilon_{2}$ for CSNF Packages Breached Under Nominal Conditions or by Seismic Events.

6.7-10. Dependence of $\varepsilon_{2}$ : c Parameter on Solubility-Controlling Solid and Type of Fluid in Waste Package

6.7-11. pH Dependence of Fluoride Uncertainty for Codisposal Waste Packages Breached Under Nominal, Seismic, or Hypothetical Igneous Intrusive Scenarios and CSNF Waste Packages Breached by Hypothetical Igneous Intrusive

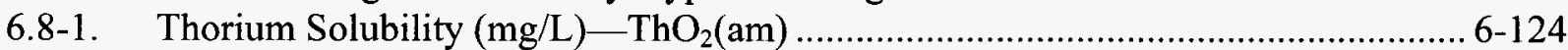

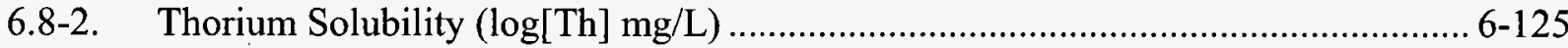

6.8-3. The Effects in Variation in Fluoride Concentration on Th Solubility ..................... 6-130

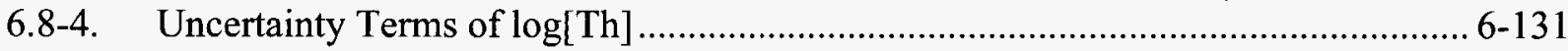

6.8-5. Alternative Uncertainty: The Effects in Variation in Fluoride Concentration on Th Solubility

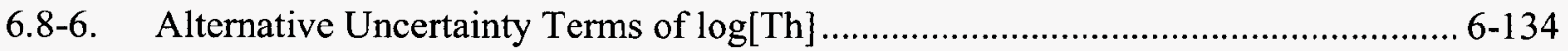

6.8-7. Multiplication Factor (N) Used to Modify Alternative $\mathrm{F}^{-}$Uncertainty Term for

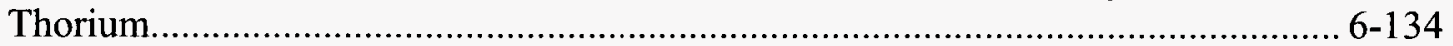

6.9-1. Americium Solubility (mg/L) Calculated with $\mathrm{AmOHCO}_{3}$ as Controlling Solid .... 6-138 


\section{TABLES (Continued)}

6.9-2. Americium Solubility $(\log [\mathrm{Am}] \mathrm{mg} / \mathrm{L})$ $6-140$

6.9-3. The Effects of Variations in Fluoride Concentrations on Americium Solubility ..... 6-141

6.9-4. Uncertainty Terms of $\log [\mathrm{Am}]$

6.9-5. Alternative Uncertainty: The Effects of Variations in Fluoride Concentrations on Americium Solubility.

6.9-6. Alternative Uncertainty Terms of $\log [\mathrm{Am}]$...................................................... 6-146

6.9-7. Multiplication Factor $(\mathrm{N})$ used to modify $\mathrm{F}^{-}$Uncertainty Term for Americium...... 6-146

6.11-1. Comparison of Analogous Neptunium and Protactinium Reactions ....................... 6-148

6.11-2. Base-Case Protactinium Solubility $(\mathrm{mg} / \mathrm{L})$......................................................... 6-150

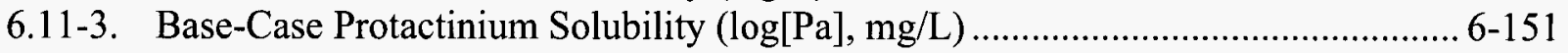

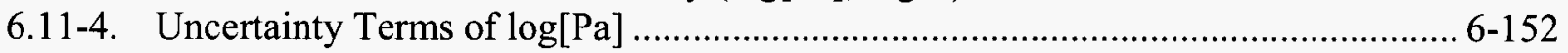

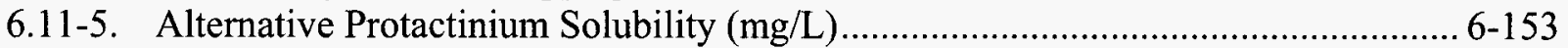

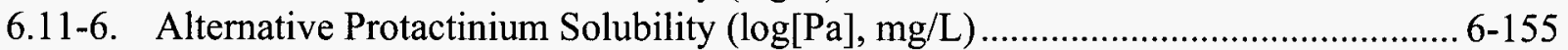

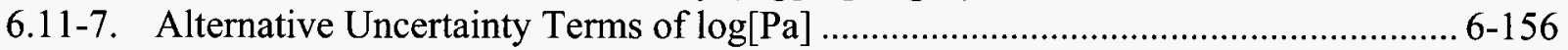

6.12-1. Radium Solubility Values ............................................................................ 6-158

6.19-1. Summary of Alternative Conceptual Models ................................................ 6-160

7-1. Corroborative Data Used for Model Validation .................................................. 7-4

7-2. Comparison of Phases Observed in Natural $\mathrm{UO}_{2}$ Alteration in a Geologic

Environment Similar to Yucca Mountain.............................................................. 7-9

8-1. Summary of Base-Case Solubility Models .......................................................... 8-2

8-2. Summary of Alternative Solubility Models ........................................................... 8-2

8-3. Summary of Uncertainty for Base-Case Solubility Models ..................................... 8-4

8-4. Summary of Alternative Solubility Model Uncertainties and Alternative Uncertainties for Base-Case Models........................................................................ 8-6

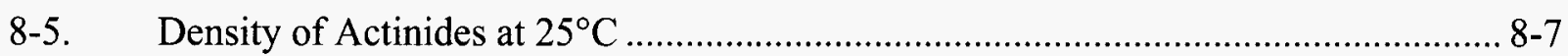

8-6. Valid Range of the Solubility Models Reported in This Report............................ 8-13 
INTENTIONALLY LEFT BLANK 


\section{ACRONYMS AND ABBREVIATIONS}

ANL

Argonne National Laboratory

ATM

approved testing material

CDSP

codisposal spent fuel package

CSNF

commercial spent nuclear fuel

$\Delta_{\mathrm{f}} \mathrm{G}^{0}$

$\Delta_{\mathrm{f}} \mathrm{H}^{0}$

$\Delta_{\mathrm{r}} \mathrm{G}^{0}$

$\Delta_{\mathrm{r}} \mathrm{H}^{0}$

Standard state Gibbs free energy of formation

Standard state enthalpy of formation

Standard state Gibbs free energy of reaction

DOE

Standard state enthalpy of reaction

EBS

U.S. Department of Energy

EELS

Engineered Barrier System

EXAFS

Electron Energy Loss Spectroscopy

Extended X-Ray Absorption Fine Structure

$\mathrm{F}_{\mathrm{c}}$

FEPs

concentrating factor

features, events, and processes

LA

License Application

LANL

Los Alamos National Laboratory

NEA

Nuclear Energy Agency

PNNL

Pacific Northwest National Laboratory

QA

quality assurance

SIT

Specific Ion Interaction Theory

TBV

to be verified

TSPA-LA total system performance assessment for license application

WP

waste package

YMP

Yucca Mountain Project 
Elemental Symbols

$\begin{array}{ll}\mathrm{Ac} & \text { actinium } \\ \mathrm{Am} & \begin{array}{l}\text { americium } \\ \text { carbon } \\ \text { cesium }\end{array} \\ \mathrm{C} & \text { hydrogen } \\ \mathrm{Cs} & \text { iodine } \\ \mathrm{H} & \text { lead } \\ \mathrm{I} & \text { sodium } \\ \mathrm{Pb} & \text { neptunium } \\ \mathrm{Na} & \text { oxygen } \\ \mathrm{Np} & \text { plutonium } \\ \mathrm{O} & \text { protactinium } \\ \mathrm{Pu} & \text { radium } \\ \mathrm{Pa} & \text { strontium } \\ \mathrm{Ra} & \text { technetium } \\ \mathrm{Sr} & \text { thorium } \\ \mathrm{Tc} & \text { uranium } \\ \mathrm{Th} & \end{array}$

Chemistry Abbreviations

$\begin{array}{ll}\text { aged } & \text { aged from fresh precipitate } \\ \text { am } & \text { amorphous solid } \\ \text { aq } & \text { aqueous } \\ \text { cr, c } & \text { crystalline } \\ \text { e } & \text { electron } \\ \text { hyd } & \text { hydrated } \\ \text { s } & \text { solid }\end{array}$




\section{PURPOSE}

The purpose of this study is to determine dissolved concentration limits (also referred to as solubility limits) of elements with radioactive isotopes under probable repository conditions via geochemical modeling calculations using equilibrium geochemical simulators, thermodynamic databases, and measurements made in the field and laboratory experiments. This report was prepared in accordance with Technical Work Plan for: Regulatory Integration Modeling and Analysis of the Waste Form and Waste Package (BSC 2004 [DIRS 171583]) and AP-SIII.10Q, Models.

The scope of this modeling activity is to predict dissolved concentrations or solubility limits as a function of environmental conditions (i.e., $f \mathrm{CO}_{2}$ and $\mathrm{pH}$ ) for all elements with radioactive isotopes important to the performance of the repository. The output of this report provides fundamental inputs for the Total System Performance Assessment for the License Application (TSPA-LA).

The selection of an appropriate set of radionuclides for TSPA-LA evaluation is documented in Radionuclide Screening (BSC 2002 [DIRS 160059]). With a 0.95 screening-product cutoff and a regulatory period of 10,000 years after emplacement, the following 14 elements with radioactive isotopes have been identified to be important to total dose calculations: actinium $(\mathrm{Ac})$, americium $(\mathrm{Am})$, carbon $(\mathrm{C})$, cesium $(\mathrm{Cs})$, iodine $(\mathrm{I})$, lead $(\mathrm{Pb})$, neptunium $(\mathrm{Np})$, plutonium $(\mathrm{Pu})$, protactinium $(\mathrm{Pa})$, radium $(\mathrm{Ra})$, strontium $(\mathrm{Sr})$, technetium $(\mathrm{Tc})$, thorium $(\mathrm{Th})$, and uranium (U).

The output of this report may be applied to different repository locations (i.e., waste packages and invert) and to different scenarios (nominal, seismic, and igneous intrusion) by the TSPA-LA model under different environmental physicochemical conditions. The TSPA-LA requires that solubilities of elements with radioactive isotopes be presented as functions of environmental conditions. The environmental conditions at different locations and in different scenarios are not defined by this report, but by several other reports. The TSPA-LA model uses the solubility models generated by this report and environmental conditions provided by other reports (BSC 2004 [DIRS 167621]; BSC 2004 [DIRS 168960]; BSC 2003 [DIRS 166845]) to generate solubilities for each element with radioactive isotopes at different locations and in different scenarios. As $\mathrm{pH}$ and $f \mathrm{CO}_{2}$ conditions for these different locations and scenarios could be very diverse, it is desirable for solubility models developed in this report to cover broad $\mathrm{pH}$ and $f \mathrm{CO}_{2}$ ranges.

Technical Work Plan for: Regulatory Integration Modeling and Analysis of the Waste Form and Waste Package (BSC 2004 [DIRS 171583]) requires that neptunium and plutonium solubility models developed in this report must be validated at a medium level of confidence (Level II). All others elements are validated at a low level (Level I) of confidence.

The solubility models developed in this report are valid for broad ranges of water composition (Table 8-6) and they may be applied inside and outside waste packages. However, as specified in Section 6.4.4, they are subject to three restrictions. First, because the B-dot equation was used in model calculations, the solubilities are restricted to ionic strengths no greater than 1 molal. Inclusion of an additional uncertainty factor to the solubility allows application of the solubility 
model to an ionic strength of 3 molal. Second, for some calculations that did not converge or gave an ionic strength higher than 1 molal, the value " 500 " was used to indicate that no equilibrium solubilities were estimated for those conditions. This value is intended as a flag to indicate that release rates, rather than concentration limits, should be selected for these physicochemical conditions in the TSPA-LA modeling. Third, for any conditions outside the $\mathrm{pH}$ range of 3.0 to 11.0 , the $\log f \mathrm{CO}_{2}$ range of -1.5 to -5.0 , or for an ionic strength greater than 3 molal (Table 8-6), the inventory concentrations should be calculated using the dissolution rate of individual waste forms, water volume, and the solubility caps presented in Table 8-6.

This report is directly supported by In-Package Chemistry Abstraction, and in turn directly supports the following: Evaluation of the Impact of Microbial Activities on Drift Chemistry, Waste-Form Features, Events, and Processes, Engineered Barrier System Features, Events, and Processes, and the Total System Performance Assessment for the License Application. 


\section{QUALITY ASSURANCE}

\subsection{QA PROGRAM APPLICABILITY}

Development of this report has been determined to be subject to the Yucca Mountain Project's quality assurance program (BSC 2004 [DIRS 171583], Section 8) because it will be used to support TSPA-LA. Approved quality assurance procedures identified in the technical work plan (BSC 2004 [DIRS 171583], Section 4) have been used to conduct and document the activities described in this model report. The report does not address any items in Q-List (BSC 2004 [DIRS 168361]).

\subsection{ELECTRONIC MANAGEMENT OF DATA}

The technical work plan contains the process control evaluation used to evaluate the control of electronic management of data (BSC 2004 [DIRS 171583], Section 8 and Attachment I) during the modeling and documentation activities. This evaluation determined that the methods in the implementing procedures are adequate and, as such, there were no deviations from these methods. 
INTENTIONALLY LEFT BLANK 


\section{USE OF SOFTWARE}

The computer software used to carry out the calculations in this model is summarized in Table 3-1.

Table 3-1. Computer Software Used

\begin{tabular}{|c|c|c|c|c|}
\hline $\begin{array}{c}\text { Software } \\
\text { Name }\end{array}$ & Version & $\begin{array}{c}\text { Software Tracking Number } \\
\text { (Qualification Status) }\end{array}$ & $\begin{array}{l}\text { Description and } \\
\text { Components Used }\end{array}$ & $\begin{array}{l}\text { Input and Output Files }{ }^{\mathrm{a}} \\
\text { (Included in Appendix I) }\end{array}$ \\
\hline \multirow[b]{2}{*}{ EQ3/6 } & \multirow[b]{2}{*}{$7.2 b$} & \multirow{2}{*}{$\begin{array}{l}\text { LLNL:UCRL-MA-110662 } \\
\text { (LSCR198) } \\
\text { (Qualified on Windows } 95 \text { and } \\
\text { HP-UX } 10.20 \mathrm{~B} \text { ) }\end{array}$} & $\begin{array}{l}\text { EQ3NR: a FORTRAN } \\
\text { speciation-solubility code }\end{array}$ & $\begin{array}{ll}\text { input: } & * \\
\text { output: } & * 3 \mathrm{i} \\
\end{array}$ \\
\hline & & & $\begin{array}{l}\text { EQPT: a data file } \\
\text { preprocessor in } \\
\text { FORTRAN }\end{array}$ & $\begin{array}{l}\text { input: data0.* } \\
\text { output: data1.* }\end{array}$ \\
\hline EQ6 & $7.2 \mathrm{bLV}$ & $\begin{array}{l}\text { 10075-7.2bLV-02 } \\
\text { (Qualified on Windows } 2000 \text { and } \\
\text { NT) }\end{array}$ & $\begin{array}{l}\text { EQ6: a reaction path code } \\
\text { which models water-rock } \\
\text { interaction or fluid mixing } \\
\text { in either a pure reaction } \\
\text { progress mode or a time } \\
\text { mode }\end{array}$ & $\begin{array}{ll}\text { input: } & { }^{\star} .6 \mathrm{i} \\
\text { pickup: } & { }^{\star} .6 \mathrm{p} \\
\text { output: } & { }^{*} .60 \\
& { }^{*} . \text {.elem_aqu.txt } \\
& { }^{*} . \text {.elem_min.txt } \\
& \text { ".elem_tot.txt } \\
& { }^{*} . \text { min_info.txt } \\
& \text { *.bin_ } \\
\end{array}$ \\
\hline GetEQData & 1.0 .1 & $\begin{array}{l}\text { 10809-1.0.1-0 } \\
\text { (Qualified on Windows NT } 4.0 \\
\text { and Windows 2000) }\end{array}$ & $\begin{array}{l}\text { A Microsoft Excel macro. } \\
\text { It is used to postprocess } \\
\text { EQ3/6 output information. }\end{array}$ & $\begin{array}{ll}\text { input: } & * .30 \\
\text { output: } & { }^{*} . x \mid s\end{array}$ \\
\hline BuildEQ3.BAS & 1.00 & $\begin{array}{l}\text { 10365-1.00-00 } \\
\text { (Qualified on Windows NT 4.0) }\end{array}$ & $\begin{array}{l}\text { A QBASIC code used to } \\
\text { generate EQ3 input files }\end{array}$ & $\begin{array}{ll}\text { input. } & * \text {.bas } \\
\text { output: } & * \\
\end{array}$ \\
\hline Microsoft Excel & 97 SR-2 & $\begin{array}{l}\text { Used only as a worksheet, not as } \\
\text { a software routine. In } \\
\text { accordance with LP-SI.11Q- } \\
\text { BSC, Software Management, it is } \\
\text { not required to be qualified or } \\
\text { documented. }\end{array}$ & $\begin{array}{l}\text { Used in this document for } \\
\text { graphical representation } \\
\text { and arithmetical } \\
\text { manipulations }\end{array}$ & $\begin{array}{ll}\text { input: } & * .30 \\
\text { output: } & { }^{*} . x \mid s\end{array}$ \\
\hline Sigma Plot & $\begin{array}{l}4.0 \text { and } \\
8.0\end{array}$ & $\begin{array}{l}\text { Used only as a worksheet, not as } \\
\text { a software routine. In } \\
\text { accordance with LP-SI.11Q- } \\
\text { BSC, Software Management, it is } \\
\text { not required to be qualified or } \\
\text { documented }\end{array}$ & $\begin{array}{l}\text { Used in this document for } \\
\text { graphical representation } \\
\text { and arithmetical } \\
\text { manipulations }\end{array}$ & $\begin{array}{ll}\text { Input: } & * .30 \\
& * .60 \\
\text { Output: } & * . j n b\end{array}$ \\
\hline
\end{tabular}

NOTE: $\quad{ }^{a}$ Files are explained in more detail in Appendix il.

All applicable products were obtained from Software Configuration Management and have been verified appropriate for the application. No macros were developed for either Microsoft Excel or Sigma Plot; thus, additional qualification was not necessary. Only the functions that are part of the off-the-shelf codes were used to make arithmetical manipulations. The software was run on standard personal computers and the Unix machine listed in Table 3-2. 
Table 3-2. Computers Used

\begin{tabular}{|l|l|l|l|}
\hline \multicolumn{1}{|c|}{ Computer Make } & \multicolumn{1}{|c|}{ CPU \# } & Operating System & \multicolumn{1}{c|}{ Software Used } \\
\hline Dell PowerEdge 2200 & 112378 & Windows NT 4.0 & $\begin{array}{l}\text { BuildEQ.BAS, GetEQData, Microsoft Excel 97 SR-2, } \\
\text { Sigma Plot }\end{array}$ \\
\hline Dell Optiplex GX400 & 151295 & Windows NT 4.0 & $\begin{array}{l}\text { BuildEQ.BAS, GetEQData, Microsoft Excel 97 SR-2, } \\
\text { EQ6 V7.2bLV }\end{array}$ \\
\hline Dell Optiplex GX260 & 152392 & Windows 2000 & GetEQData, Microsoft Excel 97 SR-2, Sigma Plot \\
\hline Dell Optiplex GX260 & 152383 & Windows 2000 & GetEQData, Microsoft Excel 97 SR-2 \\
\hline Dell Optiplex GX300 & 117728 & Windows 95 & EQ3/6 V7.2b \\
\hline Dell Optiplex GX260 & 152393 & Windows 2000 & GetEQData, Microsoft Excel 97 SR-2 \\
\hline Dell Optiplex GX260 & 152381 & Windows 2000 & GetEQData, Microsoft Excel 97 SR-2 \\
\hline $\begin{array}{l}\text { Hewlett-Packard } \\
\text { workstation }\end{array}$ & 112515 & HP-UX 10.20 B & EQ3/6 V7.2b \\
\hline
\end{tabular}

NOTE: $\quad$ CPU $=$ central processing unit.

The EQ3/6 package consists of several components: EQ3NR, EQ6, EQPT, and EQLIB. EQ3NR, the main component used in the solubility calculations, computes the thermodynamic static state of an aqueous solution by determining the distribution of chemical species using a thermodynamic database. The input to the code describes the aqueous solution in terms of total concentrations of dissolved components and such other parameters as the $\mathrm{pH}$ and Eh. The input for this report also includes a desired electrical balancing adjustment and constraints that impose equilibrium with specified pure minerals and gases. EQ3 evaluates the degree of disequilibrium in terms of saturation index and the thermodynamic affinity for mineral dissolution and precipitation; EQ6 is for reaction path simulations; EQPT is a database preprocessor; and EQLIB is the supporting library. This library was not necessary for this report and was not used. BuildEQ3.bas (a preprocessor) and GetEQData (a postprocessor) are designed for use with the EQ3/6 package. The EQ3/6 software and its pre- and postprocessors were selected for this model because they were developed to simulate equilibrium conditions in groundwater. The thermodynamic database was compiled for the Yucca Mountain Project (YMP). The use of the software listed in Table 3-1 is consistent with its intended use. There are no limitations on the output of this model due to the use of any of the software listed in this section. All of the software used in this model are appropriate for this application and were not used outside the range of parameters for which they were verified. 


\section{INPUTS}

\subsection{DIRECT INPUTS}

Sources of direct inputs used in this report to develop solubility models are summarized in Table 4-1. Data used in the direct development of this model ("direct inputs") are not used to validate the model in Section 7.

An important input for this study is the thermodynamic database (Data0.ymp.R2) used for EQ3NR and EQ6 calculations. Data0.ymp.R2 (DTN: MO0302SPATHDYN.000 [DIRS 161756]) was developed specifically for the YMP for use with the EQ3/6 software and contains the best available thermodynamic data. It is appropriate for this use and maintains consistency between models. The Data0.ymp.R2 database was modified slightly for this report (called Data0.yc3.Rl) to incorporate the equilibrium constant for sodium boltwoodite $\left(\mathrm{NaUO}_{2} \mathrm{SiO}_{3} \mathrm{OH} \cdot 1.5 \mathrm{H}_{2} \mathrm{O}\right)$ recommended as a solubility-controlling phase by the NEA Thermodynamic Database Project in Update on the Chemical Thermodynamics of Uranium, Neptunium, Americium and Technetium (Guillaumont et al. 2003 [DIRS 168382]). Update on the Chemical Thermodynamics of Uranium, Neptunium, Americium and Technetium (Guillaumont et al. 2003 [DIRS 168382]) is one in a series of publications from the NEA that are widely used and well accepted by the nuclear waste management community as handbooks and their data are considered established fact.

The Data0.ymp.R2 database contains the information necessary for extrapolations to $200^{\circ} \mathrm{C}$. The B-dot equation used in Data0.ymp.R2 and Data0.yc3.RI is considered valid up to ionic strengths of 1 molal (Steinborn et al. 2003 [DIRS 161956], p. 60). As discussed in Section 6.3.3.4, this limitation can be relaxed by adding an additional uncertainty term and the estimations can be extended to ionic strengths between 1 and 3 molal.

The majority of the sources of direct input data (Table 4-1) are handbooks (entries 3, 4, 5, 6, 7, 8, and 9), and, as such, their contents are considered established fact and the data are qualified. These sources are generally accepted by the scientific community and are, thus, considered appropriate for use in the model.

One source, the original source for the coefficients used in the extended Debye-Huckel equation for calculating single-ion activity coefficients, is a U.S. Geological Survey report (Truesdell and Jones 1974 [DIRS 170136]) and is qualified here for its intended use in this report by the following factors: reliability of data source; qualification of personnel or organizations generating the data; and prior uses of data (BSC 2004 [DIRS 171760]). All equilibrium geochemistry numerical simulators use single-ion activity coefficients in their calculations. These data are integral to the EQ3/6 simulations that were used to estimate the equilibrium solubility of the various elements with radioactive isotopes. The authors (Truesdell and Jones) are recognized senior scientists with the U.S. Geological Survey and are eminently qualified to make these calculations. The senior author has many peer-reviewed papers concerning geochemical thermodynamics and estimation of geochemical parameters. These data have been included in virtually all of the equilibrium geochemistry simulation codes (e.g., PHREEQE, MINTEQA2, etc.) since they were originally published and have been accepted by the scientific community as "established fact." 


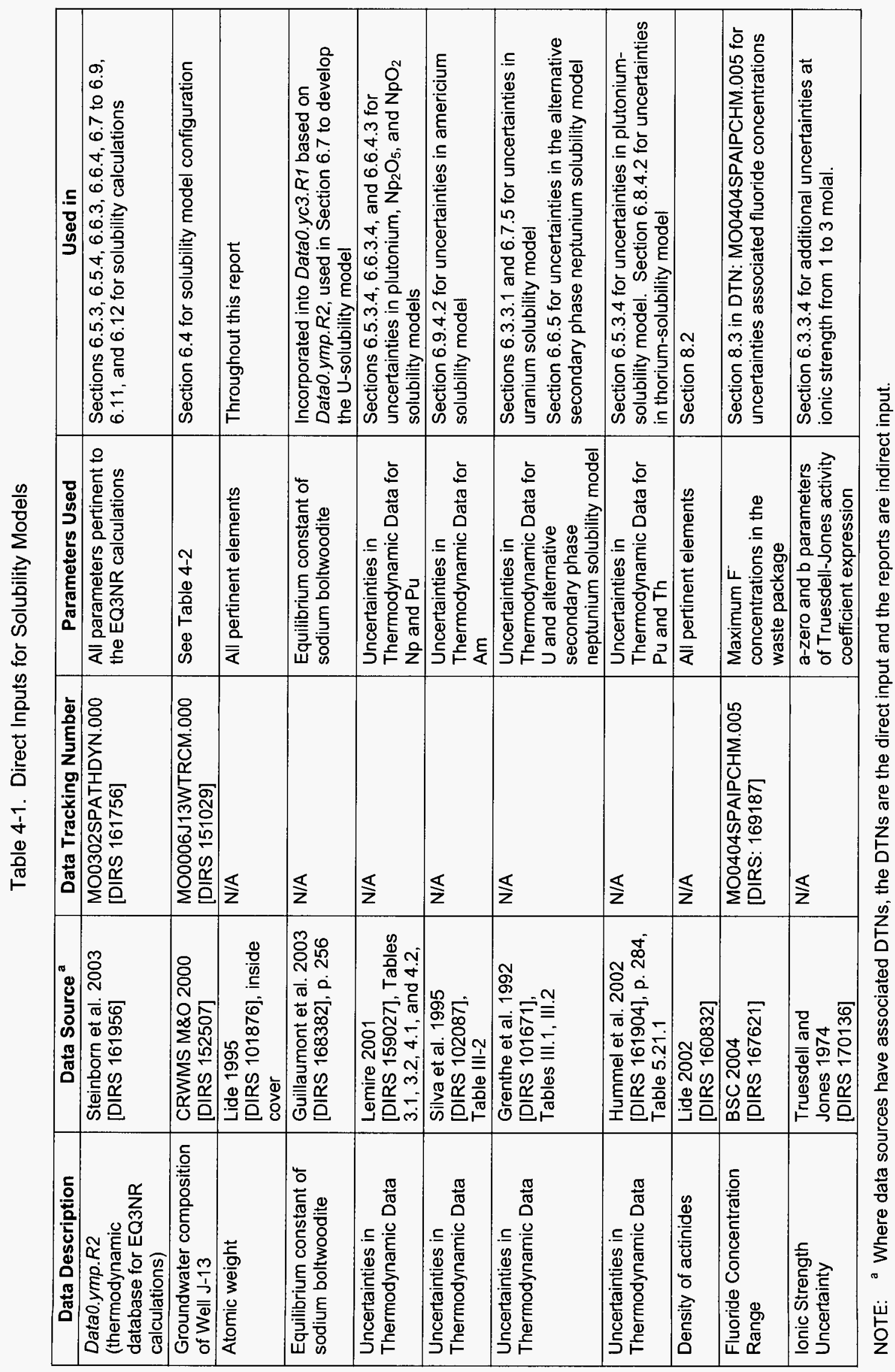


Section 6.3.3.4 compares the values of single-ion activity coefficients $\left(\gamma_{i}\right)$ that they calculated using WATEQ with those previously calculated using other methods and demonstrated that the agreement was within a few percent. Therefore, the work by Truesdell and Jones (1974 [DIRS 170136]) is qualified for intended use.

The initial water composition used as the base case, summarized in Table 4-1 with details given in Table 4-2, was intended to be generically representative of water present in the repository host rock. The composition chosen, J-13 well water (DTN: MO0006J13WTRCM.000 [DIRS 151029]), was used as a starting point to develop the solubility models. The interactions with the solid phases determined the final composition. The applicable ranges for the solubility models developed in this report are much wider than the conditions listed in Table 4-2 (Section 6.4.4). It is important to note that while initial values of $\mathrm{pH}, \mathrm{T}\left({ }^{\circ} \mathrm{C}\right)$, and $f \mathrm{CO}_{2}$ were direct input to the code, these parameters were varied over a set range during the simulation. DTN: MO0302SPATHDYN.000 [DIRS 161756] is a thermodynamic database developed specifically for speciation calculations on the YMP. Therefore, its use in this model is appropriate.

Table 4-2. Chemical Composition of Reference Water (J-13 Well Water)

\begin{tabular}{|l|c|c|}
\hline \multicolumn{1}{|c|}{ Component } & Concentration $(\mathbf{m g} / \mathbf{L})^{\mathbf{a}, \mathbf{b}}$ & Uncertainty (mg/L) \\
\hline $\mathrm{Na}^{+}$ & 45.8 & \pm 2.29 \\
\hline $\mathrm{K}^{+}$ & 5.04 & \pm 0.61 \\
\hline $\mathrm{Ca}^{2+}$ & 13.0 & \pm 0.99 \\
\hline $\mathrm{Mg}^{2+}$ & 2.01 & \pm 0.21 \\
\hline $\mathrm{Si}\left(\mathrm{SiO}_{2}(\mathrm{aq})\right)$ & $28.5(60.97)^{\mathrm{c}}$ & \pm 1.85 \\
\hline $\mathrm{Cl}^{-}$ & 7.14 & \pm 0.61 \\
\hline $\mathrm{F}^{-}$ & 2.18 & \pm 0.29 \\
\hline $\mathrm{NO}_{3}{ }^{-}$ & 8.78 & \pm 1.03 \\
\hline $\mathrm{SO}_{4}{ }^{2-}$ & 18.4 & \pm 1.03 \\
\hline $\mathrm{pH}^{2}$ & 7.41 & \pm 0.44 \\
\hline Alkalinity $\left(\mathrm{HCO}_{3}{ }^{-}\right)$ & 128.9 & \pm 8.6 \\
\hline
\end{tabular}

Source: DTN: MO0006J13WTRCM.000 [DIRS 151029].

NOTE: ${ }^{a}$ Source DTN: MO0006J13WTRCM.000 [DIRS 151029] contains recommended mean values of major constituents in $\mathrm{J}$-13 well water.

${ }^{b}$ In the TDMS database, the name of abundance was used for this DTN.

${ }^{\mathrm{c}}$ The conversion from $\mathrm{Si}$ to $\mathrm{SiO}_{2}$ is $1 \mathrm{mg} / \mathrm{L} \mathrm{Si}=2.14 \mathrm{mg} / \mathrm{L} \mathrm{SiO}$.

\subsection{CRITERIA}

Projects Requirements Document (Canori and Leitner 2003 [DIRS 166275]) identifies the high-level requirements for the Project. The requirements pertaining to this report, and their link to 10 CFR 63 [DIRS 156605], are shown in Table 4-3. 
Table 4-3. Applicable Project Requirements Criteria

\begin{tabular}{|l|l|l|}
\hline Requirement Number & \multicolumn{1}{|c|}{ Title } & \multicolumn{1}{c|}{ 10 CFR 63 Link } \\
\hline PRD-002/T-014 & $\begin{array}{l}\text { Performance Objectives for the Geologic } \\
\text { Repository After Permanent Closure }\end{array}$ & 10 CFR 63.113 [DIRS 156605] \\
\hline PRD-002/T-015 & Requirements for Performance Assessment & 10 CFR 63.114 [DIRS 156605] \\
\hline PRD-002/T-016 & Requirements for Multiple Barriers & 10 CFR 63.115 [DIRS 156605] \\
\hline
\end{tabular}

Work described in this document will support the following criteria from Yucca Mountain Review Plan (NRC 2003 [DIRS 163274]) as described in Table 3-1 of Technical Work Plan for: Regulatory Integration Modeling and Analysis of the Waste Form and Waste Package (BSC 2004 [DIRS 171583]). Applicable Yucca Mountain Review Plan acceptance criteria are presented below. The full text of these criteria is quoted in Section 8.2 along with a detailed explanation of how this document addresses those criteria and the location where the appropriate information can be found.

Radionuclide Release Rates and Solubility Limits Acceptance Criteria (NRC 2003 [DIRS 163274], Section 2.2.1.3.4.3)

- Acceptance Criterion 1 - System Description and Model Integration are Adequate

- Acceptance Criterion 2 - Data are Sufficient for Model Justification

- Acceptance Criterion 3 - Data Uncertainty is Characterized and Propagated Through the Model Abstraction

- Acceptance Criterion 4 - Model Uncertainty Is Characterized and Propagated Through the Model Abstraction

- Acceptance Criterion 5 - Model Abstraction Output is Supported by Objective Comparisons.

Section 8.3 quotes the full text of the applicable acceptance criteria with pointers to the information within this report that pertains to the criteria.

\subsection{CODES, STANDARDS, AND REGULATIONS}

10 CFR 63. Energy: Disposal of High-Level Radioactive Wastes in a Geologic Repository at Yucca Mountain, Nevada

ASTM C 1174-97 [DIRS 105725], Standard Practice for Prediction of the Long-Term Behavior of Materials, Including Waste Forms, Used in Engineered Barrier Systems (EBS) for Geological Disposal of High-Level Radioactive Waste, is used to support the model development methodology, categorize the models developed with respect to their usage for long-term TSPA-LA, and relate the information and data used to develop the model to the requirements of the standard. 


\section{ASSUMPTIONS}

\subsection{OXIDIZING CONDITIONS}

Assumption: The repository is in an oxidizing condition and oxygen fugacity equals 0.2 (bars) (the atmospheric value).

Rationale: The existence of reducing conditions has not been proven, except for transient and localized conditions. Also, since the repository is in the unsaturated zone, it is connected to the atmosphere.

Confirmation Status: Many of the radionuclides critical to dose are less soluble under reducing conditions (Langmuir 1997 [DIRS 100051], Chapter 13). Therefore, it is a conservative assumption because radionuclides are either more soluble under atmospheric oxygen fugacity or insensitive to oxygen fugacity. Thus, it does not need further confirmation.

Use in the Model: This assumption is used throughout Section 6, with an exception for Section 6.5 (Pu-solubility model), and Section 6.6 (Np-solubility model), where slightly different redox conditions are used and detailed rationale is given.

\subsection{INVENTORY VALUES}

Assumption: The abundance of ${ }^{238} \mathrm{U}$ and ${ }^{237} \mathrm{~Np}$ in the ATM-103 and ATM-106 samples used in the ANL drip tests can be represented by the inventory values given by Guenther et al. (1988 [DIRS 109205]; 1988 [DIRS 109206]) for fuels out of reactors for 15 years.

Rationale: The abundance of ${ }^{238} \mathrm{U}$ does not change with the out of reactor time, and ${ }^{237} \mathrm{~Np}$ abundance changes less than 1.5 percent over a period of 5 years (Guenther et al. 1988 [DIRS 109205], Table F.2.d, p. F.23).

Confirmation Status: This assumption is reasonable because the uncertainty it introduces is small. Therefore, no confirmation is required.

Use in the Model: This assumption is used in Section 6.6.5.1. 
INTENTIONALLY LEFT BLANK 


\section{MODEL DISCUSSION}

\subsection{MODELING OBJECTIVES}

The objective of this modeling effort is to evaluate and abstract dissolved concentration limits of certain elements with radioactive isotopes in the environments expected in the repository. Fourteen elements with radioactive isotopes (actinium, americium, carbon, cesium, iodine, neptunium, protactinium, lead, plutonium, radium, strontium, technetium, thorium, and uranium) are considered based on Radionuclide Screening (BSC 2002 [DIRS 160059]).

Dissolved concentration limits for plutonium, neptunium, uranium, thorium, americium, and protactinium are presented as tabulated functions of environmental conditions (namely, $\mathrm{pH}$ and $f \mathrm{CO}_{2}$ ) with one or more uncertainty terms or distributions. The presentation of other radionuclides is discussed in Sections 6.10 and 6.12 through 6.18. The results of this report are inputs for TSPA-LA.

The corroborating and supporting data used in this section are summarized below.

\subsubsection{Indirect Inputs}

Many of the indirect inputs are summarized in Table 6.1-1 (the remaining indirect inputs are summarized in Tables 6.5-6 and 7.1). These indirect inputs provide additional information to support, validate, or invalidate solubility models, or to establish the ranges of environmental conditions for solubility calculations. 


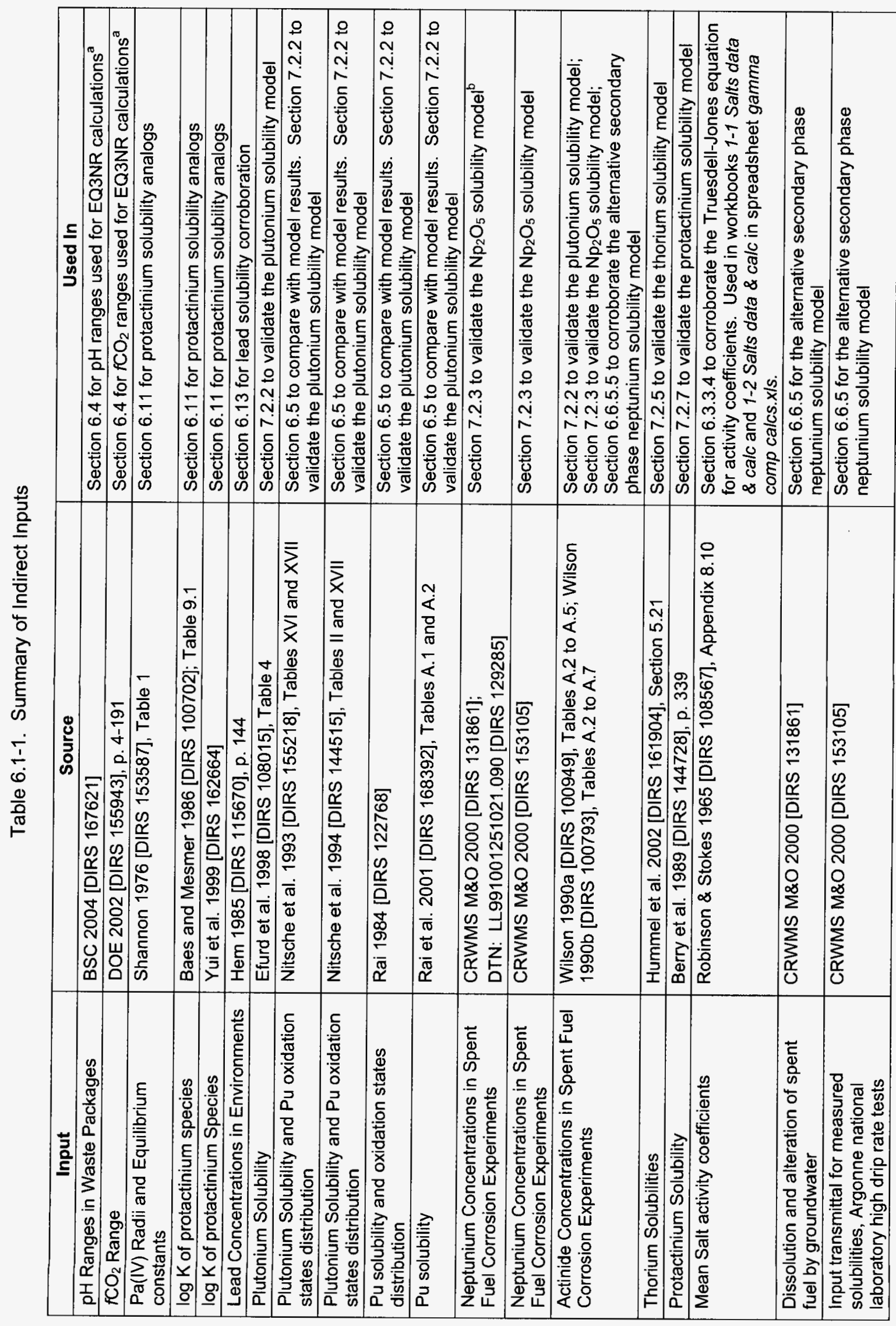




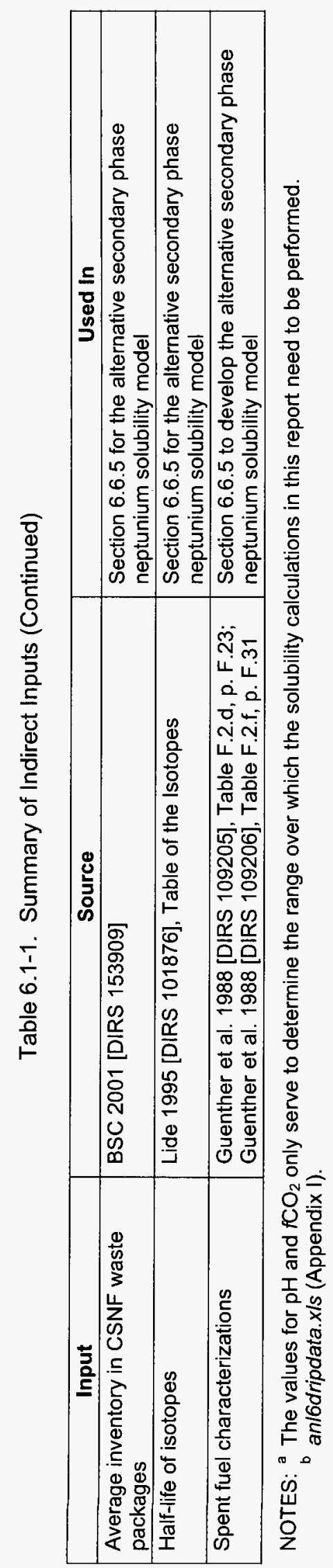




\subsection{FEATURES, EVENTS, AND PROCESSES INCLUDED IN MODEL}

Table 6.2-1 provides the FEP that is included in the TSPA-LA submodels described in this model document.

Table 6.2-1. Included FEPs for this Report

\begin{tabular}{|l|l|l|}
\hline FEP Name & FEP Number & $\begin{array}{l}\text { Section Where Disposition is } \\
\text { Discussed }\end{array}$ \\
\hline $\begin{array}{l}\text { Radionuclide Solubility, Solubility Limits, and Speciation in } \\
\text { the Waste Form and EBS }\end{array}$ & $2.1 .09 .04 .0 \mathrm{~A}$ & 6.3 .1 and 6.5 to 6.18 \\
\hline Reduction-Oxidation Potential in Waste Packages & $2.1 .09 .06 .0 \mathrm{~A}$ & 6.5 and 6.6 \\
\hline Reaction Kinetics in Waste Package & $2.1 .09 .07 .0 \mathrm{~A}$ & 6.3 \\
\hline Chemistry of Water Flowing into Waste Package & $2.2 .08 .12 .0 \mathrm{~B}$ & $\begin{array}{l}6.4,6.4 .2 .5,6.4 .3 .6, \text { and } \\
6.4 .6 .7\end{array}$ \\
\hline
\end{tabular}

Source: DTN: MO0407SEPFEPLA.000 [DIRS 170760].

\subsection{TECHNICAL ISSUES IN SOLUBILITY EVALUATION}

There are two prerequisites to solubility evaluations: 1) a thermodynamic database and compatible geochemical modeling tool and 2) environmental conditions for which solubility must be evaluated. With these prerequisites, a model is constructed based on environmental information and the chemical properties of radionuclides. Solubility limits are based on the model results.

The first prerequisite is input to this analysis and is discussed in Section 4.1. The second prerequisite is discussed in Section 6.4. The discussion in this section focuses on several technical issues common to solubility evaluation, such as the selection of solubility-controlling solids and uncertainty treatment. Specific issues related to certain elements are discussed in relevant sections.

\subsubsection{The Definition of Solubility}

From the viewpoint of laboratory chemistry, solubility is defined as the concentration of a substance when the solution is saturated with that substance (Atkins 1994 [DIRS 134303], p. 312). This definition implies that (1) solubility is defined in terms of thermodynamics, and (2) solubility is the maximum concentration (with a certain degree of uncertainty) that the substance can reach in solution at equilibrium for a given set of environmental conditions. In other words, solubility is the concentration of a substance when the substance is at equilibrium with the solution. For this case, the substance is a radionuclide-bearing solid called the solubility-controlling solid.

Performance assessments are more interested in the solubility of specific elements in water than the solubility of a substance. Except for colloidal and kinetically transient phenomena such as over-saturation, solubility is the maximum concentration that an element can reach under the conditions of interest. The phrase "maximum concentration" reflects a key requirement for solubility evaluation (i.e., it is bounding). 
Solubility limits are input for TSPA-LA analyses as one of two possible constraints on the maximum radionuclide concentrations. The other constraint is calculated within the TSPA-LA model based on the dissolution rate of individual waste forms, water volume, and the solubility caps presented in Table 8-5.

A solubility-controlling solid can be either a pure radionuclide-bearing solid or a solid solution of two (or more) endmembers. In practice, pure radionuclide-bearing solids are nearly always used to evaluate solubility principally because proof of the formation of solid solutions is a more demanding task than demonstration of the formation of pure solids. In addition, values for parameters required for solubility models based on solid-solution control are commonly not available. Use of a pure solubility-controlling phase over the use of a solid solution is acceptable because it yields higher (conservative) solubility limits.

Sorption is another mechanism that controls the radionuclide concentrations in solutions. The net effect of sorption is to lower radionuclide concentrations in solutions. This study excludes sorption from current consideration.

Concentrations in aqueous solutions may be given in several different units. The standard unit for chemical computations is moles of solute per kilogram of solvent, and is known as molality. For dilute solutions, this differs only slightly from moles per liter, known as molarity. Another common expression of units is $\mathrm{mg} / \mathrm{L}$.

\subsubsection{Identification of the Controlling Solid}

As discussed previously, element solubility is defined with respect to a solid. To evaluate solubility within a repository, the controlling solid or solids must be identified. Since solubility depends strongly on the solid phase, the outcome would be quite different (orders of magnitude) if different solids were chosen.

Laboratory experiments and observations of natural systems provide the basis for choosing the controlling phase. For example, experiments with neptunium in J-13 well water show $\mathrm{Np}_{2} \mathrm{O}_{5} \cdot x \mathrm{H}_{2} \mathrm{O}$ is the controlling solid (Efurd et al. 1998 [DIRS 108015], p. 3,896) for the time scale of the experiments. Unfortunately, laboratory evidence and field observations are not available for all the radionuclides at the environmental conditions and time scales of interest. Moreover, the identity of the controlling solid may change with environment conditions.

Thermodynamic data on actinide solids are derived from laboratory solubility measurements and from direct thermochemical measurements such as calorimetry (Nordstrom and Munoz 1986 [DIRS 153965], Chapter 11). The thermodynamic properties of the minerals uraninite $\left(\mathrm{UO}_{2}\right)$, thorianite $\left(\mathrm{ThO}_{2}\right)$, and analogous phases have been well defined using thermochemical techniques. However, naturally occurring, high-temperature phases such as $\mathrm{NpO}_{2}$ and $\mathrm{PuO}_{2}$ have not. Solubility studies of actinide dioxide (Grenthe et al. 1992 [DIRS 101671], Section v3.2.3.3; Guillaumont et al. 2003 [DIRS 168382], Section 9.3.2.2; Hummel et al. 2002 [DIRS 161904]; Neck and Kim 2001 [DIRS 168258]), using over- and under-saturation tests at $\mathrm{pH}$ greater than 3 to 5 (depending on reference) indicate that the dissolved actinide concentrations are not controlled by high-temperature crystalline phases, but solids (such as hydrated or amorphous phases) that are considerably more soluble. This is illustrated most clearly by 
Hummel et al. (2002 [DIRS 161904]). Figure 4 of that article shows that the solubility calculated from the thermodynamic properties of the high-temperature mineral form of $\mathrm{ThO}_{2}$ is nine orders of magnitude lower than concentrations measured in laboratory experiments at $\mathrm{pH}$ values above about 6 . Similarly, Figure 5 of that report shows that calculated solubility of the high-temperature mineral form of $\mathrm{UO}_{2}$ is six orders of magnitude lower than concentrations measured in laboratory experiments at $\mathrm{pH}$ values above about 3 . The more soluble phases leading to the higher, laboratory-measured concentrations are not well defined crystallographically. However, solubility values are reproducible and these solubility values do not change over a period of several years (time scale of laboratory experiments). Thus, critically compiled thermodynamic databases such as those of the NEA (Grenthe et al. 1992 [DIRS 101671]; Silva et al. 1995 [DIRS 102087]; Lemire et al. 2001 [DIRS 159027]; Guillaumont et al. 2003 [DIRS 168382]); and NAGRA/PSI (Hummel et al. 2002 [DIRS 161904]) include several actinide dioxide solids for $\mathrm{Th}, \mathrm{U}, \mathrm{Np}$, and $\mathrm{Pu}$. One is the high-temperature, crystalline variety (example, $\mathrm{PuO}_{2}$ or $\mathrm{PuO}_{2}(\mathrm{cr})(\mathrm{cr}=$ crystalline)), or referred to by its mineral name (i.e., plutonium dioxide). The others are the solids that control the laboratory solubilities (examples, written as $\mathrm{PuO}_{2}(\mathrm{am})$ (am $=$ amorphous), $\mathrm{PuO}_{2}$ (am,hyd) (hyd $=$ hydrated), $\mathrm{PuO}_{2}$ (hyd,aged), and $\mathrm{Pu}(\mathrm{OH})_{4}(\mathrm{am})$ ). The solids of this type that are included in the thermodynamic database supporting the modeling described in this report (Section 4.1) are listed in Table 6.3-1.

Table 6.3-1. Solid Phases of Four-Valent Actinides Included in Project Thermodynamic Database Data0.ymp.R2

\begin{tabular}{|l|l|l|}
\hline \multicolumn{1}{|c|}{ Element } & \multicolumn{1}{|c|}{ Highly Crystalline Solid } & \multicolumn{1}{|c|}{$\begin{array}{c}\text { Observed Solids That Control } \\
\text { Experimental Studies }\end{array}$} \\
\hline Thorium & Thorianite $\left(\mathrm{ThO}_{2}\right)$ & $\mathrm{ThO}_{2}(\mathrm{am})$ \\
\hline Uranium & Uraninite $\left(\mathrm{UO}_{2}\right)$ & See Table $6.7-1$ \\
\hline Neptunium & $\mathrm{NpO}_{2}$ & $\mathrm{NpO}_{2}(\mathrm{am}, \mathrm{hyd}), \mathrm{Np}(\mathrm{OH})_{4}(\mathrm{am})$ \\
\hline Plutonium & $\mathrm{PuO}_{2}$ & $\mathrm{PuO}_{2}$ (hyd, aged) \\
\hline
\end{tabular}

From the viewpoint of thermodynamics, the most stable solid would be selected as the controlling phase because thermodynamically less-stable phases would be ultimately replaced by the most stable phase. However, it cannot be demonstrated that the thermodynamically most stable solid appears during the regulatory period under the expected repository conditions. This fact makes identification of the controlling solid purely from thermodynamic considerations unreliable.

The Ostwald Step Rule provides a useful guide for such situations. This rule says that unstable or metastable minerals form first, followed by progressively more-stable minerals (Langmuir 1997 [DIRS 100051], p. 324). The formation of $\mathrm{Np}_{2} \mathrm{O}_{5} \cdot \mathrm{xH}_{2} \mathrm{O}$ in neptunium experiments is an example of the Ostwald Step Rule. The thermodynamically more-stable phase, $\mathrm{NpO}_{2}(\mathrm{~s})$ (s denotes solid), is sufficiently more stable than the $\mathrm{Np}_{2} \mathrm{O}_{5}(\mathrm{~s})$ under atmospheric oxygen (CRWMS M\&O 1998 [DIRS 100348], pp. 19 and 20; Efurd et al. 1998 [DIRS 108015], Figure 5). Precipitation kinetics is the governing factor for the Ostwald Step Rule. In other words, during the process of waste corrosion, more-stable minerals are prevented from precipitating because less-stable minerals are kinetically favored. Another good example of the Ostwald Step Rule is the formation of secondary uranyl minerals during spent fuel dissolution. 
Less-stable schoepite precipitates first, and is then replaced by more-stable uranyl silicates (Wronkiewicz et al. 1992 [DIRS 100493], Section 4.2).

The Ostwald Step Rule has significant implications for choosing the controlling phase. To use a more-stable phase (rather than the first formed, less-stable phase) as the controlling phase for solubility calculations, it is necessary to demonstrate that the less-stable mineral is replaced by the more-stable mineral(s) in a shorter period than the characteristic time scale of the problem. Specifically, since the time scale of repository performance is $10^{4}$ years, the time scale for morestable mineral(s) to form should be less than $10^{2}$ to $10^{3}$ years. Additionally, because several fuel types are modeled in TSPA-LA with instantaneous degradation, the majority of the fuel in these categories (such as DOE spent fuels) can be degraded in one TSPA-LA time step. The smallest time step used in TSPA-LA is 10 years. Therefore, arguments for the formation of stable minerals must also account for time periods as small as 10 years. Arguments that the more thermodynamically stable phase ultimately replaces less-stable kinetically precipitated minerals is not convincing because, under certain conditions, it may take infinite time for thermodynamic phases to replace a kinetic phase through aging or other processes. For example, the mixture of hydrogen and oxygen gases at room temperature is thermodynamically unstable with respect to water, but water never forms from the mixture unless the mixture is ignited by flame or other means. A good geologic example is the persistence of oxygen and nitrogen gas in the atmosphere in the presence of moisture and liquid water in spite of the fact that equilibrium for these substances is nitric acid.

For some elements, the identification of controlling solids for the repository by experiments has yet to be reported (e.g., protactinium), or experimental observations are not conclusive (e.g., plutonium). For situations like this, a conservative approach is, as suggested by Bruno et al. (1997 [DIRS 111794], p. 81), to choose the amorphous solids (oxide or hydroxide) as their controlling solids. The Ostwald Step Rule is the main reason for choosing an amorphous phase. Another reason is that radiation associated with spent nuclear fuel could damage the lattice structure of solids and make it less crystalline (Rai and Ryan 1982 [DIRS 112060], p. 216). It is well known that radioactive decay, especially $\alpha$-decay, can damage the crystal structure of plutonium solids. Rai and Ryan (1982 [DIRS 112060]) reported in an experiment lasting 1,266 days that ${ }^{238} \mathrm{PuO}_{2}$ (c) ( $\mathrm{c}=$ crystalline) was found to convert to an amorphous form of $\mathrm{PuO}_{2}$, which has higher solubility than $\mathrm{PuO}_{2}(\mathrm{c})$. In waste forms, the fraction of isotope ${ }^{238} \mathrm{Pu}$ in the total plutonium inventory is small (BSC 2001 [DIRS 154841], Table 36), so crystal structure damage is not expected to occur rapidly enough to be significant. However, over the regulatory time period, it is reasonable to expect that $\mathrm{PuO}_{2}(\mathrm{c})$ would gradually convert to a $\mathrm{PuO}_{2}(\mathrm{am})$. Therefore, this phenomenon is recognized, and the uncertainty it introduces to radionuclide solubility is addressed.

Freshly precipitated solids tend to be fine particles with a large specific surface area. The extra surface energy given by the large surface area makes fresh precipitates more soluble. However, with time, the freshly precipitated fine particles go through a process called aging in which particle size increases. As a result, an aged precipitate has a lower solubility than the freshly precipitated solid. Aging could be a long-lasting process. For example, in a study lasting 1,266 days, Rai and Ryan (1982 [DIRS 112060]) observed continuous aging of $\mathrm{PuO}_{2} \cdot x \mathrm{H}_{2} \mathrm{O}$ (amorphous). As solubility experiments usually last less than a year, it is reasonable to expect 
that the measured solubility is actually an upper limit. Therefore, because of aging, a solid's real solubility could be lower than its measured solubility.

In fact, aging and decay effects (radiation damage) have opposite effects on solubility. Aging could make a radionuclide less soluble if the starting material is an amorphous solid. Decay effects could make a radionuclide more soluble, provided that the initial material is a crystalline solid. Therefore, it is reasonable to speculate that the real controlling material may contain both amorphous and crystalline phases. Indeed, Rai and Ryan (1982 [DIRS 112060], p. 214) found that "the solubility of ${ }^{239} \mathrm{PuO}_{2}$ and ${ }^{239} \mathrm{PuO}_{2} \cdot x \mathrm{H}_{2} \mathrm{O}$ tend to merge; most, if not all, of the effect is due to decreased solubility of $\mathrm{PuO}_{2} \cdot x \mathrm{H}_{2} \mathrm{O}$ with time." While there is not enough information to define the thermodynamic properties of this intermediate solid quantitatively and, consequently, to calculate solubility controlled by it, the uncertainty can be bounded by use of the amorphous and crystalline phases.

For some very soluble elements (i.e., Tc), solids are not expected to precipitate from solution under the repository conditions. The transport of those elements may not be solubility controlled. An arbitrary large number is assigned to their solubility so that their release is controlled by the dissolution rate of individual waste forms, water volume, and the solubility caps presented in Table 8-5. This is a conservative approach and no further validation is needed.

For some elements, there is more than one mineral with overlapping stability fields within the range of environmental conditions. For these, a multiple controlling-mineral model has been adopted to derive solubility limits. For uranium, three solids are used (Sections 6.7.1 and 6.7.2) and for neptunium, two phases (Section 6.6.3.1).

\subsubsection{Treatment of Variation and Uncertainty}

In general, the solubility of an element in a repository changes as a function of environmental variables. As chemical conditions change over time, solubility changes as well. Knowledge of the solubility is also subject to uncertainty, because of the chemical conditions and the parameter values used to calculate it. Although variation of chemical conditions with time and uncertainty have similar effects on solubility limits, distinguishing between them is beneficial.

As environmental conditions within a repository vary, so does radionuclide solubility. A meaningful solubility evaluation should account for the variation in solubility caused by the changes in environmental conditions. As long as the environmental condition ranges are known (as inputs to the analysis), the range of solubility variation can be calculated. It is useful to understand the effects of changes in environmental conditions on solubility limits. For example, how a repository design feature would affect solubility limits and, ultimately, the repository performance could be predicted by analyzing its effects on environmental conditions.

This report has three output types, each with its own treatments of variation of chemical conditions and uncertainty. Solubilities of actinides (i.e., americium, neptunium, protactinium, plutonium, thorium, and uranium) are tabulated for certain ranges of $\mathrm{pH}$ and $f \mathrm{CO}_{2}$ values with several uncertainty terms. For radium and lead, stochastic distributions are given. For those elements for which no solubility-controlling solids are expected to form under repository conditions (carbon, cesium, iodine, strontium, and technetium), a constant of 500 is assigned to their solubility. This number is not meant to be taken literally. Rather, it is meant to indicate that for these elements and conditions, the TSPA-LA calculation should use concentrations based 
on dissolution rate of individual waste forms, water volume, and the solubility caps presented in Table 8-5 instead of solubility controls. The effects of variations in important environmental conditions (namely, $\mathrm{pH}$ and $\log f \mathrm{CO}_{2}$ ) are accounted for by functional relations (tabulated) between solubilities and those conditions developed in Sections 6.5 through 6.18.

Uncertainty is associated with all of the steps in solubility evaluations. For example, it can be associated with the thermodynamic data used for the calculation. Another source is uncertainty in environmental conditions. Distinguishing uncertainty from temporal variability and understanding the major sources of uncertainty are prerequisites to estimating the uncertainty in the solubility values presented.

The uncertainties discussed in this section apply only to those dissolved concentrations tabulated in this report. For those elements flagged by the value of 500, because they are merely flags for the TSPA-LA model to use waste form dissolution rates or mass balance considerations to constrain their releases, the uncertainties should be based on those of the release rates.

Four types of uncertainty are associated with the output of this report: 1) in the thermodynamic data supporting the EQ3NR calculations, 2) due to variations in the chemistry of the water into which dissolution is occurring, 3) in the temperature, and 4) in activity coefficients. For some elements the identities of the solubility-controlling phases that exist over the repository lifetime is also uncertain. No uncertainty term is presented as output from this model for this uncertainty because calculated base-case model solubilities have been shown to be realistic (matching experimental data) or conservative.

Uncertainties in solubilities due to uncertainties in thermodynamic data, in the chemistry of the water into which dissolution occurs, and, for some elements, in the identity of the solubility-controlling phase are included as variables in the solubility expressions given for the actinide elements. Temperature uncertainties are treated as bounding or limiting conditions on the solubilities given. Activity coefficient uncertainties are also treated as bounding conditions when the ionic strength of the solutions does not exceed 1 molal (the nominal limit of applicability of the EQ3NR modeling code) (Wolery 1992 [DIRS 100836], p. 38) and the supporting database Data0.ymp.R2 (DTN: MO0302SPATHDYN.000 [DIRS 161756]). Additional activity coefficient uncertainty in solutions with ionic strengths from 1 to 3 molal is treated by augmenting the uncertainty applied to the solubility to account for thermodynamic data uncertainty (Section 6.3.3.4).

It is possible that the thermodynamic databases (Data0.ymp.R2 and Data0.yc3.RI) used for solubility calculations do not include all the species that may occur for the system of interest. The extensive review and data compilation efforts that would have been required to ensure important species are present are examined by Steinborn et al. 2003 [DIRS 161956]. Because of the extensive reviews conducted by the NEA (Grenthe et al. 1992 [DIRS 101671]; Silva et al. 1995 [DIRS 102087]; Lemire 2001 [DIRS 159027]) and others (e.g., Hummel et al. 2002 [DIRS 161904]), the most important or abundant species controlling the system chemistry for actinides are included in the databases. Therefore, there is no reason to expect other than small uncertainty from this source.

The NEA published an update on thermodynamic data for $\mathrm{U}, \mathrm{Np}, \mathrm{Pu}, \mathrm{Am}$, and Tc (Guillaumont et al. 2003 [DIRS 168382]). Table 6.3-2 compares the new results (Guillaumont et al. 2003 [DIRS 168382]) to those used in the creation of Data0.ymp.R2 
(DTN: MO0302SPATHDYN.000 [DIRS 161756]) for the most prevalent Am, Np, Pu, and U species modeled in EQ3. Inspection of the data suggests that its effect on this report is minimal.

Table 6.3-2. Comparison of $\Delta_{f} G^{0}$ Values for Major Aqueous Species

\begin{tabular}{|c|c|c|c|}
\hline & Species & $\begin{array}{l}\text { Values Used in Data0.ymp.R2 } \\
\text { (DTN: MO0302SPATHDYN.000 } \\
\text { [DIRS 161756]) (kJ/mol) }\end{array}$ & $\begin{array}{l}\text { Updated Value (Guillaumont et al. } \\
2003 \text { [DIRS 168382]) (kJ/mol) }\end{array}$ \\
\hline \multirow{4}{*}{$\begin{array}{l}\text { Major } \\
\text { Am } \\
\text { Species } \\
\text { (Figure } \\
6.9-2 \text { ) }\end{array}$} & $\mathrm{AmSO}_{4}{ }^{+}$ & $-1364.678 \pm 4.776$ & $-1361.538 \pm 4.89$ \\
\hline & $\mathrm{AmCO}_{3}{ }^{+}$ & $-1171.120 \pm 5.069$ & $-1172.262 \pm 5.289$ \\
\hline & $\mathrm{Am}\left(\mathrm{CO}_{3}\right)_{2}^{-}$ & $-1724.706 \pm 5.332$ & $-1728.131 \pm 5.911$ \\
\hline & $\mathrm{Am}\left(\mathrm{CO}_{3}\right)_{3}{ }^{3-}$ & $-2269.159 \pm 5.976$ & $-2268.018 \pm 7.521$ \\
\hline \multirow{3}{*}{$\begin{array}{l}\text { Major Np } \\
\text { Species } \\
\text { (Figure } \\
6.6-3) \\
\end{array}$} & $\mathrm{NpO}_{2}^{+}$ & $-907.765 \pm 5.652$ & $-907.765 \pm 5.628$ \\
\hline & $\mathrm{NpO}_{2} \mathrm{CO}_{3}^{-}$ & $-1463.988 \pm 5.652$ & $-1463.988 \pm 5.652$ \\
\hline & $\mathrm{NpO}_{2}\left(\mathrm{CO}_{3}\right)_{3}^{4-}$ & $-2185.949 \pm 15.451$ & $-2185.949 \pm 15.451$ \\
\hline \multirow{5}{*}{$\begin{array}{c}\text { Major Pu } \\
\text { Species } \\
\text { (Figures } \\
6.5-3 \text { and } \\
6.5-5 \text { ) }\end{array}$} & $\mathrm{PuO}_{2} \mathrm{SO}_{4}$ (aq) & $-1525.650 \pm 3.072$ & $-1525.650 \pm 3.072$ \\
\hline & $\mathrm{PuO}_{2}{ }^{+}$ & $-852.646 \pm 2.868$ & $-852.646 \pm 2.868$ \\
\hline & $\mathrm{PuO}_{2} \mathrm{CO}_{3}(\mathrm{aq})$ & $-1356.466 \pm 17.359$ & $-1344.479 \pm 4.180$ \\
\hline & $\mathrm{PuO}_{2}\left(\mathrm{CO}_{3}\right)_{3}{ }^{4-}$ & $-2447.085 \pm 5.977$ & $-2448.797 \pm 4.180$ \\
\hline & $\mathrm{PuO}_{2} \mathrm{CO}_{3}{ }^{-}$ & $-1409.771 \pm 3.002$ & $-1263.527 \pm 1.911$ \\
\hline \multirow{6}{*}{$\begin{array}{l}\text { Major U } \\
\text { Species } \\
\text { (Figure } \\
6.7-4 \text { ) }\end{array}$} & $\mathrm{UO}_{2} \mathrm{SO}_{4}(\mathrm{aq})$ & $-1714.535 \pm 2.021$ & $-1714.535 \pm 1.800$ \\
\hline & $\mathrm{UO}_{2} \mathrm{~F}^{+}$ & $-1263.128 \pm 2.021$ & $-1263.527 \pm 1.911$ \\
\hline & ${ }^{\mathrm{a}} \mathrm{UO}_{3}(\mathrm{aq})$ & $-1368.038 \pm N / A$ & $-1357.479 \pm 1.794$ \\
\hline & $\left(\mathrm{UO}_{2}\right)_{2} \mathrm{CO}_{3}(\mathrm{OH})_{3}^{-}$ & $-3139.525 \pm 4.517$ & $-3139.526 \pm 4.517$ \\
\hline & $\mathrm{UO}_{2}\left(\mathrm{CO}_{3}\right)_{3}{ }^{4-}$ & $-2659.543 \pm 2.123$ & $-2660.914 \pm 2.116$ \\
\hline & $\mathrm{UO}_{2}\left(\mathrm{CO}_{3}\right)_{2}{ }^{2-}$ & $-2105.044 \pm 2.033$ & $-2103.161 \pm 1.982$ \\
\hline
\end{tabular}

In determining the radionuclide concentration limits to be used in the recent safety analysis of a proposed geologic repository in Switzerland (NAGRA 2002 [DIRS 170922]), an analysis was made of the completeness of thermodynamic data available for modeling the solubilities of selected actinide elements (Berner 2002 [DIRS 162000]; Hummel and Berner 2002 [DIRS 170921]). These authors developed a list of aqueous species and solids for which data were available for actinide(III) species $\left(\mathrm{Np}^{+3}, \mathrm{Pu}^{+3}\right.$, and $\left.\mathrm{Am}^{+3}\right)$ and actinide(IV) species $\left(\mathrm{Th}^{+4}\right.$, $\mathrm{U}^{+4}, \mathrm{~Np}^{+4}$, and $\mathrm{Pu}^{+4}$ ). Because of the close chemical similarity of the members of these two groups of ions, there should be analogous aqueous species and solids for each member of each group with similar stability constants. Berner (2002 [DIRS 162000]) and Hummel and Berner (2002 [DIRS 170921]) found that for some elements, data were not available for one or more species. For these cases, they estimated the missing data and calculated solubilities. When these solubilities were compared with solubilities calculated using the incomplete data sets made up of only measured data, the results of the two sets of calculations were virtually identical for most elements, indicating that the missing data had no effect on the calculated solubilities. 
For $\mathrm{Pu}$, however, including the estimated species increased the calculated solubilities by a factor of 3 to 6 . The extent of this possible effect is discussed below.

The NAGRA (2002 [DIRS 170922]) studies are directly relevant only to the solubilities of these elements under the reducing conditions of the Swiss proposed repository where the actinide(III) and actinide(IV) oxidation states of these elements dominate in solution. They are applicable in this report only to $\mathrm{Am}$ and $\mathrm{Th}$, which are present as $\mathrm{Am}^{+3}$ and $\mathrm{Th}^{+4}$, even in the oxidizing conditions of the Yucca Mountain repository. Under these same oxidizing conditions, oxidation states of $\mathrm{U}, \mathrm{Np}$, and $\mathrm{Pu}$ dissolved from waste forms is dominated by actinide(V) and actinide(VI) species. Therefore, the conclusions of the Swiss studies cannot be extended to include them. Hummel et al. (2002 [DIRS 161904], Table 3) compared the data available in the NAGRA/PSI database for complexes and solids of actinide(VI) species, $\mathrm{UO}_{2}^{+2}, \mathrm{NpO}_{2}^{+2}$, and $\mathrm{PuO}_{2}^{+2}$. Data are available for all $\mathrm{UO}_{2}{ }^{+2}$ species, fewer $\mathrm{NpO}_{2}^{+2}$ species, and still fewer $\mathrm{PuO}_{2}^{+2}$ species. This suggests that missing data could have a larger effect on calculated $\mathrm{Pu}$ solubilities than on U solubilities. The extent of this possible effect cannot be estimated with the data at hand, however.

The remainder of this section provides a general discussion of these four types of uncertainty including their sources and the general procedure used their evaluation. The discussions of each element in Section 6 include element-specific information for evaluating the uncertainty in their concentrations. Element-specific uncertainties are summarized in Tables 8-3 and 8-4.

\subsubsection{Uncertainties in the log K Values of Controlling Solid(s) and Aqueous Species}

There are uncertainties in the thermodynamic data used to make the solubility calculations. Because of the complexity of the solubility modeling code, EQ3NR (Wolery 1992 [DIRS 100836]), uncertainties in the entire suite of supporting thermodynamic data were not propagated rigorously through the solubility calculations. Rather, uncertainties in the solubilities of the elements modeled considered uncertainties in the thermodynamic properties of the solubility-controlling solid and of the aqueous species that dominate the dissolved concentration of each element.

Uncertainties in the thermodynamic properties, specifically $\Delta_{\mathrm{f}} \mathrm{G}^{0}$ values, of the controlling solids and important aqueous species and the $\log \mathrm{K}$ values of reactions connecting them are treated explicitly. Uncertainties in these values propagate directly to uncertainties in log(solubilities). The $\log \mathrm{K}$ values used in the modeling are those in Data0.ymp.R2 (DTN: MO0302SPATHDYN.000 [DIRS 161756]), which do not include uncertainties. Uncertainties of $\Delta_{\mathrm{f}} \mathrm{G}^{0}$ values for americium, neptunium, plutonium, and uranium are those recommended in the NEA compilations (Grenthe et al. 1992 [DIRS 101671]; Silva et al. 1995 [DIRS 102087]; Lemire 2001 [DIRS 159027]; Guillaumont et al. 2003 [DIRS 168382]), from which the $\log \mathrm{K}$ values in Data0.ymp.R2 were derived. The uncertainties of $\log \mathrm{K}$ values for thorium species are based on the review of thorium data made to support the NAGRA/PSI database as documented by Hummel et al. (2002 [DIRS 161904]).

Guillaumont et al. (2003 [DIRS 168382], Appendix C) describe the technique used to develop the uncertainties given in the NEA and NAGRA/PSI database compilations (Grenthe et al. 1992 [DIRS 101671]; Silva et al. 1995 [DIRS 102087]; Lemire 2001 [DIRS 159027]; Hummel et al. 2002 [DIRS 161904]; Guillaumont et al. 2003 [DIRS 168382]). These 
uncertainties are based on least squares analyses of the underlying solution equilibrium data and are characterized in the captions for the data tables in each of the NEA volumes as "...total uncertainties and correspond in principal to the statistically defined $95 \%$ confidence interval" (e.g., Guillaumont et al. 2003 [DIRS 168382], Tables 3-1, 3-2, 4-1, 4-2, 5-1, 5-2, 6-1, 6-2, 7-1, $7-2,8-1$, and 8-2). In this report, uncertainties in solubility based on uncertainties in the underlying thermodynamic data are considered to be total uncertainties. This is the manner in which these uncertainties are treated in other nuclear waste management programs (e.g., Berner 2002 [DIRS 162000]). The "95\% confidence interval" is interpreted to mean tabulated values on data uncertainty representing two standard deviations $(2 \sigma)$ in a normal distribution. The uncertainties in the solubility values given in this report are reported as $1 \sigma$ values for normal distributions. Because the uncertainties of the underlying thermodynamic data are considered to be total uncertainties the distributions of solubilities should be truncated at $\pm 2 \sigma$.

The $\log \mathrm{K}$ values in Data0.ymp.R2 (DTN: MO0302SPATHDYN.000 [DIRS 161756]) are related to the standard thermodynamic properties by the expression $\Delta_{\mathrm{r}} \mathrm{G}^{0}=-\mathrm{RT} \operatorname{lnK} . \Delta_{\mathrm{r}} \mathrm{G}^{0}$ is derived from the $\Delta_{\mathrm{f}} \mathrm{G}^{0}$ values of reactants and species by the expression $\Delta_{\mathrm{r}} \mathrm{G}^{0}=\Sigma \Delta_{\mathrm{f}} \mathrm{G}_{\text {products }}^{0}-\Sigma \Delta_{\mathrm{f}} \mathrm{G}_{\text {reactants. The }}^{0}$ Thus, uncertainties in $\Delta_{\mathrm{f}} \mathrm{G}^{0}$ values propagate directly to uncertainties in $\log \mathrm{K}$ values. These, in turn, propagate directly to uncertainties in $\log$ solubilities. The solubility data provided in this report are given as log solubility values. The uncertainties in them are expressed as normal distributions of the log solubility values because they are derived from uncertainties in the standard thermodynamic properties, which are given as normal distributions.

The solubility of a substance depends not only on the properties of its controlling solid, but also on the properties of the aqueous species that contribute to its total solution concentration. Thus, the uncertainty of the solubility includes that of the controlling solid and those of the dominant aqueous species. The uncertainty attributable to the controlling solid is constant, but the uncertainty attributable to aqueous species varies because solubilities are reported for a range of chemical conditions over which the identity and relative importance of aqueous species differ widely. The uncertainty due to aqueous species is evaluated by examining the solution speciation indicated by the EQ3NR runs at selected chemical conditions. The process by which this uncertainty is evaluated can best be illustrated by specific examples (as described here for uranium and thorium). The calculations for the other elements to which this process was applied (plutonium, neptunium, and americium) are described in Sections 6.5, 6.6, and 6.9.

Figures 6.3-1 and 6.3-2 show concentrations of total dissolved $U$ and of aqueous species contributing to that concentration calculated at $f \mathrm{CO}_{2}=10^{-3.0}$ bars, and expressed as molalities and percents total $\mathrm{U}$, respectively. The figures span the $\mathrm{pH}$ range from 3.5 to 9.5 . As discussed in Section 6.7, these calculations are based on solubility control by three solids: the minerals schoepite $\left(\mathrm{UO}_{3} \cdot 2 \mathrm{H}_{2} \mathrm{O}\right)$ and $\mathrm{Na}$-boltwoodite $\left(\mathrm{NaUO}_{2} \mathrm{SiO}_{3} \mathrm{OH} \cdot 1.5 \mathrm{H}_{2} \mathrm{O}\right)$, which prevail at low and intermediate $\mathrm{pH}$ values, respectively; and the solid $\mathrm{Na}_{4} \mathrm{UO}_{2}\left(\mathrm{CO}_{3}\right)_{3}$, which is found in laboratory experiments under conditions of high $\mathrm{pH}$ and $\mathrm{fCO}_{2}$. The cusps in Figure 6.3-1 represent the point at which solubility control by one solid gives way to control by another.

Figure 6.3-2 shows the following species constitute more than 10 percent of the dissolved uranium under the range of conditions modeled: $\mathrm{UO}_{2}\left(\mathrm{CO}_{3}\right)_{3}{ }^{4-}, \mathrm{UO}_{2}\left(\mathrm{CO}_{3}\right)_{2}{ }^{2-},\left(\mathrm{UO}_{2}\right)_{2} \mathrm{CO}_{3}(\mathrm{OH})_{3}{ }^{-}$, $\mathrm{UO}_{3}(\mathrm{aq}), \mathrm{UO}_{2} \mathrm{~F}^{+}, \mathrm{UO}_{2} \mathrm{~F}_{2}(\mathrm{aq}), \mathrm{UO}_{2}{ }^{2+}, \mathrm{UO}_{2} \mathrm{SO}_{4}(\mathrm{aq})$, and $\left(\mathrm{UO}_{2}\right)_{2}(\mathrm{OH})_{2}{ }^{2+}$. 


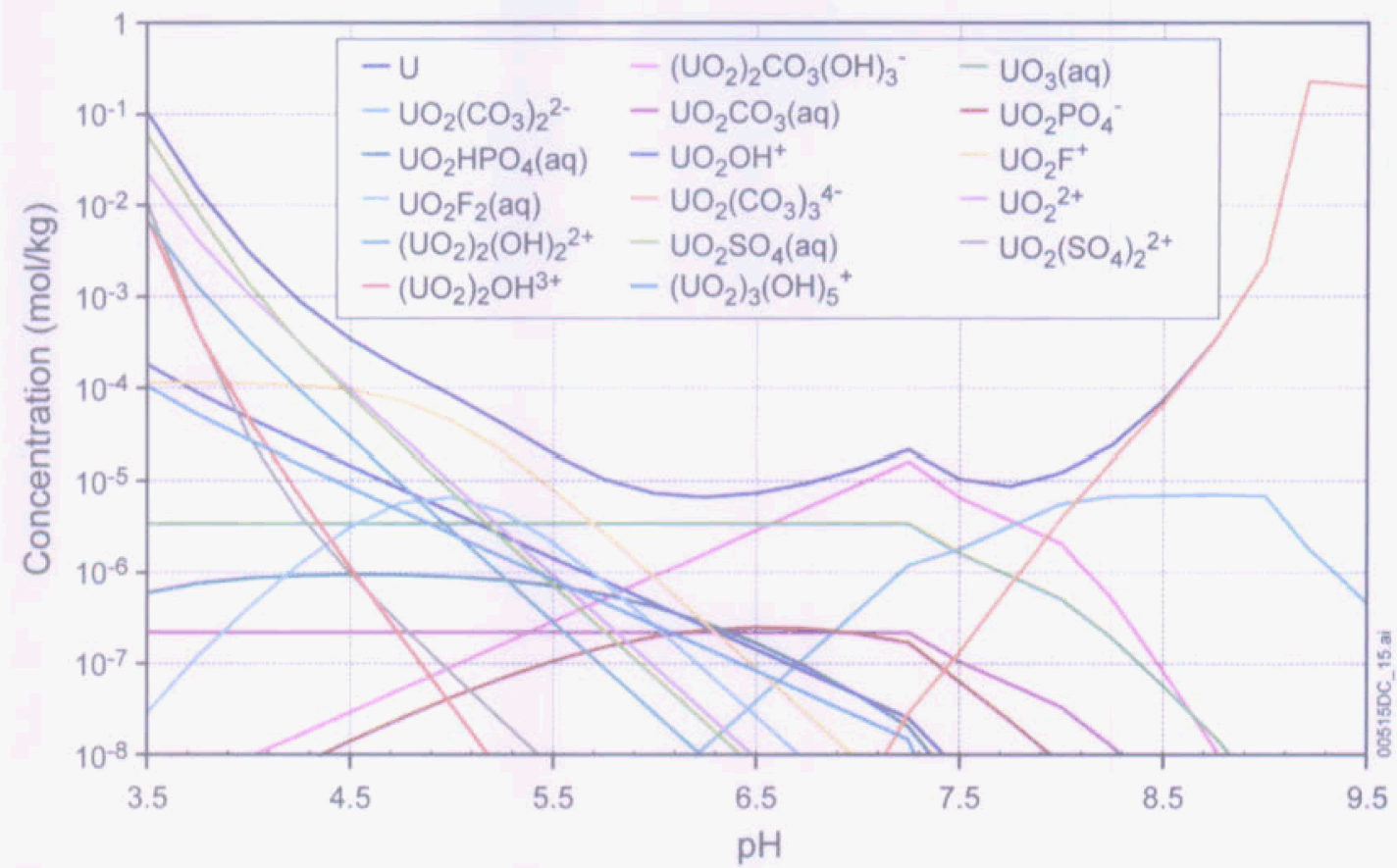

Source: Workbook $U$ chart highest, spreadsheet $U$ species plot.x/s (Appendix I).

NOTE: $\quad \mathrm{UO}_{3}(\mathrm{aq})$ (as indicated in DTN: MO0302SPATHDYN.000 [DIRS 161756]) is the nonconventional equivalent of $\mathrm{UO}_{2}(\mathrm{OH})_{2}(\mathrm{aq})$; the $\Delta_{1} \mathrm{G}^{0}$ value adopted for $\mathrm{UO}_{3}(\mathrm{aq})$ is consistent with those for $\mathrm{UO}_{2}(\mathrm{OH})_{2}(\mathrm{aq})$.

Figure 6.3-1. Total Uranium Concentration and Speciation Diagram in moles $\mathrm{U} / \mathrm{kg} \mathrm{H}_{2} \mathrm{O}$ Calculated at $\mathrm{fCO}_{2}=10^{-3.0}$ bars

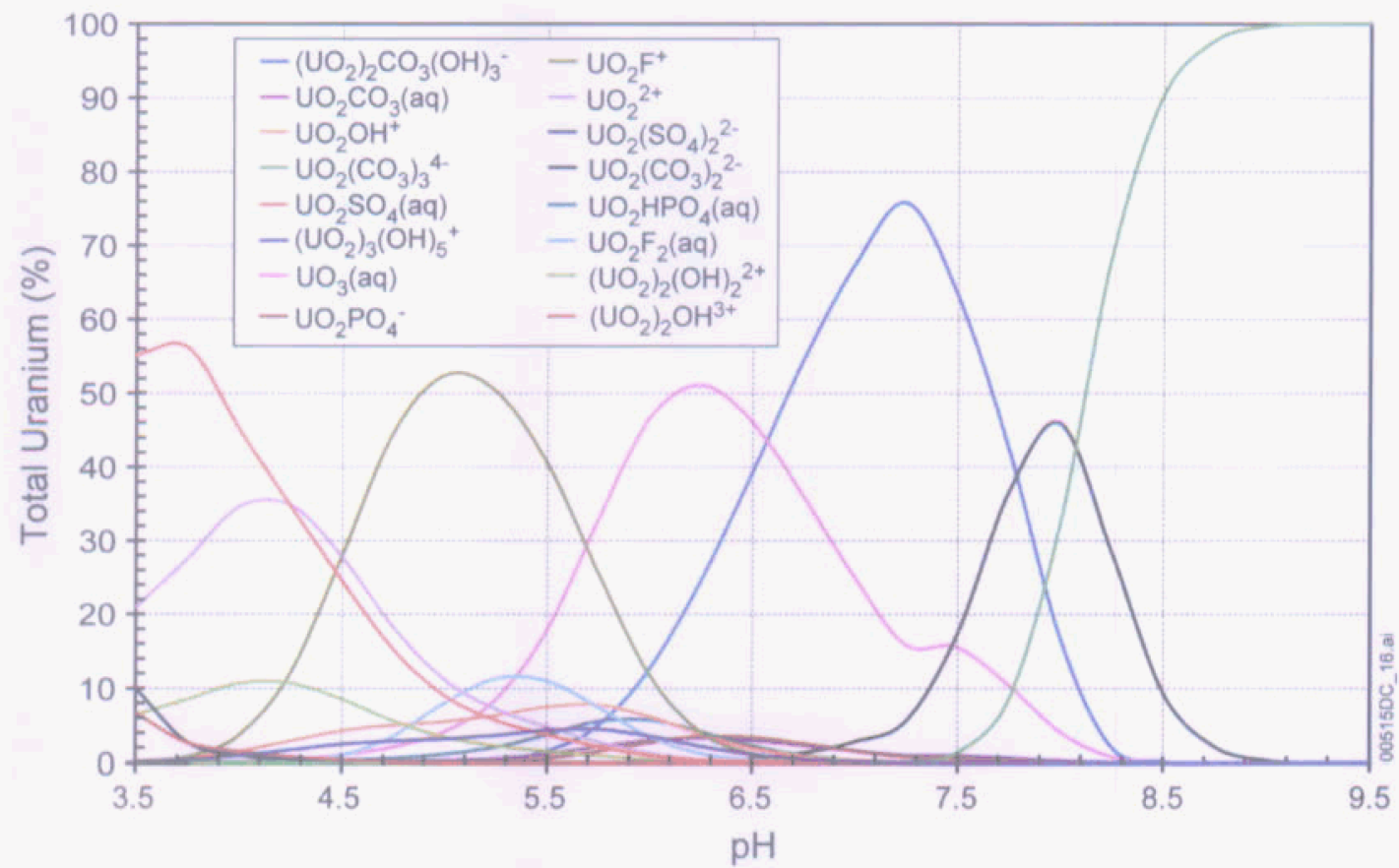

Source: Workbook Chart percent, spreadsheet $U$ species plot.xls (Appendix I).

NOTE: $\quad \mathrm{UO}_{3}(\mathrm{aq}$ ) (as indicated in DTN: MO0302SPATHDYN.000 [DIRS 161756]) is the nonconventional equivalent of $\mathrm{UO}_{2}(\mathrm{OH})_{2}(\mathrm{aq})$; the $\Delta \mathrm{G}^{0}$ value adopted for $\mathrm{UO}_{3}(\mathrm{aq})$ is consistent with those for $\mathrm{UO}_{2}(\mathrm{OH})_{2}(\mathrm{aq})$.

Figure 6.3-2. Uranium Speciation Diagram in Percent Total Uranium Calculated at $\mathrm{fCO}_{2}=10^{-3.0}$ bars 
Consider the reaction describing the dissolution of the controlling solid, $\mathrm{UO}_{3} \cdot 2 \mathrm{H}_{2} \mathrm{O}$, to one of the dominant species, $\mathrm{UO}_{2}\left(\mathrm{CO}_{3}\right)_{2}{ }^{2-}$ :

$$
\mathrm{UO}_{3} \cdot 2 \mathrm{H}_{2} \mathrm{O}+2 \mathrm{HCO}_{3}^{-}=\mathrm{UO}_{2}\left(\mathrm{CO}_{3}\right)_{2}{ }^{2-}+3 \mathrm{H}_{2} \mathrm{O} \text {. }
$$

This reaction is written in terms of $\mathrm{HCO}_{3}{ }^{-}$, rather than $\mathrm{CO}_{3}{ }^{2-}$, because under the $\mathrm{pH}$ range expected, the concentration of bicarbonate exceeds that of carbonate.

The standard-state Gibbs free energy of the reaction $\left(\Delta_{\mathrm{r}} \mathrm{G}^{0}\right)$ is the value needed to calculate its $\log \mathrm{K}$ using $\Delta_{\mathrm{r}} \mathrm{G}^{0}=-\mathrm{RT} \ln \mathrm{K}$. This equals:

$$
\Delta_{\mathrm{r}} \mathrm{G}^{0}\left(\mathrm{UO}_{2}\left(\mathrm{CO}_{3}\right)_{2}{ }^{2-}\right)=\Delta_{\mathrm{f}} \mathrm{G}^{0}\left(\mathrm{UO}_{2}\left(\mathrm{CO}_{3}\right)_{2}{ }^{2-}\right)+3 \cdot \Delta_{\mathrm{f}} \mathrm{G}^{0}\left(\mathrm{H}_{2} \mathrm{O}\right)-\Delta_{\mathrm{f}} \mathrm{G}^{0}\left(\mathrm{UO}_{3} \cdot 2 \mathrm{H}_{2} \mathrm{O}\right)-2 \cdot \Delta_{\mathrm{f}} \mathrm{G}^{0}\left(\mathrm{HCO}_{3}{ }^{-}\right) .
$$

Because this expression is a simple algebraic sum, the uncertainties of the $\Delta_{\mathrm{f}} \mathrm{G}^{0}$ terms can be combined to give the uncertainty of $\Delta_{\mathrm{r}} \mathrm{G}^{0}\left(\mathrm{UO}_{2}\left(\mathrm{CO}_{3}\right)_{2}{ }^{2-}\right)$ by the square root of the mean (Bevington 1969 [DIRS 146304], Section 4-2). This procedure gives $\pm 2.703 \mathrm{~kJ} / \mathrm{mol}$ for $2 \sigma \Delta_{\mathrm{r}} \mathrm{G}^{0}\left(\mathrm{UO}_{2}\left(\mathrm{CO}_{3}\right)_{2}{ }^{2-}\right)$. Dividing this by $-\mathrm{RT} \ln (10)(=-5.708 \mathrm{~kJ} / \mathrm{mol}$ at $298.15 \mathrm{~K})$ gives $2 \sigma \log \mathrm{K}= \pm 0.47$ ( $\log K$ Uncertainties_040624.xls in Appendix I). When this procedure is followed for all nine dominant aqueous species listed earlier, it is found that $\mathrm{pH}$ values above about 6.5 (for $f \mathrm{CO}_{2}=10^{-3.0}$ bars as used in the calculation illustrated) where the dominant species are carbonate and hydroxycarbonate complexes, the largest uncertainty is for $\left(\mathrm{UO}_{2}\right)_{2} \mathrm{CO}_{3}(\mathrm{OH})_{3}^{-}$at $2 \sigma \log \mathrm{K}= \pm 0.99$. At lower $\mathrm{pH}$ values, where fluoride and sulfate complexes and $\mathrm{UO}_{2}{ }^{2+}$ dominate, the largest uncertainties are for the two fluoride complexes, $\mathrm{UO}_{2} \mathrm{~F}_{2}(\mathrm{aq})$ and $\mathrm{UO}_{2} \mathrm{~F}^{+}$at \pm 0.55 and \pm 0.48 , respectively, and for $\mathrm{UO}_{2} \mathrm{SO}_{4}(\mathrm{aq})$ at \pm 0.44 . The largest $2 \sigma \log \mathrm{K}$ value of \pm 0.99 leads to a $1 \sigma$ standard deviation for the solubility value of \pm 0.5 , which is applied in a normal distribution truncated at $\pm 2 \sigma$ for all uranium concentrations.

A different approach must be taken to estimate the uncertainty of thorium solubilities because the source of the uncertainty data (Hummel et al. 2002 [DIRS 161904]) gives uncertainties for $\log \mathrm{K}$ values rather than for $\Delta_{\mathrm{f}} \mathrm{G}^{0}$ values. The NEA compilations (Grenthe et al. 1992 [DIRS 101671]; Silva et al. 1995 [DIRS 102087]; Lemire 2001 [DIRS 159027]; and Guillaumont et al. 2003 [DIRS 168382]), from which uncertainty data for uranium, americium, plutonium, and neptunium were taken, also give uncertainty data for some, but not all, necessary $\log \mathrm{K}$ values. Uncertainties based on $\Delta_{\mathrm{f}} \mathrm{G}^{0}$ values were used for these elements unless only uncertainties for $\log \mathrm{K}$ values were available.

The principal dissolved thorium species accounting for more than 10 percent of the total dissolved thorium ( $\mathrm{Th}\left(\mathrm{SO}_{4}\right)_{2}(\mathrm{aq}), \mathrm{ThF}_{2}{ }^{2+}, \mathrm{ThF}_{3}{ }^{+}, \mathrm{ThF}_{4}(\mathrm{aq}), \mathrm{Th}(\mathrm{OH})_{3} \mathrm{CO}_{3}{ }^{-}, \mathrm{Th}(\mathrm{OH})_{4}(\mathrm{aq})$, and $\mathrm{Th}\left(\mathrm{CO}_{3}\right)_{5}{ }^{6-}$ ) were taken from the Th-speciation diagram (Figure 6.4-13).

As an example of the approach taken for thorium, consider the reaction for the dissolution of the controlling solid, $\mathrm{ThO}_{2}(\mathrm{am})(\mathrm{am}=$ amorphous $)$, to one of the important species, $\mathrm{Th}(\mathrm{OH})_{4}(\mathrm{aq})$ :

$$
\mathrm{ThO}_{2}(\mathrm{am})+2 \mathrm{H}_{2} \mathrm{O}=\mathrm{Th}(\mathrm{OH})_{4}(\mathrm{aq})
$$


The uncertainty of this reaction is not given by Hummel et al. (2002 [DIRS 161904]). However, this reaction can be taken as the sum of two other reactions for which Hummel et al. (2002 [DIRS 161904]) provide uncertainty data. These are:

$$
\begin{gathered}
\mathrm{ThO}_{2}(\mathrm{~s})+4 \mathrm{H}^{+}=\mathrm{Th}^{4+}+2 \mathrm{H}_{2} \mathrm{O}, 2 \sigma \log \mathrm{K}= \pm 0.8 \\
\mathrm{Th}^{4+}+4 \mathrm{H}_{2} \mathrm{O}=\mathrm{Th}(\mathrm{OH})_{4}(\mathrm{aq})+4 \mathrm{H}^{+}, 2 \sigma \log \mathrm{K}= \pm 0.6
\end{gathered}
$$

These reactions sum to the overall dissolution reaction. Combining their uncertainties using the square root of the mean gives $2 \sigma \log \mathrm{K}= \pm 1.0$ (Th Uncertainty.xls in Appendix I). When this procedure is followed for all seven dominant aqueous species listed earlier, it is found that the uncertainties in $2 \sigma \log \mathrm{K}$ for the carbonate complexes, which dominate at $\mathrm{pH}$ values above about 6 , are \pm 1.3 for $\mathrm{Th}(\mathrm{OH})_{3} \mathrm{CO}_{3}{ }^{-}$and \pm 1.4 for $\mathrm{Th}\left(\mathrm{CO}_{3}\right)_{5}{ }^{6-}$. At lower $\mathrm{pH}$ values where $\mathrm{Th}\left(\mathrm{SO}_{4}\right)_{2}$ (aq), $\mathrm{ThF}_{2}{ }^{2+}, \mathrm{ThF}_{3}{ }^{+}$and $\mathrm{ThF}_{4}$ (aq) dominate, the uncertainties range from $2 \sigma \log \mathrm{K}$ values of \pm 0.8 for $\mathrm{Th}\left(\mathrm{SO}_{4}\right)_{2}(\mathrm{aq})$ to \pm 1.3 for $\mathrm{ThF}_{3}{ }^{+}$, and $\mathrm{ThF}_{4}(\mathrm{aq})$. These lead to a $1 \sigma$ standard deviation for Th solubility of \pm 0.7 , which is used in a normal distribution truncated at $\pm 2 \sigma$ for all thorium concentrations.

$\mathrm{ThO}_{2}$ (s) appears in the first of the two subreactions rather than $\mathrm{ThO}_{2}(\mathrm{am})$, which is the designation of the controlling phase in Data0.ymp.R2 (DTN: MO0302SPATHDYN.000 [DIRS 161756]) used for the modeling. The terminology of $\mathrm{ThO}_{2}$ solids is discussed in Section 5.21.2 of NAGRA/PSI Chemical Thermodynamic Data Base 01/01 (Hummel et al. 2002 [DIRS 161904]). The solid they refer to as $\mathrm{ThO}_{2}(\mathrm{~s})$ is also known as $\mathrm{ThO}_{2}(\mathrm{am})$.

The approach taken here is to apply the largest uncertainty associated with any aqueous species representing $>10 \%$ of the total concentration at any $\mathrm{pH}$ and $f \mathrm{CO}_{2}$ to concentrations at all $\mathrm{pH}$ and $f \mathrm{CO}_{2}$ values. This leads to maximum uncertainties because it is likely that other aqueous species with lower uncertainties dominate at different $\mathrm{pH}$ and $f \mathrm{CO}_{2}$ values. While it would be possible in principle to examine the results of the aqueous speciation calculations and derive uncertainty values for each $\mathrm{pH}$ and $f \mathrm{CO}_{2}$, the additional interpretive effort required would be extensive. This was not deemed necessary because the adopted approach led to the highest and, therefore, most conservative uncertainty estimates.

\subsubsection{Uncertainties in Water Chemistry}

The selection of the chemical characteristics of the water used for the solubility calculations is discussed in Section 6.4. The effects of uncertainties on the composition of that water on the modeled solubilities are examined here.

As shown in Section 6.4.2.5.1, aqueous carbonate and hydroxycarbonate complex species are the principal contributors to actinide solubilities at high $\mathrm{pH}$ values, while sulfate complexes are the principal contributors at low $\mathrm{pH}$ values. Under moderately acid conditions, solubilities are also very sensitive to fluoride because of the formation of fluoride aqueous complex species. Carbonate and hydroxide concentrations depend on $\mathrm{pH}$ and $f \mathrm{CO}_{2}$. The solubilities are tabulated in terms of $\mathrm{pH}$ and $f \mathrm{CO}_{2}$, so the sensitivities to variations in these ligands are considered explicitly. As discussed in Section 6.4.3.5, sulfate concentrations are varied in the modeling to maintain charge balance at lower $\mathrm{pH}$ values in order to simulate the occurrence of $\mathrm{H}_{2} \mathrm{SO}_{4}$ in the in-package environment from the possible oxidation of sulfur during steel degradation. In this 
way, sulfate variations are also considered explicitly in this report. Variations in fluoride concentrations are not treated explicitly in this report so their effects must be included as uncertainties in the total actinide concentrations.

Solubilities of the actinides are sensitive to the fluoride contents of the water because of the strength of actinide ion-fluoride solution complexes (Section 6.4.2.5.1). Analyses of the sensitivity of actinide concentrations to solution $\mathrm{F}^{-}$concentrations were carried out for three cases, which correspond to the three abstractions from In-Package Chemistry Abstraction (BSC 2004 [DIRS 167621]): 1) CSNF waste package breached under normal conditions or by seismic activity (CSNF water influx model), 2) codisposal waste package with alteration by water from condensation only (codisposal vapor influx model) and 3) codisposal waste package with alteration by seepage water and CSNF waste package breached by igneous activity (codisposal water influx model). The maximum fluoride concentrations in each environment are given in Table 6.3-3. Except for the first case (1), the $\mathrm{F}^{-}$contents used for each analysis are the maximum values provided in In-Package Chemistry Abstraction (BSC 2004 [DIRS 167621], Table 8-6). For case (1), the modeling supporting the sensitivity analysis was carried out using $10 \times$ the $\mathrm{J}-13$ well water $\mathrm{F}^{-}$content before the results of the abstractions were available. Because $10 \times$ the $\mathrm{J}-13$ well water $\mathrm{F}^{-}$content is slightly higher than the results of the abstractions and, thus, would lead to higher conservative actinide concentrations, the analysis was not rerun with the In-Package Chemistry Abstraction (BSC 2004 [DIRS 167621]) values.

Table 6.3-3. Fluoride Concentrations from In-Package Chemistry Abstraction Report used in Uncertainty Analyses

\begin{tabular}{|c|c|c|c|c|c|}
\hline \multirow[b]{2}{*}{ Situation } & \multicolumn{2}{|c|}{ Maximum $\mathrm{F}^{-}$} & \multirow[b]{2}{*}{ Source } & \multirow{2}{*}{$\begin{array}{c}F^{-} \text {Used for } \\
\text { Sensitivity } \\
\text { Analysis (mg/L) }\end{array}$} & \multirow{2}{*}{$\begin{array}{c}\text { Multiplication } \\
\text { Factor from Base } \\
\text { Case } \\
\end{array}$} \\
\hline & mol & $\mathrm{mg} / \mathrm{l}$ & & & \\
\hline Base Case & 1.15E-04 & 2.18 & $\begin{array}{c}\text { J-13 Well Water } \\
\text { (Table 4-2) }\end{array}$ & 2.18 & $1 x$ \\
\hline CSNF Water Influx & $9.8 \mathrm{E}-04$ & 18.6 & $\begin{array}{c}\text { (BSC 2004 [DIRS } \\
\text { 167621], Table 8-6 }\end{array}$ & 21.8 & $10 x$ \\
\hline Codisposal (Vapor Influx) & 1.1E-02 & 209.0 & $\begin{array}{c}\text { (BSC 2004 [DIRS } \\
\text { 167621], Table 8-6 }\end{array}$ & 209 & $95 x$ \\
\hline Codisposal (Water Influx) & $3.1 \mathrm{E}-03$ & 58.90 & $\begin{array}{l}\text { (BSC } 2004 \text { [DIRS } \\
\text { 167621], Table 8-6 }\end{array}$ & 58.89 & $27 x$ \\
\hline
\end{tabular}

Source: F_Cons in sens runs_a.x/s (Appendix I).

Tables showing the effects of varying fluoride concentrations on the solubilities of $\mathrm{Pu}, \mathrm{Np}, \mathrm{U}$ are given in Sections 6.5 through 6.7. They show the fluoride effect varies with $\mathrm{pH}$. To capture this variation, uncertainties applied to the $\mathrm{Pu}, \mathrm{Np}, \mathrm{U}$ concentrations to account for uncertainties in the $\mathrm{F}^{-}$concentrations are expressed as functions of $\mathrm{pH}$. These are given in uncertainty tables for each actinide listed. The values in the uncertainty tables (presented in Sections 6.5 through 6.7) are the differences between solubilities calculated using the $\mathrm{F}^{-}$values for sensitivity analyses and the base-case solubility values.

The effects of fluoride on the solubility of Th and Am are given in Sections 6.8 and 6.9, respectively. For these actinides, only the maximum uncertainty associated with fluoride 
uncertainty is used in the model with no $\mathrm{pH}$ dependence (Sections 6.8.4.2, 6.8.5, 6.9.4.2, and 6.9.5).

For $\mathrm{Pu}, \mathrm{Np}$, and $\mathrm{U}$, the uncertainties due to varying fluoride uncertainties are given as functions of $\mathrm{pH}$. However, it is difficult for the TSPA-LA model to implement uncertainty as a function of $f \mathrm{CO}_{2}$. Thus, uncertainty associated with fluoride is based on calculations made at a single $f \mathrm{CO}_{2}$ value $\left(10^{-3.0}\right.$ bars $)$.

The uncertainties due to fluoride are treated as a one-sided triangular distribution with the minimum (designated "a"), the most probable concentrations (designated " $b$ "), those of the basecase and the maximum concentration (designated "c") calculated with adjusted fluoride concentration (see individual uncertainty sections for more information). As the name suggests, the probability density function of a triangular distribution has the shape of triangle. A triangular distribution is defined by the three vertices of a triangle (the minimum, a; the most probable b; and the maximum, $\mathrm{c}$ ). The area under the triangle equals 1 . For the uncertainties due to fluoride, $\mathrm{a}=\mathrm{b}=0$, and $\mathrm{c}=$ maximum uncertainty (creating a right triangle). The maximum concentrations in each of the three environments considered are given as functions of $\mathrm{pH}$ for $\mathrm{Pu}$, $\mathrm{Np}$, and $\mathrm{U}$ and as single values for Th and Am (tables in Sections 6.5 through 6.9).

\subsubsection{Uncertainties in Temperature}

All calculations were made at $25^{\circ} \mathrm{C}$, although liquid water can exist at temperatures up to $100^{\circ} \mathrm{C}$ or more. To estimate the effects of changing temperature on solubilities, calculations were made at $100^{\circ} \mathrm{C}$ for a range of $\mathrm{pH}$ values at a single $f \mathrm{CO}_{2}$. These results are summarized in Table 6.3-4.

Because differences vary with $\mathrm{pH}$, the maximum and minimum differences for each element are given. In all cases, solubilities at $100^{\circ} \mathrm{C}$ are lower than those at $25^{\circ} \mathrm{C}$ because, for each mineral listed in Table 6.3-4, the $\log \mathrm{K}$ for the dissolution reaction in the thermodynamic database (DTN: MO0302SPATHDYN.000 [DIRS 161756]) is lower at higher temperatures. For example, the $\log \mathrm{K}$ values for schoepite dissolution at $25^{\circ} \mathrm{C}$ and $60^{\circ} \mathrm{C}$ are 4.8443 and 3.9389 , respectively. The minimum differences in the logs of the solubilities in Table 6.3-4 range from -0.27 to -2.06 , and the maximum differences from -1.77 to -4.88 .

Solubilities given in this report are for $25^{\circ} \mathrm{C}$. This is a conservative approach because the lower solubilities at higher temperatures allow for maximum dissolved concentrations of radionuclides in solution.

Table 6.3-4. Differences in Solubility of Solids Modeled at $25^{\circ} \mathrm{C}$ and $100^{\circ} \mathrm{C}$

\begin{tabular}{|l|c|c|c|c|c|c|}
\hline & Solid & $\mathrm{PuO}_{2}$ & $\mathrm{~Np}_{2} \mathrm{O}_{5}$ & $\mathrm{NpO}_{2}$ & $\begin{array}{c}\text { Schoepite } \\
\left(\mathrm{UO}_{3} \cdot 2 \mathrm{H}_{2} \mathrm{O}\right)\end{array}$ & $\mathrm{AmOHCO}_{3}$ \\
\hline Minimum Difference & $\log [\mathrm{C}]_{100 \mathrm{C}}-\log [\mathrm{C}]_{25 \mathrm{C}}$ & -0.79 & -1.48 & -1.76 & -0.27 & -2.06 \\
\hline Maximum Difference & $\log [\mathrm{C}]_{100 \mathrm{C}}-\log [\mathrm{C}]_{25 \mathrm{C}}$ & -3.74 & -4.11 & -4.88 & -1.77 & -3.85 \\
\hline
\end{tabular}

Source: Appendix I: PuO2 Solubility.x/s (cells K63:K64), Np2O5 Solubility for Pa.xls (cells W29, W32), NpO2 Solubility for Pa.x/s (cells W32, W33), U Solubility.x/s (cells AJ27, AJ28), and Am Solubility.x/s (W23, W24).

NOTE: Calculations were made at $\log \left(\mathrm{fCO}_{2}\right.$ bars $)=-3.00$ for range of $\mathrm{pH}$ values. Maximum and minimum differences occur at different $\mathrm{pH}$ values. 
Because retrograde solubilities are unusual, the results in Table 6.3-4 merit further scrutiny. Inspection of the source files for the table shows that the maximum decrease in solubility at the higher temperature occurs at high $\mathrm{pH}$ values. As the speciation diagrams in Sections 6.4 through 6.9 illustrate, the aqueous species that contribute most to actinide solubilities at high $\mathrm{pH}$ values are carbonate complexes. The solubility modeling is carried out at a series of fixed values of $\mathrm{CO}_{2}$. As temperature increases, the solubility of gases, including $\mathrm{CO}_{2}$ decreases. Thus, higher temperatures lead to lower dissolved-carbonate concentrations that generate lower concentrations of carbonate complexes leading to lower actinide solubilities.

\subsubsection{Uncertainties of Activity Coefficients}

Electrolyte solutions differ substantially from ideal solutions. Nevertheless, thermodynamic calculations for solutes are based on the equations for ideal solutions with the use of approximate corrections, known as activity coefficients. Activity coefficients are multiplied by concentrations, specifically molalities, to obtain the activities needed in calculations of solubilities (i.e., $\gamma_{i} m_{i}=a_{i}$; where $\gamma_{i}$ is the activity coefficient; $m_{i}$, the molality (such as the solubility of a solid); and $a_{i}$, the activity for the ion, i). The smaller the value of $\gamma$ for a given activity calculated, for example, from a solubility product, the larger the molality or solubility. Activity coefficients for molecular solutes tend to increase with solution ionic strength ("salting out" effect) while those for ionic solutes tend to decrease with ionic strength ("salting in" effect) (Langmuir 1997 [DIRS 100051], Section 4.4).

An equation generally used for calculating single ion activity coefficients was developed by Hückel (Langmuir 1997 [DIRS 100051], p. 133). It consists of the conventional extended Debye-Hückel equation with a second term linear in ionic strength:

$$
\log \gamma_{i}=\frac{-\mathrm{A} \times z_{i}^{2} \times \sqrt{\mu}}{1+B \times a_{i} \times \sqrt{\mu}}+b \times \mu
$$

where

$\gamma_{\mathrm{i}}=$ activity coefficient of ion, $\mathrm{i}$

$\mathrm{z}_{\mathrm{i}}=$ charge of ion, $\mathrm{i}$

A, B = temperature-dependent properties of the solvent (Langmuir 1997 [DIRS 100051], p. 128)

$\mu=$ ionic strength $=0.5 \sum_{j} m_{j} z_{j}^{2}$

$\mathrm{m}_{\mathrm{j}}, \mathrm{z}_{\mathrm{j}}=$ molality and charge of each ion $\mathrm{j}$ in the solution

$\mathrm{a}_{\mathrm{i}}=$ ion-specific parameter

$\mathrm{b}=$ ion-specific or temperature-dependent parameter.

Two variants of this equation are included in widely used aqueous speciation modeling codes. One, referred to as the B-dot equation (Wolery 1992 [DIRS 100836], Chapter 3), is used in version $7.2 b$ and $7.2 \mathrm{bLV}$ of EQ3NR and EQ6. In the equation, $\mathrm{a}_{i}$ is the effective diameter or ion-size parameter, values of which, for virtually all solute ions, are available in the literature (Kielland 1937 [DIRS 151237]) and handbooks (Langmuir 1997 [DIRS 100051], Table 4.1), or can be estimated by analogy to ions whose values are listed (Steinborn et al. 2003 
[DIRS 161956], Section 9.2.2). The B-dot parameter (b) is a function of temperature only. Values for B-dot, as well as for the solvent parameters A and B, at various temperatures are given in the "miscellaneous parameters" block of Data0.ymp.R2. Values of $\mathrm{a}_{\mathrm{i}}$ for each ion included in the database are given in the "B-dot parameters" block.

In the second variant of the Hückel equation, the $a_{i}$ and $b$ parameters are ion-specific with values based on fits to ion activity data derived from measured mean salt-activity coefficients of electrolyte solutions. In this form, it is known as the WATEQ or Truesdell-Jones equation and is employed in PHREEQC (Nordstrom and Munoz 1986 [DIRS 153965], Section 7.6; Parkhurst and Appelo 1999 [DIRS 159511], p. 11). The Truesdell-Jones equation reproduces mean salt activity coefficients to ionic strengths of several molal, but because parameters are available only for major ions its use is limited. Calculations made using the Truesdell-Jones equation are included in the comparison given here. Parameter values used are from Table 7.6 of Geochemical Thermodynamics (Nordstrom and Munoz 1986 [DIRS 153965]), and are equivalent to those in the PHREEQC database distributed with the code (Parkhurst and Appelo 1999 [DIRS 159511], Attachment B, Table 55).

The effects of the formation of ion pairs and other complex solute species are incorporated in the activity coefficient corrections through the ionic strength term. Total, or stoichiometric, ionic strength is calculated using the total concentration of dissolved salts ignoring the formation of solute complexes. The effective, or true, ionic strength is calculated from the free and complexed ions actually present in the solution and is in all cases lower than the stoichiometric ionic strength. This is because the formation of solution complexes removes charged species from the ionic strength calculation and the complex always has a lower charge than its component ions.

All known activity coefficient models have limitations, which introduce increasing uncertainty into the calculations as ionic strength increases. The B-dot equation used in Data0.ymp.R2 and Data0.yc3.R1 is considered valid up to ionic strengths of 1 molal (Steinborn et al. 2003 [DIRS 161956], p. 60). Accordingly, no uncertainty related to activity coefficients is introduced into the solubility results for solutions of ionic strengths below 1 molal. Some of the solutions modeled in the course of calculating the concentrations given in this report exceeded 1 molal. The concentration results from such solutions were rejected, with one exception: uranium concentrations at high $\mathrm{pH}$ and $f \mathrm{CO}_{2}$ values are associated with ionic strengths to 2.5 molal. As discussed in Section 6.7.5.2, the concentration uncertainty associated with $\log K$ (Section 6.3.3.1) was augmented to account for the increased uncertainty in activity coefficients in these solutions.

The remainder of this section develops the additional uncertainty associated with concentrations in solutions of ionic strengths above 1 molal. This is done by comparing ion activity coefficients calculated using the two forms of the Hückel equation with values derived from measurements of solution properties. The conclusions are corroborated by reference to other YMP documents in which activity coefficient values calculated with the B-dot form of the Hückel equation are compared with values calculated with other activity coefficient expressions.

Measured activity coefficients of electrolyte solutions found in handbooks (e.g., Robinson and Stokes 1965 [DIRS 108567]) are not those of individual ions, but mean activity coefficients of 
all ions comprising the dissolved salt. Mean salt activity coefficients are related to individual ion activity coefficients by the expression:

$$
\gamma_{ \pm}=\left(\gamma_{+}^{\nu_{+}} \gamma_{-}^{\nu_{-}}\right)^{1 /\left(v_{+}+v_{-}\right)}
$$

where

$$
\begin{aligned}
& \gamma_{ \pm}=\text {mean salt coefficient of the electrolyte } \\
& \gamma_{+}, v_{+}=\text {activity coefficient and stoichiometric coefficient of the cation } \\
& \gamma_{-}, v_{-}=\text {activity coefficient and stoichiometric coefficient of the anion. }
\end{aligned}
$$

To extract individual ion activities from mean salt activity coefficient data using this expression the activity coefficient of at least one ion must be found. This is done using the MacInnes convention (Nordstrom and Munoz 1986 [DIRS 153965], Section 7.6) that $\gamma_{\mathrm{K}+}=\gamma_{\mathrm{Cl} .}$. Thus, from the mean salt activity coefficients of $\mathrm{KCl}$, the activities of the $\mathrm{K}^{+}$and $\mathrm{Cl}^{-}$ion are calculated:

$$
\begin{aligned}
& \gamma_{K C l}=\left(\gamma_{K^{+}} \gamma_{C l^{-}}\right)^{1 / 2} \\
& \gamma_{K^{+}}=\gamma_{C l^{-}}=\gamma_{K C l}
\end{aligned}
$$

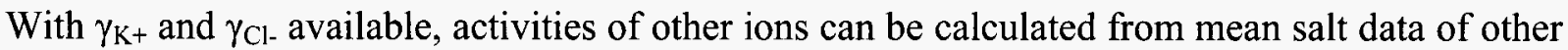
electrolytes. For example:

$$
\begin{gathered}
\gamma_{\mathrm{Na}^{+}}=\frac{\gamma_{\mathrm{NaCl}}^{2}}{\gamma_{\mathrm{Cl}^{-}}} \\
\gamma_{\mathrm{Ca}^{2+}}=\frac{\gamma_{\mathrm{CaCl} l_{2}}^{3}}{\gamma_{\mathrm{Cl}^{-}}^{2}}
\end{gathered}
$$

$\gamma_{\mathrm{SO} 4}{ }^{2-}$ could be calculated from handbook data for $\mathrm{K}_{2} \mathrm{SO}_{4}$ or $\mathrm{Na}_{2} \mathrm{SO}_{4}$ solutions except for the formation of $\mathrm{KSO}_{4}{ }^{-}$and $\mathrm{NaSO}_{4}{ }^{-}$ion pairs. To minimize the disturbing effects of $\mathrm{SO}_{4}{ }^{2-}$ ion pairs, $\gamma_{\mathrm{SO} 4}{ }^{2-}$ is better calculated using:

$$
\begin{aligned}
& \gamma_{C s^{+}}=\frac{\gamma_{C s C l}^{2}}{\gamma_{C l^{-}}} \\
& \gamma_{S_{4}^{2-}}=\frac{\gamma_{C_{2} S O_{4}}^{3}}{\gamma_{C s^{+}}^{2}}
\end{aligned}
$$

Activity coefficients for the cations $\mathrm{Na}^{+}$and $\mathrm{Ca}^{2+}$ and the anions $\mathrm{Cl}^{-}$and $\mathrm{SO}_{4}{ }^{2-}$ were calculated up to ionic strengths of 3 molal using the B-dot equation of version 7.2b of EQ3NR and EQ6 and compared with values calculated from handbook mean salt data and values calculated using the Truesdell-Jones equation. The calculations, supporting data, and results are in gamma comp calcs.xls in Appendix I. Contents of the individual worksheets within the spreadsheet are as follows. The values for the B-dot parameters used in the calculations were taken from Data0.ymp.R2 and are given in the workbook $D$-H parameters. The values for the parameters of 
the Truesdell-Jones equation are also given in $D$-H parameters. The calculations of individual ion activities from handbook mean salt data (Robinson and Stokes 1965 [DIRS 108567], Appendix 8.10) are given in 1-1 Salts data \& calc and 1-2 Salts data \& calc.

The results are summarized in Figures 6.3-3 and 6.3-4 and Table 6.3-5. Mean salt values are available only at the higher ionic strengths, but the Truesdell-Jones values, which are based on fits to mean salt data, overlap the mean salt values and extend to lower ionic strengths.

Figure 6.3-3 compares the results for the anions $\mathrm{Cl}^{-}$and $\mathrm{SO}_{4}{ }^{2-}$. For $\mathrm{Cl}^{-}$, the B-dot values are indistinguishable from the others up to an ionic strength of 1 molal. They begin to diverge at higher ionic strengths with the B-dot value about 0.04 units higher than the mean salt value at 3 molal. For $\mathrm{SO}_{4}{ }^{2-}$, the B-dot values are within 0.03 units of the mean salt and TruesdellJones values to an ionic strength of about 2 molal. At 3 molal, the B-dot values are about 0.1 units less negative than the mean salt value.

Figure 6.3-4 compares the results for the cations $\mathrm{Na}^{+}$and $\mathrm{Ca}^{2+}$. For $\mathrm{Na}^{+}$, the B-dot values are indistinguishable from the mean salt-based Truesdell-Jones values to an ionic strength of about 0.2 molal. They then diverge and are 0.03 units more negative at 1 molal and 0.1 units more negative at 3 molal. For $\mathrm{Ca}^{2+}$, the $\mathrm{B}$-dot values are within 0.01 units to an ionic strength of about 0.6 molal. They diverge at higher ionic strengths to 0.05 units at 1 molal and 0.3 units at 3 molal.

Uncertainties of activity coefficients are discussed in two other YMP documents:

- Appendix D of Degraded Mode Criticality Analysis of Immobilized Plutonium Waste Forms in a Geologic Repository (CRWMS M\&O 1997 [DIRS 100222]) provides examples comparing activity coefficients derived from experimental measurements with those calculated by EQ3/6 using the B-dot form of the Hückel equation. These comparisons are based on mean salt rather than single ion activity coefficients. Because the latter are used in the modeling described here, these comparisons are not considered further.

- Section 5.1.2 of In-Drift Accumulation of Fissile Material from Waste Packages Containing Plutonium Disposition Waste Forms (CRWMS M\&O 2000 [DIRS 135790]) includes computations made using the B-dot equation and compares them with those obtained from the Specific Ion Interaction (SIT) Theory (Grenthe et al. 1992 [DIRS 101671], Appendix B). For tetravalent ions, such as $\mathrm{Th}^{4+}$ and $\mathrm{Pu}^{4+}$, at ionic strength 1.0, the SIT value for $\gamma$ is about twice the "B-dot" value. The difference of a factor of two in $\gamma$ at 1 molal ionic strength quoted for these ions corresponds to a difference of 0.3 in $\log \gamma$. Considering the increasing deviations with ion charge, this is consistent with the difference of 0.3 in $\log \gamma$ for $\mathrm{Ca}^{2+}$ at an ionic strength of 3 molal.

This factor of two ( 0.3 in $\log$ units) between the B-dot and SIT values would translate to a doubling of the solubility as calculated using the "B-dot" equation as compared to using the SIT approach, if the dominant solution species were the $\mathrm{Th}^{4+}, \mathrm{Pu}^{4+}$, or some other tetravalent ion, such as $\mathrm{UO}_{2}\left(\mathrm{CO}_{3}\right)_{3}{ }^{4-}$. This would occur only at very low $\mathrm{pH}$ for $\mathrm{Th}^{4+}$ and $\mathrm{Pu}^{4+}$ or very high $\mathrm{pH}$ for $\mathrm{UO}_{2}\left(\mathrm{CO}_{3}\right)_{3}{ }^{4-}$. However, examination of the outputs of the EQ3NR solubility calculations 
shows that such high charges for the most important dissolved species seldom occur. Specifically, this is found only for plutonium and neptunium, in the form of the $\mathrm{PuO}_{2}\left(\mathrm{CO}_{3}\right)_{3}{ }^{4-}$ and $\mathrm{NpO}_{2}\left(\mathrm{CO}_{3}\right)_{3}{ }^{4-}$, respectively, above a $\mathrm{pH}$ of about 8 . The corresponding species for uranium also is reported in the output for some neutral to high $\mathrm{pH}$ calculations, but only as a minor species. Because the use of the "B-dot" equation, as compared to the SIT or similar approaches, results in higher solubilities, it is conservative, and may be used at sufficiently small concentrations without incorporating its uncertainty into the overall solubility uncertainty.

No uncertainties based on ionic strength calculations are presently included in the results of EQ3NR and EQ6 modeling at ionic strengths up to 1 molal. As shown in Table 6.3-5, the uncertainties in $\log \gamma$ values at this ionic strength are no more than 0.05 for divalent ions, although other calculations suggest they could be up to 0.3 for more highly charged ions.

Table 6.3-5 shows in addition that uncertainties in $\log \gamma$ values approach \pm 0.3 for divalent ions at an ionic strength of 3 . More highly charged ions would presumably have larger differences, but because such ions occur only at extreme $\mathrm{pH}$ values, they can be disregarded.

As mentioned previously, the database used in EQ3/6 calculations is qualified up to an ionic strength of 1 molal. In solutions with ionic strengths from 1 to 3 , the uncertainty in the solubility should be increased. This can be done simply by increasing the uncertainty term applied to the solubility values to account for the uncertainty in the $\log K$ values (Section 6.3.3.1). Because uncertainties in $\log \mathrm{K}$ values and uncertainties due to high ionic strengths have different causes, the two uncertainties should be combined by the square root of the mean by the following equation:

$$
\left(\log K^{2}+ \pm 0.3^{2}\right)^{1 / 2}
$$

For uranium, for example, the $\log \mathrm{K}$ uncertainty is \pm 0.5 (Section 6.3.3.1). In solutions of ionic strengths from 1 to 3 molal, this value should be increased to $\left( \pm 0.5^{2}+ \pm 0.3^{2}\right)^{1 / 2}= \pm 0.6$.

Table 6.3-5. Comparison of Ion Activity Coefficients Based on Mean Salt Data and Calculated from the B-dot Equation

\begin{tabular}{|c|c|c|c|c|c|}
\hline \multirow{2}{*}{ Ion } & \multirow{2}{*}{$\begin{array}{c}\text { lonic } \\
\text { Strength, } \\
\mu \text { (molal) }\end{array}$} & \multicolumn{3}{|c|}{$\log \gamma$} & \multirow{2}{*}{$\begin{array}{l}\text { Difference } \\
\text { in Gamma }\end{array}$} \\
\hline & & B-dot & Mean Salt & Difference & \\
\hline \multirow{3}{*}{$\mathrm{Cl}^{-}$} & 1.0 & -0.216 & -0.219 & 0.002 & $-1 \%$ \\
\hline & 2.0 & -0.220 & -0.241 & 0.022 & $-5 \%$ \\
\hline & 3.0 & -0.204 & -0.245 & 0.041 & $-10 \%$ \\
\hline \multirow{3}{*}{$\mathrm{SO}_{4}^{2-}$} & 1.0 & -0.843 & 0.806 & -0.037 & $8 \%$ \\
\hline & 2.0 & -0.930 & 0.967 & 0.037 & $-9 \%$ \\
\hline & 3.0 & -0.958 & 1.070 & 0.113 & $-30 \%$ \\
\hline \multirow{3}{*}{$\mathrm{Na}^{+}$} & 1.0 & -0.180 & -0.146 & -0.034 & $8 \%$ \\
\hline & 2.0 & -0.171 & -0.108 & 0.063 & $13 \%$ \\
\hline & 3.0 & -0.147 & -0.048 & 0.100 & $20 \%$ \\
\hline \multirow{3}{*}{$\mathrm{Ca}^{2+}$} & 1.0 & -0.647 & -0.595 & -0.052 & $11 \%$ \\
\hline & 2.0 & -0.681 & -0.535 & -0.146 & $29 \%$ \\
\hline & 3.0 & -0.679 & -0.413 & -0.266 & $46 \%$ \\
\hline
\end{tabular}

Source: gamma comp calcs.xls. 


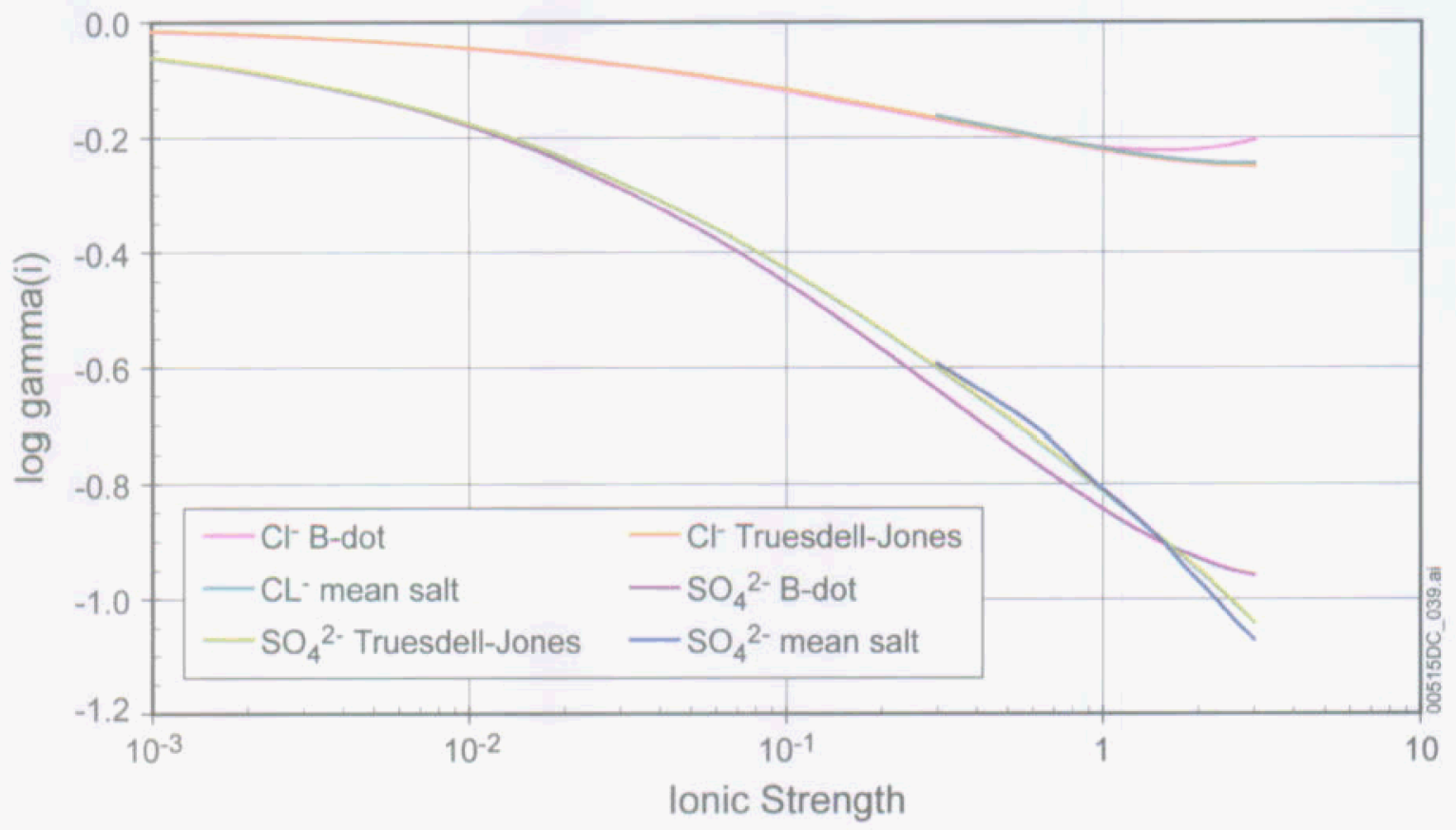

Source: gamma comp calcs.x/s.

Figure 6.3-3. Comparison of Activity Coefficients of Anions Calculated from Mean Salt (MS) Data and the B-dot and Truesdell-Jones (T-J) Equations

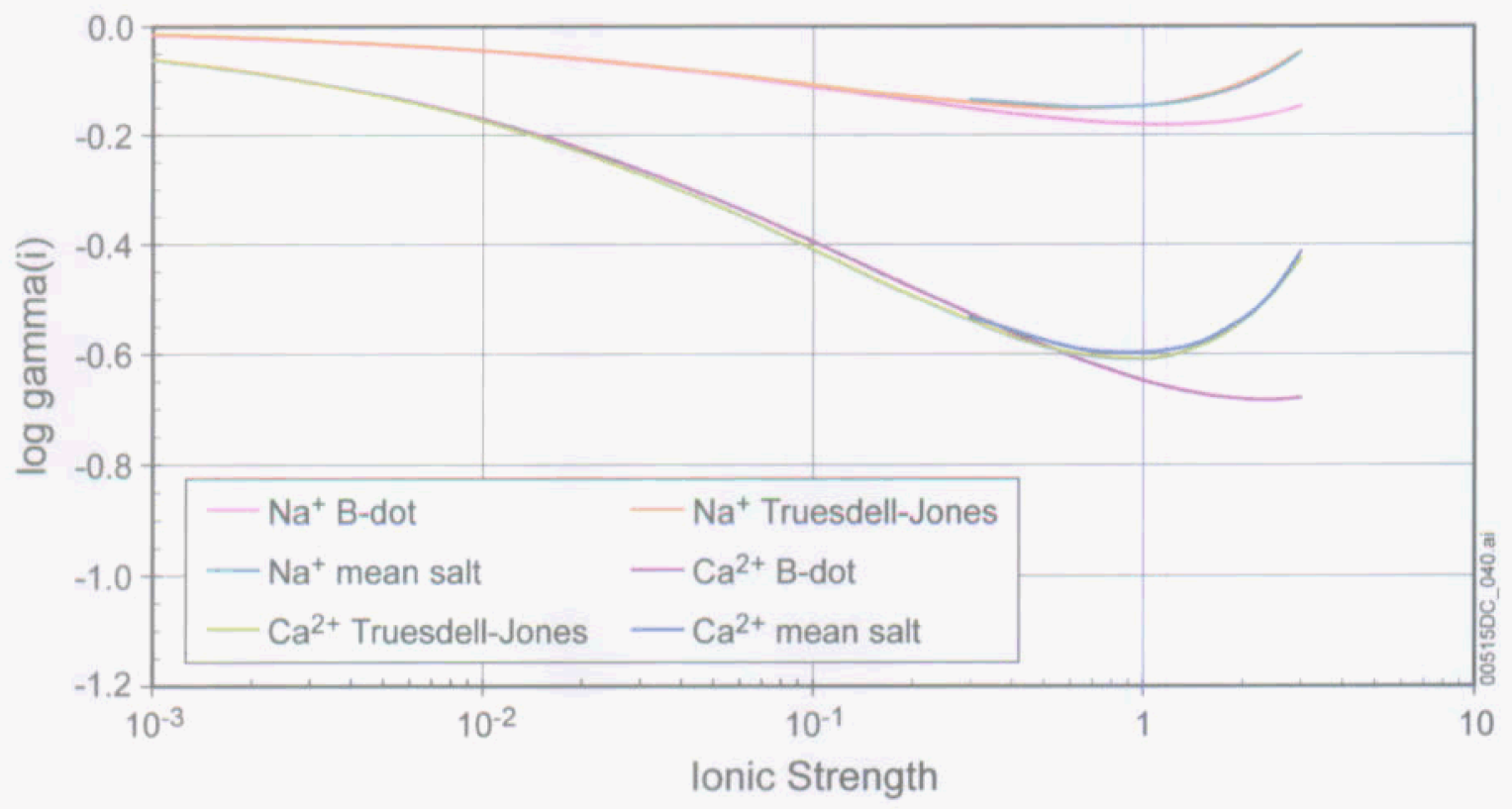

Source: gamma comp calcs.xls.

Figure 6.3-4. Comparison of Activity Coefficients of Cations Calculated from Mean Salt (MS) Data and the B-dot and Truesdell-Jones (T-J) Equations 


\subsection{CHEMICAL CONDITIONS FOR SOLUBILITY CALCULATIONS}

The solubility of an element depends on the nature of the solubility-controlling phase and the physical and chemical properties of the solution and its environment. In theory, the solubility of a phase can be calculated for a given solution. However, the interactions among solute species are too complicated for their modeling to be included directly in TSPA-LA. Simplifying solubility calculations by focusing on the most important controlling factors allows a feasible, yet realistic model to be included in TSPA-LA. To achieve the most representative simplification, the chemical conditions must be ranked by their importance. The simplification process consists of three parts: 1) simplifications based on knowledge of actinide properties and behavior, 2) simplifications to the site-specific water composition information, and 3) how these simplifications can be incorporated into the model.

\subsubsection{Actinide Properties}

The chemical and physical conditions most important to determining the solubilities of actinide elements are oxidation potential, $\mathrm{pH}$, temperature, and concentrations of ligands that form strong solution complexes (including ion pairs) with dissolved actinide species.

In general, the oxidation potential has the strongest single effect on the solubility of all actinides except thorium and americium, which are relatively redox insensitive. In the case of Yucca Mountain, however, over a range of oxidizing conditions, the oxidation state of uranium does not change. Only plutonium and neptunium are sensitive to the specific value chosen for the oxidation potential. Plutonium is discussed and illustrated in detail in Sections 6.5.3 and 6.5.4. The same logic applies to neptunium.

$\mathrm{pH}$ affects solubility in two ways. Typically, in acidic solutions, hydrogen ions react with solids to release cations to solution (e.g., by combining with oxide in the solid to form water). In basic (high $\mathrm{pH}$ ) solutions $\mathrm{OH}^{-}$may act as a ligand that forms complexes with the cations in the solid, thereby increasing the solubility. Temperature changes may raise or lower solubilities depending on the element and the specific conditions being considered.

For the most common ligands in the environment, the trend in strengths of complexation is (Silva and Nitsche 1995 [DIRS 112092]):

$$
\begin{array}{ccc}
\underset{\mathrm{OH}_{3}}{2-}, & >\mathrm{F}^{-}, \mathrm{HPO}_{4}{ }^{2-}, \mathrm{SO}_{4}{ }^{2-} & >\mathrm{Cl}^{-}, \mathrm{NO}_{3}{ }^{-} \\
\text {(Primary) } & \text { (Secondary) } & \text { (Tertiary) }
\end{array}
$$

Primary Ligands: Actinide solubilities increase with decreasing $\mathrm{pH}$. Because of the strength of $\mathrm{OH}-$ complexes, solubilities also increase with $\mathrm{pH}$ values under alkaline conditions. The concentration of $\mathrm{CO}_{3}{ }^{2-}$ increases with $f \mathrm{CO}_{2}$ and $\mathrm{pH}$, which also increases actinide solubility because of the strength of $\mathrm{CO}_{3}{ }^{2-}$ complexes. 
Secondary Ligands: The ligands $\mathrm{F}^{-}, \mathrm{HPO}_{4}{ }^{2-}$, and $\mathrm{SO}_{4}{ }^{2-}$ could affect actinide solubilities if present in high enough concentrations. The effects of these ligands are considered in Sections 6.4.2.5.1 and 6.4.3.6.

Tertiary Ligands and Cations: $\mathrm{Cl}^{-}$and $\mathrm{NO}_{3}{ }^{-}$are weakly complexing ligands and do not occur in high enough concentrations to be considered in the modeling. Generally speaking, the effect of cation concentrations on actinide solubility is weak because they do not form complexes with actinides. They influence actinide solubility through their effects on ionic strengths and as ligands competing with actinides for complex-forming anions. Because the most common cations in the repository environments $\left(\mathrm{Na}^{+}, \mathrm{K}^{+}, \mathrm{Ca}^{2+}\right.$, and $\left.\mathrm{Mg}^{2+}\right)$ form complexes with carbonate, bicarbonate, or sulfate accounting for only a few percent of their total dissolved concentrations, only their ionic strength effects are important (see EQ3NR output files contained in $U E q 3-6$ runs.zip of Appendix I).

Based on this discussion, $\mathrm{fO}_{2}, \mathrm{pH}, \mathrm{fCO}_{2}$, temperature, and concentration of ligands in water are considered in this report to calculate the actinide solubilities.

The impacts of elements other than those listed in Table 4-2, or considered specifically in Sections 6.5 through 6.18, relate either to complexes that these ions may form with radionuclides, their effect on $\mathrm{pH}$, or their effect on ionic strength. Other elements expected to be present in potentially significant amounts within the waste package or the invert are lithium, boron, aluminum, titanium, chromium, manganese, iron, nickel, zirconium, hafnium, and possibly vanadium, cobalt, niobium, molybdenum, and tungsten. None of these is shown to form significant complexes with any of the radionuclides considered in this report, as shown for the actinides by examination of Table III.1 in Chemical Thermodynamics of Uranium (Grenthe et al. 1992 [DIRS 101671]), Table III.1 in Chemical Thermodynamics of Americium (Silva et al. 1995 [DIRS 102087]), and Tables 3.1 and 4.1 in Chemical Thermodynamics of Neptunium and Plutonium (Lemire 2001 [DIRS 159027]). Therefore, they are not included in model calculations in this report. Other ligands that are not considered in this report are organic complexes that are produced by microbial activity. In Waste-Form Features, Events, and Processes (BSC 2004 [DIRS 170020]), organic complexation is screened out based on the argument that microbial populations are not sufficient to generate significant concentrations of radionuclide-chelating organics (BSC 2004 [DIRS 163116], Section 6.2.26, pp. 94 to 95).

The previous discussion considers the relative importance of various chemical conditions to actinide solubility. In order to choose the right variables to be accounted for in solubility evaluations, site-specific information, such as the levels and ranges of common cations and anions, must also be considered.

\subsubsection{Site-Specific Chemical Conditions}

The chemical conditions controlling dissolved concentrations may vary widely from place to place and at different periods of repository evolution. Thus, the solubility calculations have been made over a range of conditions that are expected to include the actual conditions. This section discusses how the countless possibilities are simplified, based on site-specific characteristics. 
This study considers two waste package types consistent with TSPA-LA models. One contains commercial spent nuclear fuel (CSNF) and the other, called codisposal spent fuel packages (CDSP), contains defense spent nuclear fuel and high-level radioactive waste glass.

\subsubsection{Oxidation Potential}

The repository is designed so the waste is under atmospheric conditions except in isolated, local situations. Thus, oxidizing conditions are assumed (Section 5.1), and all solubilities are calculated with a theoretical $\mathrm{fO}_{2}$ of 0.2 bars (the atmospheric value). The solubilities of all elements considered here except plutonium and neptunium are, within limits, insensitive to the oxidation potential. The details of the selection of the oxidation potential used in modeling plutonium and neptunium are discussed in Sections 6.5 and 6.6.

\subsubsection{Temperature}

Due to decay heat from the waste, the temperature within waste packages is increased from the ambient temperature. Immediately after the emplacement of waste packages, the temperature can rise to nearly $200^{\circ} \mathrm{C}$. The temperature in the repository relevant to this model is between $25^{\circ} \mathrm{C}$ and $100^{\circ} \mathrm{C}$, since any temperature above boiling is not important for solubility considerations because liquid water will not exist in the waste package. Only solubilities at $25^{\circ} \mathrm{C}$ are given. As discussed in Section 6.3.3.3, solubilities of actinides decrease with increasing temperature, so the use of $25^{\circ} \mathrm{C}$ solubilities is conservative.

\subsubsection{3 $\quad \mathrm{pH}$}

According to In-Package Chemistry (DTN: MO0404SPAIPCHM.005 [DIRS 169187]), the pH range for fluids reacting with CSNF is 4.5 to 8.1 , while the range for fluids reacting with codisposal materials is from 4.5 to 8 .

Engineered Barrier System: Physical and Chemical Environment Model (BSC 2004 [DIRS 169054], Section 6.13.5) documents the response surface for $\mathrm{pH}$ in the invert ranges from 3.5 to 10.5 . To cover the full range of conditions, the target $\mathrm{pH}$ for the modeling was set to a range of 3 to 11 . As discussed below, for some elements, the controlling phases are not stable over the entire $\mathrm{pH}$ range or the ionic strengths of the resulting solutions are beyond the limit for which the EQ3NR program and supporting database are applicable. In these cases, results are given for a more limited range of $\mathrm{pH}$ values. For example, the sensitivity runs for plutonium solubility presented in Section 6.4.2.5.1 cover the $\mathrm{pH}$ range of 3 to 9.75. The higher $\mathrm{pH}$ range from 9.75 to 11 is not covered because $\mathrm{PuO}_{2}$ (hyd,aged) is not stable (does not form) under those conditions.

\subsubsection{4 $\mathrm{CO}_{2}$ Fugacity}

The atmospheric value of $\mathrm{CO}_{2}$ partial pressure is $10^{-3.5}$ bars. Table 4-17 of Yucca Mountain Science and Engineering Report (DOE 2002 [DIRS 155943], p. 4-191) gives the range of $f \mathrm{CO}_{2}$ from $10^{-2.0}$ to $10^{-3.0}$ bars, except for the boiling period to which the results of this report are not applicable. This document considers a broader range of $10^{-5.0}$ to $10^{-1.5}$ bars for the plutonium, neptunium, uranium, thorium, americium, and protactinium solubility models to cover its likely range. 


\subsubsection{Water Composition}

Table 4-2 gives the composition of the base-case water used in the solubility calculations. A water of this composition has been used as the reference water composition for the Yucca Mountain site for many years. A detailed rationale for using water of this composition as a reference water for the repository has been thoroughly investigated (Harrar et al. 1990 [DIRS 100814]).

The compositions of 25 different pore waters collected from 15 ECRB-SYS-SERIES boreholes of the Yucca Mountain site (USW SD-9 and USW NRG-7/7A) were reported in DTN: GS020408312272.003 [DIRS 160899]. For the nine components ( $\mathrm{Na}, \mathrm{K}, \mathrm{Ca}, \mathrm{Mg}$, $\mathrm{SiO}_{2}(\mathrm{aq}), \mathrm{Cl}, \mathrm{F}, \mathrm{NO}_{3}$, and $\mathrm{SO}_{4}$ ) listed in Table 4-2, these pore waters are similar to the composition of the base-case water. The ratios of the average pore water values to the base-case values of those nine components range from 0.83 (for $\mathrm{SiO}_{2}(\mathrm{aq})$ ) to 8.51 (for $\mathrm{Ca}$ ), and the ratio of the maximum values of those nine components to the base-case values range from 1.07 to 18.46 (Pore Water.xls in Appendix I). As the sensitivity analysis described below covers the range up to $1,000 \times$ the base-case values for those nine components, the results and conclusions reached in this section are considered applicable to the pore waters that might become infiltrating waters.

\subsection{Sensitivity Analysis}

Two approaches are used to assess the effects of varying ligand concentrations on actinide solubilities. The first is a series of sensitivity calculations conducted over a range of $\mathrm{pH}$ values at a fixed $f \mathrm{CO}_{2}\left(10^{-3.0}\right.$ bars $)$. This analysis examines the solubility of plutonium calculated using the base-case adjusted-Eh model (Section 6.5.3) with $\mathrm{PuO}_{2}$ (hyd,aged) as the controlling solid. $\mathrm{Pu}$ was chosen rather than another actinide for the sensitivity studies because (1) $\mathrm{Pu}$ is one of the most important actinides, (2) it simplifies the process, since only one solid controls the $\mathrm{Pu}$ solubility over the entire $\mathrm{pH}$ range, unlike $\mathrm{U}$ and $\mathrm{Np}$, that have a change in the controlling mineral at higher $\mathrm{pH}$ values, and (3) the results for $\mathrm{Pu}$ would be expected to represent the results for the group of actinides as a whole, since all actinides have similar chemical properties.

Initial calculations are run with the base-case J-13 water composition given in Table 4-2. Additional sets are run with concentrations of all constituents increased up to 100 times their original values $(1 \times$ [base case], $10 \times$, and $100 \times)$, with the results shown in Figure 6.4-1. Then, separate sets of runs are conducted that varied selected solutes individually at $10 \times, 100 \times$, and $1,000 \times$ the base case concentration. These files are located in Appendix I in Sens Eq3 files.zip. The results of these calculations are shown in Figures 6.4-2 through 6.4-11. All plotted results represent solutions with an ionic strength less than one. The $\mathrm{Na}$ sensitivity at 1,000× was not plotted because the ionic strength was greater than one. See Section 6.3.3.4 for a discussion of ionic strength and activity coefficient calculations.

The objective of the sensitivity calculations is to analyze the effects of a single factor on solubility. Often, it is not possible to isolate the effects of one factor, because when that factor is changed, it causes something else to change. For example, as the specified $\mathrm{pH}$ is varied, anions or cations are mathematically added to the solution for charge balance. The effect of adding these ions is minimized by selecting the most innocuous ions for the charge-balance feature in EQ3NR. More acidic solutions are balanced by adding $\mathrm{Cl}^{-}$, while more basic solutions by adding 
$\mathrm{Cs}^{+}$. These reactants are chosen because actinide chloride and cesium species are not likely to form in large quantities under any $\mathrm{pH}$ condition, as discussed later in this section. For the specific $\mathrm{Cl}^{-}$sensitivities (Figure 6.4-8) the anion $\mathrm{Br}$ is used so as not to interfere with the actual subject of the sensitivity. All of the plutonium solubility plots (Figures 6.4-1 through 6.4-10) have similar shapes. Solubilities are high at the low and high $\mathrm{pH}$ values and decrease to minimum values at $\mathrm{pH}$ values around 8 .

The sensitivity analyses show that increases in both $\mathrm{F}^{-}$and $\mathrm{SO}_{4}{ }^{2-}$ concentrations lead to higher solubilities under neutral and moderately acid conditions (Figures 6.4-2 and 6.4-3). The effect of $\mathrm{F}^{-}$is treated explicitly as discussed in Section 6.4.3.6. $\mathrm{SO}_{4}{ }^{2-}$ concentrations are not considered to be uncertain, as also discussed in Section 6.4.3.6.

The concentrations of the four cations $\left(\mathrm{Na}^{+}, \mathrm{K}^{+}, \mathrm{Ca}^{2+}, \mathrm{Mg}^{2+}\right.$, Figures 6.4-4 through 6.4-7) affect plutonium solubility very little at low to circum-neutral $\mathrm{pH}$ values. Around $\mathrm{pH} 9$, the $1,000 \times$ levels, especially of $\mathrm{Ca}^{2+}$ and $\mathrm{Mg}^{2+}$, increase the solubilities by more than a factor of ten. However, $\mathrm{Ca}^{2+}$ and $\mathrm{Mg}^{2+}$ concentrations at these levels are physically unreasonable because of the low solubility of calcium-carbonate and magnesium-carbonate minerals (e.g., calcite and dolomite) at such high $\mathrm{pH}$ values. Solubility controls on $\mathrm{Ca}^{2+}$ and $\mathrm{Mg}^{2+}$ concentrations by such minerals are not considered in the sensitivity analysis modeling.

The concentrations of $\mathrm{Cl}^{-}, \mathrm{NO}_{3}{ }^{-}$, and $\mathrm{SiO}_{2}(\mathrm{aq})$ show little effect on $\mathrm{Pu}$ solubility as seen in Figures 6.4-8 through 6.4-10, although at the 1,000× level, $\mathrm{SiO}_{2}$ (aq) appears to increase the solubility by more than a factor of ten around $\mathrm{pH} 9 . \mathrm{SiO}_{2}$ (aq) concentrations at these high levels are physically unreasonable because of the low solubility of $\mathrm{SiO}_{2}$ minerals. Solubility controls on $\mathrm{SiO}_{2}(\mathrm{aq})$ concentrations are not considered in the sensitivity analysis modeling.

In some of the solutions, once a large quantity of an element is added, the solution becomes supersaturated with a mineral containing that element. For example, in the case of high $\mathrm{F}^{-}$ concentrations, the EQ3NR output file indicates that a solution at low $\mathrm{pH}$ is supersaturated with respect to fluorite $\left(\mathrm{CaF}_{2}\right)$ and sellaite $\left(\mathrm{MgF}_{2}\right)$. These minerals are not allowed to precipitate since the objective is to examine the effects of increased $\mathrm{F}^{-}$on solubility. See Section 6.4 .3 .7 for more discussion on supersaturation of minerals.

The effects of changing phosphate concentrations are examined using a different procedure. Because there are relatively few data available for plutonium-phosphate solids and aqueous species, the sensitivity analysis is performed using uranium for which there is much more data. The uranium solubilities in this report are based on schoepite $\left(\mathrm{UO}_{3} \cdot 2 \mathrm{H}_{2} \mathrm{O}\right)$, Na-boltwoodite $\left(\mathrm{NaUO}_{2} \mathrm{SiO}_{3} \mathrm{OH} \cdot 1.5 \mathrm{H}_{2} \mathrm{O}\right.$ ), and $\mathrm{Na}_{4} \mathrm{UO}_{2}\left(\mathrm{CO}_{3}\right)_{3}$. At low-to-moderate $\mathrm{pH}$ values, when schoepite is the uranium-controlling solid, the uranium-phosphate minerals, $\left(\mathrm{UO}_{2}\right)_{3}\left(\mathrm{PO}_{4}\right)_{2} \cdot 4 \mathrm{H}_{2} \mathrm{O}$ and $\left(\mathrm{UO}_{2}\right)_{3}\left(\mathrm{PO}_{4}\right)_{2} \cdot 6 \mathrm{H}_{2} \mathrm{O}$, are also likely to form, as evidenced by the EQ3 solubility calculations that indicate supersaturation of these phosphate minerals. If the phosphate minerals form along with the formation of schoepite, then the phosphate minerals would control the phosphate level. However, this mineral is not allowed to precipitate since the objective is to examine the effects of increased phosphate on solubility.

A sensitivity exercise is performed to examine whether the dissolved uranium concentration in the base-case solution would increase if the phosphate concentrations are controlled by 
$\left(\mathrm{UO}_{2}\right)_{3}\left(\mathrm{PO}_{4}\right)_{2} \cdot 4 \mathrm{H}_{2} \mathrm{O}$. As discussed in Section 6.4.3.6, the phosphate concentration of the base-case water is chosen as $0.1 \mathrm{mg} / \mathrm{L}$. This value is based on the phosphate analyses of the water chosen as the reference water (Table 4-2), which vary from less than $0.01 \mathrm{mg} / \mathrm{L}$ to more than $0.1 \mathrm{mg} / \mathrm{L}$ (Harrar et al. 1990 [DIRS 100814]). The base-case value is plotted as the horizontal line in Figure 6.4-11.

In the sensitivity cases, the uranium concentration is fixed by schoepite saturation and the total phosphate concentration by saturation with $\left(\mathrm{UO}_{2}\right)_{3}\left(\mathrm{PO}_{4}\right)_{2} \cdot 4 \mathrm{H}_{2} \mathrm{O}$. The cases are run for a range of $\mathrm{pH}$ values at a fixed $f \mathrm{CO}_{2}$ of $10^{-3.5}$ bars. The line on the bottom in Figure 6.4-11 shows the phosphate concentration in equilibrium with $\left(\mathrm{UO}_{2}\right)\left(\mathrm{PO}_{4}\right)_{2} \cdot 4 \mathrm{H}_{2} \mathrm{O}$ (ranging from $10^{-3}$ to $1 \mathrm{mg} / \mathrm{L}$ ). A comparison of the two phosphate concentrations shows that concentrations controlled by $\left(\mathrm{UO}_{2}\right)_{3}\left(\mathrm{PO}_{4}\right)_{2} \cdot 4 \mathrm{H}_{2} \mathrm{O}$ are below the base-case water concentration for $\mathrm{pH}$ values less than about 7.5 and above it at higher $\mathrm{pH}$ values. As the figure shows, the uranium concentrations are virtually identical whether modeled using the base-case water phosphate concentration (dotted line), or with phosphate concentrations controlled by $\left(\mathrm{UO}_{2}\right)_{3}\left(\mathrm{PO}_{4}\right)_{2} \cdot 4 \mathrm{H}_{2} \mathrm{O}$ saturation (solid line). This also means that should phosphate be added to the system from the degradation of waste glass; for example, the dissolved phosphate concentration of the solution does not rise because it is fixed by the precipitation of a uranium phosphate solid.

All J13 Components

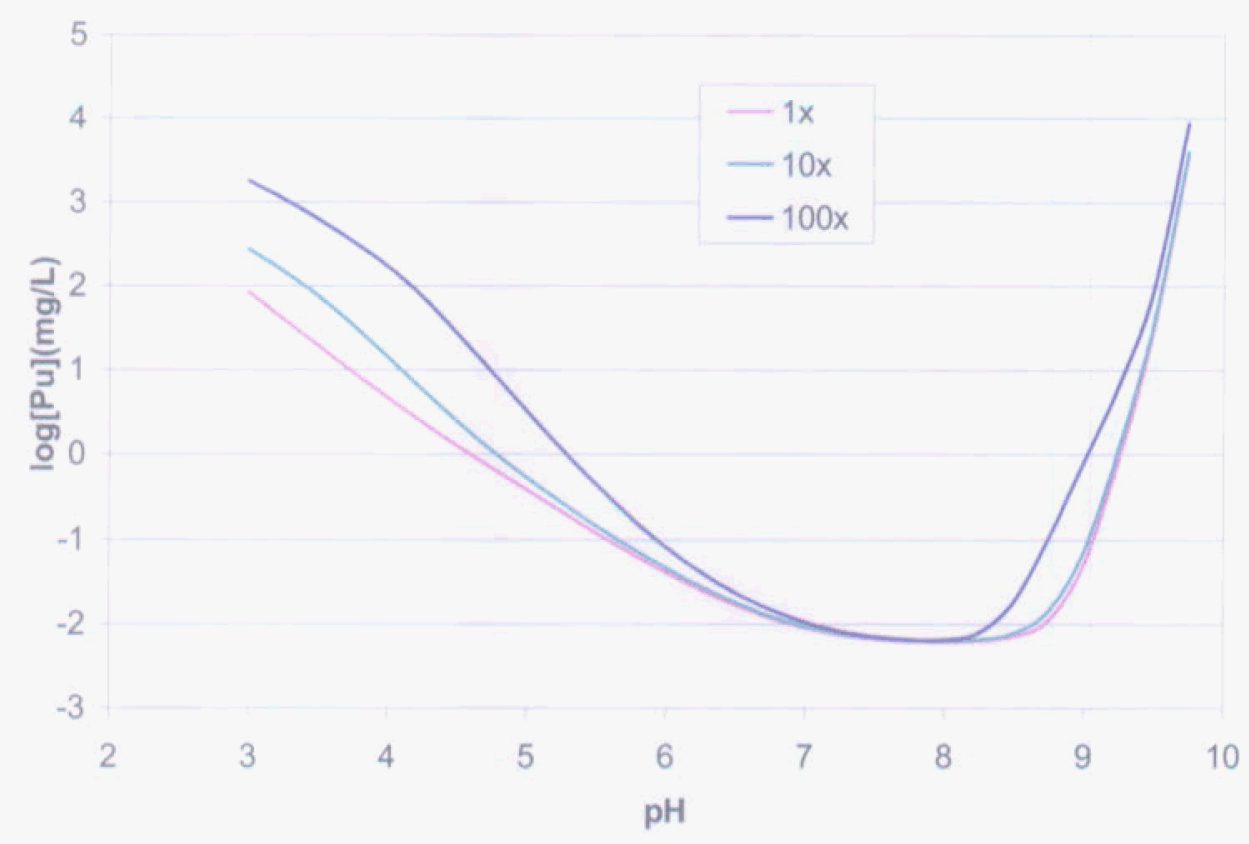

Source: Sensitivies.x/s (Appendix 1).

Figure 6.4-1. Sensitivity to Variation in the Total Concentration of the Base-Case Water 
$\mathrm{F}^{*}$

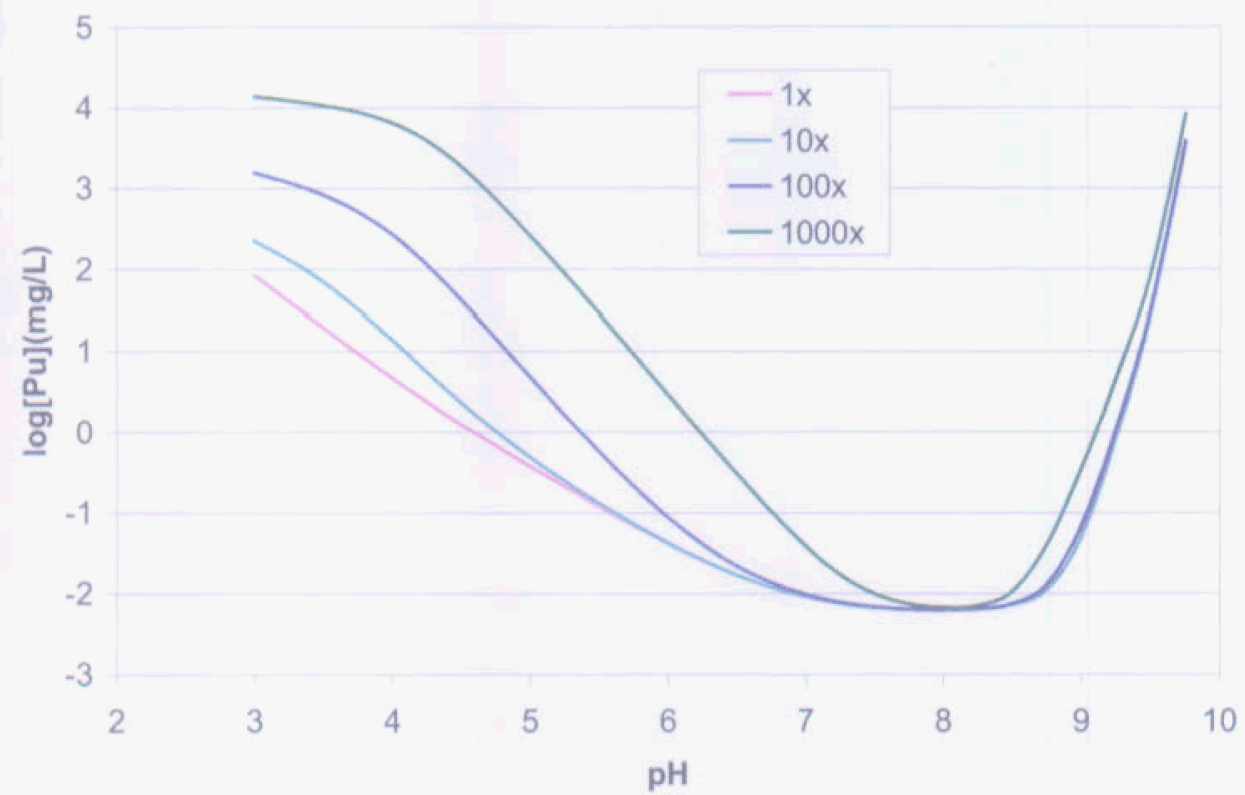

Source: Sensitivies.x/s (Appendix I).

Figure 6.4-2. F- Sensitivity

\section{$\mathrm{SO}_{4}{ }^{2-}$}

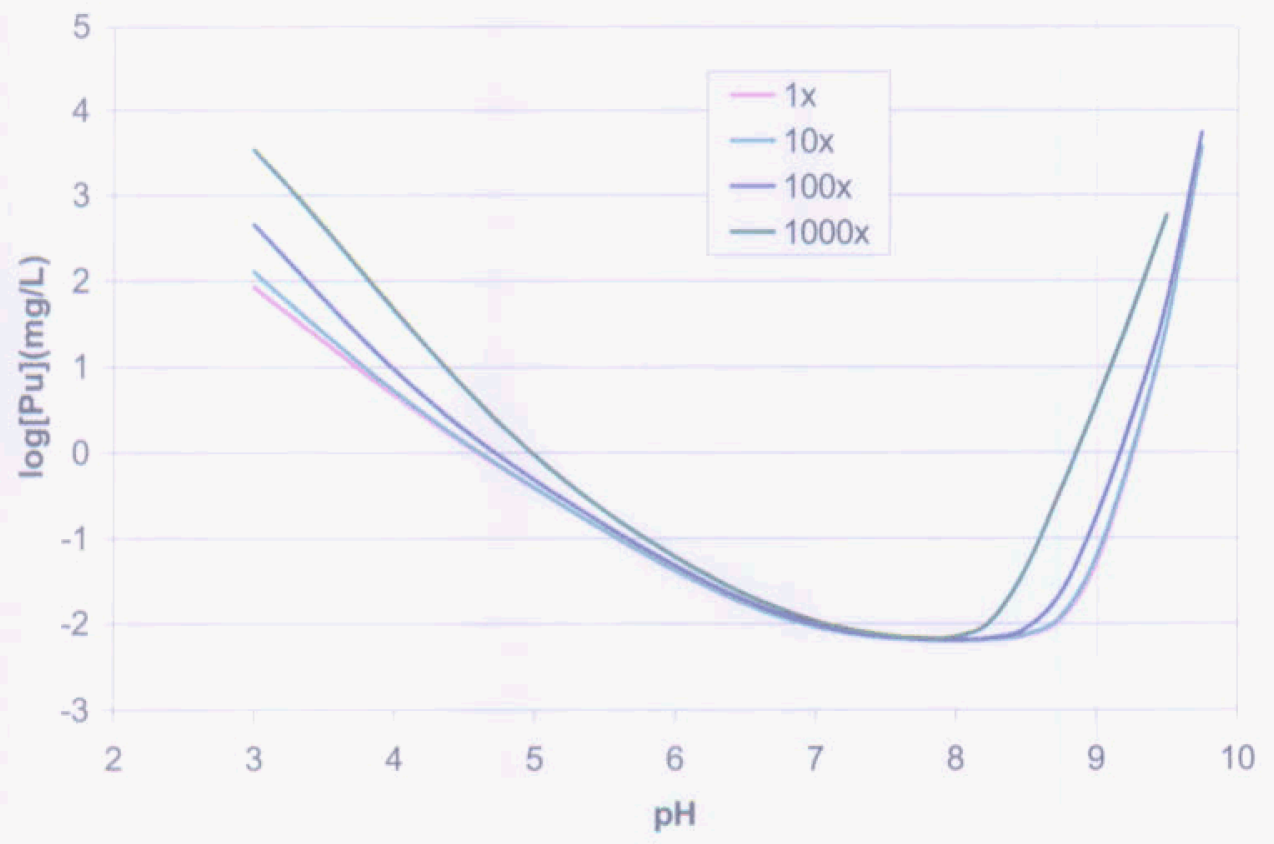

Source: Sensitivies.x/s (Appendix I).

Figure 6.4-3. $\mathrm{SO}_{4}{ }^{2-}$ Sensitivity 
$\mathrm{Na}^{+}$

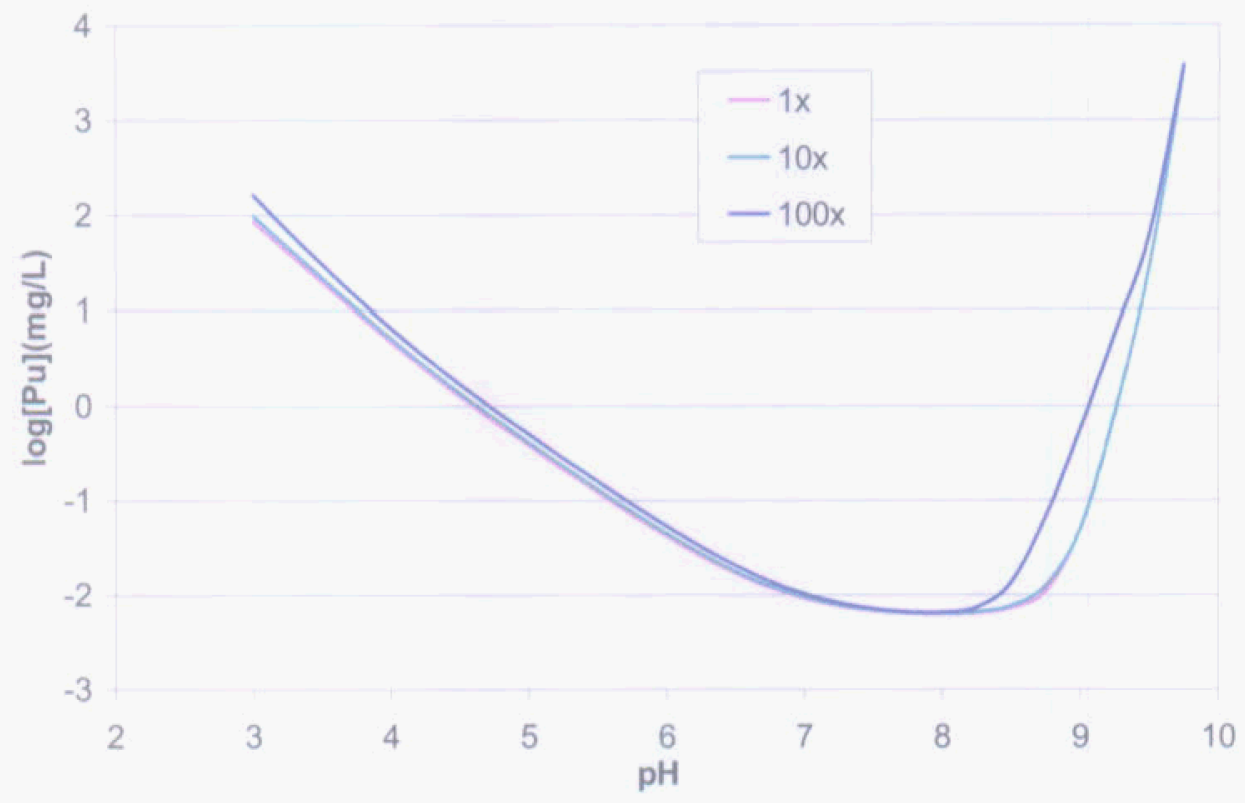

Source: Sensitivies.x/s (Appendix I).

Figure 6.4-4. $\mathrm{Na}^{+}$Sensitivity

$\mathrm{K}^{+}$

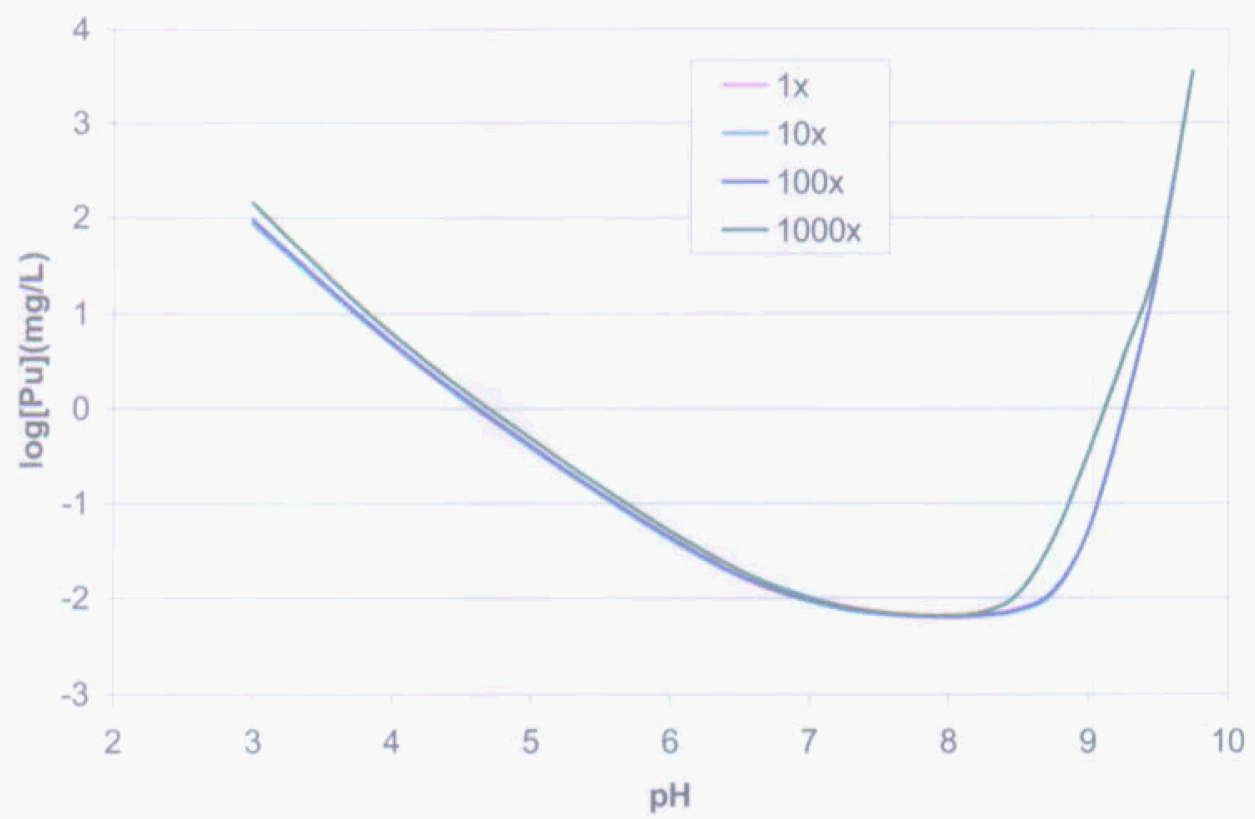

Source: Sensitivies.xls (Appendix I).

Figure 6.4-5. K' Sensitivity 


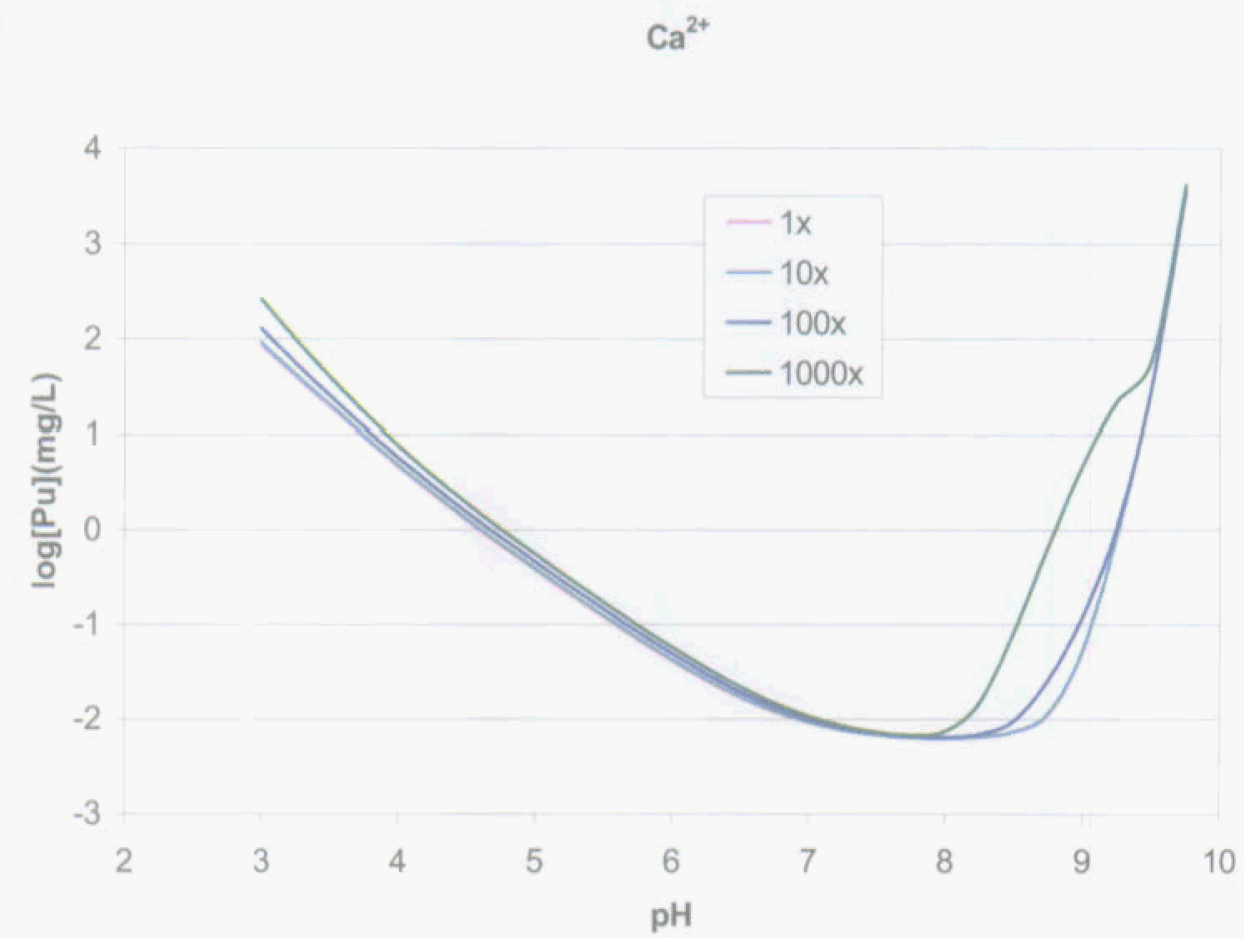

Source: Sensitivies.x/s (Appendix I).

Figure 6.4-6. $\mathrm{Ca}^{2+}$ Sensitivity

$\mathrm{Mg}^{2+}$

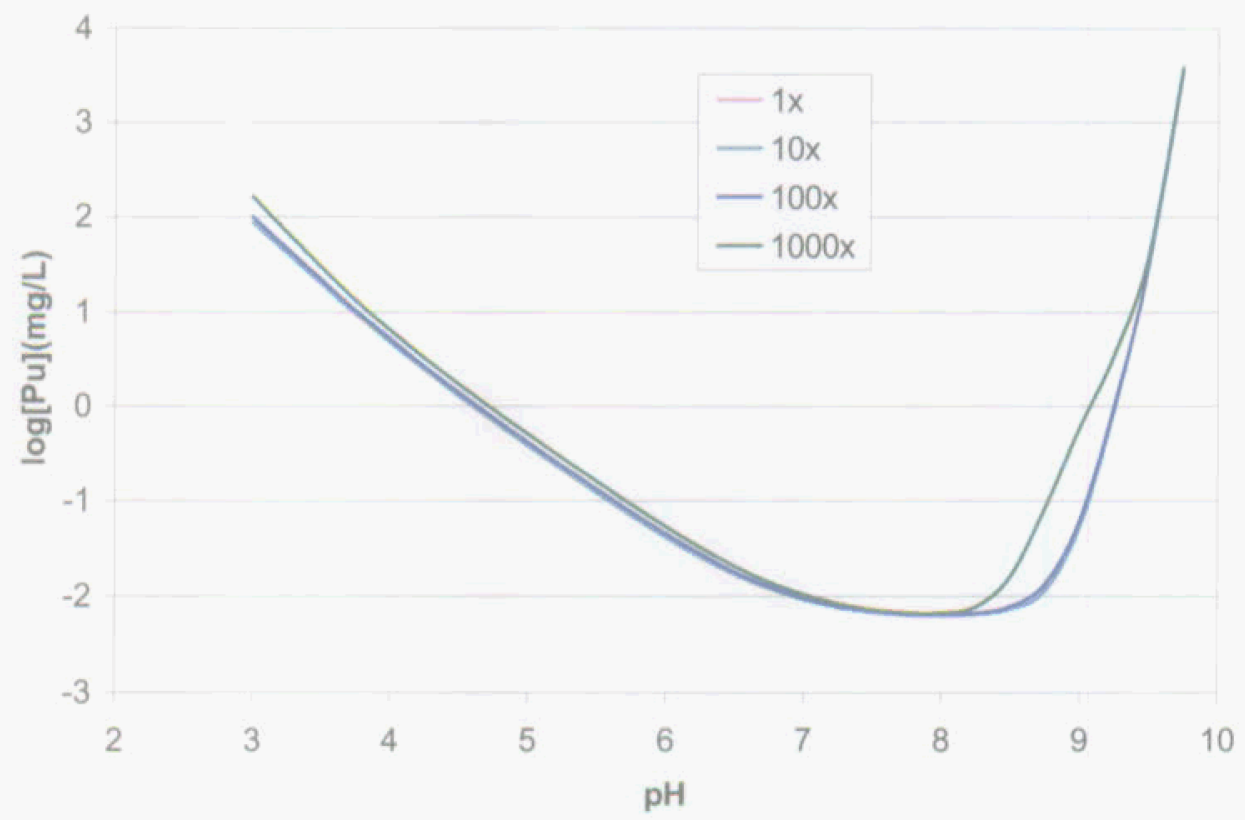

Source: Sensitivies.xIs (Appendix I).

Figure $6.4-7 . \mathrm{Mg}^{2+}$ Sensitivity 
$\mathrm{Cl}^{\circ}$

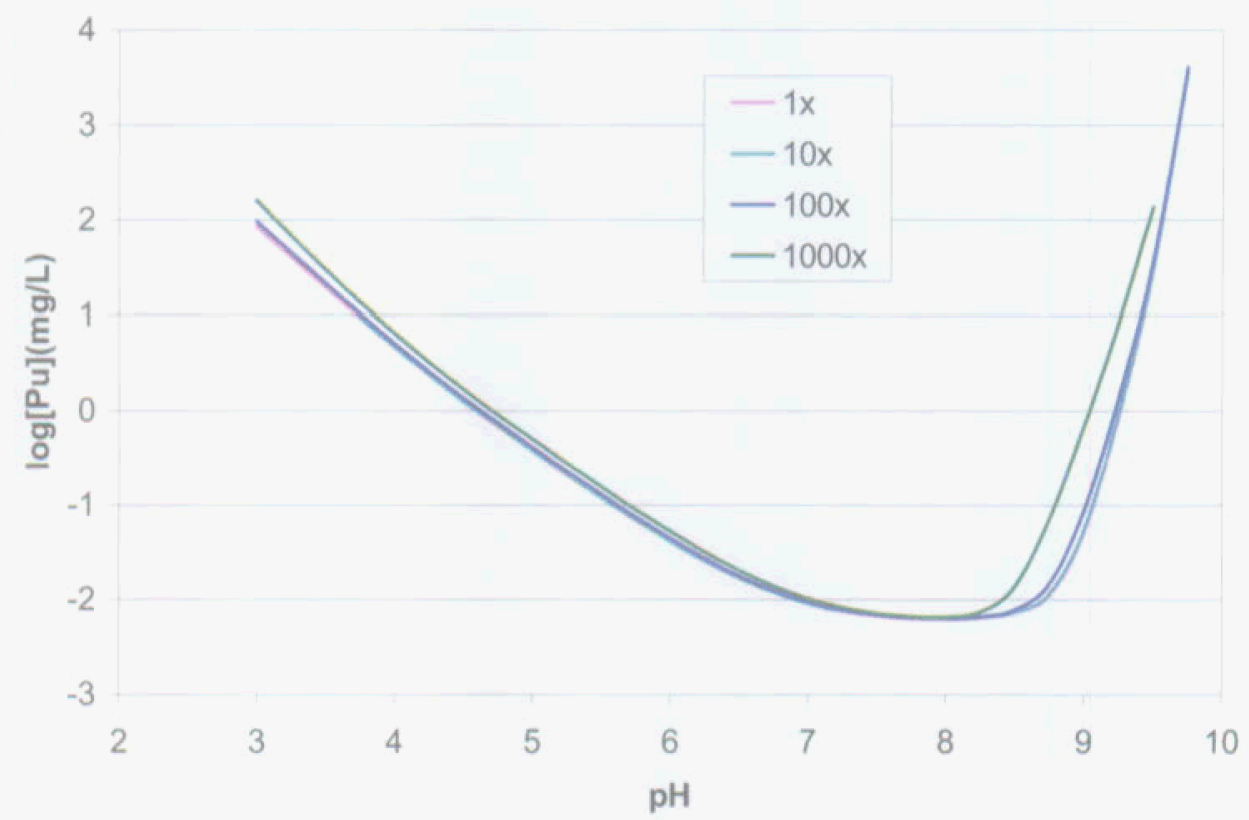

Source: Sensitivies.xls (Appendix I).

Figure 6.4-8. $\mathrm{Cl}^{-}$Sensitivity

$\mathrm{NO}_{3}{ }^{-}$

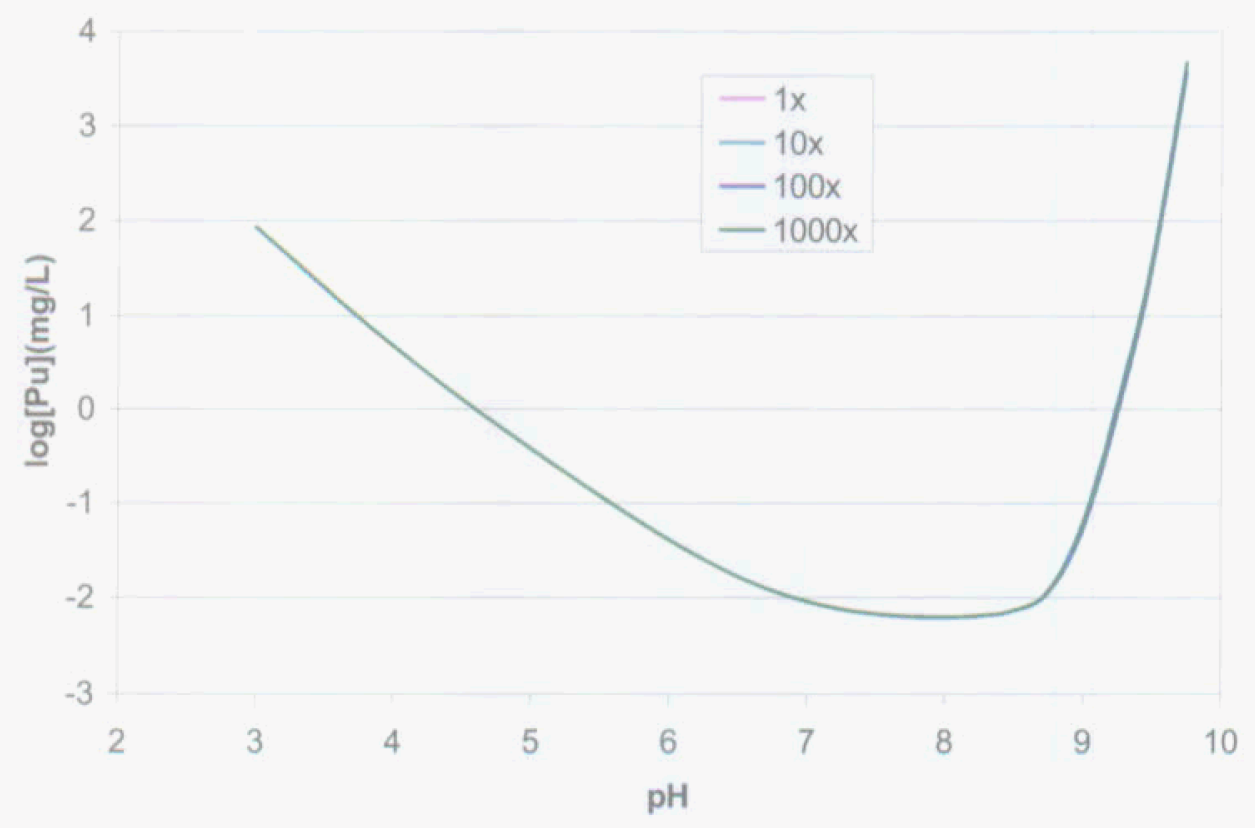

Source: Sensitivies.xls (Appendix I).

Figure 6.4-9. $\mathrm{NO}_{3}{ }^{-}$Sensitivity 
$\mathrm{SiO}_{2}(\mathrm{aq})$

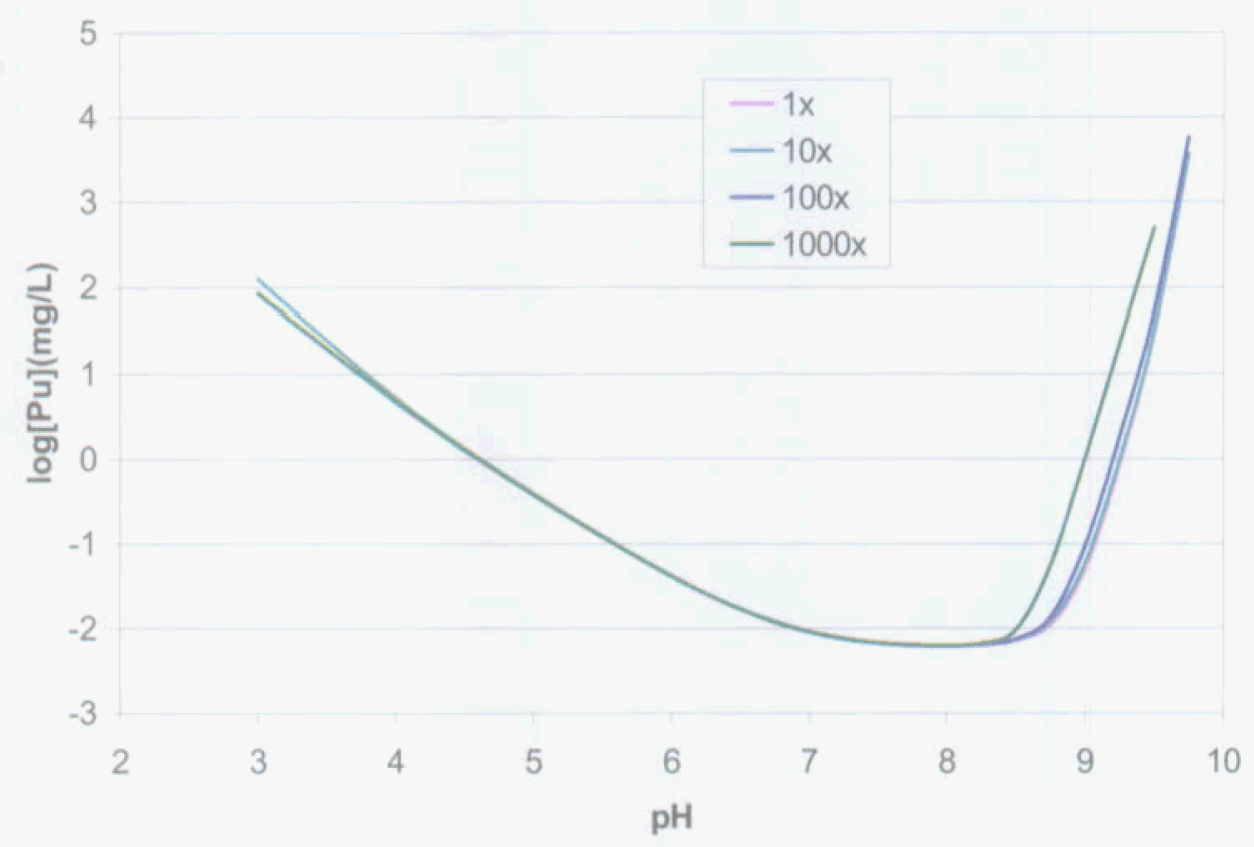

Source: Sensitivies.xIs (Appendix I).

Figure 6.4-10. $\mathrm{SiO}_{2}(\mathrm{aq})$ Sensitivity

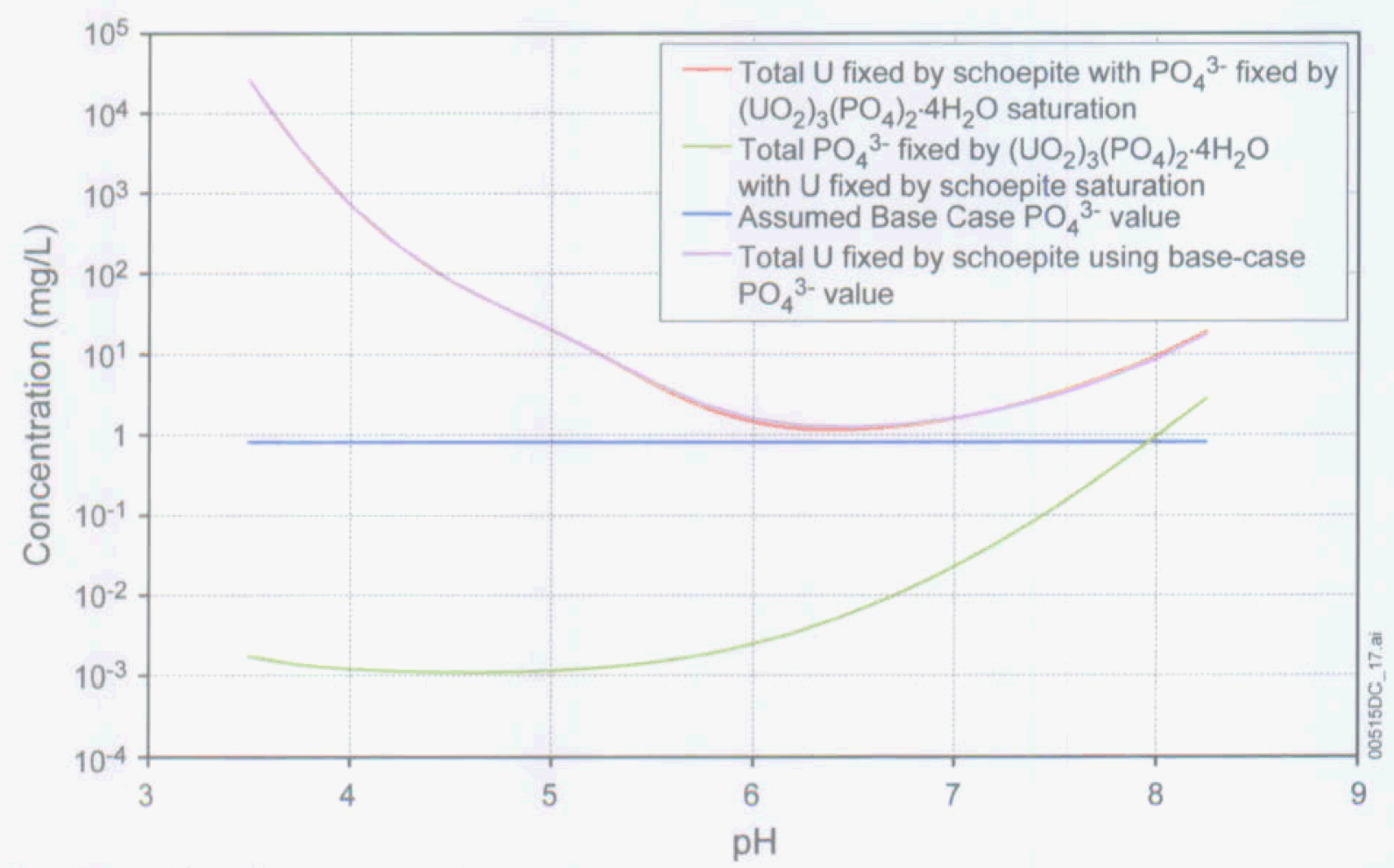

Source: PO4sensitivity.xIs (Appendix I).

Figure 6.4-11. Effect of $\left(\mathrm{UO}_{2}\right)_{3}\left(\mathrm{PO}_{4}\right)_{2} \cdot 4 \mathrm{H}_{2} \mathrm{O}$ Saturation on Uranium Solubility 
The second approach to sensitivity analysis examines the concentrations of the various aqueous complexes and species that compose the total solubility of each of the actinides. The solubilities are most sensitive to varying concentrations of those ligands that form the solution complexes contributing most to the total dissolved concentrations of the elements. Th and Pu speciation diagrams are discussed in this section as examples of this approach to sensitivity analysis. Similar diagrams for $\mathrm{Np}, \mathrm{U}$, and Am are given in the sections below devoted to those elements.

Figures 6.4-12 and 6.4-13 are speciation diagrams for Th from $\mathrm{pH} 3.25$ to 9.5. The former displays the molar concentration of total Th and its solution complexes; the latter displays the complex concentrations in percent of total Th. The diagrams represent a system at equilibrium with the solid $\mathrm{ThO}_{2}(\mathrm{am})$ at $\log f \mathrm{CO}_{2}$ (bars) $=-3.0$. The choice of this controlling solid is discussed in Section 6.8.2. Th occurs only in the Th(IV) oxidation state in aqueous solution.

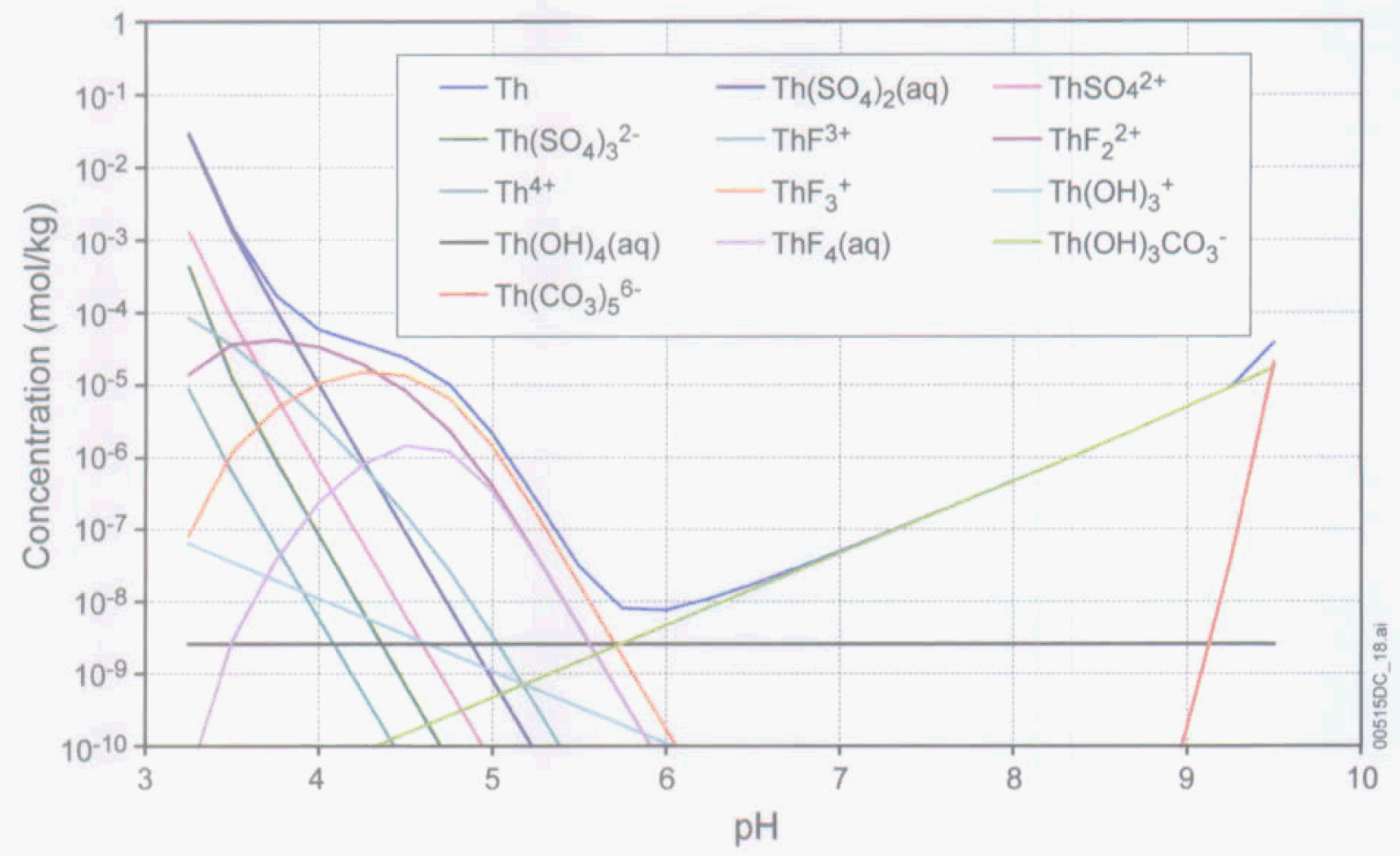

Source: Th species plot.x/s (Appendix I).

Figure 6.4-12. Total Th Concentration and Speciation Diagram at $\log f \mathrm{CO}_{2}$ (bars) $=-3.0$ in $\mathrm{mol} / \mathrm{kg} \mathrm{H}$

The calculated total Th concentration ranges from nearly $0.1 \mathrm{~mol}$ at $\mathrm{pH} 3.25$ to a minimum of less than $10^{-8} \mathrm{~mol}$ at $\mathrm{pH} 6.0$ and increases again to nearly $10^{-4} \mathrm{~mol}$ at $\mathrm{pH} 9.5$. At the lowest $\mathrm{pH}$, over $90 \%$ of the total $\mathrm{Th}$ consists of the $\mathrm{Th}\left(\mathrm{SO}_{4}\right)_{2}(\mathrm{aq})$ complex, with the $\mathrm{ThSO}_{4}{ }^{2+}$ complex contributing less than $10 \%$ of the total. At $\mathrm{pH}$ values from below 4.0 to above $5.5, \mathrm{~F}$-bearing complexes dominate the total $\mathrm{Th}$. The principal complex at $\mathrm{pH} 4.0$ is $\mathrm{ThF}_{2}{ }^{2+}$ while $\mathrm{ThF}_{3}{ }^{+}$ dominates from $\mathrm{pH} 4.5$ to 5.5 . From $\mathrm{pH} 5$ to $5.5, \mathrm{ThF}_{4}(\mathrm{aq})$ also contributes about $15 \%$ of the total, as does $\mathrm{ThF}_{2}{ }^{2+}$. At higher $\mathrm{pH}$ values, the importance of $\mathrm{F}^{-}$complexes diminishes and the principal contributors to total Th become the $\mathrm{CO}_{3}{ }^{2-}$ complexes, $\mathrm{Th}(\mathrm{OH})_{3} \mathrm{CO}_{3}{ }^{-}$and, at $\mathrm{pH} 9.5$, $\mathrm{Th}\left(\mathrm{CO}_{3}\right)_{5}{ }^{6-}$. At around $\mathrm{pH} 6.0, \mathrm{Th}(\mathrm{OH})_{4}(\mathrm{aq})$ also contributes over $30 \%$ of the total $\mathrm{Th}$. 


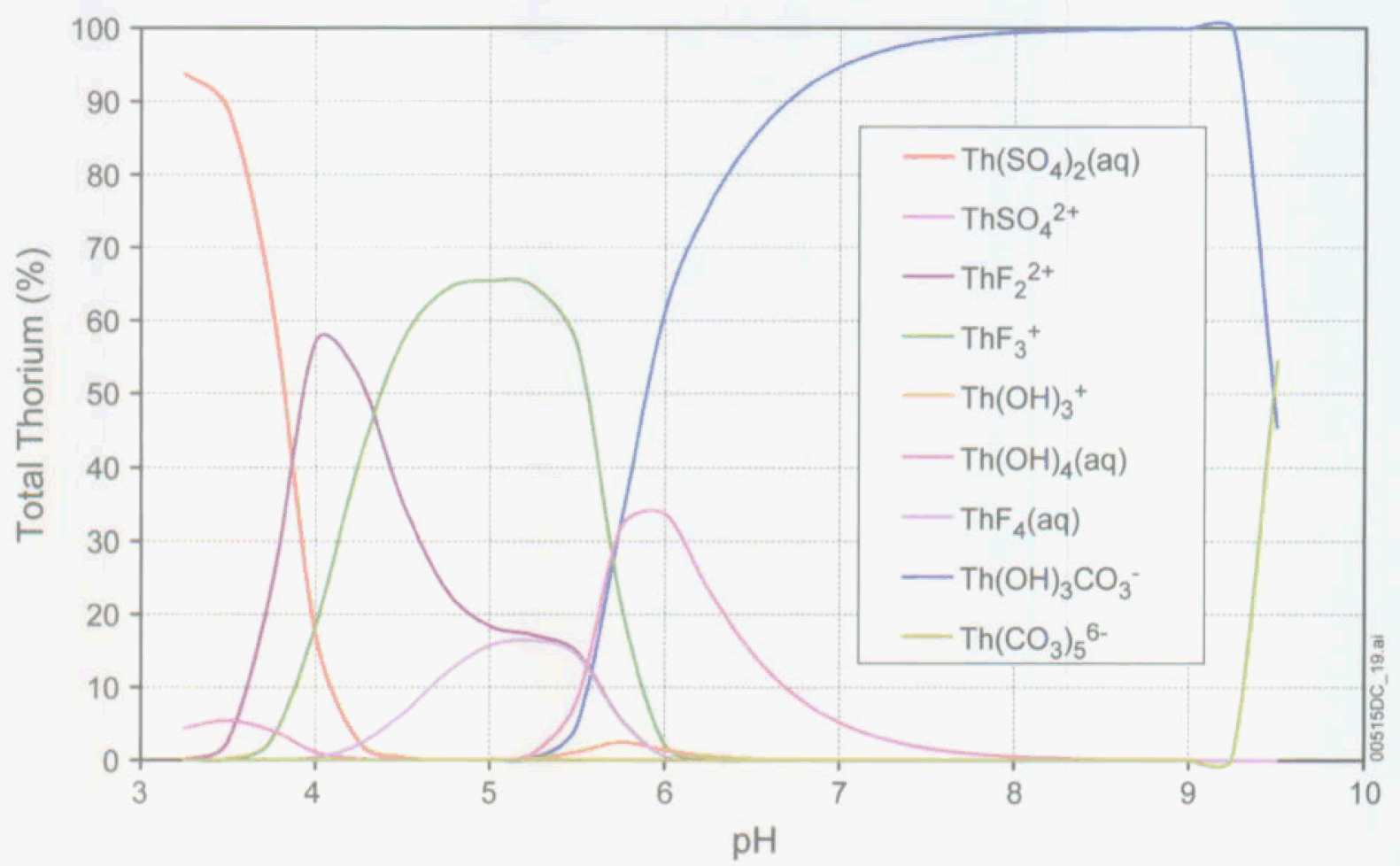

Source: Th species plot.x/s.

Figure 6.4-13. Th Speciation Diagram at $\log f \mathrm{CO}_{2}$ (bars) $=-3.0$ in Percent Total Dissolved Th

$\mathrm{Th}\left(\mathrm{CO}_{3}\right)_{5}{ }^{6-}$ is formed by the reaction:

$$
\mathrm{Th}^{4+}+5 \mathrm{HCO}_{3}{ }^{-}=\mathrm{Th}\left(\mathrm{CO}_{3}\right)_{5}{ }^{6-}+5 \mathrm{H}^{+}
$$

where $\mathrm{Th}\left(\mathrm{CO}_{3}\right)_{5}{ }^{6-}$ dominates, the total Th concentration increases by $10^{5}$ for each unit increase in the $\mathrm{pH}$. The extreme nonlinearity of the variation of total Th with $\mathrm{pH}$ where this complex dominates is why the EQ3NR program does not converge in the high $\mathrm{pH}$-high $f \mathrm{CO}_{2}$ range.

Figures 6.4-12 and 6.4-13 show that total Th concentration is sensitive to $\mathrm{SO}_{4}{ }^{2-}$ concentrations at low $\mathrm{pH}$ values, to $\mathrm{F}^{-}$concentrations under moderately acid conditions and to $\mathrm{OH}^{-}$and $\mathrm{CO}_{3}{ }^{2-}$ concentrations under circumneutral and basic conditions. The $\mathrm{OH}^{-}$concentrations depend on the $\mathrm{pH}$, and $\mathrm{CO}_{3}{ }^{2-}$ concentrations on $\mathrm{pH}$ and $f \mathrm{CO}_{2}$. The solubilities are tabulated in terms of $\mathrm{pH}$ and $f \mathrm{CO}_{2}$ so the sensitivities to $\mathrm{OH}^{-}$and $\mathrm{CO}_{3}{ }^{2-}$ variations are considered explicitly. As discussed in Section 6.4.3.5, $\mathrm{SO}_{4}{ }^{2-}$ concentrations are varied in the modeling to maintain charge balance in order to simulate the occurrence of $\mathrm{H}_{2} \mathrm{SO}_{4}$ in the in-package environment from the oxidation of sulfur during steel degradation. In this way, $\mathrm{SO}_{4}{ }^{2-}$ variations are also considered explicitly. Variations in $\mathrm{F}^{-}$concentrations are not treated explicitly, rather as uncertainties in the total Th concentrations.

Figures 6.4-14 and 6.4-15 are speciation diagrams for Pu calculated using the adjusted-Eh model for $\mathrm{Pu}$ solubility (Section 6.5.3). The figures are from $\mathrm{pH} 2$ to 9.75 at $\log f \mathrm{CO}_{2}$ (bars) $=-3.0$. The former displays the molar concentration of total $\mathrm{Pu}$ and its solution complexes; the latter displays the complex concentrations in percent of total $\mathrm{Pu}$. The oxidation state of the Pu species influences the complexes that form and is discussed in Section 6.5.4.3 


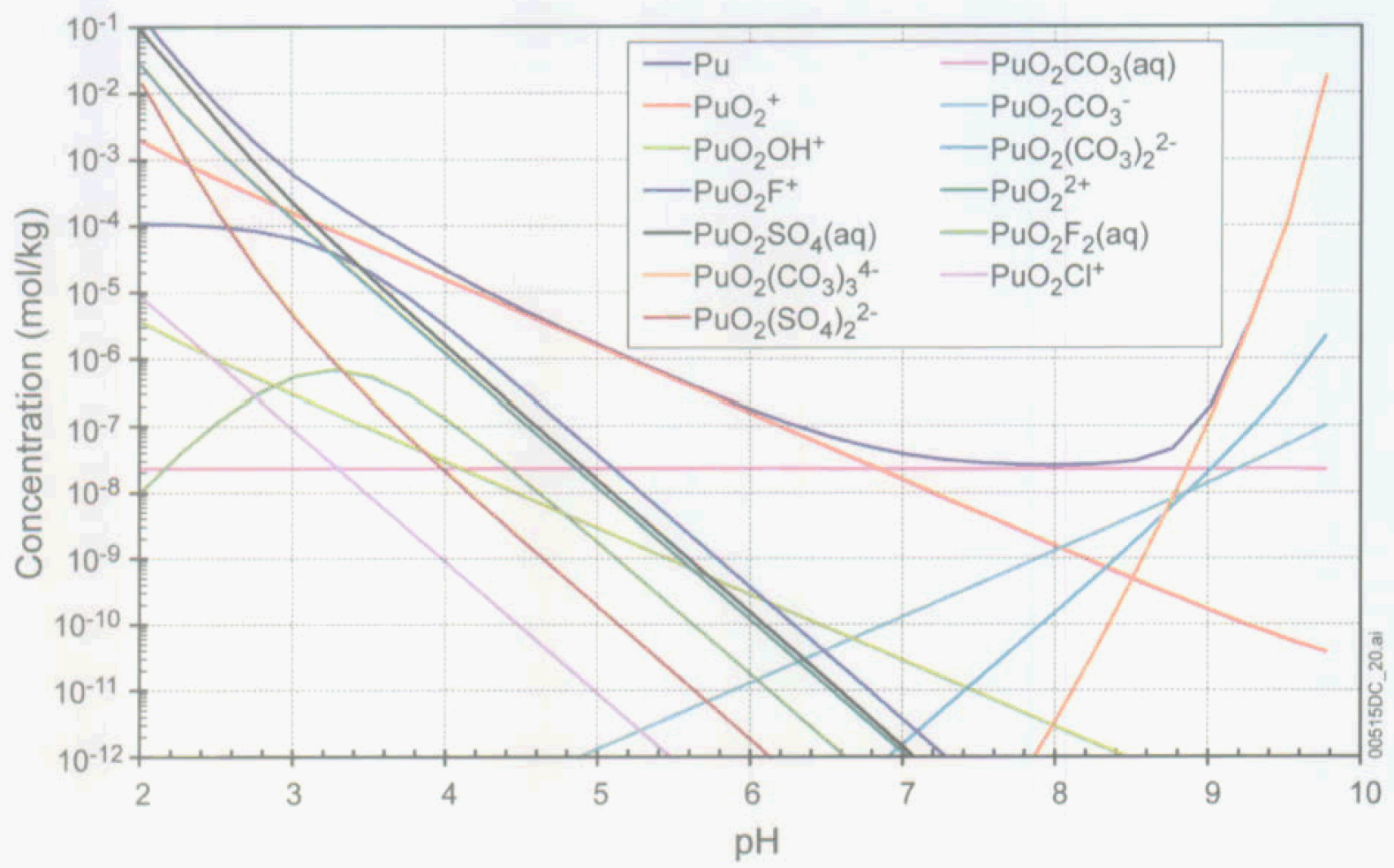

Source: Pu species plot_2.x/s.

Figure 6.4-14. Total Pu Concentration and Speciation Diagram at $\log \mathrm{fCO}_{2}$ (bars) $=-3.0$ in mol/ $/ \mathrm{kg} \mathrm{H}$

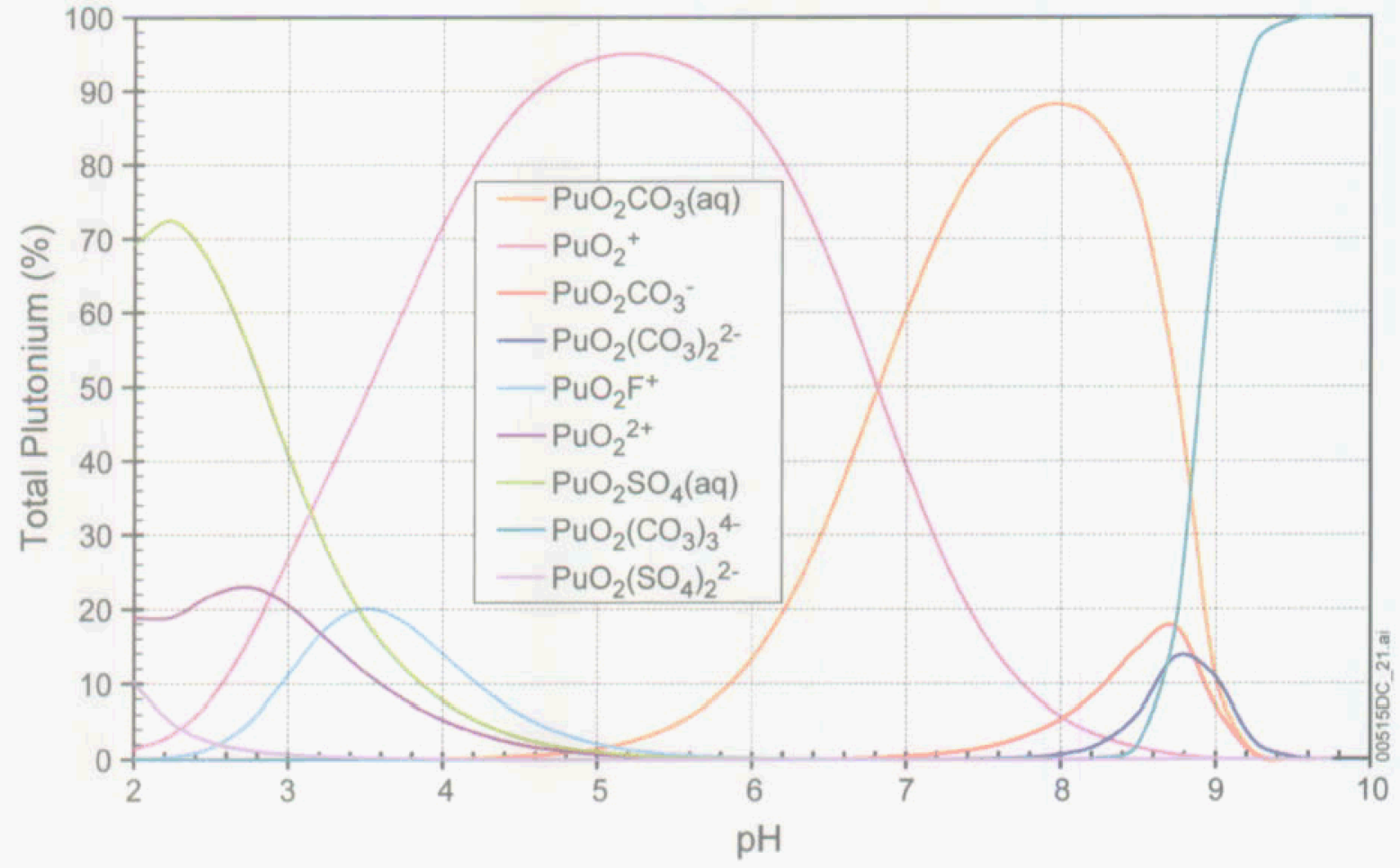

Source: Pu species plot_2.x/s.

Figure 6.4-15. Pu Speciation Diagram at $\log f \mathrm{CO}_{2}$ (bars) $=-3.0$ in Percent Total Pu 
These figures show that from about $\mathrm{pH} 3.5$ to $6.8, \mathrm{Pu}(\mathrm{V})$ is the dominant oxidation state and is represented by the species $\mathrm{PuO}_{2}{ }^{+}$. At lower and higher $\mathrm{pH}$ values, aqueous complex species of $\mathrm{SO}_{4}{ }^{2-}, \mathrm{F}^{-}$and $\mathrm{CO}_{3}{ }^{2-}$ become important. These are $\mathrm{Pu}(\mathrm{VI})$ species so, with their increasing importance, $\mathrm{Pu}(\mathrm{VI})$ becomes the dominant oxidation state. Pu speciation is described in detail in Section 6.5.3.2 focusing on information provided by these speciation diagrams concerning the sensitivity of $\mathrm{Pu}$ solubility to other species in solution.

As Figures 6.4-14 and 6.4-15 show, from below pH 7 to the highest values modeled, $\mathrm{PuO}_{2}{ }^{2+}$ $\mathrm{CO}_{3}{ }^{2-}$ complex species dominate, while at $\mathrm{pH}$ values lower than just above $3, \mathrm{PuO}_{2} \mathrm{SO}_{4}(\mathrm{aq})$ dominates and $\mathrm{PuO}_{2}\left(\mathrm{SO}_{4}\right)^{2-}$ becomes significant. The importance of $\mathrm{PuO}_{2}{ }^{2+}-\mathrm{SO}_{4}{ }^{2-}$ complexes accounts for the sensitivity of total $\mathrm{Pu}$ to $\mathrm{SO}_{4}{ }^{2-}$ at low $\mathrm{pH}$ values shown in Figure 6.4-3.

Around $\mathrm{pH} 3.5, \mathrm{PuO}_{2} \mathrm{~F}^{+}$contributes 20 percent of the total $\mathrm{Pu}$. At higher $\mathrm{F}^{-}$concentrations, this and other $\mathrm{PuO}_{2}{ }^{2+}-\mathrm{F}^{-}$complexes contribute more strongly and even dominate the total $\mathrm{Pu}$ concentration. For example, from Figure 6.4-14, it can be concluded that at $10 \times \mathrm{F}^{-}$the $\mathrm{PuO}_{2} \mathrm{~F}^{+}$ concentration exceeds that of $\mathrm{PuO}_{2}{ }^{+}$, thus approximately doubling the total $\mathrm{Pu}$; while at higher $\mathrm{F}^{-}$ concentrations, $\mathrm{PuO}_{2} \mathrm{~F}^{+}$and $\mathrm{PuO}_{2} \mathrm{~F}_{2}$ (aq) become dominant and together increase the total $\mathrm{Pu}$ concentration by orders of magnitude. This accounts for the strong effect of increasing $\mathrm{F}^{-}$on $\mathrm{Pu}$ concentrations shown in Figure 6.4-2.

To summarize, the speciation diagrams in Figures 6.4-12 through 6.4-15 show that at high pH values, $\mathrm{CO}_{3}{ }^{2-}$ aqueous complex species are the principal contributors to actinide solubilities. These diagrams, together with the results of the sensitivity calculations shown in Figures 6.4-2 and 6.4-3, show that at low $\mathrm{pH}$ values, $\mathrm{SO}_{4}{ }^{2-}$ complexes are the principal contributors to total solubilities, while under moderately acid conditions, solubilities are also very sensitive to $\mathrm{F}^{-}$ because of the formation of $\mathrm{F}^{-}$aqueous complex species. $\mathrm{CO}_{3}{ }^{2-}$ concentrations depend on $\mathrm{pH}$ and $f \mathrm{CO}_{2}$. The solubilities are tabulated in terms of $\mathrm{pH}$ and $f \mathrm{CO}_{2}$, so the sensitivities to $\mathrm{CO}_{3}{ }^{2-}$ variations are considered explicitly. As discussed in Section 6.4.3.5, $\mathrm{SO}_{4}{ }^{2-}$ concentrations are varied in the modeling to maintain charge balance at lower $\mathrm{pH}$ values in order to simulate the occurrence of $\mathrm{H}_{2} \mathrm{SO}_{4}$ in the in-package environment from the oxidation of sulfur during steel degradation. In this way, $\mathrm{SO}_{4}{ }^{2-}$ variations are also considered explicitly. Variations in $\mathrm{F}^{-}$ concentrations are not treated explicitly, rather as uncertainties in the total actinide concentrations. As the figures illustrate, the effect of $\mathrm{F}^{-}$varies with the $\mathrm{pH}$. To capture this, the uncertainty factors applied to the solubilities to account for $\mathrm{F}^{-}$uncertainty are expressed as functions of $\mathrm{pH}$ (Section 6.5.3.4)

\subsubsection{Model Configuration}

In the previous discussion, it was concluded that the important physical and chemical conditions for solubility evaluation are oxidation potential, $\mathrm{pH}, f \mathrm{CO}_{2}, \mathrm{SO}_{4}{ }^{2-}$ and $\mathrm{F}^{-}$concentrations, and temperature. This section explains how each parameter is accounted for in geochemical model calculations, whether they are treated as an independent variable or as an uncertainty term, and how each parameter is varied. 


\subsubsection{Oxidation Potential}

The oxidation state is assumed to be controlled by the atmosphere (Section 5.1). To achieve this, the value of $\mathrm{fO}_{2}$ is set to 0.2 bars. However, this assumption was modified for $\mathrm{Pu}$ and $\mathrm{Np}$ solubility calculations. Sections 6.5 and 6.6 discuss reasons and details of the selection of the oxidation potential used in modeling $\mathrm{Pu}$ and $\mathrm{Np}$ solubility.

\subsubsection{Temperature}

Solubility is calculated at $25^{\circ} \mathrm{C}$. As shown in Section 6.3 .3 .3 , the solubility of plutonium, neptunium, uranium, and americium decreases with temperature. By analogy, thorium should behave similarly to other actinide elements. Thus, it is reasonable that thorium should have retrograde solubility as well. Therefore, using actinide solubilities at $25^{\circ} \mathrm{C}$ is conservative for temperatures higher than $25^{\circ} \mathrm{C}$.

\subsubsection{3 $\mathrm{pH}$}

Because of its strong effect on actinide solubility, $\mathrm{pH}$ is selected as an independent variable in solubility calculations. In other words, solubility calculations are carried out for different $\mathrm{pH}$ values. The $\mathrm{pH}$ range for fluids reacting with CSNF is 4.5 to 8.1 , while the range for fluids reacting with codisposal materials is from 4.5 to 8 (DTN: MO0404SPAIPCHM.005 [DIRS 169187]). According to Engineered Barrier System: Physical and Chemical Environment (BSC 2004 [DIRS 169054], Section 6.13.5), the response surface for $\mathrm{pH}$ in the invert ranges from 3.5 to 10.5 . To cover the full range of conditions, the target $\mathrm{pH}$ range for the modeling was set at 3 to 11 . The $\mathrm{pH}$ values varied in 0.25 increments.

\subsubsection{4 $\mathrm{CO}_{2}$ Fugacity}

As discussed earlier, $f \mathrm{CO}_{2}$ is another important independent variable in actinide solubility models because of the strong tendency for actinides to form complexes with $\mathrm{CO}_{3}{ }^{2-}$. The atmospheric value of $\mathrm{CO}_{2}$ partial pressure is $10^{-3.5}$ bars. Table 4-17 of Yucca Mountain Science and Engineering Report (DOE 2002 [DIRS 155943], p. 4-191) gives the range of $\log f \mathrm{CO}_{2}$ from -2.0 to -2.8 bars, except for the boiling period, to which the results of this report are not applicable. The range of applicability of In-Package Chemistry Abstraction (BSC 2004 [DIRS 167621]) is from $10^{-5}$ to $10^{-1.5}$ bars (Table 8-1). The $f \mathrm{CO}_{2}$ range used for actinide solubility calculations in this report is from $10^{-5}$ to $10^{-1.5}$ bars. It is varied in increments of $0.5 \log$ units.

\subsubsection{Charge Balance Species: $\mathrm{SO}_{4}{ }^{2-}$ and $\mathrm{Na}^{+}$}

In the EQ3NR modeling performed to calculate solubilities, assigning a $\mathrm{pH}$ value different from that of the initial base-case water leads to solutions that are not electrically neutral (charge balanced). To maintain charge balance in the solution modeled, a charge-balancing cation or anion was added during the modeling. The in-package chemistry study indicates that the major driving force for lowering $\mathrm{pH}$ is the oxidation of Carbon Steel Type A516 (which contains sulfur), while the major driving force for $\mathrm{pH}$ increase is the release of alkali and alkaline earth metals from waste glass dissolution (BSC 2004 [DIRS 167621]). In accordance with these studies, $\mathrm{SO}_{4}{ }^{2-}$ is specified as the anion added to balance low $\mathrm{pH}$ solutions and $\mathrm{Na}^{+}$as the cation 
to balance high $\mathrm{pH}$ solutions. This is achieved by specifying one of them in EQ3NR calculations as the species to be adjusted for charge balance. For runs near neutral, the choice of whether to balance on $\mathrm{SO}_{4}{ }^{2-}$ or $\mathrm{Na}^{+}$is made by determining whether the code is balancing by adding or subtracting the charge-balancing ion. If the balancing ion is subtracted, the resulting solution has a lower concentration of the balancing ion than the input water composition. Only runs balanced by adding the charge-balancing ion are used. $\mathrm{SO}_{4}{ }^{2-}$, one of the balancing ions, accounts for the effects of changing concentration on solubility.

In solutions at high and low $\mathrm{pH}$, a significant increase in the charge-balancing ion concentration is required to achieve charge balance. For example, in the case of $\mathrm{PuO}_{2}$ (hyd,aged) adjusted-Eh model at a $\mathrm{pH}$ of 2 , the total sulfate in the system (expressed as $\mathrm{SO}_{4}{ }^{2-}$ ) increased from $18.4 \mathrm{mg} / \mathrm{L}$ to $14,195 \mathrm{mg} / \mathrm{L}(0.148$ molality) (directory $\mathrm{Pu} / \mathrm{Pu} \mathrm{Eq} 3$ runs.zip/Eh/AdjEh/SO4 , file pu410401.3o). At a $\mathrm{pH}$ of 9.75 , the total sodium (expressed as $\mathrm{Na}^{+}$) increased from $45.8 \mathrm{mg} / \mathrm{L}$ to $11,875 \mathrm{mg} / \mathrm{L}(0.518$ molality) in order to achieve charge balancing (path $\mathrm{Pu} / \mathrm{Pu} \mathrm{Eq} 3$ runs.zip/Eh/AdjEh/ $\mathrm{Na}^{+}$, file $p u 420432.3 o$ ). Table 6.4-1 lists the top aqueous species for both the low and high $\mathrm{pH}$ solutions. At the low $\mathrm{pH}$, a significant portion of the sulfur goes to $\mathrm{Pu}$ complexes, whereas at the high $\mathrm{pH}$, the $\mathrm{Na}$ does not form many complexes, but mainly balances charges on the carbonate and bicarbonate species.

Table 6.4-1. Major Aqueous Species at pH Extremes

\begin{tabular}{|l|l|l|c|}
\hline \multicolumn{3}{|c|}{$\begin{array}{c}\text { Species Present After Charge Balancing for } \mathrm{PuO}_{2} \text { (hyd,aged) } \\
\text { Adjusted-Eh Model, Molality Greater than } 1 \times 10^{-2}\end{array}$} \\
\hline \multicolumn{2}{|c|}{$\mathrm{pH=2}$ (balance with SO ${ }_{4}{ }^{2-}$ ) } & \multicolumn{1}{|c|}{$\mathrm{pH}=9.75$ (balance with Na ${ }^{+}$) } \\
\hline Species & Molality & \multicolumn{1}{|c|}{ Species } & Molality \\
\hline $\mathrm{PuO}_{2} \mathrm{SO}_{4}$ (aq) & $9.52 \mathrm{E}-02$ & $\mathrm{Na}^{+}$ & $4.51 \mathrm{E}-01$ \\
\hline $\mathrm{PuO}_{2}{ }^{2+}$ & $2.58 \mathrm{E}-02$ & $\mathrm{HCO}_{3}^{-}$ & $1.23 \mathrm{E}-01$ \\
\hline $\mathrm{SO}_{4}{ }^{2-}$ & $1.68 \mathrm{E}-02$ & $\mathrm{CO}_{3}{ }^{2-}$ & $1.12 \mathrm{E}-01$ \\
\hline $\mathrm{PuO}_{2}\left(\mathrm{SO}_{4}\right)_{2}{ }^{2-}$ & $1.40 \mathrm{E}-02$ & $\mathrm{NaHCO}_{3}(\mathrm{aq})$ & $3.54 \mathrm{E}-02$ \\
\hline $\mathrm{H}^{+}$ & $1.24 \mathrm{E}-02$ & $\mathrm{NaCO}_{3}^{-}$ & $3.08 \mathrm{E}-02$ \\
\hline & & $\mathrm{PuO}_{2}\left(\mathrm{CO}_{3}\right)_{3}{ }^{4-}$ & $1.81 \mathrm{E}-02$ \\
\hline
\end{tabular}

\subsubsection{Concentration of Secondary Ligands $\left(\mathrm{F}^{-}, \mathrm{HPO}_{4}^{-}\right.$, and $\left.\mathrm{SO}_{4}{ }^{2-}\right)$}

TSPA-LA models two groups of waste packages. CSNF waste packages (which include naval waste packages because of its robustness) comprise more than 90 percent of the waste inventory while codisposal waste packages comprise the remainder. The concentration range of fluorides in CSNF waste packages is given in In-Package Chemistry Abstraction (BSC 2004 [DIRS 167621], Table 8-6). The maximum value at $25^{\circ} \mathrm{C}$ is $9.8 \mathrm{E}-4 \mathrm{~mol} / \mathrm{kg}(18.6 \mathrm{mg} / \mathrm{L})$, which is about 8.5 times that of the base-case value. The minimum value is $3.0 \mathrm{E}-05 \mathrm{~mol} / \mathrm{kg}$ $(0.57 \mathrm{mg} / \mathrm{L})$, which is less than the base-case value (BSC 2004 [DIRS 167621], Figure 6-67). A range from the base-case value $(2.18 \mathrm{mg} / \mathrm{L})$ to 10 times the base-case value $(21.8 \mathrm{mg} / \mathrm{L})$ is assigned to fluoride concentration in the CSNF waste packages.

In-Package Chemistry Abstraction (BSC 2004 [DIRS 167621], Table 8-6) also gives fluoride concentrations for codisposal waste packages under both vapor influx-and water influx- 
conditions of water flow. The highest fluoride concentration is $1.1 \mathrm{E}-02 \mathrm{~mol} / \mathrm{kg}(209 \mathrm{mg} / \mathrm{L})$ for the vapor influx case, which is 95 times higher than the base-case value. The lowest concentration is many times lower than the base-case value (BSC 2004 [DIRS 167621], Figure 6-68), but a lower fluoride concentration yields a lower solubility, so it is conservative to set the minimum fluoride concentration to the base-case value. For the codisposal waste packages, for all Th and Am, a fluoride concentration of 200 times the base-case value $(436 \mathrm{mg} / \mathrm{L})$ is also investigated. There are no known sources of fluorine in the invert other than that coming from the high-level radioactive waste glass contained in the codisposal waste packages; therefore, the maximum fluoride concentration should not be greater than that in the solution in the codisposal waste packages. Thus, the same range of fluoride concentration (from the base-case value to 95 times the base-case value) is assigned to the invert.

Because of the existence of large quantities of uranium in the repository and the low solubility of uranium-phosphate minerals, Section 6.4.2.5 concludes that the influence of phosphate concentration on actinide solubility is negligible. Nonetheless, phosphate as a component is included in the model calculation and a base-case value is elected based on Table 4.2 of Report of the Committee to Review the Use of J-13 Well Water in Nevada Nuclear Waste Storage Investigations (Harrar et al. 1990 [DIRS 100814]), which gives nine measurements of $\mathrm{PO}_{4}{ }^{3-}$ for the reference water. Four of them are listed as less than $10 \mu \mathrm{g} / \mathrm{L}$, two of them as less than $100 \mu \mathrm{g} / \mathrm{L}$, and the remaining three are $120 \mu \mathrm{g} / \mathrm{L}, 100 \mu \mathrm{g} / \mathrm{L}$, and $2,800 \mu \mathrm{g} / \mathrm{L}$, respectively. However, the latter two are marked as "probably erroneous" and, thus, are excluded from consideration. Because the majority of the remaining 7 measurements are less than $100 \mu \mathrm{g} / \mathrm{L}$, this report assigns the value of $100 \mu \mathrm{g} / \mathrm{L}(0.1 \mathrm{mg} / \mathrm{L})$ to $\mathrm{HPO}_{4}{ }^{2-}$.

$\mathrm{SO}_{4}{ }^{2-}$ concentrations also have an influence on actinide solubilities. As discussed in Section 6.4.3.5, this ligand is associated with the acidity of waste package solutions and is treated as the charge-balancing species in the EQ3NR solubility calculations. As there is no known source of $\mathrm{SO}_{4}{ }^{2-}$ other than steels in waste packages, the effect of $\mathrm{SO}_{4}{ }^{2-}$ concentration on actinide solubilities is accounted for by linking its variation with $\mathrm{pH}$ changes.

\subsubsection{Concentration of Tertiary Ligands $\left(\mathrm{Cl}^{-}\right.$and $\left.\mathrm{NO}_{3}{ }^{-}\right)$and Cations}

Based on the discussion in Sections 6.4.1 and 6.4.2.5.1, the effects of the tertiary ligands $\left(\mathrm{Cl}^{-}\right.$and $\left.\mathrm{NO}_{3}{ }^{-}\right)$and the four common cations $\left(\mathrm{K}^{+}, \mathrm{Na}^{+}, \mathrm{Ca}^{2+}\right.$, and $\left.\mathrm{Mg}^{2+}\right)$ are very minor; thus, using their base-case values is justified. In addition, $\mathrm{Na}^{+}$is used to balance charge in the solution (Section 6.4.3.5), which accounts for the potential variation in common cation concentrations.

Depending on the fugacity of $\mathrm{CO}_{2}$, when $\mathrm{pH}$ increases sufficiently, some cations are expected to precipitate. This is because the solution is set to be in equilibrium with $\mathrm{CO}_{2}(\mathrm{~g})$ at a set fugacity, which could result in the formation of carbonate solids. For example, the EQ3NR runs show that the solution becomes supersaturated with calcite at $\mathrm{pH}$ between 8.0 and 8.25 when $\log f \mathrm{CO}_{2}$ (bars) $=-3.0$. Similarly, the EQ3NR outputs commonly show fluorapatite $\left[\mathrm{Ca}_{5} \mathrm{~F}\left(\mathrm{PO}_{4}\right)_{3}\right]$ supersaturation at high $\mathrm{pH}$ owing to the conversion of protonated phosphate anions, such as $\mathrm{HPO}_{4}{ }^{2-}$, to $\mathrm{PO}_{4}{ }^{3-}$. If precipitation does not occur, the ionic strength remains relatively high, thereby maintaining a somewhat higher solubility of radionuclides as a consequence of the salting in effect (i.e., activity coefficients stay relatively low). However, the main effect of the supersaturation in carbonate and fluoride is to leave these ions in solution and thereby increase 
the concentrations of carbonate and fluoride complexes with actinides. Thus, the actinide solubilities calculated by EQ3NR without precipitation is conservatively high.

The discussion on model configuration is summarized in Table 6.4-2.

Table 6.4-2. Summary of EQ3NR Model Configuration

\begin{tabular}{|c|c|c|}
\hline Variable & Treatment in Model & Value or Range \\
\hline $\mathrm{pH}$ & Independent variable & 3.0 to 11.0 \\
\hline $\log \mathrm{fCO}_{2}$ (bars) & Independent variable & -5.0 to -1.5 \\
\hline Temperature & Conservatively using $25^{\circ} \mathrm{C}$ value & $25^{\circ} \mathrm{C}$ to $100^{\circ} \mathrm{C}$ \\
\hline $\log \mathrm{fO}_{2}$ (bars) & Constant & $\begin{array}{l}-0.7 \text { (except for Pu and Np, see Sections } 6.5 \text { and } 6.6 \text { for } \\
\text { details) }\end{array}$ \\
\hline $\mathrm{F}^{-}$concentration & Uncertainty term & $\begin{array}{l}1 \text { to } 10 \text { times the base-case value for CSNF waste } \\
\text { packages; } 1 \text { to } 200 \text { times the base-case value for } \\
\text { codisposal waste packages; and } 1 \text { to } 200 \text { times the } \\
\text { base-case value for the invert for Am, Th, and Pa. For } \\
\mathrm{Pu}, \mathrm{Np} \text {, and } \mathrm{U}, 1 \text { to } 27 \text { times the base-case value for } \\
\text { water influx codisposal waste packages; and } 1 \text { to } 95 \\
\text { times the base-case value for vapor influx codisposal } \\
\text { waste packages and for the invert }\end{array}$ \\
\hline $\mathrm{SO}_{4}{ }^{2-}$ concentration & Charge balance species & $\begin{array}{l}\text { Base-case ( } \mathrm{J}-13 \text { well water) concentration or as } \\
\text { automatically determined by the code, whichever is } \\
\text { higher }\end{array}$ \\
\hline $\mathrm{Na}^{+}$concentration & Charge balance species & $\begin{array}{l}\text { Base-case ( } \mathrm{J}-13 \text { well water) concentration or as } \\
\text { automatically determined by the code, whichever is } \\
\text { higher }\end{array}$ \\
\hline $\mathrm{PO}_{4}{ }^{3-}, \mathrm{NO}_{3}{ }^{-}$, and $\mathrm{Cl}^{-}$ & Constant & The base-case ( $\mathrm{J}-13$ well water) value \\
\hline $\mathrm{K}^{+}, \mathrm{Ca}^{2+}$, and $\mathrm{Mg}^{2+}$ & Constant & The base-case ( $\mathrm{J}-13$ well water) value \\
\hline
\end{tabular}

\subsubsection{Valid Ranges of Solubility Models}

As discussed in the previous section, the solubility models developed in this report are valid for broad ranges of water composition as listed in Table 6.4-2. However, three exceptions are noted.

The first exception arises from the limitations in activity coefficient corrections. As discussed in Section 6.3.3.4, the nominal range of applicability of activity coefficients calculated by the B-dot equation (used in EQ3NR with parameter values given in Data0.ymp.R2) is to solutions with ionic strengths up to 1 molal. Thus, no uncertainties related to activity coefficients are included in the solubilities given in this report for modeled solutions with ionic strengths of 1 molal or less. However, for some elements, certain $\mathrm{pH}$ and $f \mathrm{CO}_{2}$ conditions lead to modeled solutions with ionic strengths exceeding 1 molal. In most cases when this occurs, the solubility tables for these $\mathrm{pH}$ and $f \mathrm{CO}_{2}$ conditions show the "500" placeholder. In other cases, when the modeled solution exceeds 1 molal by a factor of 3 or less and it was important to provide a solubility value to TSPA-LA, the calculated values given in the solubility tables must take into account additional uncertainty which is added to the solubility of the actinides by the square root of the mean described in Section 6.3.3.4. 
The second exception is that the solid chosen as the controlling phase may not be stable in the reference water outside a certain range of $\mathrm{pH}$ and $\mathrm{fCO}_{2}$ values allowing very high intermediate concentrations to be reached during the iterative mathematical solution by EQ3 of the equations describing the aqueous solution. Under conditions of low $\mathrm{pH}$ or of high $\mathrm{pH}$ and high $f \mathrm{CO}_{2}$, the EQ3NR calculations did not converge, indicating the solubility-controlling phase is unstable under modeled conditions. This unstable condition can occur at low $\mathrm{pH}$ values largely due to rapid increases in total actinide and $\mathrm{SO}_{4}{ }^{2-}$ concentrations. As discussed in Section 6.4.3.6, the rapid increases are due to the strength of actinide- $\mathrm{SO}_{4}{ }^{2-}$ solution complexes such as $\mathrm{AmSO}_{4}{ }^{+}$ and $\mathrm{Th}\left(\mathrm{SO}_{4}\right)_{2}(\mathrm{aq})$ and the addition of $\mathrm{SO}_{4}{ }^{2-}$ as the charge-balancing anion. Instability from this condition occurs in calculations for thorium and has a particularly strong effect on the calculations of americium solubilities (Section 6.9.4). In the high $f \mathrm{CO}_{2}$ and $\mathrm{pH}$ region, increasing $\mathrm{CO}_{3}{ }^{2-}$ concentrations favor the formation of actinide carbonate complexes such as $\mathrm{Am}\left(\mathrm{CO}_{3}\right)_{3}{ }^{3-}$, Th $\left(\mathrm{CO}_{3}\right)_{5}{ }^{6-}$, and $\mathrm{Th}(\mathrm{OH})_{3} \mathrm{CO}_{3}{ }^{-}$. The $f \mathrm{CO}_{2}$ is fixed in the modeling, so $\mathrm{CO}_{3}{ }^{2-}$ concentrations are sensitive to $\mathrm{pH}$ changes. This produces rapid changes in total actinide concentrations with $\mathrm{pH}$ changes and leads to the nonconvergence noted for all actinides under these modeling conditions. In the low $\mathrm{pH}$ and high $\mathrm{pH}$-high $f \mathrm{CO}_{2}$ regions, calculation results may be invalid even if the EQ3NR modeling converges because the total solute concentrations in these regions may exceed 1-molal ionic strength. As discussed previously in this section, EQ3NR solubility models should not be used above this ionic strength without adding allowance for the increased uncertainty.

When these two exceptions are observed, no solubility values are reported in the tables of calculated results. For the tabulated log solubility, they are flagged by "500." For TSPA-LA modeling, when values of 500 are encountered they are considered flags that concentrations should be established by its release rate, rather than from a solubility control.

A third exception arises from the assigned fluoride concentration ranges in waste packages and in the invert (Sections 6.3.3.2 and 6.4.3.6). These ranges are based on modeling results of inpackage chemistry for certain scenarios. The fluoride uncertainty term is modeled separately for each of the elements.

\subsubsection{EQ3 Input Files}

The EQ3 input file names follow the convention, Pu010203.3i:

- The first two characters are the element name

- The next two numbers are the $f \mathrm{O}_{2}$ step (since $f \mathrm{O}_{2}$ was not varied, this value is always 01 )

- The next two numbers give the $f \mathrm{CO}_{2}$ step 01 to 08 : varying the $f \mathrm{CO}_{2}$ from $10^{-1.5}$ to $10^{-5.0}$ bars in $10^{-0.5}$ bar increments

- The last two numbers give the pH step 01 to 37 : varying the $\mathrm{pH}$ from 3.0 to 12.0 in $0.25 \mathrm{pH}$ increments.

The input files are located in Appendix I, with the directory structure given in Appendix II. The runs balanced on different elements (Section 6.4.3.5) are stored in directories named for the balancing element. For example, all of the runs for the Am solubility that were balanced on $\mathrm{Na}^{+}$ are in the "na" directory under Am. 


\subsection{PLUTONIUM SOLUBILITY}

\subsubsection{Introduction}

Plutonium has a complex chemistry. Despite numerous studies, the understanding of $\mathrm{Pu}$ solubility remains uncertain. In Section 6.5.3, the base-case Pu-solubility model is presented. Section 6.5.4 describes the basis for using an adjusted-Eh solubility model for Pu.

In natural environments, Pu exists primarily as colloids (Rai and Swanson 1981 [DIRS 144599]; Choppin 1983 [DIRS 168395]; Toth et al. 1983 [DIRS 168394]; Choppin and Stout 1989 [DIRS 168379]; and Silva and Nitsche 1995 [DIRS 112092]). Colloids are defined as particles with at least one dimension between $1 \mathrm{~nm}$ to $1 \mu \mathrm{m}$ (Lide, 2001, Page 2-42). Often, particularly in reporting of experimental results, the upper end of the colloid size range is $450 \mathrm{~nm}$ and the lower limit is $>2 \mathrm{~nm}$, due to conventional dimensions of laboratory equipment (primarily filters) (BSC 2004 [DIRS: 170025]). Table 6.5-2 indicates the filter size used to separate colloids from solution used in experimental determination of aqueous $\mathrm{Pu}$. This report deals only with dissolved $\mathrm{Pu}$ as defined by the largest of these sieve sizes $(4.1 \mathrm{~nm})$. Thus, the Pu-solubility product in solubility model calculations represents $\mathrm{Pu}$ solubility controlled by dual equilibrium as discussed in Section 6.5.3.1. Pu transport by colloids is discussed in a separate report, as directed in Technical Work Plan for: Regulatory Integration Modeling and Analysis of the Waste Form and Waste Package (BSC 2004 [DIRS 171583]).

Data0.ymp.R2 (DTN: MO0302SPATHDYN.000 [DIRS 161756]) incorporates plutonium thermodynamic data compiled by the Chemical Thermodynamics project of the NEA (Lemire 2001 [DIRS 159027]). This database was used for plutonium solubility calculations. A correction was made to the $\log \mathrm{K}$ value and formula in the Data0.ymp.R2 database of the phase $\mathrm{PuO}_{2}(\mathrm{OH})_{2} \mathrm{H}_{2} \mathrm{O}$ when creating the Data0.yc3.RI database. As this solid was not used as a solubility-controlling phase in this report, this correction has no impact on the output of this report.

\subsubsection{Chemical Conditions}

See Table 6.4-2 for the chemical conditions used for the plutonium calculations. For the basecase adjusted-Eh model, different redox conditions were used, as discussed in Sections 6.5.3.2.

\subsubsection{The Adjusted-Eh Pu-Solubility Model (Base-Case Pu-Solubility Model)}

\subsubsection{Selection of Solubility-Controlling Phases}

The most studied plutonium solid for its solution behavior is a hydrated-plutonium dioxide variously written as $\mathrm{Pu}(\mathrm{OH})_{4}(\mathrm{am}), \mathrm{PuO}_{2} \cdot x \mathrm{H}_{2} \mathrm{O}$, or $\mathrm{PuO}_{2}$ (hyd,aged), where "am" stands for amorphous, "hyd" for hydrated, and "aged" for aged from fresh precipitate. The NEA data compilation (Lemire 2001 [DIRS 159027]) uses $\mathrm{PuO}_{2}$ (hyd,aged) and $\mathrm{Pu}(\mathrm{OH})_{4}$ (hyd,aged) to denote the same $\mathrm{Pu}(\mathrm{IV})$ hydrated oxide/hydroxide "aged for several months near room temperature." The solubility constant of $\mathrm{PuO}_{2}$ (hyd,aged), recommended by the NEA (Lemire 2001 [DIRS 159027]) and used in this study, is based on solubility experiments conducted by Rai (1984 [DIRS 122768]) and Kim and Kanellakopulos (1989 [DIRS 122387]). 
The NEA recently updated the $\mathrm{Pu}$ data set (Guillaumont et al. 2003 [DIRS 168382]). The revised value of $\mathrm{PuO}_{2}$ (hyd,aged) equilibrium constant given in this update does not differ much from the value used in this report (only 0.33 in $\log \mathrm{K}$ ). This is well within the uncertainty associated with the calculated $\mathrm{Pu}$ concentrations ( \pm 2.0 , Section 6.5 .3 .4 .1 ), so not adopting the new value does not change the calculated concentrations beyond the uncertainty already associated with them.

In experiments from oversaturation conducted at Los Alamos National Laboratory (LANL) (Efurd et al. 1998 [DIRS 108015]; Runde et al. 2002 [DIRS 168432]; and CRWMS M\&O 2001 [DIRS 154629]) solids precipitated have a dark green color, which is characteristic of $\mathrm{Pu}(\mathrm{IV})$ solid phases. Diffuse reflectance infrared spectra of the precipitated solid indicates that the presence of $\mathrm{Pu}(\mathrm{IV})$ and the $\mathrm{X}$-ray diffraction pattern matched that of $\mathrm{PuO}_{2}(\mathrm{~s})$. The diffuse and broad X-ray diffraction peaks suggest poorly crystalline structures (Efurd et al. 1998 [DIRS 108015]; Runde et al. 2002 [DIRS 168432]; CRWMS M\&O 2001 [DIRS 154629]). It is concluded that "plutonium hydroxides and/or colloids, aging toward $\mathrm{PuO}_{2} \cdot \mathrm{xH}_{2} \mathrm{O}$ are, therefore, interpreted to be the solubility-controlling solids in these experiments."

Similar results were obtained in another plutonium solubility experiment with Yucca Mountain waters (Nitsche et al. 1993 [DIRS 155218]; Nitsche et al. 1994 [DIRS 144515]). In that study, at least two solid phases were observed for experiments at $90^{\circ} \mathrm{C}$. One is a yellow-green powdery phase, probably noncrystalline. The other consists of darker green clumps. Nitsche et al. (1993 [DIRS 155218], p. 63) concluded, "such a combination of crystalline and amorphous materials in this solid can explain the observed powder [x-ray diffraction] pattern, which is composed of both very sharp and diffuse lines."

Besides $\mathrm{Pu}(\mathrm{IV})$ hydrous precipitates, $\mathrm{Pu}(\mathrm{IV})$ hydrolysis forms polymer suspensions (colloids) (Rai and Swanson 1981 [DIRS 144599]; Choppin 1983 [DIRS 168395]; Kim and Kanellakopulos 1989 [DIRS 122387]). The measured Pu solubility can also be measured by $\mathrm{Pu}$ colloids. In other words, a dual equilibrium is established among dissolved $\mathrm{Pu}, \mathrm{Pu}(\mathrm{OH})_{4}(\mathrm{am})$ precipitates, and Pu colloids or polymers, as shown in Figure 6.5-1.

As pointed out by Kim and Kanellakopulos (1989 [DIRS 122387]), "the experimental differentiation of the two equilibrium reactions is practically impossible." Thus, the Pu-solubility product measured in experiments actually reflects the dual equilibrium and using the measured $\mathrm{Pu}$-solubility product in solubility model calculations also represents $\mathrm{Pu}$ solubility controlled by the dual equilibrium. The following discussion states that $\mathrm{PuO}_{2}$ (hyd,aged) is used as the solubility-controlling phase for $\mathrm{Pu}$ and no distinction between $\mathrm{PuO}_{2}$ (hyd,aged) precipitates control and $\mathrm{PuO}_{2}$ (hyd,aged) colloids control is made.

Aging has been widely observed in $\mathrm{Pu}$ precipitates or polymers in solubility experiments. For example, Rai and Ryan (1982 [DIRS 112060]) observed $\mathrm{PuO}_{2} \cdot x \mathrm{H}_{2} \mathrm{O}$ (amorphous) continuously aging over a period of 1,266 days by dehydration. The dehydration process of $\mathrm{Pu}(\mathrm{IV})$ hydrous involves the conversion of hydroxy bridge into oxygen bridge (Choppin 1983 [DIRS 168395]). This aging process is irreversible (i.e., once aged, the solid becomes kinetically stable (Choppin 2003 [DIRS 168308]) and difficult to be redissolved). 


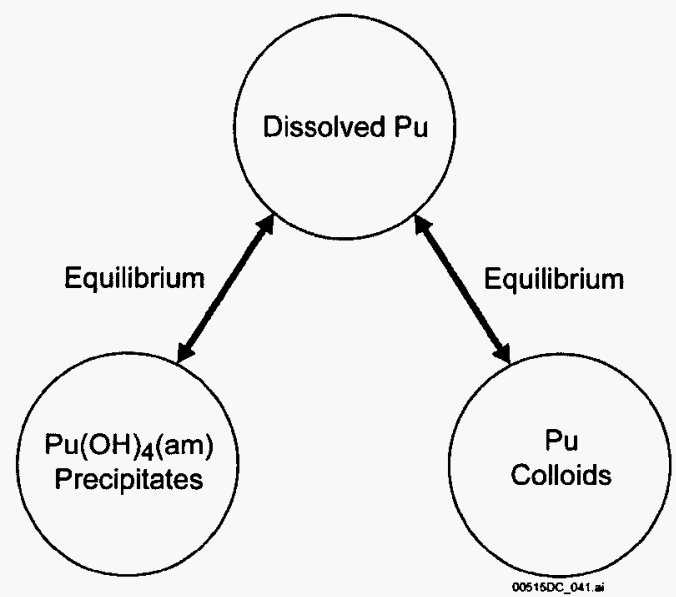

Figure 6.5-1. Dual Equilibrium Among Dissolved Pu, Pu Precipitates, and Pu Colloids

Radiolytic processes limit the extent to which dehydration of amorphous $\mathrm{PuO}_{2}$ hydrates can cause them to revert to more-crystalline, less-soluble forms. Lemire et al. (2001 [DIRS 159027], Section 17.2.2.3) point out that ${ }^{239} \mathrm{PuO}_{2}$ is slowly converted to (or becomes coated with) a lesscrystalline form when in contact with water. This form is similar to the $\mathrm{PuO}_{2}$ (hyd,aged) form produced by the dehydration of amorphous, hydrated $\mathrm{PuO}_{2}$. Lemire et al. (2001 [DIRS 159027], Section 17.2.2.3) also note that ${ }^{238} \mathrm{PuO}_{2}$ is converted to the amorphous solid in water.

Plutonium is present in $\mathrm{PuO}_{2}$ (hyd,aged) in the $\mathrm{Pu}(\mathrm{IV})$ oxidation state. Under reducing conditions where $\mathrm{Pu}(\mathrm{IV})$ is the stable oxidation state, the solid dissolves directly to $\mathrm{Pu}(\mathrm{IV})$ aqueous species. However, under the oxidizing conditions of Yucca Mountain, the dissolved $\mathrm{Pu}$ is present dominantly as $\mathrm{Pu}(\mathrm{V})$ and $\mathrm{Pu}(\mathrm{VI})$, depending on the $\mathrm{Eh}, \mathrm{pH}$, and concentrations of complexforming ligands in the solution. The following sections explore the effect of the choice of Eh (the value of which most closely reproduces laboratory experimental data). The distribution of dissolved species and of oxidation states of dissolved $\mathrm{Pu}$ are discussed in more detail below.

Recently, a solid with the general formula $\mathrm{PuO}_{2+\mathrm{x}}$ that forms from $\mathrm{PuO}_{2}$ in the presence of water vapor was described by Haschke et al. (2000 [DIRS 150367]), Haschke and Oversby (2002 [DIRS 161911]), and Haschke and Allen (2002 [DIRS 162001]). Based on a review of these papers, the recent update to the NEA compilation of chemical thermodynamic data (Guillaumont et al. 2003 [DIRS 168382], Section 11.2.2.1) concludes that "...the evidence for the formation of a thermodynamically stable bulk phase with $\mathrm{O} / \mathrm{Pu}>2$ is far from conclusive." For this reason and others discussed in Section 6.5.6, this solid was not considered in selecting the $\mathrm{Pu}$-controlling solids.

\subsubsection{Calculated Pu Solubility and Speciation Using the Adjusted-Eh Model}

The adjusted-Eh model sets Eh conditions using Equation 6.5-7, as described in Section 6.5.4.3, for $\mathrm{pH}$ values between 3.0 and 10.75. Other model calculation conditions are given by Table 6.4-2.

The calculated-Pu solubility $(\log [\mathrm{Pu}](\mathrm{mg} / \mathrm{L}))$ with $\mathrm{pH}$ and $\log f \mathrm{CO}_{2}$ as independent variables is given by Table 6.5-1. Because the independent variables are in log scales, and the table may need to be interpolated between calculated values, the logarithm of Pu solubility is given. 
Dissolved Concentration Limits of Radioactive Elements

Table 6.5-1. Calculated Pu Solubility (the Adjusted-Eh Model) (log $[\mathrm{Pu}] \mathrm{mg} / \mathrm{L}$ )

\begin{tabular}{|c|c|c|c|c|c|c|c|c|}
\hline \multirow[b]{2}{*}{ pH } & \multicolumn{8}{|c|}{$\log f \mathrm{CO}_{2}$ (bars) } \\
\hline & -1.50 & -2.00 & -2.50 & -3.00 & -3.50 & -4.00 & -4.50 & -5.00 \\
\hline 2.00 & $4.53 E+00$ & $4.53 \mathrm{E}+00$ & $4.53 \mathrm{E}+00$ & $4.53 \mathrm{E}+00$ & $4.53 \mathrm{E}+00$ & $4.53 \mathrm{E}+00$ & $4.53 \mathrm{E}+00$ & $4.53 E+00$ \\
\hline 2.25 & $3.84 E+00$ & $3.84 \mathrm{E}+00$ & $3.84 \mathrm{E}+00$ & $3.84 \mathrm{E}+00$ & $3.84 \mathrm{E}+00$ & $3.84 E+00$ & $3.84 \mathrm{E}+00$ & $3.84 \mathrm{E}+00$ \\
\hline 2.50 & $3.19 E+00$ & $3.19 E+00$ & $3.19 \mathrm{E}+00$ & $3.19 \mathrm{E}+00$ & $3.19 \mathrm{E}+00$ & $3.19 \mathrm{E}+00$ & $3.19 \mathrm{E}+00$ & $3.19 \mathrm{E}+00$ \\
\hline 2.75 & $2.62 E+00$ & $2.62 \mathrm{E}+00$ & $2.62 E+00$ & $2.62 \mathrm{E}+00$ & $2.62 \mathrm{E}+00$ & $2.62 \mathrm{E}+00$ & $2.62 \mathrm{E}+00$ & $2.62 \mathrm{E}+00$ \\
\hline 3.00 & $2.14 E+00$ & $2.14 \mathrm{E}+00$ & $2.14 \mathrm{E}+00$ & $2.14 \mathrm{E}+00$ & $2.14 \mathrm{E}+00$ & $2.14 \mathrm{E}+00$ & $2.14 \mathrm{E}+00$ & $2.14 \mathrm{E}+00$ \\
\hline 3.25 & $1.74 E+00$ & $1.74 \mathrm{E}+00$ & $1.74 \mathrm{E}+00$ & $1.74 \mathrm{E}+00$ & $1.74 \mathrm{E}+00$ & $1.74 \mathrm{E}+00$ & $1.74 \mathrm{E}+00$ & $1.74 \mathrm{E}+00$ \\
\hline 3.50 & $1.38 \mathrm{E}+00$ & $1.38 \mathrm{E}+00$ & $1.38 \mathrm{E}+00$ & $1.38 \mathrm{E}+00$ & $1.38 \mathrm{E}+00$ & $1.38 \mathrm{E}+00$ & $1.38 \mathrm{E}+00$ & $1.38 \mathrm{E}+00$ \\
\hline 3.75 & $1.04 E+00$ & $1.03 \mathrm{E}+00$ & $1.03 E+00$ & $1.03 E+00$ & $1.03 E+00$ & $1.03 E+00$ & $1.03 \mathrm{E}+00$ & $1.03 \mathrm{E}+00$ \\
\hline 4.00 & $7.22 \mathrm{E}-01$ & $7.12 \mathrm{E}-01$ & 7.09E-01 & 7.08E-01 & 7.07E-01 & 7.07E-01 & 7.07E-01 & 7.07E-01 \\
\hline 4.25 & $4.32 \mathrm{E}-01$ & $4.12 \mathrm{E}-01$ & 4.06E-01 & 4.04E-01 & 4.03E-01 & 4.03E-01 & 4.03E-01 & 4.03E-01 \\
\hline 4.50 & $1.72 \mathrm{E}-01$ & $1.35 \mathrm{E}-01$ & $1.23 \mathrm{E}-01$ & 1.19E-01 & $1.18 \mathrm{E}-01$ & 1.17E-01 & $1.17 \mathrm{E}-01$ & $1.17 \mathrm{E}-01$ \\
\hline 4.75 & $-5.78 \mathrm{E}-02$ & $-1.22 \mathrm{E}-01$ & -1.45 & $-1.52 \mathrm{E}-01$ & -01 & $-1.55 E-01$ & -1.5 & -1.5 \\
\hline 5.00 & $-2.54 E-01$ & $-3.60 \mathrm{E}-01$ & $-3.99 \mathrm{E}-01$ & $-4.12 \mathrm{E}-01$ & $-4.17 \mathrm{E}-01$ & $-4.18 \mathrm{E}-01$ & $-4.19 \mathrm{E}-01$ & $-4.19 E-01$ \\
\hline 5.25 & $-4.13 E-01$ & $-5.75 E-01$ & $-6.42 \mathrm{E}-01$ & $-6.65 \mathrm{E}-01$ & $-6.73 \mathrm{E}-01$ & $-6.75 E-01$ & $-6.76 \mathrm{E}-01$ & $-6.76 \mathrm{E}-01$ \\
\hline 5.50 & $-5.33 E-01$ & -7.62E-01 & $-8.70 \mathrm{E}-01$ & $-9.11 \mathrm{E}-01$ & $-9.25 \mathrm{E}-01$ & $-9.29 \mathrm{E}-01$ & $-9.30 \mathrm{E}-01$ & $-9.31 E-01$ \\
\hline 5.75 & $-6.17 \mathrm{E}-01$ & $-9.17 \mathrm{E}-01$ & $-1.08 \mathrm{E}+00$ & $-1.15 \mathrm{E}+00$ & $-1.17 E+00$ & $-1.18 \mathrm{E}+00$ & $-1.18 \mathrm{E}+00$ & $-1.18 \mathrm{E}+00$ \\
\hline 6.00 & $-6.73 \mathrm{E}-01$ & $-1.03 E+00$ & $-1.27 \mathrm{E}+00$ & $-1.37 E+00$ & $-1.41 \mathrm{E}+00$ & $-1.43 E+00$ & $-1.43 E+00$ & $-1.43 E+00$ \\
\hline 6.25 & -7.07E-01 & $-1.12 \mathrm{E}+00$ & $-1.42 \mathrm{E}+00$ & $-1.58 \mathrm{E}+00$ & $-1.65 E+00$ & $-1.67 E+00$ & $-1.68 E+00$ & $-1.69 \mathrm{E}+00$ \\
\hline 6.50 & $-7.28 E-01$ & $-1.17 \mathrm{E}+00$ & $-1.54 E+00$ & $-1.77 E+00$ & $-1.88 E+00$ & $-1.92 E+00$ & $-1.93 E+00$ & $-1.93 E+00$ \\
\hline 6.75 & $-7.39 E-01$ & $-1.21 \mathrm{E}+00$ & $-1.62 \mathrm{E}+00$ & $-1.92 \mathrm{E}+00$ & $-2.08 E+00$ & $-2.15 \mathrm{E}+00$ & $-2.18 \mathrm{E}+00$ & $-2.18 \mathrm{E}+00$ \\
\hline 7.00 & -7.44E-01 & $-1.23 \mathrm{E}+00$ & $-1.67 \mathrm{E}+00$ & $-2.04 \mathrm{E}+00$ & $-2.27 E+00$ & $-2.38 E+00$ & $-2.42 \mathrm{E}+00$ & $-2.43 E+00$ \\
\hline 7.25 & $-7.44 \mathrm{E}-01$ & $-1.24 \mathrm{E}+00$ & $-1.70 \mathrm{E}+00$ & $-2.12 \mathrm{E}+00$ & $-2.42 \mathrm{E}+00$ & $-2.58 E+00$ & $-2.65 \mathrm{E}+00$ & $-2.67 \mathrm{E}+00$ \\
\hline 7.50 & $-7.32 \mathrm{E}-01$ & $-1.24 E+00$ & $-1.72 E+00$ & $-2.17 \mathrm{E}+00$ & $-2.53 E+00$ & $-2.76 \mathrm{E}+00$ & $-2.87 E+00$ & $-2.91 E+00$ \\
\hline 7.75 & $-6.64 \mathrm{E}-01$ & $-1.23 E+00$ & $-1.72 E+00$ & $-2.20 \mathrm{E}+00$ & $-2.61 \mathrm{E}+00$ & $-2.91 E+00$ & $-3.08 E+00$ & $-3.15 E+00$ \\
\hline 8.00 & $-2.26 \mathrm{E}-01$ & $-1.17 E+00$ & $-1.71 \mathrm{E}+00$ & $-2.20 \mathrm{E}+00$ & $-2.65 E+00$ & $-3.02 E+00$ & $-3.25 E+00$ & $-3.37 E+00$ \\
\hline 8.25 & $9.33 \mathrm{E}-01$ & $-8.71 \mathrm{E}-01$ & $-1.66 \mathrm{E}+00$ & $-2.19 E+00$ & $-2.67 \mathrm{E}+00$ & $-3.08 E+00$ & $-3.39 E+00$ & $-3.56 \mathrm{E}+00$ \\
\hline 8.50 & $2.39 E+00$ & $1.11 \mathrm{E}-01$ & $-1.44 E+00$ & $-2.14 \mathrm{E}+00$ & $-2.65 E+00$ & $-3.11 E+00$ & $-3.48 \mathrm{E}+00$ & $-3.73 E+00$ \\
\hline 8.75 & 500 & $1.50 \mathrm{E}+00$ & $-6.37 \mathrm{E}-01$ & $-1.96 \mathrm{E}+00$ & $-2.59 \mathrm{E}+00$ & $-3.09 E+00$ & $-3.51 E+00$ & $-3.84 E+00$ \\
\hline 9.00 & 500 & $3.20 \mathrm{E}+00$ & 6.73E-01 & $-1.31 E+00$ & $-2.43 \mathrm{E}+00$ & $-3.01 E+00$ & $-3.49 E+00$ & $-3.88 \mathrm{E}+00$ \\
\hline 9.25 & 500 & 500 & $2.25 \mathrm{E}+00$ & $-8.16 \mathrm{E}-02$ & $-1.90 \mathrm{E}+00$ & $-2.85 \mathrm{E}+00$ & $-3.40 \mathrm{E}+00$ & $-3.84 E+00$ \\
\hline 9.50 & 500 & 500 & 500 & $1.46 \mathrm{E}+00$ & $-7.69 \mathrm{E}-01$ & $-2.41 E+00$ & $-3.22 E+00$ & $-3.74 E+00$ \\
\hline 9.75 & 500 & 500 & 500 & $3.65 \mathrm{E}+00$ & 7.62E-01 & $-1.39 \mathrm{E}+00$ & $-2.86 E+00$ & $-3.56 \mathrm{E}+00$ \\
\hline 10.00 & 500 & 500 & 500 & 500 & $2.74 E+00$ & 1.24E-01 & $-1.96 \mathrm{E}+00$ & $-3.24 E+00$ \\
\hline 10.25 & 500 & 500 & 500 & 500 & 500 & $2.10 \mathrm{E}+00$ & $-4.65 \mathrm{E}-01$ & $-2.47 \mathrm{E}+00$ \\
\hline 10.50 & 500 & 500 & 500 & 500 & 500 & 500 & $1.52 E+00$ & $-1.02 E+00$ \\
\hline 10.75 & 500 & 500 & 500 & 500 & 500 & 500 & 500 & $9.86 \mathrm{E}-01$ \\
\hline
\end{tabular}

Source: puehadjustmodel.xls in Appendix I.

NOTE: Cells with no valid data, because the EQ3NR calculations do not converge, are reported as 500 .

Figures 6.5-2 and 6.5-4 illustrate the total $\mathrm{Pu}$ concentration and the concentrations of $\mathrm{Pu}$ aqueous complex species that compose the total $\mathrm{Pu}$ calculated at $f \mathrm{CO}_{2}$ values of $10^{-3.0}$ and $10^{-5.0}$ bars, respectively. Figures 6.5-3 and 6.5-5 show the same aqueous $\mathrm{Pu}$ speciation results plotted as percent of total $\mathrm{Pu}$. These calculations were made at redox conditions of the adjusted-Eh model as specified by Equation 6.5-7. 


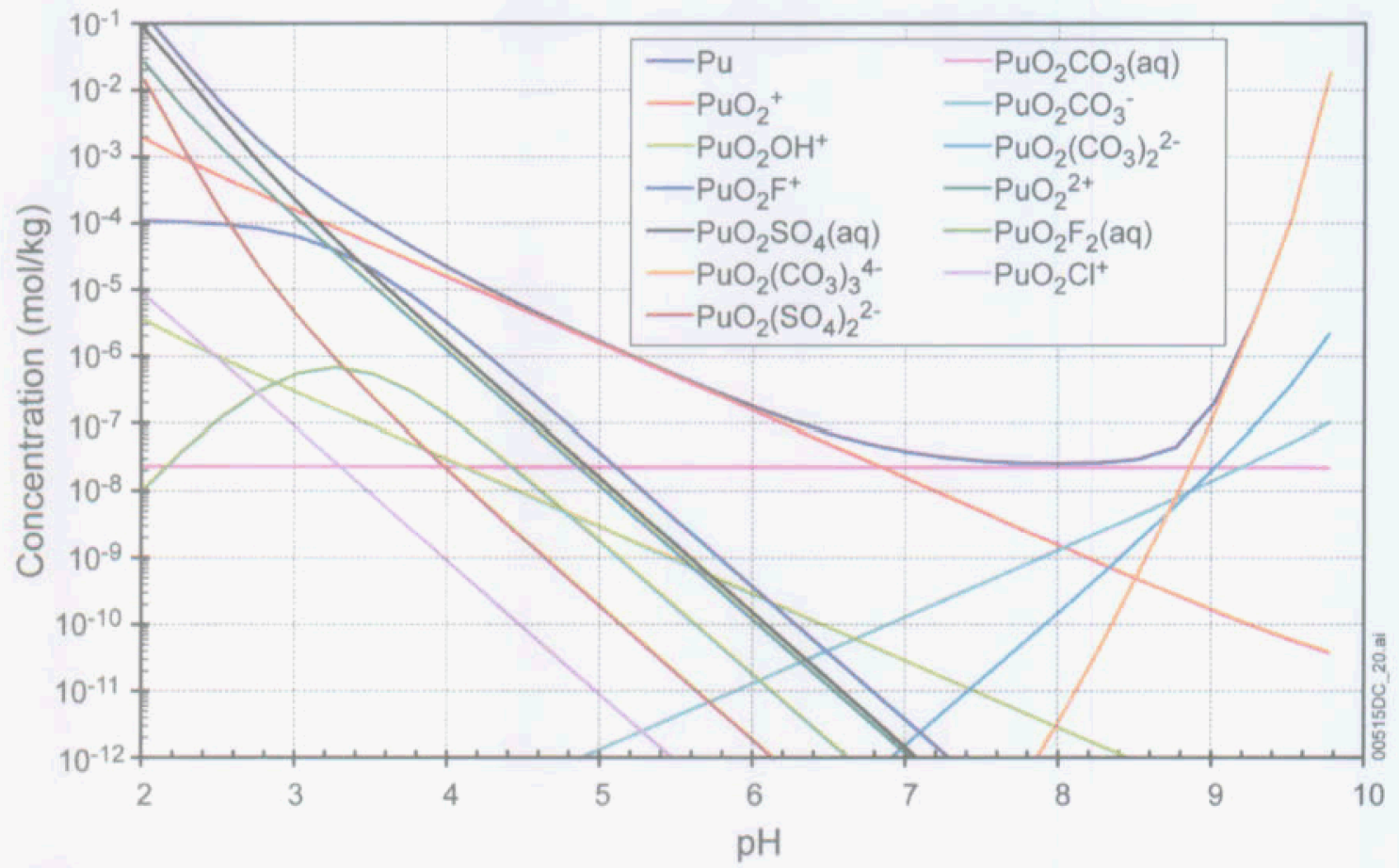

Source: Pu species plot_2.xls (Appendix I).

Figure 6.5-2. Molal Concentrations of Total Pu and Pu Aqueous Complex Species in at $\log \mathrm{fCO}_{2}$ (bars) $=-3.0$

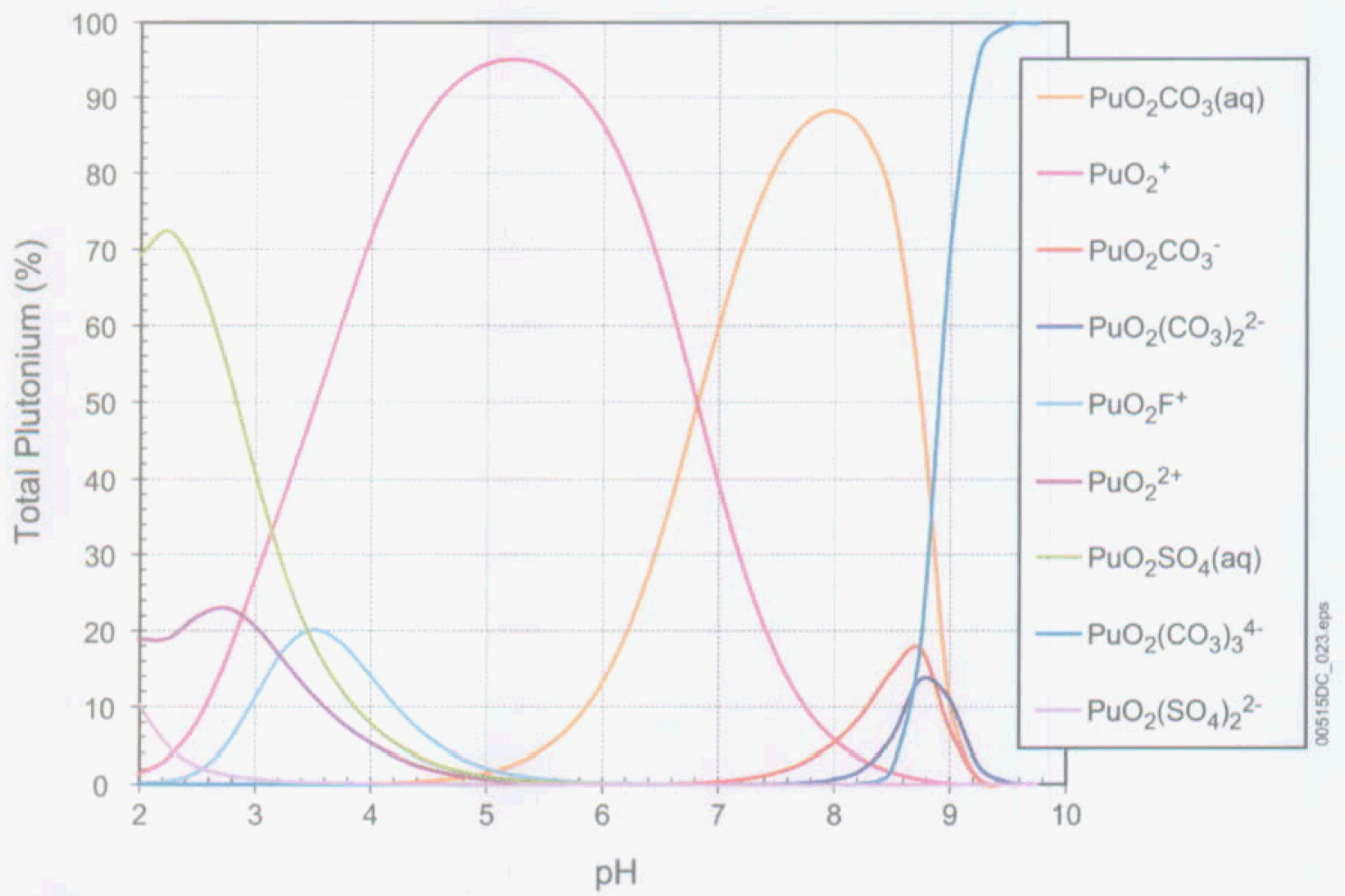

Source: Pu species plot_2.xls (Appendix I).

Figure 6.5-3. Relative Concentrations of Pu Aqueous Complex Species as Percent of Total Dissolved $\mathrm{Pu}$ at $\log \mathrm{fCO}_{2}$ (bars) $=-3.0$ 
As these figures show, at both $f \mathrm{CO}_{2}$ values $\mathrm{Pu}$ is principally in the $\mathrm{Pu}(\mathrm{V})$ oxidation state for $\mathrm{pH}$ values from just above 3 to 7 , for $\log f \mathrm{CO}_{2}=-3$, and 3 through 10 for $\log f \mathrm{CO}_{2}=-5$, with $\mathrm{PuO}_{2}^{+}$ the dominant aqueous species. At lower $\mathrm{pH}$ values, $\mathrm{Pu}(\mathrm{VI})$ becomes the dominant oxidation state as the $\mathrm{PuO}_{2} \mathrm{SO}_{4}(\mathrm{aq})$ complex becomes the chief contributor to the total dissolved $\mathrm{Pu}$ concentration. At lower $\mathrm{SO}_{4}{ }^{2-}$ concentrations, the $\mathrm{PuO}_{2} \mathrm{SO}_{4}(\mathrm{aq})$ complex would contribute less to the total $\mathrm{Pu}$ so the range of $\mathrm{Pu}(\mathrm{V})$ dominance as $\mathrm{PuO}_{2}{ }^{+}$would extend to lower $\mathrm{pH}$ values.

At higher $\mathrm{pH}$ values, the dominant redox state also shifts from $\mathrm{Pu}(\mathrm{V})$ to $\mathrm{Pu}(\mathrm{VI})$ as the principal species become $\mathrm{Pu}(\mathrm{VI})$ carbonate complexes. As Figures 6.5-2 and 6.5-3 illustrate, at $\log f \mathrm{CO}_{2}=-3.0$ bars, $\mathrm{Pu}(\mathrm{V})$ gives way to $\mathrm{Pu}(\mathrm{VI})$ at a $\mathrm{pH}$ just below 7 . From $\mathrm{pH} 7$ to just below 9, $\mathrm{PuO}_{2} \mathrm{CO}_{3}(\mathrm{aq})$ dominates while at higher $\mathrm{pH}$ values, $\mathrm{PuO}_{2}\left(\mathrm{CO}_{3}\right)_{3}{ }^{4-}$ contributes virtually all the dissolved $\mathrm{Pu}$. In solutions at $f \mathrm{CO}_{2}=10^{-5.0}$ bars (Figures $6.5-4$ and $6.5-5$ ), the $\mathrm{pH}$ range in which $\mathrm{Pu}(\mathrm{V})$ dominates extends above $\mathrm{pH}$ 10. At pH 9, the $\mathrm{Pu}(\mathrm{VI})$ species $\mathrm{PuO}_{2} \mathrm{CO}_{3}(\mathrm{aq})$ is the most prevalent but it is still less then the sum of the $\mathrm{Pu}(\mathrm{V})$ species $\mathrm{PuO}_{2}{ }^{+}$and $\mathrm{PuO}_{2} \mathrm{CO}_{3}{ }^{-}$. At the highest $\mathrm{pH}$ values $\mathrm{PuO}_{2}\left(\mathrm{CO}_{3}\right)_{3}{ }^{4-}$ dominates.

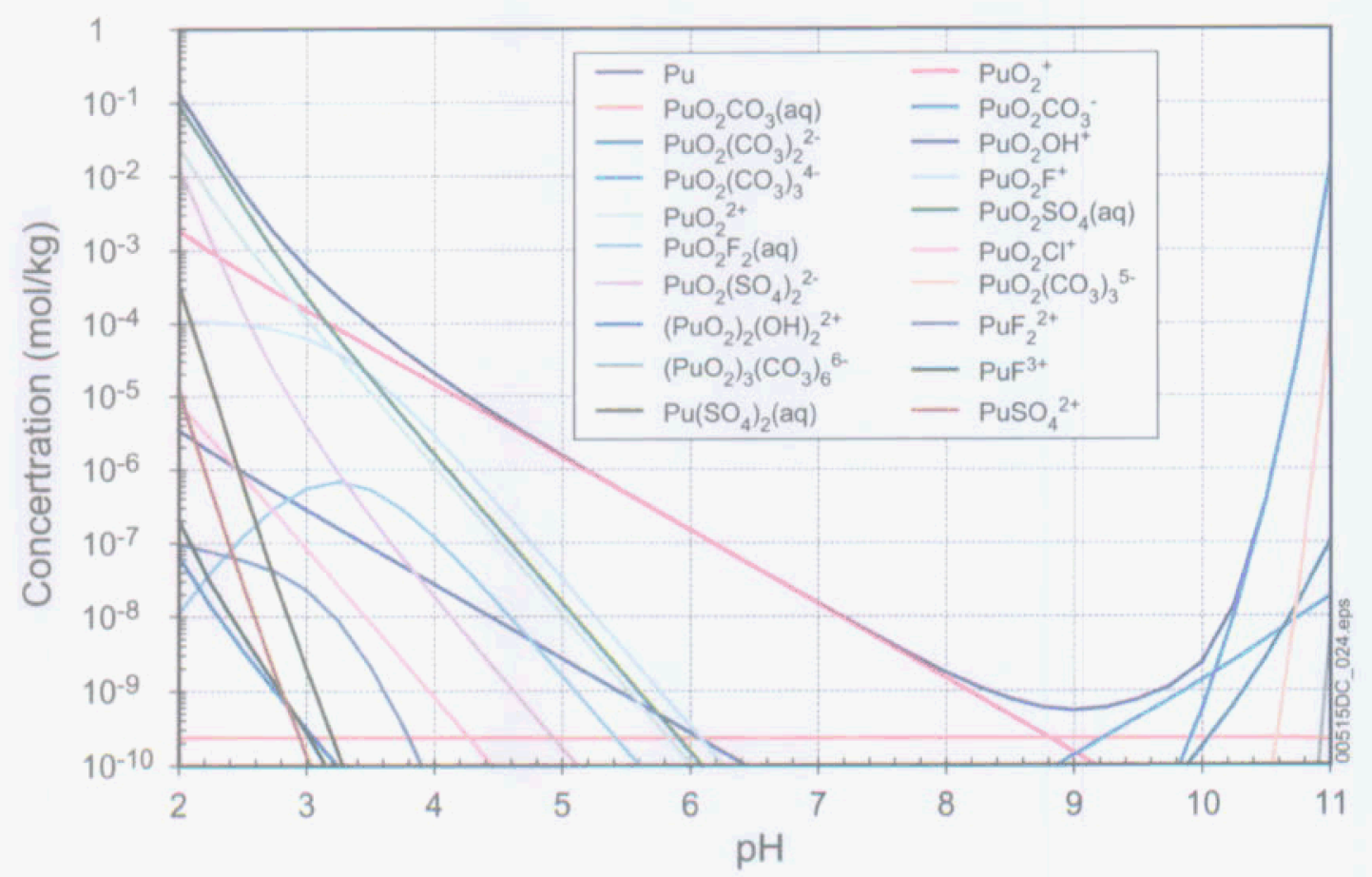

Source: Pu species plot_2.xIs (Appendix I).

Figure 6.5-4. Molal Concentrations of Total Pu and Pu Aqueous Complex Species in at $\log f \mathrm{CO}_{2}$ (bars) $=-5.0$ 


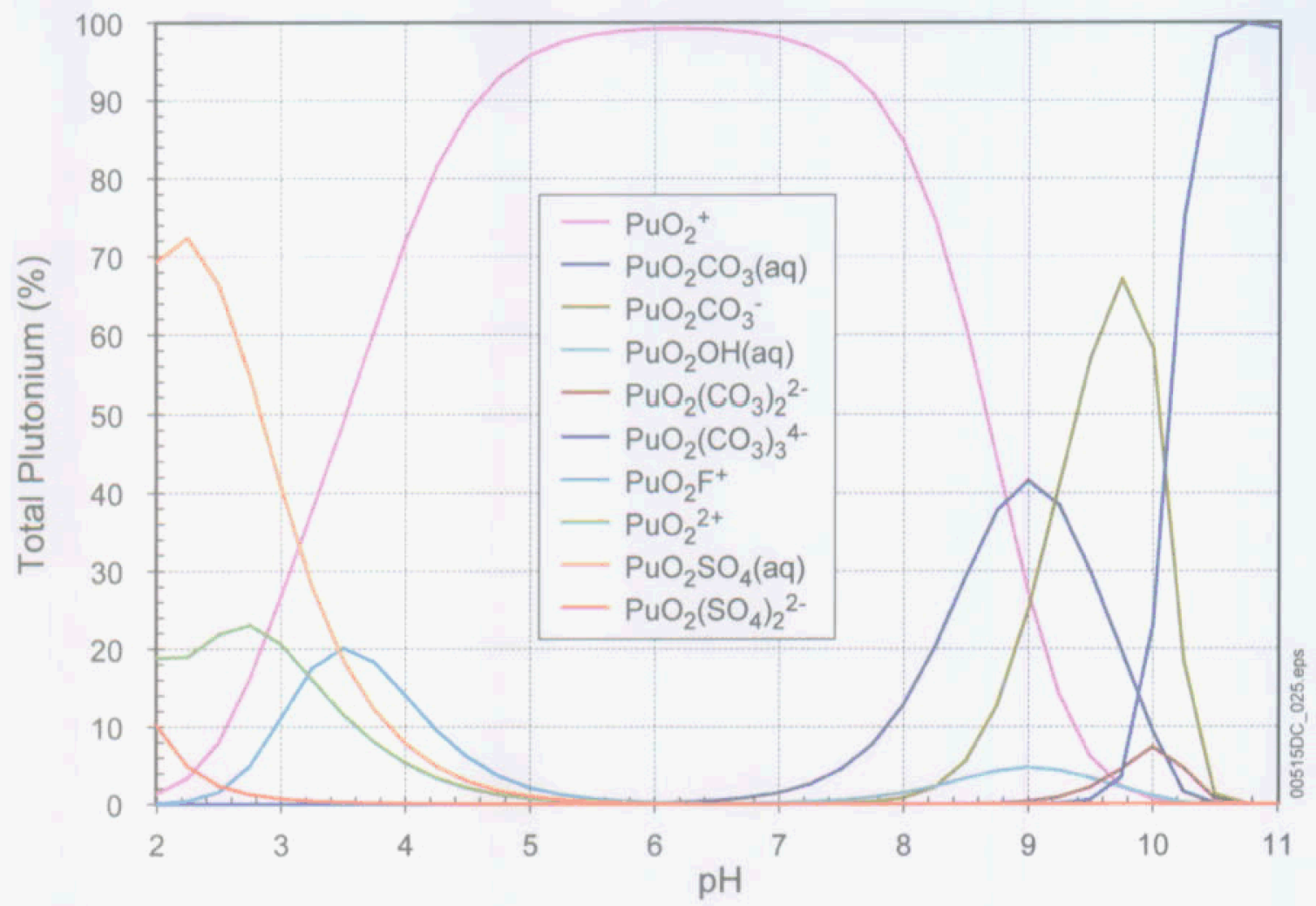

Source: Pu species plot_2.xIs (Appendix I).

Figure 6.5-5. Relative Concentrations of Pu Aqueous Complex Species as Percent of Total Dissolved Pu at $\log \mathrm{fCO}_{2}$ (bars) $=-5.0$

The modeled speciation shown in these figures is consistent only in part with the distribution of $\mathrm{Pu}(\mathrm{V})$ and $\mathrm{Pu}(\mathrm{VI})$ reported by Nitsche et al. (1993 [DIRS 155218]; 1994 [DIRS 144515]) and illustrated in Figure 6.5-9. At $\mathrm{pH}=6$, the experimental data and model results agree that $\mathrm{Pu}(\mathrm{V})$ dominates. At $\mathrm{pH}=7, \mathrm{Pu}(\mathrm{V})$ is the dominant redox state in the experiments and in the model results at $f \mathrm{CO}_{2}=10^{-5.0}$ bars, but the modeling at $f \mathrm{CO}_{2}=10^{-3.0}$ bars shows $\mathrm{Pu}(\mathrm{V})$ and $\mathrm{Pu}(\mathrm{VI})$ at about equal concentrations. At $\mathrm{pH}=8.5, \mathrm{Pu}(\mathrm{V})$ continues to dominate the experimental results, and the model results at $f \mathrm{CO}_{2}=10^{-5.0}$ bars, but at $f \mathrm{CO}_{2}=10^{-3.0}$ bars $\mathrm{Pu}$ (VI) clearly dominates the modeling. As indicated in the caption to Figure $6.5-9$, the $\mathrm{CO}_{2}$ partial pressures $\left(\approx f \mathrm{CO}_{2}\right)$ in the $\mathrm{Ar} / \mathrm{CO}_{2}$ mixtures in which the experiments were carried out are greater than $10^{-3.0}$ bars, except for one that equaled $10^{-3.2}$ bars. Thus, the persistence of $\mathrm{Pu}(\mathrm{V})$ dominance in the high $\mathrm{pH}$ experimental solutions presented by Nitsche et al. (1993 [DIRS 155218]; 1994 [DIRS 144515]) is inconsistent with the modeling. The fact that the NEA, in its review of experimental data supporting its chemical thermodynamic database, does not include the experimental studies by Nitsche et al. (1993 [DIRS 155218]; 1994 [DIRS 144515]) implies the reliability of the experiments conducted by Rai (1984 [DIRS 122768]) with which the modeled results agree.

\subsubsection{Comparison with Experimental Results}

Figure 6.5-6 presents the adjusted plutonium solubility model for $\log f \mathrm{CO}_{2}=-3.5$ bars. The solid line represents the mean values of $\log [\mathrm{Pu}]$; the dotted line and the dashed lines represent upper and lower thermodynamic uncertainty ranges at the $95 \%$ confidence interval, respectively. 
Eight sets of experimental data are also plotted in Figure 6.5-6. These data are relevant to the repository and are directly applicable for comparison to the calculations presented in this report.

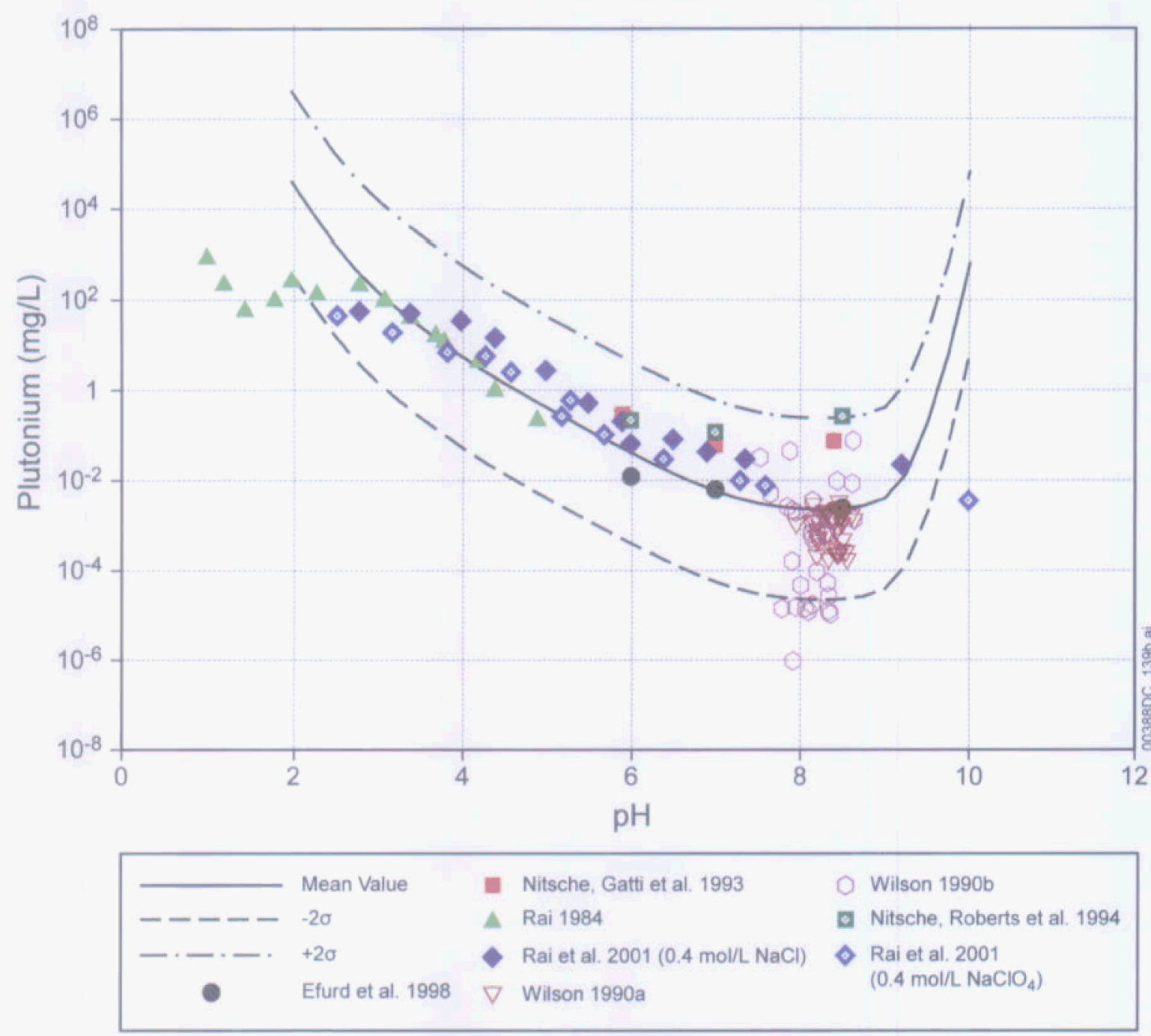

Source: pu solb 110.jnb in Appendix I.

NOTE: Modeled results are for $\log f \mathrm{CO}_{2}=-3.5$

Figure 6.5-6. Comparison of Experimental Data with the Predictions of Plutonium-Solubility Model

Experiments conducted by Rai (1984 [DIRS 122768]) and Rai et al. (2001, [DIRS 168392]) were open to air while experiments conducted by Nitsche et al. (1993 [DIRS 155218], Nitsche et al. 1994 [DIRS 144515]), and Efurd et al. (1998 [DIRS 108015]) were conducted in argon/ $\mathrm{CO}_{2}$ atmospheres of various $\mathrm{CO}_{2}$ contents. Other conditions are also comparable to the modeled conditions. Four different types of solutions were used in the experiments conducted by $\mathrm{Rai}$ et al. (2001 [DIRS 168392]): 1) $0.403-\mathrm{m} \mathrm{NaCl}$ solution, 2) $0.408-\mathrm{m} \mathrm{NaClO}_{4}$ solution, 3) 4.36- $\mathrm{m} \mathrm{NaCl}$ solution, and 4) 4.92- $\mathrm{m} \mathrm{NaClO}_{4}$ solution. Since the thermodynamic database used in this report is invalid for high ionic strength solutions, only the results of Types 1 and 2 solutions reported by Rai et al. (2001 [DIRS 168392]) are discussed in this report. The solutions were filtered before measuring $\mathrm{Pu}$ concentration. Table 6.5-2 lists the calculated pore sizes of 
filters used for filtration. Colloids are defined as particles with at least one dimension between 1 $\mathrm{nm}$ to $1 \mu \mathrm{m}$ (or $0.45 \mu \mathrm{m}$ ) (BSC 2004 [DIRS 166845]). Nitsche et al. (1993 [DIRS 155218]; 1994 [DIRS 144515]) reported in their $25^{\circ} \mathrm{C}$ experiments, that $\mathrm{Pu}$ colloids consist of only 3 percent to 5 percent of total $\mathrm{Pu}$ in the solution. Therefore, the measured $\mathrm{Pu}$ solubility is considered as true dissolved $\mathrm{Pu}$ concentration (since only a small amount of $\mathrm{Pu}$ will be in colloidal form).

Table 6.5-2. Pore Size of Filters Used in Experiments

\begin{tabular}{|l|c|}
\hline \multicolumn{1}{|c|}{ Experiment } & $\begin{array}{c}\text { Pore Size of Filter } \\
(\mathbf{n m})\end{array}$ \\
\hline Rai 1984 [DIRS 122768] & 1.8 \\
\hline Rai et al. 2001 [DIRS 168392] & 1.8 \\
\hline Efurd et al. 1998 [DIRS 108015] & 4.1 \\
\hline Nitsche et al. 1993 [DIRS 155218] & 4.1 \\
\hline Nitsche et al. 1994 [DIRS 144515] & 4.1 \\
\hline
\end{tabular}

The other two data sets plotted in Figure 6.5-6 are plutonium concentrations measured in spent fuel leaching experiments by Wilson (1990a [DIRS 100949]; 1990b [DIRS 100793]). These two data sets are not solubility measurements, but are $\mathrm{Pu}$ concentrations measured in spent fuel dissolution experiments. They may be a more-realistic benchmark for $\mathrm{Pu}$ released from spent fuel, as spent fuel was used in these experiments as the source of $\mathrm{Pu}$. The fact that most of these data fall in the lower half of the uncertainty range suggests that the model may be conservative when it is used to predict $\mathrm{Pu}$ release from spent fuel.

Most of the data points from these five solubility experiments fall within the uncertainty range of the model. More importantly, no data points are above the upper bound of the model. The good match between model prediction and experimental measurement indicates that this is a good model to represent Pu behavior. Model validation is further discussed in Section 7.2.2.

\subsubsection{Uncertainties}

This section discusses uncertainties of the Eh-adjusted Pu-solubility model.

\subsection{Uncertainty in $\log \mathrm{K}$ of the Solubility-Controlling Solids and Aqueous Species}

The uncertainty in $\log \mathrm{K}$ includes uncertainties in the thermodynamic properties of both the controlling solid and significant dissolved species. The rationale behind the evaluation and combination of these uncertainties is discussed in some detail in Section 6.3.3.1. The total uncertainties applied to the solubility values correspond to that for $\log \mathrm{K}$ of the dissolution reaction. This, in turn, includes the uncertainties in both the controlling solid species and the aqueous species.

The aqueous plutonium species accounting for more than 10 percent of the dissolved plutonium in the adjusted-Eh model adopted in Section 6.5.3.2 are evident by inspection of Figures 6.5-2 and 6.5-4. They are $\mathrm{PuO}_{2} \mathrm{SO}_{4}(\mathrm{aq}), \mathrm{PuO}_{2}{ }^{+}, \mathrm{PuO}_{2} \mathrm{~F}^{+}, \mathrm{PuO}_{2}{ }^{2+}, \mathrm{PuO}_{2} \mathrm{CO}_{3}$ (aq), $\mathrm{PuO}_{2} \mathrm{CO}_{3}{ }^{-}$, $\mathrm{PuO}_{2}\left(\mathrm{CO}_{3}\right)_{2}{ }^{2-}$, and $\mathrm{PuO}_{2}\left(\mathrm{CO}_{3}\right)_{3}{ }^{4-}$. The total uncertainties in $\log \mathrm{K}$ given for these species by the 
NEA (Lemire 2001 [DIRS 159027], Table 4.2) range, with two exceptions, from \pm 0.1 to \pm 0.9 . The exceptions are $\mathrm{PuO}_{2} \mathrm{CO}_{3}(\mathrm{aq})$ and $\mathrm{PuO}_{2}\left(\mathrm{CO}_{3}\right)_{2}{ }^{-}$to which Lemire (2001 [DIRS 159027], Table 4.2) assigns uncertainties of \pm 3.0 and \pm 2.6 . Hummel et al. (2002 [DIRS 161904], p. 284) disagree with the assignment of such large errors. They derive their log $\mathrm{K}$ values differently from Lemire (2001 [DIRS 159027]) and assign them uncertainties of \pm 0.5 and \pm 0.9 . The updated NEA data set (Guillaumont et al. 2003 [DIRS 168382]) also assigned uncertainties of \pm 0.5 to both these species. In calculating the uncertainty of the dissolution reactions to these species, the $\log \mathrm{K}$ uncertainties given by NEA (Lemire 2001 [DIRS 159027], Table 4.2) were used for all aqueous species except $\mathrm{PuO}_{2} \mathrm{CO}_{3}(\mathrm{aq})$ and $\mathrm{PuO}_{2}\left(\mathrm{CO}_{3}\right)_{2}{ }^{2-}$, for which values of \pm 0.5 were used.

The extensive review of Lemire's (2001 [DIRS 159027]) report recommends $-963.654 \pm 6.324 \mathrm{~kJ} / \mathrm{mol}$ for Gibbs free energies of formation for $\mathrm{PuO}_{2}$ (hyd,aged). Dissolution reactions for this solid to each of the eight dissolved plutonium species identified earlier were evaluated in $\log K$ uncertainties_a.xls, included in Appendix I. The two greatest uncertainties were for the reactions to $\mathrm{PuO}_{2} \overline{\mathrm{CO}}_{3}{ }^{-}$and $\mathrm{PuO}_{2}\left(\mathrm{CO}_{3}\right)_{3}{ }^{4-}$. These are significant only at high $\mathrm{pH}$. For $\mathrm{PuO}_{2} \mathrm{CO}_{3}^{-}$the total uncertainty in $\log \mathrm{K}$ for $\mathrm{PuO}_{2}$ (hyd,aged) is \pm 1.2 . Corresponding uncertainties for $\mathrm{PuO}_{2}\left(\mathrm{CO}_{3}\right)_{3}{ }^{4-}$ are \pm 1.5 . Uncertainties for other dissolved species range from \pm 0.5 to \pm 1.3 .

Therefore, the maximum uncertainty in $\log [\mathrm{Pu}]$ values due to uncertainty in $\log \mathrm{K}$ values is given the rounded value \pm 2.0 . These total uncertainties are treated as normal distributions truncated at $2 \sigma$ values (Section 6.3.3.1) so $1 \sigma$ values are passed to TSPA-LA. The $1 \sigma$-uncertainty assigned to $\log [\mathrm{Pu}]$ values is \pm 1.0 .

\subsection{Uncertainty from Fluoride Concentration}

Table 6.5-3 lists the calculated logarithm of plutonium solubilities using the adjusted-Eh model using the fluoride levels indicated in Table 6.3-3, (10 times base case for CSNF waste packages and 27 and 95 times for codisposal waste packages and the invert). The three right hand columns are the differences between the respective elevated $\mathrm{F}^{-}$cases and the base case. The fugacity of $\mathrm{CO}_{2}$ is set to $10^{-3.0}$.

The Pu-solubility model is summarized by Equation 6.5-1:

$$
\log [\mathrm{Pu}]=\mathrm{S}\left(\mathrm{pH}, \log f \mathrm{CO}_{2}\right)+\varepsilon_{1}+\left(\varepsilon_{2} \times \mathrm{N}\right)
$$

The values for the parameters in this equation depend on the waste package type. Parameter $S\left(p H, \log f_{\mathrm{CO}_{2}}\right)$ is the base solubility and is taken from Table 6.5-1. Parameter $\varepsilon_{1}$ is associated with the uncertainties in the $\log \mathrm{K}$ data. Parameter $\varepsilon_{2}$ is associated with the uncertainties in the fluoride concentrations. Table 6.5-5 gives the values for the parameters $\varepsilon_{1}$ and $\varepsilon_{2}$.

Table 6.5-3 shows that the uncertainty terms $\varepsilon_{2}{ }^{\text {CSNF }}, \varepsilon_{2}{ }^{\text {CDSP-water influx }}$, and $\varepsilon_{2}{ }^{\text {CDSP-vapor influx vary }}$ with $\mathrm{pH}$. This $\mathrm{pH}$ dependence is implemented into the TSPA-LA model through the use of a multiplication factor $(\mathrm{N})$ that is a function of $\mathrm{pH}$. Values for $\mathrm{N}(\mathrm{pH})$ for both fuel types are given in Table 6.5-4. This modification requires that $\varepsilon_{2}{ }^{\mathrm{CSNF}}, \varepsilon_{2}{ }^{\text {CDSP-water influx }}$, and $\varepsilon_{2}$ CDSP-vapor influx 
values be fixed at the maximum value given in Table 6.5-3. For each realization in the TSPA-LA model the uncertainty parameters are sampled at the beginning of the realization. This sample value is then multiplied by ' $N$ ' at each time step to produce a modified $\varepsilon_{2}$, which is then added to the base solubility value.

Table 6.5-3. The Effect of Variations in Fluoride Concentration on Plutonium Solubility

\begin{tabular}{|c|c|c|c|c|c|c|c|}
\hline \multirow[b]{2}{*}{$\mathrm{pH}$} & Base Case & CSNF & $\begin{array}{c}\text { CDSP - } \\
\text { Water } \\
\text { Influx } \\
\text { Scenario }\end{array}$ & $\begin{array}{l}\text { CDSP - } \\
\text { Vapor } \\
\text { Influx } \\
\text { Scenario } \\
\end{array}$ & CSNF & $\begin{array}{c}\text { CDSP - } \\
\text { Water } \\
\text { Influx } \\
\text { Scenario } \\
\end{array}$ & $\begin{array}{l}\text { CDSP - } \\
\text { Vapor } \\
\text { Influx } \\
\text { Scenario }\end{array}$ \\
\hline & \multicolumn{4}{|c|}{$\log [\mathrm{Pu}] \mathrm{mg} / \mathrm{L}$} & \multicolumn{3}{|c|}{ Difference } \\
\hline 2.25 & $3.84 \mathrm{E}+00$ & $3.87 \mathrm{E}+00$ & $3.95 E+00$ & $4.13 E+00$ & $2.78 \mathrm{E}-02$ & 1.10E-01 & $2.89 \mathrm{E}-01$ \\
\hline 2.50 & $3.19 \mathrm{E}+00$ & $3.27 \mathrm{E}+00$ & $3.43 \mathrm{E}+00$ & $3.73 E+00$ & $7.76 \mathrm{E}-02$ & $2.43 E-01$ & 5.41E-01 \\
\hline 2.75 & $2.62 \mathrm{E}+00$ & $2.80 \mathrm{E}+00$ & $3.05 \mathrm{E}+00$ & $3.44 E+00$ & $1.76 \mathrm{E}-01$ & 4.27E-01 & 8.23E-01 \\
\hline 3.00 & $2.14 \mathrm{E}+00$ & $2.45 \mathrm{E}+00$ & $2.77 \mathrm{E}+00$ & $3.24 \mathrm{E}+00$ & $3.086 \mathrm{E}-01$ & $6.28 \mathrm{E}-01$ & $1.10 \mathrm{E}+00$ \\
\hline 3.25 & $1.74 \mathrm{E}+00$ & $2.17 E+00$ & $2.54 \mathrm{E}+00$ & $3.08 \mathrm{E}+00$ & $4.264 \mathrm{E}-01$ & 7.99E-01 & $1.34 \mathrm{E}+00$ \\
\hline 3.50 & $1.38 \mathrm{E}+00$ & $1.87 E+00$ & $2.29 \mathrm{E}+00$ & $2.91 \mathrm{E}+00$ & 4.931E-01 & $9.15 E-01$ & $1.53 \mathrm{E}+00$ \\
\hline 3.75 & $1.03 \mathrm{E}+00$ & $1.53 E+00$ & $1.99 \mathrm{E}+00$ & $2.69 \mathrm{E}+00$ & $4.962 \mathrm{E}-01$ & 9.57E-01 & $1.66 \mathrm{E}+00$ \\
\hline 4.00 & $7.08 \mathrm{E}-01$ & $1.15 \mathrm{E}+00$ & $1.62 \mathrm{E}+00$ & $2.40 E+00$ & $4.421 \mathrm{E}-01$ & $9.15 E-01$ & $1.69 E+00$ \\
\hline 4.25 & 4.04E-01 & $7.58 \mathrm{E}-01$ & $1.21 \mathrm{E}+00$ & $2.02 \mathrm{E}+00$ & $3.539 \mathrm{E}-01$ & $8.05 \mathrm{E}-01$ & $1.62 E+00$ \\
\hline 4.50 & 1.19E-01 & 3.77E-01 & 7.77E-01 & $1.58 \mathrm{E}+00$ & $2.581 \mathrm{E}-01$ & $6.58 \mathrm{E}-01$ & $1.47 E+00$ \\
\hline 4.75 & $-1.52 \mathrm{E}-01$ & $2.18 \mathrm{E}-02$ & $3.51 \mathrm{E}-01$ & $1.12 \mathrm{E}+00$ & 1.737E-01 & 5.03E-01 & $1.27 \mathrm{E}+00$ \\
\hline 5.00 & $-4.12 \mathrm{E}-01$ & $-3.03 E-01$ & $-5.22 E-02$ & $6.50 \mathrm{E}-01$ & $1.093 \mathrm{E}-01$ & $3.60 \mathrm{E}-01$ & $1.06 \mathrm{E}+00$ \\
\hline 5.25 & $-6.65 \mathrm{E}-01$ & $-6.00 \mathrm{E}-01$ & $-4.23 \mathrm{E}-01$ & 1.84E-01 & $6.512 \mathrm{E}-02$ & $2.42 \mathrm{E}-01$ & $8.49 \mathrm{E}-01$ \\
\hline 5.50 & $-9.11 \mathrm{E}-01$ & $-8.74 \mathrm{E}-01$ & $-7.57 \mathrm{E}-01$ & $-2.65 \mathrm{E}-01$ & $3.701 \mathrm{E}-02$ & $1.54 \mathrm{E}-01$ & $6.46 \mathrm{E}-01$ \\
\hline 5.75 & $-1.15 E+00$ & $-1.13 \mathrm{E}+00$ & $-1.05 \mathrm{E}+00$ & $-6.86 \mathrm{E}-01$ & $2.004 \mathrm{E}-02$ & $9.41 \mathrm{E}-02$ & 4.62E-01 \\
\hline 6.00 & $-1.37 E+00$ & $-1.36 E+00$ & $-1.32 \mathrm{E}+00$ & $-1.07 \mathrm{E}+00$ & $1.019 \mathrm{E}-02$ & $5.56 \mathrm{E}-02$ & $3.08 \mathrm{E}-01$ \\
\hline 6.25 & $-1.58 \mathrm{E}+00$ & $-1.58 E+00$ & $-1.55 \mathrm{E}+00$ & $-1.39 \mathrm{E}+00$ & $4.708 \mathrm{E}-03$ & 3.22E-02 & 1.90 E-01 \\
\hline 6.50 & $-1.77 E+00$ & $-1.76 E+00$ & $-1.75 E+00$ & $-1.66 \mathrm{E}+00$ & 1.797E-03 & $1.84 \mathrm{E}-02$ & $1.08 \mathrm{E}-01$ \\
\hline 6.75 & $-1.92 \mathrm{E}+00$ & $-1.92 \mathrm{E}+00$ & $-1.91 \mathrm{E}+00$ & $-1.86 \mathrm{E}+00$ & $4.319 \mathrm{E}-04$ & $1.05 E-02$ & $5.69 \mathrm{E}-02$ \\
\hline 7.00 & $-2.04 \mathrm{E}+00$ & $-2.04 \mathrm{E}+00$ & $-2.03 E+00$ & $-2.01 \mathrm{E}+00$ & $-1.083 E-04$ & $5.93 \mathrm{E}-03$ & $2.86 \mathrm{E}-02$ \\
\hline 7.25 & $-2.12 \mathrm{E}+00$ & $-2.12 E+00$ & $-2.11 E+00$ & $-2.10 \mathrm{E}+00$ & $-2.442 \mathrm{E}-04$ & $3.39 \mathrm{E}-03$ & $1.41 \mathrm{E}-02$ \\
\hline 7.50 & $-2.17 \mathrm{E}+00$ & $-2.17 \mathrm{E}+00$ & $-2.17 \mathrm{E}+00$ & $-2.16 \mathrm{E}+00$ & $-2.366 \mathrm{E}-04$ & $2.00 \mathrm{E}-03$ & $7.20 \mathrm{E}-03$ \\
\hline 7.75 & $-2.20 E+00$ & $-2.20 E+00$ & $-2.19 \mathrm{E}+00$ & $-2.19 \mathrm{E}+00$ & $-2.044 E-04$ & 1.35E-03 & $4.22 \mathrm{E}-03$ \\
\hline 8.00 & $-2.20 \mathrm{E}+00$ & $-2.20 \mathrm{E}+00$ & $-2.20 \mathrm{E}+00$ & $-2.20 \mathrm{E}+00$ & $1.388 \mathrm{E}-04$ & $1.28 \mathrm{E}-03$ & $3.65 \mathrm{E}-03$ \\
\hline 8.25 & $-2.19 \mathrm{E}+00$ & $-2.19 E+00$ & $-2.19 \mathrm{E}+00$ & $-2.18 \mathrm{E}+00$ & $7.128 \mathrm{E}-04$ & $1.90 \mathrm{E}-03$ & $5.64 \mathrm{E}-03$ \\
\hline 8.50 & $-2.14 E+00$ & $-2.14 E+00$ & $-2.13 E+00$ & $-2.12 \mathrm{E}+00$ & $1.736 \mathrm{E}-03$ & $4.86 \mathrm{E}-03$ & 1.62E-02 \\
\hline 8.75 & $-1.96 \mathrm{E}+00$ & $-1.95 E+00$ & $-1.94 E+00$ & $-1.89 \mathrm{E}+00$ & $6.765 \mathrm{E}-03$ & $1.93 \mathrm{E}-02$ & $6.75 \mathrm{E}-02$ \\
\hline 9.00 & $-1.31 E+00$ & $-1.29 \mathrm{E}+00$ & $-1.26 \mathrm{E}+00$ & $-1.16 E+00$ & 1.487E-02 & $4.21 \mathrm{E}-02$ & $1.42 \mathrm{E}-01$ \\
\hline 9.25 & $-8.16 \mathrm{E}-02$ & $-6.96 \mathrm{E}-02$ & $-4.75 \mathrm{E}-02$ & $3.49 \mathrm{E}-02$ & $1.205 \mathrm{E}-02$ & $3.41 \mathrm{E}-02$ & 1.16E-01 \\
\hline 9.50 & $1.46 \mathrm{E}+00$ & $1.47 \mathrm{E}+00$ & $1.48 \mathrm{E}+00$ & $1.53 \mathrm{E}+00$ & $6.534 \mathrm{E}-03$ & 1.83E-02 & $6.45 \mathrm{E}-02$ \\
\hline 9.75 & $3.65 \mathrm{E}+00$ & $3.65 \mathrm{E}+00$ & $3.66 \mathrm{E}+00$ & $3.68 \mathrm{E}+00$ & $3.715 \mathrm{E}-03$ & $1.00 \mathrm{E}-02$ & $3.64 \mathrm{E}-02$ \\
\hline \multicolumn{5}{|c|}{ Maximum } & 4.96E-01 & 9.57E-01 & $1.68 \mathrm{E}+00$ \\
\hline
\end{tabular}

Source: puehadj f uncert.x/s and Pu F Uncertainty.x/s in Appendix I. 
Table 6.5-4. The Multiplication Factor, $(\mathrm{N})$, used to modify $\mathrm{F}^{-}$Uncertainty Terms for Plutonium

\begin{tabular}{|c|c|c|c|}
\hline \multirow{2}{*}{$\mathbf{p H}$} & \multicolumn{3}{|c|}{ Multiplication Factor for F Uncertainty } \\
\cline { 2 - 4 } & CSNF & $\begin{array}{c}\text { CDSP }- \text { Water } \\
\text { Influx Scenario }\end{array}$ & $\begin{array}{c}\text { CDSP - Vapor } \\
\text { Influx Scenario }\end{array}$ \\
\hline 2.25 & $5.60 \mathrm{E}-02$ & $1.15 \mathrm{E}-01$ & $1.71 \mathrm{E}-01$ \\
\hline 2.50 & $1.56 \mathrm{E}-01$ & $2.54 \mathrm{E}-01$ & $3.21 \mathrm{E}-01$ \\
\hline 2.75 & $3.54 \mathrm{E}-01$ & $4.46 \mathrm{E}-01$ & $4.87 \mathrm{E}-01$ \\
\hline 3.00 & $6.22 \mathrm{E}-01$ & $6.56 \mathrm{E}-01$ & $6.50 \mathrm{E}-01$ \\
\hline 3.25 & $8.59 \mathrm{E}-01$ & $8.35 \mathrm{E}-01$ & $7.91 \mathrm{E}-01$ \\
\hline 3.50 & $9.94 \mathrm{E}-01$ & $9.56 \mathrm{E}-01$ & $9.06 \mathrm{E}-01$ \\
\hline 3.75 & $1.00 \mathrm{E}+00$ & $1.00 \mathrm{E}+00$ & $9.81 \mathrm{E}-01$ \\
\hline 4.00 & $8.91 \mathrm{E}-01$ & $9.56 \mathrm{E}-01$ & $1.00 \mathrm{E}+00$ \\
\hline 4.25 & $7.13 \mathrm{E}-01$ & $8.41 \mathrm{E}-01$ & $9.57 \mathrm{E}-01$ \\
\hline 4.50 & $5.20 \mathrm{E}-01$ & $6.88 \mathrm{E}-01$ & $8.68 \mathrm{E}-01$ \\
\hline 4.75 & $3.50 \mathrm{E}-01$ & $5.26 \mathrm{E}-01$ & $7.54 \mathrm{E}-01$ \\
\hline 5.00 & $2.20 \mathrm{E}-01$ & $3.76 \mathrm{E}-01$ & $6.29 \mathrm{E}-01$ \\
\hline 5.25 & $1.31 \mathrm{E}-01$ & $2.53 \mathrm{E}-01$ & $5.03 \mathrm{E}-01$ \\
\hline 5.50 & $7.46 \mathrm{E}-02$ & $1.61 \mathrm{E}-01$ & $3.83 \mathrm{E}-01$ \\
\hline 5.75 & $4.04 \mathrm{E}-02$ & $9.83 \mathrm{E}-02$ & $2.74 \mathrm{E}-01$ \\
\hline 6.00 & $2.05 \mathrm{E}-02$ & $5.81 \mathrm{E}-02$ & $1.83 \mathrm{E}-01$ \\
\hline 6.25 & $9.49 \mathrm{E}-03$ & $3.37 \mathrm{E}-02$ & $1.12 \mathrm{E}-01$ \\
\hline 6.50 & $3.62 \mathrm{E}-03$ & $1.92 \mathrm{E}-02$ & $6.38 \mathrm{E}-02$ \\
\hline 6.75 & $8.70 \mathrm{E}-04$ & $1.09 \mathrm{E}-02$ & $3.37 \mathrm{E}-02$ \\
\hline 7.00 & $-2.18 \mathrm{E}-04$ & $6.20 \mathrm{E}-03$ & $1.69 \mathrm{E}-02$ \\
\hline 7.25 & $-4.92 \mathrm{E}-04$ & $3.54 \mathrm{E}-03$ & $8.35 \mathrm{E}-03$ \\
\hline 7.50 & $-4.77 \mathrm{E}-04$ & $2.09 \mathrm{E}-03$ & $4.26 \mathrm{E}-03$ \\
\hline 7.75 & $-4.12 \mathrm{E}-04$ & $1.41 \mathrm{E}-03$ & $2.50 \mathrm{E}-03$ \\
\hline 8.00 & $2.80 \mathrm{E}-04$ & $1.34 \mathrm{E}-03$ & $2.16 \mathrm{E}-03$ \\
\hline 8.25 & $1.44 \mathrm{E}-03$ & $1.99 \mathrm{E}-03$ & $3.34 \mathrm{E}-03$ \\
\hline 8.50 & $3.50 \mathrm{E}-03$ & $5.07 \mathrm{E}-03$ & $9.60 \mathrm{E}-03$ \\
\hline 8.75 & $1.36 \mathrm{E}-02$ & $2.01 \mathrm{E}-02$ & $4.00 \mathrm{E}-02$ \\
\hline 9.00 & $3.00 \mathrm{E}-02$ & $4.39 \mathrm{E}-02$ & $8.39 \mathrm{E}-02$ \\
\hline 9.25 & $2.43 \mathrm{E}-02$ & $3.56 \mathrm{E}-02$ & $6.90 \mathrm{E}-02$ \\
\hline 9.50 & $1.32 \mathrm{E}-02$ & $1.91 \mathrm{E}-02$ & $3.82 \mathrm{E}-02$ \\
\hline 9.75 & $7.49 \mathrm{E}-03$ & $1.04 \mathrm{E}-02$ & $2.16 \mathrm{E}-02$ \\
\hline & & & \\
\hline & & & \\
\hline
\end{tabular}

Source: Pu F Uncertainty.xls in Appendix I.

\subsection{Summary of Pu-Solubility Model Uncertainty}

The $\mathrm{Pu}$ concentrations used in the TSPA-LA modeling are selected from a distribution of values defined by the concentrations given in Table 6.5-1 plus or minus the uncertainties in 
concentrations due to uncertainties in the $\log \mathrm{K}$ values and resulting from uncertainties in the fluoride concentrations (Sections 6.5.3.4.1 and 6.5.3.4.2).

These are described by the following equation:

$$
\log [\mathrm{Pu}]=\mathrm{S}\left(\mathrm{pH}, \log f \mathrm{CO}_{2}\right)+\varepsilon_{1}+\left(\varepsilon_{2} \times \mathrm{N}\right)
$$

where

$S\left(p H, \log f_{\mathrm{CO}_{2}}\right)$ is $\log$ of the modeled $\mathrm{Pu}$ concentration as a function of $\mathrm{pH}$ and $\log f_{\mathrm{CO} 2}$ given by Table $6.5-1$

$\varepsilon_{1}$ is the uncertainty term associated with uncertainty in $\log \mathrm{K}$ values. As discussed in Section 6.5.3.4.1, this term has a normal distribution with $\sigma=1.0$, truncated at $2 \sigma$. The value used during a given run is chosen from within this distribution by the TSPA-LA model.

$\varepsilon_{2}$ is the uncertainty term associated with variations in fluoride concentration. As discussed in Section 6.5.3.4.2, the range of fluoride uncertainty for a given TSPA-LA run depends on the type of waste package being considered and the $\mathrm{pH}$. This term has a onesided triangular distribution with the minimum (a) and most probable (b) values equal to one another and the maximum (c) value corresponding to the maximum value in the appropriate column of Table 6.5-3.

$\mathrm{N}$ is the factor by which the maximum uncertainty $\varepsilon_{2}$ is normalized for $\mathrm{pH}$. Values of $\mathrm{N}$ are given by Table $6.5-4$ and are $\leq 1.0$.

The distribution properties of these uncertainty terms are summarized in Table 6.5-5.

Table 6.5-5. Uncertainty Terms of $\log [\mathrm{Pu}]$

\begin{tabular}{|l|l|l|l|l|}
\hline \multicolumn{1}{|c|}{$\begin{array}{c}\text { Uncertainty } \\
\text { Term }\end{array}$} & \multicolumn{1}{|c|}{ Associated With } & $\begin{array}{l}\text { Distribution } \\
\text { Type }\end{array}$ & \multicolumn{1}{c|}{$\begin{array}{c}\text { Distribution } \\
\text { Parameter }\end{array}$} & \multicolumn{1}{c|}{ Applicable To } \\
\hline$\varepsilon_{1}$ & Uncertainties in log $\mathrm{K}$ & $\begin{array}{l}\text { Normal } \\
\text { Truncated at } \\
\pm 2 \sigma\end{array}$ & $\mu=0, \sigma=1.0^{\mathrm{a}}$ & Values in Table $6.5-1$ \\
\hline$\varepsilon_{2}{ }^{\text {CSNF }}$ & $\begin{array}{l}\text { Fluoride concentration in } \\
\text { CSNF waste packages }\end{array}$ & Triangular & $\mathrm{a}=\mathrm{b}=0, \mathrm{c}=0.496$ & CSNF waste packages \\
\hline$\varepsilon_{2}$ CDSP-Water Influx & $\begin{array}{l}\text { Fluoride concentration in } \\
\text { Codisposal waste packages } \\
\text { (water influx scenario) }\end{array}$ & Triangular & $\mathrm{a}=\mathrm{b}=0, \mathrm{c}=0.957$ & $\begin{array}{l}\text { Codisposal waste } \\
\text { packages and the invert }\end{array}$ \\
\hline$\varepsilon_{2}$ CDSP-Vapor Influx & $\begin{array}{l}\text { Fluoride concentration In } \\
\text { CDNR waste package (vapor } \\
\text { influx scenario) }\end{array}$ & Triangular & $\mathrm{a}=\mathrm{b}=0, \mathrm{c}=1.69$ & $\begin{array}{l}\text { Codisposal waste } \\
\text { packages and the invert }\end{array}$ \\
\hline
\end{tabular}

NOTE: $\quad$ For ionic strength values between 1 and $3, \log \mathrm{K}$ uncertainty should be treated as a normal distribution truncated at $\pm 2 \sigma$ with distribution parameters $\mu=0, \sigma=1.04$ (Section 6.3.3.4, Equation 6.3-7). 


\subsubsection{Redox Conditions Within Waste Packages}

No direct measurements of redox conditions within breached waste packages are available. Nonetheless, since (1) corrosion of waste package materials and waste forms consumes oxygen and, thus, it lowers redox conditions within waste packages; and (2) breached waste packages are not totally open to air, and transport of oxygen gas into the waste package is limited by waste package cracks or holes that can be plugged by corrosion products of waste package materials and waste forms; redox conditions within waste packages cannot be higher than that given by Equation 6.5-5. Therefore, the adjusted-Eh Pu-solubility model, which uses Equation 6.5-7 to set redox conditions, is conservative.

\subsubsection{Logic Basis for Eh-Adjusted Pu-Solubility Model}

\subsubsection{Theoretical $\mathrm{fO}_{2}$ Model}

The calculations for this model are carried out with the solution redox conditions controlled by theoretical equilibrium between the solution and the atmosphere with an oxygen fugacity $\left(f \mathrm{O}_{2}\right)$ of 0.2 bars.

\subsection{Modeling results}

The plutonium solubility for a range of $\mathrm{pH}$ and $f \mathrm{CO}_{2}$ values calculated using $\mathrm{PuO}_{2}$ (hyd,aged) as the controlling solid with $f \mathrm{O}_{2}=0.2$ bars is shown in Figure 6.5-7. The variation of solubility with $\mathrm{pH}$ and $f \mathrm{CO}_{2}$ results from the presence in solution of $\mathrm{Pu}(\mathrm{V})$ and $\mathrm{Pu}(\mathrm{VI})$ species including $\mathrm{PuO}_{2}{ }^{2+}$ and $\mathrm{Pu}(\mathrm{V})$ and(VI) aqueous complexes with $\mathrm{CO}_{3}{ }^{2-}, \mathrm{F}^{-}$and $\mathrm{SO}_{4}{ }^{2-}$. The stability constants used in the modeling were those of the NEA compilation of chemical thermodynamic data (Lemire et al. 2001 [DIRS 159027]) included in the project databases Data0.ymp.R2 (Section 4.1 and Table 4-1). At each $f \mathrm{CO}_{2}$, plutonium solubility increases with $\mathrm{pH}$ under alkaline conditions while under acidic conditions, it increases conversely to $\mathrm{pH}$. This $\mathrm{U}$-shape (or $\mathrm{V}$-shape) curve is typical for actinides.

When modeling with $f \mathrm{O}_{2}=0.2$ bars at $\mathrm{pH}<3.75$, the EQ3NR calculations do not converge. Neither do EQ3NR calculations when $\mathrm{pH}$ is greater than 7.5 to 10.5 , depending on $f \mathrm{CO}_{2}$. The lack of convergence is because the modeling code is unable to reach a mathematical solution at these conditions. For example, at high $\mathrm{pH}$ values, and especially at high $f \mathrm{CO}_{2}$ values, formation of the strong $\mathrm{PuO}_{2}\left(\mathrm{CO}_{3}\right)_{3}{ }^{4-}$ complex may require the code to add very large amounts of $\mathrm{CO}_{2}$ or $\mathrm{Pu}$, or both, to form the complex, or to add a very large amount of $\mathrm{Na}^{+}$to balance the charge of large quantities of this complex. At low $\mathrm{pH}$ values, $\mathrm{PuO}_{2} \mathrm{SO}_{4}(\mathrm{aq})$ dominates. Under the relatively high oxidation state represented by $\mathrm{fO}_{2}=0.2$ bars and with the use of $\mathrm{SO}_{4}{ }^{2-}$ as the charge-balancing anion at low $\mathrm{pH}$ values, EQ3NR is also unable to reach a mathematical solution at low $\mathrm{pH}$ values (Section 6.4.4). 


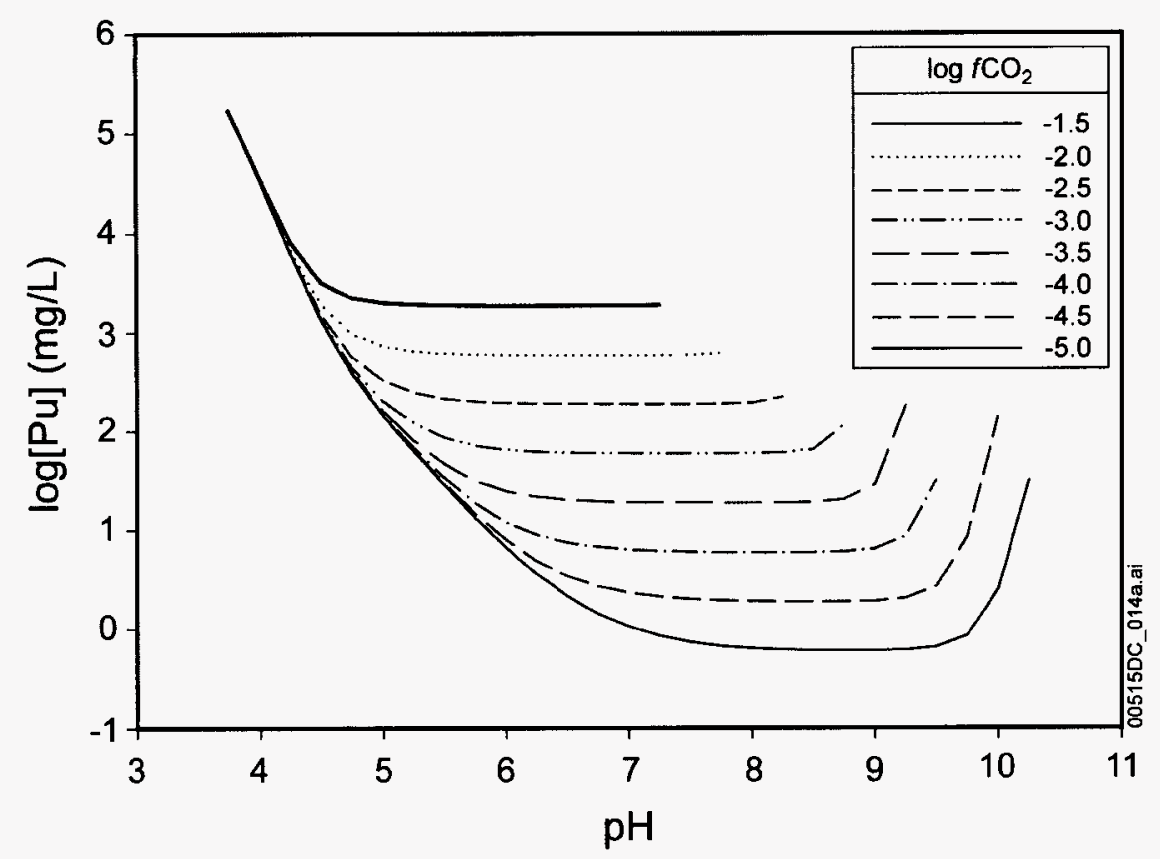

Source: PuO2_hyd_aged_sol.jnb in Appendix I.

Figure 6.5-7. $\mathrm{PuO}_{2}$ (hyd,aged) Solubility Modeled With the Theoretical $\mathrm{fO}_{2}$ as a Function of $\mathrm{pH}$ and $\log \mathrm{fCO}_{2}$

\subsection{Comparison with Experimental Measurements}

Figure 6.5-8 presents the modeling results at $\log f \mathrm{CO}_{2}=-3.5$ (bars) along with Pu-solubility measurements from five experiments (Rai 1984 [DIRS 122768]; Nitsche et al. 1993 [DIRS 155218]; Nitsche et al. 1994 [DIRS 144515]; Efurd et al. 1998 [DIRS 108015]; Rai et al. 2001 [DIRS 168392]). These five experiments have been discussed in Section 6.5.3.3. 


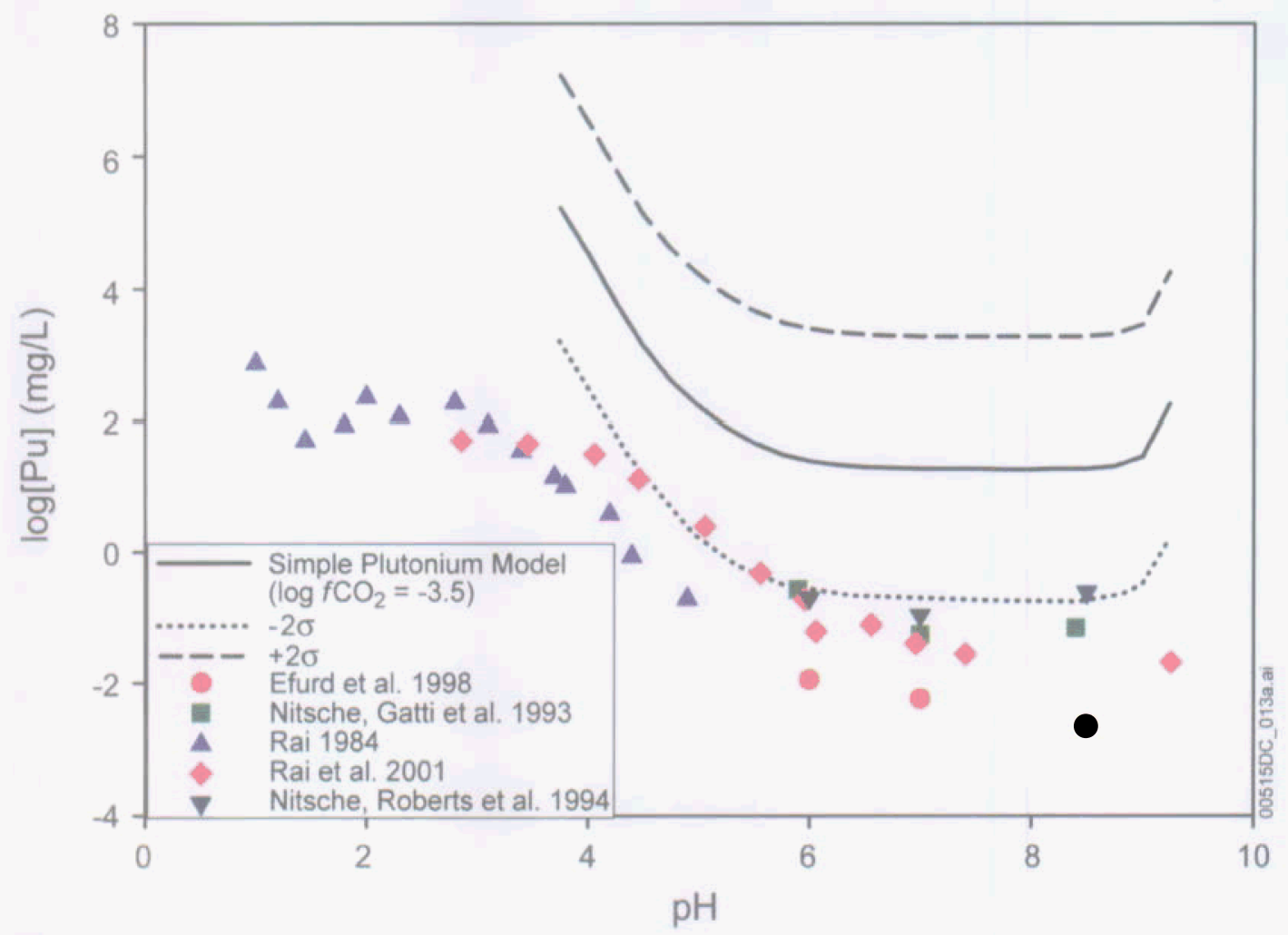

Source: simple pu solb.jnb in Appendix I.

Figure 6.5-8. Comparison of the Theoretical $f \mathrm{CO}_{2}, \mathrm{PuO}_{2}$ (hyd, aged) Model with Pu Solubility Measurements

The inconsistency and the large difference between the experimental and modeling results strongly suggest that this model using a redox potential calculated from $f \mathrm{O}_{2}=0.2$ bars does not represent $\mathrm{Pu}$-solubility behavior. Furthermore, the high $\mathrm{Pu}$ concentrations predicted by the theoretical $\mathrm{fO}_{2}$ model are unrealistic because it does not take into account the formation of $\mathrm{Pu}$ colloids. It is well known that when the total concentration of plutonium is higher than 1.0E-6 mol/L, plutonium polymers (colloids) form (Choppin 1983 [DIRS 168395]). The formation of Pu colloids is quite rapid and its rate is third order in Pu concentration. Colloids remove $\mathrm{Pu}$ from the aqueous phase and, thus, reduce the dissolved $\mathrm{Pu}$ concentration. The predicted $\mathrm{Pu}$ concentration by the theoretical $\mathrm{fO}_{2}$ model ranges from $2.54 \mathrm{E}-6 \mathrm{~mol} / \mathrm{L}$ to $2.25 \mathrm{~mol} / \mathrm{L}$, which is above the threshold for colloids. Thus, it is reasonable to expect that these high concentrations of $\mathrm{Pu}$ in aqueous phase cannot be sustained. In other words, because of colloids, such a high $\mathrm{Pu}$ solubility predicted by the theoretical $f \mathrm{O}_{2}$ model is unrealistic.

\subsection{Determining the Cause of the Discrepancy}

The discussion in Section 6.5.4.1.2 concluded that the theoretical $f \mathrm{O}_{2}$ model with redox potential calculated from $f_{2}=0.2$ bars does not correctly represent $\mathrm{Pu}$ behavior in solution. Therefore, more sophisticated Pu-solubility model(s) are needed to correctly represent Pu behavior in water. The first step in developing such a model is to examine in more detail the cause of the discrepancy between this model and experimental results. 
One of the properties of $\mathrm{Pu}$ is that species of different oxidation states (from III to VII) can coexist in equilibrium in many aqueous systems (Choppin 1983 [DIRS 168395]; 2003 [DIRS 168308]), although for natural aqueous environments, Pu(VII) is not important (Silva and Nitsche 1995 [DIRS 112092]). The oxidation state has a large impact on the geochemical behavior of $\mathrm{Pu}$ in aqueous environments.

Figure 6.5-9 shows the distribution of different oxidation states in experiments reported by Nitsche et al. (1993 [DIRS 155218]; 1994 [DIRS 144515]). For $\mathrm{pH}$ from 6 to 8.5, the dominant $\mathrm{Pu}$ species is $\mathrm{Pu}(\mathrm{V})$.
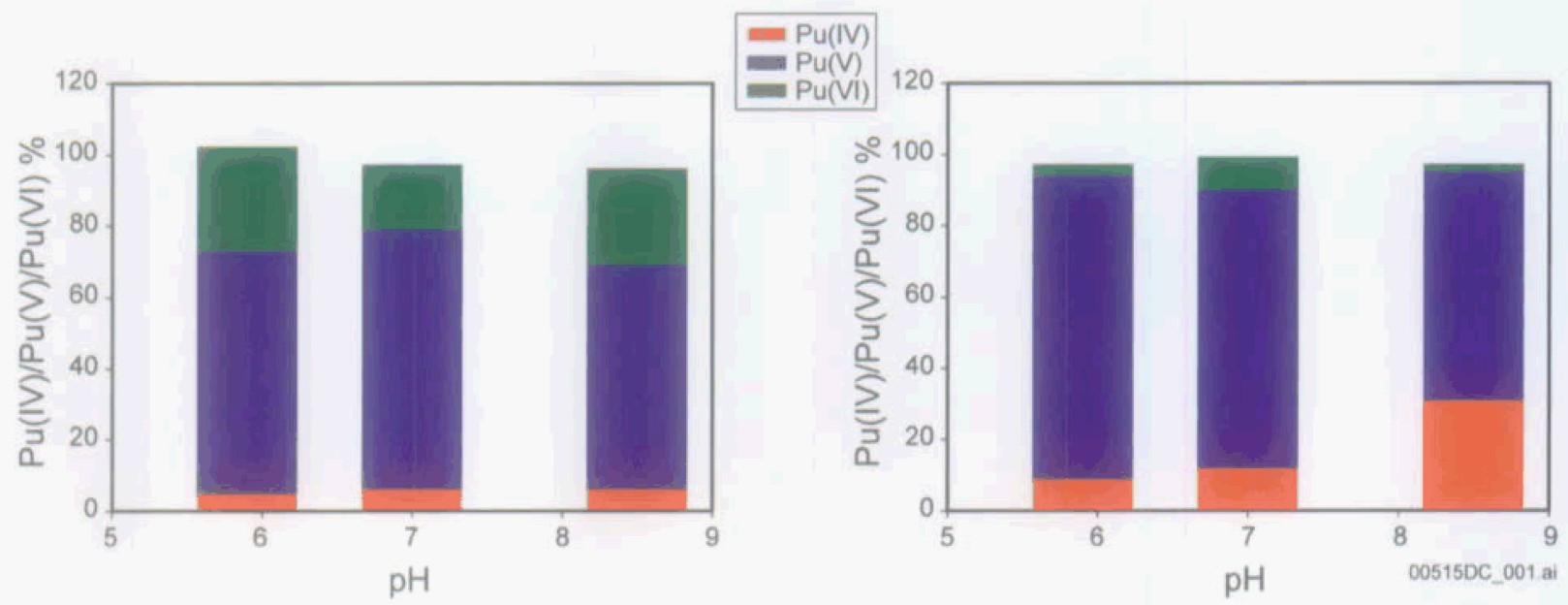

Source: Nitsche93aSDist.jnb and Nitsche94SDist.jnb in Appendix I

NOTE: Data in the left figure are from Nitsche et al. (1993 [DIRS 155218]), while data in the right figure are from Nitsche et al. 1994 [DIRS 144515]. The $\mathrm{fCO}_{2}$ values used in these experiments were $10^{-1.2}, 10^{-1.8}$, and $10^{-3.2}$ bars for the left figure and $10^{-0.5}, 10^{-1.2}$, and $10^{-2.6}$ bars in the right figure for $\mathrm{pH}$ values of 6,7 , and 8.5 , respectively.

Figure 6.5-9. Pu-Oxidation States Distribution in Pu-Solubility Experiments

$\mathrm{Pu}(\mathrm{V})$ is also the dominant species in the experiments conducted by Rai (1984 [DIRS 122768]) for $\mathrm{pH}$ from 3.5 to 5, as shown in Figure 6.5-10.

In natural waters, $\mathrm{Pu}(\mathrm{V})$ is observed to be the dominant dissolved species (Choppin et al. 1986 [DIRS 168377]; Choppin and Stout 1989 [DIRS 168379]; Choppin 2003 [DIRS 168308]; and Murphy and Shock 1999 [DIRS 168433]).

However, the oxidation state distribution in the EQ3 results using the theoretical $\mathrm{fO}_{2}$ model with $f \mathrm{O}_{2}=0.2$ bars shows that $\mathrm{Pu}(\mathrm{VI})$ is the dominant species over the entire $\mathrm{pH}$ range modeled. (Appendix I, Spreadsheet $\mathrm{PuO2}$ _hyd_aged Solubility.xls). 


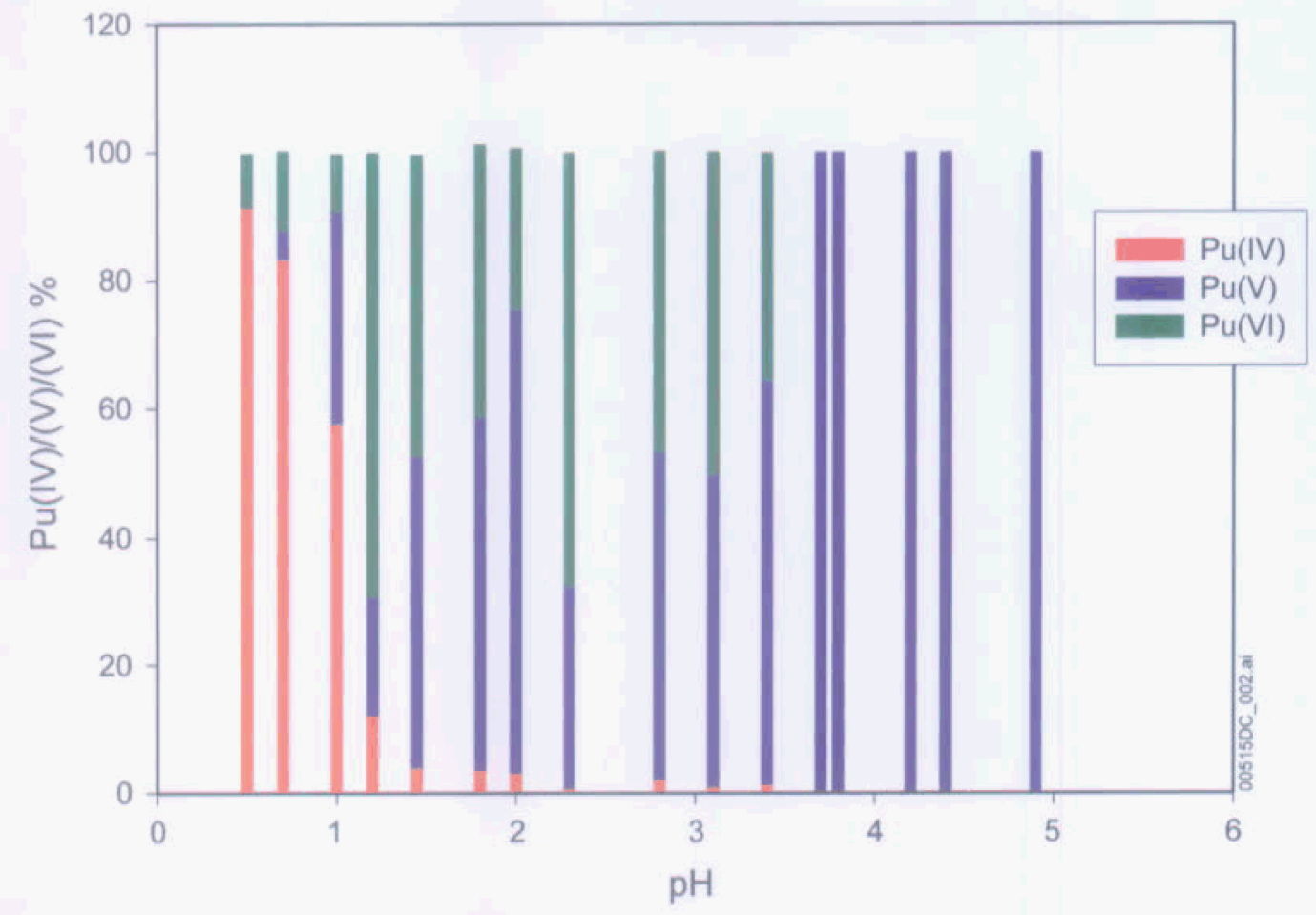

Source: Rai84SpecDistr.jnb in Appendix I.

NOTE: Data is from Rai 1984 [DIRS 122768].

Figure 6.5-10. Pu-Oxidation States Distribution in Pu-Solubility Experiments

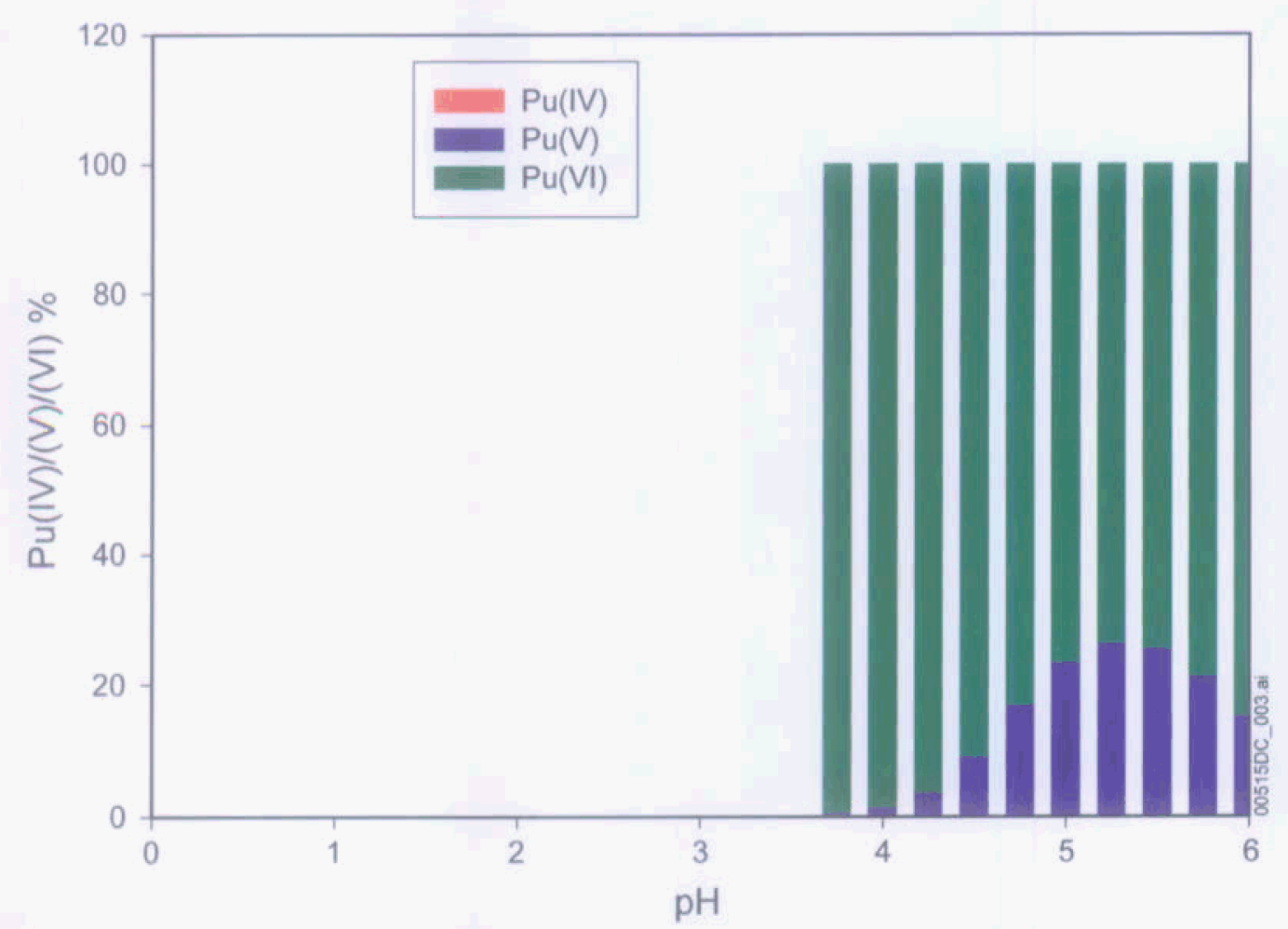

Source: simplespecdistr.jnb in Appendix I.

Figure 6.5-11. Pu Oxidation States Distribution Given by the Simple $\mathrm{PuO}_{2}$ (hyd,aged) Model 
Since the distribution of different oxidation states is mainly controlled by redox reactions, the discrepancy between the theoretical $\mathrm{fO}_{2}$ model results and solubility experiments as well as observations in natural waters strongly suggests that the redox potential, based on $f \mathrm{O}_{2}=0.2$ bars, causes the discrepancy.

\subsubsection{Redox Potential}

\subsection{Redox Potentials in Natural Waters}

There are several different ways to represent redox potential. Oxygen fugacity is convenient and commonly used in geochemistry. In many systems, the oxygen fugacity is approximately equal to its partial pressure, so when a system is open to air, it is assumed that $\mathrm{fO}_{2}=0.2$ bars. As already pointed out, this convention was used in the theoretical $f \mathrm{O}_{2}$ model described earlier.

Other parameters used to represent redox conditions are $\mathrm{Eh}$ and pe $\left(\mathrm{Eh}=0.0592 \mathrm{pe}\right.$ at $\left.25^{\circ} \mathrm{C}\right)$. Assuming $\mathrm{fO}_{2}=0.2$ bars is equivalent to assuming (Wolery 1992 [DIRS 100836]; Krauskopf and Bird 1995 [DIRS 101702]; and Langmuir 1997 [DIRS 100051]):

$$
E h(\text { volt. })=1.22-0.0592 p H
$$

Equation $6.5-3$ is given by the Nernst equation for reaction:

$$
2 \mathrm{H}_{2} \mathrm{O}=\mathrm{O}_{2}+4 \mathrm{H}^{+}+4 \mathrm{e}^{-}
$$

when $f \mathrm{O}_{2}=0.2$ bars. This is the upper bound of the water stability field in an Eh-pH diagram. Because water is unstable above this line, natural aqueous systems do not exist.

However, by analyzing 6,200 Eh and $\mathrm{pH}$ measurements in natural waters, Baas Becking et al. (1960 [DIRS 168371]) found that for $\mathrm{pH}$ between 3.2 and 12.6, there is an upper boundary for $\mathrm{Eh}-\mathrm{pH}$ conditions in natural waters, that is:

$$
E h(\text { volt } .)=1.04-0.0592 p H
$$

In other words, in these 6,200 samples, not one measurement exceeds the limit set by Equation 6.5-5. This equation is a more-realistic boundary of redox conditions in natural waters that are in contact with the atmosphere (Krauskopf and Bird 1995 [DIRS 101702]). However, "none of the likely inorganic reactions yielded characteristics remotely resembling" Equation 6.5-5 (Baas Becking et al. 1960 [DIRS 168371]). Thus, this upper limit is empirical.

There are several plausible explanations for the discrepancy between the theoretical upper boundaries given by Equations 6.5-3 and 6.5-5. One is that the noble metal electrodes commonly used to measure solution Eh values do not respond to the couple defined by Equation 6.5-4 (Langmuir 1997 [DIRS 100051], Section 11.1.4). Other researchers attribute it to the slow kinetics of redox reactions involving $\mathrm{O}_{2}$ (Krauskopf and Bird 1995 [DIRS 101702]; Stumm and Morgan 1996 [DIRS 125332]; Langmuir 1997 [DIRS 100051]). It has been accepted that "dissolved oxygen does not exert the potential expected if it is functioning at equilibrium" (Garrels and Christ 1990 [DIRS 144877]). 
For $\mathrm{pH}$ values between -0.6 to 3.2, the upper limit of Eh follows (Baas Becking et al. 1960 [DIRS 168371]):

$$
\text { Eh(volt. })=0.860
$$

\subsection{Redox Potential Measurements at Yucca Mountain}

Figure 6.5-12 presents measured $\mathrm{Eh}-\mathrm{pH}$ values for waters obtained from wells at or near Yucca Mountain. Table 6.5-6 lists the data sources. Most of these measurements were made in situ, either downhole or using a flow-through cell. Some samples are bailed samples. The in situ samples provide more accurate Eh measurements since equilibration with the atmosphere at the wellhead does not occur as may happen in bailed samples taken in open containers.

Equations 6.5-3 and 6.5-5 are also plotted in Figure 6.5-12 for comparison with measured Eh-pH values. Figure 6.5-12 shows that all the Eh-pH measurements made at Yucca Mountain are below Equation 6.5-5.

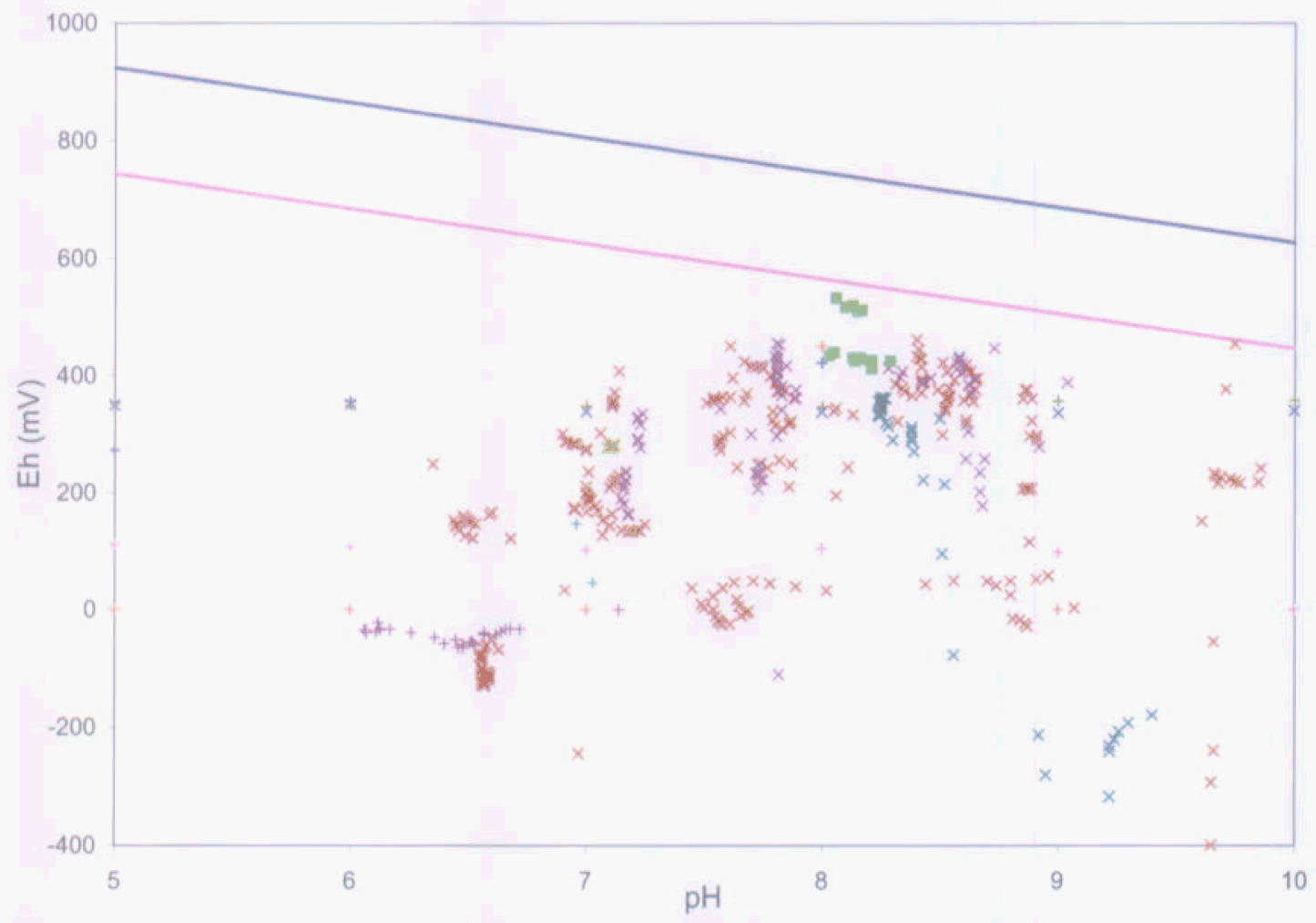

\begin{tabular}{|cl|l|}
\hline $\mathbf{2}$ & USW SD-6ST1 Flow-through & + UE-25 WT \#3 Downhole \\
\hline$x$ & NC- '99 to '01 Flow-through & + UE-25 WT \#3 Flow-through \\
\hline$x$ & NC-EWDP-01S Flow-through & + UE-25 WT \#17 Downhole \\
\hline$x$ & NC-EWDP-03S Downhole & + UE-25 WT \#17 Pumped \\
\hline$x$ & NC-EWDP-01DX Downhole & + UE-25 WT \#17 Bailed \\
\hline$x$ & NC-EWDP-01,3,9S $(X)$ Flow-through & + UE-25 WT \#17 Flow-through Pumped \\
\hline
\end{tabular}

Source: Table 6.5-6.

NOTES: The upper line shows the theoretical oxidation potential at $\mathrm{fO}_{2}=0.2$ bars (Equation $6.5-3$ ) and the lower line shows the upper limit for empirical Eh measurements in natural waters (Equation 6.5-5).

Figure 6.5-12. Eh-pH Measurements at Yucca Mountain 
Table 6.5-6. Data Sources for Figure 6.5-12

\begin{tabular}{|c|c|c|c|}
\hline & Sample & Source & Details \\
\hline घ & USW SD-6ST1 & $\begin{array}{l}\text { LA9907AM831234.010 } \\
\text { [DIRS 149210] }\end{array}$ & $\begin{array}{l}\text { Flow-through cell measurements for well water USW SD- } \\
6 S T 1 \text {. Depth is pump depth. No casing in this well below the } \\
\text { water table. }\end{array}$ \\
\hline$x$ & NC- '99 to '01 & $\begin{array}{l}\text { LA0206AM831234.001 } \\
\text { [DIRS 160051] }\end{array}$ & $\begin{array}{l}\text { Flow-through cell measurements from Nye County EWDP } \\
\text { wells, Nevada }\end{array}$ \\
\hline$x$ & NC-EWDP-01S & $\begin{array}{l}\text { LA0004AM831234.001 } \\
\text { [DIRS 149202] }\end{array}$ & $\begin{array}{l}\text { Flow-through cell measurements from well NC-EWDP-O1S in } \\
\text { Amargosa Valley, Nevada }\end{array}$ \\
\hline$x$ & NC-EWDP-03S & $\begin{array}{l}\text { LA0004AM831234.002 } \\
\text { [DIRS 149213] }\end{array}$ & $\begin{array}{l}\text { Downhole probe measurements from well NC-EWDP-03S, in } \\
\text { Amargosa Valley, Nevada }\end{array}$ \\
\hline$x$ & NC-EWDP-01DX & $\begin{array}{l}\text { LA9907AM831234.003 } \\
\text { [DIRS 149196] }\end{array}$ & $\begin{array}{l}\text { Downhole measurements from well NC-EWDP-01DX in } \\
\text { Amargosa Valley, Nevada }\end{array}$ \\
\hline$x$ & $\begin{array}{l}\text { NC-EWDP- } \\
01,3,9 S(X)\end{array}$ & $\begin{array}{l}\text { LA9907AM831234.009 } \\
\text { [DIRS 149209] }\end{array}$ & $\begin{array}{l}\text { Flow-through cell measurements from wells NC-EWDP-01S, } \\
\text { NC-EWDP-03S and NC-EWDP-09SX in Amargosa Valley, } \\
\text { Nevada }\end{array}$ \\
\hline+ & $\begin{array}{l}\text { UE-25 WT \#3 } \\
\text { Downhole }\end{array}$ & $\begin{array}{l}\text { LAAM831311AQ98.004 } \\
\text { [DIRS 168346] }\end{array}$ & Eh data of downhole measurements from well UE-25 WT \#3 \\
\hline+ & $\begin{array}{l}\text { UE-25 WT \#3 Flow- } \\
\text { through }\end{array}$ & $\begin{array}{l}\text { LAAM831311AQ98.007 } \\
\text { [DIRS 149520] }\end{array}$ & $\begin{array}{l}\text { Flow-through cell and static measurements of water from UE- } \\
25 \text { WT \#3. Analysis made on flow-through samples as they } \\
\text { flowed directly from pump outlet through a cell, to avoid } \\
\text { contact with air. }\end{array}$ \\
\hline+ & $\begin{array}{l}\text { UE-25 WT \#17 } \\
\text { Downhole }\end{array}$ & $\begin{array}{l}\text { LAAM831311AQ98.003 } \\
\text { [DIRS 168347] }\end{array}$ & Eh data of downhole measurements from well UE-25 WT \#17 \\
\hline+ & $\begin{array}{l}\text { UE-25 WT \#17 } \\
\text { Pumped }\end{array}$ & $\begin{array}{l}\text { LAAM831311AQ98.005 } \\
\text { [DIRS 149181] }\end{array}$ & $\begin{array}{l}\text { Field measurements of pumped water samples from well } \\
\text { UE-25 WT \#17. Static measurements obtained in open } \\
\text { containers open to the atmosphere during analysis. }\end{array}$ \\
\hline+ & $\begin{array}{l}\text { UE-25 WT \#17 } \\
\text { Bailed }\end{array}$ & $\begin{array}{l}\text { LAAM831311AQ98.008 } \\
\text { [DIRS 149521] }\end{array}$ & $\begin{array}{l}\text { Analysis of bailed samples from well UE- } 25 \text { WT \#17. Data } \\
\text { values are static field measurements in an open beaker. }\end{array}$ \\
\hline+ & $\begin{array}{l}\text { UE-25 WT \#17 F-t } \\
\text { Pumped }\end{array}$ & $\begin{array}{l}\text { LAAM831311AQ98.009 } \\
\text { [DIRS 168348] }\end{array}$ & $\begin{array}{l}\text { Eh data from flow-through cell measurements of pumped } \\
\text { water samples from well UE- } 25 \text { WT \#17 }\end{array}$ \\
\hline
\end{tabular}

\subsubsection{The Empirical-Eh Pu-Solubility Model}

Section 6.5.4.1.2, concludes that the theoretical $f \mathrm{O}_{2}$ model with $\mathrm{fO}_{2}=0.2$ bars does not correctly represent $\mathrm{Pu}$ behavior in aqueous systems because the model (due to differing oxidation states of plutonium) is sensitive to redox potential. The discussion in Section 6.5.4.2 further suggests that Equation 6.5-5 is a more-realistic upper limit for redox conditions in natural waters and for the repository than Equation 6.5-3, which corresponds to $f \mathrm{O}_{2}=0.2$ bars as used in the theoretical $f \mathrm{O}_{2}$ model previously discussed.

A modified Pu-solubility model (the empirical-Eh model) uses Equation 6.5-5 to set redox conditions for $\mathrm{pH}$ values between 3.2 to 12, and Equation 6.5-6 to set redox conditions for $\mathrm{pH}$ values between 1.0 to 3.2 , while all other conditions are kept the same as described in Section 6.5.2. The controlling phase is still $\mathrm{PuO}_{2}$ (hyd,aged). 
Figure 6.5-13 shows the distribution of different oxidation states of $\mathrm{Pu}$ species in the empirical-Eh model. It shows that $\mathrm{Pu}(\mathrm{V})$ is the dominant oxidation state for $\mathrm{pH}$ values between 3 and 9. This matches experimental results very well (Figures 6.5-9 and 6.5-10).

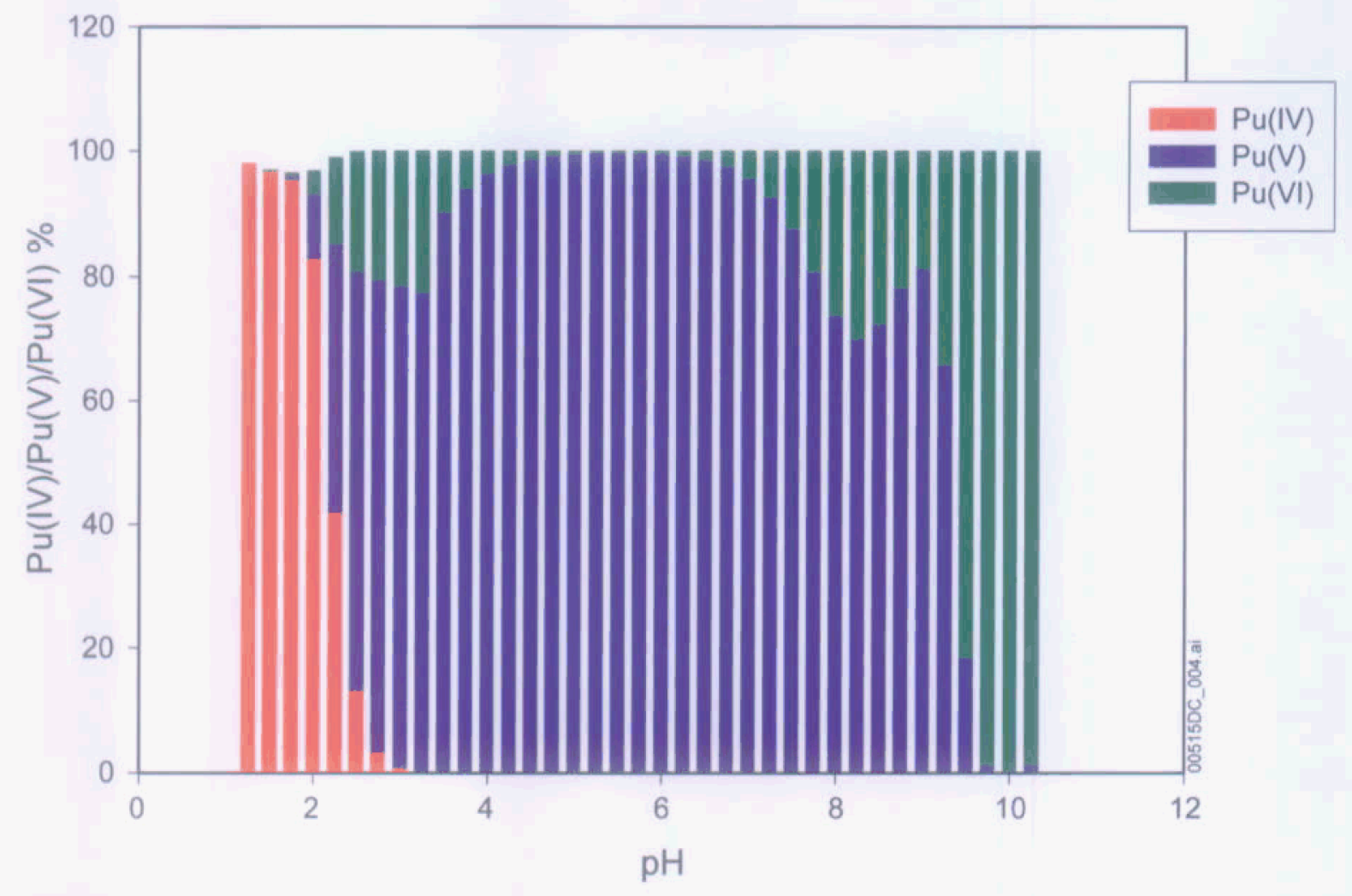

Source: $\quad$ pu 104 spe dist.jnb in Appendix I.

NOTE: $\quad\left(\log \mathrm{fCO}_{2}=-3.5\right.$ bars, Equation $6.5-5$ for $\mathrm{pH}>3.2$, Equation $6.5-6$ for $\left.\mathrm{pH}<3.2\right)$. Note that for $\mathrm{pH} \leq 2$, the total of $\mathrm{Pu}(\mathrm{IV}), \mathrm{Pu}(\mathrm{V})$, and $\mathrm{Pu}(\mathrm{VI})$ is less than $100 \%$ because of the existence of $\mathrm{Pu}(\mathrm{III})$.

Figure 6.5-13. Pu Oxidation States Distribution Given by the Eh Model

$\mathrm{Pu}$ solubility given by the empirical-Eh model is presented in Figure 6.5-14, along with measured $\mathrm{Pu}$ solubilities under compatible conditions (Rai 1984 [DIRS 122768]; Nitsche et al. 1993 [DIRS 155218]; Nitsche et al. 1994 [DIRS 144515]; Efurd et al. 1998 [DIRS 108015]; and Rai et al. 2001 [DIRS 168392]). These results agree much more closely with the experimental results than those obtained from the $\mathrm{fO}_{2}$ model and most of the measured $\mathrm{Pu}$ solubilities fall within the uncertainty range.

The good match between the modeling results and experimental results in the oxidation state distribution and $\mathrm{Pu}$ solubility indicate that the empirical-Eh model better represents $\mathrm{Pu}$ solubility.

However, Figure 6.5-14 also shows that although the mean modeled $\mathrm{Pu}$ concentration is below most of the experimental results, most are within the upper half of the uncertainty range model. There are several possible explanations for this uneven distribution. 


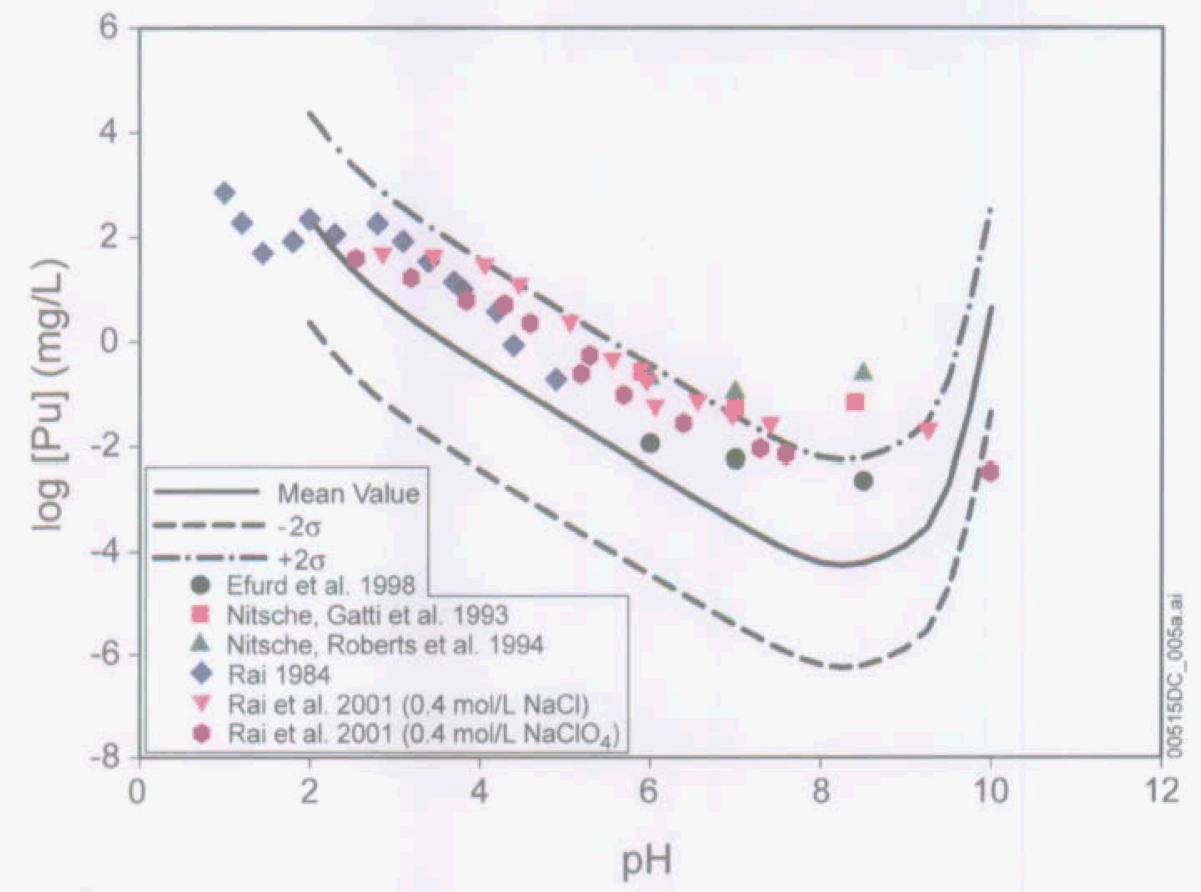

Source: pu solb 104-3.jnb in Appendix I.

NOTE: $\quad\left(\log f \mathrm{CO}_{2}=-3.5\right.$ bars, Equation $6.5-5$ for $\mathrm{pH}>3.2$, Equation $6.5-6$ for $\mathrm{pH}<3.2$ ).

Figure 6.5-14. Pu Solubility Given by the Eh model

The first explanation is that the actual Eh in the experiments does not exactly follow Equations 6.5-5 and 6.5-6. Note that Equations 6.5-5 and 6.5-6 are empirical relations obtained from measurements of natural waters. The Eh measured in individual experiments may have a slightly different value. For example, in Rai's (1984 [DIRS 122768]) experiments, measured Eh values for $\mathrm{pH}<4.2$ are systematically higher than the values given by Equations 6.5-5 and 6.5-6, as shown in Figure 6.5-14. Moreover, the transition point where Eh becomes horizontal also shifts from $\mathrm{pH}=3.2$ given by Baas Becking et al. (1960 [DIRS 168371]) to about $\mathrm{pH}=2.0$ in Rai's (1984 [DIRS 122768]) experiments. For pH between 2 and 3.8, the measured Eh is about 50 to $60 \mathrm{mv}$ higher than the values given by Equation 6.5-6. The measured Eh for $\mathrm{pH}>4.25$ in Rai's (1984 [DIRS 122768]) experiments is lower than the values given by Equation 6.5-5 by 200 to $300 \mathrm{mv}$. This was attributed to poor system poise (Rai 1984 [DIRS 122768]).

Adding $60 \mathrm{mv}$ to the calculated Eh value given by Equation 6.5-5, a modified $\mathrm{Eh}-\mathrm{pH}$ relation is given below:

$$
E h=1.10-0.0592 p H
$$

Using it for $\mathrm{pH} \leq 3$, the calculated Pu solubility matches Rai's measured Pu solubility very well, as shown in Figure 6.5-15. Moreover, this model also reproduces results found by Efurd et al. (1998 [DIRS 108015]) (Figure 6.5-16). 


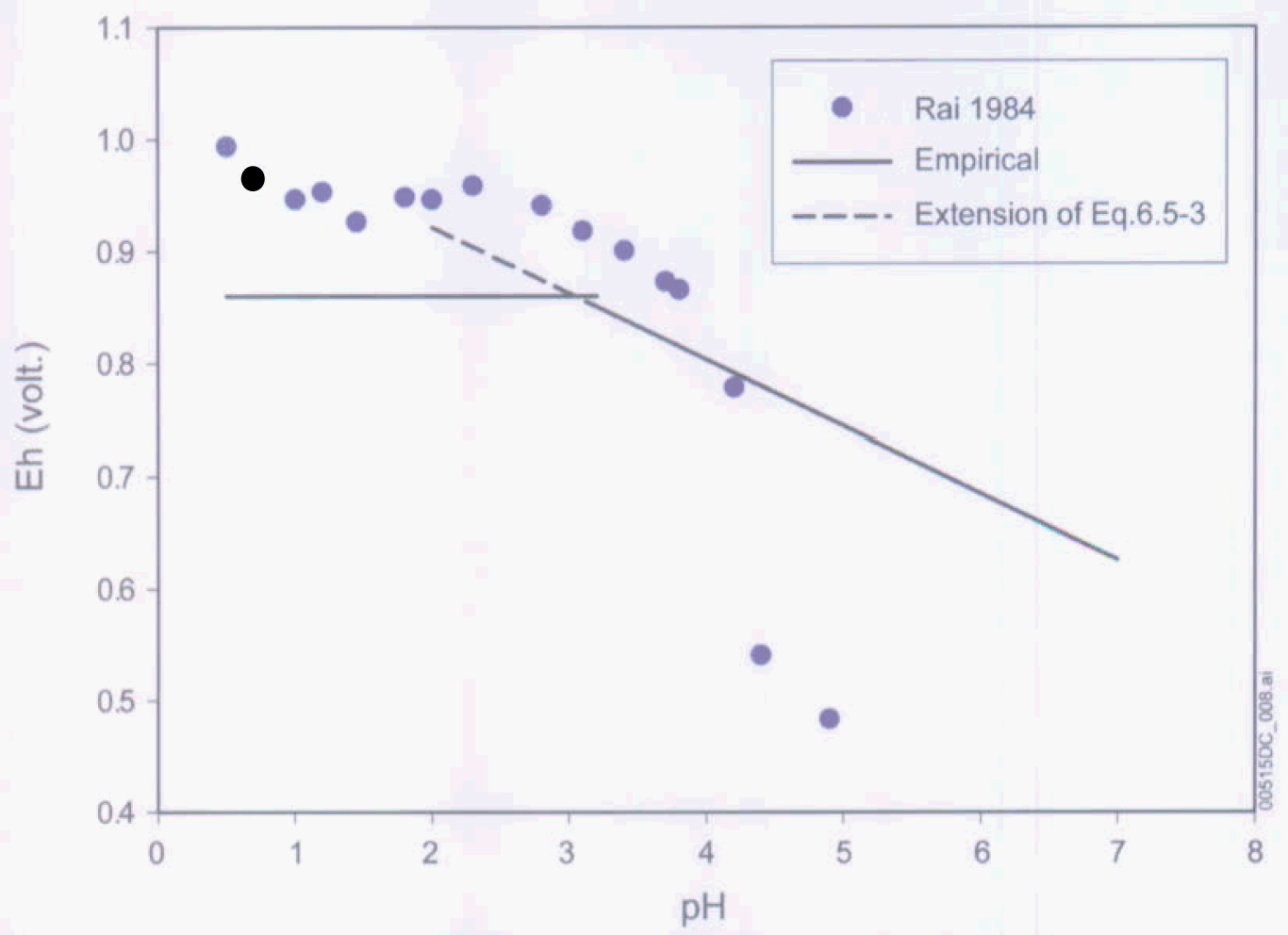

Source: pu solb 104-3.jnb in Rai 1984 [DIRS 122768], Appendix I and Baas Becking et al. 1960 [DIRS 168371].

Figure 6.5-15. Measured Eh in Rai 1984 Experiments and the Empirical-Eh Relation Given by Baas Becking et al. 1960 [DIRS 168371]

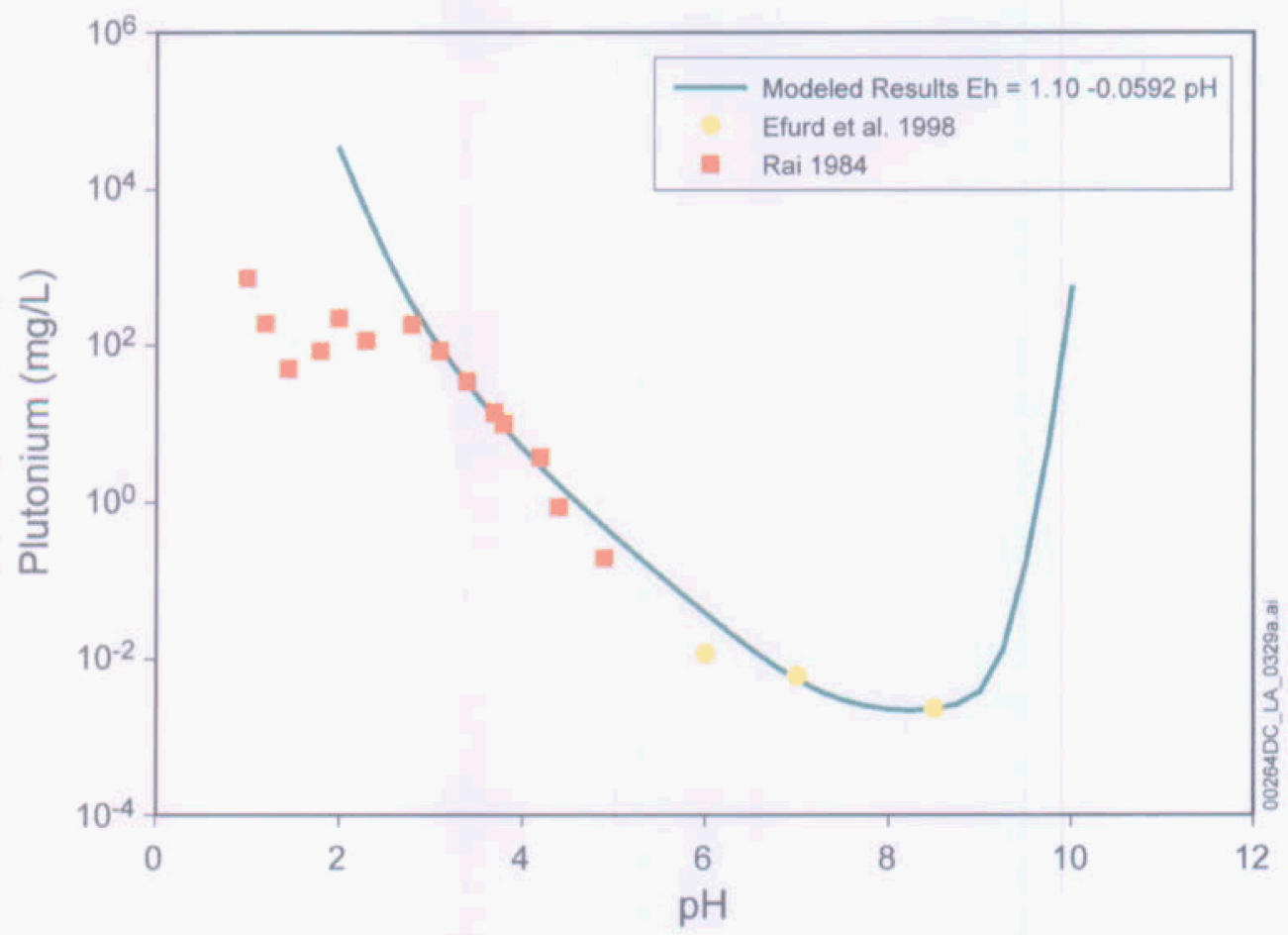

Source: PuEhAdjModel.jnb in Appendix I.

Figure 6.5-16. Modeled Results with Eh-Adjusted $(E h=1.10-0.0592 \mathrm{pH})$ and Experimental Results 
The second explanation is that the measured $\mathrm{Pu}$ concentrations are not true dissolved $\mathrm{Pu}$, but contain $\mathrm{Pu}$ colloids or polymers, or both, which could be smaller than the filter size. For example, Kim and Kanellakopulos (1989 [DIRS 122387]) reported in their experiments a large percent $(80 \%)$ of $\mathrm{Pu}$ is in $\mathrm{Pu}(\mathrm{IV})$ colloid form even though the filter size is as small as $1 \mathrm{~nm}$.

The third explanation is that the experimental solutions have a higher ionic strength than that modeled, which yields a higher solubility because of the "salting-in" effect. For example, as discussed in Section 6.5.3.3, in experiments conducted by Rai et al. (2001 [DIRS 168392]), the solutions are $0.402 \mathrm{~m} \mathrm{NaCl}$ and $0.408 \mathrm{~m} \mathrm{NaClO} 4$. The ionic strengths of these solutions are about 1 molal.

\subsubsection{Effect of Mineral Aging on the Model}

The adjusted-Eh model produces results that match experimental results very well. The solubility product of $\mathrm{PuO}_{2}$ (hyd,aged) recommended by the NEA (Lemire 2001 [DIRS 159027]) is for Pu(IV) hydrated oxide/hydroxide "aged for several months near room temperature." The experiments used to validate the model were also carried out for only a few months. The aging process of $\mathrm{Pu}(\mathrm{IV})$ hydrated oxide/hydroxide actually can go on for several years. For example, Rai and Ryan (1982 [DIRS 112060]) observed continuous aging for a period of 1,266 days, during which the measured Pu solubility continuously decreased.

Lemire (2001 [DIRS 159027], Section 17.2.2.3) notes that radiolysis tends to decrease the stability of $\mathrm{PuO}_{2}$ solids and that when the crystalline dioxide ${ }^{239} \mathrm{PuO}_{2}$ is in contact with water, it slowly converts to (or becomes coated with) a less-crystalline form. Likewise, Rai and Ryan (1982 [DIRS 112060]) point out that crystalline ${ }^{238} \mathrm{PuO}_{2}$ in contact with water converts to the amorphous solid. Thus, the decreased solubility brought about by aging is balanced by the increased solubility due to radiolysis. For comparison, the solubilities for both minerals $\left(\mathrm{PuO}_{2}\right.$ (hyd,aged) and $\left.\mathrm{PuO}_{2}(\mathrm{c})\right)$ are shown in Figure 6.5-17.

The NEA chemical thermodynamic data for $\mathrm{PuO}_{2}$ (hyd,aged) are based on several studies using different experimental approaches and aging times that gave similar results. Their data represent a solid for which the effects of aging are balanced by the effects of radiolysis. Therefore, Pu solubilities calculated using this solid and the adjusted Eh should give realistic $\mathrm{Pu}$ concentrations. 


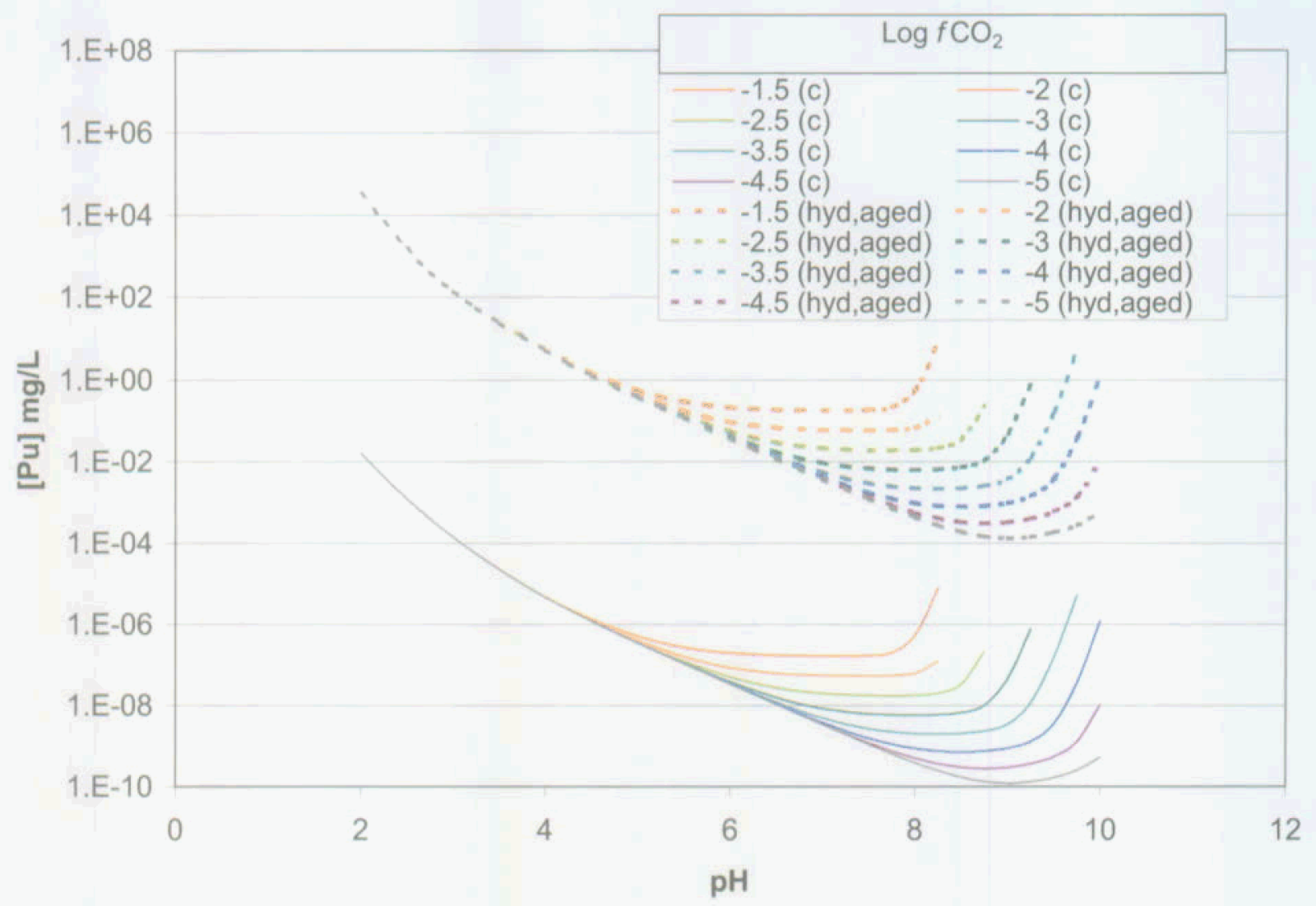

Source: Pu Alternative.xls in Appendix I.

Figure 6.5-17. Comparison of Solubilities Between Crystalline $\mathrm{PuO}_{2}(\mathrm{c})$ and $\mathrm{PuO}_{2}$ (hyd,aged)

\subsubsection{Relationship of $\mathrm{PuO}_{2+x}$ to Plutonium Solubility}

Haschke et al. (2000 [DIRS 150367]), Haschke and Oversby (2002 [DIRS 161911]), and Haschke and Allen (2002 [DIRS 162001]) describe a solid with the general formula $\mathrm{PuO}_{2+x}$ that forms from $\mathrm{PuO}_{2}$ in the presence of water vapor at temperatures from $25^{\circ} \mathrm{C}$ to $350^{\circ} \mathrm{C}$. At $300 \mathrm{~K}$, free energies of formation of this solid range from $-1,033 \mathrm{~kJ} / \mathrm{mol}$ at $\mathrm{x}=0.1$ to $-1,146 \mathrm{~kJ} / \mathrm{mol}$ at $\mathrm{x}$ $=0.5$ (Haschke and Allen 2002 [DIRS 162001]). At $298.15 \mathrm{~K}$ the free energy of formation of $\mathrm{PuO}_{2}$ (hyd,aged) is $-964 \mathrm{~kJ} / \mathrm{mol}$ (Lemire 2001 [DIRS 159027], Table 4.1). This phase was used to calculate the base-case, Eh-adjusted plutonium solubility in Section 6.5.3.

$\mathrm{PuO}_{2+\mathrm{x}}$ contains both $\mathrm{Pu}(\mathrm{IV})$ and $\mathrm{Pu}(\mathrm{V})$ in the proportion (1-x):x. Haschke et al. (2000 [DIRS 150367]) attributed the increase in the average oxidation state in $\mathrm{PuO}_{2+\mathrm{x}}$ to the presence of $\mathrm{Pu}(\mathrm{VI})$, and concluded that this would make plutonium more soluble than $\mathrm{PuO}_{2}$ because $\mathrm{Pu}(\mathrm{VI})$ ions are more soluble than Pu(IV) ions. Haschke et al. (2000 [DIRS 150367]) also concludes that because $\mathrm{PuO}_{2+\mathrm{x}}$ forms from $\mathrm{PuO}_{2}$ in the presence of $\mathrm{O}_{2}$, it is more stable. This is borne out by the free energy data by Haschke and Allen (2002 [DIRS 162001]) showing that as ' $x$ ' increases, the free energy becomes more negative. However, Haschke and Allen (2002 [DIRS 162001]) also concluded from extended x-ray absorption fine structure (EXAFS) spectra that $\mathrm{PuO}_{2+\mathrm{x}}$ contains $\mathrm{Pu}(\mathrm{V})$ rather than $\mathrm{Pu}(\mathrm{VI})$. 
The recent update to the NEA compilation of chemical thermodynamic data (Guillaumont et al. 2003 [DIRS 168382], Section 11.2.2.1) includes a review of the results presented by Haschke et al. (2000 [DIRS 150367]) and Haschke and Allen (2002 [DIRS 162001]). The conclusion is that "...the evidence for the formation of a thermodynamically stable bulk phase with $\mathrm{O} / \mathrm{Pu}>2$ is far from conclusive."

The dissolution reaction for $\mathrm{PuO}_{2+\mathrm{x}}$ under the oxidizing conditions used for the calculations described earlier can be written:

$$
\mathrm{PuO}_{2+\mathrm{x}}+\mathrm{H}^{+}+(0.5-\mathrm{x}) / 2 \mathrm{O}_{2}=\mathrm{PuO}_{2}^{+}+0.5 \mathrm{H}_{2} \mathrm{O}
$$

The results of such calculations are given in Table 6.5-7 and show that at equilibrium, $\mathrm{PuO}_{2+\mathrm{x}}$ solubilities decrease by 24 orders of magnitude as $x$ ranges from 0.0 to 0.5 . These calculations were made without considering activity coefficients or the formation of aqueous complexes. To illustrate the magnitude of the errors that may have been introduced by these simplifications, the last column of Table 6.5-7 gives the total plutonium contents calculated by EQ3NR using the adjusted-Eh model at $\mathrm{pH}=6$ and $f \mathrm{CO}_{2}=10^{-5}$ bars for $\mathrm{PuO}_{2}$ (hyd,aged) from Table 6.5-1 The solubility from the simple calculation is within 25 percent of that from the EQ3NR calculation, a considerably smaller difference than the solubility differences due to increasing values of $\mathrm{x}$.

Thus, it can be concluded that the equilibrium solubility of $\mathrm{PuO}_{2+\mathrm{x}}$ is considerably lower than that of $\mathrm{PuO}_{2}$ (hyd,aged), so that choosing solubility control by the latter phase leads to higher calculated-Pu concentrations and is conservative.

Haschke and Bassett (2002 [DIRS 162699]) review whether modeling with solids designated as $\mathrm{PuO}_{2}(\mathrm{~s})$ or $\mathrm{Pu}(\mathrm{OH})_{4}(\mathrm{am})$ better describes plutonium concentrations reported in a number of laboratory investigations. These phases correspond to the phases designated $\mathrm{PuO}_{2}(\mathrm{cr})$ and $\mathrm{PuO}_{2}$ (hyd,aged) by Lemire (2001 [DIRS 159027], Sections 17.2.1.2 and 17.2.2.3). Haschke and Bassett (2002 [DIRS 162699]) conclude that $\mathrm{Pu}(\mathrm{OH})_{4}(\mathrm{am})$ is a better predictor of laboratory results than the $\mathrm{PuO}_{2}(\mathrm{~s})$. This is understandable because the properties of the amorphous or poorly crystalline hydrated actinide dioxide solids, of which $\mathrm{Pu}(\mathrm{OH})_{4}(\mathrm{am})$ $\left(=\mathrm{PuO}_{2}\right.$ (hyd,aged $\left.)+2 \mathrm{H}_{2} \mathrm{O}\right)$ are one example, are derived from laboratory solubility experiments as illustrated by Lemire (2001 [DIRS 159027], Section 17.2.2.3) for plutonium, Hummel et al. (2002 [DIRS 161904], Section 5.21.2) for thorium, and Section 5.23.3.1.3 for uranium.

Haschke and Bassett's (2002 [DIRS 162699]) conclusions are not directly relevant to the solubility calculations in this report for two reasons. First, their calculations were made at lower oxidation potentials than used in this report. Their Eh values range from $0.92 \mathrm{~V}$ at $\mathrm{pH}=3$ to $0.26 \mathrm{~V}$ at $\mathrm{pH}=8$ (Haschke and Bassett 2002 [DIRS 162699], Table 3), while those of the adjusted-Eh model are 0.92 and $0.63 \mathrm{~V}$, respectively. The Eh values used by Haschke and Bassett (2002 [DIRS 162699]) correspond to $\mathrm{fO}_{2}$ values from $10^{-10}$ to $10^{-35}$ bars (Langmuir 1997 [DIRS 100051], Figure 11.2), while the adjusted-Eh model calculations for this report correspond to a $\mathrm{O}_{2}$ of $10^{-8.1}$ bars. Second, Haschke and Bassett (2002 [DIRS 162699]) used thermodynamic data for their calculations that predate and are superseded by Chemical Thermodynamics of Neptunium and Plutonium (Lemire 2001 [DIRS 159027]). The latter data are included in Data0.ymp.R2, the thermodynamic database used for this report. In addition, Haschke and Bassett (2002 [DIRS 162699]) do not include $\mathrm{PuO}_{2+\mathrm{x}}$ in their review of plutoniumcontrolling phases. 
Table 6.5-7. Data of $\mathrm{PuO}_{2+x}$ Stability

\begin{tabular}{|c|c|c|c|c|c|}
\hline $\begin{array}{l}X \text { value in } \\
\mathrm{PuO}_{2+x}\end{array}$ & $\Delta \mathrm{Gf} \mathrm{kJ/mol}$ & $\Delta \mathrm{Gr} \mathrm{kJ} / \mathrm{mol}$ & $\begin{array}{c}\text { at } \mathrm{pH}=6 \\
\mathrm{fO}_{2}=10^{-8.1} \text { bars } \\
\log \left(\mathrm{PuO}_{2}^{+}\right)\end{array}$ & $\mathrm{mg} \mathrm{Pu} / \mathrm{L}$ & $\begin{array}{c}\mathrm{mg} \mathrm{Pu} / \mathrm{L} \text { at } f \mathrm{CO}_{2}=10^{-5} \\
\text { bars [Pu] Table 6.5-1 }\end{array}$ \\
\hline 0.00 & -998.113 & 26.943 & -12.75 & 4.30E-08 & \\
\hline 0.10 & $-1,032.611$ & 61.441 & -18.39 & $9.88 \mathrm{E}-14$ & \\
\hline 0.20 & $-1,060.958$ & 89.788 & -22.95 & $2.72 \mathrm{E}-18$ & \\
\hline 0.30 & $-1,089.304$ & 118.134 & -27.51 & 7.47E-23 & \\
\hline 0.40 & $-1,117.651$ & 146.481 & -32.07 & 2.05E-27 & \\
\hline 0.50 & $-1,145.998$ & 174.828 & -36.63 & $5.65 \mathrm{E}-32$ & \\
\hline \multicolumn{6}{|c|}{$\mathrm{PuO}_{2}$ (hyd,aged) } \\
\hline 0.00 & -963.654 & -7.516 & -6.71 & $4.68 \mathrm{E}-02$ & $3.72 \mathrm{E}-02$ \\
\hline
\end{tabular}

Source: PuO(2+x)_Calc_REV03.x/s (Appendix I).

NOTE: Free energies of formation, free energy of reaction for Equation 6.5-7, and $\mathrm{PuO}_{2}{ }^{+}$ concentrations calculated at $\mathrm{fO}_{2}=10^{-8.1}$ bars, corresponding to adjusted-Eh model and $\mathrm{pH}=6$ for $\mathrm{PuO}_{2+x}$ with $x$ ranging from 0.0 to 0.5 , and for $\mathrm{PuO}_{2}$ (hyd,aged). The last column gives the total plutonium contents calculated at $\mathrm{CCO}_{2}=10^{-5}$ bars for $\mathrm{PuO}_{2}$ (hyd,aged) from Table 6.5-1.

Haschke and Oversby (2002 [DIRS 161911], p. 193) review selected experimental data on plutonium concentrations in laboratory experiments and conclude "...that a dissolution model based solely on equilibrium thermodynamics and solubility of $\mathrm{PuO}_{2}$ and $\mathrm{Pu}(\mathrm{OH})_{4}(\mathrm{am})$ is not consistent with the experimental data." Instead, they propose "...a kinetically controlled chemical process involving release of $\mathrm{Pu}(\mathrm{V})$ from $\mathrm{PuO}_{2+\mathrm{x}}$ formed by spontaneous reaction of dioxide or hydroxide with water." They propose a sequence of equilibrium and kinetic processes (summarized in their Table 2) that lead to steady-state solution plutonium concentrations similar to the experimental data they review (Haschke and Oversby 2002 [DIRS 161911], Table 3). The initiating reaction they propose is the formation of $\mathrm{PuO}_{2+\mathrm{x}}$ by reaction with water according to:

$$
\mathrm{PuO}_{2}(\mathrm{~s})+x \mathrm{H}_{2} \mathrm{O}=\mathrm{PuO}_{2+x}(\mathrm{~s})+x \mathrm{H}_{2}(\mathrm{~g})
$$

Haschke and Oversby (2002 [DIRS 161911]) also note that because this reaction produces hydrogen gas, which leaves the system, their plutonium cycle is not an equilibrium process. There is considerable uncertainty in the steady state concentrations they calculate because of uncertainties in the rate constants required to evaluate the kinetic expressions in their model. In addition, uncertainties exist because of the lack of experimental data to evaluate one of the key factors in their model: the conversion factor between rates expressed in terms of areas and those expressed in terms of volumes (Haschke and Oversby 2002 [DIRS 161911], p. 196).

The results of Haschke and Oversby's (2002 [DIRS 161911]) model are given in their Table 3. For conditions most like those modeled in this report (controlling-phase $\mathrm{Pu}(\mathrm{OH})_{4}(\mathrm{am}), \mathrm{pH} 6$ to 7 , low ionic strength) their modeled concentrations are from -0.1 to $-0.9 \log [\mathrm{Pu}]$ (in $\mathrm{mg} / \mathrm{L}$ ), and the range of observed concentrations they cite is -0.1 to $-2.0 \log [\mathrm{Pu}]$. Both are within the uncertainty range of the adjusted-Eh Pu-solubility model (Fig 6.5-6).

The data of Haschke et al. (2000 [DIRS 150367]) and the model developed to account for them by Haschke and Oversby (2002 [DIRS 161911]) are of considerable interest and possible 
importance to the understanding of plutonium chemistry. However, because the steady-state model is only in its first stages of development and in any case leads to concentrations lower than those calculated under the same conditions in this report, the theoretically more-robust thermodynamic equilibrium model is retained here.

\subsubsection{Effects of Small Eh Change on Other Elements}

The other elements considered in this report that are sensitive to redox conditions are $\mathrm{Np}$ and $\mathrm{U}$. As discussed in Section 6.6.2, Np solubilities were also calculated using the adjusted-Eh values used for $\mathrm{Pu}$ and given in Equation 6.5-7. $\mathrm{U}$ had previously been modeled with the theoretical $\mathrm{fO}_{2}=0.2$ bars. Published Eh-pH diagrams for U (e.g., Langmuir 1997 [DIRS 100051], Figures 13.8 and 13.9) show all solute species of $U$ are in the U(VI) state with Eh values at least as low as $200 \mathrm{mv}$ from $\mathrm{pH} 0$ to 12 . Thus, the relatively small reduction in $\mathrm{E}^{0}$ from 1.22 to 1.10 in going from the theoretical $\mathrm{fO}_{2}$ model to the adjusted-Eh model (compare Equations 6.5-3 and 6.5-7), although important to the speciation of $\mathrm{Pu}$ and $\mathrm{Np}$, does not change $\mathrm{U}$ speciation. In addition, the solubility-controlling phases for $U$ all contain $U(V I)$, so no redox reactions are associated with their dissolution. Because the difference between the theoretical $f \mathrm{O}_{2}$ and adjusted-Eh models would have no effect on $U$ concentrations as modeled here, the $U$ concentrations were calculated with the theoretical $\mathrm{fO}_{2}$ model.

\subsection{NEPTUNIUM SOLUBILITY}

\subsubsection{Conceptual Models}

Several studies concerning neptunium-bearing phase(s) that could form under the repository conditions have been conducted. Several types of solubility-controlling phases have been examined. One is pure neptunium phases, consisting primarily of neptunium oxides, hydroxides, and carbonates. The other is neptunium-bearing uranium phases, wherein neptunium constitutes a minor element component in solid solutions.

It is recommended that the $\mathrm{Np}_{2} \mathrm{O}_{5}-\mathrm{NaNpO}_{2} \mathrm{CO}_{3}$ solubility model (Table 6.6-3 and uncertainty terms defined in Table 6.6-5) be used for the base case of TSPA-LA. These two phases have been identified as forming from aqueous solutions at $25^{\circ} \mathrm{C}$ (Section 6.6.3).

$\mathrm{NpO}_{2}$ (cr) is considered an alternative controlling phase ("Alternative Neptunium Solubility Model I: $\mathrm{NpO}_{2}$ Model," Section 6.6.4). It has not been observed to form at temperature conditions relevant to the repository.

Incorporation of neptunium into uranyl minerals is also considered an alternative controlling phase ("Alternative Neptunium Solubility Model II: Secondary Phase Model," Section 6.6.5). The results produced by this alternative model capture experimental results very well (Section 6.6.5.5). It eliminates the built-in conservatism in the conventional pure-phase solubility approach and, thus, gives more-realistic source terms. Moreover, the model enhances the understanding about radionuclide migration and the performance of the repository. However, experimental studies do not provide a solid basis for recommending this as the base-case model for use in the TSPA-LA model. Therefore, it is presented only as an alternative model. 


\subsubsection{Chemical Conditions}

$\mathrm{Np}$ is known to exist in four oxidation states in natural waters (Langmuir 1997 [DIRS 100051]). $\mathrm{Np}$ had previously been modeled with the theoretical $f \mathrm{O}_{2}=0.2$ bars. Published Eh- $\mathrm{pH}$ diagrams for Np (e.g., Langmuir 1997 [DIRS 100051]) show that the higher oxidation states of Np exist with Eh values as low as $250 \mathrm{mv}$ above a $\mathrm{pH}$ of 9 and, thus, is important to the speciation of $\mathrm{Np}$. This shift in species oxidation state is also seen in the EQ3 calculations used to derive the solubilities for $\mathrm{Np}$. Because of this possible change in oxidation state at higher $\mathrm{pH}$ values, $\mathrm{Np}$ solubilities were calculated using the adjusted-Eh values given in Equation 6.5-7. See Table 6.42 for other chemical conditions used for the $\mathrm{Np}_{2} \mathrm{O}_{5} / \mathrm{NaNpO}_{2} \mathrm{CO}_{3}$-solubility calculations.

\subsubsection{Base-Case Neptunium Solubility Model: $\mathrm{Np}_{2} \mathrm{O}_{5}-\mathrm{NaNpO}_{2} \mathrm{CO}_{3}$ Model}

\subsubsection{Selection of Solubility-Controlling Phases}

Several pure-neptunium phases have been identified in neptunium solubility experiments, including $\mathrm{Np}_{2} \mathrm{O}_{5} \cdot \mathrm{xH}_{2} \mathrm{O}, \mathrm{Np}_{2} \mathrm{O}_{5}, \mathrm{NaNpO}_{2} \mathrm{CO}_{3} \cdot \mathrm{xH}_{2} \mathrm{O}$, and $\mathrm{NpO}_{2}$ (Efurd et al. 1998 [DIRS 108015]; Nitsche et al. 1993 [DIRS 155218]; Roberts et al. 2003 [DIRS 162536]), at various temperatures and solution compositions. At the conditions relevant to solubility limits in the repository (oxidizing conditions and temperatures from $25^{\circ} \mathrm{C}$ to $100^{\circ} \mathrm{C}$ ), the observed precipitates in solubility experiments are $\mathrm{Np}_{2} \mathrm{O}_{5} \cdot \mathrm{xH}_{2} \mathrm{O}, \mathrm{Np}_{2} \mathrm{O}_{5}$, and $\mathrm{NaNpO}_{2} \mathrm{CO}_{3} \cdot \mathrm{xH}_{2} \mathrm{O}$ (Efurd et al. 1998 [DIRS 108015]; Nitsche et al. 1993 [DIRS 155218], p. 37). Based on the discussion below, the base-case model uses $\mathrm{Np}_{2} \mathrm{O}_{5}$ and $\mathrm{NaNpO}_{2} \mathrm{CO}_{3}$ (for high $\mathrm{pH}$-end only) as the solubility-controlling phases for dissolved neptunium concentrations.

Efurd et al. (1998 [DIRS 108015]) conducted neptunium solubility experiments using J-13 well water at $\mathrm{pH}$ values of about $6.0,7.0$, and 8.5 at temperatures of $25^{\circ} \mathrm{C}, 60^{\circ} \mathrm{C}$, and $90^{\circ} \mathrm{C}$. These studies were conducted from both oversaturation and undersaturation to demonstrate that the steady-state concentrations attained represented equilibrium with the solid phases formed (even if these were metastable equilibrium conditions). They identified the neptunium-controlling solid using $\mathrm{x}$-ray diffraction as $\mathrm{Np}_{2} \mathrm{O}_{5} \cdot x \mathrm{H}_{2} \mathrm{O}$ and noted that the crystallinity of the solid, as shown by the sharpness of the diffraction patterns, increased with increasing temperature. These laboratory experiments were conducted over a period of about one year. Because the more crystalline form of the solid was produced in these laboratory tests at temperatures of $90^{\circ} \mathrm{C}$ after about 1 year, and (in general) reaction rates double for each 10-degree-rise in temperature, this transformation would require about 100 years at ambient temperature. For the 10,000-year regulatory period for the postclosure system, this increased crystallinity would be expected to occur even faster than 100 years because the temperature of the waste form will be elevated well above ambient temperatures in most cases. As a typical TSPA-LA time step is approximately 100 years or more (with the smallest time step being 10 years), it is expected that within one (or two) TSPA-LA timesteps, the crystalline phase would form and control the dissolved neptunium concentrations.

As outlined later in Section 6.6.3.4, the NEA thermochemical database handbook review volume on neptunium (Lemire 2001 [DIRS 159027]) recommended $-2031.6 \pm 11.2 \mathrm{~kJ} / \mathrm{mol}$ for the Gibbs free energy of formation of crystalline $\mathrm{Np}_{2} \mathrm{O}_{5}$ based on calorimetric studies. For the solubility product reaction of $\mathrm{Np}_{2} \mathrm{O}_{5}$, the procedure outlined in Section 6.3.3.1 leads to a $\log \mathrm{K}$ of 3.7 with a $2 \sigma$ uncertainty of \pm 2.8 (at $25^{\circ} \mathrm{C}$ ). Efurd et al. (1998 [DIRS 108015]) report a log K value of 5.2 
for the solubility product reaction of $\mathrm{Np}_{2} \mathrm{O}_{5} \cdot \mathrm{xH}_{2} \mathrm{O}$. This higher $\log \mathrm{K}$ value is attributed to the hydrated nature of the precipitate, which is expected to convert to crystalline $\mathrm{Np}_{2} \mathrm{O}_{5}$ solid with time due to the aging process (Efurd et al. 1998 [DIRS 108015]). This conversion would effectively lower the log K value from that reported in Efurd et al. 1998 (DIRS 108015) to that given by Lemire (2001 [DIRS 159027]). The Lemire (2001 [DIRS 159027]) value has been adopted in the Project's thermodynamic database (Data0.ymp.R2) and differs from the value obtained by Efurd et al. (1998 [DIRS 108015]) for the hydrated, amorphous phase by 1.5 units. This means that the value for the $\mathrm{Np}_{2} \mathrm{O}_{5} \cdot \mathrm{xH}_{2} \mathrm{O}$ falls within the calculated $2 \sigma$ range for the Lemire (2001 [DIRS 159027]) value that is based on the critically reviewed NEA data $( \pm 2.8)$, which is within the model uncertainty presented in Table 6.6-5.

$\mathrm{NaNpO}_{2} \mathrm{CO}_{3} \cdot \mathrm{xH}_{2} \mathrm{O}$ was observed in neptunium solubility experiments also using $\mathrm{J}-13$ well water (Nitsche et al. 1993 [DIRS 155218], p. 37). However, a detailed analysis by Runde in Pure Phase Solubility Limits-LANL (CRWMS M\&O 2001 [DIRS 154629]) found that $\mathrm{NaNpO} \mathrm{CO}_{3} \cdot \mathrm{xH}_{2} \mathrm{O}$ is stable only when $\left[\mathrm{Na}^{+}\right]$is greater than 0.05 molar at neutral $\mathrm{pH}$. Based on the x-ray diffraction data and by further analyzing the stability field for $\mathrm{Np}(\mathrm{V})$ solid phases $\left(\mathrm{Np}_{2} \mathrm{O}_{5}, \mathrm{NpO}_{2}(\mathrm{OH})\right.$, and $\left.\mathrm{NaNpO}_{2} \mathrm{CO}_{3} \cdot \mathrm{xH}_{2} \mathrm{O}\right)$, CRWMS M\&O (2001 [DIRS 154629]) concluded that $\mathrm{Np}_{2} \mathrm{O}_{5}$ is the most stable pentavalent neptunium phase in $\mathrm{J}-13$ well water under oxidizing conditions (CRWMS M\&O 2001 [DIRS 154629], p. 21). In Lemire (2001 [DIRS 159027]), equilibrium solubility product constants for both $\mathrm{NaNpO}_{2} \mathrm{CO}_{3}$ and $\mathrm{NaNpO}_{2} \mathrm{CO}_{3} \cdot 3.5 \mathrm{H}_{2} \mathrm{O}$ were given. The anhydrous phase is considered as the aging product of the hydrated solid. Given that this difference between their $\log \mathrm{K}$ is only 0.5 units, which is within the uncertainty ranges for each constant and this difference is well within the uncertainty range of the model presented in Table 6.6-5, these solids are considered to be the same from a thermochemical standpoint. In this study, $\mathrm{NaNpO}_{2} \mathrm{CO}_{3}$ is selected as the solubility-controlling solid at high $\mathrm{pH}$ at conditions where $\mathrm{Np}_{2} \mathrm{O}_{5}$ is unstable.

It is recognized that the determination of the Np-solubility-controlling phase is very complex and depends upon a number of parameters such as temperature, time, redox controls, and solution composition. However, there are numerous reasons to conclude that the Np-solubility model based on the pentavalent neptunium $(\mathrm{Np}(\mathrm{V}))$ solids described above is a very conservative representation of the possible controls on dissolved neptunium concentrations over geologic time (Section 7.2.3), further justifying the use of the more crystalline solids.

\subsubsection{EQ3NR Results}

Table 6.6-1 gives the calculated neptunium solubility (in units of $\mathrm{mg} / \mathrm{L}$ ) using $\mathrm{Np}_{2} \mathrm{O}_{5}$ as the controlling solid.

Figure 6.6-1 shows the calculated solubility using $\mathrm{Np}_{2} \mathrm{O}_{5}$ as the controlling solid as a function of $\mathrm{pH}$ and fugacity of $\mathrm{CO}_{2}$. Under the same $f \mathrm{CO}_{2}$, neptunium solubility increases with $\mathrm{pH}$ under alkaline conditions; while under acid conditions, it increases with decrease in $\mathrm{pH}$. Note the insensitivity to $f \mathrm{CO}_{2}$ on the acid leg, but extreme sensitivity on the basic leg. 
Dissolved Concentration Limits of Radioactive Elements

Table 6.6-1. Calculated $\mathrm{Np}_{2} \mathrm{O}_{5}$ Solubility (mg/L)

\begin{tabular}{|c|c|c|c|c|c|c|c|c|}
\hline \multirow[b]{2}{*}{ pH } & \multicolumn{8}{|c|}{$\log \mathrm{fCO}_{2}$ (bars) } \\
\hline & -1.50 & -2.00 & -2.50 & -3.00 & -3.50 & -4.00 & -4.50 & -5.00 \\
\hline 3.00 & $2.40 \mathrm{E}+04$ & $2.40 \mathrm{E}+04$ & $2.40 \mathrm{E}+04$ & $2.40 E+04$ & $2.40 \mathrm{E}+04$ & $2.40 \mathrm{E}+04$ & $2.40 E+04$ & $2.40 E+04$ \\
\hline 3.25 & $1.25 \mathrm{E}+04$ & $1.25 E+04$ & $1.25 E+04$ & $1.25 \mathrm{E}+04$ & $1.25 E+04$ & $1.25 E+04$ & $1.25 E+04$ & $1.25 \mathrm{E}+04$ \\
\hline 3.50 & $6.65 \mathrm{E}+03$ & $6.65 E+03$ & $6.65 \mathrm{E}+03$ & $6.65 \mathrm{E}+03$ & $6.65 \mathrm{E}+03$ & $6.65 \mathrm{E}+03$ & $6.65 \mathrm{E}+03$ & $6.65 \mathrm{E}+03$ \\
\hline 3.75 & $3.57 E+03$ & $3.57 E+03$ & $3.57 E+03$ & $3.57 \mathrm{E}+03$ & $3.57 E+03$ & $3.57 \mathrm{E}+03$ & $3.57 E+03$ & $3.57 E+03$ \\
\hline 4.00 & $1.94 E+03$ & $1.94 E+03$ & $1.94 \mathrm{E}+03$ & $1.94 \mathrm{E}+03$ & $1.94 \mathrm{E}+03$ & $1.94 E+03$ & $1.94 E+03$ & $1.94 E+03$ \\
\hline 4.25 & $1.07 E+03$ & $1.07 E+03$ & $1.07 \mathrm{E}+03$ & $1.07 \mathrm{E}+03$ & $1.07 E+03$ & $1.07 E+03$ & $1.07 \mathrm{E}+03$ & $1.07 E+03$ \\
\hline 4.50 & $5.90 \mathrm{E}+02$ & $5.90 \mathrm{E}+02$ & $5.90 \mathrm{E}+02$ & $5.90 \mathrm{E}+02$ & $5.90 \mathrm{E}+02$ & $5.90 \mathrm{E}+02$ & $5.90 \mathrm{E}+02$ & $5.90 \mathrm{E}+02$ \\
\hline 4.75 & $3.28 \mathrm{E}+02$ & $3.29 \mathrm{E}+02$ & $3.29 \mathrm{E}+02$ & $3.29 \mathrm{E}+02$ & $3.29 \mathrm{E}+02$ & $3.29 \mathrm{E}+02$ & $3.29 \mathrm{E}+02$ & $3.29 \mathrm{E}+02$ \\
\hline 5.00 & $1.84 \mathrm{E}+02$ & $1.84 \mathrm{E}+02$ & $1.84 \mathrm{E}+02$ & $1.84 \mathrm{E}+02$ & $1.84 \mathrm{E}+02$ & $1.84 \mathrm{E}+02$ & $1.84 \mathrm{E}+02$ & $1.84 \mathrm{E}+02$ \\
\hline 5.25 & $1.03 E+02$ & $1.03 E+02$ & $1.03 E+02$ & $1.03 E+02$ & $1.03 E+02$ & $1.03 \mathrm{E}+02$ & $1.03 E+02$ & $1.03 E+02$ \\
\hline 5.50 & $5.77 \mathrm{E}+01$ & $5.77 \mathrm{E}+01$ & $5.77 \mathrm{E}+01$ & $5.77 \mathrm{E}+01$ & 5.77E+01 & $5.77 \mathrm{E}+01$ & $5.77 \mathrm{E}+01$ & $5.77 E+01$ \\
\hline 5.75 & $3.24 \mathrm{E}+01$ & $3.24 \mathrm{E}+01$ & $3.24 \mathrm{E}+01$ & $3.24 \mathrm{E}+01$ & $3.24 E+01$ & $3.24 \mathrm{E}+01$ & $3.24 \mathrm{E}+01$ & $3.24 \mathrm{E}+01$ \\
\hline 6.00 & $1.82 \mathrm{E}+01$ & $1.82 \mathrm{E}+01$ & $1.82 \mathrm{E}+01$ & $1.82 \mathrm{E}+01$ & \begin{tabular}{|l}
$1.82 \mathrm{E}+01$ \\
\end{tabular} & $1.82 \mathrm{E}+01$ & $1.82 \mathrm{E}+01$ & $1.82 \mathrm{E}+01$ \\
\hline 6.25 & $1.03 E+01$ & $1.02 E+01$ & $1.02 E+01$ & $1.02 \mathrm{E}+01$ & $1.02 E+01$ & $1.02 \mathrm{E}+01$ & $1.02 E+01$ & $1.02 E+01$ \\
\hline 6.50 & $5.83 \mathrm{E}+00$ & $5.78 \mathrm{E}+00$ & $5.77 \mathrm{E}+00$ & $5.76 \mathrm{E}+00$ & $5.76 \mathrm{E}+00$ & $5.76 \mathrm{E}+00$ & $5.76 \mathrm{E}+00$ & $5.76 \mathrm{E}+00$ \\
\hline 6.75 & $3.43 \mathrm{E}+00$ & $3.29 \mathrm{E}+00$ & $3.25 \mathrm{E}+00$ & $3.24 \mathrm{E}+00$ & $3.24 \mathrm{E}+00$ & $3.24 \mathrm{E}+00$ & $3.24 \mathrm{E}+00$ & $3.24 \mathrm{E}+00$ \\
\hline 7.00 & $2.22 \mathrm{E}+00$ & $1.92 E+00$ & $1.85 \mathrm{E}+00$ & $1.83 \mathrm{E}+00$ & $1.82 E+00$ & $1.82 \mathrm{E}+00$ & $1.82 \mathrm{E}+00$ & $1.82 \mathrm{E}+00$ \\
\hline 7.25 & $1.74 \mathrm{E}+00$ & $1.23 E+00$ & $1.08 \mathrm{E}+00$ & $1.04 \mathrm{E}+00$ & $1.03 \mathrm{E}+00$ & $1.03 \mathrm{E}+00$ & $1.02 \mathrm{E}+00$ & $1.02 \mathrm{E}+00$ \\
\hline 7.50 & $1.89 \mathrm{E}+00$ & 9.56E-01 & 6.87E-01 & $6.11 \mathrm{E}-01$ & 5.87E-01 & 5.79E-01 & 5.77E-01 & 5.76E-01 \\
\hline 7.75 & $2.86 \mathrm{E}+00$ & $1.02 E+00$ & 5.29E-01 & $3.87 \mathrm{E}-01$ & $3.44 \mathrm{E}-01$ & 3.30E-01 & $3.26 \mathrm{E}-01$ & $3.24 \mathrm{E}-01$ \\
\hline 8.00 & $3.41 E+00$ & $1.48 \mathrm{E}+00$ & 5.59E-01 & $2.96 \mathrm{E}-01$ & 2.18E-01 & 1.94E-01 & $1.86 \mathrm{E}-01$ & 1.83E-01 \\
\hline 8.25 & - & $2.81 E+00$ & 7.96E-01 & $3.08 \mathrm{E}-01$ & \begin{tabular}{|l}
$1.67 \mathrm{E}-01$ \\
\end{tabular} & 1.23E-01 & 1.09E-01 & $1.04 \mathrm{E}-01$ \\
\hline 8.50 & - & $1.01 E+01$ & $1.40 \mathrm{E}+00$ & 4.35E-01 & $1.72 \mathrm{E}-01$ & 9.39E-02 & $6.91 \mathrm{E}-02$ & $6.13 \mathrm{E}-02$ \\
\hline 8.75 & - & - & $3.45 \mathrm{E}+00$ & \begin{tabular}{|l|}
$7.41 \mathrm{E}-01$ \\
\end{tabular} & \begin{tabular}{|l|}
$2.40 \mathrm{E}-01$ \\
\end{tabular} & $9.70 \mathrm{E}-02$ & $5.29 \mathrm{E}-02$ & $3.89 \mathrm{E}-02$ \\
\hline 9.00 & - & - & - & $1.54 \mathrm{E}+00$ & \begin{tabular}{|l|}
$4.02 E-01$ \\
\end{tabular} & 1.33E-01 & $5.46 \mathrm{E}-02$ & $2.98 \mathrm{E}-02$ \\
\hline 9.25 & - & - & - & $6.59 \mathrm{E}+00$ & $7.80 \mathrm{E}-01$ & 2.22E-01 & 7.51E-02 & $3.08 \mathrm{E}-02$ \\
\hline 9.50 & - & - & - & - & $2.36 \mathrm{E}+00$ & 4.16E-01 & $1.23 \mathrm{E}-01$ & $4.23 \mathrm{E}-02$ \\
\hline 9.75 & - & - & - & - & - & $1.05 \mathrm{E}+00$ & $2.27 \mathrm{E}-01$ & $6.88 \mathrm{E}-02$ \\
\hline 10.00 & - & - & - & - & - & $9.04 \mathrm{E}+00$ & 5.27E-01 & 1.26E-01 \\
\hline 10.25 & - & - & - & - & - & - & $3.34 \mathrm{E}+00$ & $2.80 \mathrm{E}-01$ \\
\hline 10.50 & - & - & - & - & - & - & - & $1.48 \mathrm{E}+00$ \\
\hline
\end{tabular}

Source: Np base case-Ehadjusted.xls (Appendix I).

NOTE: Some cells have no data because the EQ3NR calculations do not converge (Section 6.4.4).

Under the modeled conditions, depending on $f \mathrm{CO}_{2}, \mathrm{~Np}_{2} \mathrm{O}_{5}$ becomes unstable when $\mathrm{pH}$ increases and $\mathrm{NaNpO}_{2} \mathrm{CO}_{3}$ becomes a stable phase. Table 6.6-2 lists calculated $\mathrm{Np}$ solubility for conditions where $\mathrm{Np}_{2} \mathrm{O}_{5}$ is unstable and $\mathrm{NaNpO}_{2} \mathrm{CO}_{3}$ is stable. It clearly shows that the stability field of $\mathrm{NaNpO}_{2} \mathrm{CO}_{3}$ is quite narrow (about a 0.25 to $0.5 \mathrm{pH}$ unit). These solubilities are shown separately from those controlled by $\mathrm{Np}_{2} \mathrm{O}_{5}$ because they are the results of different EQ3 calculations. 


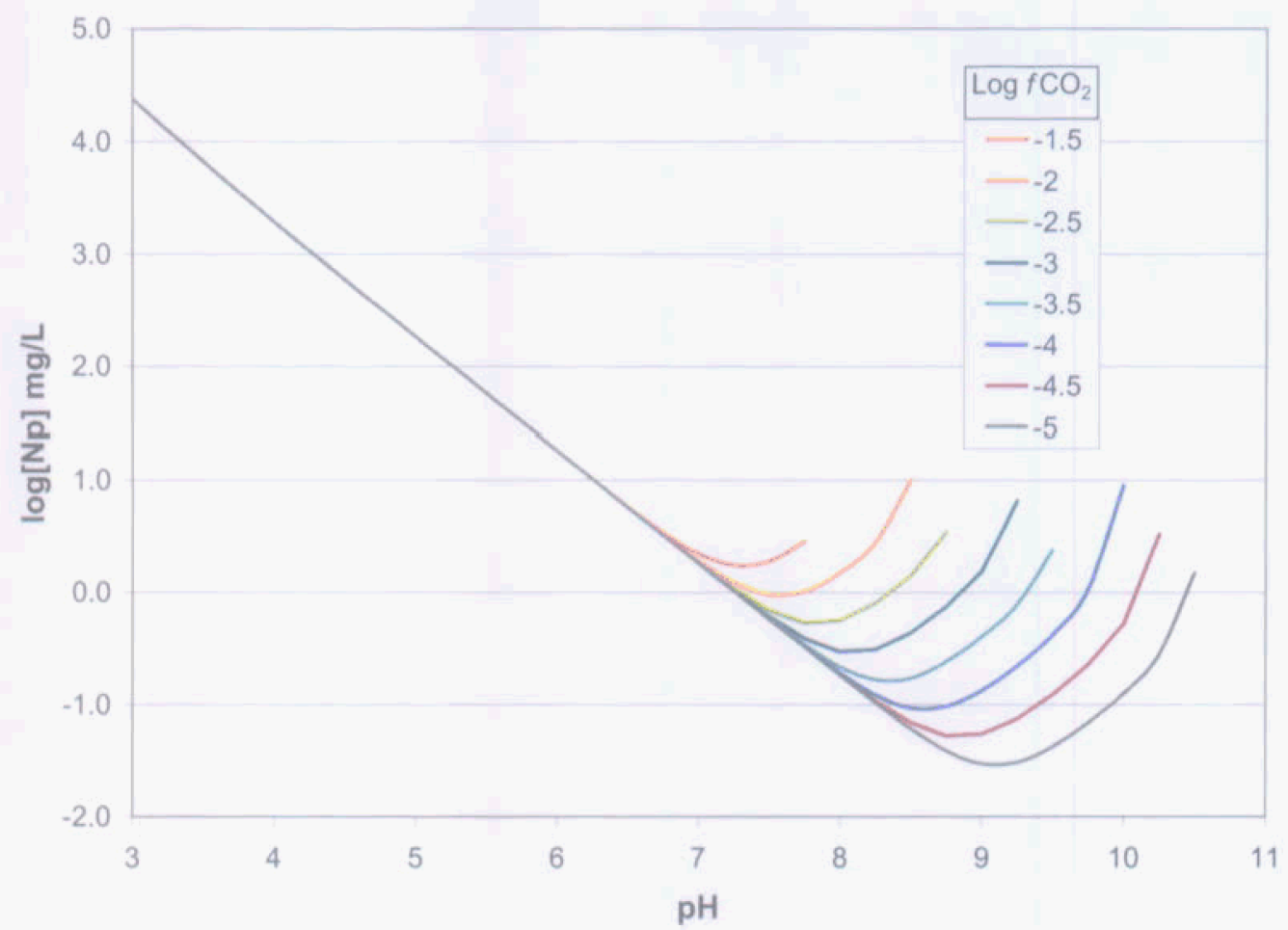

Source: Np base case-Ehadjusted.xls (Appendix 1).

Figure 6.6-1. $\mathrm{Np}_{2} \mathrm{O}_{5}$ Solubility Modeled as a Function of $\mathrm{pH}$ and $\log f \mathrm{CO}_{2}$

Table 6.6-2. Calculated $\mathrm{Np}$ Solubility Using $\mathrm{NaNpO}_{2} \mathrm{CO}_{3}$. as the Controlling Phase ([Np] mg/L)

\begin{tabular}{|c|c|c|c|c|c|c|c|}
\hline \multirow{2}{*}{$\mathrm{pH}$} & \multicolumn{7}{|c|}{$\log f \mathrm{CO}_{2}$ (bars) } \\
\hline & -1.5 & -2.0 & -2.5 & -3.0 & -3.5 & -4.0 & -4.5 \\
\hline 8.25 & $3.96 \mathrm{E}+00$ & & & \multirow{6}{*}{\multicolumn{2}{|c|}{$\mathrm{Np}_{2} \mathrm{O}_{5}$ controlled }} & & \\
\hline 8.50 & 2. $66 \mathrm{E}+01$ & & & & & & \\
\hline 8.75 & & 1.15E+01 & & & & & \\
\hline 9.00 & & & $6.21 \mathrm{E}+00$ & & & & \\
\hline 9.25 & & & & & & & \\
\hline 9.50 & & & & & & & \\
\hline 9.75 & & & & & 1.32E+01 & & \\
\hline 10.00 & & & & & & & \\
\hline 10.25 & & & & & & $9.17 E+01$ & \\
\hline 10.50 & & & & & & & $5.72 E+01$ \\
\hline
\end{tabular}

Source: Np base case-Ehadjusted.xls in Appendix I.

Figures 6.6-2 and 6.6-3 show concentrations of total dissolved $\mathrm{Np}$ and of aqueous species contributing to that concentration calculated at $f \mathrm{CO}_{2}=10^{-3.0}$ bars, expressed as molalities and percent total $\mathrm{Np}$, respectively. The figures span the $\mathrm{pH}$ range from 3 to 10 . 


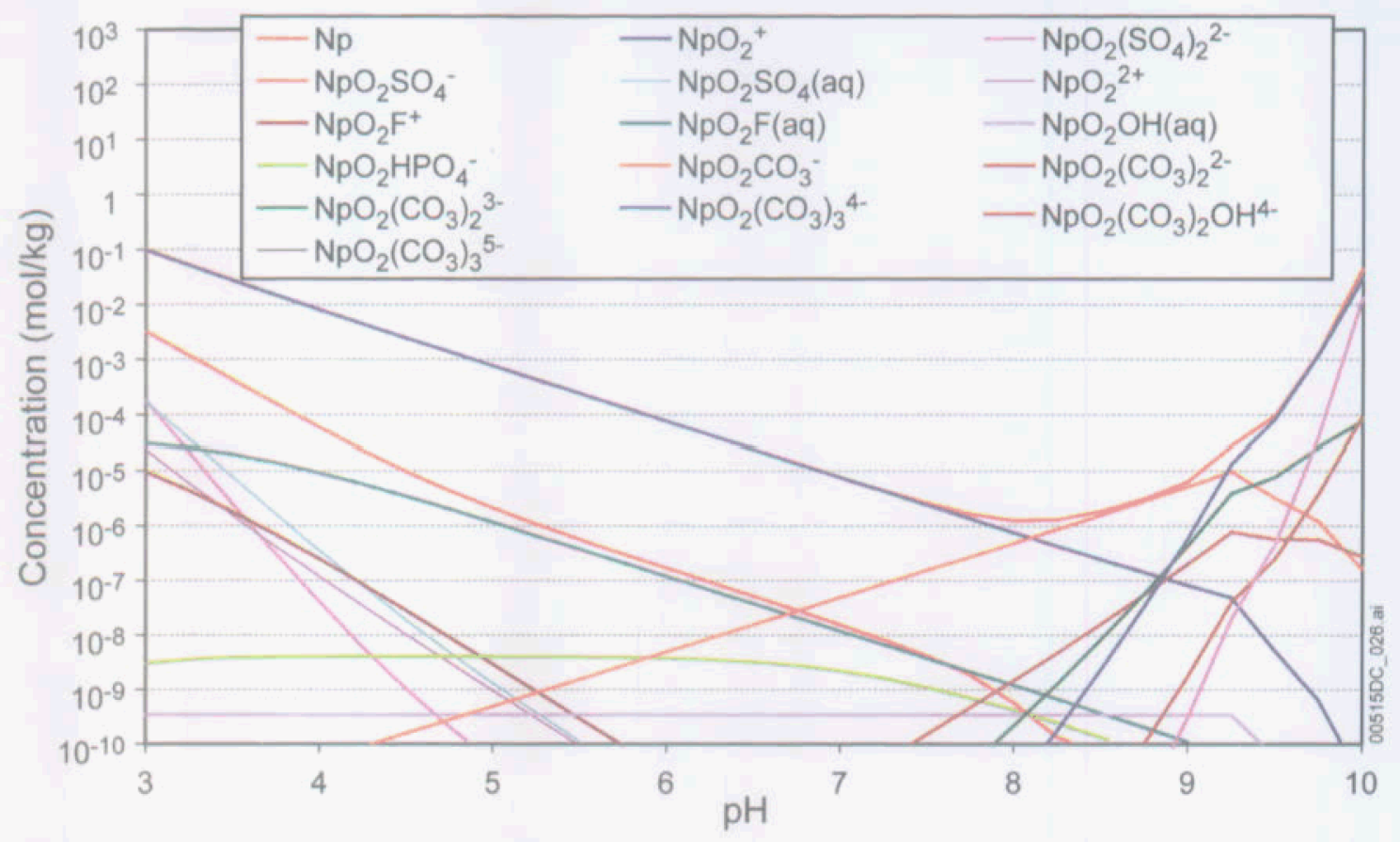

Source: Np adj Eh species plot.xls (Appendix I).

Figure 6.6-2. Molal Concentrations of Total $\mathrm{Np}$ and of Np Aqueous Complex Species in at $\log \mathrm{fCO}_{2}$ (bars) $=-3.0$

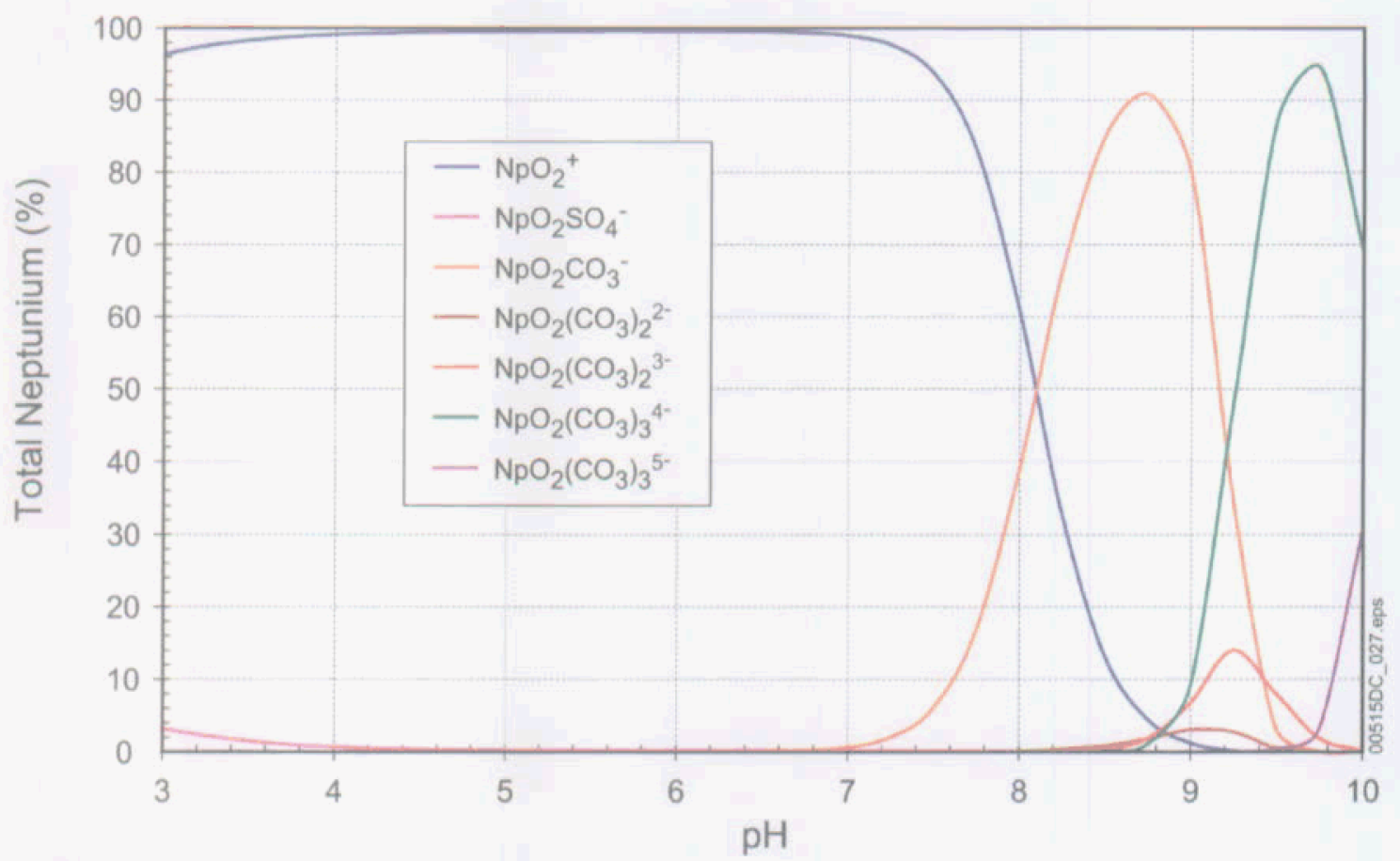

Source: Np adj Eh species plot.xls (Appendix I).

Figure 6.6-3. Relative Concentrations of Np Aqueous Complex Species as Percent of Total Dissolved Np at $\log f \mathrm{CO}_{2}$ (bars) $=-3.0$ 
As these figures show, at $f \mathrm{CO}_{2}$ equal to $10^{-3}, \mathrm{~Np}$ is principally in the $\mathrm{Np}(\mathrm{V})$ oxidation state with $\mathrm{NpO}_{2}{ }^{+}$the dominant aqueous species for $\mathrm{pH}$ values from 3 to approximately 8 . At $\mathrm{pH}$ values above 8 , virtually all the dissolved $\mathrm{Np}$ is present as carbonate complexes including $\mathrm{NpO}_{2} \mathrm{CO}_{3}^{-}$, $\mathrm{NpO}_{2}\left(\mathrm{CO}_{3}\right)_{3}{ }^{4-}, \mathrm{NpO}_{2}\left(\mathrm{CO}_{3}\right)_{3}{ }^{5-}, \mathrm{NpO}_{2}\left(\mathrm{CO}_{3}\right)_{2}{ }^{3-}, \mathrm{NpO}_{2}\left(\mathrm{CO}_{3}\right)_{2}{ }^{4-}$, and $\mathrm{NpO}_{2}\left(\mathrm{CO}_{3}\right)_{2} \mathrm{OH}^{4-}$. Figure 6.63 shows that $\mathrm{NpO}_{2} \mathrm{CO}_{3}{ }^{-}$is the primary carbonate species between a pH of 8 to 9 and from 9 to 10 is dominated by $\mathrm{NpO}_{2}\left(\mathrm{CO}_{3}\right)_{3}{ }^{4-}$. At a $\mathrm{pH}$ of 9, the dominant redox state also shifts from $\mathrm{Np}(\mathrm{V})$ to $\mathrm{Np}(\mathrm{VI})$ as the principal species become $\mathrm{Np}(\mathrm{VI})$ carbonate complexes as indicated by Figure 6.6-3.

\subsubsection{Abstraction}

Combining the calculated-Np solubility using $\mathrm{Np}_{2} \mathrm{O}_{5}$ as the controlling phase (Table 6.6-1) and that using $\mathrm{NaNpO}_{2} \mathrm{CO}_{3}$ (Table 6.6-2), Table 6.6-3 is presented for use in TSPA-LA. The logarithm of solubility values is given here to facilitate interpolation that may be needed by the user, because the independent variables of the table are in log scales.

For those calculations that do not converge or are not valid, a large number (500) is entered to flag that under such $\mathrm{pH}$ and $\mathrm{fCO}_{2}$ conditions, solubility of neptunium is not defined or the calculation results are outside the valid range of the computing tool. The user of the table needs to ensure that when the flag (500) is encountered, the concentrations are calculated according to the dissolution rate of individual waste forms, water volume, and the solubility caps presented in Table 8-5 should be used instead of the flag itself. For any conditions that fall between a valid solubility and a flag of 500, the flag should be used. In addition, for any conditions outside of the 3.0 to $11.0 \mathrm{pH}$ range, or the $f \mathrm{CO}_{2}$ range from $10^{-1.5}$ to $10^{-5.0}$ bars, the concentrations calculated according to the dissolution rate of individual waste forms, water volume, and the solubility caps presented in Table 8-5. 
Table 6.6-3. $\mathrm{Np}_{2} \mathrm{O}_{5}-\mathrm{NaNpO}_{2} \mathrm{CO}_{3}$ Solubility (log[Np], mg/L)

\begin{tabular}{|c|c|c|c|c|c|c|c|c|}
\hline \multirow{2}{*}{ pH } & \multicolumn{8}{|c|}{ Log $f \mathrm{CO}_{2}$ (bars) } \\
\hline & -1.5 & -2.0 & -2.5 & -3.0 & -3.5 & -4.0 & -4.5 & -5.0 \\
\hline 3.00 & $4.38 \mathrm{E}+00$ & $4.38 \mathrm{E}+00$ & $4.38 \mathrm{E}+00$ & $4.38 E+00$ & $4.38 \mathrm{E}+00$ & $4.38 \mathrm{E}+00$ & $4.38 \mathrm{E}+00$ & $4.38 E+00$ \\
\hline 3.25 & 4.10E+00 & $4.10 \mathrm{E}+00$ & $4.10 \mathrm{E}+00$ & $4.10 \mathrm{E}+00$ & $4.10 \mathrm{E}+00$ & $4.10 E+00$ & $4.10 \mathrm{E}+00$ & $4.10 \mathrm{E}+00$ \\
\hline 3.50 & $3.82 \mathrm{E}+00$ & $3.82 \mathrm{E}+00$ & $3.82 E+00$ & $3.82 \mathrm{E}+00$ & $3.82 \mathrm{E}+00$ & $3.82 \mathrm{E}+00$ & $3.82 \mathrm{E}+00$ & $3.82 \mathrm{E}+00$ \\
\hline 3.75 & $3.55 E+00$ & $3.55 \mathrm{E}+00$ & $3.55 \mathrm{E}+00$ & $3.55 \mathrm{E}+00$ & $3.55 \mathrm{E}+00$ & $3.55 E+00$ & $3.55 E+00$ & $3.55 \mathrm{E}+00$ \\
\hline 4.00 & $3.29 \mathrm{E}+00$ & $3.29 \mathrm{E}+00$ & $3.29 \mathrm{E}+00$ & $3.29 \mathrm{E}+00$ & $3.29 \mathrm{E}+00$ & $3.29 \mathrm{E}+00$ & $3.29 \mathrm{E}+00$ & $3.29 \mathrm{E}+00$ \\
\hline 4.25 & $3.03 E+00$ & $3.03 E+00$ & $3.03 \mathrm{E}+00$ & $3.03 \mathrm{E}+00$ & $3.03 E+00$ & $3.03 \mathrm{E}+00$ & $3.03 E+00$ & $3.03 E+00$ \\
\hline 4.50 & $2.77 \mathrm{E}+00$ & $2.77 \mathrm{E}+00$ & $2.77 \mathrm{E}+00$ & $2.77 \mathrm{E}+00$ & $2.77 \mathrm{E}+00$ & $2.77 \mathrm{E}+00$ & $2.77 \mathrm{E}+00$ & $2.77 E+00$ \\
\hline 4.75 & $2.52 \mathrm{E}+00$ & $2.52 \mathrm{E}+00$ & $2.52 \mathrm{E}+00$ & $2.52 \mathrm{E}+00$ & $2.52 \mathrm{E}+00$ & $2.52 \mathrm{E}+00$ & $2.52 \mathrm{E}+00$ & $2.52 \mathrm{E}+00$ \\
\hline 5.00 & $2.26 \mathrm{E}+00$ & $2.26 \mathrm{E}+00$ & $2.26 \mathrm{E}+00$ & $2.26 \mathrm{E}+00$ & $2.26 \mathrm{E}+00$ & $2.26 \mathrm{E}+00$ & $2.26 \mathrm{E}+00$ & $2.26 \mathrm{E}+00$ \\
\hline 5.25 & $2.01 \mathrm{E}+00$ & $2.01 \mathrm{E}+00$ & $2.01 E+00$ & $2.01 \mathrm{E}+00$ & $2.01 \mathrm{E}+00$ & $2.01 E+00$ & $2.01 \mathrm{E}+00$ & $2.01 \mathrm{E}+00$ \\
\hline 5.50 & $1.76 \mathrm{E}+00$ & $1.76 \mathrm{E}+00$ & $1.76 \mathrm{E}+00$ & $1.76 \mathrm{E}+00$ & $1.76 \mathrm{E}+00$ & $1.76 \mathrm{E}+00$ & $1.76 \mathrm{E}+00$ & $1.76 \mathrm{E}+00$ \\
\hline 5.75 & $1.51 \mathrm{E}+00$ & $1.51 E+00$ & $1.51 \mathrm{E}+00$ & $1.51 \mathrm{E}+00$ & $1.51 \mathrm{E}+00$ & $1.51 \mathrm{E}+00$ & $1.51 E+00$ & $1.51 \mathrm{E}+00$ \\
\hline 6.00 & $1.26 \mathrm{E}+00$ & $1.26 \mathrm{E}+00$ & $1.26 \mathrm{E}+00$ & $1.26 \mathrm{E}+00$ & $1.26 \mathrm{E}+00$ & $1.26 \mathrm{E}+00$ & $1.26 \mathrm{E}+00$ & $1.26 \mathrm{E}+00$ \\
\hline 6.25 & $1.01 \mathrm{E}+00$ & $1.01 \mathrm{E}+00$ & $1.01 \mathrm{E}+00$ & $1.01 \mathrm{E}+00$ & $1.01 \mathrm{E}+00$ & $1.01 \mathrm{E}+00$ & $1.01 \mathrm{E}+00$ & $1.01 \mathrm{E}+00$ \\
\hline 6.50 & $7.66 \mathrm{E}-01$ & 7.62E-01 & 7.61E-01 & $7.60 \mathrm{E}-01$ & $7.60 \mathrm{E}-01$ & $7.60 \mathrm{E}-01$ & $7.60 \mathrm{E}-01$ & $7.60 \mathrm{E}-01$ \\
\hline 6.75 & $5.35 \mathrm{E}-01$ & 5.17E-01 & 5.12E-01 & 5.11E-01 & $5.10 \mathrm{E}-01$ & $5.10 \mathrm{E}-01$ & $5.10 \mathrm{E}-01$ & $5.10 \mathrm{E}-01$ \\
\hline 7.00 & $3.46 \mathrm{E}-01$ & 2.84E-01 & $2.68 \mathrm{E}-01$ & 2.63E-01 & 2.61E-01 & $2.60 \mathrm{E}-01$ & 2.60E-01 & $2.60 \mathrm{E}-01$ \\
\hline 7.25 & 2.41E-01 & 8.83E-02 & $3.52 \mathrm{E}-02$ & $1.83 \mathrm{E}-02$ & $1.28 \mathrm{E}-02$ & $1.11 \mathrm{E}-02$ & $1.05 \mathrm{E}-02$ & $1.03 E-02$ \\
\hline 7.50 & $2.76 \mathrm{E}-01$ & $-1.94 \mathrm{E}-02$ & $-1.63 \mathrm{E}-01$ & $-2.14 \mathrm{E}-01$ & $-2.31 \mathrm{E}-01$ & $-2.37 \mathrm{E}-01$ & $-2.39 \mathrm{E}-01$ & $-2.39 E-01$ \\
\hline 7.75 & 4.56E-01 & 8.77E-03 & $-2.77 \mathrm{E}-01$ & $-4.12 \mathrm{E}-01$ & $-4.64 \mathrm{E}-01$ & $-4.81 \mathrm{E}-01$ & $-4.87 \mathrm{E}-01$ & $-4.89 \mathrm{E}-01$ \\
\hline 8.00 & $5.33 \mathrm{E}-01$ & $1.71 \mathrm{E}-01$ & $-2.53 E-01$ & $-5.29 E-01$ & $-6.61 E-01$ & $-7.13 \mathrm{E}-01$ & $-7.31 \mathrm{E}-01$ & $-7.37 \mathrm{E}-01$ \\
\hline 8.25 & $5.98 \mathrm{E}-01$ & 4.49E-01 & $-9.89 \mathrm{E}-02$ & $-5.11 E-01$ & $-7.78 \mathrm{E}-01$ & $-9.11 E-01$ & $-9.63 E-01$ & $-9.81 E-01$ \\
\hline 8.50 & $1.42 \mathrm{E}+00$ & $1.00 \mathrm{E}+00$ & 1.47E-01 & $-3.62 \mathrm{E}-01$ & $-7.64 \mathrm{E}-01$ & $-1.03 E+00$ & $-1.16 \mathrm{E}+00$ & $-1.21 E+00$ \\
\hline 8.75 & 500 & $1.06 \mathrm{E}+00$ & $5.38 \mathrm{E}-01$ & $-1.30 \mathrm{E}-01$ & $-6.20 \mathrm{E}-01$ & $-1.01 E+00$ & $-1.28 \mathrm{E}+00$ & $-1.41 \mathrm{E}+00$ \\
\hline 9.00 & 500 & 500 & $7.93 \mathrm{E}-01$ & $1.89 \mathrm{E}-01$ & $-3.95 \mathrm{E}-01$ & $-8.75 E-01$ & $-1.26 E+00$ & $-1.53 \mathrm{E}+00$ \\
\hline 9.25 & 500 & 500 & 500 & $8.19 \mathrm{E}-01$ & $-1.08 \mathrm{E}-01$ & $-6.54 \mathrm{E}-01$ & $-1.12 E+00$ & $-1.51 \mathrm{E}+00$ \\
\hline 9.50 & 500 & 500 & 500 & $1.36 \mathrm{E}+00$ & 3.72E-01 & $-3.81 \mathrm{E}-01$ & $-9.10 \mathrm{E}-01$ & $-1.37 E+00$ \\
\hline 9.75 & 500 & 500 & 500 & 500 & $1.12 \mathrm{E}+00$ & $2.16 \mathrm{E}-02$ & $-6.44 \mathrm{E}-01$ & $-1.16 \mathrm{E}+00$ \\
\hline 10.00 & 500 & 500 & 500 & 500 & 500 & 9.56E-01 & $-2.78 \mathrm{E}-01$ & $-9.00 E-01$ \\
\hline 10.25 & 500 & 500 & 500 & 500 & 500 & $1.96 \mathrm{E}+00$ & $5.24 \mathrm{E}-01$ & $-5.52 E-01$ \\
\hline 10.50 & 500 & 500 & 500 & 500 & 500 & 500 & $1.76 \mathrm{E}+00$ & 1.72E-01 \\
\hline
\end{tabular}

Source: Np base case-Ehadjusted.xls (Appendix I).

NOTE: Some cells have no valid solubility values because the EQ3NR calculations do not converge, and those calculations results are reported as 500 (Section 6.4.4). 


\subsubsection{Uncertainties}

This section discusses uncertainties of the Eh-adjusted Np-solubility model.

\subsection{Uncertainties in log $\mathrm{K}$ Values of Controlling Solid and Aqueous Species}

The uncertainty in solubility involves uncertainties in the thermodynamic properties of both the controlling solid and significant dissolved species. The rationale behind the evaluation and combination of these uncertainties are discussed in some detail in Section 6.3.3.1.

The dissolved species accounting for more than 10 percent of the total dissolved neptunium were found by inspection of Figure 6.6-3. They are $\mathrm{NpO}_{2}{ }^{+}, \mathrm{NpO}_{2} \mathrm{CO}_{3}{ }^{-}, \mathrm{NpO}_{2}\left(\mathrm{CO}_{3}\right)_{3}{ }^{4-}, \mathrm{NpO}_{2}\left(\mathrm{CO}_{3}\right)_{2}{ }^{3-}$, and $\mathrm{NpO}_{2}\left(\mathrm{CO}_{3}\right)_{3}{ }^{5-}$,

After an extensive review, Lemire (2001 [DIRS 159027]) recommended -2,031.6 $\pm 11.2 \mathrm{~kJ} / \mathrm{mol}$ for the Gibbs free energy of formation of $\mathrm{Np}_{2} \mathrm{O}_{5}$ based on calorimetric studies. The procedure outlined in Section 6.3.3.1 leads to a $\log \mathrm{K}$ of 3.7 with a $2 \sigma$ uncertainty of \pm 2.8 (at $25^{\circ} \mathrm{C}$ ) for the reaction:

$$
\mathrm{Np}_{2} \mathrm{O}_{5}+2 \mathrm{H}^{+}=2 \mathrm{NpO}_{2}^{+}+\mathrm{H}_{2} \mathrm{O}
$$

This $\log \mathrm{K}$ value is adopted in Data0.ymp.R2. Efurd et al. (1998 [DIRS 108015]) report a $\log \mathrm{K}$ value of 5.2 for the reaction presented in Equation 6.6-1 based on solubility experiments using $\mathrm{J}-13$ well water. This higher $\log \mathrm{K}$ value is attributed to the hydrated nature of the precipitate, which is expected to become a crystalline solid with time due to the aging process. The difference between the $\log \mathrm{K}$ value adopted in Data0.ymp.R2 and the value obtained by Efurd et al. (1998 [DIRS 108015]) is 1.5. This is within the calculated $2 \sigma$ range based on the NEA data $( \pm 2.8)$.

An evaluation of reactions from $\mathrm{Np}_{2} \mathrm{O}_{5}$ to each of the six dissolved species noted earlier leads to a maximum uncertainty in $\log \mathrm{K}$ of \pm 2.83 for reaction of $\mathrm{Np}_{2} \mathrm{O}_{5}$ to $\mathrm{NpO}_{2}\left(\mathrm{CO}_{3}\right)_{3}{ }^{4-}$. This applies at $\mathrm{pH}$ above about 7 . For lower $\mathrm{pH}$ values, $\mathrm{NpO}_{2}{ }^{+}$prevails with a $\log \mathrm{K}$ uncertainty of \pm 2.78 . Conservatively, the higher of these is chosen to represent all neptunium solubilities.

The selected $\mathrm{Np}_{2} \mathrm{O}_{5}$ dissolution reaction discussed in the previous paragraph, which has a $2 \sigma$ uncertainty in $\log K$ of \pm 3.0 (rounded up from 2.83), produces 2 moles of neptunium in solution per $\mathrm{Np}_{2} \mathrm{O}_{5}$ formula unit. The uncertainty of the $\log \mathrm{K}$ of this reaction per mol neptunium is half this value, or \pm 1.5 . This is a $2 \sigma$ uncertainty, so the $1 \sigma$ uncertainty to be applied to $\log [\mathrm{Np}]$ is \pm 0.8 .

The uncertainty of $\log \mathrm{K}$ for $\mathrm{NaNpO}_{2} \mathrm{CO}_{3}$ dissolution reaction:

$$
\mathrm{NaNpO}_{2} \mathrm{CO}_{3}=\mathrm{Na}^{+}+\mathrm{NpO}_{2}^{+}+\mathrm{CO}_{3}{ }^{2-}
$$

given by Lemire (2001 [DIRS 159027]) is $\pm 0.501(2 \sigma)$, which is much smaller than the uncertainty in $\log \mathrm{K}$ for $\mathrm{Np}_{2} \mathrm{O}_{5}$ dissolution reaction. Thus, the uncertainty in $\log \mathrm{K}$ of $\mathrm{NaNpO}_{2} \mathrm{CO}_{3}$ would not affect the overall uncertainty of the model calculation. 


\subsection{Uncertainty from Fluoride Concentration}

Table 6.6-4 lists the calculated logarithm of $\mathrm{Np}_{2} \mathrm{O}_{5}$ solubilities using the fluoride levels indicated in Table 6.3-3, (10 times base case for CSNF waste packages and 27 and 95 times for codisposal waste packages and the invert). The fugacity of $\mathrm{CO}_{2}$ is set to $10^{-3.0}$. The differences between the base-case results and the uncertainty case results vary with $\mathrm{pH}$. The three right hand columns are the differences between the respective elevated $F^{*}$ cases and the base case. The maximum difference between the base-case results and the $10 \times$ fluoride results expressed as $\log [\mathrm{Np}]$ is $\mathbf{0 . 0 1 0}$. The maximum uncertainty for fluoride is for codisposal waste packages (vapor influx scenario) and the invert, the uncertainty term $\varepsilon_{2}$ CDSP-vapor influx expressed as $\log [\mathrm{Np}]$ is 0.079 . Unlike uranium, neptunium solubility is not very sensitive to fluoride concentration.

Table 6.6-4. The Effects of Variations in Fluoride Concentration on Np Solubility

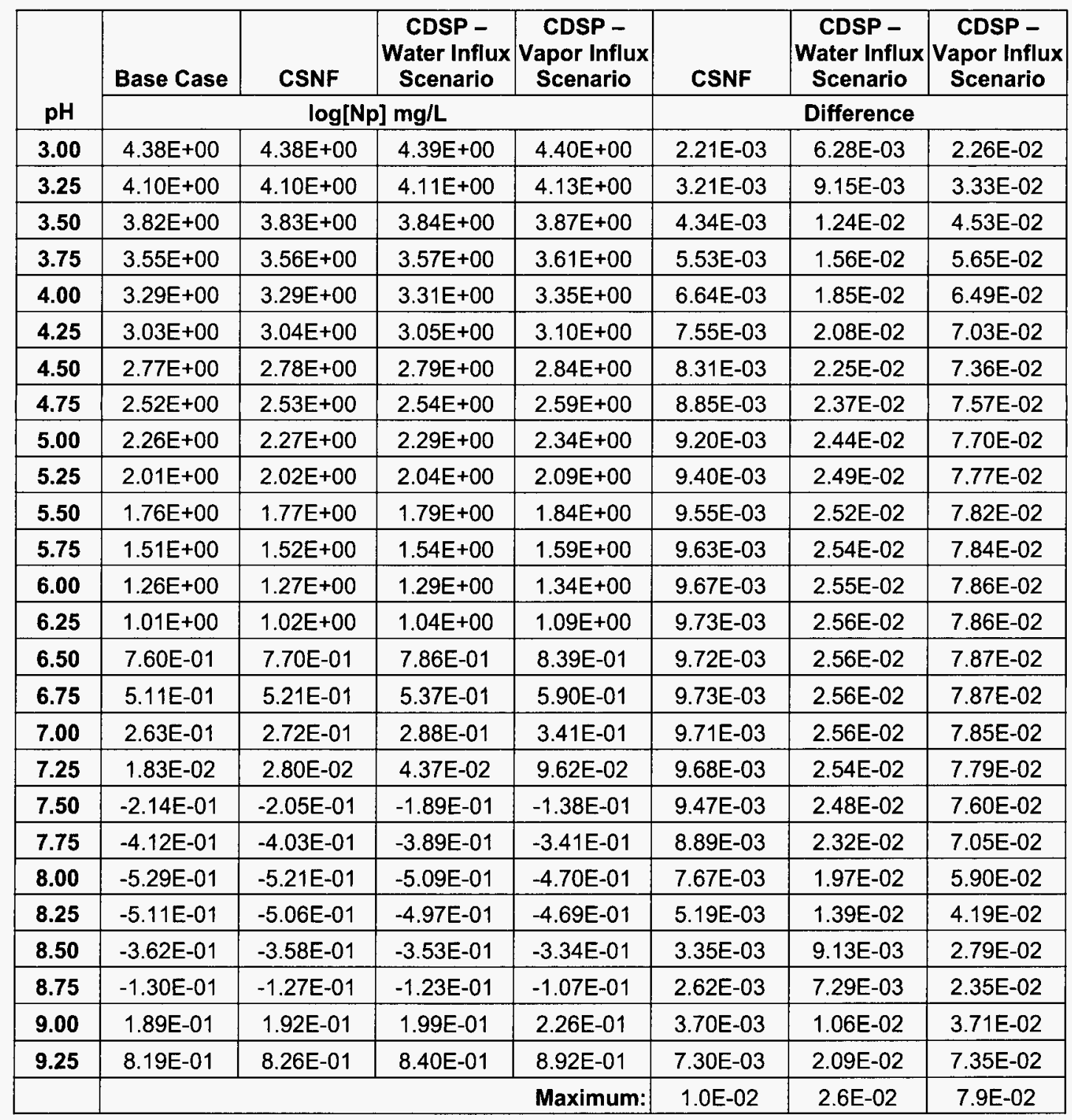

Source: Np2O5 and Carb-F unc.x/s (Appendix 1).

NOTE: $\quad \mathrm{CCO}_{2}=-3.0$ bars. 


\subsection{Summary of $\mathrm{Np}_{2} \mathrm{O}_{5}-\mathrm{NaNpO}_{2} \mathrm{CO}_{3}$ Solubility Model Uncertainty}

The $\mathrm{Np}_{2} \mathrm{O}_{5}-\mathrm{NaNpO}_{2} \mathrm{CO}_{3}$ solubility model is summarized by Equation 6.6-3:

$$
\log [\mathrm{Np}]=S\left(p H, \log f \mathrm{CO}_{2}\right)+\varepsilon_{1}+\left(\varepsilon_{2} \times N\right)
$$

The values for the parameters in this equation depend on the type of waste package. Parameter $S\left(p H, \log f_{\mathrm{CO}_{2}}\right)$ is the base solubility and is taken from Table 6.6-3. Parameter $\varepsilon_{1}$ is associated with the uncertainties in the $\log \mathrm{K}$ data. Parameter $\varepsilon_{2}$ is associated with the uncertainties in the fluoride concentrations. Table 6.6-5 gives the values for parameters $\varepsilon_{1}$ and $\varepsilon_{2}$.

Table 6.6-4 shows that the uncertainty terms $\varepsilon_{2}{ }^{\mathrm{CSNF}}, \varepsilon_{2}{ }^{\text {CDSP-water influx }}$, and $\varepsilon_{2}{ }^{\text {CDSP-vapor influx }}$ vary with $\mathrm{pH}$. This $\mathrm{pH}$ dependence can be implemented into the TSPA-LA model through the use of a multiplication factor $(\mathrm{N})$ that is a function of $\mathrm{pH}$. Values for $\mathrm{N}(\mathrm{pH})$ for both fuel types are given in Table 6.6-6. This modification requires that the $\varepsilon_{2}{ }^{\text {CSNF }}, \varepsilon_{2}{ }^{\text {CDSP-water influx }}$, and $\varepsilon_{2}{ }^{\text {CDSP-vapor }}$ influx values be fixed at the maximum value given in Table 6.6-4. For each realization in the TSPA-LA model, the uncertainty parameters are sampled at the beginning of the realization. This sampled value is then multiplied by $N$ at each timestep to produce a modified $\varepsilon_{2}$, which is then added to the base solubility value.

Table 6.6-5. Uncertainty Terms of $\log [\mathrm{Np}]$ of $\mathrm{Np}_{2} \mathrm{O}_{5} / \mathrm{NaNpO}_{2} \mathrm{CO}_{3}$ Model

\begin{tabular}{|c|c|c|c|c|}
\hline $\begin{array}{c}\text { Uncertainty } \\
\text { Term } \\
\end{array}$ & Associated with & $\begin{array}{c}\text { Distribution } \\
\text { Type }\end{array}$ & $\begin{array}{c}\text { Distribution } \\
\text { Parameter }\end{array}$ & Applicable to \\
\hline$\varepsilon_{1}$ & $\begin{array}{l}\log \mathrm{K} \text { of controlling solid } \\
\text { and aqueous species }\end{array}$ & $\begin{array}{l}\text { Normal } \\
\text { Truncated at } \pm 2 \sigma \\
\end{array}$ & $\mu=0, \sigma=0.8^{a}$ & Values in Table 6.6-3 \\
\hline$\varepsilon_{2}{ }^{\mathrm{CSNF}}$ & $\begin{array}{l}\text { Fluoride concentration in } \\
\text { CSNF waste packages }\end{array}$ & Triangular & $a=b=0, c=0.010$ & CSNF waste packages \\
\hline$\varepsilon_{2}{ }^{\text {CDSP-water influx }}$ & $\begin{array}{l}\text { Fluoride concentration in } \\
\text { codisposal waste packages } \\
\text { (water influx scenario) }\end{array}$ & Triangular & $a=b=0, c=0.026$ & $\begin{array}{l}\text { Codisposal waste } \\
\text { packages and the invert }\end{array}$ \\
\hline$\varepsilon_{2}$ CDSP-vapor influx & $\begin{array}{l}\text { Fluoride concentration In } \\
\text { CDNR waste package } \\
\text { (vapor influx scenario) }\end{array}$ & Triangular & $a=b=0, c=0.079$ & $\begin{array}{l}\text { Codisposal waste } \\
\text { packages and the invert }\end{array}$ \\
\hline
\end{tabular}

NOTE: ${ }^{a}$ For ionic strength values between 1 and 3 , Log $\mathrm{K}$ uncertainty should be treated as a normal distribution truncated at $\pm 2 \sigma$ with distribution parameters $\mu=0, \sigma=0.85$ (Section 6.3.3.4, Equation 6.3-7). 
Table 6.6-6. Multiplication Factor (N) used to Modify $\mathrm{F}^{-}$Uncertainty Term for Neptunium

\begin{tabular}{|c|c|c|c|}
\hline \multirow[b]{2}{*}{ pH } & \multicolumn{3}{|c|}{ Multiplication Factor for $\mathrm{F}^{-}$Uncertainty } \\
\hline & CSNF & $\begin{array}{c}\text { CDSP - } \\
\text { Water Influx } \\
\text { Scenario } \\
\end{array}$ & $\begin{array}{c}\text { CDSP - } \\
\text { Vapor Influx } \\
\text { Scenario }\end{array}$ \\
\hline 3.00 & 2.27E-01 & $2.45 \mathrm{E}-01$ & $2.88 \mathrm{E}-01$ \\
\hline 3.25 & 3.30E-01 & 3.57E-01 & 4.23E-01 \\
\hline 3.50 & 4.46E-01 & 4.84E-01 & $5.76 \mathrm{E}-01$ \\
\hline 3.75 & $5.69 E-01$ & $6.10 \mathrm{E}-01$ & 7.18E-01 \\
\hline 4.00 & $6.82 E-01$ & 7.21E-01 & 8.24E-01 \\
\hline 4.25 & 7.76E-01 & $8.10 \mathrm{E}-01$ & 8.93E-01 \\
\hline 4.50 & 8.54E-01 & 8.78E-01 & 9.36E-01 \\
\hline 4.75 & 9.09E-01 & 9.25E-01 & 9.62E-01 \\
\hline 5.00 & 9.45E-01 & 9.54E-01 & 9.78E-01 \\
\hline 5.25 & $9.65 \mathrm{E}-01$ & $9.74 \mathrm{E}-01$ & $9.87 \mathrm{E}-01$ \\
\hline 5.50 & $9.81 \mathrm{E}-01$ & 9.85E-01 & 9.93E-01 \\
\hline 5.75 & $9.90 \mathrm{E}-01$ & $9.92 \mathrm{E}-01$ & 9.96E-01 \\
\hline 6.00 & 9.93E-01 & $9.95 \mathrm{E}-01$ & $9.98 \mathrm{E}-01$ \\
\hline 6.25 & 9.99E-01 & $9.98 \mathrm{E}-01$ & 9.99E-01 \\
\hline 6.50 & 9.99E-01 & 9.99E-01 & $1.00 \mathrm{E}+00$ \\
\hline 6.75 & $1.00 \mathrm{E}+00$ & $1.00 \mathrm{E}+00$ & $1.00 \mathrm{E}+00$ \\
\hline 7.00 & $9.98 \mathrm{E}-01$ & $9.98 \mathrm{E}-01$ & $9.98 \mathrm{E}-01$ \\
\hline 7.25 & $9.94 \mathrm{E}-01$ & 9.91E-01 & $9.90 \mathrm{E}-01$ \\
\hline 7.50 & 9.73E-01 & $9.69 \mathrm{E}-01$ & $9.66 \mathrm{E}-01$ \\
\hline 7.75 & $9.13 \mathrm{E}-01$ & $9.05 E-01$ & 8.96E-01 \\
\hline 8.00 & $7.88 \mathrm{E}-01$ & 7.69E-01 & 7.49E-01 \\
\hline 8.25 & $5.33 \mathrm{E}-01$ & 5.44E-01 & 5.32E-01 \\
\hline 8.50 & $3.44 \mathrm{E}-01$ & 3.57E-01 & $3.54 \mathrm{E}-01$ \\
\hline 8.75 & $2.69 \mathrm{E}-01$ & $2.84 \mathrm{E}-01$ & 2.99E-01 \\
\hline 9.00 & $3.80 \mathrm{E}-01$ & 4.13E-01 & 4.71E-01 \\
\hline 9.25 & $7.50 \mathrm{E}-01$ & $8.16 \mathrm{E}-01$ & 9.34E-01 \\
\hline
\end{tabular}

Source: Np2O5 and Carb-F unc.x/s (Appendix I). 


\subsubsection{Alternative Neptunium Solubility Model I: $\mathrm{NpO}_{2}$ Model}

Lemire (2001 [DIRS 159027], Table 3.1, p. 41) gives the free energy of formation $\left(\Delta_{f} G^{0}\right)$ of $\mathrm{NpO}_{2}$ as $-1,021.731 \mathrm{~kJ} / \mathrm{mol}$, while $\Delta_{f} G^{0}$ of $\mathrm{Np}_{2} \mathrm{O}_{5}$ is $-2,031.574 \mathrm{~kJ} / \mathrm{mol}$. If the data are correct, then, $\mathrm{NpO}_{2}$ is more stable than $\mathrm{Np}_{2} \mathrm{O}_{5}$ at $298.15 \mathrm{~K}$, because of the following reaction:

$$
\begin{gathered}
\mathrm{Np}_{2} \mathrm{O}_{5}=2 \mathrm{NpO}_{2}+\frac{1}{2} \mathrm{O}_{2}(\mathrm{~g}) \\
\Delta_{r} G^{0}=2 \times \Delta_{f} G_{N p O 2}^{o}-\Delta_{f} G_{N p 2 O 5}^{o}=2 \times(-1,021.731)-(-2,031.574)=-11.888(\mathrm{~kJ})
\end{gathered}
$$

If kinetic barriers do not prevent $\mathrm{NpO}_{2}$ from precipitating, it should control neptunium equilibrium solubility under most conditions, even those with atmospheric $f \mathrm{O}_{2}$.

In laboratory solubility experiments, $\mathrm{NpO}_{2}$ has been found to precipitate at $200^{\circ} \mathrm{C}$ (Roberts et al. 2003 [DIRS 162536]). $\mathrm{NpO}_{2}$ is also the neptunium phase in solid solution with the $\mathrm{UO}_{2}$ matrix in spent fuel. Even a small amount of $\mathrm{NpO}_{2}$ in contact with the solution would enable further growth of $\mathrm{NpO}_{2}$, making it a solubility-controlling phase.

At temperature conditions relevant to the repository $\left(25^{\circ} \mathrm{C}\right.$ to $\left.90^{\circ} \mathrm{C}\right)$, in contrast to what is predicted by thermodynamics, $\mathrm{Np}_{2} \mathrm{O}_{5} \cdot \mathrm{xH}_{2} \mathrm{O}$ has been identified experimentally as controlling neptunium solubility (Efurd et al. 1998 [DIRS 108015]). As discussed in Section 6.3.2, the Ostwald Step Rule can be used to explain the contrast between the thermodynamic prediction and laboratory observations.

In selection of solubility-controlling solids, laboratory observations override thermodynamic prediction (Section 6.3.2). Nonetheless, neptunium solubility controlled by $\mathrm{NpO}_{2}$ is considered an alternative conceptual model.

\subsubsection{Water Composition Used for the Calculation}

Table 6.4-2 lists the chemical conditions for the $\mathrm{NpO}_{2}$ calculations.

\subsubsection{EQ3NR Results}

The results of the $\mathrm{NpO}_{2}$-solubility calculations are presented in Table 6.6-7. The $\mathrm{pH}$ range within which the calculation converges varies under different $f \mathrm{CO}_{2}$ conditions. The higher the $f \mathrm{CO}_{2}$, the narrower the converging $\mathrm{pH}$ range. The lower ends are $\mathrm{pH} 3.0$, while the upper ends change from 8.25 to 10.75 . Of those converged calculations, the maximum solubility is $1.10 \mathrm{E}+01 \mathrm{mg} / \mathrm{L}$, which appears at the high $\mathrm{pH}$ end (under both $\log f \mathrm{CO}_{2}=-2.00$ and -3.00 bars) before the calculation diverges. The minimum solubility is $1.75 \mathrm{E}-05 \mathrm{mg} / \mathrm{L}$, which appears at $\mathrm{pH}$ of 9.0 and $\log f \mathrm{CO}_{2}=-5.0$ bars. Possible reasons why calculations may not converge are the same as those given in Section 6.6.3.2.

As shown in Figure 6.6-4, $\log [\mathrm{Np}]$ varies linearly for the most part as a function of $\mathrm{pH}$ and $\log f \mathrm{CO}_{2}$. Accordingly, highly accurate interpolations of $\log [\mathrm{Np}]$ can be obtained by linear interpolation of nearest $\mathrm{pH}$ and $\log f \mathrm{CO}_{2}$ values. For those calculations that do not converge or are not valid, a large number (500) is entered to flag that under such $\mathrm{pH}$ and $\mathrm{fCO}_{2}$ conditions, 
solubility of neptunium is not defined or the calculation results are outside the valid range of the computing tool. The user of the table needs to ensure that when the flag (500) is encountered, the concentrations calculated according to the dissolution rate of individual waste forms, water volume, and the solubility caps presented in Table 8-5 should be used instead of the flag itself. For any conditions that fall between a valid solubility and a flag of 500 , the flag (representing use of the dissolution rate of waste forms) should be used. In addition, for any conditions outside of the 3.0 to $10.0 \mathrm{pH}$ range, the -1.5 to -5.0 bar $\log f \mathrm{CO}_{2}$ range, or with an ionic strength greater than 1.0 molal, the concentrations calculated according to the dissolution rate of individual waste forms, water volume, and the solubility caps presented in Table 8-5.

Table 6.6-7. $\mathrm{NpO}_{2}$ Solubility $(\log [\mathrm{Np}], \mathrm{mg} / \mathrm{L})$

\begin{tabular}{|c|c|c|c|c|c|c|c|c|}
\hline \multirow{2}{*}{ pH } & \multicolumn{8}{|c|}{ Log $f \mathrm{CO}_{2}$ (bars) } \\
\hline & -1.5 & -2.0 & -2.5 & -3.0 & -3.5 & -4.0 & -4.5 & -5.0 \\
\hline 3.00 & $3.09 \mathrm{E}+00$ & $3.09 \mathrm{E}+00$ & $3.09 E+00$ & $3.09 \mathrm{E}+00$ & $3.09 \mathrm{E}+00$ & $3.09 \mathrm{E}+00$ & $3.09 \mathrm{E}+00$ & $3.09 E+00$ \\
\hline 3.25 & $2.82 E+00$ & $2.82 \mathrm{E}+00$ & $2.82 \mathrm{E}+00$ & $2.82 \mathrm{E}+00$ & $2.82 E+00$ & $2.82 \mathrm{E}+00$ & $2.82 \mathrm{E}+00$ & $2.82 E+00$ \\
\hline 3.50 & $2.56 \mathrm{E}+00$ & $2.56 \mathrm{E}+00$ & $2.56 \mathrm{E}+00$ & $2.56 \mathrm{E}+00$ & $2.56 \mathrm{E}+00$ & $2.56 \mathrm{E}+00$ & $2.56 \mathrm{E}+00$ & $2.56 \mathrm{E}+00$ \\
\hline 3.75 & $2.30 \mathrm{E}+00$ & $2.30 \mathrm{E}+00$ & $2.30 \mathrm{E}+00$ & $2.30 \mathrm{E}+00$ & $2.30 \mathrm{E}+00$ & $2.30 \mathrm{E}+00$ & $2.30 \mathrm{E}+00$ & $2.30 \mathrm{E}+00$ \\
\hline 4.00 & $2.05 E+00$ & $2.05 \mathrm{E}+00$ & $2.05 \mathrm{E}+00$ & $2.05 \mathrm{E}+00$ & $2.05 \mathrm{E}+00$ & $2.05 \mathrm{E}+00$ & $2.05 \mathrm{E}+00$ & $2.05 \mathrm{E}+00$ \\
\hline 4.25 & $1.80 \mathrm{E}+00$ & $1.80 \mathrm{E}+00$ & $1.80 \mathrm{E}+00$ & $1.80 \mathrm{E}+00$ & $1.80 \mathrm{E}+00$ & $1.80 \mathrm{E}+00$ & $1.80 \mathrm{E}+00$ & $1.80 \mathrm{E}+00$ \\
\hline 4.50 & $1.55 \mathrm{E}+00$ & $1.55 \mathrm{E}+00$ & $1.55 \mathrm{E}+00$ & $1.55 \mathrm{E}+00$ & $1.55 \mathrm{E}+00$ & $1.55 \mathrm{E}+00$ & $1.55 \mathrm{E}+00$ & $1.55 \mathrm{E}+00$ \\
\hline 4.75 & $1.29 E+00$ & $1.29 \mathrm{E}+00$ & $1.29 \mathrm{E}+00$ & $1.29 \mathrm{E}+00$ & $1.29 E+00$ & $1.29 \mathrm{E}+00$ & $1.29 E+00$ & $1.29 \mathrm{E}+00$ \\
\hline 5.00 & $1.04 \mathrm{E}+00$ & $1.04 \mathrm{E}+00$ & $1.04 \mathrm{E}+00$ & $1.04 \mathrm{E}+00$ & $1.04 \mathrm{E}+00$ & $1.04 E+00$ & $1.04 E+00$ & $1.04 E+00$ \\
\hline 5.25 & 7.94E-01 & $7.94 \mathrm{E}-01$ & 7.94E-01 & 7.94E-01 & 7.94E-01 & 7.94E-01 & 7.94E-01 & 7.94E-01 \\
\hline 5.50 & $5.44 \mathrm{E}-01$ & $5.44 \mathrm{E}-01$ & $5.44 \mathrm{E}-01$ & 5.44E-01 & 5.44E-01 & 5.44E-01 & $5.44 \mathrm{E}-01$ & $5.44 \mathrm{E}-01$ \\
\hline 5.75 & $2.93 \mathrm{E}-01$ & $2.94 \mathrm{E}-01$ & $2.94 \mathrm{E}-01$ & $2.94 \mathrm{E}-01$ & $2.94 \mathrm{E}-01$ & $2.94 \mathrm{E}-01$ & $2.94 \mathrm{E}-01$ & $2.94 \mathrm{E}-01$ \\
\hline 6.00 & 4.37E-02 & 4.36E-02 & 4.36E-02 & 4.36E-02 & 4.36E-02 & 4.36E-02 & 4.36E-02 & 4.36E-02 \\
\hline 6.25 & $-2.05 E-01$ & $-2.06 E-01$ & $-2.06 \mathrm{E}-01$ & $-2.06 \mathrm{E}-01$ & $-2.06 E-01$ & $-2.06 \mathrm{E}-01$ & $-2.06 \mathrm{E}-01$ & $-2.06 \mathrm{E}-01$ \\
\hline 6.50 & $-4.48 E-01$ & $-4.54 \mathrm{E}-01$ & $-4.56 \mathrm{E}-01$ & $-4.56 \mathrm{E}-01$ & $-4.56 \mathrm{E}-01$ & $-4.56 \mathrm{E}-01$ & $-4.56 \mathrm{E}-01$ & $-4.56 \mathrm{E}-01$ \\
\hline 6.75 & $-6.65 \mathrm{E}-01$ & $-6.98 \mathrm{E}-01$ & $-7.04 \mathrm{E}-01$ & $-7.06 \mathrm{E}-01$ & $-7.06 \mathrm{E}-01$ & $-7.06 \mathrm{E}-01$ & $-7.06 \mathrm{E}-01$ & $-7.06 \mathrm{E}-01$ \\
\hline 7.00 & $-8.00 \mathrm{E}-01$ & $-9.24 \mathrm{E}-01$ & $-9.48 E-01$ & $-9.54 \mathrm{E}-01$ & $-9.56 \mathrm{E}-01$ & $-9.56 \mathrm{E}-01$ & $-9.56 \mathrm{E}-01$ & $-9.56 \mathrm{E}-01$ \\
\hline 7.25 & $-7.26 \mathrm{E}-01$ & $-1.09 E+00$ & $-1.18 \mathrm{E}+00$ & $-1.20 \mathrm{E}+00$ & $-1.20 \mathrm{E}+00$ & $-1.21 \mathrm{E}+00$ & $-1.21 E+00$ & $-1.21 \mathrm{E}+00$ \\
\hline 7.50 & $-3.77 \mathrm{E}-01$ & $-1.09 E+00$ & $-1.36 \mathrm{E}+00$ & $-1.43 E+00$ & $-1.45 E+00$ & $-1.45 \mathrm{E}+00$ & $-1.46 \mathrm{E}+00$ & $-1.46 \mathrm{E}+00$ \\
\hline 7.75 & $2.05 \mathrm{E}-01$ & $-8.33 \mathrm{E}-01$ & $-1.41 \mathrm{E}+00$ & $-1.62 \mathrm{E}+00$ & $-1.68 \mathrm{E}+00$ & $-1.70 \mathrm{E}+00$ & $-1.70 \mathrm{E}+00$ & $-1.71 \mathrm{E}+00$ \\
\hline 8.00 & $1.10 \mathrm{E}+00$ & $-3.51 E-01$ & $-1.23 E+00$ & $-1.70 \mathrm{E}+00$ & $-1.87 E+00$ & $-1.93 E+00$ & $-1.95 E+00$ & $-1.95 E+00$ \\
\hline 8.25 & $2.39 \mathrm{E}+00$ & 4.02E-01 & $-8.43 E-01$ & $-1.59 E+00$ & $-1.97 \mathrm{E}+00$ & $-2.12 E+00$ & $-2.18 E+00$ & $-2.20 \mathrm{E}+00$ \\
\hline 8.50 & 500 & $1.53 \mathrm{E}+00$ & $-2.14 E-01$ & $-1.27 E+00$ & $-1.90 E+00$ & $-2.23 E+00$ & $-2.37 E+00$ & $-2.43 E+00$ \\
\hline 8.75 & 500 & $3.16 \mathrm{E}+00$ & 7.71E-01 & $-7.55 \mathrm{E}-01$ & $-1.65 E+00$ & $-2.18 \mathrm{E}+00$ & $-2.48 E+00$ & $-2.63 \mathrm{E}+00$ \\
\hline 9.00 & 500 & 500 & $2.12 \mathrm{E}+00$ & $9.62 \mathrm{E}-02$ & $-1.22 E+00$ & $-1.98 \mathrm{E}+00$ & $-2.45 E+00$ & $-2.74 \mathrm{E}+00$ \\
\hline 9.25 & 500 & 500 & 500 & $1.33 E+00$ & $-5.02 \mathrm{E}-01$ & $-1.63 \mathrm{E}+00$ & $-2.27 E+00$ & $-2.71 \mathrm{E}+00$ \\
\hline 9.50 & 500 & 500 & 500 & $3.16 \mathrm{E}+00$ & $6.43 \mathrm{E}-01$ & $-1.03 E+00$ & $-1.98 \mathrm{E}+00$ & $-2.55 \mathrm{E}+00$ \\
\hline 9.75 & 500 & 500 & 500 & 500 & $2.21 \mathrm{E}+00$ & $2.13 \mathrm{E}-02$ & $-1.48 E+00$ & $-2.29 \mathrm{E}+00$ \\
\hline 10.00 & 500 & 500 & 500 & 500 & 500 & $1.54 \mathrm{E}+00$ & $-5.42 \mathrm{E}-01$ & $-1.88 \mathrm{E}+00$ \\
\hline
\end{tabular}

Source: NpO2 Solubilityfo2reg.x/s (Appendix I).

NOTE: Some cells have no valid data because the EQ3NR calculations do not converge, and those results are reported as 500 (Section 6.4.4). 
Figure 6.6-4 shows the calculated solubility using $\mathrm{NpO}_{2}$ as the controlling solid. It is a function of $\mathrm{pH}$ and fugacity of $\mathrm{CO}_{2}$. Under the same $f \mathrm{CO}_{2}$, just like $\mathrm{Np}_{2} \mathrm{O}_{5}$ solubility, $\mathrm{NpO}_{2}$ solubility increases with $\mathrm{pH}$ under alkaline conditions, while under acid conditions it increases as $\mathrm{pH}$ decreases.

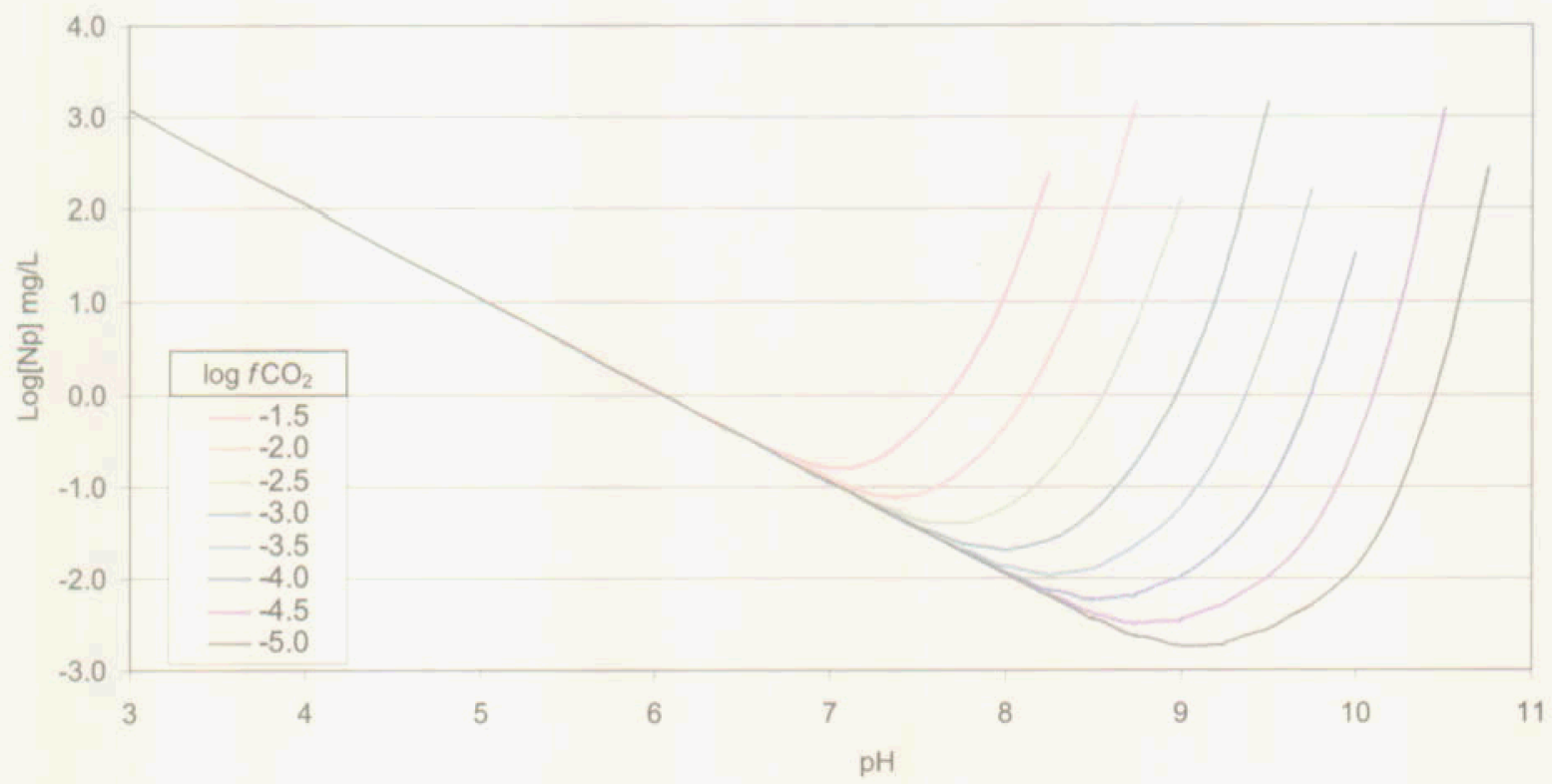

Source: NpO2 Solubilityfo2reg.x/s (Appendix I).

Figure 6.6-4. $\mathrm{NpO}_{2}$ Solubility Modeled as a Function of pH and $\log \mathrm{fCO}_{2}$

\subsubsection{Uncertainty}

\subsection{Uncertainties in $\log \mathrm{K}$ Values of Controlling Solid and Aqueous Species}

The uncertainty in solubility involves uncertainties in the thermodynamic properties of both the controlling solid and significant dissolved species. The rationale behind the evaluation and combination of these uncertainties are discussed in some detail in Section 6.3.3.1.

The dissolved species accounting for more than 10 percent of the dissolved neptunium were found by examining the EQ3NR output for runs at $\log f \mathrm{CO}_{2}=-3.0$. They are the same as those for the $\mathrm{Np}_{2} \mathrm{O}_{5}$ calculations described in Section 6.6.3.4.1.

After an extensive review, Lemire (2001 [DIRS 159027]) recommended -1,021.731 $\pm 2.514 \mathrm{~kJ} / \mathrm{mol}$ for the Gibbs free energy of formation of $\mathrm{NpO}_{2}$, based on calorimetric studies. Following the procedure outlined in Section 6.3.3.1 leads to $\log \mathrm{K}$ of 0.81 with a $2 \sigma$ uncertainty of \pm 1.1 (at $25^{\circ} \mathrm{C}$ ) for the reaction:

$$
\mathrm{NpO}_{2}+0.25 \mathrm{O}_{2}(\mathrm{~g})+\mathrm{H}^{+}=\mathrm{NpO}_{2}^{+}+0.5 \mathrm{H}_{2} \mathrm{O}
$$

The evaluation of reactions from $\mathrm{NpO}_{2}$ to each of the six dissolved species noted earlier leads to a maximum uncertainty in $\log \mathrm{K}$ for reaction to $\mathrm{NpO}_{2}\left(\mathrm{CO}_{3}\right)_{3}{ }^{4}$ of \pm 1.11 . This is a $2 \sigma$ uncertainty, so the $1 \sigma$ uncertainty to be applied to $\log [\mathrm{Np}]$ is \pm 0.6 . 


\subsection{Uncertainty from Fluoride Concentration}

Table 6.6-8 lists the calculated logarithm of $\mathrm{NpO}_{2}$ solubilities using the fluoride levels indicated in Section 6.3.3.2 (10 times base case for CSNF waste packages and 200 times for codisposal waste packages and the invert). The fugacity of $\mathrm{CO}_{2}$ is set to $10^{-3}$. The differences between the base-case results and the uncertainty case results vary with $\mathrm{pH}$. The two right-hand columns are the differences between the respective elevated $\mathrm{F}^{-}$cases and the base case.

Table 6.6-8. The Effects of Variations in Fluoride Concentration on $\mathrm{NpO}_{2}$ Solubility

\begin{tabular}{|c|c|c|c|c|c|}
\hline \multirow[b]{2}{*}{ pH } & Base Case & CSNF & $\begin{array}{c}\text { Codisposal } \\
\left(200 \times F^{\prime}\right)\end{array}$ & CSNF & $\begin{array}{c}\text { Codisposal } \\
\left(200 \times F^{-}\right)\end{array}$ \\
\hline & \multicolumn{3}{|c|}{ [Np] $\mathrm{mg} / \mathrm{L}$} & \multicolumn{2}{|c|}{ Difference } \\
\hline 3.00 & $1.24 \mathrm{E}+03$ & $1.35 \mathrm{E}+03$ & $3.80 \mathrm{E}+03$ & 3.67E-02 & 4.87E-01 \\
\hline 3.25 & $6.63 E+02$ & $7.32 \mathrm{E}+02$ & $2.78 \mathrm{E}+03$ & 4.27E-02 & $6.23 \mathrm{E}-01$ \\
\hline 3.50 & $3.63 \mathrm{E}+02$ & $4.01 E+02$ & $2.06 \mathrm{E}+03$ & 4.31E-02 & 7.53E-01 \\
\hline 3.75 & $2.01 E+02$ & $2.19 \mathrm{E}+02$ & $1.42 \mathrm{E}+03$ & $3.73 \mathrm{E}-02$ & $8.50 \mathrm{E}-01$ \\
\hline 4.00 & $1.12 \mathrm{E}+02$ & $1.20 \mathrm{E}+02$ & $8.64 \mathrm{E}+02$ & 2.83E-02 & 8.87E-01 \\
\hline 4.25 & $6.26 \mathrm{E}+01$ & $6.56 \mathrm{E}+01$ & $4.40 \mathrm{E}+02$ & $1.98 \mathrm{E}-02$ & $8.46 \mathrm{E}-01$ \\
\hline 4.50 & $3.51 \mathrm{E}+01$ & $3.62 E+01$ & $1.91 \mathrm{E}+02$ & $1.37 \mathrm{E}-02$ & 7.35E-01 \\
\hline 4.75 & $1.97 E+01$ & $2.02 E+01$ & $7.71 \mathrm{E}+01$ & $9.76 \mathrm{E}-03$ & 5.93E-01 \\
\hline 5.00 & 1.11E+01 & $1.13 \mathrm{E}+01$ & $3.18 \mathrm{E}+01$ & 7.39E-03 & 4.58E-01 \\
\hline 5.25 & $6.22 \mathrm{E}+00$ & $6.31 \mathrm{E}+00$ & 1.39E+01 & $6.00 \mathrm{E}-03$ & $3.49 \mathrm{E}-01$ \\
\hline 5.50 & $3.50 \mathrm{E}+00$ & $3.54 \mathrm{E}+00$ & $6.51 \mathrm{E}+00$ & $5.20 \mathrm{E}-03$ & 2.70E-01 \\
\hline 5.75 & $1.97 \mathrm{E}+00$ & $1.99 \mathrm{E}+00$ & $3.24 E+00$ & 4.75E-03 & 2.17E-01 \\
\hline 6.00 & $1.11 E+00$ & $1.12 \mathrm{E}+00$ & $1.69 \mathrm{E}+00$ & 4.49E-03 & $1.85 E-01$ \\
\hline 6.25 & $6.22 \mathrm{E}-01$ & $6.28 \mathrm{E}-01$ & 9.09E-01 & 4.34E-03 & $1.65 \mathrm{E}-01$ \\
\hline 6.50 & $3.50 \mathrm{E}-01$ & 3.53E-01 & $4.98 E-01$ & $4.25 E-03$ & $1.54 \mathrm{E}-01$ \\
\hline 6.75 & 1.97E-01 & 1.99E-01 & 2.76E-01 & 4.21E-03 & 1.47E-01 \\
\hline 7.00 & $1.11 \mathrm{E}-01$ & 1.12E-01 & 1.55E-01 & 4.16E-03 & $1.43 \mathrm{E}-01$ \\
\hline 7.25 & $6.34 \mathrm{E}-02$ & $6.40 \mathrm{E}-02$ & $8.75 \mathrm{E}-02$ & 4.05E-03 & $1.40 \mathrm{E}-01$ \\
\hline 7.50 & $3.73 \mathrm{E}-02$ & 3.77E-02 & $5.10 \mathrm{E}-02$ & $3.76 \mathrm{E}-03$ & $1.35 \mathrm{E}-01$ \\
\hline 7.75 & 2.42E-02 & $2.43 E-02$ & $3.24 \mathrm{E}-02$ & $2.25 \mathrm{E}-03$ & $1.26 \mathrm{E}-01$ \\
\hline 8.00 & $2.01 \mathrm{E}-02$ & 2.04E-02 & $2.60 \mathrm{E}-02$ & 5.48E-03 & $1.11 \mathrm{E}-01$ \\
\hline 8.25 & $2.60 \mathrm{E}-02$ & $2.64 E-02$ & 3.30E-02 & $7.56 \mathrm{E}-03$ & 1.03E-01 \\
\hline 8.50 & $5.33 \mathrm{E}-02$ & $5.43 \mathrm{E}-02$ & 7.24E-02 & $8.51 \mathrm{E}-03$ & 1.33E-01 \\
\hline 8.75 & $1.76 \mathrm{E}-01$ & 1.81E-01 & 2.89E-01 & 1.23E-02 & 2.16E-01 \\
\hline 9.00 & $1.25 \mathrm{E}+00$ & $1.29 \mathrm{E}+00$ & $2.34 \mathrm{E}+00$ & 1.53E-02 & 2.73E-01 \\
\hline 9.25 & $2.16 \mathrm{E}+01$ & $2.22 \mathrm{E}+01$ & $3.62 \mathrm{E}+01$ & $1.20 \mathrm{E}-02$ & $2.25 \mathrm{E}-01$ \\
\hline \multirow[t]{2}{*}{9.50} & $1.44 E+03$ & $1.47 \mathrm{E}+03$ & $2.35 E+03$ & $9.68 \mathrm{E}-03$ & 2.13E-01 \\
\hline & \multicolumn{3}{|r|}{ Maximum: } & 4.31E-02 & 8.87E-01 \\
\hline
\end{tabular}

Source: NpO2 Solubilityfo2reg.x/s (Appendix I)

\subsection{Summary of $\mathrm{NpO}_{2}$ Solubility Model Uncertainty}

The $\mathrm{NpO}_{2}$ solubility model is summarized by the following equation:

$$
\log [\mathrm{Np}]=S\left(p H, \log f \mathrm{CO}_{2}\right)+\varepsilon_{l}+\left(\varepsilon_{2} \times N\right)
$$


The values for the parameters in this equation depend on the waste package type. Parameter $S\left(p H, \log f_{\mathrm{CO}_{2}}\right)$ is the base solubility and is taken from Table 6.6-7. Parameter $\varepsilon_{1}$ is associated with the uncertainties in the $\log \mathrm{K}$ data. Parameter $\varepsilon_{2}$ is associated with the uncertainties in the fluoride concentrations. Table 6.6-9 gives the values for the parameters $\varepsilon_{1}$ and $\varepsilon_{2}$.

Table 6.6-8 shows that the uncertainty terms $\varepsilon_{2}{ }^{\mathrm{CSNF}}$ and $\varepsilon_{2}{ }^{\mathrm{CDSP}-200 \times \mathrm{F}}$ vary with $\mathrm{pH}$. This $\mathrm{pH}$ dependence can be implemented into the TSPA-LA model through the use of a multiplication factor $(\mathrm{N})$ that is a function of $\mathrm{pH}$. Values for $\mathrm{N}(\mathrm{pH})$ for both fuel types are given in Table 6.610. This modification requires that the $\varepsilon_{2}{ }^{\mathrm{CSNF}}$ and $\varepsilon_{2}{ }^{\mathrm{CDSP}-200 \times \mathrm{F}}$ values be fixed at the maximum value given in Table 6.6-8. For each realization in the TSPA-LA model, the uncertainty parameters are sampled at the beginning of the realization. This sampled value is then multiplied by $\mathrm{N}$ at each timestep to produce a modified $\varepsilon_{2}$, which is then added to the base solubility value.

Table 6.6-9. Uncertainty Terms of $\log [\mathrm{Np}]$ of $\mathrm{NpO}_{2}$ Model

\begin{tabular}{|l|l|l|l|l|}
\hline $\begin{array}{c}\text { Uncertainty } \\
\text { Term }\end{array}$ & \multicolumn{1}{|c|}{ Associated With } & $\begin{array}{l}\text { Distribution } \\
\text { Type }\end{array}$ & \multicolumn{1}{|c|}{$\begin{array}{c}\text { Distribution } \\
\text { Parameter }\end{array}$} & \multicolumn{1}{|c|}{ Applicable to } \\
\hline$\varepsilon_{1}$ & Uncertainty in log $\mathrm{K}$ & $\begin{array}{l}\text { Normal } \\
\text { Truncated at } \\
\pm 2 \sigma\end{array}$ & $\mu=0, \sigma=0.6^{\mathrm{a}}$ & Values in Table 6.6-7 \\
\hline$\varepsilon_{2}{ }^{\mathrm{CSNF}}$ & $\begin{array}{l}\text { Fluoride concentration } \\
\text { In CSNF waste package }\end{array}$ & Triangular & $\mathrm{a}=\mathrm{b}=0, \mathrm{c}=0.043$ & CSNF Waste Packages \\
\hline$\varepsilon_{2}{ }_{\text {CDSP-200x F }}$ & $\begin{array}{l}\text { Fluoride concentration } \\
\text { In CDNR waste } \\
\text { package }\end{array}$ & Triangular & $\mathrm{a}=\mathrm{b}=0, \mathrm{c}=0.887$ & $\begin{array}{l}\text { Codisposal waste } \\
\text { packages (water influx } \\
\text { scenario) and invert }\end{array}$ \\
\hline
\end{tabular}

NOTE: $\quad{ }^{a}$ For ionic strength values between 1 and $3, \log \mathrm{K}$ uncertainty should be treated as a normal distribution truncated at $\pm 2 \sigma$ with distribution parameters $\mu=0, \sigma=0.67$ (Section 6.3.3.4, Equation 6.3-7) 
Table 6.6-10. Multiplication Factor (N) used to Modify $\mathrm{F}^{-}$Uncertainty Terms

\begin{tabular}{|c|c|c|}
\hline \multirow[b]{2}{*}{ pH } & \multicolumn{2}{|c|}{ Multiplication Factor for F' Uncertainty } \\
\hline & CSNF & $\begin{array}{c}\text { Codisposal } \\
\left(200 \times F^{-}\right)\end{array}$ \\
\hline 3.00 & 8.52E-01 & 5.49E-01 \\
\hline 3.25 & $9.90 \mathrm{E}-01$ & 7.02E-01 \\
\hline 3.50 & $1.00 E+00$ & 8.49E-01 \\
\hline 3.75 & 8.66E-01 & $9.58 \mathrm{E}-01$ \\
\hline 4.00 & $6.56 \mathrm{E}-01$ & $1.00 \mathrm{E}+00$ \\
\hline 4.25 & 4.60E-01 & 9.54E-01 \\
\hline 4.50 & $3.18 \mathrm{E}-01$ & 8.29E-01 \\
\hline 4.75 & 2.27E-01 & $6.68 \mathrm{E}-01$ \\
\hline 5.00 & 1.72E-01 & $5.16 \mathrm{E}-01$ \\
\hline 5.25 & 1.39E-01 & 3.93E-01 \\
\hline 5.50 & $1.21 \mathrm{E}-01$ & 3.04E-01 \\
\hline 5.75 & 1.10E-01 & $2.45 \mathrm{E}-01$ \\
\hline 6.00 & $1.04 \mathrm{E}-01$ & 2.08E-01 \\
\hline 6.25 & 1.01E-01 & $1.86 \mathrm{E}-01$ \\
\hline 6.50 & $9.86 \mathrm{E}-02$ & 1.73E-01 \\
\hline 6.75 & $9.78 \mathrm{E}-02$ & $1.66 \mathrm{E}-01$ \\
\hline 7.00 & $9.65 \mathrm{E}-02$ & $1.61 \mathrm{E}-01$ \\
\hline 7.25 & $9.39 \mathrm{E}-02$ & $1.58 \mathrm{E}-01$ \\
\hline 7.50 & 8.73E-02 & 1.53E-01 \\
\hline 7.75 & $5.23 \mathrm{E}-02$ & 1.42E-01 \\
\hline 8.00 & 1.27E-01 & 1.25E-01 \\
\hline 8.25 & $1.75 \mathrm{E}-01$ & 1.17E-01 \\
\hline 8.50 & $1.97 \mathrm{E}-01$ & $1.50 E-01$ \\
\hline 8.75 & 2.86E-01 & 2.44E-01 \\
\hline 9.00 & 3.55E-01 & 3.07E-01 \\
\hline 9.25 & 2.77E-01 & 2.53E-01 \\
\hline
\end{tabular}

Source: NpO2 Solubilityfo2reg.x/s (Appendix I).

It should be noted that the $\mathrm{NpO}_{2}$ model was also run (for comparison) with the same Ehadjustment as indicated in Equation 6.5-7. These results can be found on Appendix I in NpAlternate.xls. The typical trend when the Eh adjustment is applied is that the $\mathrm{Np}$ solubilities decrease significantly from the base case $\mathrm{Np}_{2} \mathrm{O}_{5}-\mathrm{NaNpO}_{2} \mathrm{CO}_{3}$ model, up to 3 orders of magnitude. 


\subsubsection{Alternative Neptunium Solubility Models II: Secondary Phase Model}

Although by definition, solubility-controlling solids can be either a pure solid or a solid solution, in practice, pure solids are generally used to evaluate radionuclide solubility. Using pure-phase control is acceptable for TSPA-LA calculations because it is conservative. However, it is well recognized that the concentration of most radionuclides released during the corrosion of spent nuclear fuel is likely to be very low (except for uranium and thorium) and that the radionuclides may not form their own pure phases (Grenthe 1991 [DIRS 161964], pp. 429 and 430; Langmuir 1997 [DIRS 100051], p. 531). Rather, they may be incorporated into secondary uranium minerals as solid solutions because of the large availability of uranium in the repository.

Neptunium concentrations in solution have been measured in a number of spent fuel degradation experiments (Finn et al. 1994 [DIRS 100746]; Finn et al. 1997 [DIRS 124142]; CRWMS M\&O 2000 [DIRS 131861]; Wilson 1990a [DIRS 100949]; Wilson 1990b [DIRS 100793]). Neptunium concentrations based on $\mathrm{Np}_{2} \mathrm{O}_{5}$ and $\mathrm{NpO}_{2}$ solubilities are several orders of magnitude higher than the neptunium concentrations measured in the degradation experiments, as discussed in Section 7.2.3. This suggests that neptunium concentrations resulting from fuel degradation in a repository may be lower than the concentrations predicted by pure phase solubility models. It is also notable that no pure neptunium phases have ever been reported in any spent fuel corrosion experiments.

This discrepancy between the experimental and calculated actinide solubility, which is usually several orders of magnitude, has also been noted by others (Werme and Spahiu 1998 [DIRS 113466]; Quinones et al. 1996 [DIRS 161925], p. 42). Simple mass-balance calculations (Werme and Spahiu 1998 [DIRS 113466]) on the results of these degradation experiments revealed that the amount of neptunium in the aqueous solution was just a small portion of what should have been released from the dissolved spent fuel. An explanation for this observation is that released neptunium is included in uranyl solids that form during the degradation process. Thus there is theoretical and experimental support for the inclusion of neptunium in uranyl solids.

Based on an analysis of the crystal-chemical properties of the $\mathrm{U}-\mathrm{O}, \mathrm{Np}-\mathrm{O}$, and $\mathrm{Pu}-\mathrm{O}$ bonds, Burns et al. (1997 [DIRS 100389], p. 8) predicted, "the substitutions $\mathrm{Pu}^{6+}$ for $\mathrm{U}^{6+}$ and $\left(\mathrm{Np}^{5+}\right.$, $\mathrm{Pu}^{5+}$ ) for $\mathrm{U}^{6+}$ are likely to occur in most $\mathrm{U}^{6+}$ structures."

The previous theoretical prediction has been confirmed by direct observations of neptunium in uranyl minerals. Buck et al. (1998 [DIRS 100388]) examined corrosion products of spent fuel drip tests by electron energy loss spectroscopy (EELS) analyses in a transmission electron microscope. Their study reported that neptunium was incorporated into dehydrated schoepite $\left(\mathrm{UO}_{3} \cdot 0.8 \mathrm{H}_{2} \mathrm{O}\right)$ or metaschoepite $\left(\mathrm{UO}_{3} \cdot 2 \mathrm{H}_{2} \mathrm{O}\right)$. Finch et al. (2002 [DIRS 161979]) also reported experimental results on neptunium incorporation into dehydrated schoepite and estimated that the amount of neptunium incorporated in dehydrated schoepite can be as high as 2 percent of the host solid based on EELS measurement.

More significant progress in this direction is the successful synthesis of neptunium-bearing uranium minerals. Burns et al. (1997 [DIRS 100389]) reported the synthesis of uranophane $\left(\mathrm{Ca}\left(\mathrm{UO}_{2} \mathrm{SiO}_{3} \mathrm{OH}\right)_{2} \cdot 5 \mathrm{H}_{2} \mathrm{O}\right)$ and Na-compreignacite $\left(\mathrm{Na}_{2}\left[\left(\mathrm{UO}_{2}\right)_{3} \mathrm{O}_{2}(\mathrm{OH})_{3}\right]_{2} \cdot 5 \mathrm{H}_{2} \mathrm{O}\right)$ containing 
neptunium ranging up to $497 \mathrm{ppm}$ (Burns et al. 2004 [DIRS 171442]). Furthermore, they found that "there is a linear relationship between the neptunium content of $\alpha$-uranophane and $\mathrm{Na}$-compreignacite and the $\mathrm{Np}^{5+}$ concentration in the initial solution," and " $\mathrm{Np}$ is incorporated into crystals of alpha-uranophane and Np-compreignacite in approximately the same concentrations as presented in the mother solutions." In the neptunium incorporation experiments conducted by Burns et al. (2004 [DIRS 171442]), it is found that schoepite, the major secondary uranyl mineral that forms in the process of spent fuel degradation and is believed to be critical for neptunium immobilization, contains only a small amount of neptunium (a few parts per million). Burns et al. (2004 [DIRS 171442]) attribute this to the lack of suitable low-valence cations in their experiments. This may have prevented a charge-balance mechanism from happening, which is a prerequisite for neptunium incorporation into uranyl minerals.

Finally, Chen (2001 [DIRS 161997]) and Chen et al. (2002 [DIRS 161996]) analyzed the relative release rates of neptunium and uranium in the fuel degradation experiments referred to earlier and found a close correlation between neptunium and uranium concentrations in the leachates. In other words, the ratio of neptunium to uranium in the leachate is equal to the ratio in the spent fuel used in the experiments. Bruno et al. (1998 [DIRS 101565]) have also observed a coherent relation between neptunium and uranium in spent fuel dissolution experiments in the Spanish Nuclear Waste Program. These results are corroborated by the linear relationship between neptunium contents in uranophane and $\mathrm{Na}$-compreignacite and the mother solution that was found by Burns et al. (2004 [DIRS 171442]).

There are several conceivable explanations for this coherent relation between neptunium and uranium. A simple explanation is that it is the result of congruent dissolution of fuel matrix with few effects of secondary phases. Another explanation is that neptunium and uranium behave coherently, not only in the dissolution process but also in the process of secondary phase precipitation. A third explanation poses uranium and neptunium form their own solid phases, and the uranium and neptunium solubility controlled by them, respectively, would have a ratio equal to the ratio of uranium to neptunium in the fuel. Because in spent fuel corrosion experiments a large portion of reacted uranium was precipitated as secondary uranium minerals, the experiments represent incongruent reactions. Thus, the first explanation does not hold. The third hypothesis relies on coincidence, and as stated earlier, no neptunium pure phases have been reported in fuel dissolution experiments; thus, it is unsubstantiated. Therefore, the second explanation is the most reasonable explanation. In other words, the coherent relation between neptunium and uranium is the result of formation of solid solutions between them.

\subsubsection{Concentrating Factor of Neptunium}

The experimental data described above show that the neptunium concentrations in solutions degrading spent fuel are considerably lower than concentrations controlled by pure-neptunium solids. An empirical neptunium solubility limit was developed based on drip test measurements, which does not rely on the identification of neptunium-bearing phases or assumptions about neptunium retention mechanisms (Chen 2001 [DIRS 161997]; Chen et al. 2002 [DIRS 161996]). 
The concentrating factor of neptunium in solution is defined as:

$$
F_{c}=\frac{(N p / U)_{\text {soln }}}{(N p / U)_{\text {fuel }}}
$$

where $(\mathrm{Np} / \mathrm{U})_{\text {soln }}$ denotes the ratio of neptunium to uranium in solution and $(\mathrm{Np} / U)_{\text {fuel }}$ denotes the same ratio in spent fuel. The concentrating factor $\left(F_{c}\right)$ of neptunium describes the degree of neptunium being concentrated in solution relative to the spent fuel with which it is in contact.

Rearranging Equation 6.6-8 yields:

$$
[\mathrm{Np}]=\mathrm{F}_{\mathrm{c}}(\mathrm{Np} / \mathrm{U})_{\mathrm{fuel}}[\mathrm{U}]
$$

where $[\mathrm{Np}]$ and $[\mathrm{U}]$ denote the concentrations of neptunium and uranium in solution, respectively.

Equation 6.6-9 indicates neptunium concentration is proportional to uranium concentration. The proportionality constant, $(\mathrm{Np} / \mathrm{U})_{\text {fuel }}$, is a product of a known value of the ratio of neptunium and uranium in the fuel. The uncertain concentrating factor, $F_{c}$, is obtained from spent fuel dissolution experimental data.

\subsubsection{Simple Estimation of $F_{\mathrm{c}}$ of Neptunium Using Data from ANL Drip Tests}

Unsaturated spent fuel dissolution tests developed for the YMP have been described in detail in several journal articles (Finn et al. 1994 [DIRS 100746]; Finn et al. 1997 [DIRS 124142]) and in Secondary Uranium-Phase Paragenesis and Incorporation of Radionuclides into Secondary Phases (BSC 2001 [DIRS 154844]). Based on the rates of water added to the spent fuel samples, those experiments were grouped into three categories: high drip-rate tests, low drip-rate tests, and vapor tests. All other environmental conditions were constant. The tests are designed to simulate the evolution of spent nuclear fuel and the release of radionuclides in the repository. The concentrations of several radionuclides in the leachate were measured and reported (CRWMS M\&O 2000 [DIRS 131861]; CRWMS M\&O 2000 [DIRS 153105]; and DTN: LL991001251021.090 [DIRS 129285]).

Two types of commercial spent fuels, approved testing material (ATM)-103 with a burn-up of $30 \mathrm{MW}-\mathrm{d} / \mathrm{kgU}$ and ATM-106 with a burnup of $43 \mathrm{MW}-\mathrm{d} / \mathrm{kgU}$ (Finn et al. 1994 [DIRS 100746]), were used in the experiments. The calculated ${ }^{237} \mathrm{~Np} /{ }^{238} \mathrm{U}$ ratios in those two fuels are listed in Table 6.6-11 using the inventory tables given by Guenther et al. (1988 [DIRS 109205]; 1988 [DIRS 109206]), assuming 15 years out of the reactor (Section 5.2).

Table 6.6-11. Calculated Mole Ratio of ${ }^{237} \mathrm{~Np}$ to ${ }^{238} \mathrm{U}$ in the Fuels Used in ANL Experiments

\begin{tabular}{|c|c|c|}
\hline & ATM-103 & ATM-106 \\
\hline Burnup & $30 \mathrm{MW}-\mathrm{d} / \mathrm{kgU}$ & $43 \mathrm{MW}-\mathrm{d} / \mathrm{kgU}$ \\
\hline Np-237/U-238 & $4.20 \mathrm{E}-04$ & $6.44 \mathrm{E}-04$ \\
\hline
\end{tabular}

Source: ANL6dripdata.x/s (Appendix I). 
There are 46 concentration values of ${ }^{237} \mathrm{~Np}$ and ${ }^{238} \mathrm{U}$ available from the high drip-rate and low drip-rate tests (DTN: LL991001251021.090 [DIRS 129285]; CRWMS M\&O 2000 [DIRS 153105]). Because isotope fractionation is not expected to significantly change the isotopic ratios of the leachate from that of the fuel, it is concluded that:

$$
F_{c}=\frac{(N p / U)_{\text {soln }}}{(N p / U)_{\text {fuel }}}=\frac{\left(N p^{237} / U^{238}\right)_{\text {soln }}}{\left(N p^{237} / U^{238}\right)_{\text {fuel }}}
$$

Figure 6.6-5 is a histogram of the $\log F_{c}$ values calculated from the 46 sets of experiments reported. $\log \mathrm{F}_{\mathrm{c}}$ has a normal distribution with a mode around 0.0 (i.e., $\mathrm{F}_{\mathrm{c}}$ has a mode of 1.0).

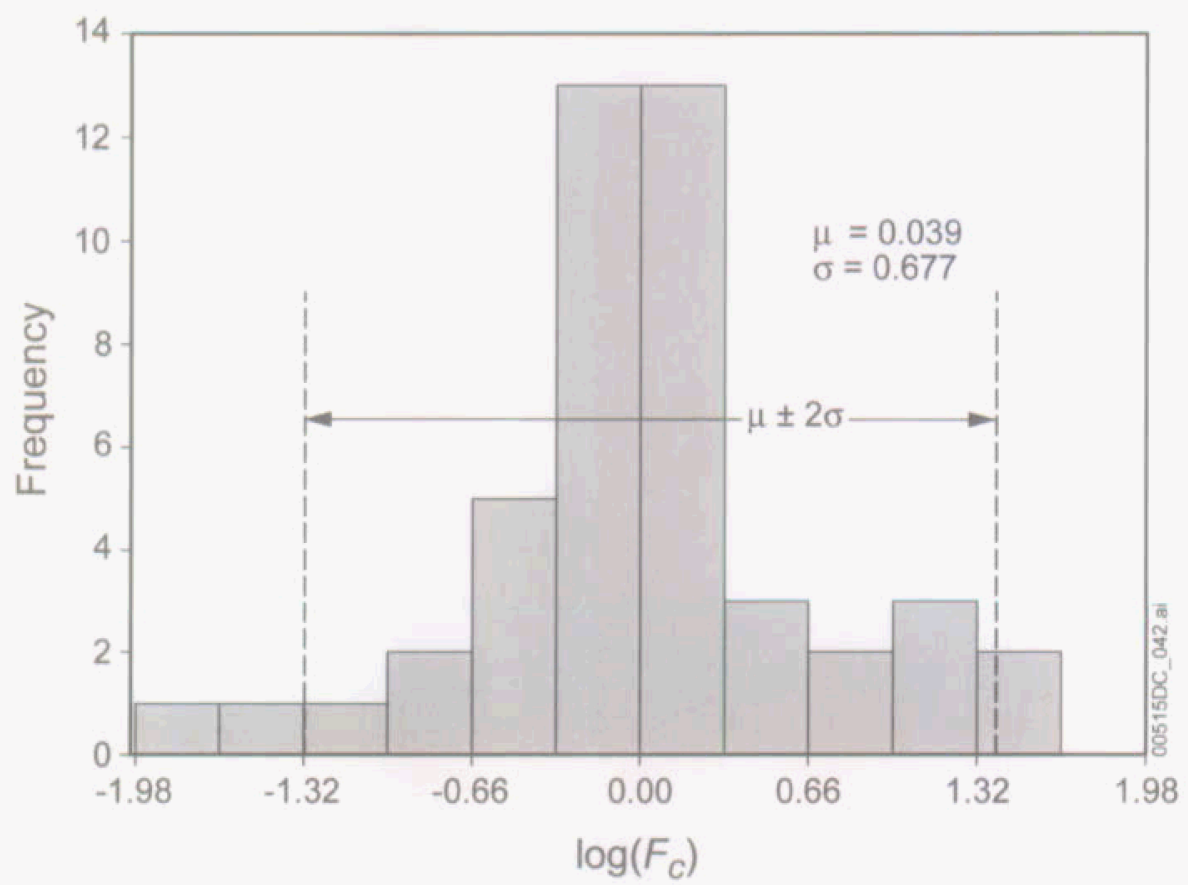

Source: FC histogram.jnb (Appendix I).

Figure 6.6-5. Histogram of $F_{c}$ on a $\log$ Scale

Table 6.6-12 lists the statistical description of $F_{c}$ for neptunium determined from the ANL high and low drip tests. Of the 46 data points, the geometric mean of $F_{c}$ is 1.094 , which is very close to 1 . In other words, the arithmetic mean of $\log \mathrm{F}_{\mathrm{c}}$ is 0.039 , which is very close to 0 . The standard deviation of $\log \mathrm{F}_{\mathrm{c}}$ is 0.667 . With a confidence level of 95 percent, the upper and lower statistical limits $(\mu \pm 2 \sigma)$ of $\log F_{c}$ are 1.394 and -1.316 , respectively. In other words, the probability for $\log F_{c}$ falling between the statistical limits $(-1.316,1.394)$ is 95.5 percent. Translated back to $F_{c}$, the upper and lower limits of $F_{c}$ are 24.787 and 0.048 , respectively. That is the range of uncertainty in $\mathrm{F}_{\mathrm{c}}$ of neptunium from ANL high-drip and low-drip tests. It spans less than 3 orders of magnitude.

The fact that the average of $\log \mathrm{F}_{\mathrm{c}}$ is very close to 0.0 and has a mode of 0.0 strongly suggests that the neptunium-uranium values in the solutions are very close to the neptunium-uranium 
values in the fuels. In other words, uranium and neptunium are released from the fuel coherently.

In fact, the coherent relation between uranium and neptunium has also been observed in other spent fuel dissolution experiments. For example, based on PNNL Series 2 and Series 3 steady-state test results (Wilson 1990a [DIRS 100949]; Wilson 1990b [DIRS 100793]; CRWMS M\&O 1998 [DIRS 100348]) states that "the data suggest that Np enters the aqueous phase congruently with uranium as the fuel dissolves." The calculated $\mathrm{F}_{\mathrm{c}}$ for Series 2 tests ranges from 0.44 to 2.59, with a geometric mean of 1.13 (PNL-wilson.xls in Appendix I). The calculated $\mathrm{F}_{\mathrm{c}}$ for Series 3 tests ranges from 3.38 to 11.73 , with a geometric mean of 5.90 (PNL-wilson.xls in Appendix I).

Table 6.6-12. Statistics of $F_{c}$ of Neptunium from High and Low Drip Tests

\begin{tabular}{|l|c|c|}
\hline & $\mathbf{F}_{\mathrm{c}}$ & $\log \boldsymbol{F}_{\mathrm{c}}$ \\
\hline Number of Samples & 46 & 46 \\
\hline Maximum & 30.260 & 1.481 \\
\hline Minimum & 0.015 & -1.833 \\
\hline Arithmetic Mean $(\mu)$ & 3.363 & 0.039 \\
\hline Geometric Mean & 1.094 & \\
\hline Standard Deviation $(\sigma)$ & & 0.677 \\
\hline$\mu+2 \sigma$ & & 1.394 \\
\hline$\mu-2 \sigma$ & 24.787 & -1.316 \\
\hline $\begin{array}{l}\text { Upper Limit (UL) of 95\% Confidence } \\
\text { Level } \\
\left(\text { UL }=10^{\mu+2 \sigma}\right)\end{array}$ & 0.048 & \\
\hline $\begin{array}{l}\text { Lower Limit (LL) of 95\% Confidence } \\
\text { Level } \\
\left(\text { LL }=10^{\mu-2 \sigma}\right)\end{array}$ & 513.407 & \\
\hline \begin{tabular}{l} 
Ratio of Upper to Lower Limit \\
\hline
\end{tabular} & & \\
\hline
\end{tabular}

Source: ANL6dripdata.xls (Appendix I).

Bruno et al. (1998 [DIRS 101565]) have also observed the coherent relation between neptunium and uranium in spent fuel dissolution experiments in the Spanish Nuclear Waste Program as shown in Table 6.6-13.

Table 6.6-13. Neptunium-Uranium Ratios in Spent Fuel and Its Solution

\begin{tabular}{|c|c|c|}
\hline & Fuel Inventory & Solution \\
\hline $\mathrm{Np} / \mathrm{U}$ & $4.88 \mathrm{E}-4$ & $5.25 \mathrm{E}-4$ \\
\hline
\end{tabular}

Source: Bruno et al. 1998 [DIRS 101565]. 
It is unlikely that the coherent relation between uranium and neptunium is a coincidence. Rather, it reflects the similarity of geochemical behaviors of $\mathrm{U}(\mathrm{VI})$ and $\mathrm{Np}(\mathrm{V})$. Incorporation of neptunium into uranyl minerals is the most reasonable explanation for this relation.

In summary, based on the simple statistics of ANL drip test data, $F_{c}$ is a log-normal random variable, with a mean of 1.094. At a confidence level of 95.5 percent, it ranges from 0.048 to 24.787 , an uncertainty range of less than three orders of magnitude. However, as explained in Section 6.6.5.3, the large departures from $F_{c} \sim 1$ are observed under conditions not relevant to TSPA-LA.

\subsubsection{Trend Analysis of $F_{c}$ of Neptunium Using Data from ANL Drip Tests}

The previous section discussed the conventional statistics of $F_{c}$ of neptunium. This section further analyzes the variation of $F_{c}$ in time.

Figure 6.6-6 shows the $F_{c}$ of neptunium in the ANL high-drip tests as a function of time. The low-drip results are shown in Figure 6.6-7. The solid lines are tests with ATM-103 fuel, while the dashed lines are tests for ATM-106 fuel. They show that in those four tests, $F_{c}$ of neptunium fluctuates around 1.0. Moreover, in all the 4 tests, the highest $F_{c}$ occurs in the first sample, and then $F_{c}$ decreases and reaches the lowest value within two years. In other words, the big variations in $F_{c}$ occur in the first two years, and decrease with time. This suggests that the coherent relation between neptunium and uranium becomes more obvious as time increases, and the spikes of $F_{c}$ values observed in the first two years are transient phenomena in the drip tests. The rapid release of neptunium at the early stage of experiments has also been observed in PNNL Series 2 and Series 3 tests (Wilson 1990a [DIRS 100949], Figure 3.5, p. 3.18; Wilson 1990b [DIRS 100793], Figure 3.19, p. 3.39). Early transient phenomena are thought to be due to fuel fines and supersaturation effects. Because this report focuses on long-term performance of the repository, these spikes are not considered to be important. Therefore, it is reasonable to exclude the early data from the ANL drip tests when $F_{c}$ is estimated.

Excluding those data points measured at time less than two years, subset data (containing 28 data points) of the four drip tests were obtained. Table 6.6-14 presents the statistical results for the subset data. The geometric mean of this reduced dataset is still close to $1.0(1.142)$, but with a smaller standard deviation. The upper and lower limits of $F_{c}$ at a confidence level of 95.5 percent now are 10.653 and 0.122 , respectively. The dataset spans less than 2 orders of magnitude. 
Table 6.6-14. Statistics of $F_{c}$ of Neptunium from the Subset of High and Low Drip Tests $(t \geq 2 y r$.)

\begin{tabular}{|l|c|c|}
\hline & $F_{\mathrm{c}}$ & $\log \mathbf{F}_{\mathrm{c}}$ \\
\hline Number of Samples & 28 & 28 \\
\hline Maximum & 16.347 & 1.213 \\
\hline Minimum & 0.032 & -1.048 \\
\hline Arithmetic Mean $(\mu)$ & 1.954 & 0.058 \\
\hline Geometric Mean & 1.142 & \\
\hline Std Dev $(\sigma)$ & & 0.485 \\
\hline$\mu+2 \sigma$ & & 1.027 \\
\hline$\mu-2 \sigma$ & & -0.912 \\
\hline Upper Limit of 95\% Confidence Level $\left(\mathrm{UL}=10^{\mu+2 \sigma}\right)$ & 10.653 & \\
\hline Lower Limit of 95\% Confidence Level $\left(\mathrm{LL}=10^{\mu-2 \sigma}\right)$ & 0.122 & \\
\hline Ratio of Upper Limit to Lower Limit & 86.974 & \\
\hline
\end{tabular}

Source: ANL6dripdata.x/s (Appendix I).

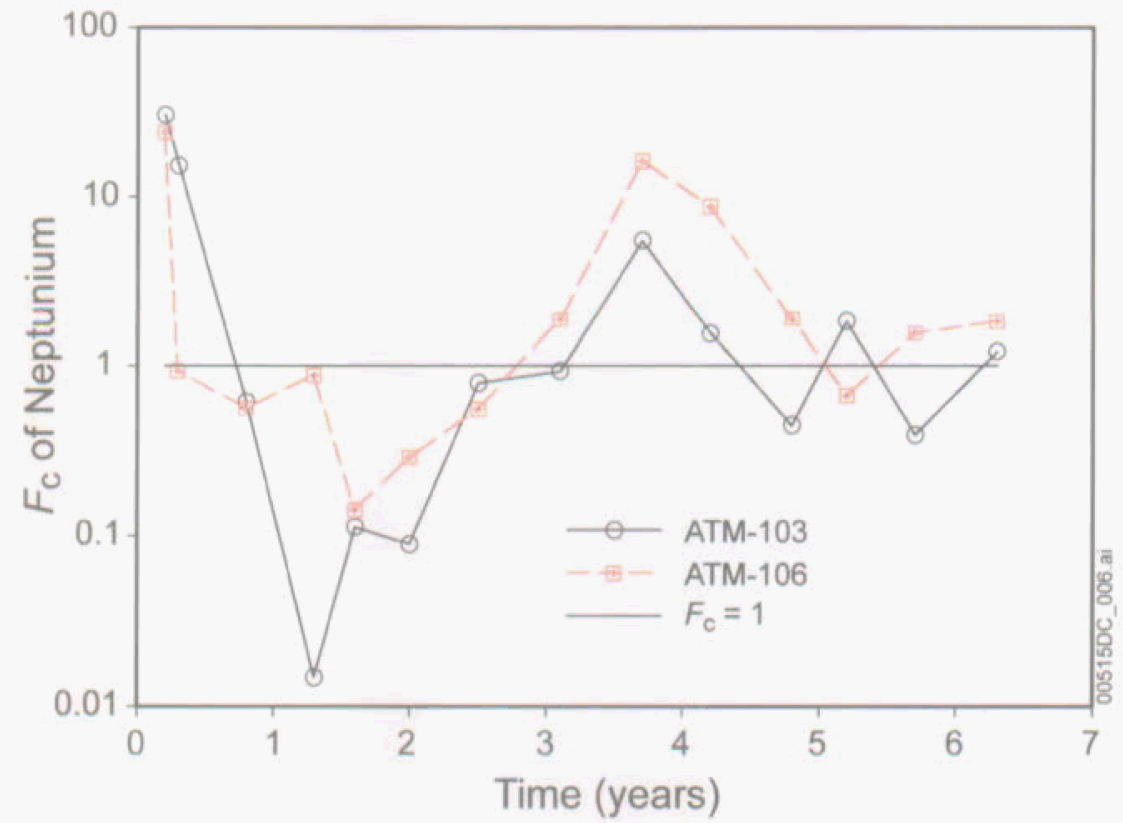

Source: HighDrip-Fc.jnb (Appendix I).

NOTE: $\quad F_{c}$ of neptunium fluctuates around 1 and appears to damp to 1 as time increases.

Figure 6.6-6. $F_{c}$ Values of Neptunium in the ANL High-Drip Tests as a Function of Time 


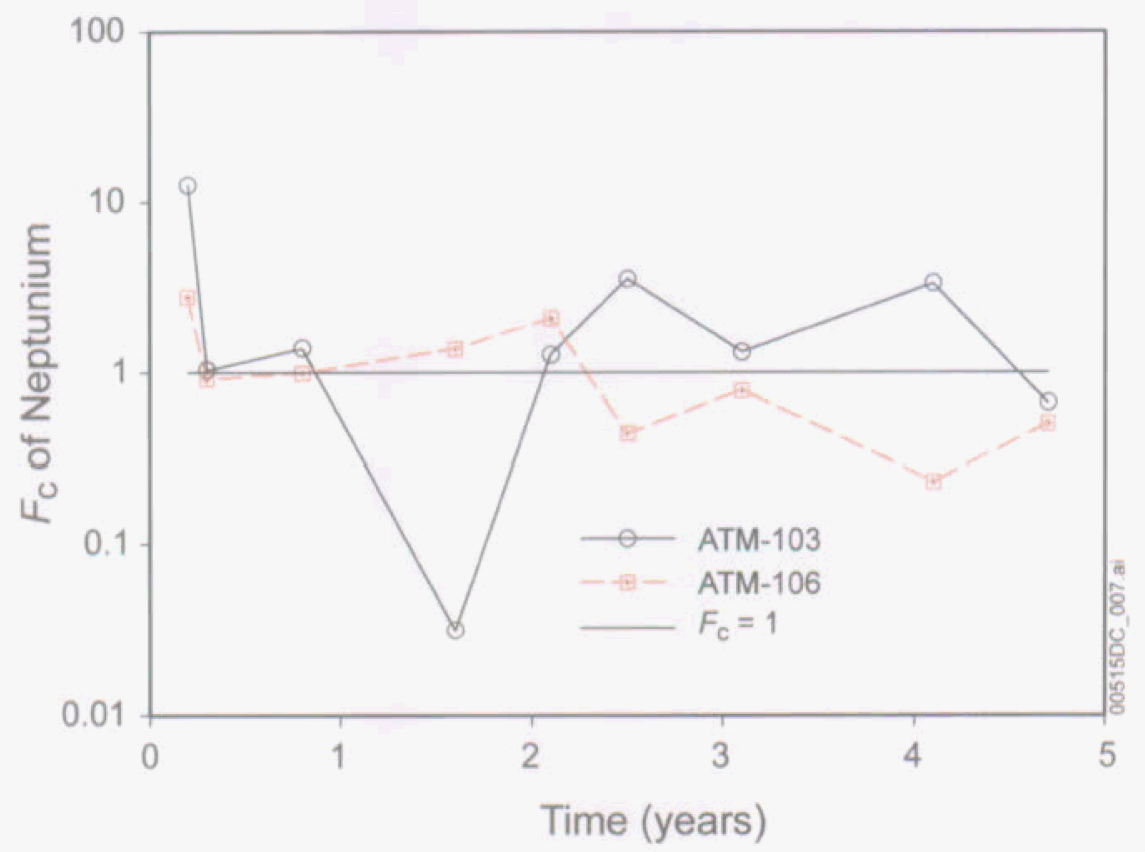

Source: LowDrip-Fc.jnb (Appendix I).

NOTE: $\quad$ Similar to Figure $4, F_{c}$ of neptunium fluctuates around 1 and appears to damp to 1 as time increases.

Figure 6.6-7. $F_{\mathrm{c}}$ Values of Neptunium in the ANL Low-Drip Tests as a Function of Time

In summary, excluding the early data points that represent the transient period, $\mathrm{F}_{\mathrm{c}}$ was estimated with a geometric mean of 1.142 and ranges from 0.122 to 10.653 .

\subsubsection{Abstracted Neptunium Solubility Based on $\mathbf{F}_{\mathrm{c}}$}

As discussed in Section 6.6.5.1, neptunium solubility [Np] can be calculated from uranium solubility, $\mathrm{F}_{\mathrm{c}}$, and the neptunium-uranium ratio of the fuel (Equation 6.6-9).

As discussed in the previous section, $\mathrm{F}_{\mathrm{c}}$ is around 1.0, with an uncertainty range of about two orders of magnitude. $F_{c}$ has a geometric mean of 1.0 , ranging from 0.1 to 10.0 .

The ratio of neptunium-uranium in the fuel can be calculated from the waste inventory, which is a function of time. In order to have long-term predictive capability, the effect of decay-chain ingrowth on $(\mathrm{Np} / \mathrm{U})_{\text {fuel }}$ should be considered. Otherwise, the calculated neptunium solubility would be nonconservative over the regulatory time period. For example, for ATM-103 fuel with a burnup of $30 \mathrm{MWd} / \mathrm{kg}$ and 10 years storage, $(\mathrm{Np} / \mathrm{U})_{\text {fuel }}$ is $4.15 \mathrm{E}-4$ (ANL6dripdata.xls). However, if the in-growth from ${ }^{241} \mathrm{Am}$ and ${ }^{241} \mathrm{Pu}$ decay are included, $(\mathrm{Np} / \mathrm{U})_{\text {fuel }}$ should be $1.68 \mathrm{E}$ 3 (ANL6dripdata.xls), an increase of a factor of 4.04. Using the average waste inventory (DTN: SN0011T0810599.023 [DIRS 152993]) with adjustment for decay of ${ }^{241}$ Am for CSNF waste packages, the ratio equals $1.93 \mathrm{E}-3$ (ANL6dripdata.xls).

Using schoepite as the uranium solubility-controlling solid, uranium solubility is represented as a table with $\mathrm{pH}$ and $\log f \mathrm{CO}_{2}$ (Table 6.7-3) as independent variables, with uncertainty terms given in Section 6.7.6. 
Using the values of $F_{c},(N p / U)_{\text {fuel }}$, and $[U]$ described earlier, the abstracted neptunium solubility is given by Equation 6.6-11 and listed in Table 6.6-15. The difference between the atomic weights of uranium and neptunium is very small and is neglected.

$$
\log [\mathrm{Np}]=\log \mathrm{F}_{\mathrm{c}}+\log (\mathrm{Np} / \mathrm{U})_{\text {fuel }}+\log [\mathrm{U}]=\log [\mathrm{U}]-2.71
$$

Equation 6.6-11 and Table 6.6-15 include the adjustment for long-term decay of ${ }^{241} \mathrm{Am}$. To calculate the short-term solubility of $\mathrm{Np}$ with this model, an additional 0.61 ( $\log$ of the factor of 4.04 ) must be subtracted from the $\log [\mathrm{U}]$, as was done in Figure 6.6-8.

The user of the table needs to ensure that when the flag (500) is encountered, the concentrations calculated according to the dissolution rate of individual waste forms, water volume, and the solubility caps presented in Table 8-5. For any conditions that fall between a valid solubility and a flag of 500, the flag should be used. In addition, for any conditions outside of the 3.0 to 11.0 $\mathrm{pH}$ range, the -1.5 to $-5.0 f \mathrm{CO}_{2}$ range, or with an ionic strength greater than 1.0 molal, the concentrations calculated according to the dissolution rate of individual waste forms, water volume, and the solubility caps presented in Table 8-5.

The uncertainty terms given to the uranium solubility model in Section 6.7 .6 also apply to this neptunium solubility model. In addition, this neptunium solubility has an additional uncertainty term, $\varepsilon_{3}$, which represents the uncertainty in the $F_{c}$ variable. The uncertainty term $\varepsilon_{3}$ obeys a normal distribution with $\mu=0$ and a standard deviation of \pm 0.5 (Equation 6.6-12)

This model was mainly developed for CSNF waste packages. For codisposal waste packages, some adjustment may be needed to account for the difference of isotope inventory between the two types of waste packages. However, as an alternative model, this model can also be used as a first order approximation for codisposal waste packages. 
Table 6.6-15. Secondary-Phase Neptunium-Solubility Model (log[Np] (mg/L))

\begin{tabular}{|c|c|c|c|c|c|c|c|c|}
\hline \multirow[b]{2}{*}{$\mathrm{pH}$} & \multicolumn{8}{|c|}{ Log $\mathrm{fCO}_{2}$ (bars) } \\
\hline & -1.50 & -2.00 & -2.50 & -3.00 & -3.50 & -4.00 & -4.50 & -5.00 \\
\hline 3.50 & $1.70 \mathrm{E}+00$ & $1.70 \mathrm{E}+00$ & $1.70 \mathrm{E}+00$ & $1.70 \mathrm{E}+00$ & $1.70 \mathrm{E}+00$ & $1.70 E+00$ & $1.70 \mathrm{E}+00$ & $1.70 \mathrm{E}+00$ \\
\hline 3.75 & 8.43E-01 & $8.42 \mathrm{E}-01$ & $8.42 E-01$ & $8.42 E-01$ & $8.42 E-01$ & 8.42E-01 & 8.42E-01 & 8.42E-01 \\
\hline 4.00 & $1.56 \mathrm{E}-01$ & $1.56 \mathrm{E}-01$ & $1.56 \mathrm{E}-01$ & $1.56 \mathrm{E}-01$ & $1.56 \mathrm{E}-01$ & $1.56 \mathrm{E}-01$ & $1.56 \mathrm{E}-01$ & $1.56 \mathrm{E}-01$ \\
\hline 4.25 & $-3.76 \mathrm{E}-01$ & $-3.78 \mathrm{E}-01$ & $-3.79 \mathrm{E}-01$ & $-3.79 \mathrm{E}-01$ & $-3.79 \mathrm{E}-01$ & $-3.79 \mathrm{E}-01$ & -3.79E-01 & $-3.79 \mathrm{E}-01$ \\
\hline 4.50 & $-7.84 \mathrm{E}-01$ & $-7.90 \mathrm{E}-01$ & $-7.92 \mathrm{E}-01$ & $-7.93 \mathrm{E}-01$ & $-7.93 E-01$ & $-7.93 \mathrm{E}-01$ & $-7.93 \mathrm{E}-01$ & $-7.93 \mathrm{E}-01$ \\
\hline 4.75 & $-1.09 E+00$ & $-1.11 \mathrm{E}+00$ & $-1.11 \mathrm{E}+00$ & $-1.12 \mathrm{E}+00$ & $-1.12 E+00$ & $-1.12 E+00$ & $-1.12 E+00$ & $-1.12 E+00$ \\
\hline 5.00 & $-1.36 \mathrm{E}+00$ & $-1.39 E+00$ & $-1.40 \mathrm{E}+00$ & $-1.40 \mathrm{E}+00$ & $-1.41 E+00$ & $-1.41 E+00$ & $-1.41 E+00$ & $-1.41 E+00$ \\
\hline 5.25 & $-1.61 E+00$ & $-1.68 \mathrm{E}+00$ & $-1.71 E+00$ & $-1.71 \mathrm{E}+00$ & $-1.72 E+00$ & $-1.72 \mathrm{E}+00$ & $-1.72 E+00$ & $-1.72 \mathrm{E}+00$ \\
\hline 5.50 & $-1.78 \mathrm{E}+00$ & $-1.95 E+00$ & $-2.01 E+00$ & $-2.04 E+00$ & $-2.04 E+00$ & $-2.05 E+00$ & $-2.05 E+00$ & $-2.05 E+00$ \\
\hline 5.75 & $-1.81 E+00$ & $-2.09 \mathrm{E}+00$ & $-2.24 \mathrm{E}+00$ & $-2.30 \mathrm{E}+00$ & $-2.32 E+00$ & $-2.33 E+00$ & $-2.33 E+00$ & $-2.33 E+00$ \\
\hline 6.00 & $-1.68 \mathrm{E}+00$ & $-2.08 \mathrm{E}+00$ & $-2.33 E+00$ & $-2.46 \mathrm{E}+00$ & $-2.51 E+00$ & $-2.52 E+00$ & $-2.53 E+00$ & $-2.53 E+00$ \\
\hline 6.25 & $-1.46 \mathrm{E}+00$ & $-1.95 E+00$ & $-2.30 \mathrm{E}+00$ & $-2.50 \mathrm{E}+00$ & $-2.59 \mathrm{E}+00$ & $-2.63 \mathrm{E}+00$ & $-2.64 \mathrm{E}+00$ & $-2.64 E+00$ \\
\hline 6.50 & $-1.19 \mathrm{E}+00$ & $-1.75 E+00$ & $-2.18 E+00$ & $-2.46 \mathrm{E}+00$ & $-2.61 E+00$ & $-2.67 E+00$ & $-2.69 \mathrm{E}+00$ & $-2.70 \mathrm{E}+00$ \\
\hline 6.75 & $-8.47 \mathrm{E}-01$ & $-1.50 \mathrm{E}+00$ & $-2.00 \mathrm{E}+00$ & $-2.36 \mathrm{E}+00$ & $-2.58 \mathrm{E}+00$ & $-2.68 \mathrm{E}+00$ & $-2.71 E+00$ & $-2.73 E+00$ \\
\hline 7.00 & $-3.83 E-01$ & $-1.20 \mathrm{E}+00$ & $-1.77 \mathrm{E}+00$ & $-2.21 E+00$ & $-2.50 E+00$ & $-2.66 \mathrm{E}+00$ & $-2.72 E+00$ & $-2.74 E+00$ \\
\hline 7.25 & 500 & $-8.23 \mathrm{E}-01$ & $-1.51 \mathrm{E}+00$ & $-2.01 E+00$ & $-2.38 \mathrm{E}+00$ & $-2.60 \mathrm{E}+00$ & $-2.70 \mathrm{E}+00$ & $-2.74 \mathrm{E}+00$ \\
\hline 7.50 & 500 & $-1.74 \mathrm{E}-01$ & $-1.19 \mathrm{E}+00$ & $-1.78 \mathrm{E}+00$ & $-2.22 \mathrm{E}+00$ & $-2.51 E+00$ & $-2.67 \mathrm{E}+00$ & $-2.73 E+00$ \\
\hline 7.75 & 500 & 500 & $-7.29 \mathrm{E}-01$ & $-1.50 E+00$ & $-2.01 E+00$ & $-2.38 E+00$ & $-2.60 E+00$ & $-2.70 E+00$ \\
\hline 8.00 & 500 & 500 & 500 & $-1.13 E+00$ & $-1.77 \mathrm{E}+00$ & $-2.21 E+00$ & $-2.50 \mathrm{E}+00$ & $-2.65 E+00$ \\
\hline 8.25 & 500 & 500 & 500 & $-4.43 \mathrm{E}-01$ & $-1.47 E+00$ & $-2.00 \mathrm{E}+00$ & $-2.36 E+00$ & $-2.57 E+00$ \\
\hline 8.50 & 500 & 500 & 500 & 500 & $-9.83 E-01$ & $-1.75 E+00$ & $-2.18 \mathrm{E}+00$ & $-2.45 E+00$ \\
\hline 8.75 & 500 & 500 & 500 & 500 & 500 & $-1.37 E+00$ & $-1.96 \mathrm{E}+00$ & $-2.29 E+00$ \\
\hline 9.00 & 500 & 500 & 500 & 500 & 500 & $-5.98 \mathrm{E}-01$ & $-1.67 E+00$ & $-2.10 E+00$ \\
\hline 9.25 & 500 & 500 & 500 & 500 & 500 & 500 & $-1.13 E+00$ & $-1.85 E+00$ \\
\hline 9.50 & 500 & 500 & 500 & 500 & 500 & 500 & 500 & $-1.47 \mathrm{E}+00$ \\
\hline 9.75 & 500 & 500 & 500 & 500 & 500 & 500 & 500 & $-6.30 \mathrm{E}-01$ \\
\hline
\end{tabular}

Source: Np 2ndPhase Solubility.xls (Appendix I).

NOTE: Some cells have no valid data because the EQ3NR calculations do not converge and the results are reported as 500 .

\subsubsection{Model Corroboration}

The secondary-phase neptunium solubility model developed in Section 6.5.5 is an alternative model and is not recommended for the TSPA-LA base-case analyses because a weakness exists in the model's bases, as discussed previously. Therefore, it has no impact on the estimate of mean annual dose. According to Appendix B of Scientific Processes Guidelines Manual (BSC 2002 [DIRS 160313], p. B-1), no model validation is required for this alternative model. This section describes corroboration activities to enhance the confidence in the secondary phase model. 
Figure 6.6-8 compares the model (which was presented without decay train in-growth adjustment to match the neptunium-uranium ratio in the spent fuel), and the $\mathrm{Np}_{2} \mathrm{O}_{5}$ solubility model developed in Section 6.6.3 with spent fuel corrosion experimental data (Wilson 1990a [DIRS 100949]; Wilson 1990b [DIRS 100793]). The solid curve is the mean value at $\log f \mathrm{CO}_{2}=-5$ bars. The double-dot dashed curve and the dashed curve are ten times and onetenth of the mean value, respectively, which correspond to adding $\pm 2 \sigma$ of $\log F_{c}$ to the $\log$ of neptunium solubility. The cited experimental results were not used in the development of this model. The figure clearly shows that the secondary phase model captures the experimental results, and the fluctuations in the experimental measurements are well within the uncertainty range of the model. In contrast, the $\mathrm{Np}_{2} \mathrm{O}_{5}$ solubility model does not match the experimental results. The agreement between the alternative secondary phase model and the experimental results corroborates this alternative model.

A mechanistic model was developed (CRWMS M\&O 1998 [DIRS 100362]; Chen et al. 1999 [DIRS 145441]) based on the concept that neptunium is incorporated into secondary uranyl minerals. The model is a reactive-transport model that considers equilibrium reactions and kinetic dissolution-precipitation reactions of solids under flow conditions. The modeling results have been compared against laboratory measurements and observations of natural analogs. For repository conditions, the model predicted that neptunium solubility ranges from $1.0 \mathrm{E}-9$ to $1.0 \mathrm{E}-6 \mathrm{~mol} / \mathrm{L}$.

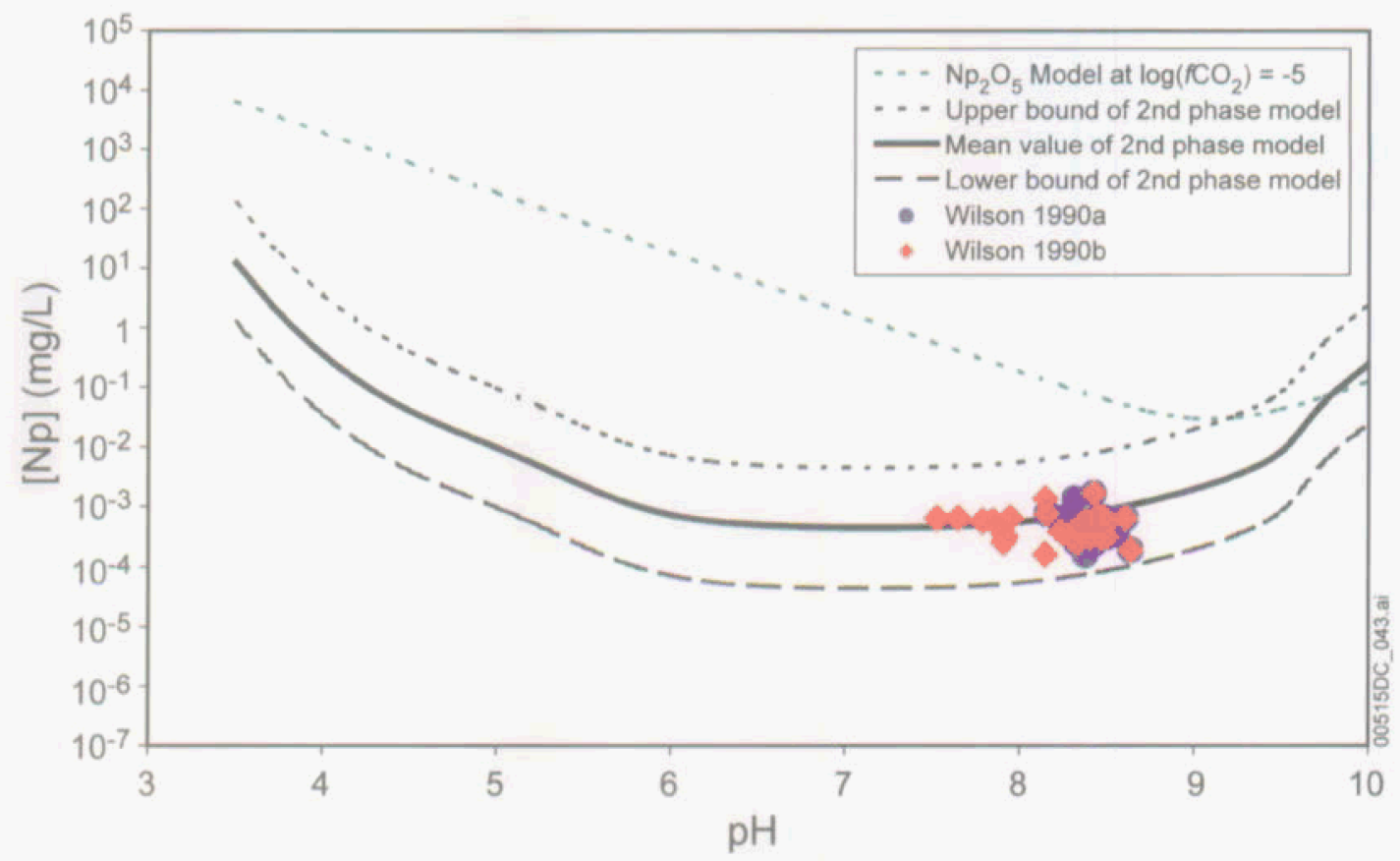

Data Source: Wilson 1990a [DIRS 100949]; Wilson 1990b [DIRS 100793] (PNL-Wilson.x/s in Appendix I).

Source: fig668.x/s (in Appendix 1).

Figure 6.6-8. Comparison of Secondary Phase Neptunium Solubility Model (Without Inventory Adjustment) with PNNL and ANL Measurements and Calculated $\mathrm{Np}_{2} \mathrm{O}_{5}$ Solubility

A reactive-transport modeling study of the release of neptunium during the process of spent fuel corrosion was published in Computers \& Geosciences (Chen 2003 [DIRS 162709]). This study 
considers several scenarios of neptunium release from spent nuclear fuel corrosion. The simulation results show that experimental observations are consistent with the hypothesis that neptunium is incorporated into every uranyl mineral (including schoepite). This study further supports the conceptual model of neptunium incorporation into uranyl minerals.

\subsubsection{Summary of Secondary-Phase Neptunium-Solubility Model}

The secondary phase neptunium-solubility model can be summarized by the following equation:

$$
\log [N p]=S\left(p H, \log f_{\mathrm{CO}_{2}}\right)+\varepsilon_{1}+\varepsilon_{2}+\varepsilon_{3}
$$

where

$S\left(p H, \log f_{\mathrm{CO}_{2}}\right)$ is given by Table 6.6-15

$\varepsilon_{1}$ is the uncertainty term associated with uncertainty in $\log K$ values of the uranium solubility when schoepite is the controlling phase (Section 6.7.6). That is the case for all $\mathrm{pH}$ and $f \mathrm{CO}_{2}$ values for CSNF packages breached under nominal and seismic conditions and for low $\mathrm{pH}$ and $f \mathrm{CO}_{2}$ values (Table 6.7-5) for CSNF packages breached by an intrusive event, codisposal packages breached under any conditions and in the invert.

$\varepsilon_{2}$ is the uncertainty term associated with variations in fluoride concentration

$\varepsilon_{3}$ is the uncertainty term in $F_{c}$.

The distribution properties of these uncertainty terms are listed in Table 6.6-16.

Table 6.6-16. Uncertainty Terms of $\log [\mathrm{Np}]$ of the Secondary Phase Neptunium Solubility Model

\begin{tabular}{|c|l|l|l|l|}
\hline $\begin{array}{c}\text { Uncertainty } \\
\text { Term }\end{array}$ & \multicolumn{1}{|c|}{ Associated With } & Distribution Type & $\begin{array}{c}\text { Distribution } \\
\text { Parameter }\end{array}$ & \multicolumn{1}{c|}{ Applicability } \\
\hline$\varepsilon_{1}$ & Uncertainties in log $\mathrm{K}$ & Normal & $\mu=0, \sigma=0.5^{\mathrm{a}}$ & All values in Table 6.6-15 \\
\hline$\varepsilon_{2}$ & $\begin{array}{l}\text { Fluoride concentration in } \\
\text { CSNF waste packages }\end{array}$ & Triangular & $\mathrm{a}=\mathrm{b}=0, \mathrm{c}=1.03$ & CSNF waste packages \\
\hline$\varepsilon_{3}$ & Uncertainty in $\mathrm{F}_{\mathrm{c}}$ & Normal & $\mu=0, \sigma=0.5$ & All values in Table $6.6-15$ \\
\hline NOTE: $\quad \begin{array}{l}\text { For ionic strength values between } 1 \text { and } 3, \log \mathrm{K} \text { uncertainty should be treated as a normal distribution } \\
\text { truncated at } \pm 2 \sigma \text { with distribution parameters } \mu=0, \sigma=0.60 \text { (rounded from } 0.58 \text { ) (Section } 6.3 .3 .4, \\
\text { Equation } 6.3-7) .\end{array}$
\end{tabular}

\subsection{URANIUM SOLUBILITY}

\subsubsection{Introduction}

Under the oxidizing conditions of the repository, uranium is in the U(VI) (uranyl) oxidation state. To provide $U$ concentrations over the full range of possible environmental conditions, the solubilities of three uranyl $\left(\mathrm{UO}_{2}{ }^{2+}\right)$ solids have been modeled: the minerals schoepite $\left(\mathrm{UO}_{3} \cdot 2 \mathrm{H}_{2} \mathrm{O}\right)$ and $\mathrm{Na}$-boltwoodite $\left(\mathrm{NaUO}_{2} \mathrm{SiO}_{3} \mathrm{OH} \cdot 1.5 \mathrm{H}_{2} \mathrm{O}\right)$, and $\mathrm{Na}_{4} \mathrm{UO}_{2}\left(\mathrm{CO}_{3}\right)_{3}$. The conditions under which each is the controlling solid depend on the ambient water chemistry, $\mathrm{pH}$, and $f \mathrm{CO}_{2}$. For the case of water found on CSNF following waste package breaching under nominal 
conditions or by a hypothetical seismic event, $U$ concentrations are controlled by schoepite under all $\mathrm{pH}$ and $f \mathrm{CO}_{2}$ conditions. For codisposal packages under all breach scenarios, CSNF packages breached in the course of an intrusive event and in the invert, all three minerals control the $\mathrm{U}$ concentration under various ranges of $\mathrm{pH}$ and $f \mathrm{CO}_{2}$.

Section, 6.7.2 discusses the selection of the controlling solids and the conditions under which each is active. Section 6.7.3 describes the chemical conditions for which the calculations were made. The results are given in Section 6.7.4 and include tables of U concentrations for CSNF and codisposal packages at a range of $\mathrm{pH}$ and $f \mathrm{CO}_{2}$ values for various breach scenarios. Section 6.7.5 discusses the uncertainties associated with the $U$ concentrations, while Section 6.7 .6 is a concluding summary.

\subsubsection{Factors Considered in Selecting Controlling Solids}

Following a waste package breach, the exposed waste and other waste package components react with incoming water, either seepage dripping (water influx scenario) into the failed waste package or water condensed or sorbed (vapor influx scenario) on waste package internal surfaces (BSC 2004 [DIRS 167621]). The oxidizing state of the repository promotes oxidation of U(IV) to U(VI) and its subsequent dissolution to uranyl ions and other aqueous uranyl species. When the concentration of uranyl and its aqueous species reaches the solubility of uranium solids, precipitation occurs and limits further increases in the total dissolved concentration of uranium. The selection of the uranium-controlling solids was based on three factors: (1) the paragenesis of uranium minerals in laboratory and natural studies, (2) the stability of uranium phases in the possible environments of TSPA-LA, and (3) the availability of thermodynamic data for the phases of interest. If there is no thermodynamic data for a $U$ solid, the phase was eliminated from further consideration as a solubility-controlling phase because it is not possible to determine the solubility of a mineral phase and the resultant aqueous concentration of uranium if there are no thermodynamic data available for that phase.

Laboratory and natural analog studies are the basis for the selection and validation of the controlling phases (CRWMS M\&O 1998 [DIRS 100362], Section 6.4.3.2; Finch et al. 1996 [DIRS 113056], Table 1; Murphy 1997 [DIRS 101731]; and Wronkiewicz et al. 1992 [DIRS 100493]). A recent and thorough laboratory study (Wronkiewicz et al. 1996 [DIRS 102047]) describes the results of a 10-year study of $\mathrm{UO}_{2}$ degradation at $90^{\circ} \mathrm{C}$ in dripping $\mathrm{J}-13$ type water equilibrated with tuff. The U-bearing alteration phases observed in that study are given in Table 6.7-1. The availability of thermodynamic data for modeling is also shown in the table.

The alteration paragenesis found in the laboratory and natural analog studies begins with uranyl-oxide hydrate minerals (principally of the schoepite group) and passes to alkali and alkaline earth uranyl silicate hydrates, ultimately Na-boltwoodite. As discussed in Section 7.2.4, in the natural analog, the principal silicate alteration product is uranophane. Weeksite and boltwoodite are also found, but they occur further from the uraninite deposit and tend to form over earlier-formed phases. Pearcy et al. (1994 [DIRS 100486], p. 726) conclude, “...the specific uranyl silicate formed in a given area depended on the local geochemical conditions rather than on the broad evolution of the oxidizing system." In the laboratory study, uranophane 
is also an important secondary silicate but it is clear that the final silicate phase is Na-boltwoodite (Wronkiewicz et al. 1996 [DIRS 102047], Section 4.2.1 and Figure 7).

Table 6.7-1. Phases Observed During 10-Year Degradation of $\mathrm{UO}_{2}$ by Dripping Water of $\mathrm{J}-13$ Composition and Corresponding Phases in Modeling Database, DataO.ymp.R2

\begin{tabular}{|c|c|c|}
\hline Mineral & $\begin{array}{l}\text { Phases Formed During Laboratory } \\
\text { Degradation of } \mathrm{UO}_{2} \text { and Composition } \\
\text { (Wronkiewicz et al. } 1996 \\
\text { [DIRS 102047], Table 5) }\end{array}$ & $\begin{array}{c}\text { Composition of Phases for Thermodynamic } \\
\text { Data Available in DataO.ymp.R2 }\end{array}$ \\
\hline \multicolumn{3}{|c|}{ Uranyl-Oxide Hydrates } \\
\hline lanthinite & $\mathrm{UO}_{2} \cdot 5 \mathrm{UO}_{3} \cdot 10 \mathrm{H}_{2} \mathrm{O}$ & $\begin{array}{l}\text { No thermodynamic data available for placement } \\
\text { into DataO.ymp.R2 }\end{array}$ \\
\hline $\begin{array}{l}\text { Dehydrated } \\
\text { Schoepite }\end{array}$ & $\mathrm{UO}_{3} \cdot\left(0.8\right.$ to $\left.1.0 \mathrm{H}_{2} \mathrm{O}\right)$ & $\mathrm{UO}_{2}(\mathrm{OH})_{2}$ \\
\hline Schoepite & $\mathrm{UO}_{3} \cdot \mathrm{nH}_{2} \mathrm{O}(\mathrm{n}<2)$ & $\mathrm{UO}_{3} \cdot 2 \mathrm{H}_{2} \mathrm{O}$ \\
\hline Compreignacite & $\mathrm{K}_{2}\left[\left(\mathrm{UO}_{2}\right)_{6} \mathrm{O}_{4}(\mathrm{OH})_{6}\right] \cdot 8 \mathrm{H}_{2} \mathrm{O}$ & $\begin{array}{l}\text { No thermodynamic data available for placement } \\
\text { into DataO.ymp.R2 }\end{array}$ \\
\hline Becquerelite & $\mathrm{Ca}\left[\left(\mathrm{UO}_{2}\right)_{6} \mathrm{O}_{4}(\mathrm{OH})_{6}\right] \cdot 8 \mathrm{H}_{2} \mathrm{O}$ & $\begin{array}{l}\text { No thermodynamic data available for placement } \\
\text { into Data0.ymp.R2 }\end{array}$ \\
\hline \multicolumn{3}{|c|}{ Uranyl Silicate Hydrate } \\
\hline Soddyite & $\left(\mathrm{UO}_{2}\right)_{2} \mathrm{SiO}_{4} \cdot 2 \mathrm{H}_{2} \mathrm{O}$ & $\left(\mathrm{UO}_{2}\right)_{2} \mathrm{SiO}_{4} \cdot 2 \mathrm{H}_{2} \mathrm{O}$ \\
\hline \multicolumn{3}{|c|}{ Alkali and Alkaline Earth Uranyl Silicate Hydrates } \\
\hline Uranophane & $\mathrm{Ca}\left[\left(\mathrm{UO}_{2}\right)\left(\mathrm{SiO}_{3}\right)(\mathrm{OH})\right]_{2} \cdot 5 \mathrm{H}_{2} \mathrm{O}^{\mathrm{a}}$ & $\mathrm{Ca}\left(\mathrm{UO}_{2} \mathrm{SiO}_{3} \mathrm{OH}\right)_{2} \cdot 5 \mathrm{H}_{2} \mathrm{O}$ \\
\hline Sklodowskite & $\mathrm{Mg}\left(\mathrm{UO}_{2}\right)_{2}\left(\mathrm{SiO}_{4}\right)_{2}\left(\mathrm{H}_{3} \mathrm{O}\right)_{2} \cdot 2 \mathrm{H}_{2} \mathrm{O}$ & $\begin{array}{l}\text { No thermodynamic data available for placement } \\
\text { into DataO.ymp.R2 }\end{array}$ \\
\hline Weeksite & $\mathrm{K}_{2}\left(\mathrm{UO}_{2}\right)_{2}\left(\mathrm{Si}_{2} \mathrm{O}_{5}\right)_{3} \cdot 4 \mathrm{H}_{2} \mathrm{O}$ & $\begin{array}{l}\text { No thermodynamic data available for placement } \\
\text { into Data0.ymp.R2 }\end{array}$ \\
\hline Boltwoodite & $\mathrm{K}_{2}\left(\mathrm{UO}_{2}\right)_{2}\left(\mathrm{SiO}_{4}\right)_{2}\left(\mathrm{H}_{3} \mathrm{O}\right)_{2} \cdot 2 \mathrm{H}_{2} \mathrm{O}$ & $\begin{array}{l}\text { No thermodynamic data available for placement } \\
\text { into Data0.ymp.R2 }\end{array}$ \\
\hline Na-boltwoodite & $(\mathrm{Na}, \mathrm{K})\left(\mathrm{UO}_{2}\right)\left(\mathrm{SiO}_{4}\right)\left(\mathrm{H}_{3} \mathrm{O}\right) \cdot \mathrm{H}_{2} \mathrm{O}$ & $\mathrm{NaUO}_{2} \mathrm{SiO}_{3} \mathrm{OH} \cdot 1.5 \mathrm{H}_{2} \mathrm{O}$ \\
\hline
\end{tabular}

NOTE: ${ }^{a}$ Brackets missing in Wronkiewicz et al. 1996 [DIRS 102047], Table 5.

As waste packages degrade, the total aqueous $U$ concentration is controlled by the concentration of the complexing ligands (Section 6.4.3) in solution and by the least-soluble uranium phase that is stable for the current $f \mathrm{CO}_{2}$ and $\mathrm{pH}$ conditions. For TSPA-LA, U solubilities must be available for a wide range of possible in-drift-in-package environments, $\mathrm{pH}$ and $\mathrm{fCO}_{2}$ values. For conditions of high $\mathrm{pH}$ and high $f \mathrm{CO}_{2}$, there were neither natural analogs nor laboratory studies to provide a framework for selecting a solubility-controlling phase. In these conditions, model runs were executed to simulate the environment in question and determine if a particular mineral phase was stable in that environment. These model runs showed that when the dissolved carbonate reaches a high enough concentration, the solid $\mathrm{Na}_{4} \mathrm{UO}_{2}\left(\mathrm{CO}_{3}\right)_{3}$ forms, limiting further increase in dissolved U.

Data0.yc3.R1 incorporates uranium thermodynamic data compiled by the NEA Thermodynamic Data Project (Grenthe et al. 1992 [DIRS 101671]; Silva and Nitsche 1995 [DIRS 112092]; Guillaumont et al. 2003 [DIRS 168382]). This database was used to calculate uranium solubility and uncertainty terms that account for the effects of temperature and fluoride concentration. 
Uncertainties in the thermodynamic data themselves were based on values provided in the NEA volumes (Grenthe et al. 1992 [DIRS 101671]; Silva and Nitsche 1995 [DIRS 112092]; Guillaumont et al. 2003 [DIRS 168382]).

Table 6.7-1 shows the uranyl minerals found during laboratory degradation studies for which data are available in Data0.ymp.R2 (DTN: MO0302SPATHDYN.000 [DIRS 161756]). These are dehydrated schoepite, schoepite, soddyite, uranophane, and Na-boltwoodite. Schoepite, rather than dehydrated schoepite, is selected as one of the controlling phases because laboratory studies show it to be the dominant early formed phase in $\mathrm{UO}_{2}$ degradation (Wronkiewicz et al. 1996 [DIRS 102047]). Soddyite and uranophane are found in laboratory degradation studies and natural analogues, but Na-boltwoodite was chosen because it is reported to be the final silicate phase. In the calculations discussed here, the solubility of soddyite is virtually the same as that of schoepite and considerably higher than that of Na-Boltwoodite. Uranophane was not included because it contains calcium. The high carbonate contents of waters with high $f \mathrm{CO}_{2}$ and $\mathrm{pH}$ values leads to low calcium contents because of the limited solubility and rapid formation of calcite $\left(\mathrm{CaCO}_{3}\right)$ or similar alkaline-earth carbonate minerals. Under these conditions, uranophane would be relatively soluble.

\subsubsection{Chemical Conditions}

The chemical conditions for the solubility calculations are given in Table 6.4-2. The range of $\mathrm{pH}$ and $f \mathrm{CO}_{2}$ values within the CSNF and codisposal packages and in the invert is discussed in Sections 6.4.2.3 and 6.4.2.4. For CSNF packages, the minimum $\mathrm{pH}$ is 4.5 and the maximum increases from 7.0 at $\log f \mathrm{CO}_{2}=-1.5$ bars to 8.1 at -5.0 bars. For codisposal packages, the $\mathrm{pH}$ range is from 5.0 to 8.4, while waters in the invert may have $\mathrm{pH}$ values ranging from 3.5 to 10.5 . As discussed in Section 4.1, the composition of the base-case water used for the solubility calculations is that of J-13 well water (Table 4-2). During modeling, $\mathrm{Na}^{+}$or $\mathrm{SO}_{4}^{-}$is added as needed to achieve solution electroneutrality at the $\mathrm{pH}$ values specified as discussed in Section 6.4.3.5.

Solubility calculations were carried out for two environments based on those used for modeling the chemistry of in-package fluids (BSC 2004 [DIRS 167621]). The first comprises CSNF packages breached under the nominal or seismic scenarios. In these, the source of the degrading water is water vapor entering the packages, which has low or no initial dissolved $\mathrm{Na}$ or silica contents. Although the actual modeling of solubilities in all packages is carried out using the base-case J-13 well water, the mass of silica available is small relative to the mass of $U$ available because of the small volume of water available in this scenario. Thus, should conditions favoring Na-boltwoodite precipitation occur, precipitation of even small amounts of this mineral forces dissolved silica concentrations to very low values so that the effective control of $\mathrm{U}$ concentrations under all conditions is schoepite. U solubilities in the first environment were modeled using $\mathrm{J}-13$ well water with $\mathrm{U}$ concentrations determined by schoepite solubility for all conditions of $\mathrm{pH}$ and $\mathrm{fCO}_{2}$.

The second environment comprises codisposal packages breached under all scenarios, CSNF packages breached under the intrusion scenario and the invert. In this environment, silica is available to the degrading water from the codisposal glass, surrounding igneous material and invert construction material so Na-boltwoodite is included as a U-controlling phase. 
U concentrations based on this mineral vary inversely with dissolved silica concentrations so selection of the silica concentration used in the modeling is important.

Table 6.7-2 compares the $\log \mathrm{K}\left(25^{\circ} \mathrm{C}\right)$ values of all the $\mathrm{SiO}_{2}$ solids in Data0.ymp.R2 (DTN: MO0302SPATHDYN.000 [DIRS 161756]). The table also gives the dissolved Si and $\mathrm{SiO}_{2}$ (aq) concentrations corresponding to these $\log \mathrm{K}\left(25^{\circ} \mathrm{C}\right)$ values in pure water (water with ionic strength, $\mathrm{i}=0$, so solute activity $=$ solute molality). For comparison, Table 6.7-2 also gives the Si content of J-13 well water in corresponding units. This concentration corresponds to solubility with a phase intermediate between cristobalite (alpha) and coesite. Because of other sources of silica in the second environment, the silica content of J-13 well water was not used as the silica concentration in the modeling. Instead, dissolved silica is modeled as controlled by the mineral chalcedony, which leads to concentrations within the upper range of silica concentrations in natural groundwater (Section 7.2.4). Choosing chalcedony saturation leads to silica content about one-third that of J-13 well water and to higher, more conservative modeled U concentrations.

Table 6.7-2. Silica Phases for which Data are Given in Thermodynamic Database, Data0.ymp.R2

\begin{tabular}{|c|c|c|c|c|}
\hline Phase & $\begin{array}{c}\log \mathrm{K}\left(25^{\circ} \mathrm{C}\right)^{\mathrm{a}} \\
\text { DataO.ymp.R2 }\end{array}$ & $\begin{array}{c}\mathrm{Si} \\
(\mathrm{mol} / \mathrm{L} \text { at I }=0)^{\mathrm{c}}\end{array}$ & $\begin{array}{c}\mathrm{Si} \\
(\mathrm{mg} / \mathrm{L} \text { at } \mathrm{I}=0)^{\mathrm{c}}\end{array}$ & $\begin{array}{c}\mathrm{SiO}_{2} \\
(\mathrm{mg} / \mathrm{L} \text { at I }=0)^{\circ}\end{array}$ \\
\hline Tridymite & -3.82 & $1.51 \mathrm{E}-04$ & 4.3 & 9.1 \\
\hline Quartz & -3.75 & $1.78 \mathrm{E}-04$ & 5.0 & 10.7 \\
\hline Chalcedony & -3.47 & $3.39 \mathrm{E}-04$ & 9.5 & 20.4 \\
\hline Cristobalite(alpha) & -3.19 & $6.46 \mathrm{E}-04$ & 18.1 & 38.8 \\
\hline Coesite & -2.93 & 1.17E-03 & 33.0 & 70.6 \\
\hline Cristobalite(beta) & -2.75 & $1.78 \mathrm{E}-03$ & 49.9 & 106.8 \\
\hline \multirow[t]{2}{*}{$\mathrm{SiO}_{2}(\mathrm{am})$} & -2.71 & $1.95 \mathrm{E}-03$ & 54.8 & 117.2 \\
\hline & $\log (\text { Si mol/L })^{b}$ & & & \\
\hline $\mathrm{J}-13$ well water & -2.99 & 1.01E-03 & 28.5 & 60.97 \\
\hline
\end{tabular}

Source: ${ }^{a} \log \mathrm{K}\left(25^{\circ} \mathrm{C}\right)$ data from DTN: MO0302SPATHDYN.000 [DIRS 161756].

b $\mathrm{J}-13$ well water data from Table 4-2.

c Silica solids_a.xIs (Appendix I).

The $\mathrm{Na}$ concentration of $\mathrm{J}-13$ well water is $\sim 2$ mmol. This increases above $\mathrm{pH} 8$ (at $\log f \mathrm{CO}_{2}=-3.0$ bars) because $\mathrm{Na}$ is added as the charge-balancing cation. The Si concentration fixed by chalcedony saturation is $\sim 0.35 \mathrm{mmol}$ to $\mathrm{pH} 8$, increasing to $\sim 0.6$ $\mathrm{mmol}$ at $\mathrm{pH} 9$.

The $\mathrm{Na}$ and Si contents of waters predicted by Engineered Barrier System: Physical and Chemical Environment Model (BSC 2004 [DIRS 167461]) and In-Package Chemistry Abstraction (BSC 2004 [DIRS 167621]) have been examined for consistency with those used for Na-boltwoodite modeling. The comparisons were made at $\log f \mathrm{CO}_{2}=-3.0$ bars, because that is the value at which In-Package Chemistry Abstraction (BSC 2004 [DIRS 167621]) calculations were made. Calculations in this report and in In-Package Chemistry Abstraction (BSC 2004 [DIRS 167621]) were made at $25^{\circ} \mathrm{C}$. The closest temperature used in Engineered Barrier System: Physical and Chemical Environment Model (BSC 2004 [DIRS 167461]) was $40^{\circ} \mathrm{C}$. 
Calculations supporting Engineered Barrier System: Physical and Chemical Environment Model (BSC 2004 [DIRS 167461]) go to very high ionic strengths. For consistency with the range of applicability of the results of this report, Engineered Barrier System: Physical and Chemical Environment Model (BSC 2004 [DIRS 167461]) waters with ionic strengths above 3 were not considered (Section 6.3.3.4).

Data used for the comparison were from file checked MOALT r1.xls, which is included in "Attachment_1.zip" of Engineered Barrier System: Physical and Chemical Environment Model (BSC 2004 [DIRS 167461]). Eight of the more than 5,000 realizations of seepage water chemistry in this file have $\mathrm{Na}$ concentrations below $2 \mathrm{mmol}$, the lowest of which is $1.3 \mathrm{mmol}$. None of the realizations have Si concentrations below $0.35 \mathrm{mmol}$. Use of the higher $\mathrm{Na}$ and $\mathrm{Si}$ contents of Engineered Barrier System: Physical and Chemical Environment Model (BSC 2004 [DIRS 167461]) waters would lead to lower $U$ concentrations in equilibrium with Na-boltwoodite. Therefore, the concentrations given in this report are conservative with respect to Engineered Barrier System: Physical and Chemical Environment Model (BSC 2004 [DIRS 167461]) waters.

Data used for the in-package chemistry abstraction were from Section 8.1 in DTN: MO0404SPAIPCHM.005 [DIRS 169187]. None of the Na concentrations in the waters emanating from codisposal packages are below $2 \mathrm{mmol}$. The Si contents of these waters range from $\sim 0.1 \mathrm{mmol}$ at lower $\mathrm{pH}$ values to as low as $\sim 0.03 \mathrm{mmol}$ at $\mathrm{pH}$ values above 7.5 . These low Si contents appear to be because of the precipitation of silica-bearing nontronite clays (BSC 2004 [DIRS 167621], Figures 6-8 and 6-15). The comparison with groundwater concentrations described earlier indicates the selection of chalcedony as the silica-controlling phase for these calculations is appropriate.

\subsubsection{Results: Speciation and Solubility}

Figures 6.7-3 and 6.7-4 show concentrations of total dissolved uranium and of aqueous species contributing to that total calculated at $f \mathrm{CO}_{2}=10^{-3.0}$ bars, expressed as molalities and percents total uranium, respectively.

The inflection points in the line representing total $U$ concentrations in Figure 6.7-3 are where solubility control by one mineral gives way to control by another. As illustrated in Figure 6.7-2, schoepite, the controlling phase at low $\mathrm{pH}$ values, is replaced by $\mathrm{Na-boltwoodite}$ at a $\mathrm{pH}$ of about 7.25, which in turn is replaced by $\mathrm{Na}_{3} \mathrm{UO}_{2}\left(\mathrm{CO}_{3}\right)_{3}$ at a $\mathrm{pH}$ of about 9.25 . The decrease in $\mathrm{U}$ concentration above $\mathrm{pH} 9.25$ in Figure 6.7-3 is because the $\mathrm{Na}^{+}$added to charge balance the solutions at higher $\mathrm{pH}$ values decreases the solubility of $\mathrm{Na}_{3} \mathrm{UO}_{2}\left(\mathrm{CO}_{3}\right)_{3}$.

The dominant dissolved species from the highest $\mathrm{pH}$ values modeled to about $\mathrm{pH} 8.1$ is $\mathrm{UO}_{2}\left(\mathrm{CO}_{3}\right)_{3}{ }^{3-}$. With decreasing $\mathrm{pH}$, this is succeeded by $\mathrm{UO}_{2}\left(\mathrm{CO}_{3}\right)_{2}{ }^{2-}$ and $\left(\mathrm{UO}_{2}\right)_{2} \mathrm{CO}_{3}(\mathrm{OH})_{3}{ }^{-}$. Below about $\mathrm{pH} 6.6, \mathrm{UO}_{3}(\mathrm{aq})$ prevails. This species is more commonly (e.g., NEA and NAGRA/PSI databases) written $\mathrm{UO}_{2}(\mathrm{OH})_{2}$. Uranyl fluoride complexes, principally $\mathrm{UO}_{2} \mathrm{~F}^{+}$but with up to more than 10 percent $\mathrm{UO}_{2} \mathrm{~F}_{2}(\mathrm{aq})$, prevail from below about $\mathrm{pH} 6.2$ to 4.5 . Around $\mathrm{pH}$ of $4.5, \mathrm{UO}_{2}{ }^{2+}$ is an important species and, under conditions more acidic than $\mathrm{pH}$ of 4.25 , $\mathrm{UO}_{2} \mathrm{SO}_{4}(\mathrm{aq})$ predominates. 
Table 6.7-3 and Figure 6.7-1 show the U concentrations calculated for the first environment described in the previous section (CSNF packages breached under nominal conditions or by seismic events). Although values are given for $\mathrm{pH}$ values from 3.5 to 7.0 at $f \mathrm{CO}_{2}=10^{-1.5}$ bars and to 9.75 at $f \mathrm{CO}_{2}=10^{-5.0}$ bars, the actual $\mathrm{pH}$ range in this environment is the more narrow region between the heavy lines in the table and the shaded lines in the figure. As discussed, only schoepite controls U solubility in this environment.

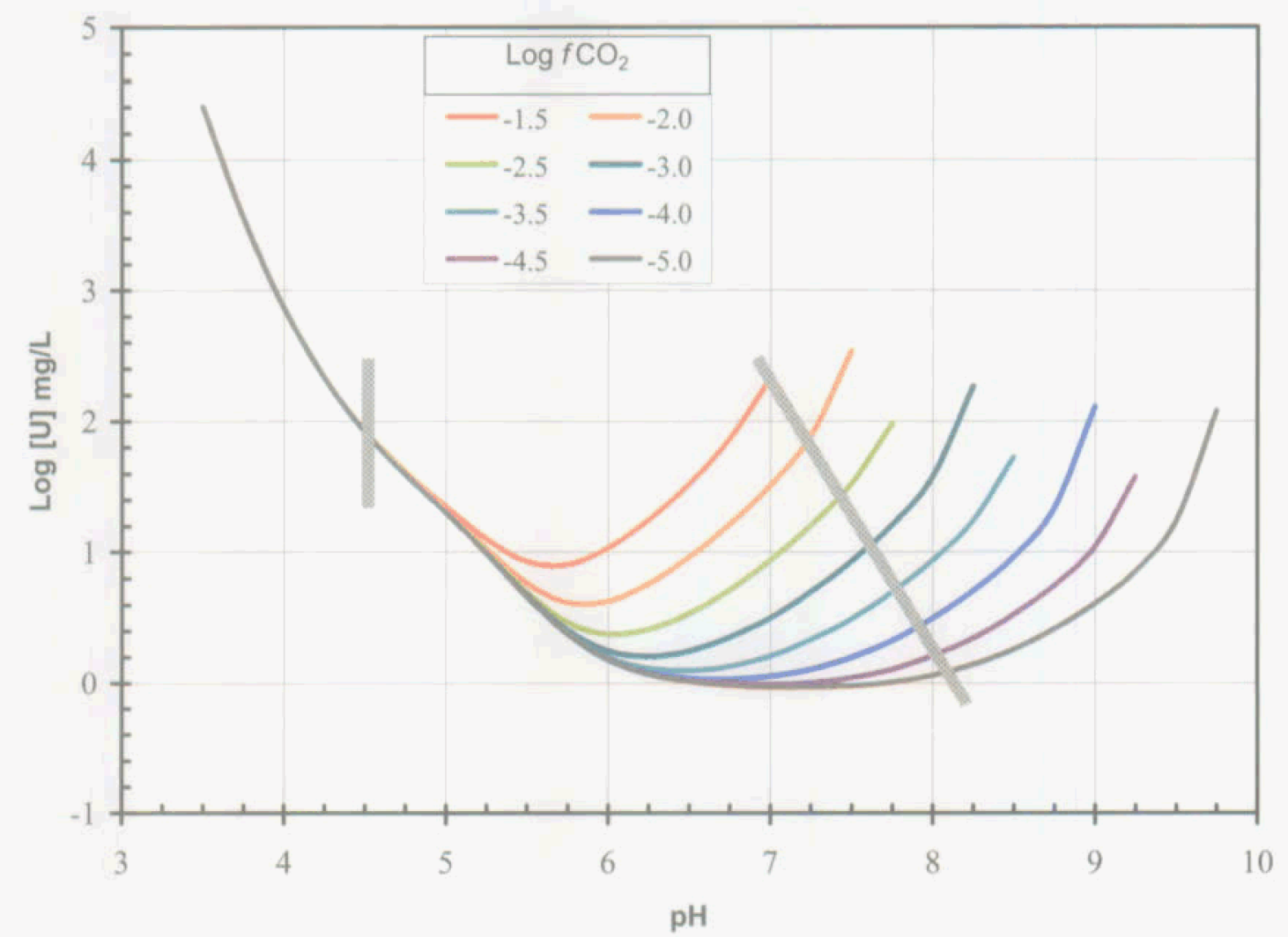

Source: $U$ solubility plots.xls.

NOTE: Schoepite is the controlling mineral under all conditions of $\mathrm{pH}$ and $f \mathrm{CO}_{2}$. Shaded bars are boundaries of $\mathrm{pH}$ and $\mathrm{FCO}_{2}$ conditions possible in such packages.

Figure 6.7-1. Uranium Solubility in CSNF Packages Breached Under Nominal and Seismic Scenarios Modeled as a Function of $\mathrm{pH}$ and $\mathrm{fCO}_{2}$ 
Table 6.7-3. Calculated Uranium Solubility as Log [U] (mg/L) Within CSNF Waste Packages Breached Under Nominal Conditions or by Seismic Activity

\begin{tabular}{|c|c|c|c|c|c|c|c|c|}
\hline \multirow{2}{*}{ pH } & \multicolumn{8}{|c|}{$\log \mathrm{fCO}_{2}$ (bars) } \\
\hline & -1.5 & -2.0 & -2.5 & -3.0 & -3.5 & -4.0 & -4.5 & -5.0 \\
\hline 3.50 & $4.41 \mathrm{E}+00$ & $4.41 \mathrm{E}+00$ & $4.41 E+00$ & $4.41 E+00$ & $4.41 \mathrm{E}+00$ & $4.41 E+00$ & $4.41 \mathrm{E}+00$ & $4.41 E+00$ \\
\hline 3.75 & $3.55 \mathrm{E}+00$ & $3.55 \mathrm{E}+00$ & $3.55 E+00$ & $3.55 \mathrm{E}+00$ & $3.55 \mathrm{E}+00$ & $3.55 \mathrm{E}+00$ & $3.55 E+00$ & $3.55 \mathrm{E}+00$ \\
\hline 4.00 & $2.87 E+00$ & $2.87 E+00$ & $2.87 E+00$ & $2.87 \mathrm{E}+00$ & $2.87 E+00$ & $2.87 \mathrm{E}+00$ & $2.87 \mathrm{E}+00$ & $2.87 \mathrm{E}+00$ \\
\hline 4.25 & $2.33 E+00$ & $2.33 E+00$ & $2.33 E+00$ & $2.33 E+00$ & $2.33 \mathrm{E}+00$ & $2.33 \mathrm{E}+00$ & $2.33 \mathrm{E}+00$ & $2.33 E+00$ \\
\hline 4.50 & $1.93 \mathrm{E}+00$ & $1.92 \mathrm{E}+00$ & $1.92 \mathrm{E}+00$ & $1.92 E+00$ & $1.92 \mathrm{E}+00$ & $1.92 \mathrm{E}+00$ & $1.92 \mathrm{E}+00$ & $1.92 E+00$ \\
\hline 4.75 & $1.62 \mathrm{E}+00$ & $1.60 \mathrm{E}+00$ & $1.60 \mathrm{E}+00$ & $1.59 \mathrm{E}+00$ & $1.59 \mathrm{E}+00$ & $1.59 \mathrm{E}+00$ & $1.59 E+00$ & $1.59 E+00$ \\
\hline 5.00 & $1.35 \mathrm{E}+00$ & $1.32 E+00$ & $1.31 E+00$ & $1.31 E+00$ & 1. $30 \mathrm{E}+00$ & $1.30 \mathrm{E}+00$ & $1.30 E+00$ & $1.30 \mathrm{E}+00$ \\
\hline 5.25 & $1.10 \mathrm{E}+00$ & $1.03 E+00$ & $1.00 \mathrm{E}+00$ & $9.95 \mathrm{E}-01$ & $9.93 E-01$ & $9.92 \mathrm{E}-01$ & 9.92E-01 & 9.91E-01 \\
\hline 5.50 & $9.31 \mathrm{E}-01$ & $7.65 \mathrm{E}-01$ & 6.97E-01 & $6.74 \mathrm{E}-01$ & $6.66 \mathrm{E}-01$ & $6.63 \mathrm{E}-01$ & $6.63 E-01$ & 6.62E-01 \\
\hline 5.75 & $9.05 \mathrm{E}-01$ & $6.19 \mathrm{E}-01$ & 4.67E-01 & 4.07E-01 & $3.86 \mathrm{E}-01$ & 3.79E-01 & 3.77E-01 & 3.76E-01 \\
\hline 6.00 & $1.03 E+00$ & $6.26 \mathrm{E}-01$ & $3.76 \mathrm{E}-01$ & $2.51 \mathrm{E}-01$ & $2.03 \mathrm{E}-01$ & 1.87E-01 & $1.82 \mathrm{E}-01$ & $1.80 \mathrm{E}-01$ \\
\hline 6.25 & $1.25 \mathrm{E}+00$ & $7.58 \mathrm{E}-01$ & 4.13E-01 & 2.07E-01 & 1.17E-01 & 8.36E-02 & $7.27 \mathrm{E}-02$ & $6.92 \mathrm{E}-02$ \\
\hline 6.50 & $1.52 \mathrm{E}+00$ & $9.60 \mathrm{E}-01$ & 5.30E-01 & $2.48 \mathrm{E}-01$ & $9.90 \mathrm{E}-02$ & 3.93E-02 & 1.87E-02 & $1.19 \mathrm{E}-02$ \\
\hline 6.75 & $1.86 \mathrm{E}+00$ & $1.21 \mathrm{E}+00$ & 7.12E-01 & 3.53E-01 & 1.32E-01 & $3.21 \mathrm{E}-02$ & $-4.74 E-03$ & $-1.71 E-02$ \\
\hline 7.00 & $2.33 \mathrm{E}+00$ & $1.51 \mathrm{E}+00$ & 9.38E-01 & $5.01 \mathrm{E}-01$ & $2.11 \mathrm{E}-01$ & $5.47 \mathrm{E}-02$ & $-8.42 E-03$ & $-3.04 E-02$ \\
\hline 7.25 & 500 & $1.89 \mathrm{E}+00$ & $1.20 \mathrm{E}+00$ & $6.98 \mathrm{E}-01$ & 3.34E-01 & $1.09 \mathrm{E}-01$ & $6.00 \mathrm{E}-03$ & $-3.21 \mathrm{E}-02$ \\
\hline 7.50 & 500 & $2.54 \mathrm{E}+00$ & $1.52 \mathrm{E}+00$ & 9.32E-01 & 4.92E-01 & $2.00 \mathrm{E}-01$ & 4.29E-02 & $-2.10 \mathrm{E}-02$ \\
\hline 7.75 & 500 & 500 & $1.98 \mathrm{E}+00$ & $1.21 \mathrm{E}+00$ & 6.96E-01 & $3.26 \mathrm{E}-01$ & $1.09 \mathrm{E}-01$ & $7.58 \mathrm{E}-03$ \\
\hline 8.00 & 500 & 500 & 500 & $1.58 \mathrm{E}+00$ & $9.38 \mathrm{E}-01$ & 4.97E-01 & 2.12E-01 & $6.04 \mathrm{E}-02$ \\
\hline 8.25 & 500 & 500 & 500 & $2.27 E+00$ & $1.24 \mathrm{E}+00$ & 7.07E-01 & $3.47 \mathrm{E}-01$ & $1.45 \mathrm{E}-01$ \\
\hline 8.50 & 500 & 500 & 500 & 500 & $1.73 \mathrm{E}+00$ & 9.65E-01 & 5.26E-01 & $2.59 \mathrm{E}-01$ \\
\hline 8.75 & 500 & 500 & 500 & 500 & 500 & $1.34 \mathrm{E}+00$ & 7.47E-01 & $4.16 \mathrm{E}-01$ \\
\hline 9.00 & 500 & 500 & 500 & 500 & 500 & $2.11 \mathrm{E}+00$ & $1.04 E+00$ & $6.11 \mathrm{E}-01$ \\
\hline 9.25 & 500 & 500 & 500 & 500 & 500 & 500 & $1.58 \mathrm{E}+00$ & 8.56E-01 \\
\hline 9.50 & 500 & 500 & 500 & 500 & 500 & 500 & 500 & $1.24 \mathrm{E}+00$ \\
\hline 9.75 & 500 & 500 & 500 & 500 & 500 & 500 & 500 & $2.08 \mathrm{E}+00$ \\
\hline
\end{tabular}

Source: u solubility_dtn.xls.

NOTE: These concentrations correspond to schoepite saturation.

The $U$ concentrations calculated for the second environment (CSNF packages breached by a hypothetical igneous event, all codisposal packages and water in the invert) are given in Tables 6.7-5 and 6.7-6 and illustrated in Figure 6.7-2. In this environment, $U$ concentrations are controlled by schoepite, Na-boltwoodite, or $\mathrm{Na}_{3} \mathrm{UO}_{2}\left(\mathrm{CO}_{3}\right)_{3}$ depending on the $\mathrm{pH}$ and $f \mathrm{CO}_{2}$ as illustrated in the Figure 6.7-2.

At the lower $\mathrm{pH}$ values, schoepite is the least soluble phase. At $\mathrm{pH}$ values around neutral, there is an inflection in the concentration curves where the solubility curves of Na-Boltwoodite cross 
those of schoepite, so that controlling mineral phase changes. With increasing $\mathrm{pH}$ values, $\mathrm{U}$ concentrations increase steeply. The $\mathrm{pH}$ values corresponding to this increase vary with $f \mathrm{CO}_{2}$, being lowest at the highest $f \mathrm{CO}_{2}$ values. This is due to the increasing carbonate content of the water with increasing $\mathrm{pH}$ and $f \mathrm{CO}_{2}$, which leads to the formation of high concentrations of uranyl carbonate-solution complexes. When the carbonate content reaches sufficiently high values, the uranyl carbonate solid, $\mathrm{Na}_{4} \mathrm{UO}_{2}\left(\mathrm{CO}_{3}\right)_{3}$, becomes stable, thereby limiting further increases in the $\mathrm{U}$ concentration.

The $\mathrm{pH}$ values at which schoepite control of $U$ concentrations gives way to control by Na-boltwoodite at a given $f \mathrm{CO}_{2}$ was calculated directly using EQ3NR to solve for the $\mathrm{pH}$ at which both minerals were in equilibrium. EQ3NR would not converge when solving for the $\mathrm{pH}$ at which both $\mathrm{Na}$-boltwoodite and $\mathrm{Na}_{4} \mathrm{UO}_{2}\left(\mathrm{CO}_{3}\right)_{3}$ were in equilibrium because $\mathrm{Na}^{+}$is the chargebalancing cation and a constituent of the solubility-controlling phases. Thus, an indirect approach was taken by modeling a reaction path using EQ6. The path began with a solution at a given $f \mathrm{CO}_{2}$ and $\mathrm{pH}$ at equilibrium with an excess of Na-boltwoodite. This solution was titrated with $\mathrm{NaOH}$ while maintaining $\mathrm{Na}$-boltwoodite saturation and the initial $f \mathrm{CO}_{2}$. The $\mathrm{pH}$ and $\mathrm{U}$ concentration rose with added $\mathrm{NaOH}$ until $\mathrm{Na}_{4} \mathrm{UO}_{2}\left(\mathrm{CO}_{3}\right)_{3}$ saturation was reached. At this point, the $\mathrm{pH}$ and $\mathrm{U}$ concentration remained constant with further $\mathrm{NaOH}$ addition as the initial Na-boltwoodite reacted to form $\mathrm{Na}_{4} \mathrm{UO}_{2}\left(\mathrm{CO}_{3}\right)_{3}$. This constant $\mathrm{pH}$ is that of the crossover from Na-boltwoodite to $\mathrm{Na}_{4} \mathrm{UO}_{2}\left(\mathrm{CO}_{3}\right)_{3}$. The crossover $\mathrm{pH}$ values are given in Table 6.7-4 and shown schematically in Figure 6.7-2.

Table 6.7-4. pH Values at Which Control of $U$ Concentrations Gives Way from Schoepite to Naboltwoodite and From Na-boltwoodite to $\mathrm{Na}_{4} \mathrm{UO}_{2}\left(\mathrm{CO}_{3}\right)_{3}$ at Various $\mathrm{fCO}_{2}$ Values

\begin{tabular}{|l|c|c|c|c|c|c|c|c|}
\hline \multirow{2}{*}{\multicolumn{1}{c|}{ Mineral }} & \multicolumn{7}{|c|}{$\log \mathrm{CO}_{2}$ (bars) } \\
\cline { 2 - 9 } & $-\mathbf{- 1 . 5}$ & $\mathbf{- 2 . 0}$ & $\mathbf{- 2 . 5}$ & $\mathbf{- 3 . 0}$ & $-\mathbf{3 . 5}$ & $-\mathbf{4 . 0}$ & $-\mathbf{4 . 5}$ & $\mathbf{- 5 . 0}$ \\
\hline Schoepite - Na-boltwoodite & 6.85 & 7.12 & 7.18 & 7.18 & 7.18 & 7.18 & 7.18 & 7.18 \\
\hline Na-boltwoodite - $\mathrm{Na}_{4} \mathrm{UO}_{2}\left(\mathrm{CO}_{3}\right)_{3}$ & 7.71 & 8.21 & 8.71 & 9.21 & 9.71 & 10.19 & 10.61 & 10.91 \\
\hline
\end{tabular}

Source: U LogK Uncertainty_a.x/s (Appendix I). 


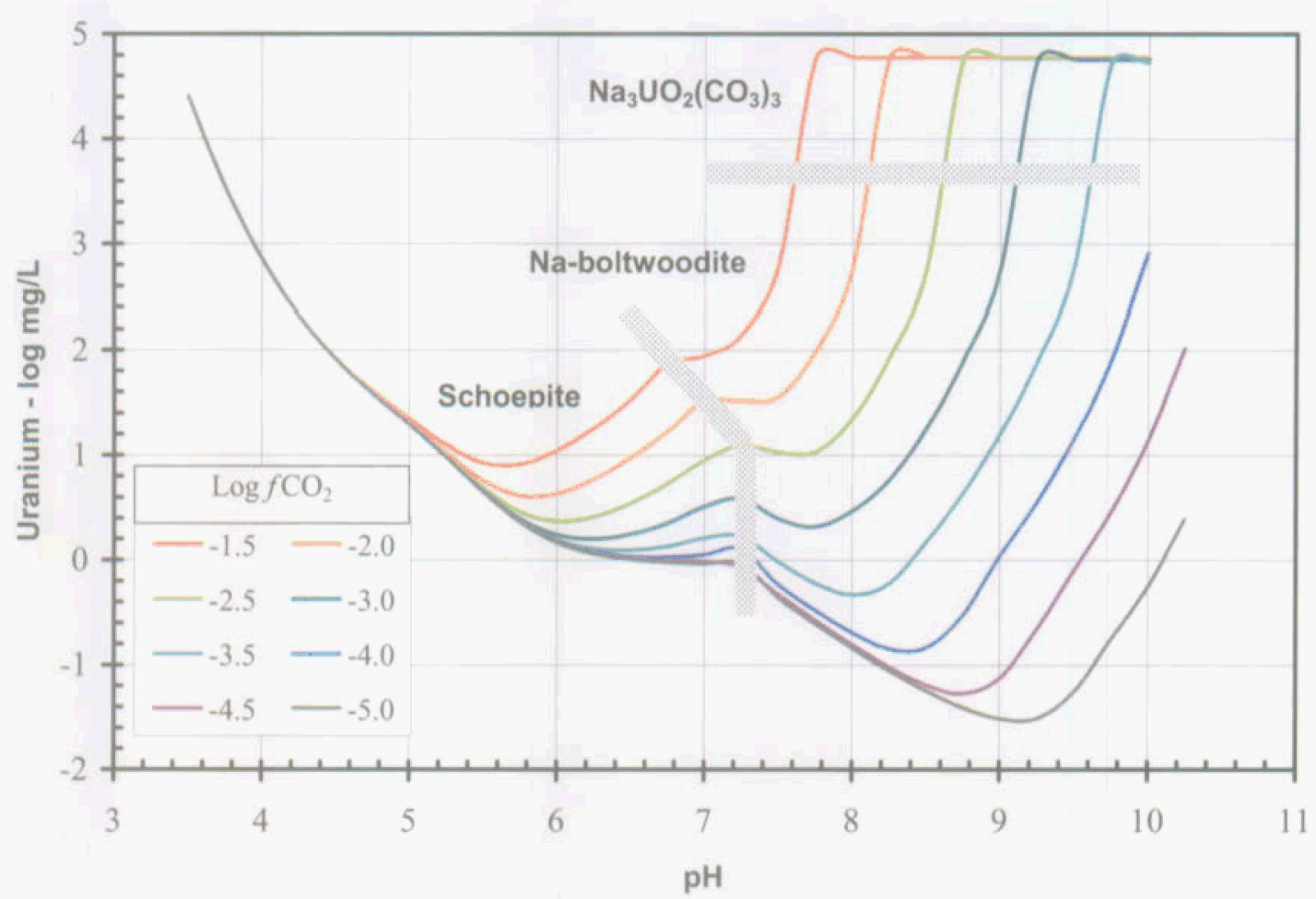

Source: U solubility plots.xIs (Appendix I).

NOTE: Shaded areas are boundaries between $\mathrm{pH}-\mathrm{f} \mathrm{CO}_{2}$ regions controlled by indicated minerals.

Figure 6.7-2. Uranium Solubility in CSNF Packages Breached by a Hypothetical Igneous Event, Codisposal Packages Under any Breach Scenario and Waters in the Invert Modeled as a Function of $\mathrm{pH}$ and $\mathrm{fCO}_{2}$

The concentrations in Table 6.7-5 represent schoepite solubility and extend over lower pH values where this mineral is the least soluble of the three phases considered. Table 6.7-6 represents solubilities of $\mathrm{Na}$-boltwoodite and $\mathrm{Na}_{4} \mathrm{UO}_{2}\left(\mathrm{CO}_{3}\right)_{3}$ and covers the higher $\mathrm{pH}$ ranges. As discussed in Section 6.7.5.1, uncertainties in thermodynamic data lead to a range of $\mathrm{pH}$ and $\log f \mathrm{CO}_{2}$ values in which either schoepite or Na-boltwoodite could control the $\mathrm{U}$ concentration. This range is indicated by the green shading in Tables 6.7-5 and 6.7-6. In implementing these tables in the TSPA-LA model, for conditions in this range, the $U$ concentration should be sampled from a uniform distribution with bounds based on the values in these tables.

In Table 6.7-6, the value " 500 " appears as the concentration at $\mathrm{pH}=10.25$ for $\log f \mathrm{CO}_{2}$ values of -3.5 bars and higher. This is not to be taken literally, but as a flag that the $U$ concentrations are undefined under these conditions. Solutions saturated with $\mathrm{Na}_{4} \mathrm{UO}_{2}\left(\mathrm{CO}_{3}\right)_{3}$ under these conditions have ionic strengths greater than 3 molal, which is taken as the limit of reliability of these calculations (Section 6.3.3.4). The $\mathrm{pH}$ and $\log f \mathrm{CO}_{2}$ values at which they appear are beyond the range possible for the environment to which this table is applicable. 
Tables 6.7-3 and 6.7-5 give $U$ concentrations based on schoepite saturation for overlapping ranges of $\mathrm{pH}$ and $f \mathrm{CO}_{2}$, yet there are differences of up to $0.13 \mathrm{log} \mathrm{mg} \mathrm{U} / \mathrm{L}$ between them. This difference results from the use of $\mathrm{J}-13$ well water silica concentrations $\left(60.97 \mathrm{mg} \mathrm{SiO}_{2}(\mathrm{aq}) / \mathrm{L}\right)$ in the modeling for Table 6.7-3, and chalcedony saturation $\left(\sim 20.4 \mathrm{mg} \mathrm{SiO}_{2}(\mathrm{aq}) / \mathrm{L}\right.$; Table 6.7-2) in the modeling for Table 6.7-5. Higher dissolved silica concentrations give rise to higher $\mathrm{U}$ concentrations because of the presence of the $\mathrm{UO}_{2} \mathrm{OSi}(\mathrm{OH})_{3}{ }^{+}$solution complex. Higher silica contents lead to higher concentrations of this complex and, in turn, to higher total dissolved U concentrations. The minimum uncertainty in schoepite concentrations is that due to uncertainties in thermodynamic data and equals $\pm 0.5\left(\varepsilon_{1}\right.$ parameter in Equation 6.7-4; Section 6.7.6). The concentration difference due to the differing silica contents is within this minimum uncertainty. Note that the Pu concentration shown in Figure 6.4-10 has no sensitivity to varying silica contents at these concentrations. This is because the database used for modeling includes no $\mathrm{Pu}$-silicate aqueous complex species analogous to that which causes $U$ sensitivity to silica.

Table 6.7-5. Calculated Uranium Solubility as Log [U] (mg/L) Within Codisposal Waste Packages Breached Under any Scenario, CSNF Waste Packages Breached by a Hypothetical Igneous Intrusion and in the Invert.

\begin{tabular}{|c|c|c|c|c|c|c|c|c|}
\hline \multicolumn{9}{|c|}{ Schoepite } \\
\hline \multirow[b]{2}{*}{$\mathrm{pH}$} & \multicolumn{8}{|c|}{$\log f \mathrm{CO}_{2}$ (bars) } \\
\hline & -1.5 & -2.0 & -2.5 & -3.0 & -3.5 & -4.0 & -4.5 & -5.0 \\
\hline 3.50 & $4.41 E+00$ & $4.41 E+00$ & $4.41 E+00$ & $4.41 E+00$ & $4.41 E+00$ & $4.41 \mathrm{E}+00$ & $4.41 \mathrm{E}+00$ & $4.41 E+00$ \\
\hline 3.75 & $3.55 E+00$ & $3.55 E+00$ & $3.55 E+00$ & $3.55 E+00$ & $3.55 E+00$ & $3.55 E+00$ & $3.55 E+00$ & $3.55 E+00$ \\
\hline 4.00 & $2.86 \mathrm{E}+00$ & $2.86 E+00$ & $2.86 E+00$ & $2.86 E+00$ & $2.86 E+00$ & $2.86 E+00$ & $2.86 E+00$ & $2.86 E+00$ \\
\hline 4.25 & $2.33 E+00$ & $2.33 E+00$ & $2.33 E+00$ & $2.33 E+00$ & $2.33 E+00$ & $2.33 E+00$ & $2.33 E+00$ & $2.33 E+00$ \\
\hline 4.50 & $1.92 E+00$ & $1.91 E+00$ & $1.91 E+00$ & $1.91 E+00$ & $1.91 E+00$ & $1.91 E+00$ & $1.91 E+00$ & $1.91 E+00$ \\
\hline 4.75 & $1.61 \mathrm{E}+00$ & $1.59 E+00$ & $1.59 E+00$ & $1.59 \mathrm{E}+00$ & $1.59 E+00$ & 1.59E+00 & $1.59 \mathrm{E}+00$ & 1.59E+00 \\
\hline 5.00 & $1.34 \mathrm{E}+00$ & $1.31 E+00$ & 1. $30 E+00$ & 1. $30 E+00$ & 1. $30 E+00$ & 1. $30 E+00$ & $1.30 E+00$ & 1. $30 E+00$ \\
\hline 5.25 & $1.10 E+00$ & $1.02 E+00$ & 9.94E-01 & 9.85E-01 & 9.83E-01 & $9.82 E-01$ & $9.81 \mathrm{E}-01$ & $9.81 \mathrm{E}-01$ \\
\hline 5.50 & $9.24 \mathrm{E}-01$ & $7.55 \mathrm{E}-01$ & $6.86 \mathrm{E}-01$ & $6.62 E-01$ & $6.54 E-01$ & $6.51 E-01$ & $6.51 \mathrm{E}-01$ & $6.50 \mathrm{E}-01$ \\
\hline 5.75 & 9.10E-01 & 6.11E-01 & 4.57E-01 & $3.94 \mathrm{E}-01$ & $3.73 \mathrm{E}-01$ & $3.66 \mathrm{E}-01$ & 3.64E-01 & $3.63 E-01$ \\
\hline 6.00 & $1.04 E+00$ & 6.30E-01 & 3.68E-01 & $2.41 \mathrm{E}-01$ & $1.92 \mathrm{E}-01$ & 1.75E-01 & $1.70 \mathrm{E}-01$ & $1.68 \mathrm{E}-01$ \\
\hline 6.25 & 1.25E+00 & $7.66 \mathrm{E}-01$ & $4.09 \mathrm{E}-01$ & $2.01 \mathrm{E}-01$ & 1.09E-01 & $7.55 E-02$ & $6.43 \mathrm{E}-02$ & $6.08 \mathrm{E}-02$ \\
\hline 6.50 & $1.52 E+00$ & $9.70 \mathrm{E}-01$ & 5.37E-01 & 2.45E-01 & $9.45 E-02$ & $3.42 E-02$ & 1.33E-02 & 6.55E-03 \\
\hline 6.75 & $1.86 \mathrm{E}+00$ & $1.22 E+00$ & 7. $22 \mathrm{E}-01$ & $3.52 \mathrm{E}-01$ & 1.30E-01 & 2.93E-02 & $-7.88 \mathrm{E}-03$ & $-2.03 E-02$ \\
\hline 7.00 & $2.33 E+00$ & $1.51 E+00$ & $9.48 E-01$ & $5.09 E-01$ & 2.10E-01 & $5,32 \mathrm{E}-02$ & $-1.02 E-02$ & $-3.22 E-02$ \\
\hline 7.25 & & $1.89 E+00$ & $1.21 E+00$ & $7.08 \mathrm{E}-01$ & 3.34E-01 & $1.08 \mathrm{E}-01$ & $5.05 E-03$ & $-3.31 \mathrm{E}-02$ \\
\hline 7.50 & & $2.54 E+00$ & $1.53 E+00$ & 9.44E-01 & 5.01E-01 & $2.00 E-01$ & $4.24 \mathrm{E}-02$ & $-2.16 \mathrm{E}-02$ \\
\hline 7.75 & & & $1.98 E+00$ & $1.22 E+00$ & 7.07E-01 & 3.33E-01 & $1.09 E-01$ & $7.28 \mathrm{E}-03$ \\
\hline 8.00 & & & & $1.57 E+00$ & $9.51 \mathrm{E}-01$ & $5.06 \mathrm{E}-01$ & 2.12E-01 & $6.02 \mathrm{E}-02$ \\
\hline
\end{tabular}

Source: $u$ solubility_dtn.xls (Appendix I).

NOTE: These concentrations correspond to schoepite saturation. The green area indicates the region where it is uncertain whether $\mathrm{U}$ is controlled by schoepite or $\mathrm{Na}$-boltwoodite saturation. 
Table 6.7-6. Calculated Uranium Solubility as Log [U] (mg/L) Within Codisposal Waste Packages Breached Under any Scenario, CSNF Waste Packages Breached by a Hypothetical Igneous Intrusion and in the Invert

\begin{tabular}{|c|c|c|c|c|c|c|c|c|}
\hline \multicolumn{9}{|c|}{ Na-boltwoodite and $\mathrm{Na}_{4} \mathrm{UO}_{2}\left(\mathrm{CO}_{3}\right)_{3}$} \\
\hline \multirow[b]{2}{*}{$\mathrm{pH}$} & \multicolumn{8}{|c|}{$\log f \mathrm{CO}_{2}$ (bars) } \\
\hline & -1.5 & -2.0 & -2.5 & -3.0 & -3.5 & -4.0 & -4.5 & -5.0 \\
\hline 6.50 & $2.56 \mathrm{E}+00$ & & & & & & & \\
\hline 6.75 & $2.16 E+00$ & $2.00 E+00$ & $1.51 E+00$ & $1.07 E+00$ & 7.46E-01 & 5.56E-01 & 4.73E-01 & $4.43 E-01$ \\
\hline 7.00 & $1.94 \mathrm{E}+00$ & $1.82 E+00$ & $1.28 \mathrm{E}+00$ & $8.21 E-01$ & $4.79 \mathrm{E}-01$ & 2.77E-01 & $1.88 \mathrm{E}-01$ & $1.56 \mathrm{E}-01$ \\
\hline 7.25 & $2.14 \mathrm{E}+00$ & $1.51 E+00$ & $1.09 E+00$ & $5.88 \mathrm{E}-01$ & 2.28E-01 & $2.04 E-02$ & $-7.08 E-02$ & $-1.04 E-01$ \\
\hline 7.50 & $2.79 \mathrm{E}+00$ & $1.55 E+00$ & $1.03 E+00$ & $3.97 E-01$ & $-9.31 E-03$ & $-2.29 E-01$ & $-3.23 E-01$ & $-3.56 \mathrm{E}-01$ \\
\hline 7.75 & $4.78 \mathrm{E}+00$ & $1.98 \mathrm{E}+00$ & $1.03 E+00$ & 3.18E-01 & $-2.14 E-01$ & $-4.68 E-01$ & $.5 .67 E-01$ & $-6.01 E-01$ \\
\hline 8.00 & $4.78 E+00$ & $2.76 \mathrm{E}+00$ & $1.34 E+00$ & 4.67E-01 & $-3.27 E-01$ & $-6.84 E-01$ & $-8.00 E-01$ & $-8.35 E-01$ \\
\hline 8.25 & $4.78 E+00$ & $4.78 E+00$ & $1.92 E+00$ & $7.59 \mathrm{E}-01$ & $-2.27 \mathrm{E}-01$ & $-8.41 E-01$ & $-1.01 E+00$ & $-1.05 E+00$ \\
\hline 8.50 & $4.78 \mathrm{E}+00$ & $4.78 \mathrm{E}+00$ & $2.75 E+00$ & $1.25 E+00$ & 1.67E-01 & $-8.36 E-01$ & $-1.19 E+00$ & $-1.25 E+00$ \\
\hline 8.75 & $4.78 E+00$ & $4.78 E+00$ & $4.77 E+00$ & 1.89E+00 & 6.32E-01 & $-5.27 \mathrm{E}-01$ & $-1.27 E+00$ & $-1.41 E+00$ \\
\hline 9.00 & $4.78 \mathrm{E}+00$ & $4.78 E+00$ & $4.77 E+00$ & $2.75 E+00$ & $1.20 \mathrm{E}+00$ & $3.81 \mathrm{E}-02$ & $-1.13 E+00$ & $-1.51 E+00$ \\
\hline 9.25 & $4.78 E+00$ & $4.78 E+00$ & $4.77 E+00$ & $4.76 E+00$ & $1.88 \mathrm{E}+00$ & $5.47 \mathrm{E}-01$ & $-6.60 \mathrm{E}-01$ & $-1.51 E+00$ \\
\hline 9.50 & $4.78 E+00$ & $4.78 E+00$ & $4.77 E+00$ & $4.76 \mathrm{E}+00$ & $2.78 E+00$ & 1.15E+00 & $-9.89 \mathrm{E}-02$ & $-1.26 \mathrm{E}+00$ \\
\hline 9.75 & $4.78 \mathrm{E}+00$ & $4.78 E+00$ & $4.77 E+00$ & $4.76 E+00$ & $4.73 \mathrm{E}+00$ & $1.89 E+00$ & $4.56 \mathrm{E}-01$ & $-7.58 \mathrm{E}-01$ \\
\hline 10.00 & $4.78 E+00$ & $4.78 \mathrm{E}+00$ & $4.77 E+00$ & $4.76 \mathrm{E}+00$ & $4.73 E+00$ & $2.92 E+00$ & 1.13E+00 & $-2.57 E-01$ \\
\hline 10.25 & 500 & 500 & 500 & 500 & 500 & 500 & $2.02 E+00$ & 3.92E-01 \\
\hline
\end{tabular}

Source: 4 solubility_dtn.x/s (Appendix I).

NOTE: Values of 500 (yellow shading) indicate that no valid solubility data are available because the ionic strength of the solutions are above 3 molal. See text Section 6.3.3.4. These concentrations correspond to $\mathrm{Na}$-boltwoodite and $\mathrm{Na}_{4} \mathrm{UO}_{2}\left(\mathrm{CO}_{3}\right)_{3}$ saturation. The green area indicates the region where it is uncertain whether $\mathrm{U}$ is controlled by schoepite or Na-boltwoodite saturation, the blue area where solubility is controlled by $\mathrm{Na}_{4} \mathrm{UO}_{2}\left(\mathrm{CO}_{3}\right)_{3}$.

Figures 6.7-3 and 6.7-4 show concentrations of total dissolved $U$ and of aqueous species contributing to that concentration calculated at $f \mathrm{CO}_{2}=10^{-3.0}$ bars, expressed as molalities and percents total $\mathrm{U}$, respectively. The figures span the $\mathrm{pH}$ range from 3.5 to 9.5 . As discussed in this section, these calculations are based on solubility control by three solids: the minerals schoepite $\left(\mathrm{UO}_{3} \cdot 2 \mathrm{H}_{2} \mathrm{O}\right)$ and $\mathrm{Na}$-boltwoodite $\left(\mathrm{NaUO}_{2} \mathrm{SiO}_{3} \mathrm{OH} \cdot 1.5 \mathrm{H}_{2} \mathrm{O}\right)$, which prevail at low and intermediate $\mathrm{pH}$ values, respectively; and the solid $\mathrm{Na}_{4} \mathrm{UO}_{2}\left(\mathrm{CO}_{3}\right)_{3}$, which is found in laboratory experiments under conditions of high $\mathrm{pH}$ and $f \mathrm{CO}_{2}$. The cusps in the represent the point at which solubility control by one solid gives way to control by another.

These figures show that the following species constitute more than 10 percent of the dissolved uranium under the range of conditions modeled: $\mathrm{UO}_{2}\left(\mathrm{CO}_{3}\right)_{3}{ }^{-}, \mathrm{UO}_{2}\left(\mathrm{CO}_{3}\right)_{2}{ }^{2-},\left(\mathrm{UO}_{2}\right)_{2} \mathrm{CO}_{3}(\mathrm{OH})_{3}{ }^{-}$, $\mathrm{UO}_{3}(\mathrm{aq}), \mathrm{UO}_{2} \mathrm{~F}^{+}, \mathrm{UO}_{2} \mathrm{~F}_{2}(\mathrm{aq}), \mathrm{UO}_{2}{ }^{2+}, \mathrm{UO}_{2} \mathrm{SO}_{4}(\mathrm{aq})$, and $\left(\mathrm{UO}_{2}\right)_{2}(\mathrm{OH})_{2}{ }^{2+}$. 


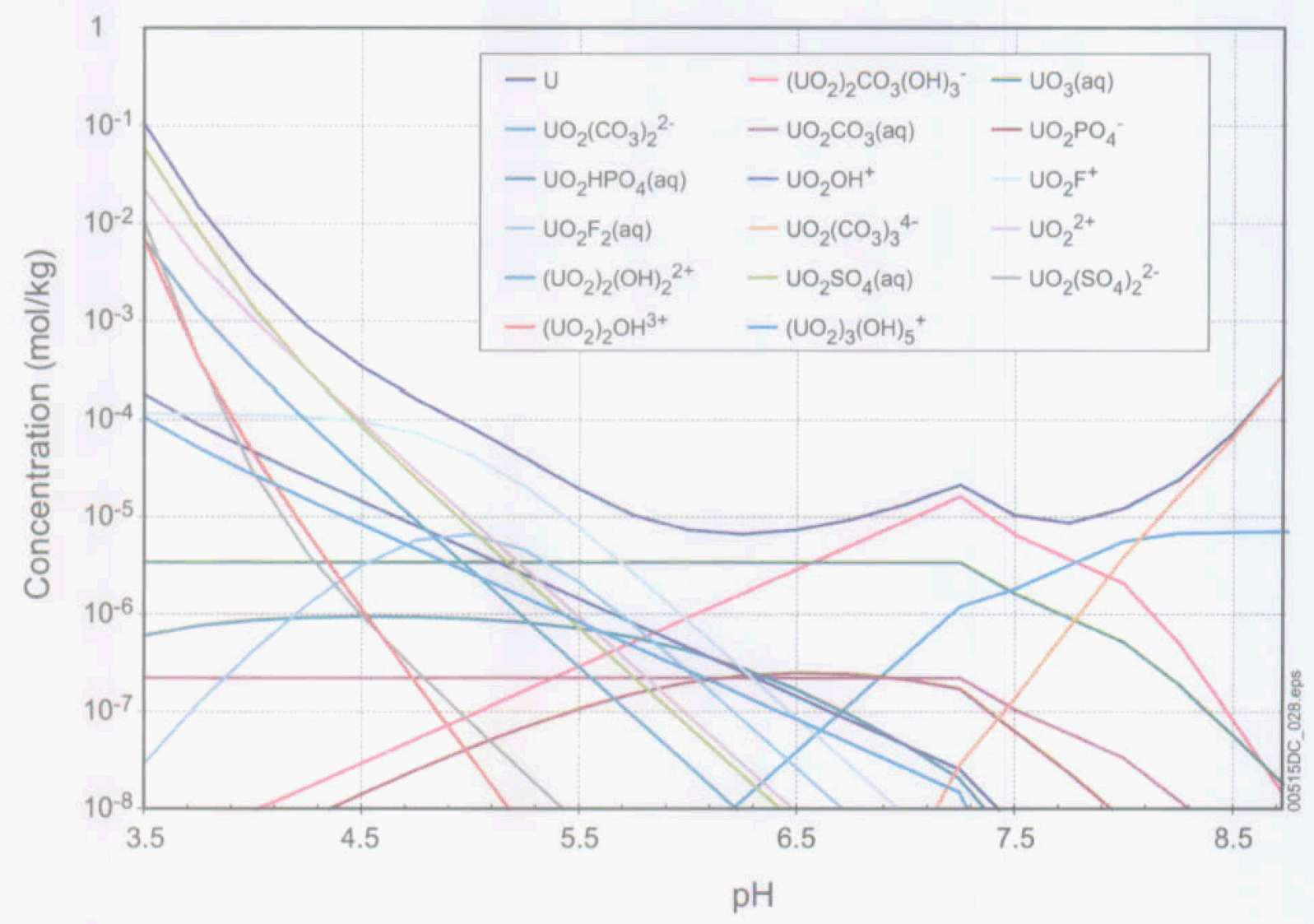

Source: $U$ species plot.xls (Appendix I).

NOTE: $\quad \mathrm{UO}_{3}(\mathrm{aq})$ (as indicated in DTN: MO0302SPATHDYN.000 [DIRS 161756]) is the nonconventional equivalent of $\mathrm{UO}_{2}(\mathrm{OH})_{2}(\mathrm{aq})$; the $\Delta_{1} \mathrm{G}^{0}$ value adopted for $\mathrm{UO}_{3}(\mathrm{aq})$ is consistent with those for $\mathrm{UO}_{2}(\mathrm{OH})_{2}(\mathrm{aq})$.

Figure 6.7-3. Total Uranium Concentration and Speciation Diagram in mol U/kg H $\mathrm{H}_{2} \mathrm{O}$ Calculated at $\mathrm{fCO}_{2}=10^{-3.0}$ bars

Consider the reaction describing the dissolution of the controlling solid, $\mathrm{UO}_{3} \cdot 2 \mathrm{H}_{2} \mathrm{O}$, to one of the dominant species, $\mathrm{UO}_{2}\left(\mathrm{CO}_{3}\right)_{2}{ }^{2-}$ :

$$
\mathrm{UO}_{3} \cdot 2 \mathrm{H}_{2} \mathrm{O}+2 \mathrm{HCO}_{3}{ }^{-}=\mathrm{UO}_{2}\left(\mathrm{CO}_{3}\right)_{2}{ }^{2-}+3 \mathrm{H}_{2} \mathrm{O}
$$

This reaction is written in terms of $\mathrm{HCO}_{3}{ }^{-}$rather than $\mathrm{CO}_{3}{ }^{2-}$ because under the $\mathrm{pH}$ range expected, the concentration of bicarbonate exceeds that of carbonate.

The standard state Gibbs free energy of the reaction $\left(\Delta_{\mathrm{r}} \mathrm{G}^{0}\right)$ is the value needed to calculate its $\log \mathrm{K}$ using $\Delta_{\mathrm{r}} \mathrm{G}^{0}=-\mathrm{RT} \ln \mathrm{K}$. This equals:

$$
\Delta_{\mathrm{r}} \mathrm{G}^{0}\left(\mathrm{UO}_{2}\left(\mathrm{CO}_{3}\right)_{2}{ }^{2-}\right)=\Delta_{\mathrm{f}} \mathrm{G}^{0}\left(\mathrm{UO}_{2}\left(\mathrm{CO}_{3}\right)_{2}{ }^{2-}\right)+3 \cdot \Delta_{\mathrm{f}} \mathrm{G}^{0}\left(\mathrm{H}_{2} \mathrm{O}\right)-\Delta_{\mathrm{f}} \mathrm{G}^{0}\left(\mathrm{UO}_{3} \cdot 2 \mathrm{H}_{2} \mathrm{O}\right)-2 \cdot \Delta_{\mathrm{f}} \mathrm{G}^{0}\left(\mathrm{HCO}_{3}{ }^{-}\right)
$$




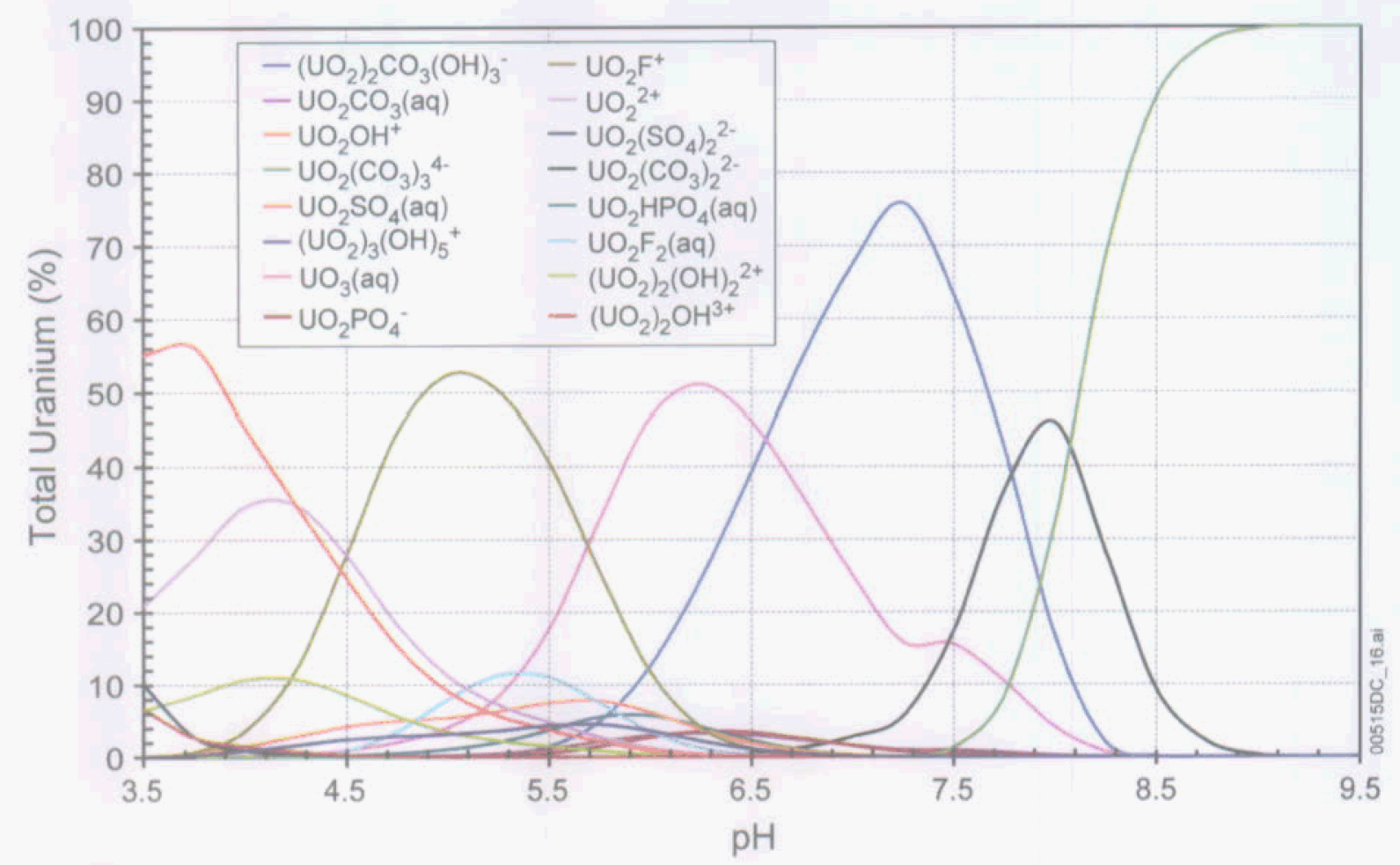

Source: $\quad U$ species plot.xls (Appendix I).

NOTE: $\quad \mathrm{UO}_{3}(\mathrm{aq})$ (as indicated in DTN: MO0302SPATHDYN.000 [DIRS 161756]) is the nonconventional equivalent of $\mathrm{UO}_{2}(\mathrm{OH})_{2}(\mathrm{aq})$; the $\Delta \mathrm{G}^{0}$ value adopted for $\mathrm{UO}_{3}(\mathrm{aq})$ is consistent with those for $\mathrm{UO}_{2}(\mathrm{OH})_{2}(\mathrm{aq})$.

Figure 6.7-4. Uranium Speciation Diagram in Percent Total Uranium Calculated at $\mathrm{fCO}_{2}=10^{-3.0}$ bars

Because this expression is a simple algebraic sum, the uncertainties of the $\Delta_{\mathrm{f}} \mathrm{G}^{0}$ terms can be combined to give the uncertainty of $\Delta_{\mathrm{r}} \mathrm{G}^{0}\left(\mathrm{UO}_{2}\left(\mathrm{CO}_{3}\right)_{2}{ }^{2-}\right)$ by the usual square root of the mean (Bevington 1969 [DIRS 146304], Section 4-2). This procedure gives $\pm 2.703 \mathrm{~kJ} / \mathrm{mol}$ for $2 \sigma \Delta_{\mathrm{r}} \mathrm{G}^{0}\left(\mathrm{UO}_{2}\left(\mathrm{CO}_{3}\right)_{2}{ }^{2-}\right)$. Dividing this by $-\mathrm{RT} \ln (10)(=-5.708 \mathrm{~kJ} / \mathrm{mol}$ at $298.15 \mathrm{~K})$ gives $2 \sigma \log \mathrm{K}$ $= \pm 0.47$ ( $\log K$ Uncertainties_040624.xls in Appendix I). When this procedure is followed for all nine dominant aqueous species listed earlier, it is found that above $\mathrm{pH}$ about 6.5 (for $f \mathrm{CO}_{2}=$ $10^{-3.0}$ bars as used in the calculation illustrated) where the dominant species are carbonate and hydroxy-carbonate complexes, the largest uncertainty is for $\left(\mathrm{UO}_{2}\right)_{2} \mathrm{CO}_{3}(\mathrm{OH})_{3}{ }^{-}$at $2 \sigma \log \mathrm{K}=$ \pm 0.99 . At lower $\mathrm{pH}$ values, where fluoride and sulfate complexes and $\mathrm{UO}_{2}{ }^{2+}$ dominate, the largest uncertainties are for the two fluoride complexes, $\mathrm{UO}_{2} \mathrm{~F}_{2}(\mathrm{aq})$ and $\mathrm{UO}_{2} \mathrm{~F}^{+}$at \pm 0.55 and \pm 0.48 , respectively, and for $\mathrm{UO}_{2} \mathrm{SO}_{4}(\mathrm{aq})$ at \pm 0.44 . The largest $2 \sigma \log \mathrm{K}$ value of \pm 0.99 leads to a $1 \sigma$ standard deviation for the solubility value of \pm 0.5 , which is applied in a normal distribution truncated at $\pm 2 \sigma$ for all uranium concentrations.

\subsubsection{Uncertainty}

\subsubsection{Uncertainty in log $\mathrm{K}$ Values of the Controlling Solid and Aqueous Species}

This total uncertainty in solubility includes uncertainties in the log $\mathrm{K}$ values of the thermodynamic properties of the controlling solid and those for the dissolved species. The evaluation and combination of these uncertainties are discussed in more detail in Section 6.3.3.1. 
The total uncertainty applicable to all $\log [\mathrm{U}]$ values is \pm 0.99 units. This represents the $2 \sigma$ limit of a normal distribution with a $1 \sigma$ uncertainty of \pm 0.5 .

When more than one solubility-controlling solid is used, an additional source of uncertainty, is in the $\mathrm{pH}$ at which solubility control by one solid gives way to control by another and results from the uncertainties in the $\log \mathrm{K}$ values of both solids. The uncertainty in crossover $\mathrm{pH}$ was evaluated by modeling the $\mathrm{pH}$ at which both solids were saturated when the $\log \mathrm{K}$ values for each are set at the upper and lower limits of their uncertainty ranges.

The uncertainties in the $\log \mathrm{K}$ values of the solids are not available in Data0.ymp.R2, but are given (or can be derived from) the NEA chemical thermodynamic handbooks (e.g., Guillaumont et al. 2003 [DIRS 168382]) from which the $\log \mathrm{K}$ values in Data0.yc3.RI were themselves derived. The range of $\log \mathrm{K}$ values and the calculations on which they are based are given in spreadsheet $U$-Solids-uncertainty.xls in Appendix I.

Table 6.7-7 shows the ranges of $\mathrm{pH}$ at which schoepite saturation gives way to Na-boltwoodite saturation. This range is based on EQ3 calculations of the $\mathrm{pH}$ of solutions at equilibrium with both schoepite and Na-boltwoodite for all combinations of the high and low values of $\log \mathrm{K}$ (workbook Raw data, spreadsheet $U \log K$ Uncertainty_a.xls in Appendix I). The difference between the maximum and minimum $\mathrm{pH}$ varies from $1.46 \mathrm{pH}$ units at $\log f \mathrm{CO}_{2}=-5.0$ bars to $0.77 \mathrm{pH}$ units at $\log f \mathrm{CO}_{2}=-1.5$ bars. This range is shaded green in Tables 6.7-5 and 6.7-6 and solubility values are given for schoepite and $\mathrm{Na}$-boltwoodite. The solubility to be used at a given $\mathrm{pH}$ and $\log f \mathrm{CO}_{2}$ is to be chosen randomly from a uniform distribution between the solubilities of the two minerals.

Table 6.7-7. Range of $\mathrm{pH}$ Values at Which Schoepite Saturation Gives Way to Na-Boltwoodite Saturation Based on Uncertainties in the log K Values of the Solids

\begin{tabular}{|c|c|c|c|c|}
\hline \multirow{2}{*}{$\begin{array}{c}\text { log } f_{\text {(bars) }} \\
\text { bars }\end{array}$} & \multicolumn{3}{|c|}{$\mathbf{p H}^{\mathbf{a}}$} \\
\hline-5.0 & Maximum & Nominal & Minimum & \\
\hline-4.5 & 7.77 & 7.18 & 6.59 \\
\hline-4.0 & 7.77 & 7.18 & 6.59 \\
\hline-3.5 & 7.77 & 7.18 & 6.59 \\
\hline-3.0 & 7.77 & 7.18 & 6.59 \\
\hline-2.5 & 7.67 & 7.18 & 6.59 \\
\hline-2.0 & 7.41 & 7.18 & 6.59 \\
\hline-1.5 & 7.14 & 6.85 & 6.59 \\
\hline
\end{tabular}

Source: LogK SCHO_NA-BOLT Uncertainty.xls (Appendix 1).

NOTE: ${ }^{a} \mathrm{pH}$ value at which schoepite saturation equals $\mathrm{Na}$-boltwoodite saturation.

The ranges of $\mathrm{pH}$ at which $\mathrm{Na}$-boltwoodite saturation gives way to $\mathrm{Na}_{4} \mathrm{UO}_{2}\left(\mathrm{CO}_{3}\right)_{3}$ saturation was not modeled explicitly as was the schoepite-Na-boltwoodite crossover because of the extent of the EQ6 calculations that would have been required. Instead, the uncertainty was calculated directly from the uncertainties to the $\log \mathrm{K}$ values of the two solids. 
The reaction between the two solids can be written:

$$
\mathrm{NaUO}_{2} \mathrm{SiO}_{3} \mathrm{OH}: 1.5 \mathrm{H}_{2} \mathrm{O}+3 \mathrm{Na}^{+}+3 \mathrm{CO}_{3}^{-2}+3 \mathrm{H}^{+}=\mathrm{Na}_{4} \mathrm{UO}_{2}\left(\mathrm{CO}_{3}\right)_{3}+\mathrm{SiO}_{2}(\mathrm{aq})+3.5 \mathrm{H}_{2} \mathrm{O}
$$

The uncertainties in the $\log \mathrm{K}$ values for the solids is \pm 0.16 for Na-boltwoodite and \pm 0.25 for $\mathrm{Na}_{4} \mathrm{UO}_{2}\left(\mathrm{CO}_{3}\right)_{3}$. The uncertainty in the equilibrium position of this reaction due to the uncertainties in the $\log \mathrm{K}$ values of the solids is $\left(0.16^{2}+0.25^{2}\right)^{1 / 2}= \pm 0.30$ (Section 6.3.3.1). Because there are three $\mathrm{H}^{+}$ions in the reaction, the uncertainty per $\mathrm{pH}$ unit is $0.30 / 3= \pm 0.10$. This is less than the difference between the $\mathrm{pH}$ values of adjacent cells in Table 6.7-6, so the crossover uncertainty for these two minerals is not treated explicitly.

\subsubsection{Uncertainty Addition from High Ionic Strength Solutions}

At the high $\mathrm{pH}$ and $f \mathrm{CO}_{2}$ values at which $\mathrm{Na}_{4} \mathrm{UO}_{2}\left(\mathrm{CO}_{3}\right)_{3}$ is the controlling phase, the ionic strength of the solution is above 1 molal and may be as high as 2.5 molal. The nominal range of applicability of the EQ3/6 codes and the Data0.ymp.R2 database is to 1 molal ionic strength. However, as discussed in Section 6.3.3.4, they can be used to an ionic strength of 3 molal if an additional uncertainty of \pm 0.3 is added by the square root of the mean to the results of calculations with ionic strengths between 1 and 3 molal. This uncertainty can be combined with the \pm 0.5 uncertainty in the $\log \mathrm{K}$ values discussed in Section 6.7.5.1 to give a $1 \sigma$ uncertainty of \pm 0.6 to be applied uniformly to $\log [\mathrm{U}]$ for solutions with ionic strengths above 1 molal. These are the solutions shaded blue in Table 6.7-6. Section 6.7.6 already takes this into account in the reported uncertainty values for $\log \mathrm{K}$.

\subsubsection{Uncertainty from Fluoride Concentration}

The effects of fluoride uncertainty were evaluated by calculating uranium solubilities at a range of $\mathrm{pH}$ values for $f \mathrm{CO}_{2}=10^{-3.0}$ bars with fluoride concentrations equal to the highest values expected in each of the three in-package and invert environments. These environments and their fluoride concentrations are described in Section 6.3.3.2 and Table 6.3-3. These results are displayed in Figure 6.7-5 and Table 6.7-8. The values in the tables are the differences between solubilities calculated using the $\mathrm{F}^{-}$values for sensitivity analyses and the base-case solubility values. As the figure and table show, at a fluoride concentration of $21.8 \mathrm{mg} / \mathrm{L}$ (the CSNF environment, $10 \times$ the base-case value), the maximum difference from the base-case concentration is $+1.03 \log [\mathrm{U}]$ (in $\mathrm{mg} / \mathrm{L}$ ) units at a $\mathrm{pH}$ of 5.75. At a fluoride concentration of $209 \mathrm{mg} / \mathrm{L}$ (the codisposal vapor influx scenario and invert environment, about $100 \times$ the base-case value), the solubility controlled by schoepite is higher by a maximum value of $+2.40 \log [\mathrm{U}]$ (in $\mathrm{mg} / \mathrm{L}$ ) at a $\mathrm{pH}$ of 5.75 and the solubility controlled by Na-boltwoodite is higher by a maximum value of $+1.17 \log [\mathrm{U}]$ (in $\mathrm{mg} / \mathrm{L}$ ) at the lowest $\mathrm{pH}$ modeled for the sensitivity analysis, 6.50 . 


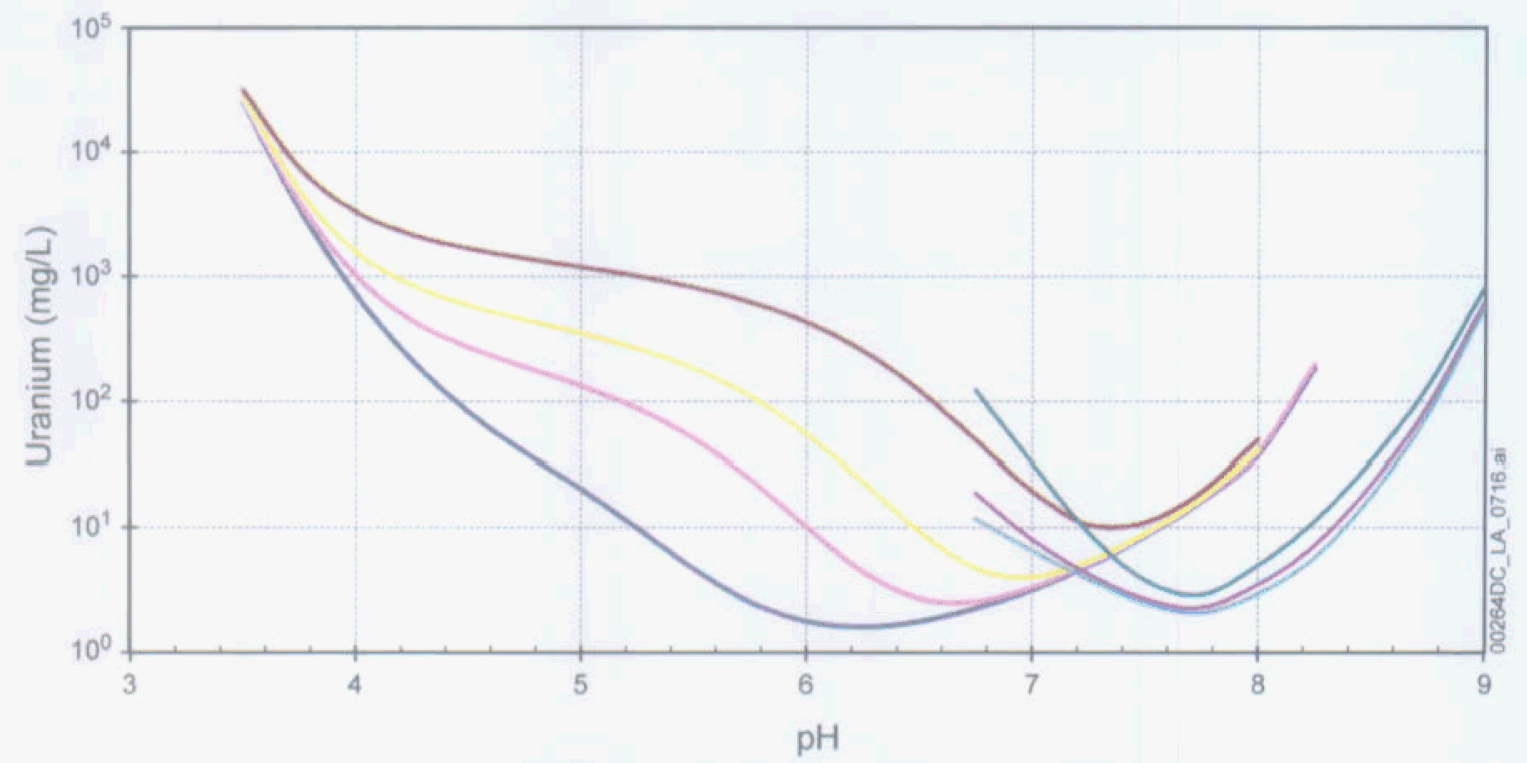

- Schoepite base case
- Schoepite commercial spent nuclear fuel nominal and seismic breach

Schoepite codisposal waste packages condensation water only (vapor flux model)

Na-boltwoodite base case

Na-boltwoodite codisposal waste packages condensation water only (vapor flux model)

Schoepite codisposal waste packages seepage water and commercial spent nuclear fuel igneous intrusion breach (liquid flux model)

Na-boltwoodite codisposal waste packages seepage water and commercial spent nuclear fuel igneous intrusion breach (liquid flux model)

Source: U-F Sensitivity_a.x/s (Appendix I).

Note: See Table 6,7-8 for corresponding F concentrations.

Figure 6.7-5. Effect of Fluoride on Solubilities of Schoepite and Na-Boltwoodite at $\log f \mathrm{CO}_{2}=-3.0$ bars 
Table 6.7-8. Increases in Solubilities of Schoepite and Na-boltwoodite with Additional $\mathrm{F}^{-}$at Various $\mathrm{pH}$ Values

\begin{tabular}{|c|c|c|c|c|c|c|c|}
\hline \multicolumn{2}{|c|}{$\begin{array}{l}\text { F- Uncertainty for } \\
\text { CSNF Waste } \\
\text { Packages }\end{array}$} & \multicolumn{3}{|c|}{$\begin{array}{l}\text { F- Uncertainty for Water Influx } \\
\text { CDSP Waste Packages }\end{array}$} & \multicolumn{3}{|c|}{$\begin{array}{l}F^{-} \text {Uncertainty for Vapor Influx } \\
\text { CDSP Waste Packages }\end{array}$} \\
\hline $\mathrm{pH}$ & Schoepite & $\mathrm{pH}$ & Schoepite & $\begin{array}{c}\text { Boltwoodite- } \\
\mathrm{Na}\end{array}$ & pH & Schoepite & $\begin{array}{l}\text { Boltwoodite- } \\
\mathrm{Na}\end{array}$ \\
\hline 3.50 & $1.00 \mathrm{E}-02$ & 3.50 & $2.80 \mathrm{E}-02$ & & 3.50 & $9.05 \mathrm{E}-02$ & \\
\hline 3.75 & $4.88 \mathrm{E}-02$ & 3.75 & $1.25 \mathrm{E}-01$ & & 3.75 & 3.23E-01 & \\
\hline 4.00 & $1.48 \mathrm{E}-01$ & 4.00 & $3.26 \mathrm{E}-01$ & & 4.00 & $6.60 \mathrm{E}-01$ & \\
\hline 4.25 & $3.20 \mathrm{E}-01$ & 4.25 & $5.95 \mathrm{E}-01$ & & 4.25 & $1.01 \mathrm{E}+00$ & \\
\hline 4.50 & 5.17E-01 & 4.50 & $8.54 \mathrm{E}-01$ & & 4.50 & $1.32 \mathrm{E}+00$ & \\
\hline 4.75 & $6.81 \mathrm{E}-01$ & 4.75 & $1.06 \mathrm{E}+00$ & & 4.75 & $1.56 \mathrm{E}+00$ & \\
\hline 5.00 & $8.18 \mathrm{E}-01$ & 5.00 & $1.24 \mathrm{E}+00$ & & 5.00 & $1.78 \mathrm{E}+00$ & \\
\hline 5.25 & $9.47 \mathrm{E}-01$ & 5.25 & $1.43 E+00$ & & 5.25 & $2.02 E+00$ & \\
\hline 5.50 & $1.03 \mathrm{E}+00$ & 5.50 & $1.60 \mathrm{E}+00$ & & 5.50 & $2.25 E+00$ & \\
\hline 5.75 & $9.78 \mathrm{E}-01$ & 5.75 & $1.65 \mathrm{E}+00$ & & 5.75 & $2.40 \mathrm{E}+00$ & \\
\hline 6.00 & $7.58 \mathrm{E}-01$ & 6.00 & $1.50 \mathrm{E}+00$ & & 6.00 & $2.39 \mathrm{E}+00$ & \\
\hline 6.25 & 4.46E-01 & 6.25 & 1.16E+00 & & 6.25 & $2.20 \mathrm{E}+00$ & \\
\hline 6.50 & $1.85 \mathrm{E}-01$ & 6.50 & 7.15E-01 & $3.68 \mathrm{E}-01$ & 6.50 & $1.84 E+00$ & $1.17 \mathrm{E}+00$ \\
\hline 6.75 & $5.36 \mathrm{E}-02$ & 6.75 & 3.17E-01 & 1.99E-01 & 6.75 & $1.34 \mathrm{E}+00$ & $1.02 E+00$ \\
\hline 7.00 & $2.03 E-02$ & 7.00 & $9.35 \mathrm{E}-02$ & $8.88 \mathrm{E}-02$ & 7.00 & $7.79 \mathrm{E}-01$ & $6.90 \mathrm{E}-01$ \\
\hline 7.25 & $1.13 \mathrm{E}-02$ & 7.25 & 2.15E-02 & 4.47E-02 & 7.25 & $3.16 \mathrm{E}-01$ & $3.74 \mathrm{E}-01$ \\
\hline 7.50 & $9.76 \mathrm{E}-03$ & 7.50 & $6.88 \mathrm{E}-03$ & 3.33E-02 & 7.50 & $9.76 \mathrm{E}-02$ & 1.85E-01 \\
\hline 7.75 & $8.78 \mathrm{E}-03$ & 7.75 & $9.69 \mathrm{E}-03$ & $4.28 \mathrm{E}-02$ & 7.75 & $5.99 \mathrm{E}-02$ & $1.46 \mathrm{E}-01$ \\
\hline 8.00 & $1.55 \mathrm{E}-02$ & 8.00 & $4.16 \mathrm{E}-02$ & $7.73 \mathrm{E}-02$ & 8.00 & $1.25 \mathrm{E}-01$ & $2.30 \mathrm{E}-01$ \\
\hline 8.25 & $3.30 \mathrm{E}-02$ & 8.25 & & $9.97 \mathrm{E}-02$ & 8.25 & $2.90 \mathrm{E}-01$ & $2.88 \mathrm{E}-01$ \\
\hline $\max$ & $1.03 E+00$ & 8.50 & & $9.55 \mathrm{E}-02$ & 8.50 & & 2.82E-01 \\
\hline & & 8.75 & & 7.37E-02 & 8.75 & & $2.28 \mathrm{E}-01$ \\
\hline & & 9.00 & & $4.92 \mathrm{E}-02$ & 9.00 & & $1.60 \mathrm{E}-01$ \\
\hline & & $\max$ & $1.65 \mathrm{E}+00$ & 3.68E-01 & $\max$ & $2.40 E+00$ & $1.17 E+00$ \\
\hline
\end{tabular}

Source: U-F Sensitivity_a.x/s (Appendix I).

\subsubsection{Summary}

Uranium solubility is given by the following equation:

$$
\log [\mathrm{U}]=S\left(p H, \log f \mathrm{CO}_{2}\right)+\varepsilon_{1}+\left(\varepsilon_{2} \times N\right)
$$

The values for the parameters in this equation depend on the waste package type and breach scenario. Parameter $S\left(p H, \log f_{\mathrm{CO}_{2}}\right)$ is the base-case solubility and is taken from Tables 6.7-3, 6.7-5, or 6.7-6, as described below. Parameter $\varepsilon_{1}$ is associated with the uncertainties in the $\log K$ data. It is normally distributed with mean $(\mu)$ and standard deviation $(\sigma)$ given below. 
Parameter $\varepsilon_{2}$ is associated with the uncertainties in the fluoride concentrations. It has a triangular distribution with values of $a, b$, and $c$ given below.

CSNF packages breached under nominal conditions or by seismic events:

$$
\begin{aligned}
& S\left(p H, \log f_{\mathrm{CO}_{2}}\right): \text { Table 6.7-3 } \\
& \varepsilon_{1:} \mu=0, \sigma=0.5 \\
& \varepsilon_{2}: \mathrm{a}=\mathrm{b}=0, \mathrm{c}=1.03 \\
& \mathrm{~N}(\mathrm{pH}): \text { Given in Table 6.7-9. }
\end{aligned}
$$

Table 6.7-9. Normalized pH Dependence, $\mathrm{N}(\mathrm{pH})$, of c-Parameter of Fluoride Uncertainty Factor $\varepsilon_{2}$ for CSNF Packages Breached Under Nominal Conditions or by Seismic Events

\begin{tabular}{|c|c|}
\hline $\mathbf{p H}$ & $\mathbf{N}(\mathbf{p H})$ \\
\hline 3.50 & $9.74 \mathrm{E}-03$ \\
\hline 3.75 & $4.74 \mathrm{E}-02$ \\
\hline 4.00 & $1.44 \mathrm{E}-01$ \\
\hline 4.25 & $3.11 \mathrm{E}-01$ \\
\hline 4.50 & $5.03 \mathrm{E}-01$ \\
\hline 4.75 & $6.62 \mathrm{E}-01$ \\
\hline 5.00 & $7.94 \mathrm{E}-01$ \\
\hline 5.25 & $9.20 \mathrm{E}-01$ \\
\hline 5.50 & $1.00 \mathrm{E}+00$ \\
\hline 5.75 & $9.50 \mathrm{E}-01$ \\
\hline 6.00 & $7.36 \mathrm{E}-01$ \\
\hline 6.25 & $4.34 \mathrm{E}-01$ \\
\hline 6.50 & $1.79 \mathrm{E}-01$ \\
\hline 6.75 & $5.21 \mathrm{E}-02$ \\
\hline 7.00 & $1.97 \mathrm{E}-02$ \\
\hline 7.25 & $1.10 \mathrm{E}-02$ \\
\hline 7.50 & $9.49 \mathrm{E}-03$ \\
\hline 7.75 & $8.53 \mathrm{E}-03$ \\
\hline 8.00 & $1.50 \mathrm{E}-02$ \\
\hline 8.25 & $3.21 \mathrm{E}-02$ \\
\hline & \\
\hline 0500 & \\
\hline
\end{tabular}

Source: Workbook Normalized $F$ uncertainty, spreadsheet U-F Sensitivity_a.x/s (Appendix I).

\section{Codisposal Packages Breached Under Nominal Conditions or by Seismic or Intrusive} Events; CSNF Packages Breached by Intrusive Events:

$S\left(p H, \log f_{\mathrm{CO}_{2}}\right):$ Either Table $6.7-5$ or $6.7-6$, or both:

If $\mathrm{pH}$ and $\log f \mathrm{CO}_{2}$ fall within unshaded areas of tables, schoepite or Na-boltwoodite is the controlling solid. Select value from appropriate table. 
If $\mathrm{pH}$ and $\log f \mathrm{CO}_{2}$ fall within green-shaded areas of tables, it is uncertain whether schoepite or Na-boltwoodite is the controlling solid. Select a value randomly from a uniform distribution bounded by values from each table.

If $\mathrm{pH}$ and $\log f \mathrm{CO}_{2}$ fall within blue-shaded areas of tables, $\mathrm{Na}_{4} \mathrm{UO}_{2}\left(\mathrm{CO}_{3}\right)_{3}$ is the controlling solid. Select value from Table 6.7-6.

$\varepsilon_{1:} \quad$ If $\mathrm{pH}$ and $\log f \mathrm{CO}_{2}$ fall within unshaded areas of tables, $\mu=0, \sigma=0.5$

If $\mathrm{pH}$ and $\log f \mathrm{CO}_{2}$ fall within green-shaded areas of tables, $\mu=0, \sigma=0.5$.

If $\mathrm{pH}$ and $\log \mathrm{CO}_{2}$ fall within blue-shaded areas of tables, $\mu=0, \sigma=0.6$ (already takes into account the adjustment to $\log \mathrm{K}$ values required at ionic strengths between 1 and 3. Section 6.7.5.2)

$\varepsilon_{2}$ : Depends on the controlling solid and the appropriate in-package chemical abstraction as given in Table 6.7-10 (denoted by "c").

Table 6.7-10. Dependence of $\varepsilon_{2}$ : c Parameter on Solubility-Controlling Solid and Type of Fluid in Waste Package

\begin{tabular}{|l|l|c|c|}
\hline $\begin{array}{c}\text { Solubility- } \\
\text { Controlling Solid }\end{array}$ & \multicolumn{1}{|c|}{ Area of Tables } & $\begin{array}{c}\text { Water Influx: Codisposal and } \\
\text { CSNF Packages Breached } \\
\text { during Igneous Intrusion }\end{array}$ & $\begin{array}{c}\text { Vapor Influx: } \\
\text { Codisposal Packages }\end{array}$ \\
\hline Schoepite & Table 6.7-3, unshaded or green & $a=b=0, c=1.65$ & $a=b=0, c=2.40$ \\
\hline Na-boltwoodite & Table 6.7-5, unshaded or green & $a=b=0, c=0.368$ & $a=b=0, c=1.17$ \\
\hline $\mathrm{Na}_{4} \mathrm{UO}_{2}\left(\mathrm{CO}_{3}\right)_{3}$ & Table 6.7-6, blue shaded & $a=b=0, c=0$ & $a=b=0, c=0$ \\
\hline
\end{tabular}

NOTES: c values correspond to "max" values in Table 6.7-9.

$\mathrm{N}(\mathrm{pH})$ : Depends on water influx or vapor influx in package as shown in Table 6.7-11.

The concentrations of $\mathrm{UO}_{2}-\mathrm{F}$ ion pairs at $f \mathrm{CO}_{2}=10^{-3}$ and $\mathrm{pH} 7$ are less than $10^{-8} \mathrm{~mol} / \mathrm{kg}$ $(-2.6 \log \mathrm{mgU} / \mathrm{L})$ are decreasing at the rate of two powers of 10 per increasing $\mathrm{pH}$ unit (Figure 6.7-3). At this $f \mathrm{CO}_{2}, \mathrm{Na}_{4} \mathrm{UO}_{2}\left(\mathrm{CO}_{3}\right)_{3}$ becomes the controlling phase at $\mathrm{pH} 9.25$. At this $\mathrm{pH}$, the total $\mathrm{U}$ is $4.76 \mathrm{log} \mathrm{mg} / \mathrm{L}$ (Table 6.7-6) while the concentrations of $\mathrm{UO}_{2}-\mathrm{F}$ would be less than $-2.6-4=-6.6 \mathrm{log} \mathrm{mg} / \mathrm{L}$ (extrapolation from Figure 6.3-1). Thus, $\mathrm{UO}_{2}-\mathrm{F}$ complexes make up less than $10^{-11}$ of the total $\mathrm{U}$ when $\mathrm{Na}_{4} \mathrm{UO}_{2}\left(\mathrm{CO}_{3}\right)_{3}$ controls, so there is no need to include $\mathrm{F}^{-}$ sensitivity. 
Table 6.7-11. pH Dependence of Fluoride Uncertainty for Codisposal Waste Packages Breached Under Nominal, Seismic, or Hypothetical Igneous Intrusive Scenarios and CSNF Waste Packages Breached by Hypothetical Igneous Intrusive

\begin{tabular}{|c|c|c|c|c|c|}
\hline \multicolumn{3}{|c|}{$\begin{array}{c}\text { N(pH) for Water Influx: CDSP and } \\
\text { CSNF Packages Breached by } \\
\text { Igneous Intrusion }\end{array}$} & \multicolumn{3}{|c|}{$\begin{array}{c}\mathrm{N}(\mathrm{pH}) \text { for Vapor Influx: CDSP Waste } \\
\text { Packages }\end{array}$} \\
\hline $\mathrm{pH}$ & Schoepite & Boltwoodite-Na & pH & Schoepite & Boltwoodite-Na \\
\hline 3.50 & $1.70 \mathrm{E}-02$ & & 3.50 & $3.77 \mathrm{E}-02$ & \\
\hline 3.75 & $7.59 \mathrm{E}-02$ & & 3.75 & 1.34E-01 & \\
\hline 4.00 & $1.98 \mathrm{E}-01$ & & 4.00 & $2.75 \mathrm{E}-01$ & \\
\hline 4.25 & $3.61 \mathrm{E}-01$ & & 4.25 & 4.21E-01 & \\
\hline 4.50 & $5.18 \mathrm{E}-01$ & & 4.50 & $5.48 \mathrm{E}-01$ & \\
\hline 4.75 & $6.44 \mathrm{E}-01$ & & 4.75 & $6.49 \mathrm{E}-01$ & \\
\hline 5.00 & $7.54 \mathrm{E}-01$ & & 5.00 & $7.41 \mathrm{E}-01$ & \\
\hline 5.25 & $8.70 \mathrm{E}-01$ & & 5.25 & $8.40 \mathrm{E}-01$ & \\
\hline 5.50 & $9.70 \mathrm{E}-01$ & & 5.50 & 9.37E-01 & \\
\hline 5.75 & $1.00 \mathrm{E}+00$ & & 5.75 & $1.00 \mathrm{E}+00$ & \\
\hline 6.00 & $9.08 \mathrm{E}-01$ & & 6.00 & $9.96 \mathrm{E}-01$ & \\
\hline 6.25 & 7.01E-01 & & 6.25 & 9.17E-01 & \\
\hline 6.50 & 4.34E-01 & $1.00 \mathrm{E}+00$ & 6.50 & 7.66E-01 & $1.00 \mathrm{E}+00$ \\
\hline 6.75 & $1.92 \mathrm{E}-01$ & $5.41 \mathrm{E}-01$ & 6.75 & 5.57E-01 & $8.70 \mathrm{E}-01$ \\
\hline 7.00 & $5.67 \mathrm{E}-02$ & 2.41E-01 & 7.00 & 3.24E-01 & $5.91 \mathrm{E}-01$ \\
\hline 7.25 & $1.31 \mathrm{E}-02$ & 1.21E-01 & 7.25 & 1.31E-01 & $3.21 \mathrm{E}-01$ \\
\hline 7.50 & $4.18 \mathrm{E}-03$ & $9.03 E-02$ & 7.50 & 4.06E-02 & $1.59 \mathrm{E}-01$ \\
\hline 7.75 & $5.88 \mathrm{E}-03$ & 1.16E-01 & 7.75 & $2.49 \mathrm{E}-02$ & $1.25 \mathrm{E}-01$ \\
\hline 8.00 & 2.52E-02 & $2.10 \mathrm{E}-01$ & 8.00 & $5.20 \mathrm{E}-02$ & 1.97E-01 \\
\hline 8.25 & & 2.71E-01 & 8.25 & $1.21 \mathrm{E}-01$ & 2.47E-01 \\
\hline 8.50 & & $2.59 \mathrm{E}-01$ & 8.50 & & 2.41E-01 \\
\hline 8.75 & & $2.00 \mathrm{E}-01$ & 8.75 & & $1.95 \mathrm{E}-01$ \\
\hline 9.00 & & 1.34E-01 & 9.00 & & 1.37E-01 \\
\hline
\end{tabular}

Source: U-F Sensitivity_a.xIs (Appendix I).

\subsection{THORIUM SOLUBILITY}

\subsubsection{Introduction}

Data0.ymp.R2 (DTN: MO0302SPATHDYN.000 [DIRS 161756]) includes thorium data from a variety of sources. These have been used with EQ3NR to calculate the thorium concentrations discussed in this section. 


\subsubsection{Controlling Mineral}

$\mathrm{ThO}_{2}(\mathrm{am})$ was chosen as the controlling phase for the full range of $\mathrm{pH}$ and $f \mathrm{CO}_{2}$ values. Data0.ymp.R2 also includes data for the $\mathrm{ThO}_{2}$ mineral thorianite and for a number of other thorium solids. Thorianite is about $5.5 \mathrm{log}$ units more stable (less soluble) than $\mathrm{ThO}_{2}(\mathrm{am})$. However, as discussed in Section 6.3.2 and, in more detail, by Hummel et al. (2002 [DIRS 161904], Section 5.21.2), solubilities as low as those predicted using thorianite are measured only at $\mathrm{pH}$ values below about 5. Calculations using $\mathrm{ThO}_{2}(\mathrm{am})$ lead to dissolved thorium concentrations like those commonly measured in solubility studies, as discussed in Section 7.2.5.

Several other solids in Data0.ymp.R2 are less soluble than $\mathrm{ThO}_{2}(\mathrm{am})$ in the nominal reference water under certain conditions of $\mathrm{pH}$ and $f \mathrm{CO}_{2} . \mathrm{Th}_{0.75} \mathrm{PO}_{4}$ is less soluble under acid conditions. However, because of the amount of uranium available in the waste package environment, phosphate concentrations there are likely to be very low, as discussed in Section 6.4.2.5. Thus, $\mathrm{Th}_{0.75} \mathrm{PO}_{4}$ is excluded. $\mathrm{Th}\left(\mathrm{SO}_{4}\right)_{2}, \mathrm{ThF}_{4}$, and $\mathrm{ThF}_{4} \cdot 2.5 \mathrm{H}_{2} \mathrm{O}$ are also less soluble than $\mathrm{ThO}_{2}(\mathrm{am})$ under acid conditions, with $\mathrm{Th}\left(\mathrm{SO}_{4}\right)_{2}$ particularly insoluble at the lowest $\mathrm{pH}$ values where $\mathrm{SO}_{4}{ }^{2-}$ concentrations are high because of the use of this anion for charge balance of the modeled solutions. Data for $\mathrm{ThF}_{4} \cdot 2.5 \mathrm{H}_{2} \mathrm{O}$ and $\mathrm{Th}\left(\mathrm{SO}_{4}\right)_{2}$ are taken from a previous compilation of data (Wagman et al. 1982 [DIRS 159216]). In reviewing the data from Wagman et al. 1982 ([DIRS 159216]), Hummel et al. (2002 [DIRS 161904], Sections 5.21.6 and 7) note that the properties of $\mathrm{ThF}_{4} \cdot 2.5 \mathrm{H}_{2} \mathrm{O}$ are based on an estimate and could not determine the original source for the properties of $\mathrm{Th}\left(\mathrm{SO}_{4}\right)_{2}$. Thus, these two solids are also excluded from consideration. The relevant $\mathrm{F}^{-}$concentrations are uncertain, so $\mathrm{ThF}_{4}$ is also excluded.

Section 6.8.4.2.2 addresses uncertainty associated with the properties of the controlling phase.

\subsubsection{Chemical Conditions}

Table 6.4-2 lists the chemical conditions for the thorium calculations.

\subsubsection{Thorium Solubility Model Results}

\subsubsection{Speciation and Solubility}

The identity and relative concentrations of the aqueous species that compose the total dissolved Th concentrations modeled are discussed in detail in Section 6.4.2.5.1 and illustrated in Figures 6.4-12 and 6.4-13. That discussion is summarized here.

At $f \mathrm{CO}_{2}=10^{-3.0}$, the principal Th species above $\mathrm{pH} 6$ is $\mathrm{Th}(\mathrm{OH})_{3} \mathrm{CO}_{3}{ }^{-}$, shifting to $\mathrm{Th}\left(\mathrm{CO}_{3}\right)_{5}{ }^{6-}$ at $\mathrm{pH}$ 9.5. Where the latter species dominates, the Th concentration increases by $10^{5}$ per $\mathrm{pH}$ unit. This extreme nonlinearity limits the ability of the EQ3NR program to find a mathematical solution for solutions at higher $\mathrm{pH}$ values. At $\mathrm{pH}$ values from about 4 to 5.75 , the principal species contributing to $\mathrm{Th}$ solubility are $\mathrm{Th}^{4+}-\mathrm{F}^{-}$aqueous complexes including $\mathrm{ThF}_{2}{ }^{2+}, \mathrm{ThF}_{3}{ }^{+}$, and $\mathrm{ThF}_{4}(\mathrm{aq})$. These species account for the strong increases in dissolved $\mathrm{Th}$ concentrations shown in Figure 6.8-2 when $\mathrm{F}^{-}$concentrations are increased above the value in the base-case $(\mathrm{J}-13)$ water. At $\mathrm{pH}$ values below about $3.75, \mathrm{Th}\left(\mathrm{SO}_{4}\right)^{2+}$ and $\mathrm{Th}\left(\mathrm{SO}_{4}\right)_{2}(\mathrm{aq})$ are the principal 
contributors to the total Th concentrations. Because $\mathrm{SO}_{4}{ }^{2-}$ is both the charge-balancing ion and $\mathrm{Th}^{4+}-\mathrm{SO}_{4}{ }^{2-}$ complexes make up nearly $95 \%$ of the total dissolved species of the most acid solutions, EQ3NR is also unable to solve for solution compositions at $\mathrm{pH}$ values below $\mathrm{pH} 3.25$ (th010402.3o in file Th Eq3 runs.zip, Appendix I).

Table 6.8-1 show the thorium concentrations given in $\mathrm{mg} / \mathrm{L}$. Table 6.8-2 and Figure 6.8-1 show the thorium concentrations given in $\log$ [Th] (in $\mathrm{mg} / \mathrm{L}$ ) for the reference water calculated using $\mathrm{ThO}_{2}(\mathrm{am})$ as the controlling mineral for $\mathrm{pH}$ values from 3.25 to 10.75 and $\log f \mathrm{CO}_{2}$ values from -1.5 to -5.0 bars. Calculations did not converge for conditions outside this range and where empty cells appear in the table. The pattern of Th solubility exhibited is a result of the speciation of the solutions modeled. With increasing $f \mathrm{CO}_{2}$ values the range of dominance of Th-hydroxide-carbonate complexes extends to lower $\mathrm{pH}$ values, as do the points of minimum $\mathrm{Th}$ concentrations. Likewise, the $\mathrm{pH}$ values at which $\mathrm{Th}\left(\mathrm{CO}_{3}\right)_{5}{ }^{6-}$ becomes dominant (evident by the sharp up-ticks in Th concentrations) also decrease with increasing $f \mathrm{CO}_{2}$ values. As the empty cells in Table 6.8-1 show, EQ3NR calculations no longer converge at higher $\mathrm{pH}$ values. At low $\mathrm{pH}$ values, Th solubilities also increase as $\mathrm{Th}^{4+}-\mathrm{SO}_{4}{ }^{2-}$ complexes become important.

Calculations did not converge for conditions outside this range as designated by empty cells in the table. In the high $f \mathrm{CO}_{2}$ and $\mathrm{pH}$ region, increasing $\mathrm{CO}_{3}{ }^{2-}$ concentrations favor the formation of complexes such as $\mathrm{Th}\left(\mathrm{CO}_{3}\right)_{5}{ }^{6-}$ and $\mathrm{Th}(\mathrm{OH})_{3} \mathrm{CO}_{3}{ }^{-}$. This is evident in the sharp increases in the thorium concentrations in the highest $\mathrm{pH}$ point of each $\mathrm{CO}_{2}$ line. Even sharper increases at the next $\mathrm{pH}$ or $f \mathrm{CO}_{2}$ step of the modeling prevent EQ3NR from converging.

At $\mathrm{pH}$ values below 3.25, the EQ3NR calculations also do not converge. This is due to the rapid increases in total thorium and $\mathrm{SO}_{4}$ concentrations due to the strength of the $\mathrm{Th}\left(\mathrm{SO}_{4}\right)_{2}(\mathrm{aq})$ ion pair and the addition of $\mathrm{SO}_{4}{ }^{2-}$ as the charge-balancing anion (Figures 6.8-2 and 6.8-3). Instability from this cause occurs in calculations on other actinides as well, and has a particularly strong effect on the calculations of americium solubilities (Section 6.9.4.1).

Because the independent variables of calculated Th solubility are in log scales and the user of the table may need to interpolate between calculated values, the logarithm of Th solubility is given in Table 6.8-2 for use in the TSPA-LA modeling for LA. The second table includes the value " 500 " for those ranges of conditions for which no concentrations were given in Table 6.8-1. This value is intended as a flag to indicate that release rates, rather than concentration limits, for thorium should be selected for these conditions in the TSPA-LA modeling. For any conditions that fall between a valid solubility and a flag of 500, the flag should be used. In addition, for any conditions outside of the 3.25 to $10.75 \mathrm{pH}$ range and the -1.5 to $-5.0 f \mathrm{CO}_{2}$ range of the table, the concentrations calculated according to the dissolution rate of individual waste forms, water volume, and the solubility caps presented in Table 8-5. 
Table 6.8-1. Thorium Solubility (mg/L)- $-\mathrm{ThO}_{2}(\mathrm{am})$

\begin{tabular}{|c|c|c|c|c|c|c|c|c|}
\hline \multirow[b]{2}{*}{ pH } & \multicolumn{8}{|c|}{$\log \mathrm{fCO}_{2}$ (bars) } \\
\hline & -1.50 & -2.00 & -2.50 & -3.00 & -3.50 & -4.00 & -4.50 & -5.00 \\
\hline 3.25 & $6.94 \mathrm{E}+03$ & $6.95 \mathrm{E}+03$ & $6.95 \mathrm{E}+03$ & $6.95 E+03$ & $6.95 E+03$ & $6.95 E+03$ & $6.95 E+03$ & $6.95 E+03$ \\
\hline 3.50 & $3.45 \mathrm{E}+02$ & $3.45 \mathrm{E}+02$ & $3.45 \mathrm{E}+02$ & $3.45 \mathrm{E}+02$ & $3.45 \mathrm{E}+02$ & $3.45 \mathrm{E}+02$ & $3.45 \mathrm{E}+02$ & $3.45 \mathrm{E}+02$ \\
\hline 3.75 & $4.12 E+01$ & $4.12 E+01$ & 4.12E+01 & $4.12 \mathrm{E}+01$ & $4.12 \mathrm{E}+01$ & $4.12 \mathrm{E}+01$ & $4.12 E+01$ & $4.12 E+01$ \\
\hline 4.00 & 1.37E+01 & 1.37E+01 & 1.37E+01 & 1.37E+01 & $1.37 E+01$ & 1.37E+01 & 1.37E+01 & $1.37 E+01$ \\
\hline 4.25 & $8.73 E+00$ & $8.73 \mathrm{E}+00$ & $8.73 E+00$ & $8.73 E+00$ & $8.73 \mathrm{E}+00$ & $8.73 E+00$ & $8.73 E+00$ & $8.73 \mathrm{E}+00$ \\
\hline 4.50 & $5.52 E+00$ & $5.52 \mathrm{E}+00$ & $5.52 \mathrm{E}+00$ & $5.52 \mathrm{E}+00$ & $5.52 \mathrm{E}+00$ & $5.52 \mathrm{E}+00$ & $5.52 \mathrm{E}+00$ & $5.52 \mathrm{E}+00$ \\
\hline 4.75 & $2.41 E+00$ & $2.41 \mathrm{E}+00$ & $2.41 E+00$ & $2.41 \mathrm{E}+00$ & $2.41 E+00$ & $2.41 \mathrm{E}+00$ & $2.41 E+00$ & $2.41 \mathrm{E}+00$ \\
\hline 5.00 & $5.10 \mathrm{E}-01$ & $5.08 \mathrm{E}-01$ & 5.07E-01 & 5.07E-01 & 5.07E-01 & $5.07 \mathrm{E}-01$ & 5.07E-01 & 5.07E-01 \\
\hline 5.25 & 6.69E-02 & 6.27E-02 & $6.14 \mathrm{E}-02$ & $6.10 \mathrm{E}-02$ & 6.08E-02 & $6.08 \mathrm{E}-02$ & 6.08E-02 & $6.08 \mathrm{E}-02$ \\
\hline 5.50 & 1.77E-02 & $1.03 \mathrm{E}-02$ & 7.93E-03 & 7.19E-03 & 6.96E-03 & 6.89E-03 & $6.86 \mathrm{E}-03$ & $6.86 \mathrm{E}-03$ \\
\hline 5.75 & $2.04 \mathrm{E}-02$ & 7.33E-03 & $3.18 \mathrm{E}-03$ & 1.87E-03 & $1.46 \mathrm{E}-03$ & $1.32 \mathrm{E}-03$ & $1.28 \mathrm{E}-03$ & 1.27E-03 \\
\hline 6.00 & $3.48 \mathrm{E}-02$ & 1.15E-02 & \begin{tabular}{|l|}
$4.10 \mathrm{E}-03$ \\
\end{tabular} & $1.76 \mathrm{E}-03$ & 1.03E-03 & $7.92 \mathrm{E}-04$ & $7.18 \mathrm{E}-04$ & $6.95 \mathrm{E}-04$ \\
\hline 6.25 & $6.03 \mathrm{E}-02$ & $1.98 \mathrm{E}-02$ & $6.69 \mathrm{E}-03$ & 2.54E-03 & $1.22 \mathrm{E}-03$ & $8.09 \mathrm{E}-04$ & $6.78 \mathrm{E}-04$ & 6.36E-04 \\
\hline 6.50 & $1.07 \mathrm{E}-01$ & $3.47 \mathrm{E}-02$ & 1.14E-02 & 4.02E-03 & 1.68E-03 & $9.46 \mathrm{E}-04$ & 7.13E-04 & 6.39E-04 \\
\hline 6.75 & $1.92 \mathrm{E}-01$ & $6.03 \mathrm{E}-02$ & $1.98 \mathrm{E}-02$ & 6.67E-03 & 2.52E-03 & $1.21 \mathrm{E}-03$ & 7.93E-04 & 6.62E-04 \\
\hline 7.00 & 3.47E-01 & 1.07E-01 & $3.47 \mathrm{E}-02$ & 1.14E-02 & $4.01 \mathrm{E}-03$ & $1.68 \mathrm{E}-03$ & $9.40 \mathrm{E}-04$ & 7.07E-04 \\
\hline 7.25 & $6.28 \mathrm{E}-01$ & 1.93E-01 & $6.03 \mathrm{E}-02$ & $1.98 \mathrm{E}-02$ & $6.67 \mathrm{E}-03$ & $2.52 \mathrm{E}-03$ & $1.21 \mathrm{E}-03$ & $7.90 \mathrm{E}-04$ \\
\hline 7.50 & $1.14 \mathrm{E}+00$ & $3.47 \mathrm{E}-01$ & 1.07E-01 & 3.47E-02 & 1.14E-02 & 4.01E-03 & 1.68E-03 & $9.39 \mathrm{E}-04$ \\
\hline 7.75 & $2.10 \mathrm{E}+00$ & $6.28 \mathrm{E}-01$ & 1.93E-01 & $6.03 \mathrm{E}-02$ & $1.98 \mathrm{E}-02$ & $6.67 \mathrm{E}-03$ & $2.52 \mathrm{E}-03$ & $1.20 \mathrm{E}-03$ \\
\hline 8.00 & $3.89 \mathrm{E}+00$ & $1.15 \mathrm{E}+00$ & 3.47E-01 & 1.07E-01 & $3.47 E-02$ & $1.14 \mathrm{E}-02$ & $4.01 \mathrm{E}-03$ & $1.68 \mathrm{E}-03$ \\
\hline 8.25 & $1.09 \mathrm{E}+01$ & $2.10 E+00$ & $6.29 \mathrm{E}-01$ & 1.93E-01 & $6.03 E-02$ & $1.98 \mathrm{E}-02$ & 6.67E-03 & $2.52 \mathrm{E}-03$ \\
\hline 8.50 & - & $3.95 \mathrm{E}+00$ & $1.15 \mathrm{E}+00$ & 3.47E-01 & $1.08 \mathrm{E}-01$ & 3.47E-02 & 1.14E-02 & $4.01 \mathrm{E}-03$ \\
\hline 8.75 & - & $2.56 \mathrm{E}+01$ & $2.12 \mathrm{E}+00$ & 6.31E-01 & $1.93 \mathrm{E}-01$ & $6.04 \mathrm{E}-02$ & 1.98E-02 & 6.66E-03 \\
\hline 9.00 & - & - & $4.25 \mathrm{E}+00$ & $1.16 \mathrm{E}+00$ & $3.49 \mathrm{E}-01$ & $1.08 \mathrm{E}-01$ & $3.41 \mathrm{E}-02$ & 1.14E-02 \\
\hline 9.25 & - & - & 4.17E+02 & $2.15 E+00$ & $6.36 \mathrm{E}-01$ & $1.94 \mathrm{E}-01$ & $6.06 \mathrm{E}-02$ & $1.97 \mathrm{E}-02$ \\
\hline 9.50 & - & - & - & $8.90 \mathrm{E}+00$ & $1.18 \mathrm{E}+00$ & $3.53 \mathrm{E}-01$ & 1.09E-01 & $3.43 \mathrm{E}-02$ \\
\hline 9.75 & - & - & - & - & $2.41 E+00$ & $6.52 \mathrm{E}-01$ & 1.96E-01 & $6.10 \mathrm{E}-02$ \\
\hline 10.00 & - & - & - & - & - & $1.25 \mathrm{E}+00$ & 3.63E-01 & 1.10E-01 \\
\hline 10.25 & $=$ & - & - & - & - & $4.64 \mathrm{E}+01$ & 6.91E-01 & 2.03E-01 \\
\hline 10.50 & - & - & - & - & - & - & $4.37 \mathrm{E}+00$ & 3.86E-01 \\
\hline 10.75 & - & - & - & - & - & - & - & $1.01 \mathrm{E}+00$ \\
\hline
\end{tabular}

Source: Th solubility.x/s (Appendix 1).

NOTE: Some cells have no data because the EQ3NR calculations do not converge. 
Table 6.8-2. Thorium Solubility $(\log [\mathrm{Th}] \mathrm{mg} / \mathrm{L})$

\begin{tabular}{|c|c|c|c|c|c|c|c|c|}
\hline \multirow[b]{2}{*}{ pH } & \multicolumn{8}{|c|}{$\log \mathrm{fCO}_{2}$ (bars) } \\
\hline & -1.50 & -2.00 & -2.50 & -3.00 & -3.50 & -4.00 & -4.50 & -5.00 \\
\hline 3.25 & $3.84 \mathrm{E}+00$ & $3.84 E+00$ & $3.84 E+00$ & $3.84 \mathrm{E}+00$ & $3.84 E+00$ & $3.84 E+00$ & $3.84 E+00$ & $3.84 \mathrm{E}+00$ \\
\hline 3.50 & $2.54 \mathrm{E}+00$ & $2.54 \mathrm{E}+00$ & $2.54 E+00$ & $2.54 E+00$ & $2.54 E+00$ & $2.54 \mathrm{E}+00$ & $2.54 \mathrm{E}+00$ & $2.54 \mathrm{E}+00$ \\
\hline 3.75 & $1.61 \mathrm{E}+00$ & $1.61 E+00$ & $1.62 E+00$ & $1.62 E+00$ & $1.62 \mathrm{E}+00$ & $1.62 \mathrm{E}+00$ & $1.62 E+00$ & $1.62 \mathrm{E}+00$ \\
\hline 4.00 & $1.14 \mathrm{E}+00$ & $1.14 \mathrm{E}+00$ & $1.14 \mathrm{E}+00$ & $1.14 \mathrm{E}+00$ & $1.14 E+00$ & $1.14 \mathrm{E}+00$ & $1.14 \mathrm{E}+00$ & $1.14 \mathrm{E}+00$ \\
\hline 4.25 & $9.41 \mathrm{E}-01$ & $9.41 \mathrm{E}-01$ & $9.41 E-01$ & $E-01$ & $9.41 \mathrm{E}-01$ & $9.41 E-01$ & 9.41E-01 & $9.41 \mathrm{E}-01$ \\
\hline 4.50 & 7.42E-01 & 7.42E-01 & 7.42 & 01 & 7.42E-01 & $7.42 \mathrm{E}-01$ & 01 & 7.42E-01 \\
\hline 4.75 & 3.82E-01 & $3.82 E-01$ & $0.0 \angle C-01$ & & $3.82 \mathrm{E}-01$ & $3.82 \mathrm{E}-01$ & & $3.82 \mathrm{E}-01$ \\
\hline 5.00 & 01 & -01 & 1 & 1 & 01 & -2 & 01 & 01 \\
\hline 5.25 & $.17 \mathrm{E}+00$ & $-1.20 \mathrm{E}+00$ & $-1.21 E+00$ & $-1.21 \mathrm{E}+00$ & $-1.22 \mathrm{E}+00$ & $-1.22 \mathrm{E}+00$ & $-1.22 \mathrm{E}+00$ & $-1.22 \mathrm{E}+00$ \\
\hline 5.50 & $-1.75 E+00$ & $-1.99 \mathrm{E}+00$ & $-2.10 \mathrm{E}+00$ & $-2.14 E+00$ & $-2.16 E+00$ & $-2.16 \mathrm{E}+00$ & $-2.16 E+00$ & $-2.16 \mathrm{E}+00$ \\
\hline 5.75 & $-1.69 E+00$ & $-2.13 E+00$ & $-2.50 \mathrm{E}+00$ & $-2.73 E+00$ & $-2.84 E+00$ & $-2.88 \mathrm{E}+00$ & $-2.89 E+00$ & $-2.90 \mathrm{E}+00$ \\
\hline 6.00 & $-1.46 E+00$ & $-1.94 E+00$ & $-2.39 E+00$ & $-2.75 E+00$ & $-2.99 E+00$ & $-3.10 E+00$ & $-3.14 E+00$ & $-3.16 E+00$ \\
\hline 6.25 & $-1.22 E+00$ & $-1.70 \mathrm{E}+00$ & $-2.17 E+00$ & $-2.60 \mathrm{E}+00$ & $-2.91 E+00$ & $-3.09 \mathrm{E}+00$ & $-3.17 E+00$ & $-3.20 E+00$ \\
\hline 6.50 & $69 \mathrm{E}-01$ & $-1.46 \mathrm{E}+00$ & $-1.94 E+00$ & $-2.40 \mathrm{E}+00$ & $-2.77 E+00$ & $-3.02 E+00$ & $-3.15 E+00$ & $-3.19 E+00$ \\
\hline 6.75 & $-7.16 \mathrm{E}-01$ & $-1.22 \mathrm{E}+00$ & $-1.70 E+00$ & $-2.18 \mathrm{E}+00$ & $-2.60 \mathrm{E}+00$ & $-2.92 \mathrm{E}+00$ & $-3.10 E+00$ & $-3.18 E+00$ \\
\hline 7.00 & $-4.60 \mathrm{E}-01$ & $-9.69 \mathrm{E}-01$ & $-1.46 \mathrm{E}+00$ & $-1.94 E+00$ & $-2.40 E+00$ & $-2.78 \mathrm{E}+00$ & $-3.03 E+00$ & $-3.15 E+00$ \\
\hline 7.25 & $-2.02 \mathrm{E}-01$ & $-7.16 \mathrm{E}-01$ & $-1.22 \mathrm{E}+00$ & $-1.70 E+00$ & $-2.18 \mathrm{E}+00$ & $-2.60 \mathrm{E}+00$ & $-2.92 E+00$ & $-3.10 E+00$ \\
\hline 7.50 & $5.88 \mathrm{E}-02$ & $-4.60 \mathrm{E}-01$ & $-9.69 \mathrm{E}-01$ & $-1.46 E+00$ & $-1.94 E+00$ & $-2.40 E+00$ & $-2.78 E+00$ & $-3.03 E+00$ \\
\hline 7.75 & $3.22 \mathrm{E}-01$ & $-2.02 E-01$ & $-7.15 \mathrm{E}-01$ & $-1.22 E+00$ & $-1.70 \mathrm{E}+00$ & $-2.18 \mathrm{E}+00$ & $-2.60 \mathrm{E}+00$ & $-2.92 E+00$ \\
\hline 8.00 & $0 \mathrm{E}-01$ & .02 & -01 & $9 \mathrm{E}-01$ & $-1.46 \mathrm{E}+00$ & $-1.94 E+00$ & $-2.40 \mathrm{E}+00$ & $-2.78 E+00$ \\
\hline 8.25 & $1.04 \mathrm{E}+00$ & $E-01$ & -2.0 & $E-01$ & $-1.22 E+00$ & $-1.70 \mathrm{E}+00$ & $-2.18 \mathrm{E}+00$ & $-2.60 \mathrm{E}+00$ \\
\hline 8.50 & 500 & 5.96E-01 & $6.01 \mathrm{E}-02$ & $-4.59 \mathrm{E}-01$ & $-9.68 \mathrm{E}-01$ & $-1.46 \mathrm{E}+00$ & $-1.94 E+00$ & $-2.40 E+00$ \\
\hline 8.75 & 500 & $1.41 \mathrm{E}+00$ & $3.25 \mathrm{E}-01$ & $-2.00 E-01$ & $-7.14 \mathrm{E}-01$ & $-1.22 E+00$ & $-1.70 E+00$ & $-2.18 E+00$ \\
\hline 9.00 & 500 & 500 & $6.29 \mathrm{E}-01$ & $6.31 \mathrm{E}-02$ & $-4.57 \mathrm{E}-01$ & -9.67E-01 & $-1.47 E+00$ & $-1.94 E+00$ \\
\hline 9.25 & 50 & 500 & $2.62 \mathrm{E}+00$ & 3.33E-01 & $-1.96 \mathrm{E}-01$ & $-7.12 \mathrm{E}-01$ & $-1.22 E+00$ & $-1.70 E+00$ \\
\hline 9.50 & 500 & 5 & 0 & $9.49 \mathrm{E}-01$ & 7.17E-02 & $-4.53 E-01$ & $-9.65 \mathrm{E}-01$ & $-1.47 E+00$ \\
\hline 9.75 & 300 & 0 & 500 & 300 & $3.81 \mathrm{E}-01$ & $-1.86 \mathrm{E}-01$ & -7.07E-01 & $-1.21 E+00$ \\
\hline 10.00 & 500 & 10 & 00 & 10 & 00 & $9.60 \mathrm{E}-02$ & $-4.41 \mathrm{E}-01$ & $-9.58 \mathrm{E}-01$ \\
\hline 10.25 & 500 & 500 & 500 & 500 & 500 & $1.67 \mathrm{E}+00$ & $-1.61 \mathrm{E}-01$ & $-6.93 \mathrm{E}-01$ \\
\hline 10.50 & 500 & 500 & 500 & 500 & 500 & 500 & $6.41 \mathrm{E}-01$ & $-4.13 \mathrm{E}-01$ \\
\hline 10.75 & 500 & 500 & 500 & 500 & 500 & 500 & 500 & 4.71E-03 \\
\hline
\end{tabular}

Source: Th solubility.xls (Appendix I).

NOTE: Some cells have no valid data because the EQ3NR calculations do not converge and the results are reported as 500 . 


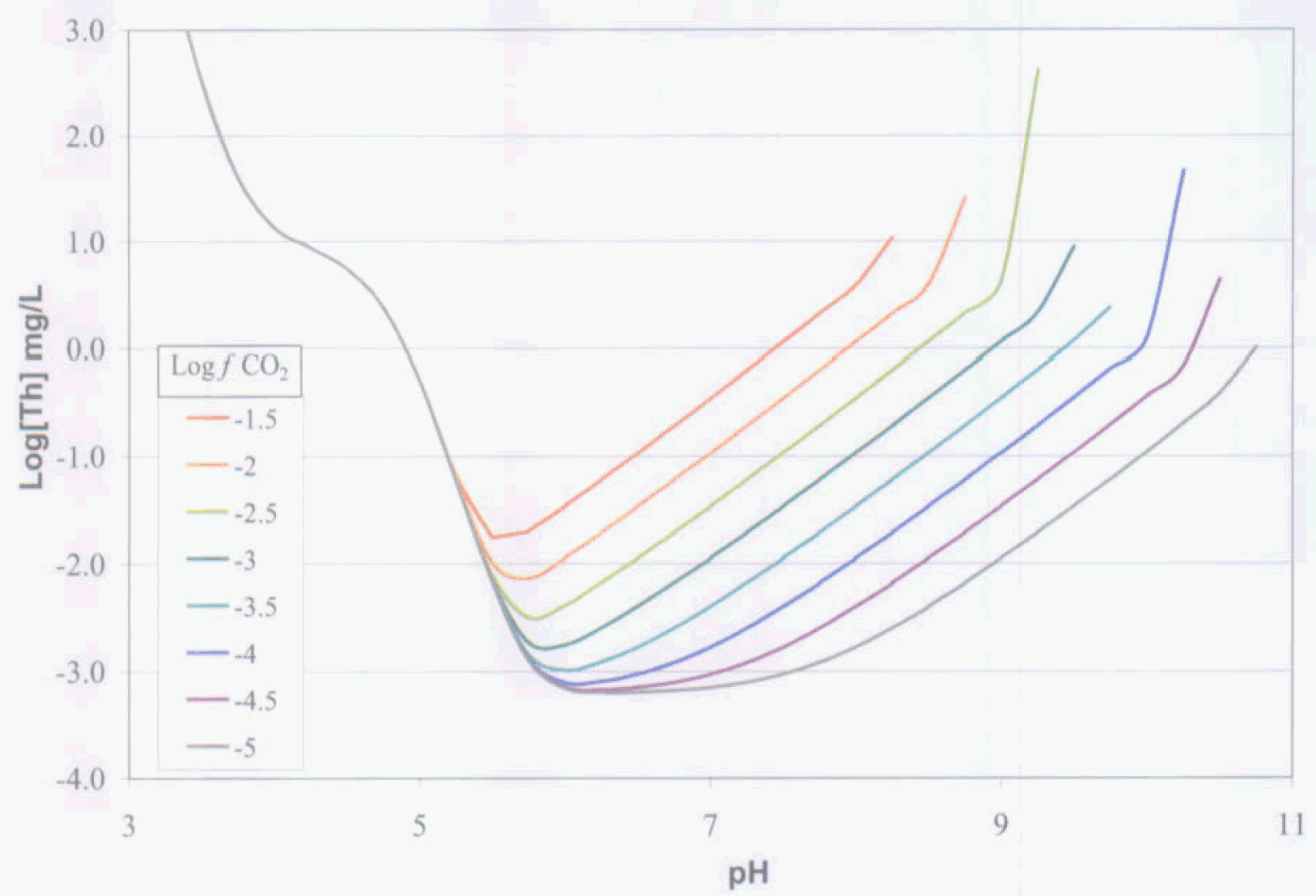

Source: Th Solubility.xls (Appendix I).

Figure 6.8-1. $\mathrm{ThO}_{2}(\mathrm{am})$ Solubility Modeled as a Function of $f \mathrm{CO}_{2}$ and $\mathrm{pH}$

Figures 6.8-2 and 6.8-3 are speciation diagrams for Th values from $\mathrm{pH} 3.25$ to 9.5. The former displays the molar concentration of total Th and its solution complexes; the latter displays the complex concentrations in percent of total Th. The diagrams represent a system at equilibrium with the solid $\mathrm{ThO}_{2}(\mathrm{am})$ at $\log f \mathrm{CO}_{2}$ (bars) $=-3.0$. The choice of this controlling solid is discussed in Section 6.8.2. Th occurs only in the Th(IV) oxidation state in aqueous solution. Therefore, small changes in the Eh of the system do not have any effect on the solubilities shown in Table 6.8-2

The calculated total Th concentration ranges from nearly $0.1 \mathrm{~mol}$ at $\mathrm{pH} 3.25$ to a minimum of less than $10^{-8} \mathrm{~mol}$ at $\mathrm{pH} 6.0$ and increases again to nearly $10^{-4} \mathrm{~mol}$ at $\mathrm{pH} 9.5$. At the lowest $\mathrm{pH}$, over $90 \%$ the total $\mathrm{Th}$ consists of the $\mathrm{Th}\left(\mathrm{SO}_{4}\right)_{2}(\mathrm{aq})$ complex, with the $\mathrm{ThSO}_{4}{ }^{2+}$ complex contributing less than $10 \%$ of the total. At $\mathrm{pH}$ values from below 4.0 to above 5.5 , $\mathrm{F}^{-}$-bearing complexes dominate the total Th. The principal complex at $\mathrm{pH} 4.0$ is $\mathrm{ThF}_{2}{ }^{2+}$, while $\mathrm{ThF}_{3}{ }^{+}$ dominates from $\mathrm{pH} 4.5$ to 5.5 . From $\mathrm{pH} 5$ to $5.5, \mathrm{ThF}_{4}(\mathrm{aq})$ also contributes about $15 \%$ of the total, as does $\mathrm{ThF}_{2}{ }^{2+}$. At higher $\mathrm{pH}$ values, the importance of $\mathrm{F}$ complexes diminishes and the principal contributors to total Th become the $\mathrm{CO}_{3}{ }^{2-}$ complexes, $\mathrm{Th}(\mathrm{OH})_{3} \mathrm{CO}_{3}{ }^{-}$and, at $\mathrm{pH} 9.5$, $\mathrm{Th}\left(\mathrm{CO}_{3}\right)_{5}{ }^{6-}$. At around $\mathrm{pH} 6.0, \mathrm{Th}(\mathrm{OH})_{4}(\mathrm{aq})$ also contributes over $30 \%$ of the total Th. 


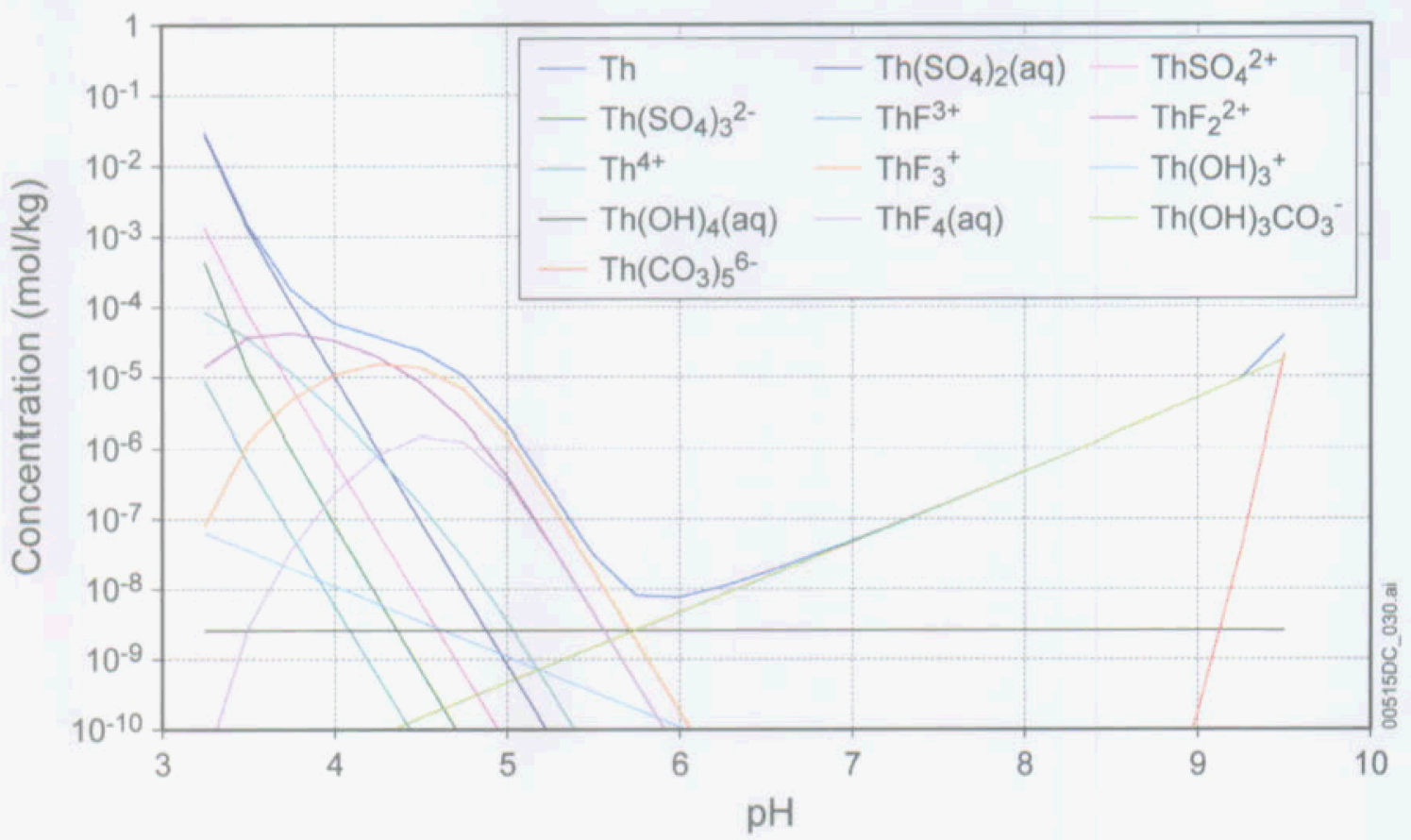

Source: Th species plot.xls (Appendix I).

Figure 6.8-2. Total Th Concentration and Speciation Diagram at $\log f \mathrm{CO}_{2}$ (bars) $=-3.0$ in $\mathrm{mol} / \mathrm{kg} \mathrm{H}$

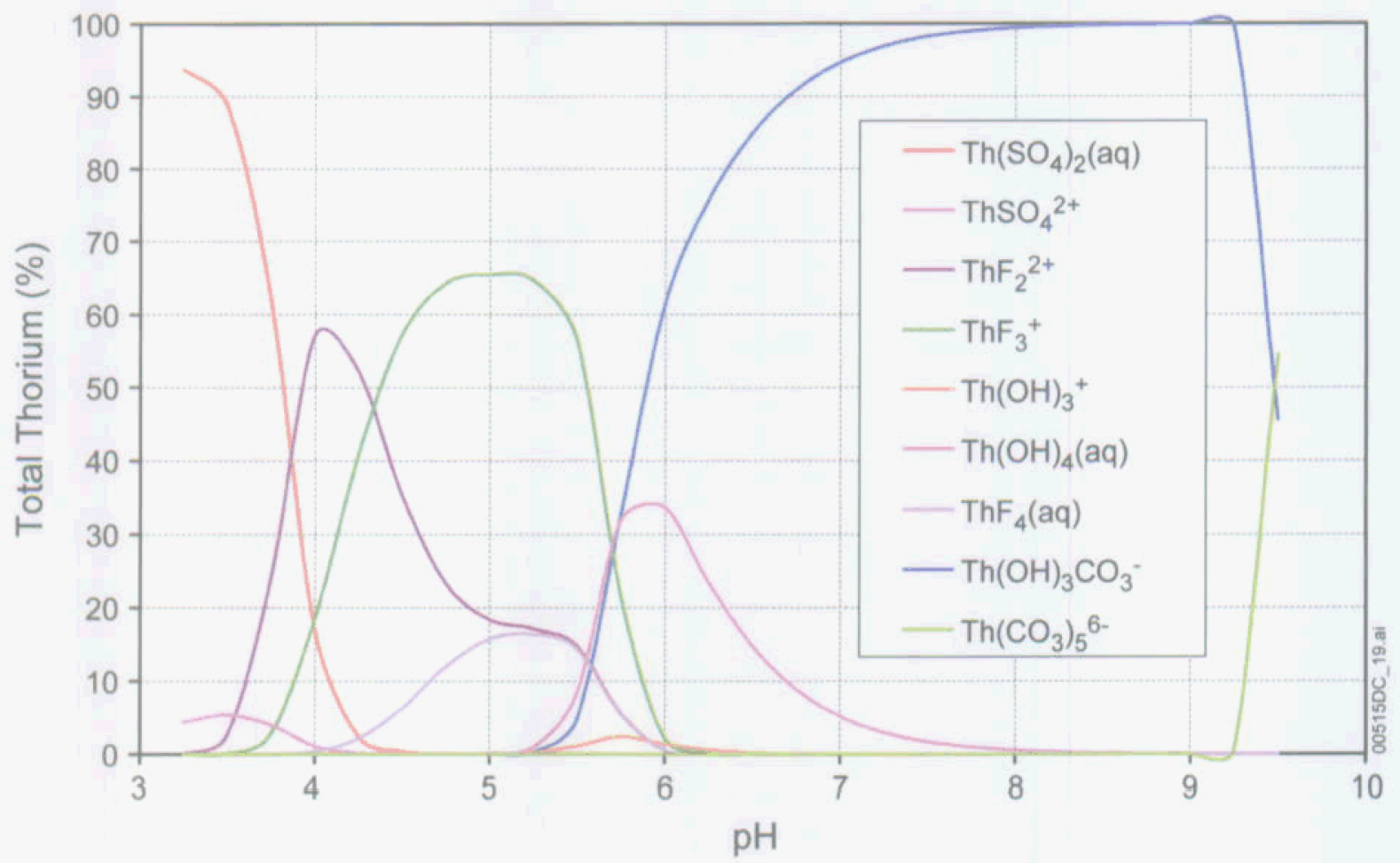

Source: Th species plot.xls.

Figure 6.8-3. Th-Speciation Diagram at $\log f \mathrm{CO}_{2}$ (bars) $=-3.0$ in Percent Total Dissolved Th 
$\mathrm{Th}\left(\mathrm{CO}_{3}\right)_{5}{ }^{6-}$ is formed by the reaction:

$$
\mathrm{Th}^{4+}+5 \mathrm{HCO}_{3}^{-}=\mathrm{Th}\left(\mathrm{CO}_{3}\right)_{5}^{6-}+5 \mathrm{H}^{+}
$$

where $\mathrm{Th}\left(\mathrm{CO}_{3}\right)_{5}{ }^{6-}$ dominates, the total Th concentration increases by $10^{5}$ for each unit decrease in the $\mathrm{pH}$. The extreme nonlinearity of the variation of total $\mathrm{Th}$ with $\mathrm{pH}$, where this complex dominates, is why the EQ3NR program does not converge in the high $\mathrm{pH}$ - high $f \mathrm{CO}_{2}$ range.

Figures 6.8-2 and 6.8-3 show that total Th concentration is sensitive to $\mathrm{SO}_{4}{ }^{2-}$ concentrations at low $\mathrm{pH}$ values, to $\mathrm{F}^{-}$concentrations under moderately acid conditions and to $\mathrm{OH}^{-}$and $\mathrm{CO}_{3}{ }^{2-}$ concentrations under circumneutral and basic conditions. The $\mathrm{OH}^{-}$concentrations depend on the $\mathrm{pH}$, and $\mathrm{CO}_{3}{ }^{2-}$ concentrations on $\mathrm{pH}$ and $f \mathrm{CO}_{2}$. The solubilities are tabulated in terms of $\mathrm{pH}$ and $\mathrm{fCO}_{2}$ so the sensitivities to $\mathrm{OH}^{-}$and $\mathrm{CO}_{3}{ }^{2-}$ variations are considered explicitly. As discussed in Section 6.4.3.5, $\mathrm{SO}_{4}{ }^{2-}$ concentrations are varied in the modeling to maintain charge balance in order to simulate the occurrence of $\mathrm{H}_{2} \mathrm{SO}_{4}$ in the in-package environment from the oxidation of sulfur during steel degradation. In this way, $\mathrm{SO}_{4}{ }^{2-}$ variations are also considered explicitly. Variations in $\mathrm{F}^{-}$concentrations are not treated explicitly but rather as uncertainties in the total Th concentrations.

\subsubsection{Uncertainties}

As described in Section 6.3.3, uncertainty in the solubilities has been evaluated considering uncertainties in the thermodynamic data for the solubility-controlling phase and principal aqueous species and uncertainties in the fluoride content of the matrix fluid.

\subsection{Uncertainties in $\log K$}

The uncertainty in thorium solubility due to uncertainties in thermodynamic data was calculated as described in Section 6.3.3.1, allowing for uncertainties in $\log \mathrm{K}$ values of both the controlling solid and the important aqueous thorium species. The total uncertainty applicable to all $\log$ [Th] values in Table $6.8-2$ is 1.4 units. This represents the $2 \sigma$ limit of a normal distribution with a $1 \sigma$ uncertainty of 0.7 .

\subsection{Uncertainty from Fluoride Concentration}

The effects of fluoride uncertainty were evaluated by calculating thorium solubilities at a range of $\mathrm{pH}$ values for $f \mathrm{CO}_{2}=10^{-3.0}$ bars with fluoride concentrations equal to the highest values expected in each of the in-package and invert environments. These environments and their fluoride concentrations are described in Section 6.3.3.2 and Table 6.3-3. These results are displayed in Figure 6.8-4. Table 6.8-3 gives the calculated concentrations, including those for the base-case fluoride concentration and also shows the differences between the higher-fluoride and base-case solubilities. As the figure and table show, at a fluoride concentration of $2.18 \mathrm{mg} / \mathrm{L}$, (the CSNF environment; $10 \times$ the base-case value) the maximum difference from the base-case concentration is $+3.10 \log [\mathrm{Th}]$ (in $\mathrm{mg} / \mathrm{L}$ ) units at a $\mathrm{pH}$ of 5.75. At a fluoride concentration $200 \times$ the base-case value, the solubility is higher by a maximum value of $+5.72 \log [\mathrm{Th}](\mathrm{in} \mathrm{mg} / \mathrm{L})$ at a $\mathrm{pH}$ of 6.00 . 
Increasing fluoride has a stronger effect on thorium solubility than on the solubility of any other actinide examined in this report because Th is the only actinide present in the IV oxidation state under the oxidizing conditions of the repository. Fluoride complexes of actinide(IV) ions are many orders of magnitude more stable than those of corresponding actinide(VI) ions, as can be seen by comparing Tables 3.1 .1 and 3.1 .3 of Nagra/PSI Chemical Thermodynamic Data Base 01/01 (Hummel et al. 2002 [DIRS 161904]). The importance of thorium-fluoride complexes even at the lowest base-case fluoride content is also evident from the inflection in the Th-solubility curves in the 4 to $5 \mathrm{pH}$ range (Figure 6.8-1) and in the Th-speciation diagrams (Figures 6.8-2 and 6.8-3) as discussed in Section 6.8.4.1.

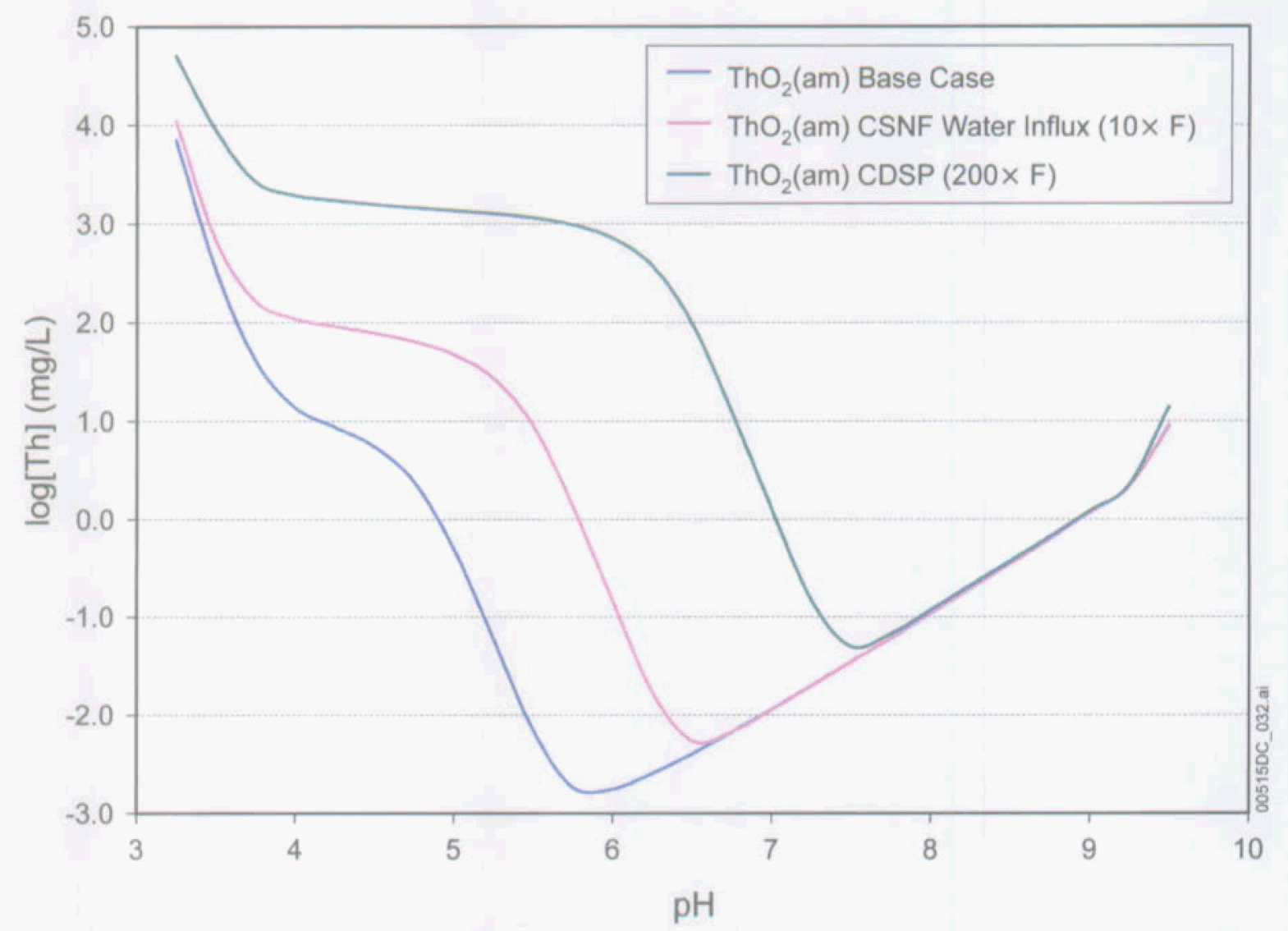

Source: Th Solubility.xls and Th F Sensitivity.x/s (Appendix I).

Figure 6.8-4. $\mathrm{ThO}_{2}(\mathrm{am})$ Solubility at $\log f \mathrm{CO}_{2}=-3.0$ bars as a Function of $\mathrm{pH}$ and $\mathrm{F}^{-}$Concentrations 
Table 6.8-3. The Effects in Variation in Fluoride Concentration on Th Solubility

\begin{tabular}{|c|c|c|c|c|c|}
\hline \multirow[t]{2}{*}{ pH } & Base Case & CSNF & $\begin{array}{c}200 \times \text { Base } \\
\text { Case }\end{array}$ & CSNF & $200 \times$ Base Case \\
\hline & \multicolumn{3}{|c|}{$\log [T h] \mathrm{mg} / \mathrm{L}$} & \multicolumn{2}{|c|}{ Difference } \\
\hline 3.25 & 3.842 & 4.035 & 4.697 & 0.193 & 0.856 \\
\hline 3.50 & 2.538 & 2.836 & 3.947 & 0.298 & 1.408 \\
\hline 3.75 & 1.615 & 2.215 & 3.427 & 0.600 & 1.812 \\
\hline 4.00 & 1.135 & 2.038 & 3.289 & 0.902 & 2.153 \\
\hline 4.25 & 0.941 & 1.962 & 3.237 & 1.021 & 2.296 \\
\hline 4.50 & 0.742 & 1.894 & 3.199 & 1.152 & 2.457 \\
\hline 4.75 & 0.382 & 1.808 & 3.166 & 1.426 & 2.784 \\
\hline 5.00 & -0.295 & 1.675 & 3.136 & 1.970 & 3.431 \\
\hline 5.25 & -1.215 & 1.435 & 3.104 & 2.650 & 4.319 \\
\hline 5.50 & -2.143 & 0.955 & 3.062 & 3.098 & 5.205 \\
\hline 5.75 & -2.728 & 0.142 & 2.991 & 2.870 & 5.719 \\
\hline 6.00 & -2.753 & -0.824 & 2.856 & 1.930 & 5.610 \\
\hline 6.25 & -2.596 & -1.757 & 2.573 & 0.839 & 5.169 \\
\hline 6.50 & -2.396 & -2.259 & 1.987 & 0.137 & 4.382 \\
\hline 6.75 & -2.176 & -2.172 & 1.095 & 0.004 & 3.270 \\
\hline 7.00 & -1.943 & -1.949 & 0.112 & -0.005 & 2.055 \\
\hline 7.25 & -1.704 & -1.709 & -0.825 & -0.005 & 0.879 \\
\hline 7.50 & -1.460 & -1.464 & -1.300 & -0.004 & 0.160 \\
\hline 7.75 & -1.220 & -1.216 & -1.173 & 0.004 & 0.047 \\
\hline 8.00 & -0.969 & -0.965 & -0.932 & 0.004 & 0.037 \\
\hline 8.25 & -0.715 & -0.712 & -0.682 & 0.003 & 0.033 \\
\hline 8.50 & -0.459 & -0.457 & -0.430 & 0.002 & 0.029 \\
\hline 8.75 & -0.200 & -0.198 & -0.176 & 0.002 & 0.024 \\
\hline 9.00 & 0.063 & 0.064 & 0.081 & 0.001 & 0.018 \\
\hline 9.25 & 0.333 & 0.334 & 0.348 & 0.001 & 0.015 \\
\hline 9.50 & 0.949 & 0.958 & 1.142 & 0.008 & 0.193 \\
\hline & & & Maximum & 3.10 & 5.72 \\
\hline
\end{tabular}

Source: Th Solubility.x/s and Th F Sensitivity.xls (Appendix I).

\subsection{Summary of Th Solubility Model Uncertainty}

The uncertainties in thorium solubilities are summarized by the following equation:

$$
\log [\mathrm{Th}]=S\left(p H, \log f \mathrm{CO}_{2}\right)+\varepsilon_{1}+\varepsilon_{2}
$$

The values for the parameters in this equation depend on the waste package. Parameter $S\left(p H, \log f_{\mathrm{CO}_{2}}\right)$ is the base solubility and is taken from Tables 6.8-2. Parameter $\varepsilon_{1}$ is associated with the uncertainties in the $\log \mathrm{K}$ data. Parameter $\varepsilon_{2}$ is associated with the 
uncertainties in the fluoride concentrations. Table 6.8-4 gives the values for the parameters $\varepsilon_{1}$ and $\varepsilon_{2}$.

Table 6.8-4. Uncertainty Terms of $\log [\mathrm{Th}]$

\begin{tabular}{|c|c|c|c|c|}
\hline $\begin{array}{c}\text { Uncertainty } \\
\text { Term }\end{array}$ & Associated with & $\begin{array}{c}\text { Distribution } \\
\text { Type }\end{array}$ & $\begin{array}{c}\text { Distribution } \\
\text { Parameter }\end{array}$ & Applicability \\
\hline$\varepsilon_{1}$ & $\begin{array}{l}\log K \text { of controlling solid } \\
\text { and aqueous species }\end{array}$ & $\begin{array}{l}\text { Normal } \\
\text { Truncated at } \pm 2 \sigma\end{array}$ & $\mu=0, \sigma=0.7^{\mathrm{a}}$ & Values in Table 6.8-2 \\
\hline$\varepsilon_{2}{ }^{\operatorname{CSNF}}$ & $\begin{array}{l}\text { Fluoride concentration in } \\
\text { CSNF waste packages }\end{array}$ & Triangular & $a=b=0, c=3.10$ & CSNF waste packages \\
\hline$\varepsilon_{2} \operatorname{CDSP}-200 \times F$ & $\begin{array}{l}\text { Fluoride concentration In } \\
\text { Codisposal waste } \\
\text { packages (all scenarios) }\end{array}$ & Triangular & $a=b=0, c=5.72$ & $\begin{array}{l}\text { Codisposal waste } \\
\text { packages and the invert }\end{array}$ \\
\hline
\end{tabular}

\subsubsection{Alternative Uncertainty Terms}

Fluoride concentrations are given in Table 6.3-3. The base-case solubility involves the use of $\mathrm{J}-13$ well water with a fluoride content of $2.18 \mathrm{mg} / \mathrm{L}$. The fluoride content of CSNF waste packages (water influx scenario - BSC 2004 [DIRS 167621]) is increases 10x to a value of $21.8 \mathrm{mg} / \mathrm{L}(9.8 \mathrm{E}-04 \mathrm{~mol})$. The fluoride content for codisposal packages uses a value of $200 \times$ the base-case scenario ( $436 \mathrm{mg} / \mathrm{L}$ ), which is the conservative maximum value with no $\mathrm{pH}$ dependence currently implemented in TSPA-LA calculations. The $\varepsilon_{2}{ }^{\text {CSNF }}$ is also conservatively used in TSPA-LA without $\mathrm{pH}$ dependence. New fluoride information from In-Package Chemistry Abstraction (BSC 2004 [DIRS 167621], Table 8-6) indicates fluoride concentrations of $58.89 \mathrm{mg} / \mathrm{L}(3.1 \mathrm{E}-03 \mathrm{~mol})$ for the water influx scenario and $209 \mathrm{mg} / \mathrm{L}(1.1 \mathrm{E}-02 \mathrm{~mol})$ for the vapor influx scenario.

The effects of fluoride uncertainty were evaluated by calculating thorium solubilities at a range of $\mathrm{pH}$ values for $f \mathrm{CO}_{2}=10^{-3.0}$ bars with fluoride concentrations equal to the highest values expected in each of the in-package and invert environments. These environments and their fluoride concentrations are described in Section 6.3.3.2 and Table 6.3-3. These results are displayed in Figure 6.8-5. Table 6.8-5 gives the calculated concentrations, including those for the base-case fluoride concentration and also shows the differences between the higher-fluoride and base-case solubilities. As the figure and table show, at a fluoride concentration of $2.18 \mathrm{mg} / \mathrm{L}$ (the CSNF environment, $10 \times$ the base-case value) the maximum difference from the base-case concentration is $+3.10 \log [\mathrm{Th}](\mathrm{in} \mathrm{mg} / \mathrm{L})$ units at a $\mathrm{pH}$ of 5.75. At a fluoride concentration of $209 \mathrm{mg} / \mathrm{L}$ (the codisposal vapor influx scenario and invert environment, about $95 \times$ the base-case value), the solubility is higher by a maximum value of $+5.27 \log [\mathrm{Th}](\mathrm{in} \mathrm{mg} / \mathrm{L}$ ) at a pH of 6.00 . 


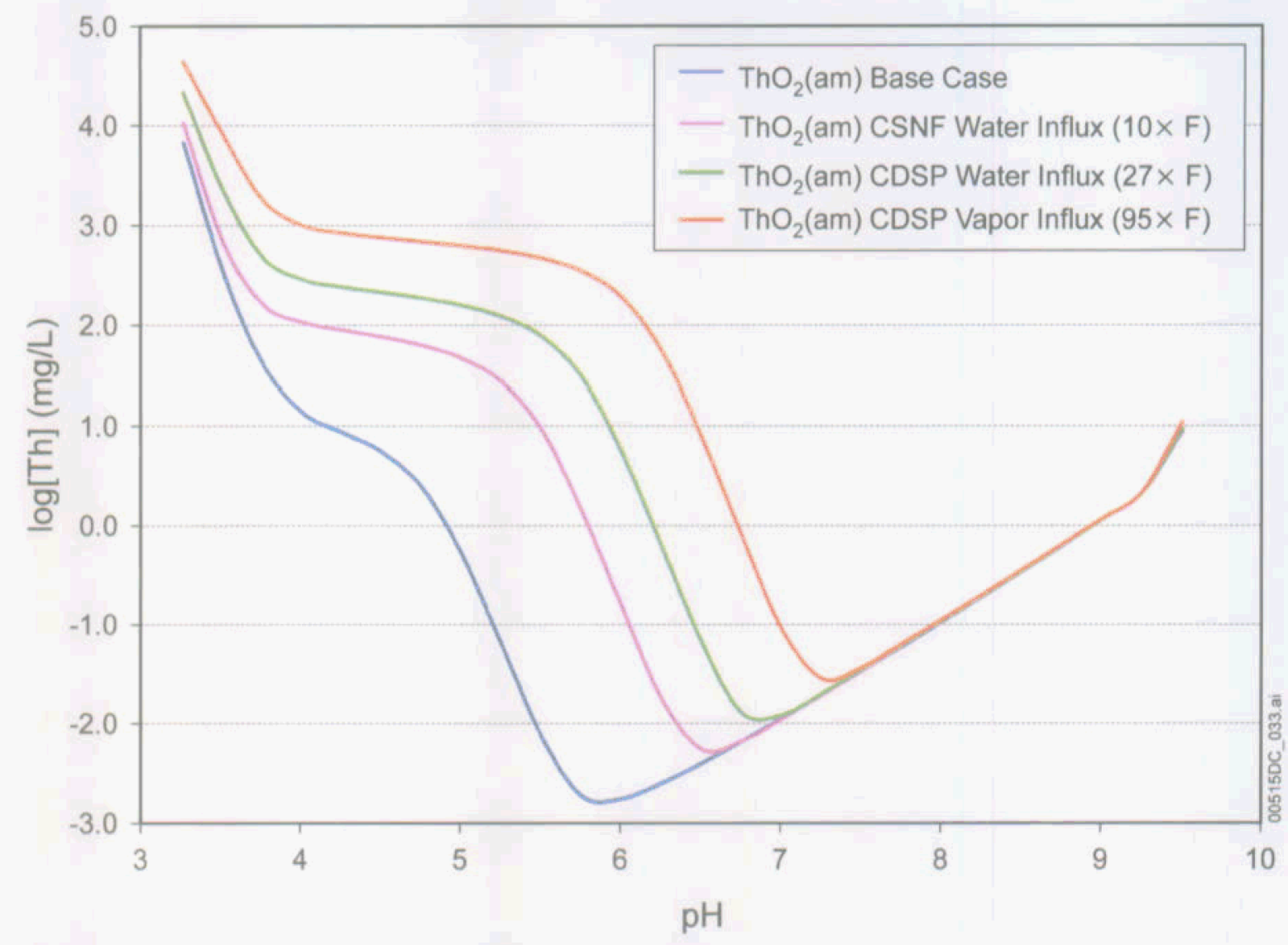

Source: Th Solubility.xls and Th F Sensitivity.x/s (Appendix I).

Figure 6.8-5. $\mathrm{ThO}_{2}(\mathrm{am})$ Solubility at $\log \mathrm{fCO}_{2}=-3.0$ bars as a Function of $\mathrm{pH}$ and $\mathrm{F}^{-}$Concentrations

The uncertainties in thorium solubilities are summarized in the following equation:

$$
\log [\mathrm{Th}]=S\left(p H, \log f \mathrm{CO}_{2}\right)+\varepsilon_{l}+\left(\varepsilon_{2} \times N\right)
$$

The values for the parameters in this equation depend on the waste package type. Parameter $S\left(p H, \log f_{\mathrm{CO}_{2}}\right)$ is the base solubility and is taken from Table 6.8-2. Parameter $\varepsilon_{1}$ is associated with the uncertainties in the $\log \mathrm{K}$ data. Parameter $\varepsilon_{2}$ is associated with the uncertainties in the fluoride concentrations. Table 6.8-6 gives the values for the parameters $\varepsilon_{1}$ and $\varepsilon_{2}$.

Table 6.8-5 shows that the uncertainty terms $\varepsilon_{2}{ }^{\text {CSNF }}, \varepsilon_{2}{ }^{\text {CDSP-water influx }}$, and $\varepsilon_{2}{ }^{\text {CDSP-vapor influx }}$ vary with $\mathrm{pH}$. This $\mathrm{pH}$ dependence can be implemented through the use of a multiplication factor $(\mathrm{N})$ that is a function of $\mathrm{pH}$. Values for $\mathrm{N}$ for both fuel types are given in Table 6.8-7. This modification requires that the $\varepsilon_{2}{ }^{\mathrm{CSNF}}, \varepsilon_{2}{ }^{\text {CDSP-water influx }}$, and $\varepsilon_{2}{ }^{\text {CDSP-vapor influx }}$ values be fixed at the maximum value given in Table 6.8-6. For each realization in the TSPA-LA model the uncertainty parameters are sampled at the beginning of the realization. This sampled value is then multiplied by ' $N$ ' at each timestep to produce a modified $\varepsilon_{2}$, which is then added to the base solubility value. 
Table 6.8-5. Alternative Uncertainty: The Effects in Variation in Fluoride Concentration on Th Solubility

\begin{tabular}{|c|c|c|c|c|c|c|c|}
\hline & Base Case & CSNF & $\begin{array}{c}\text { CDSP - } \\
\text { Water } \\
\text { Influx } \\
\text { Scenario }\end{array}$ & $\begin{array}{c}\text { CDSP - } \\
\text { Vapor } \\
\text { Influx } \\
\text { Scenario }\end{array}$ & CSNF & $\begin{array}{c}\text { CDSP - } \\
\text { Water } \\
\text { Influx } \\
\text { Scenario }\end{array}$ & $\begin{array}{c}\text { CDSP - } \\
\text { Vapor } \\
\text { Influx } \\
\text { Scenario }\end{array}$ \\
\hline $\mathrm{pH}$ & \multicolumn{4}{|c|}{$\log [T h] \mathrm{mg} / \mathrm{L}$} & \multicolumn{3}{|c|}{ Difference } \\
\hline 3.25 & 3.842 & 4.035 & 4.342 & 4.656 & 0.193 & 0.501 & 0.814 \\
\hline 3.50 & 2.538 & 2.836 & 3.363 & 3.917 & 0.298 & 0.825 & 1.378 \\
\hline 3.75 & 1.615 & 2.215 & 2.685 & 3.260 & 0.600 & 1.070 & 1.644 \\
\hline 4.00 & 1.135 & 2.038 & 2.466 & 3.008 & 0.902 & 1.331 & 1.873 \\
\hline 4.25 & 0.941 & 1.962 & 2.392 & 2.934 & 1.021 & 1.451 & 1.993 \\
\hline 4.50 & 0.742 & 1.894 & 2.338 & 2.889 & 1.152 & 1.596 & 2.147 \\
\hline 4.75 & 0.382 & 1.808 & 2.280 & 2.848 & 1.426 & 1.899 & 2.467 \\
\hline 5.00 & -0.295 & 1.675 & 2.206 & 2.806 & 1.970 & 2.502 & 3.102 \\
\hline 5.25 & -1.215 & 1.435 & 2.094 & 2.756 & 2.650 & 3.309 & 3.971 \\
\hline 5.50 & -2.143 & 0.955 & 1.891 & 2.680 & 3.098 & 4.034 & 4.823 \\
\hline 5.75 & -2.728 & 0.142 & 1.480 & 2.546 & 2.870 & 4.208 & 5.274 \\
\hline 6.00 & -2.753 & -0.824 & 0.729 & 2.279 & 1.930 & 3.483 & 5.033 \\
\hline 6.25 & -2.596 & -1.757 & -0.224 & 1.732 & 0.839 & 2.372 & 4.328 \\
\hline 6.50 & -2.396 & -2.259 & -1.192 & 0.865 & 0.137 & 1.204 & 3.261 \\
\hline 6.75 & -2.176 & -2.172 & -1.892 & -0.113 & 0.004 & 0.284 & 2.063 \\
\hline 7.00 & -1.943 & -1.949 & -1.914 & -1.052 & -0.005 & 0.030 & 0.892 \\
\hline 7.25 & -1.704 & -1.709 & -1.694 & -1.546 & -0.005 & 0.009 & 0.158 \\
\hline 7.50 & -1.460 & -1.464 & -1.452 & -1.430 & -0.004 & 0.008 & 0.030 \\
\hline 7.75 & -1.220 & -1.216 & -1.205 & -1.192 & 0.004 & 0.014 & 0.028 \\
\hline 8.00 & -0.969 & -0.965 & -0.958 & -0.944 & 0.004 & 0.011 & 0.024 \\
\hline 8.25 & -0.715 & -0.712 & -0.708 & -0.695 & 0.003 & 0.007 & 0.021 \\
\hline 8.50 & -0.459 & -0.457 & -0.453 & -0.442 & 0.002 & 0.006 & 0.017 \\
\hline 8.75 & -0.200 & -0.198 & -0.196 & -0.186 & 0.002 & 0.004 & 0.014 \\
\hline 9.00 & 0.063 & 0.064 & 0.066 & 0.073 & 0.001 & 0.003 & 0.010 \\
\hline 9.25 & 0.333 & 0.334 & 0.335 & 0.341 & 0.001 & 0.002 & 0.007 \\
\hline \multirow[t]{2}{*}{9.50} & 0.949 & 0.958 & 0.973 & 1.038 & 0.008 & 0.024 & 0.089 \\
\hline & \multicolumn{4}{|r|}{ Maximum: } & 3.10 & 4.21 & 5.27 \\
\hline
\end{tabular}

Source: Th Solubility.x/s and Th F Sensitivity.x/s in Appendix I. 
Table 6.8-6. Alternative Uncertainty Terms of $\log [T h]$

\begin{tabular}{|l|l|l|l|l|}
\hline \multicolumn{1}{|c|}{$\begin{array}{c}\text { Uncertainty } \\
\text { Term }\end{array}$} & \multicolumn{1}{|c|}{ Associated with } & \multicolumn{1}{c|}{$\begin{array}{c}\text { Distribution } \\
\text { Type }\end{array}$} & \multicolumn{1}{c|}{$\begin{array}{c}\text { Distribution } \\
\text { Parameter }\end{array}$} & \multicolumn{1}{c|}{ Applicability } \\
\hline${ }^{a} \varepsilon_{1}$ & $\begin{array}{l}\text { log K of controlling solid } \\
\text { and aqueous species }\end{array}$ & $\begin{array}{l}\text { Normal } \\
\text { Truncated at } \pm 2 \sigma\end{array}$ & $\mu=0, \sigma=0.7$ a,b & Values in Table $6.8-2$ \\
\hline${ }^{a} \varepsilon_{2}$ CSNF & $\begin{array}{l}\text { Fluoride concentration in } \\
\text { CSNF waste packages }\end{array}$ & Triangular & $\mathrm{a}=\mathrm{b}=0, \mathrm{c}=3.10^{\mathrm{a}}$ & CSNF waste packages \\
\hline$\varepsilon_{2}{ }^{\text {CDSP-water influx }}$ & $\begin{array}{l}\text { Fluoride concentration in } \\
\text { codisposal waste } \\
\text { packages (water influx } \\
\text { scenario) }\end{array}$ & Triangular & $\mathrm{a}=\mathrm{b}=0, \mathrm{c}=4.21$ & $\begin{array}{l}\text { Codisposal waste } \\
\text { packages and the invert }\end{array}$ \\
\hline$\varepsilon_{2}{ }^{\text {CDSP-vapor influx }}$ & $\begin{array}{l}\text { Fluoride concentration In } \\
\text { codisposal waste package } \\
\text { (vapor influx scenario) }\end{array}$ & Triangular & $\mathrm{a}=\mathrm{b}=0, \mathrm{c}=5.27$ & $\begin{array}{l}\text { Codisposal waste } \\
\text { packages and the invert }\end{array}$ \\
\hline
\end{tabular}

NOTE: a Same as base-case model. Uncertainty term $\varepsilon_{2}{ }^{\mathrm{CSNF}}$ used in base case without pH dependence applied

b For ionic strength values between 1 and 3 , Log $\mathrm{K}$ uncertainty should be treated as a normal distribution truncated at $\pm 2 \sigma$ with distribution parameters $\mu=0, \sigma=0.76$ (Section 6.3.3.4).

Table 6.8-7. Multiplication Factor (N) Used to Modify Alternative $\mathrm{F}^{-}$Uncertainty Term for Thorium

\begin{tabular}{|c|c|c|c|}
\hline \multirow[b]{2}{*}{ pH } & \multicolumn{3}{|c|}{ Multiplication Factor for F- Uncertainty } \\
\hline & CSNF & $\begin{array}{l}\text { CDSP - Water } \\
\text { Influx Scenario }\end{array}$ & $\begin{array}{c}\text { CDSP - Vapor Influx } \\
\text { Scenario }\end{array}$ \\
\hline 3.25 & $6.23 E-02$ & 1.19E-01 & 1.54E-01 \\
\hline 3.50 & $9.62 \mathrm{E}-02$ & $1.96 \mathrm{E}-01$ & $2.61 \mathrm{E}-01$ \\
\hline 3.75 & $1.94 \mathrm{E}-01$ & 2.54E-01 & $3.12 E-01$ \\
\hline 4.00 & 2.91E-01 & $3.16 \mathrm{E}-01$ & $3.55 E-01$ \\
\hline 4.25 & 3.30E-01 & 3.45E-01 & $3.78 \mathrm{E}-01$ \\
\hline 4.50 & 3.72E-01 & 3.79E-01 & 4.07E-01 \\
\hline 4.75 & $4.60 \mathrm{E}-01$ & 4.51E-01 & $4.68 \mathrm{E}-01$ \\
\hline 5.00 & 6.36E-01 & $5.95 E-01$ & $5.88 \mathrm{E}-01$ \\
\hline 5.25 & 8.55E-01 & $7.86 \mathrm{E}-01$ & 7.53E-01 \\
\hline 5.50 & $1.00 \mathrm{E}+00$ & 9.59E-01 & 9.14E-01 \\
\hline 5.75 & $9.26 \mathrm{E}-01$ & $1.00 \mathrm{E}+00$ & $1.00 \mathrm{E}+00$ \\
\hline 6.00 & $6.23 E-01$ & 8.28E-01 & 9.54E-01 \\
\hline 6.25 & 2.71E-01 & $5.64 \mathrm{E}-01$ & $8.21 E-01$ \\
\hline 6.50 & $4.42 \mathrm{E}-02$ & 2.86E-01 & $6.18 \mathrm{E}-01$ \\
\hline 6.75 & $1.36 \mathrm{E}-03$ & 6.74E-02 & $3.91 E-01$ \\
\hline 7.00 & $-1.70 \mathrm{E}-03 / 0.00^{\mathrm{a}}$ & $7.08 \mathrm{E}-03$ & 1.69E-01 \\
\hline 7.25 & $-1.70 \mathrm{E}-03 / 0.00^{\mathrm{a}}$ & $2.20 \mathrm{E}-03$ & 2.99E-02 \\
\hline 7.50 & $-1.34 \mathrm{E}-03 / 0.00^{\mathrm{a}}$ & $1.95 \mathrm{E}-03$ & 5.73E-03 \\
\hline 7.75 & $1.31 E-03$ & $3.45 \mathrm{E}-03$ & $5.36 \mathrm{E}-03$ \\
\hline 8.00 & $1.14 \mathrm{E}-03$ & $2.54 \mathrm{E}-03$ & $4.61 \mathrm{E}-03$ \\
\hline 8.25 & 9.43E-04 & $1.75 \mathrm{E}-03$ & $3.92 \mathrm{E}-03$ \\
\hline 8.50 & 7.32E-04 & $1.40 \mathrm{E}-03$ & 3.31E-03 \\
\hline 8.75 & $5.30 \mathrm{E}-04$ & $1.05 \mathrm{E}-03$ & $2.60 \mathrm{E}-03$ \\
\hline 9.00 & 3.39E-04 & $7.12 \mathrm{E}-04$ & $1.85 \mathrm{E}-03$ \\
\hline 9.25 & 2.40E-04 & 4.97E-04 & $1.40 \mathrm{E}-03$ \\
\hline 9.50 & 2.72E-03 & $5.68 \mathrm{E}-03$ & $1.68 \mathrm{E}-02$ \\
\hline
\end{tabular}

Source: Th F Sensitivitty.x/s (Appendix I).

NOTE: $\quad{ }^{a}$ Negative values set to 0.00 , indicating that no normalization is applied. 


\subsection{AMERICIUM SOLUBILITY}

\subsubsection{Introduction}

Data0.ymp.R2 includes americium data from the NEA compilation by Silva et al. (1995 [DIRS 102087]). Only Am(III) is significant under the reference conditions.

The database (Data0.ymp.R2) includes a number of americium solids: oxide and hydroxides $\mathrm{AmO}_{2}, \mathrm{Am}(\mathrm{OH})_{3}$, and $\mathrm{Am}(\mathrm{OH})_{3}(\mathrm{am})$; carbonate and hydroxy carbonate $\mathrm{Am}_{2}\left(\mathrm{CO}_{3}\right)_{2}$ and $\mathrm{AmOHCO}_{3}$; fluoride $\mathrm{AmF}_{3}$, and phosphate, $\mathrm{AmPO}_{4}(\mathrm{am})$. Under none of the conditions modeled were $\mathrm{Am}_{2}\left(\mathrm{CO}_{3}\right)_{2}$ or $\mathrm{AmF}_{3}$ oversaturated, so these can be discounted as solubility-controlling phases. $\mathrm{AmPO}_{4}(\mathrm{am})$ was oversaturated under all conditions. However, as discussed in Section 6.4.2.5, because of the amount of uranium available in the waste package environment, the phosphate concentrations in the waste package are very low. In addition, although the $\log \mathrm{K}$ value for this solid is taken from the NEA data compilation (Silva et al. 1995 [DIRS 102087]), it is excluded from the NAGRA/PSI database because, "The solubility constant has been derived at $\mathrm{pH}<3$. It is not clear whether the same solid is in equilibrium with phosphate containing solutions at neutral or alkaline conditions. In addition, since "...only one dihydrogen phosphate complex, $\mathrm{AmH}_{2} \mathrm{PO}_{4}{ }^{2+} \ldots$ ". is in the NAGRA database and Data0, "... any geochemical model calculation for environmental systems including phosphate at $\mathrm{pH}>3$ would most probably lead to large errors in dissolved americium concentrations due to the inadequate aqueous speciation model" (Hummel et al. 2002 [DIRS 161904], Section 5.2.6.2). For these reasons, $\mathrm{AmPO}_{4}(\mathrm{am})$ is also excluded from consideration here. This is conservative because concentrations would be lower if solubility control by this solid was selected. The solubilities of the oxides and hydroxides increase in the order: $\mathrm{AmO}_{2}<\mathrm{Am}(\mathrm{OH})_{3}<\mathrm{Am}(\mathrm{OH})_{3}(\mathrm{am})$.

According to Hummel et al. (2002 [DIRS 161904], Section 5.2.3.2), the properties of $\mathrm{AmO}_{2}$ are based on thermochemical studies and no solubility data are available to assess whether this phase ever actually controls dissolved Am concentrations under the conditions modeled. Thus it is also

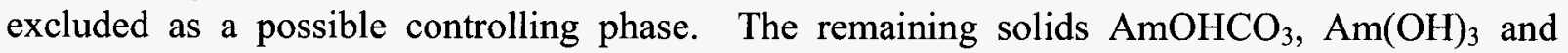
$\mathrm{Am}(\mathrm{OH})_{3}(\mathrm{am})$ are considered as controlling or alternative controlling phases.

The recent update volume of NEA Chemical Thermodynamics series (Guillaumont et al. 2003 [DIRS 168382]) reports revised values for the $\log \mathrm{K}^{0}$ value for the dissolution reaction of the controlling solid used in the modeling:

$$
\mathrm{AmOHCO}_{3}=\mathrm{Am}^{3+}+\mathrm{CO}_{3}^{2-}+\mathrm{OH}^{-}
$$

This was revised from $-21.2 \pm 1.4$ in the original volume (Silva et al. 1995 [DIRS 102087]), which was the source of the modeling data, to $-20.2 \pm 1.0$ in the update volume (Guillaumont et al. 2003 [DIRS 168382]). This difference corresponds to an increase of an order of magnitude in Am solubility, but with a smaller uncertainty. It is within the uncertainty applied to the solubilities given here (Section 6.9.4.2).

\subsubsection{Controlling Phase}

$\mathrm{AmOHCO}_{3}$ was chosen as the controlling solid phase in all calculations. The choice of this mineral is based on the studies by Nitsche et al. (1993 [DIRS 155218]; 1994 [DIRS 144515]), 
which identify $\mathrm{AmOHCO}_{3}$ as the solid phase precipitated from water similar to the $\mathrm{J}-13$ water composition used in these calculations at a $\mathrm{pH}$ range from 5.9 to 8.4 and temperatures from $25^{\circ} \mathrm{C}$ to $90^{\circ} \mathrm{C}$. This is the most likely controlling phase under the range of environmental variables of interest to this analysis.

As discussed in Section 6.3.3.1, the uncertainty of the solubility product of this mineral is provided by Silva et al. (1995 [DIRS 102087], Table III.2) as $\pm 1.4 \log \mathrm{K}$ units.

\subsubsection{Chemical Conditions}

Table 6.4-2 lists the chemical conditions for the americium calculations.

\subsubsection{Americium Solubility Model Results}

\subsubsection{Speciation and Solubility}

Figures 6.9-1 and 6.9-2 show concentrations of total dissolved Am and of aqueous species contributing to that concentration calculated at $f \mathrm{CO}_{2}=10^{-3.0}$ bars, expressed as molalities and percent total Am, respectively. The figures span the $\mathrm{pH}$ range from 6 to 10 beyond which EQ3NR was mathematically unable to solve for the solution compositions at this $f \mathrm{CO}_{2}$.

As these figures illustrate, at $\mathrm{pH}$ values above 9, virtually all the dissolved $\mathrm{Am}$ is present as $\mathrm{Am}\left(\mathrm{CO}_{3}\right)_{3}{ }^{3-}$. Note that at $\mathrm{pH} 10$ the concentration of $\mathrm{Am}\left(\mathrm{CO}_{3}\right)_{5}{ }^{6-}$ is increasing rapidly and dominates at higher $\mathrm{pH}$ values. The fact that $\mathrm{Am}$ concentrations dominated by these complexes increase so rapidly with $\mathrm{pH}$ limits the ability of EQ3NR to converge at high $\mathrm{pH}$ and $f \mathrm{CO}_{2}$ values.

As the $\mathrm{pH}$ decreases toward $8.5, \mathrm{Am}\left(\mathrm{CO}_{3}\right)_{2}{ }^{-}$becomes dominant and is succeeded by $\mathrm{AmCO}_{3}{ }^{+}$ that dominates to about $\mathrm{pH}$ 7. Around $\mathrm{pH}$ 7, the three species $\mathrm{AmCO}_{3}{ }^{+}, \mathrm{AmOH}^{2+}$, and $\mathrm{AmSO}_{4}{ }^{+}$ are of nearly equal importance. At $\mathrm{pH}$ values lower than about 6.5, virtually all dissolved Am is $\mathrm{AmSO}_{4}{ }^{+}$. Results of solubility calculations made at higher $f \mathrm{CO}_{2}$ values, where calculations were possible at lower $\mathrm{pH}$ values, show that with decreasing $\mathrm{pH}, \mathrm{Am}\left(\mathrm{SO}_{4}\right)_{2}{ }^{-}$concentrations become significant (EQ3NR output files in $\mathrm{Am} \mathrm{Eq3}$ runs.zip in Appendix I). The combination of $\mathrm{SO}_{4}{ }^{2-}$ as the charge balancing species and its presence in the aqueous species dominating the Am concentration limits the ability of EQ3NR to mathematically solve for the solution composition at low pH values. The instability linked to $\mathrm{SO}_{4}{ }^{2-}$ at lower $\mathrm{pH}$ and $f \mathrm{CO}_{2}$ values is specific to americium and thorium. It results from the fact that these elements are present as Am(III) and Th(IV) while the other actinides occur principally in the (V) or higher oxidation states. The $\mathrm{SO}_{4}{ }^{2-}$ complexes of actinide(III) and actinide(IV) species are relatively stronger than those of higher oxidation states (compare Hummel et al. 2002 [DIRS 161904], Tables 3.1.1, 3.1.2, and 3.1.3).

Finally, although Am-F complexes do not dominate under any of the base-case conditions modeled, Figure 6.9-1 shows that at $\mathrm{pH}$ values about 7.25 , the concentration of $\mathrm{AmF}^{2+}$ is within two orders of magnitude of the total Am concentration. Thus, at concentrations of $100 \times$ to $200 \times$ the base-case $\mathrm{F}^{-}$concentrations, Am-F complexes are the dominant Am species. This effect is shown by the $\mathrm{F}^{-}$sensitivity calculations illustrated in Figure 6.9-4. 


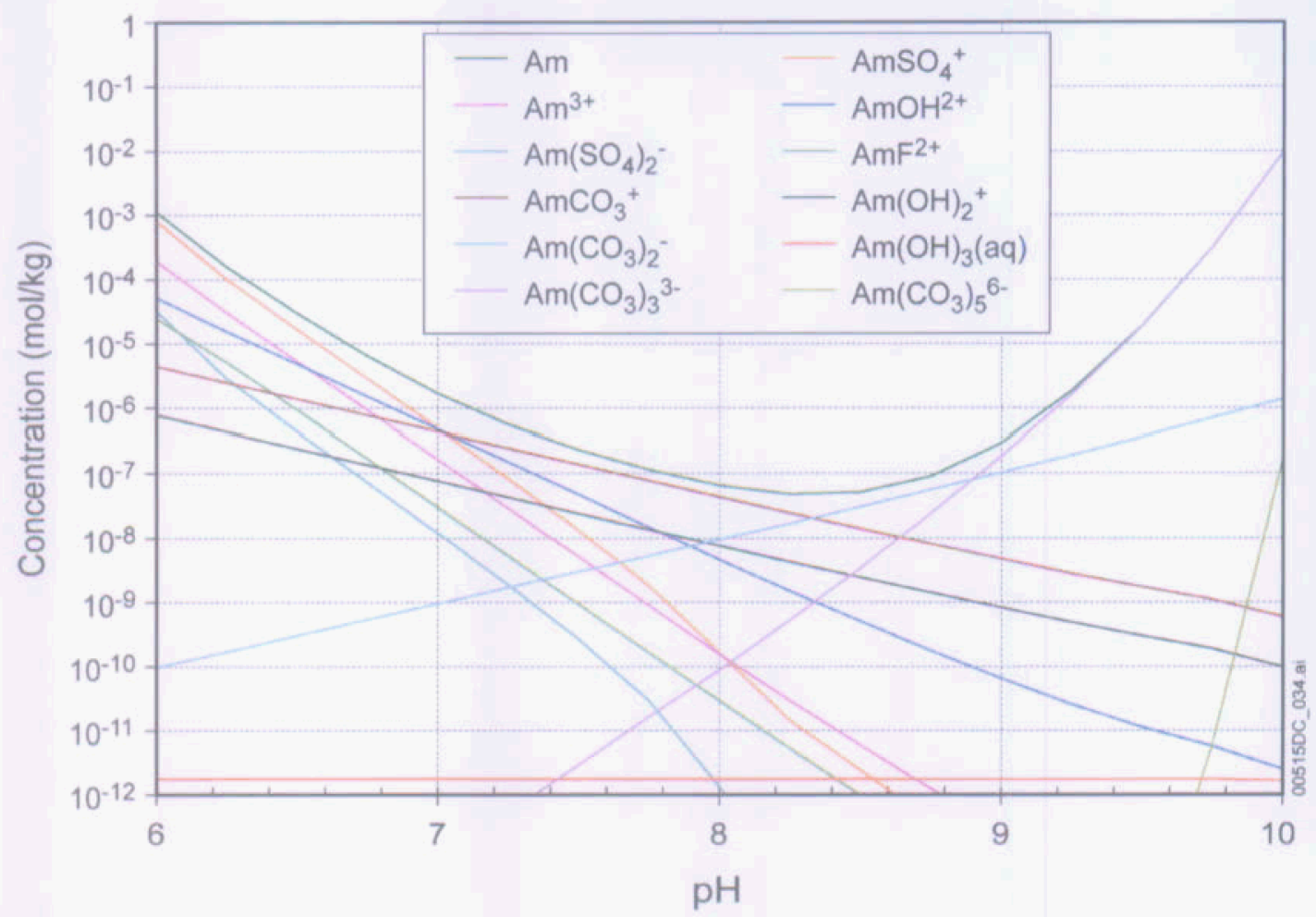

Source: Am species plot.xls (Appendix I).

Figure 6.9-1. Total Am Concentration and Speciation Diagram in $\mathrm{mol} A m / \mathrm{kg} \mathrm{H}_{2} \mathrm{O}$ at $\log \mathrm{fCO}_{2}$ (bars) $=-3.0$

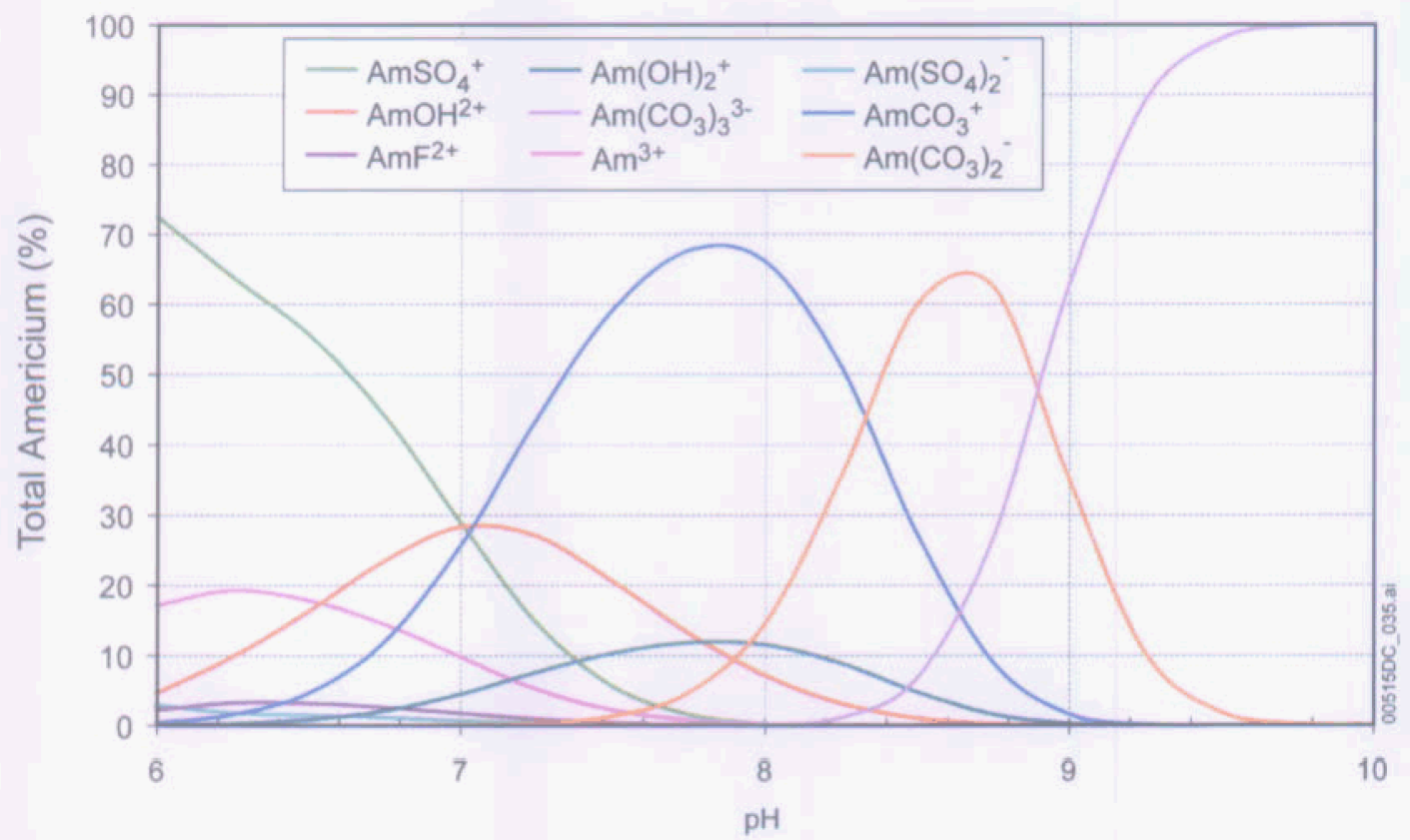

Source: Am species plot.xls (Appendix I).

Figure 6.9-2. Am Speciation Diagram in Percent Total Am at $\log f \mathrm{CO}_{2}$ (bars) $=-3.0$ 
Table 6.9-1 and Figure 6.9-3 give the americium concentrations using $\mathrm{AmOHCO}_{3}$ as the controlling mineral for $\mathrm{pH}$ values from 5.5 to 10.75 , and $\log f \mathrm{CO}_{2}$ values from -1.5 to 5.0. Calculations for conditions outside this range and where empty cells appear in the table either did not converge for the reasons discussed earlier, or led to solution ionic strengths above $1 \mathrm{~mol}$, (outside the range of validity of EQ3NR). At the low $\mathrm{pH}$ values, the modeling instability was due to the rapid increases in total americium and $\mathrm{SO}_{4}$ concentrations due to the strength of the $\mathrm{AmSO}_{4}{ }^{+}$ion pair and the addition of $\mathrm{SO}_{4}{ }^{2-}$ as the charge-balancing anion. At high $\mathrm{pH}$ and $f \mathrm{CO}_{2}$ values, the instability was due to rapid increases in total americium and $\mathrm{Na}^{+}$concentrations due to the strength of the $\mathrm{Am}\left(\mathrm{CO}_{3}\right)_{3}{ }^{3-}$ complexes and the addition of $\mathrm{Na}^{+}$as the cation balancing the increasing $\mathrm{CO}_{3}{ }^{2-}$ concentrations at these conditions. Instability from this occurs in calculations of other actinides as well, but the $\mathrm{SO}_{4}{ }^{2-}$-linked instability at lower $\mathrm{pH}$ and $f \mathrm{CO}_{2}$ values is specific to americium and thorium. It results from the fact that these elements are present as Am(III) and Th(IV) while the other actinides occur principally in the (V) or higher oxidation states. The $\mathrm{SO}_{4}{ }^{2-}$ complexes of $\mathrm{M}(\mathrm{III})$ and $\mathrm{M}(\mathrm{IV})$ (M stands for metal) species are relatively stronger than those of higher oxidation states.

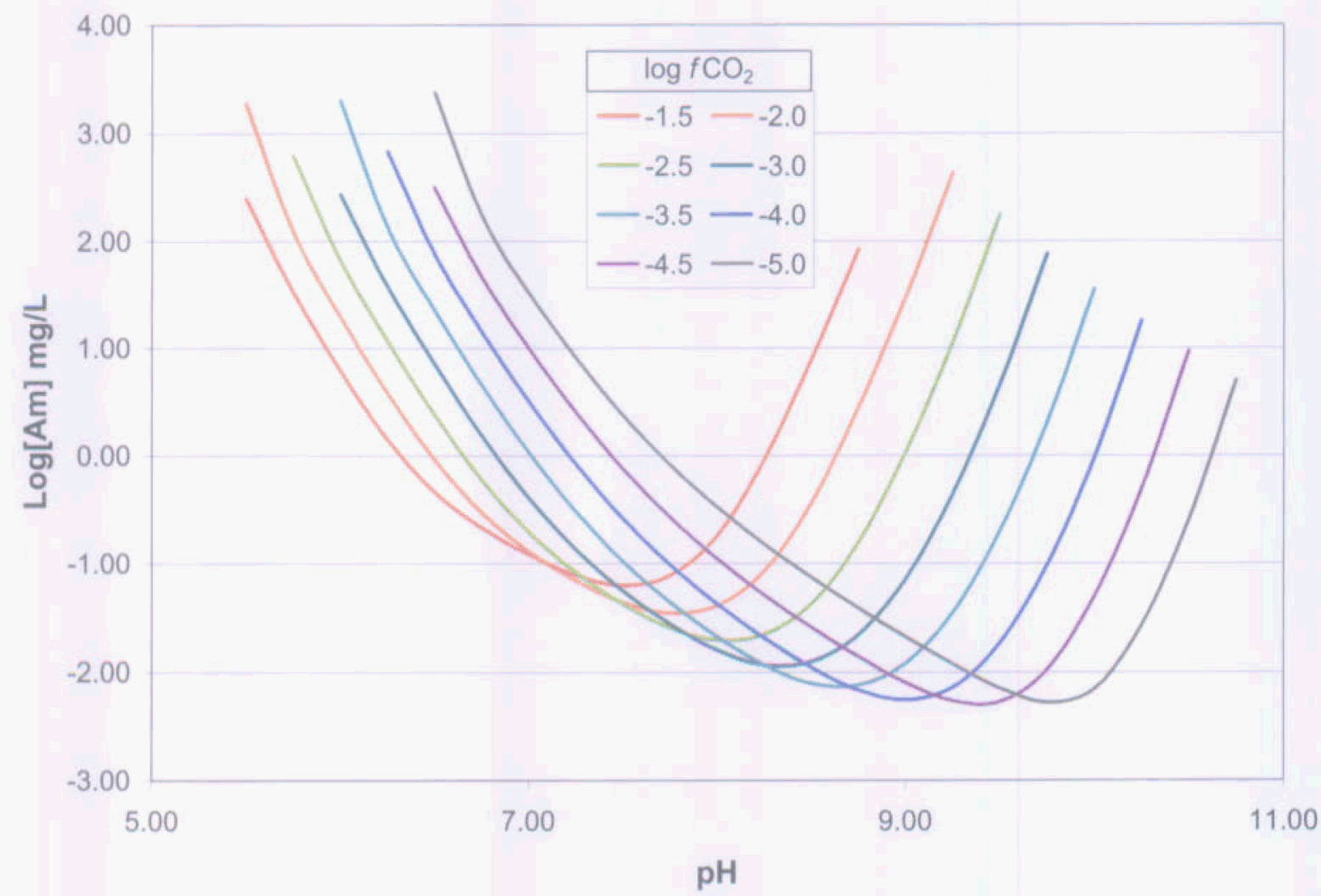

Source: Am Solubility.xls (Appendix I).

Figure 6.9-3. $\mathrm{AmOHCO}_{3}$ Solubility Modeled as a Function of $f \mathrm{CO}_{2}$ and $\mathrm{pH}$

Because the independent variables of calculated Am solubility are in log scales and the user of the table may need to interpolate between calculated values, the logarithm of Am solubility is given in Table 6.9-2 for use in the TSPA-LA modeling for LA. Table 6.9-2 includes the value " 500 " for those ranges of conditions for which no concentrations were given in Table 6.9-1. 
This value is intended as a flag to indicate that release rates, rather than concentration limits, for americium should be selected for these conditions in the TSPA-LA modeling. For any conditions that fall between a valid solubility and a flag of 500, the flag should be used. In addition, for any conditions outside the $\mathrm{pH}$ range of 3.0 to 11.0 , the -1.5 to -5.0 bar $\log f \mathrm{CO}_{2}$ range, or with an ionic strength greater than 1.0 molal, the concentrations calculated according to the dissolution rate of individual waste forms, water volume, and the solubility caps presented in Table 8-5.

Table 6.9-1. Americium Solubility (mg/L) Calculated with $\mathrm{AmOHCO}_{3}$ as Controlling Solid

\begin{tabular}{|c|c|c|c|c|c|c|c|c|}
\hline \multirow[b]{2}{*}{$\mathrm{pH}$} & \multicolumn{8}{|c|}{$\log \mathrm{fCO}_{2}$ (bars) } \\
\hline & -1.50 & -2.00 & -2.50 & -3.00 & -3.50 & -4.00 & -4.50 & -5.00 \\
\hline 5.50 & $2.52 E+02$ & $1.88 \mathrm{E}+03$ & - & - & - & - & - & - \\
\hline 5.75 & $3.42 \mathrm{E}+01$ & $1.26 \mathrm{E}+02$ & $6.25 E+02$ & - & - & - & - & - \\
\hline 6.00 & $6.30 \mathrm{E}+00$ & $2.00 E+01$ & $6.77 E+01$ & $2.72 E+02$ & $2.00 \mathrm{E}+03$ & - & - & - \\
\hline 6.25 & $1.45 \mathrm{E}+00$ & $3.92 \mathrm{E}+00$ & $1.19 \mathrm{E}+01$ & $3.84 \mathrm{E}+01$ & $1.38 \mathrm{E}+02$ & $6.90 \mathrm{E}+02$ & - & - \\
\hline 6.50 & $\begin{array}{l}4.37 \mathrm{E}-01^{\mathrm{a}} / \\
4.65 \mathrm{E}-01^{\mathrm{b}}\end{array}$ & $9.38 \mathrm{E}-01$ & $2.44 E+00$ & $7.25 E+00$ & $2.29 \mathrm{E}+01$ & $7.78 \mathrm{E}+01$ & $3.17 E+02$ & $2.37 E+03$ \\
\hline 6.75 & $2.18 \mathrm{E}-01$ & 3.02E-01 & $6.08 \mathrm{E}-01$ & $1.58 \mathrm{E}+00$ & $4.67 \mathrm{E}+00$ & $1.46 \mathrm{E}+01$ & $4.81 \mathrm{E}+01$ & $1.76 \mathrm{E}+02$ \\
\hline 7.00 & 1.22E-01 & $\begin{array}{l}1.27 \mathrm{E}-01^{\mathrm{a}} / \\
1.30 \mathrm{E}-01^{\mathrm{b}}\end{array}$ & 1.97E-01 & 4.13E-01 & $1.10 E+00$ & $3.27 E+00$ & $1.02 \mathrm{E}+01$ & $3.30 E+01$ \\
\hline 7.25 & $7.79 \mathrm{E}-02$ & $6.98 \mathrm{E}-02$ & $8.30 \mathrm{E}-02$ & 1.37E-01 & $3.08 \mathrm{E}-01$ & $8.52 \mathrm{E}-01$ & $2.58 \mathrm{E}+00$ & $8.07 E+00$ \\
\hline 7.50 & $6.28 \mathrm{E}-02$ & $4.38 \mathrm{E}-02$ & $4.15 \mathrm{E}-02$ & $5.65 \mathrm{E}-02$ & $1.06 \mathrm{E}-01$ & $2.65 \mathrm{E}-01$ & $7.69 \mathrm{E}-01$ & $2.36 \mathrm{E}+00$ \\
\hline 7.75 & $7.67 \mathrm{E}-02$ & $3.46 \mathrm{E}-02$ & $2.54 \mathrm{E}-02$ & $2.78 \mathrm{E}-02$ & $4.43 \mathrm{E}-02$ & $9.88 \mathrm{E}-02$ & $2.72 \mathrm{E}-01$ & $8.21 \mathrm{E}-01$ \\
\hline 8.00 & $1.80 \mathrm{E}-01$ & $4.06 \mathrm{E}-02$ & $1.96 \mathrm{E}-02$ & $1.59 \mathrm{E}-02$ & $2.14 \mathrm{E}-02$ & $4.28 \mathrm{E}-02$ & $1.12 \mathrm{E}-01$ & $3.31 \mathrm{E}-01$ \\
\hline 8.25 & $9.20 \mathrm{E}-01$ & $8.42 \mathrm{E}-02$ & $2.21 \mathrm{E}-02$ & $1.17 \mathrm{E}-02$ & $1.18 \mathrm{E}-02$ & $2.08 \mathrm{E}-02$ & $5.18 \mathrm{E}-02$ & $1.51 \mathrm{E}-01$ \\
\hline 8.50 & $7.84 \mathrm{E}+00$ & $3.62 \mathrm{E}-01$ & $4.18 \mathrm{E}-02$ & $1.25 \mathrm{E}-02$ & $7.90 \mathrm{E}-03$ & 1.12E-02 & $2.60 \mathrm{E}-02$ & $7.44 \mathrm{E}-02$ \\
\hline 8.75 & $8.49 \mathrm{E}+01$ & $2.80 \mathrm{E}+00$ & $1.54 \mathrm{E}-01$ & $2.18 \mathrm{E}-02$ & $7.63 \mathrm{E}-03$ & $6.89 \mathrm{E}-03$ & $1.39 \mathrm{E}-02$ & $3.88 \mathrm{E}-02$ \\
\hline 9.00 & - & $3.02 E+01$ & $1.07 \mathrm{E}+00$ & $7.10 \mathrm{E}-02$ & 1.20E-02 & $5.55 \mathrm{E}-03$ & $8.05 E-03$ & $2.11 \mathrm{E}-02$ \\
\hline 9.25 & - & $4.31 \mathrm{E}+02$ & $1.14 \mathrm{E}+01$ & $4.44 \mathrm{E}-01$ & $3.49 \mathrm{E}-02$ & $7.25 \mathrm{E}-03$ & $\begin{array}{l}5.38 \mathrm{E}-03^{\mathrm{a}} / \\
5.43 \mathrm{E}-03^{\mathrm{b}}\end{array}$ & $1.18 \mathrm{E}-02$ \\
\hline 9.50 & - & - & $1.75 \mathrm{E}+02$ & $4.62 \mathrm{E}+00$ & $1.99 \mathrm{E}-01$ & $1.83 \mathrm{E}-02$ & $5.29 \mathrm{E}-03$ & $7.14 \mathrm{E}-03$ \\
\hline 9.75 & - & - & - & $7.66 \mathrm{E}+01$ & $2.03 E+00$ & $9.57 \mathrm{E}-02$ & $1.04 \mathrm{E}-02$ & $5.25 \mathrm{E}-03$ \\
\hline 10.00 & - & - & - & - & $3.59 \mathrm{E}+01$ & $9.62 \mathrm{E}-01$ & $4.90 \mathrm{E}-02$ & 7.02E-03 \\
\hline 10.25 & - & - & - & - & - & $1.79 \mathrm{E}+01$ & $4.84 \mathrm{E}-01$ & $2.67 \mathrm{E}-02$ \\
\hline 10.50 & - & - & - & - & - & - & $9.33 \mathrm{E}+00$ & $2.55 \mathrm{E}-01$ \\
\hline 10.75 & - & - & - & - & - & - & - & $5.02 \mathrm{E}+00$ \\
\hline
\end{tabular}

Source: Am Solubility.x/s (Appendix I).

NOTE: Some cells have no data because the EQ3NR calculations do not converge. Runs with ionic strengths $>1.0$ are not reported.

a values used in TSPA-LA calculations.

b correct values obtained from EQ3NR calculations. Since the values are in the regions of low solubilities and changes are small, there is no effect on total dose calculated in TSPA-LA. 
Table 6.9-2. Americium Solubility (log[Am] mg/L)

\begin{tabular}{|c|c|c|c|c|c|c|c|c|}
\hline \multirow[b]{2}{*}{$\mathrm{pH}$} & \multicolumn{8}{|c|}{$\log \mathrm{fCO}_{2}$ (bars) } \\
\hline & -1.50 & -2.00 & -2.50 & -3.00 & -3.50 & -4.00 & -4.50 & -5.00 \\
\hline 5.50 & $2.40 \mathrm{E}+00$ & $3.27 \mathrm{E}+00$ & 500 & 500 & 500 & 500 & 500 & 500 \\
\hline 5.75 & $1.53 \mathrm{E}+00$ & $2.10 \mathrm{E}+00$ & $2.80 \mathrm{E}+00$ & 500 & 500 & 500 & 500 & 500 \\
\hline 6.00 & 7.99E-01 & $1.30 \mathrm{E}+00$ & $1.83 E+00$ & $2.43 E+00$ & $3.30 \mathrm{E}+00$ & 500 & 500 & 500 \\
\hline 6.25 & $1.60 \mathrm{E}-01$ & $5.93 \mathrm{E}-01$ & $1.07 E+00$ & $1.58 \mathrm{E}+00$ & $2.14 \mathrm{E}+00$ & $2.84 \mathrm{E}+00$ & 500 & 500 \\
\hline 6.50 & $\begin{array}{l}-3.60 \mathrm{E}-01^{\mathrm{a}} / \\
-3.33 \mathrm{E}-01^{\mathrm{b}} \\
\end{array}$ & $-2.76 \mathrm{E}-02$ & 3.88E-01 & $8.60 \mathrm{E}-01$ & $1.36 \mathrm{E}+00$ & $1.89 E+00$ & $2.50 \mathrm{E}+00$ & $3.37 \mathrm{E}+00$ \\
\hline 6.75 & $-6.62 \mathrm{E}-01$ & $-5.20 \mathrm{E}-01$ & $-2.16 \mathrm{E}-01$ & $1.98 \mathrm{E}-01$ & $6.69 \mathrm{E}-01$ & $1.16 \mathrm{E}+00$ & $1.68 \mathrm{E}+00$ & $2.25 \mathrm{E}+00$ \\
\hline 7.00 & $-9.13 E-01$ & $\begin{array}{l}-8.97 \mathrm{E}-01^{\mathrm{a}} / \\
-8.85 \mathrm{E}-01^{\mathrm{b}} \\
\end{array}$ & $-7.05 \mathrm{E}-01$ & $-3.84 E-01$ & $3.99 \mathrm{E}-02$ & 5.14E-01 & $1.01 \mathrm{E}+00$ & $1.52 \mathrm{E}+00$ \\
\hline 7.25 & $-1.11 E+00$ & $-1.16 E+00$ & $-1.08 E+00$ & $-8.65 E-01$ & \begin{tabular}{|l}
$-5.11 E-01$ \\
\end{tabular} & $-6.96 \mathrm{E}-02$ & 4.11E-01 & $9.07 E-01$ \\
\hline 7.50 & $-1.20 \mathrm{E}+00$ & $-1.36 \mathrm{E}+00$ & $-1.38 \mathrm{E}+00$ & $-1.25 \mathrm{E}+00$ & $-9.73 E-01$ & $-5.76 \mathrm{E}-01$ & $-1.14 \mathrm{E}-01$ & $3.74 \mathrm{E}-01$ \\
\hline 7.75 & $-1.12 E+00$ & $-1.46 \mathrm{E}+00$ & $-1.60 \mathrm{E}+00$ & $-1.56 \mathrm{E}+00$ & $-1.35 \mathrm{E}+00$ & $-1.01 E+00$ & $-5.65 \mathrm{E}-01$ & $-8.59 \mathrm{E}-02$ \\
\hline 8.00 & $-7.46 \mathrm{E}-01$ & $-1.39 \mathrm{E}+00$ & $-1.71 E+00$ & $-1.80 E+00$ & $-1.67 \mathrm{E}+00$ & $-1.37 E+00$ & $-9.51 E-01$ & $-4.80 \mathrm{E}-01$ \\
\hline 8.25 & $-3.64 \mathrm{E}-02$ & $-1.07 E+00$ & $-1.66 \mathrm{E}+00$ & $-1.93 E+00$ & $-1.93 E+00$ & $-1.68 \mathrm{E}+00$ & $-1.29 \mathrm{E}+00$ & $-8.22 E-01$ \\
\hline 8.50 & $8.95 \mathrm{E}-01$ & $-4.41 \mathrm{E}-01$ & $-1.38 E+00$ & $-1.90 E+00$ & $-2.10 E+00$ & $-1.95 E+00$ & $-1.58 \mathrm{E}+00$ & $-1.13 E+00$ \\
\hline 8.75 & $1.93 \mathrm{E}+00$ & 4.47E-01 & $-8.11 \mathrm{E}-01$ & $-1.66 \mathrm{E}+00$ & $-2.12 E+00$ & $-2.16 E+00$ & $-1.86 \mathrm{E}+00$ & $-1.41 \mathrm{E}+00$ \\
\hline 9.00 & 500 & $1.48 \mathrm{E}+00$ & $3.02 \mathrm{E}-02$ & $-1.15 E+00$ & $-1.92 E+00$ & $-2.26 E+00$ & $-2.09 E+00$ & $-1.68 \mathrm{E}+00$ \\
\hline 9.25 & 500 & $2.63 E+00$ & $1.06 \mathrm{E}+00$ & $-3.53 \mathrm{E}-01$ & $-1.46 \mathrm{E}+00$ & $-2.14 \mathrm{E}+00$ & $-2.27 \mathrm{E}+00^{\mathrm{c}}$ & $-1.93 E+00$ \\
\hline 9.50 & 500 & 500 & $2.24 \mathrm{E}+00$ & $6.65 \mathrm{E}-01$ & $-7.01 \mathrm{E}-01$ & $-1.74 E+00$ & $-2.28 \mathrm{E}+00$ & $-2.15 E+00$ \\
\hline 9.75 & 500 & 500 & 500 & $1.88 \mathrm{E}+00$ & 3.08E-01 & $-1.02 E+00$ & $-1.98 E+00$ & $-2.28 \mathrm{E}+00$ \\
\hline 10.00 & 500 & 500 & 500 & 500 & $1.56 \mathrm{E}+00$ & $-1.70 \mathrm{E}-02$ & $-1.31 \mathrm{E}+00$ & $-2.15 E+00$ \\
\hline 10.25 & 500 & 500 & 500 & 500 & 500 & $1.25 \mathrm{E}+00$ & $-3.16 \mathrm{E}-01$ & $-1.57 E+00$ \\
\hline 10.50 & 500 & 500 & 500 & 500 & 500 & 500 & $9.70 \mathrm{E}-01$ & $-5.94 \mathrm{E}-01$ \\
\hline 10.75 & 500 & 500 & 500 & 500 & 500 & 500 & 500 & $7.01 \mathrm{E}-01$ \\
\hline
\end{tabular}

Source: Am Solubility.x/s (Appendix I)

NOTES: Some cells have no valid data because the EQ3NR calculations do not converge and the results are reported as 500 . Runs with ionic strengths $>1.0$ are also reported as 500 .

a Values used in TSPA-LA calculations.

${ }^{b}$ Correct values obtained from EQ3NR calculations. Since the values are in the regions indicating very low solubilities, these small changes have no effects on total dose calculated in TSPA-LA.

${ }^{c}$ Values from Table $6.9-1$ both indicate a Log[Am] value of $-2.27 \mathrm{E}+00$ for these conditions. Therefore, no corrected value must be reported.

\subsubsection{Uncertainties}

\subsection{Uncertainty in Log $\mathrm{K}$ of the Solubility-Controlling Solid and Aqueous Species}

As described in Section 6.3.3, uncertainties in the solubilities have been evaluated considering uncertainties in thermodynamic data and uncertainties in the fluoride content of the matrix fluid. The uncertainty in thermodynamic data was calculated as described in Section 6.3.3.1, allowing for uncertainties in $\log \mathrm{K}$ values of the controlling solid and the important aqueous americium species. 
The principal dissolved americium species accounting for more than 10 percent of the total dissolved americium $\left(\mathrm{Am}\left(\mathrm{CO}_{3}\right)_{3}{ }^{3-}, \mathrm{Am}\left(\mathrm{CO}_{3}\right)_{2}{ }^{-}, \mathrm{AmCO}_{3}{ }^{+}, \mathrm{Am}(\mathrm{OH})_{2}{ }^{+}, \mathrm{AmOH}^{2+}, \mathrm{AmSO}_{4}{ }^{+}\right.$, $\mathrm{Am}\left(\mathrm{SO}_{4}\right)_{2}{ }^{-}$, and $\mathrm{Am}^{3+}$ ) are evident in Figure 6.9-2. Uncertainties for $\log \mathrm{K}$ values of these species given by Silva et al. (1995 [DIRS 102087], Table III.2) range from \pm 0.03 to \pm 0.8 . Uncertainty in the $\log \mathrm{K}$ of $\mathrm{AmOHCO}_{3}$, the controlling solid, also taken from Chemical Thermodynamics of Americium (Silva et al. 1995 [DIRS 102087], Table III.2), is \pm 1.4 . The largest $\log \mathrm{K}$ uncertainty was found for the reaction to $\mathrm{Am}\left(\mathrm{CO}_{3}\right)_{3}{ }^{3-}$ and equals \pm 1.94 (see file $\log$ $K$ concentrations_060424.xls in Appendix I). This represents a $2 \sigma$ value. The $1 \sigma$ uncertainty assigned to the $\log [\mathrm{Am}]$ values is \pm 1.0 .

\subsection{Uncertainty from Fluoride Concentration}

The effects of fluoride uncertainty were evaluated by calculating americium solubilities at a range of $\mathrm{pH}$ values for $f \mathrm{CO}_{2}=10^{-3.0}$ bars with fluoride concentrations equal to the highest values expected in each of the three in-package and invert environments. These environments and their fluoride concentrations are described in Section 6.3.3.2 and Table 6.3-3. These results are displayed in Figure 6.9-4. Table 6.9-3 gives the calculated concentrations, including those for the base-case fluoride concentration, and also shows the differences between the higher-fluoride and base-case solubilities. As the figure and table show, at fluoride a concentration of $2.18 \mathrm{mg} / \mathrm{L}$ (the CSNF environment, $10 \times$ the base-case value), the maximum difference from the base-case concentration is $+0.06 \log [\mathrm{Am}]$ (in $\mathrm{mg} / \mathrm{L}$ ) units at the lowest $\mathrm{pH}$ calculated (6.00). At a fluoride concentration of $200 \times$ the base-case value), the solubility is higher by a maximum value of $+1.00 \log [\mathrm{Am}]($ in $\mathrm{mg} / \mathrm{L})$ at $\mathrm{pH} 6.50$.

Table 6.9-3. Effects of Variations in Fluoride Concentrations on Americium Solubility

\begin{tabular}{|c|c|c|c|c|c|}
\hline \multirow[t]{2}{*}{ pH } & Base Case & CSNF & $\begin{array}{l}200 \times \text { Base } \\
\text { Case }\end{array}$ & CSNF & $\begin{array}{c}200 \times \text { Base } \\
\text { Case }\end{array}$ \\
\hline & \multicolumn{3}{|c|}{$\log [A m] \mathrm{mg} / \mathrm{L}$} & \multicolumn{2}{|c|}{ Difference } \\
\hline 6.00 & 2.435 & 2.494 & $3.36 \mathrm{E}+00$ & 0.059 & $9.25 \mathrm{E}-01$ \\
\hline 6.25 & 1.584 & 1.633 & $2.91 \mathrm{E}+00$ & 0.049 & $1.33 E+00$ \\
\hline 6.50 & 0.860 & 0.902 & $2.32 \mathrm{E}+00$ & 0.042 & $1.46 E+00$ \\
\hline 6.75 & 0.198 & 0.232 & $1.62 E+00$ & 0.033 & $1.42 E+00$ \\
\hline 7.00 & -0.384 & -0.362 & 8.83E-01 & 0.022 & $1.27 E+00$ \\
\hline 7.25 & -0.865 & -0.854 & $1.58 \mathrm{E}-01$ & 0.011 & $1.02 \mathrm{E}+00$ \\
\hline 7.50 & -1.248 & -1.245 & $-5.33 \mathrm{E}-01$ & 0.003 & $7.15 \mathrm{E}-01$ \\
\hline 7.75 & -1.556 & -1.557 & $-1.14 E+00$ & -0.002 & 4.15E-01 \\
\hline 8.00 & -1.800 & -1.793 & $-1.60 E+00$ & 0.007 & 2.02E-01 \\
\hline 8.25 & -1.933 & -1.928 & $-1.84 \mathrm{E}+00$ & 0.004 & $8.84 \mathrm{E}-02$ \\
\hline 8.50 & -1.904 & -1.900 & $-1.84 E+00$ & 0.004 & 6.36E-02 \\
\hline 8.75 & -1.661 & -1.656 & $-1.56 \mathrm{E}+00$ & 0.006 & 9.64E-02 \\
\hline 9.00 & -1.149 & -1.141 & $-1.02 \mathrm{E}+00$ & 0.007 & 1.33E-01 \\
\hline 9.25 & -0.353 & -0.346 & $-2.35 \mathrm{E}-01$ & 0.006 & 1.17E-01 \\
\hline 9.50 & 0.665 & 0.668 & 7.36E-01 & 0.004 & 7.12E-02 \\
\hline \multirow[t]{2}{*}{9.75} & 1.884 & 1.885 & $1.91 E+00$ & 0.001 & $2.89 \mathrm{E}-02$ \\
\hline & \multicolumn{3}{|r|}{ Maximum: } & 0.059 & 1.46 \\
\hline
\end{tabular}

Source: Am F Uncertainty.x/s (Appendix I). 


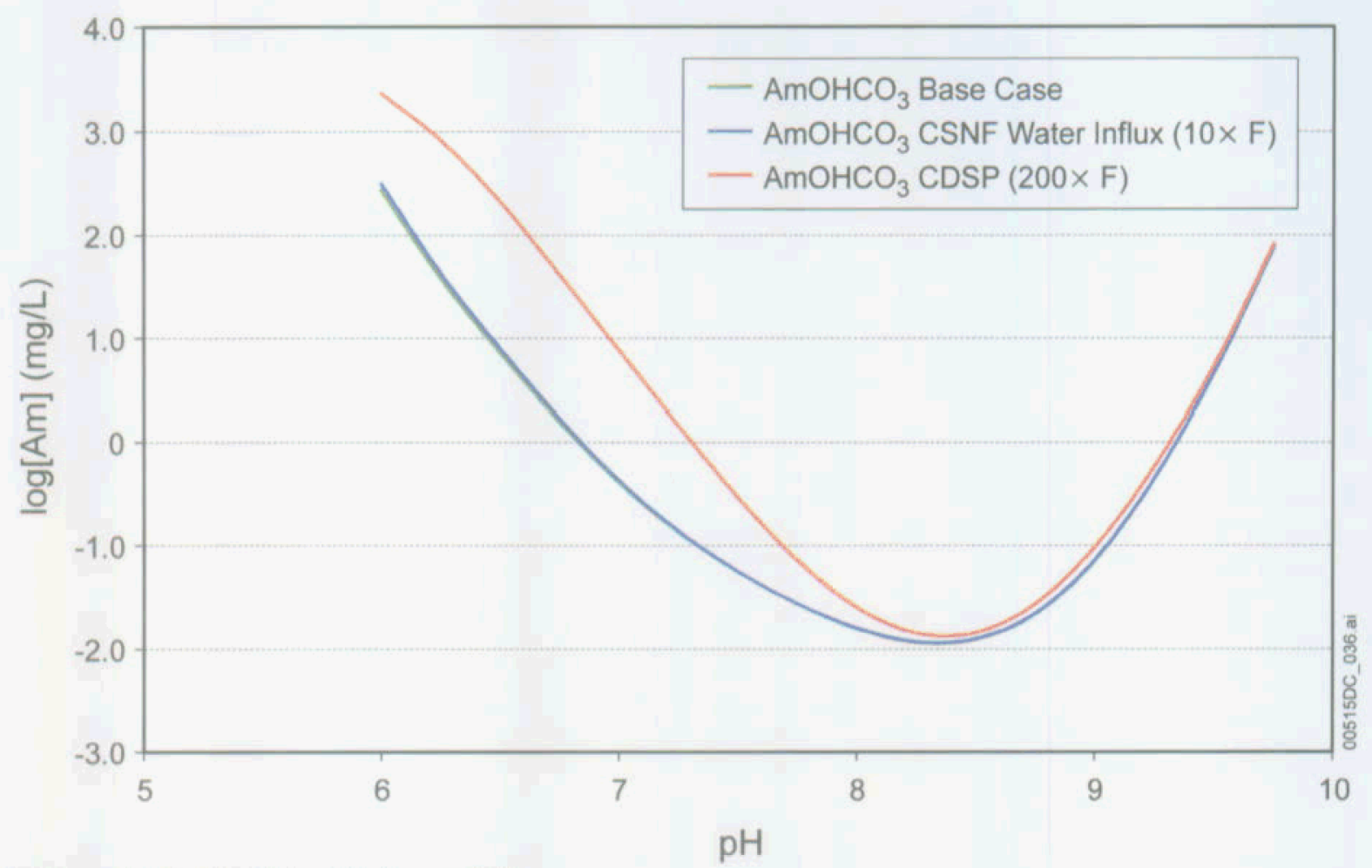

Source: Am F Uncertainty.x/s (Appendix I).

Figure 6.9-4. Sensitivity of Americium Solubility at $\log f \mathrm{CO}_{2}=-3.0$ bars to Variations of Fluoride Concentrations

\subsection{Summary of Am Solubility Model Uncertainty}

The uncertainties in americium solubilities are summarized by the following equation:

$$
\log [\mathrm{Am}]=S\left(p H, \log f \mathrm{CO}_{2}\right)+\varepsilon_{1}+\varepsilon_{2}
$$

The values for the parameters in this equation depend on the waste package type. Parameter $S\left(p H, \log f \mathrm{CO}_{2}\right)$ is the base-case solubility and is taken from Table 6.9-2. Parameter $\varepsilon_{1}$ is associated with the uncertainties in the $\log \mathrm{K}$ data. Parameter $\varepsilon_{2}$ is associated with the uncertainties in the fluoride concentrations. Table $6.9-4$ gives the values for the parameters $\varepsilon_{1}$ and $\varepsilon_{2}$.

Table 6.9-4. Uncertainty Terms of $\log [\mathrm{Am}]$

\begin{tabular}{|c|l|l|l|l|}
\hline $\begin{array}{c}\text { Uncertainty } \\
\text { Term }\end{array}$ & \multicolumn{1}{|c|}{ Associated With } & Distribution Type & \multicolumn{1}{c|}{$\begin{array}{c}\text { Distribution } \\
\text { Parameter }\end{array}$} & \multicolumn{1}{c|}{ Applicability } \\
\hline$\varepsilon_{1}$ & $\begin{array}{l}\text { log K of controlling solid } \\
\text { and aqueous species }\end{array}$ & $\begin{array}{l}\text { Normal Truncated } \\
\text { at } \pm 2 \sigma\end{array}$ & $\mu=0, \sigma=1.0^{\mathrm{a}}$ & Values in Table $6.9-2$ \\
\hline$\varepsilon_{2}{ }^{\text {CSNF }}$ & $\begin{array}{l}\text { Fluoride concentration in } \\
\text { CSNF waste packages }\end{array}$ & Triangular & $\mathrm{a}=\mathrm{b}=0, \mathrm{c}=5.91 \mathrm{E}-2$ & CSNF waste packages \\
\hline$\varepsilon_{2}{ }_{\text {CDSP-200,F }}$ & $\begin{array}{l}\text { Fluoride concentration In } \\
\text { Codisposal waste } \\
\text { packages (all scenarios) }\end{array}$ & Triangular & $\mathrm{a}=0, \mathrm{c}=1.46$ & $\begin{array}{l}\text { Codisposal waste } \\
\text { packages and the invert }\end{array}$ \\
\hline
\end{tabular}

NOTE: a For ionic strength values between 1 and $3, \log \mathrm{K}$ uncertainty should be treated as a normal distribution truncated at $\pm 2 \sigma$ with distribution parameters $\mu=0, \sigma=1.04$ (Section 6.3.3.4, Equation 6.3-7). 


\subsubsection{Alternative Conceptual Model}

As mentioned in Section 6.9.1, other solids with properties specified in Data0.ymp.R2 are potential controls on americium solubility. Hummel et al. (2002 [DIRS 161904], Section 5.2.3.2) describe experimental observations of solids with properties ranging from those of $\mathrm{Am}(\mathrm{OH})_{3}$ to those of $\mathrm{Am}(\mathrm{OH})_{3}(\mathrm{am})$. The less-stable solid appears to form first in many experiments and to invert to the more-stable solid with time. However, with additional time, the stable solid becomes less stable once again, presumably as a result of radiation damage. An alternative controlling phase could be chosen conservatively to have properties of $\mathrm{Am}(\mathrm{OH})_{3}(\mathrm{am})$.

Examination of the EQ3NR output files shows that $\mathrm{Am}(\mathrm{OH})_{3}(\mathrm{am})$ becomes oversaturated under conditions of the lowest $f \mathrm{CO}_{2}$, but under the remaining conditions modeled it is more soluble than $\mathrm{AmOHCO}_{3}$ (the controlling phase selected). The choice of the controlling solid phase $\mathrm{AmOHCO}_{3}$ in the base-case model is based on the studies by Nitsche et al. (1993 [DIRS 155218]; 1994 [DIRS 144515]), which identify $\mathrm{AmOHCO}_{3}$ as the solid phase precipitated from water similar to the $\mathrm{J}-13$ well water composition used in these calculations at a $\mathrm{pH}$ range from 5.9 to 8.4 and temperatures from $25^{\circ} \mathrm{C}$ to $90^{\circ} \mathrm{C}$.

\subsubsection{Alternative Uncertainty Terms}

Fluoride concentrations are given in Table 6.3-3. The base-case solubility involves the use of $J-13$ well water with a fluoride content of $2.18 \mathrm{mg} / \mathrm{L}$. The fluoride content of CSNF waste packages (water influx scenario - BSC 2004 [DIRS 167621]) is increases 10x to a value of $21.8 \mathrm{mg} / \mathrm{L} .(9.8 \mathrm{E}-04 \mathrm{~mol})$. The fluoride content for codisposal packages uses a value of $200 \times$ the base-case scenario $(436 \mathrm{mg} / \mathrm{L})$, which is the conservative maximum value with no $\mathrm{pH}$ dependence currently implemented in TSPA-LA calculations. The $\varepsilon_{2}{ }^{\text {CSNF }}$ is also conservatively used in TSPA-LA without $\mathrm{pH}$ dependence. New fluoride information from In-Package Chemistry Abstraction (BSC 2004 [DIRS 167621], Table 8-6) indicates fluoride concentrations of $58.89 \mathrm{mg} / \mathrm{L}(3.1 \mathrm{E}-03 \mathrm{~mol})$ for the water influx scenario and $209 \mathrm{mg} / \mathrm{L}(1.1 \mathrm{E}-02 \mathrm{~mol})$ for the vapor influx scenario.

The effects of fluoride uncertainty were evaluated by calculating americium solubilities at a range of $\mathrm{pH}$ values for $f \mathrm{CO}_{2}=10^{-3.0}$ bars with fluoride concentrations equal to the highest values expected in each of the three in-package and invert environments. These environments and their fluoride concentrations are described in Section 6.3.3.2 and Table 6.3-3. These results are displayed in Figure 6.9-5. Table 6.9-5 gives the calculated concentrations, including those for the base-case fluoride concentration, and also shows the differences between the higher-fluoride and base-case solubilities. As the figure and table show, at fluoride a concentration of $2.18 \mathrm{mg} / \mathrm{L}$ (the CSNF environment, $10 \times$ the base-case value), the maximum difference from the base-case concentration is $+0.06 \log [\mathrm{Am}]$ (in $\mathrm{mg} / \mathrm{L}$ ) units at the lowest $\mathrm{pH}$ calculated (6.00). At a fluoride concentration of $209 \mathrm{mg} / \mathrm{L}$ (the codisposal vapor influx scenario and invert environment, about $95 \times$ the base-case value), the maximum difference from the base-case concentration is $+1.00 \log [\mathrm{Am}]($ in $\mathrm{mg} / \mathrm{L}$ ) units at $\mathrm{pH} 6.50$. 


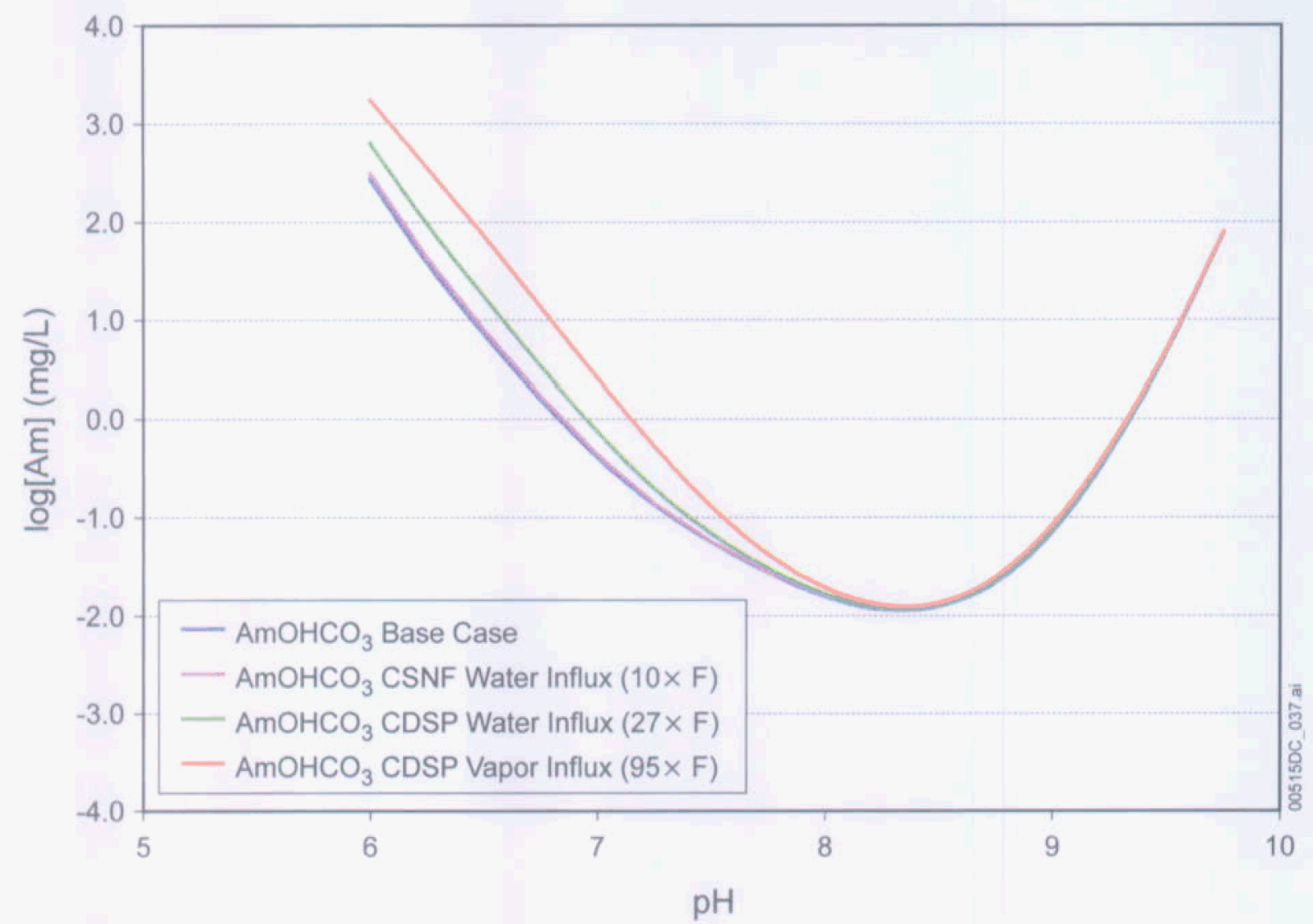

Source: Am F sensitivity.xIs (Appendix I)

Figure 6.9-5. Sensitivity of Americium Solubility at $\log f \mathrm{CO}_{2}=-3.0$ bars to Variations of Alternative Fluoride Concentrations 
Table 6.9-5. Alternative Uncertainty: The Effects of Variations in Fluoride Concentrations on Americium Solubility

\begin{tabular}{|c|c|c|c|c|c|c|c|}
\hline & Base Case & CSNF & \begin{tabular}{|c|} 
CDSP - \\
Water Influx \\
Scenario \\
\end{tabular} & \begin{tabular}{|c|} 
CDSP - \\
Vapor Influx \\
Scenario \\
\end{tabular} & CSNF & \begin{tabular}{|c|} 
CDSP - \\
Water Influx \\
Scenario
\end{tabular} & \begin{tabular}{|c|} 
CDSP - \\
Vapor Influx \\
Scenario \\
\end{tabular} \\
\hline pH & \multicolumn{4}{|c|}{$\log [A m] \mathrm{mg} / \mathrm{L}$} & \multicolumn{3}{|c|}{ Difference } \\
\hline 6.00 & 2.435 & 2.494 & 2.799 & 3.242 & 0.059 & 0.364 & 0.807 \\
\hline 6.25 & 1.584 & 1.633 & 1.981 & 2.551 & 0.049 & 0.397 & 0.967 \\
\hline 6.50 & 0.860 & 0.902 & 1.242 & 1.855 & 0.042 & 0.382 & 0.995 \\
\hline 6.75 & 0.198 & 0.232 & 0.533 & 1.129 & 0.033 & 0.335 & 0.930 \\
\hline 7.00 & -0.384 & -0.362 & -0.128 & 0.407 & 0.022 & 0.256 & 0.791 \\
\hline 7.25 & -0.865 & -0.854 & -0.703 & -0.280 & 0.011 & 0.162 & 0.585 \\
\hline 7.50 & -1.248 & -1.245 & -1.164 & -0.891 & 0.003 & 0.084 & 0.357 \\
\hline 7.75 & -1.556 & -1.557 & -1.517 & -1.377 & -0.002 & 0.039 & 0.179 \\
\hline 8.00 & -1.800 & -1.793 & -1.776 & -1.715 & 0.007 & 0.024 & 0.085 \\
\hline 8.25 & -1.933 & -1.928 & -1.921 & -1.892 & 0.004 & 0.012 & 0.041 \\
\hline 8.50 & -1.904 & -1.900 & -1.894 & -1.870 & 0.004 & 0.011 & 0.034 \\
\hline 8.75 & -1.661 & -1.656 & -1.646 & -1.610 & 0.006 & 0.016 & 0.052 \\
\hline 9.00 & -1.149 & -1.141 & -1.128 & -1.079 & 0.007 & 0.021 & 0.070 \\
\hline 9.25 & -0.353 & -0.346 & -0.335 & -0.292 & 0.006 & 0.018 & 0.061 \\
\hline 9.50 & 0.665 & 0.668 & 0.675 & 0.700 & 0.004 & 0.010 & 0.035 \\
\hline 9.75 & 1.884 & 1.885 & 1.888 & 1.897 & 0.001 & 0.004 & 0.013 \\
\hline & & & & Maximum: & 0.059 & 0.397 & 0.995 \\
\hline
\end{tabular}

Source: $A m$ Solubility.x/s and $A m F$ sensitivity.x/s (Appendix I).

NOTE: $\quad \mathrm{fCO}_{2}=-3.0$ bars.

The uncertainties in americium solubilities are summarized in the following equation:

$$
\log [\mathrm{Am}]=S\left(p H, \log f \mathrm{CO}_{2}\right)+\varepsilon_{1}+\left(\varepsilon_{2} \times N\right)
$$

The values for the parameters in this equation depend on the waste package type. Parameter $S\left(p H, \log f_{\mathrm{CO}_{2}}\right)$ is the base solubility and is taken from Table 6.9-2. Parameter $\varepsilon_{1}$ is associated with the uncertainties in the $\log \mathrm{K}$ data. Parameter $\varepsilon_{2}$ is associated with the uncertainties in the fluoride concentrations. Table 6.9-6 gives the values for the parameters $\varepsilon_{1}$ and $\varepsilon_{2}$.

Table 6.9-5 shows that the uncertainty terms $\varepsilon_{2}{ }^{\text {CSNF }}, \varepsilon_{2}{ }^{\text {CDSP-water influx }}$, and $\varepsilon_{2}{ }^{\text {CDSP-vapor influx }}$ vary with $\mathrm{pH}$. This $\mathrm{pH}$ dependence can be implemented through the use of a multiplication factor (N) that is a function of $\mathrm{pH}$. Values for $\mathrm{N}$ for both fuel types are given in Table 6.9-7. This modification requires that the $\varepsilon_{2}{ }^{\mathrm{CSNF}}, \varepsilon_{2}{ }^{\text {CDSP-water influx }}$, and $\varepsilon_{2}{ }^{\text {CDSP-vapor influx }}$ values be fixed at the maximum value given in Table 6.9-5. For each realization, the uncertainty parameters are sampled at the beginning of the realization. This sampled value is then multiplied by $N$ at each timestep to produce a modified $\varepsilon_{2}$ that is then added to the base solubility value. 
Table 6.9-6. Alternative Uncertainty Terms of $\log [A m]$

\begin{tabular}{|l|l|l|l|l|}
\hline \multicolumn{1}{|c|}{$\begin{array}{c}\text { Uncertainty } \\
\text { Term }\end{array}$} & \multicolumn{1}{|c|}{ Associated With: } & $\begin{array}{c}\text { Distribution } \\
\text { Type }\end{array}$ & \multicolumn{1}{c|}{$\begin{array}{c}\text { Distribution } \\
\text { Parameter }\end{array}$} & \multicolumn{1}{c|}{ Applicable To: } \\
\hline${ }^{a} \varepsilon_{1}$ & $\begin{array}{l}\text { log K of controlling solid } \\
\text { and aqueous species }\end{array}$ & $\begin{array}{l}\text { Normal } \\
\text { Truncated at } \\
\pm 2 \sigma\end{array}$ & $\mu=0, \sigma=1.0^{b}$ & Values in Table 6.9-2 \\
\hline${ }^{a} \varepsilon_{2}$ CSNF & $\begin{array}{l}\text { Fluoride concentration in } \\
\text { CSNF waste packages }\end{array}$ & Triangular & $\mathrm{a}=\mathrm{b}=0, \mathrm{c}=5.91 \mathrm{E}-2$ & CSNF waste packages \\
\hline$\varepsilon_{2}$ CDSP-water influx & $\begin{array}{l}\text { Fluoride concentration in } \\
\text { codisposal waste } \\
\text { packages (water influx } \\
\text { scenario) }\end{array}$ & Triangular & $\mathrm{a}=\mathrm{b}=0, \mathrm{c}=0.40$ & $\begin{array}{l}\text { Codisposal waste } \\
\text { packages and the invert }\end{array}$ \\
\hline$\varepsilon_{2}^{\text {CDSP-vapor influx }}$ & $\begin{array}{l}\text { Fluoride concentration In } \\
\text { codisposal waste package } \\
\text { (vapor influx scenario) }\end{array}$ & Triangular & $\mathrm{a}=\mathrm{b}=0, \mathrm{c}=0.99$ & $\begin{array}{l}\text { Codisposal waste } \\
\text { packages and the invert }\end{array}$ \\
\hline
\end{tabular}

NOTES: ${ }^{a}$ Same as base-case model. Uncertainty term $\varepsilon_{2}{ }^{C S N F}$ used in base case without $\mathrm{pH}$ dependence applied.

${ }^{b}$ For ionic strength values between 1 and $3, \log \mathrm{K}$ uncertainty should be treated as a normal distribution truncated at $\pm 2 \sigma$ with distribution parameters $\mu=0, \sigma=1.04$ (Section 6.3.3.4, Equation 6.3-7).

Table 6.9-7. Multiplication Factor $(\mathrm{N})$ used to modify $\mathrm{F}^{-}$Uncertainty Term for Americium

\begin{tabular}{|c|c|c|c|}
\hline \multirow{2}{*}{$\mathrm{pH}$} & \multicolumn{3}{|c|}{ Multiplication Factor for F- Uncertainty } \\
\cline { 2 - 4 } & CSNF & $\begin{array}{c}\text { CDSP - Water } \\
\text { Influx Scenario }\end{array}$ & $\begin{array}{c}\text { CDSP - Vapor } \\
\text { Influx Scenario }\end{array}$ \\
\hline $\mathbf{6 . 0 0}$ & $1.00 \mathrm{E}+00$ & $9.18 \mathrm{E}-01$ & $8.11 \mathrm{E}-01$ \\
\hline $\mathbf{6 . 2 5}$ & $8.28 \mathrm{E}-01$ & $1.00 \mathrm{E}+00$ & $9.72 \mathrm{E}-01$ \\
\hline $\mathbf{6 . 5 0}$ & $7.12 \mathrm{E}-01$ & $9.62 \mathrm{E}-01$ & $1.00 \mathrm{E}+00$ \\
\hline $\mathbf{6 . 7 5}$ & $5.64 \mathrm{E}-01$ & $8.44 \mathrm{E}-01$ & $9.35 \mathrm{E}-01$ \\
\hline $\mathbf{7 . 0 0}$ & $3.69 \mathrm{E}-01$ & $6.46 \mathrm{E}-01$ & $7.96 \mathrm{E}-01$ \\
\hline $\mathbf{7 . 2 5}$ & $1.79 \mathrm{E}-01$ & $4.07 \mathrm{E}-01$ & $5.88 \mathrm{E}-01$ \\
\hline $\mathbf{7 . 5 0}$ & $5.37 \mathrm{E}-02$ & $2.11 \mathrm{E}-01$ & $3.58 \mathrm{E}-01$ \\
\hline $\mathbf{7 . 7 5}$ & $-2.67 \mathrm{E}-02 /(0.00)^{\mathrm{a}}$ & $9.93 \mathrm{E}-02$ & $1.80 \mathrm{E}-01$ \\
\hline $\mathbf{8 . 0 0}$ & $1.18 \mathrm{E}-01$ & $5.93 \mathrm{E}-02$ & $8.56 \mathrm{E}-02$ \\
\hline $\mathbf{8 . 2 5}$ & $7.32 \mathrm{E}-02$ & $2.93 \mathrm{E}-02$ & $4.10 \mathrm{E}-02$ \\
\hline $\mathbf{8 . 5 0}$ & $6.68 \mathrm{E}-02$ & $2.65 \mathrm{E}-02$ & $3.42 \mathrm{E}-02$ \\
\hline $\mathbf{8 . 7 5}$ & $9.63 \mathrm{E}-02$ & $3.92 \mathrm{E}-02$ & $5.19 \mathrm{E}-02$ \\
\hline $\mathbf{9 . 0 0}$ & $1.26 \mathrm{E}-01$ & $5.25 \mathrm{E}-02$ & $7.05 \mathrm{E}-02$ \\
\hline $\mathbf{9 . 2 5}$ & $1.06 \mathrm{E}-01$ & $4.44 \mathrm{E}-02$ & $6.09 \mathrm{E}-02$ \\
\hline $\mathbf{9 . 5 0}$ & $6.00 \mathrm{E}-02$ & $2.50 \mathrm{E}-02$ & $3.52 \mathrm{E}-02$ \\
\hline $\mathbf{9 . 7 5}$ & $2.31 \mathrm{E}-02$ & $9.21 \mathrm{E}-03$ & $1.32 \mathrm{E}-02$ \\
\hline
\end{tabular}

Source: Am F sensitivity.x/s (Appendix 1).

NOTE: $\quad$ a Negative value set to 0.00 , indicating that no normalization is applied. 


\subsection{ACTINIUM SOLUBILITY}

\subsubsection{Introduction}

No thermodynamic data for actinium are included in Data0.ymp.R2, so actinium solubilities have not been calculated. Also, transport of Ac is not modeled in the TSPA-LA model because of its extremely short half-life. Actinium dose is calculated in the end by assuming secular equilibrium with $\mathrm{Pa}^{231}$. Therefore, solubilities of actinium are not investigated in this model.

\subsection{PROTACTINIUM SOLUBILITY}

\subsubsection{Introduction}

No thermodynamic data for protactinium are included in Data0.ymp.R2, so protactinium solubilities have not been calculated using EQ3NR. It is an established chemical principle that properties of elements are consistent with their position in the periodic table. Thus, corresponding solids of elements of similar positions in the table have similar solubilities.

Properties of elements in solution can be related to their charge $(\mathrm{z})$ and ionic radius (r) (Hummel et al. 2002 [DIRS 161904], Figures 3.1.1 through 3.1.5). Figure 6.11-1 plots z $\mathrm{z}^{2} / \mathrm{r}$ of selected cations against the $\log \mathrm{K}\left(25^{\circ} \mathrm{C}\right)$ of dissociation of their monohydroxyl solution complexes, for example:

$$
\mathrm{MOH}^{+(\mathrm{z}-1)}+\mathrm{H}^{+}=\mathrm{M}^{+\mathrm{z}}+\mathrm{H}_{2} \mathrm{O}
$$

where $\mathrm{M}$ represents any metal.

Figure 6.11-1 illustrates the correlation of chemical properties - in this case, solute complexation behavior-with charge and size. The sources of the $\log \mathrm{K}\left(25^{\circ} \mathrm{C}\right)$ values are provided in the figure caption.

Figure 6.11-1 also shows what would be expected from inspection of the periodic table, that $\mathrm{Pa}$ (IV) behavior is similar to that of $\mathrm{Np}$ (IV) and members of the lanthanide and actinide series in their trivalent states. Solubility calculations for $\mathrm{Np}$ (IV), one of the elements which $\mathrm{Pa}$ (IV) resembles, have been performed as part of this report (Section 6.6). In the absence of data for protactinium in Data0.ymp.R2, the protactinium concentrations given here are based on those calculated for neptunium (at atmospheric oxygen levels, Sections 6.6 and 6.11.6) and thorium. To corroborate this approach, it is necessary to evaluate the differences between protactinium, neptunium, and thorium solubilities based on the limited protactinium data that are available in the literature.

Thermodynamic data has been extracted from experiments by Baes and Mesmer (1986 [DIRS 100702], Section 9.1), Shibutani et al. (1998 [DIRS 161998]), and Yui et al. (1999 [DIRS 162664]). Protactinium most likely occurs in aqueous solution as $\mathrm{Pa}(\mathrm{IV})$ and $\mathrm{Pa}(\mathrm{V})$. As Figure 6.11-1 illustrates, the solution properties of $\mathrm{Pa}(\mathrm{IV})$ are similar to those of other actinides in their (IV) oxidation state. Thus, if protactinium occurred only as $\mathrm{Pa}(\mathrm{IV})$, its solubility would resemble that of thorium (Section 6.8). 


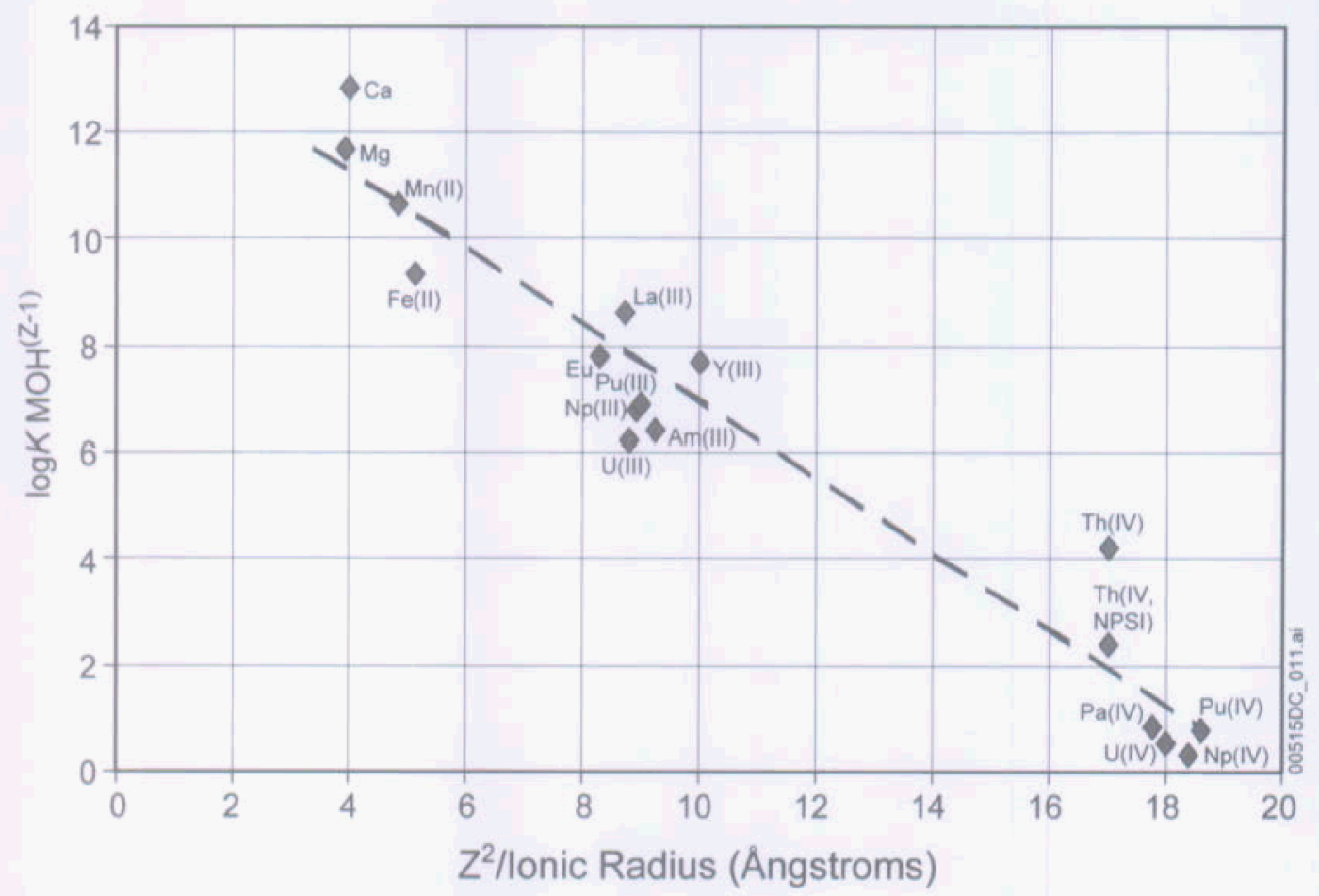

NOTE: $\quad z=$ charge and $r=$ ionic radius in Ángstroms.

The value for $\mathrm{Ac}$ (III) is a maximum value. The arrow in the figure shows the actual value would be lower than the value plotted.

Data Sources: Values for $r$ are from Shannon 1976 [DIRS 153587], Table $1 . \log \mathrm{K}\left(25^{\circ} \mathrm{C}\right)$ values are from Data0.ymp.R2, except those for Pa(IV), which are from Baes and Mesmer 1986 [DIRS 100702] (Table 9.1) and Th(IV, NPSI), which is from Hummel et al. 2002 [DIRS 161904], Table 5.21.1.

Source: Fig 6_10-1_2 data and plots.x/s (Appendix I).

Figure 6.11-1. Correlation Between $\mathrm{z}^{2} / \mathrm{r}$ and $\log \mathrm{K}\left(25^{\circ} \mathrm{C}\right)$ for the Formation of the Monohydroxyl Complex of Selected lons

Baes and Mesmer (1986 [DIRS 100702], Section 9.1.2) also derive equilibrium constant values for several $\mathrm{Pa}(\mathrm{V})$ reactions. These can be compared with data for analogous reactions of $\mathrm{Np}(\mathrm{V})$ as follows:

Table 6.11-1. Comparison of Analogous Neptunium and Protactinium Reactions

\begin{tabular}{|l|c|c|}
\hline \multicolumn{1}{|c|}{ Reaction } & $\log \mathrm{K}-\mathrm{Np}(\mathrm{V})^{\mathbf{a}}$ & $\log \mathrm{K}-\mathrm{Pa}(\mathrm{V})^{\mathrm{b}}$ \\
\hline $\mathrm{MO}_{2} \mathrm{OH}(\mathrm{aq})+\mathrm{H}^{+}=\mathrm{MO}_{2}{ }^{+}+\mathrm{H}_{2} \mathrm{O}$ & 11.3 & 4.5 \\
\hline $\mathrm{M}_{2} \mathrm{O}_{5}+2 \mathrm{H}^{+}=2 \mathrm{MO}_{2}{ }^{+}+2 \mathrm{H}_{2} \mathrm{O}$ & 3.7 & $<-4$ \\
\hline
\end{tabular}

Sources: ${ }^{a}$ Data0.ymp.R2.

${ }^{b}$ Baes and Mesmer 1986 [DIRS 100702], Table 9.1.

The stability of the $\mathrm{Pa}(\mathrm{V})$ solid is greater than that of the analogous $\mathrm{Np}(\mathrm{V})$ solid while that of the $\mathrm{Pa}(\mathrm{V})$ aqueous complex is lower. This indicates that if protactinium occurred only as $\mathrm{Pa}(\mathrm{V})$, its solubility would be less than that of neptunium. Baes and Mesmer (1986 [DIRS 100702], Section 9.1.2) describe experimental difficulties in maintaining protactinium in a stable oxidation 
state in solution, so calculations of the protactinium oxidation state required for solubilities calculation are not unreliable.

\subsubsection{Solubility Development}

Based on the considerations of chemical analogy, protactinium solubility should range from above that of thorium to below that of $\mathrm{Np}(\mathrm{V})$. Figure 6.11-2 shows the difference between the solubilities of $\mathrm{Np}_{2} \mathrm{O}_{5}$ and $\mathrm{ThO}_{2}(\mathrm{am})$. Under the widest range of $\mathrm{pH}$ and $f \mathrm{CO}_{2}$ conditions, $\mathrm{Np}_{2} \mathrm{O}_{5}$ solubility is greater than that of $\mathrm{ThO}_{2}(\mathrm{am})$. The base-case protactinium solubility is taken equal to that of $\mathrm{Np}_{2} \mathrm{O}_{5}$ (non-Eh adjusted) with the difference to the $\mathrm{ThO}_{2}(\mathrm{am})$ solubility accommodated in the uncertainty term.

\subsubsection{Chemical Conditions}

Because the protactinium solubility is based on the neptunium and thorium calculations, the chemical conditions given in Table 6.4-2 and used for the neptunium and thorium calculations also apply to the protactinium values.

\subsubsection{Protactinium Solubility Model}

Table 6.11-2 provides protactinium concentrations in $\mathrm{mg} / \mathrm{L}$.

Because the independent variables of calculated $\mathrm{Pa}$ solubility are in $\log$ scales and the user of the table may need to interpolate between calculated values, the logarithm of $\mathrm{Pa}$ solubility is given in Table 6.11-3 for use in the TSPA-LA modeling. The second table includes the value " 500 " for those ranges of conditions for which no concentrations were provided in Table 6.11-2. This value is intended as a flag to indicate that release rates rather than concentration limits for protactinium should be selected for these conditions in the TSPA-LA modeling. For any conditions that fall between a valid solubility and a flag of 500 , the flag should be used. In addition, for any conditions outside of the 3.0 to $11.0 \mathrm{pH}$ range, the -1.5 to -5.0 bar $\log f \mathrm{CO}_{2}$ range, or with an ionic strength greater than 1.0 molal, the concentrations calculated according to the dissolution rate of individual waste forms, water volume, and the solubility caps presented in Table 8-5. 
Table 6.11-2. Base-Case Protactinium Solubility (mg/L)

\begin{tabular}{|c|c|c|c|c|c|c|c|c|}
\hline \multirow[b]{2}{*}{ pH } & \multicolumn{8}{|c|}{$\log \mathrm{fCO}_{2}$ (bars) } \\
\hline & -1.50 & -2.00 & -2.50 & -3.00 & -3.50 & -4.00 & -4.50 & -5.00 \\
\hline 3.25 & $1.40 \mathrm{E}+04$ & $1.40 \mathrm{E}+04$ & $1.40 \mathrm{E}+04$ & $1.40 \mathrm{E}+04$ & $1.40 \mathrm{E}+04$ & $1.40 \mathrm{E}+04$ & $1.40 \mathrm{E}+04$ & $1.40 E+04$ \\
\hline 3.50 & $6.95 E+03$ & $6.95 \mathrm{E}+03$ & $6.95 E+03$ & $6.95 \mathrm{E}+03$ & $6.95 E+03$ & $6.95 \mathrm{E}+03$ & $6.95 \mathrm{E}+03$ & $6.95 \mathrm{E}+03$ \\
\hline 3.75 & $3.64 \mathrm{E}+03$ & $3.64 \mathrm{E}+03$ & $3.64 E+03$ & $3.64 \mathrm{E}+03$ & $3.64 E+03$ & $3.64 \mathrm{E}+03$ & $3.64 \mathrm{E}+03$ & $3.64 \mathrm{E}+03$ \\
\hline 4.00 & $1.96 \mathrm{E}+03$ & $1.96 \mathrm{E}+03$ & $1.96 \mathrm{E}+03$ & $1.96 \mathrm{E}+03$ & $1.96 \mathrm{E}+03$ & $1.96 \mathrm{E}+03$ & $1.96 \mathrm{E}+03$ & $1.96 \mathrm{E}+03$ \\
\hline 4.25 & $1.07 \mathrm{E}+03$ & $1.07 \mathrm{E}+03$ & $1.07 \mathrm{E}+03$ & $1.07 E+03$ & $1.07 \mathrm{E}+03$ & $1.07 E+03$ & $1.07 E+03$ & $1.07 E+03$ \\
\hline 4.50 & $5.91 \mathrm{E}+02$ & $5.91 \mathrm{E}+02$ & $5.91 \mathrm{E}+02$ & $5.91 \mathrm{E}+02$ & $5.91 \mathrm{E}+02$ & $5.91 E+02$ & $5.91 \mathrm{E}+02$ & $5.91 \mathrm{E}+02$ \\
\hline 4.75 & $3.29 \mathrm{E}+02$ & $3.29 \mathrm{E}+02$ & $3.29 E+02$ & $3.29 \mathrm{E}+02$ & $3.29 \mathrm{E}+02$ & $3.29 \mathrm{E}+02$ & $3.29 \mathrm{E}+02$ & $3.29 \mathrm{E}+02$ \\
\hline 5.00 & $1.84 \mathrm{E}+02$ & $1.84 \mathrm{E}+02$ & $1.84 E+02$ & $1.84 \mathrm{E}+02$ & $1.84 \mathrm{E}+02$ & $1.84 \mathrm{E}+02$ & $1.84 \mathrm{E}+02$ & $1.84 \mathrm{E}+02$ \\
\hline 5.25 & $1.03 E+02$ & $1.03 E+02$ & $1.03 E+02$ & $1.03 \mathrm{E}+02$ & $1.03 E+02$ & $1.03 \mathrm{E}+02$ & $1.03 E+02$ & $1.03 E+02$ \\
\hline 5.50 & $5.77 \mathrm{E}+01$ & $5.77 E+01$ & $5.77 E+01$ & $5.77 E+01$ & $5.77 \mathrm{E}+01$ & $5.77 \mathrm{E}+01$ & $5.77 \mathrm{E}+01$ & $5.77 \mathrm{E}+01$ \\
\hline 5.75 & $3.24 \mathrm{E}+01$ & $3.24 \mathrm{E}+01$ & $3.24 \mathrm{E}+01$ & $3.24 \mathrm{E}+01$ & $3.24 \mathrm{E}+01$ & $3.24 \mathrm{E}+01$ & $3.24 \mathrm{E}+01$ & $3.24 E+01$ \\
\hline 6.00 & $1.82 \mathrm{E}+01$ & $1.82 \mathrm{E}+01$ & $1.82 \mathrm{E}+01$ & 1.82E+01 & $1.82 E+01$ & $1.82 E+01$ & $1.82 E+01$ & $1.82 \mathrm{E}+01$ \\
\hline 6.25 & $1.03 \mathrm{E}+01$ & $1.02 \mathrm{E}+01$ & $1.02 E+01$ & $1.02 E+01$ & $1.02 E+01$ & $1.02 \mathrm{E}+01$ & $1.02 E+01$ & $1.02 E+01$ \\
\hline 6.50 & $5.83 \mathrm{E}+00$ & $5.78 \mathrm{E}+00$ & $5.76 \mathrm{E}+00$ & $5.76 \mathrm{E}+00$ & $5.76 \mathrm{E}+00$ & $5.75 \mathrm{E}+00$ & $5.75 \mathrm{E}+00$ & $5.75 \mathrm{E}+00$ \\
\hline 6.75 & $3.56 \mathrm{E}+00$ & $3.30 \mathrm{E}+00$ & $3.25 \mathrm{E}+00$ & $3.24 E+00$ & $3.24 \mathrm{E}+00$ & $3.24 \mathrm{E}+00$ & $3.24 \mathrm{E}+00$ & $3.24 \mathrm{E}+00$ \\
\hline 7.00 & $2.61 \mathrm{E}+00$ & $1.95 \mathrm{E}+00$ & $1.86 \mathrm{E}+00$ & $1.83 E+00$ & $1.82 E+00$ & $1.82 \mathrm{E}+00$ & $1.82 E+00$ & $1.82 E+00$ \\
\hline 7.25 & $3.09 \mathrm{E}+00$ & $1.34 \mathrm{E}+00$ & $1.10 \mathrm{E}+00$ & $1.04 E+00$ & $1.03 E+00$ & $1.03 \mathrm{E}+00$ & $1.02 \mathrm{E}+00$ & $1.02 \mathrm{E}+00$ \\
\hline 7.50 & $6.92 \mathrm{E}+00$ & $1.35 \mathrm{E}+00$ & $7.18 \mathrm{E}-01$ & $6.14 \mathrm{E}-01$ & 5.87E-01 & 5.79E-01 & 5.77E-01 & $5.76 \mathrm{E}-01$ \\
\hline 7.75 & $2.66 \mathrm{E}+01$ & $2.42 E+00$ & $6.45 \mathrm{E}-01$ & $3.99 \mathrm{E}-01$ & $3.45 \mathrm{E}-01$ & $3.30 \mathrm{E}-01$ & 3.26E-01 & $E-01$ \\
\hline 8.00 & $2.33 E+02$ & $7.35 \mathrm{E}+00$ & $9.61 \mathrm{E}-01$ & $3.29 \mathrm{E}-01$ & 2.22E-01 & $1.94 \mathrm{E}-01$ & $1.86 \mathrm{E}-01$ & $1.83 \mathrm{E}-01$ \\
\hline 8.25 & - & 4.26E+01 & $2.37 E+00$ & $4.28 \mathrm{E}-01$ & $1.78 \mathrm{E}-01$ & $1.24 \mathrm{E}-01$ & 1.09E-01 & $1.04 \mathrm{E}-01$ \\
\hline 8.50 & - & $1.04 \mathrm{E}+03$ & $1.01 \mathrm{E}+01$ & $8.77 \mathrm{E}-01$ & $2.08 \mathrm{E}-01$ & $9.75 \mathrm{E}-02$ & $6.95 \mathrm{E}-02$ & $6.13 \mathrm{E}-02$ \\
\hline 8.75 & - & - & $1.07 E+02$ & $2.90 \mathrm{E}+00$ & $3.69 \mathrm{E}-01$ & $1.09 \mathrm{E}-01$ & $5.40 \mathrm{E}-02$ & $3.90 \mathrm{E}-02$ \\
\hline 9.00 & - & - & - & $2.10 \mathrm{E}+01$ & $9.84 \mathrm{E}-01$ & 1.72E-01 & $5.83 \mathrm{E}-02$ & $3.01 \mathrm{E}-02$ \\
\hline 9.25 & - & - & - & $6.00 \mathrm{E}+02$ & $5.21 E+00$ & $3.88 \mathrm{E}-01$ & $8.66 \mathrm{E}-02$ & $3.19 \mathrm{E}-02$ \\
\hline 9.50 & - & - & - & - & $8.00 E+01$ & $1.55 \mathrm{E}+00$ & 1.73E-01 & 4.56E-02 \\
\hline 9.75 & - & - & - & - & - & $1.77 \mathrm{E}+01$ & $5.41 \mathrm{E}-01$ & $8.40 \mathrm{E}-02$ \\
\hline 10.00 & - & - & - & - & - & $1.68 \mathrm{E}+03$ & $4.76 \mathrm{E}+00$ & $2.18 \mathrm{E}-01$ \\
\hline 10.25 & - & - & - & - & - & - & $1.70 \mathrm{E}+02$ & $1.46 \mathrm{E}+00$ \\
\hline 10.50 & - & - & - & - & - & - & - & 4.23E+01 \\
\hline
\end{tabular}

Source: $\mathrm{Np}_{2} \mathrm{O}_{5}$ Solubility for Pa.xls (Appendix I).

NOTE: Some cells have no data because the EQ3NR calculations do not converge.

Runs with ionic strengths $>1.0$ are outside the range of validation, and are not reported. 
Table 6.11-3. Base-Case Protactinium Solubility (log[Pa], mg/L)

\begin{tabular}{|c|c|c|c|c|c|c|c|c|}
\hline \multirow{2}{*}{ pH } & \multicolumn{8}{|c|}{$\log \mathrm{fCO}_{2}$ (bars) } \\
\hline & -1.50 & -2.00 & -2.50 & -3.00 & -3.50 & -4.00 & -4.50 & -5.00 \\
\hline 3.25 & $4.15 \mathrm{E}+00$ & $4.15 \mathrm{E}+00$ & $4.15 \mathrm{E}+00$ & $4.15 \mathrm{E}+00$ & $4.15 \mathrm{E}+00$ & $4.15 E+00$ & $4.15 \mathrm{E}+00$ & $4.15 \mathrm{E}+00$ \\
\hline 3.50 & $3.84 \mathrm{E}+00$ & $3.84 \mathrm{E}+00$ & $3.84 \mathrm{E}+00$ & $3.84 \mathrm{E}+00$ & $3.84 \mathrm{E}+00$ & $3.84 E+00$ & $3.84 \mathrm{E}+00$ & $3.84 \mathrm{E}+00$ \\
\hline 3.75 & $3.56 \mathrm{E}+00$ & $3.56 \mathrm{E}+00$ & $3.56 \mathrm{E}+00$ & $3.56 \mathrm{E}+00$ & $3.56 \mathrm{E}+00$ & $3.56 \mathrm{E}+00$ & $3.56 \mathrm{E}+00$ & $3.56 \mathrm{E}+00$ \\
\hline 4.00 & $3.29 \mathrm{E}+00$ & $3.29 \mathrm{E}+00$ & $3.29 \mathrm{E}+00$ & $3.29 \mathrm{E}+00$ & $3.29 \mathrm{E}+00$ & $3.29 \mathrm{E}+00$ & $3.29 \mathrm{E}+00$ & $3.29 \mathrm{E}+00$ \\
\hline 4.25 & $3.03 E+00$ & $3.03 E+00$ & $3.03 E+00$ & $3.03 E+00$ & $3.03 E+00$ & $3.03 E+00$ & $3.03 E+00$ & $3.03 E+00$ \\
\hline 4.50 & $2.77 \mathrm{E}+00$ & $2.77 \mathrm{E}+00$ & $2.77 \mathrm{E}+00$ & $2.77 \mathrm{E}+00$ & $2.77 \mathrm{E}+00$ & $2.77 E+00$ & $2.77 \mathrm{E}+00$ & $2.77 E+00$ \\
\hline 4.75 & $2.52 \mathrm{E}+00$ & $2.52 \mathrm{E}+00$ & $2.52 \mathrm{E}+00$ & $2.52 E+00$ & $2.52 \mathrm{E}+00$ & $2.52 \mathrm{E}+00$ & $2.52 \mathrm{E}+00$ & $2.52 E+00$ \\
\hline 5.00 & $2.26 \mathrm{E}+00$ & $2.26 \mathrm{E}+00$ & $2.26 \mathrm{E}+00$ & $2.26 \mathrm{E}+00$ & $2.26 \mathrm{E}+00$ & $2.26 \mathrm{E}+00$ & $2.26 \mathrm{E}+00$ & $2.26 \mathrm{E}+00$ \\
\hline 5.25 & $2.01 E+00$ & $2.01 \mathrm{E}+00$ & $2.01 \mathrm{E}+00$ & $2.01 \mathrm{E}+00$ & $2.01 \mathrm{E}+00$ & $2.01 \mathrm{E}+00$ & $2.01 \mathrm{E}+00$ & $2.01 \mathrm{E}+00$ \\
\hline 5.50 & $1.76 \mathrm{E}+00$ & $1.76 \mathrm{E}+00$ & $1.76 \mathrm{E}+00$ & $1.76 \mathrm{E}+00$ & $1.76 \mathrm{E}+00$ & $1.76 \mathrm{E}+00$ & $1.76 \mathrm{E}+00$ & $1.76 \mathrm{E}+00$ \\
\hline 5.75 & $1.51 \mathrm{E}+00$ & $1.51 \mathrm{E}+00$ & $1.51 \mathrm{E}+00$ & $1.51 \mathrm{E}+00$ & $1.51 \mathrm{E}+00$ & $1.51 \mathrm{E}+00$ & $1.51 \mathrm{E}+00$ & $1.51 \mathrm{E}+00$ \\
\hline 6.1 & $1.26 \mathrm{E}+00$ & $1.26 \mathrm{E}+00$ & $1.26 \mathrm{E}+00$ & $1.26 \mathrm{E}+00$ & $1.26 \mathrm{E}+00$ & $1.26 \mathrm{E}+00$ & $1.26 \mathrm{E}+00$ & $1.26 \mathrm{E}+00$ \\
\hline 6.25 & $1.01 \mathrm{E}+00$ & $1.01 E+00$ & $1.01 \mathrm{E}+00$ & $1.01 \mathrm{E}+00$ & $.01 \mathrm{E}+00$ & $1.01 \mathrm{E}+00$ & $1.01 \mathrm{E}+00$ & $1.01 \mathrm{E}+00$ \\
\hline 6.50 & $7.66 \mathrm{E}-01$ & 7.62E-01 & 7.61E-01 & 7.60E-01 & 7.60E-01 & $7.60 \mathrm{E}-01$ & $7.60 \mathrm{E}-01$ & 7.60E-01 \\
\hline 6.75 & $5.51 \mathrm{E}-01$ & $5.19 \mathrm{E}-01$ & 5.12E-01 & 5.11E-01 & $5.10 \mathrm{E}-01$ & $5.10 \mathrm{E}-01$ & $5.10 \mathrm{E}-01$ & 5.10E-01 \\
\hline 7.00 & 4.17E-01 & $2.89 \mathrm{E}-01$ & 2.69E-01 & 2.63E-01 & $2.61 \mathrm{E}-01$ & $2.60 \mathrm{E}-01$ & $2.60 \mathrm{E}-01$ & $2.60 \mathrm{E}-01$ \\
\hline 7.25 & $4.90 \mathrm{E}-01$ & $1.28 \mathrm{E}-01$ & $3.98 \mathrm{E}-02$ & $1.87 \mathrm{E}-02$ & $1.27 \mathrm{E}-02$ & $1.09 \mathrm{E}-02$ & $1.03 \mathrm{E}-02$ & $1.01 \mathrm{E}-02$ \\
\hline 7.50 & $8.40 \mathrm{E}-01$ & $1.30 \mathrm{E}-01$ & -1.44E-01 & $-2.11 E-01$ & $-2.31 E-01$ & $-2.37 \mathrm{E}-01$ & $-2.39 \mathrm{E}-01$ & $-2.40 \mathrm{E}-01$ \\
\hline 7.75 & $1.42 \mathrm{E}+00$ & 3.83E-01 & $-1.90 \mathrm{E}-01$ & $-3.99 \mathrm{E}-01$ & $-4.62 \mathrm{E}-01$ & $-4.81 \mathrm{E}-01$ & $-4.87 \mathrm{E}-01$ & $-4.89 E-01$ \\
\hline 8.00 & $2.37 E+00$ & 8.66E-01 & $-1.73 E-02$ & $-4.82 \mathrm{E}-01$ & $-6.54 \mathrm{E}-01$ & $-7.13 \mathrm{E}-01$ & $-7.31 \mathrm{E}-01$ & $-7.37 \mathrm{E}-01$ \\
\hline 8.25 & 500 & $1.63 E+00$ & 3.74E-01 & $-3.69 \mathrm{E}-01$ & $-7.49 \mathrm{E}-01$ & $-9.07 \mathrm{E}-01$ & $-9.63 E-01$ & $-9.81 E-01$ \\
\hline 8.50 & 500 & $3.01 \mathrm{E}+00$ & $1.00 \mathrm{E}+00$ & $-5.70 \mathrm{E}-02$ & $-6.83 \mathrm{E}-01$ & $-1.01 E+00$ & $-1.16 E+00$ & $-1.21 \mathrm{E}+00$ \\
\hline 8. & 500 & 500 & $2.03 E+00$ & 4.62E-01 & $-4.32 \mathrm{E}-01$ & $-9.64 E-01$ & $-1.27 E+00$ & $-1.41 E+00$ \\
\hline 9.0 & 500 & 500 & 500 & $1.32 \mathrm{E}+00$ & $-7.19 \mathrm{E}-03$ & $-7.63 \mathrm{E}-01$ & $-1.23 \mathrm{E}+00$ & $-1.52 \mathrm{E}+00$ \\
\hline 9.25 & 500 & 500 & 500 & $2.78 \mathrm{E}+00$ & 7.17E-01 & $-4.12 \mathrm{E}-01$ & $-1.06 E+00$ & $-1.50 E+00$ \\
\hline 9.50 & 500 & 500 & 500 & 500 & $1.90 \mathrm{E}+00$ & 1.90E-01 & $-7.63 E-01$ & $-1.34 \mathrm{E}+00$ \\
\hline 9.75 & 500 & 500 & 500 & 500 & 500 & $1.25 \mathrm{E}+00$ & $-2.67 \mathrm{E}-01$ & $-1.08 \mathrm{E}+00$ \\
\hline 10.00 & 500 & 500 & 500 & 500 & 500 & $3.22 \mathrm{E}+00$ & $6.78 \mathrm{E}-01$ & $-6.62 \mathrm{E}-01$ \\
\hline 10.25 & 500 & 500 & 500 & 500 & 500 & 500 & $2.23 E+00$ & 1.64E-01 \\
\hline 10.50 & 500 & 500 & 500 & 500 & 500 & 500 & 500 & $1.63 E+00$ \\
\hline
\end{tabular}

Source: Np2O5 solubility for Pa.xls (Appendix I).

NOTE: Some cells have no valid data because the EQ3NR calculations do not converge and those results are reported as 500 . Runs with ionic strengths $>1.0$ are outside the range of validation and are reported as 500 .

\subsubsection{Uncertainty}

It is difficult to assign formal uncertainty to the protactinium solubility because the values are based on chemical analogy, rather than on thermodynamic data, and are supported by only one 
experimental study made in waters unlike those used for modeling the solubilities of other elements.

The uncertainty range for protactinium solubility is taken as the difference between the solubilities of neptunium and thorium. The uncertainty distribution is taken as a uniform distribution in $\log [\mathrm{Pa}] \mathrm{mg} / \mathrm{L}$ ranging from neptunium and thorium solubilities. As Figure 6.11-2 illustrates, these differences range from +3.04 to -1.02 in $\log \mathrm{mg} / \mathrm{L}$.

The uncertainty in protactinium solubilities due to fluoride contents is also unknown. It is taken as the larger of the corresponding uncertainty of the $\mathrm{Np}_{2} \mathrm{O}_{5}$ or $\mathrm{ThO}_{2}(\mathrm{am})$ solubilities.

The protactinium solubility model is summarized by the following equation:

$$
\log [\mathrm{Pa}]=S\left(p H, \log f \mathrm{CO}_{2}\right)+\varepsilon_{1}+\varepsilon_{2}
$$

The values for the parameters in this equation depend on the waste package type. Parameter $S\left(p H, \log f_{\mathrm{CO}_{2}}\right)$ is the base-case solubility and is taken from Table 6.11-3. Parameter $\varepsilon_{1}$ is associated with the uncertainties in the $\log \mathrm{K}$ data. Parameter $\varepsilon_{2}$ is associated with the uncertainties in the fluoride concentrations. Table $6.11-4$ gives the values for the parameters $\varepsilon_{1}$ and $\varepsilon_{2}$.

The distribution properties of these uncertainty terms are listed in Table 6.11-4.

Table 6.11-4. Uncertainty Terms of $\log [\mathrm{Pa}]$

\begin{tabular}{|c|l|l|l|l|}
\hline $\begin{array}{c}\text { Uncertainty } \\
\text { Term }\end{array}$ & \multicolumn{1}{|c|}{ Associated With } & Distribution Type & \multicolumn{1}{|c|}{$\begin{array}{c}\text { Distribution } \\
\text { Parameter }\end{array}$} & \multicolumn{1}{c|}{ Applicability } \\
\hline$\varepsilon_{1}$ & Analogs & Uniform & $\begin{array}{l}\text { Over an interval } \\
{[-1.02,3.04]^{a}}\end{array}$ & Values in Table 6.11-3 \\
\hline$\varepsilon_{2}{ }^{C S N F}$ & $\begin{array}{l}\text { Fluoride concentration in } \\
\text { CSNF waste packages }\end{array}$ & Triangular & $\begin{array}{l}\mathrm{a}=\mathrm{b}=0, \\
\mathrm{c}=3.10\end{array}$ & CSNF waste packages \\
\hline$\varepsilon_{2}{ }^{\mathrm{CDSP}}$ & $\begin{array}{l}\text { Fluoride concentration in } \\
\text { codisposal waste packages }\end{array}$ & Triangular & $\begin{array}{l}\mathrm{a}=\mathrm{b}=0, \\
\mathrm{c}=5.79^{\mathrm{a}}\end{array}$ & $\begin{array}{l}\text { Codisposal waste } \\
\text { packages and the invert }\end{array}$ \\
\hline
\end{tabular}

Source: $\varepsilon_{1}$ term from spreadsheet Pa-Np-Th solubility.x/s (see Note), $\varepsilon_{2}{ }^{\text {CSNF }}$ term from Table $6.8-4, \varepsilon_{2}{ }^{\text {CDSP }}$ term from Table 6.8.4 (see Note).

NOTE: a TSPA-LA currently implements the $\varepsilon_{1}$ and $\varepsilon_{2}{ }^{C D S P} F$ uncertainty terms as indicated in output DTN: MO0408SPADCLRE.000. However, the $\varepsilon_{1}$ range is incorrectly pulled from spreadsheet $\mathrm{Pa}-\mathrm{Np}-\mathrm{Th}$ solubility.x/s in Appendix I (actual range from spreadsheet $=-1.09$ to 3.20) (see additional information following this table). Additionally, the maximum fluoride uncertainty for codisposal waste packages $\left(\varepsilon_{2}{ }^{\operatorname{CDSP}}\right)$, which stems from Th uncertainty, should be 5.72 (From Table 6.8-4). This term as implemented in TSPALA is slightly conservative.

The $\varepsilon_{1}$ uncertainty term presented as a uniform distribution in Table $6.11-4$ is implemented in TSPA-LA calculations. This uncertainty term is based on the solubility of a non-Eh-adjusted $\mathrm{NpO}_{2}$ model. To be more consistent with the rest of the solubility model for protactinium, the values for $\mathrm{Np}_{2} \mathrm{O}_{5}$ should be used in the calculation of the $\varepsilon_{1}$ term. Additionally, even though the maximum difference between the neptunium and thorium solubilities is 3.04 (Figure 6.11-2) and the minimum is -1.02 , these are to be applied to the solubilities presented in Table $6.11-3$ based 
on $\mathrm{Np}$ solubility (Section 6.11.2). Therefore, the sign should be switched to create an interval of 1.02 to -3.04 . The true range for $\varepsilon_{1}$ based on an Eh-adjusted $\mathrm{Np}_{2} \mathrm{O}_{5}$-solubility model (Table 6.11-7) is a uniform distribution from -0.05 to -4.42 . The distribution presented in Table 6.11-4 (implemented values) is conservative for solubility calculations since the values in Table 6.11-7 (correct values) would make protactinium less soluble.

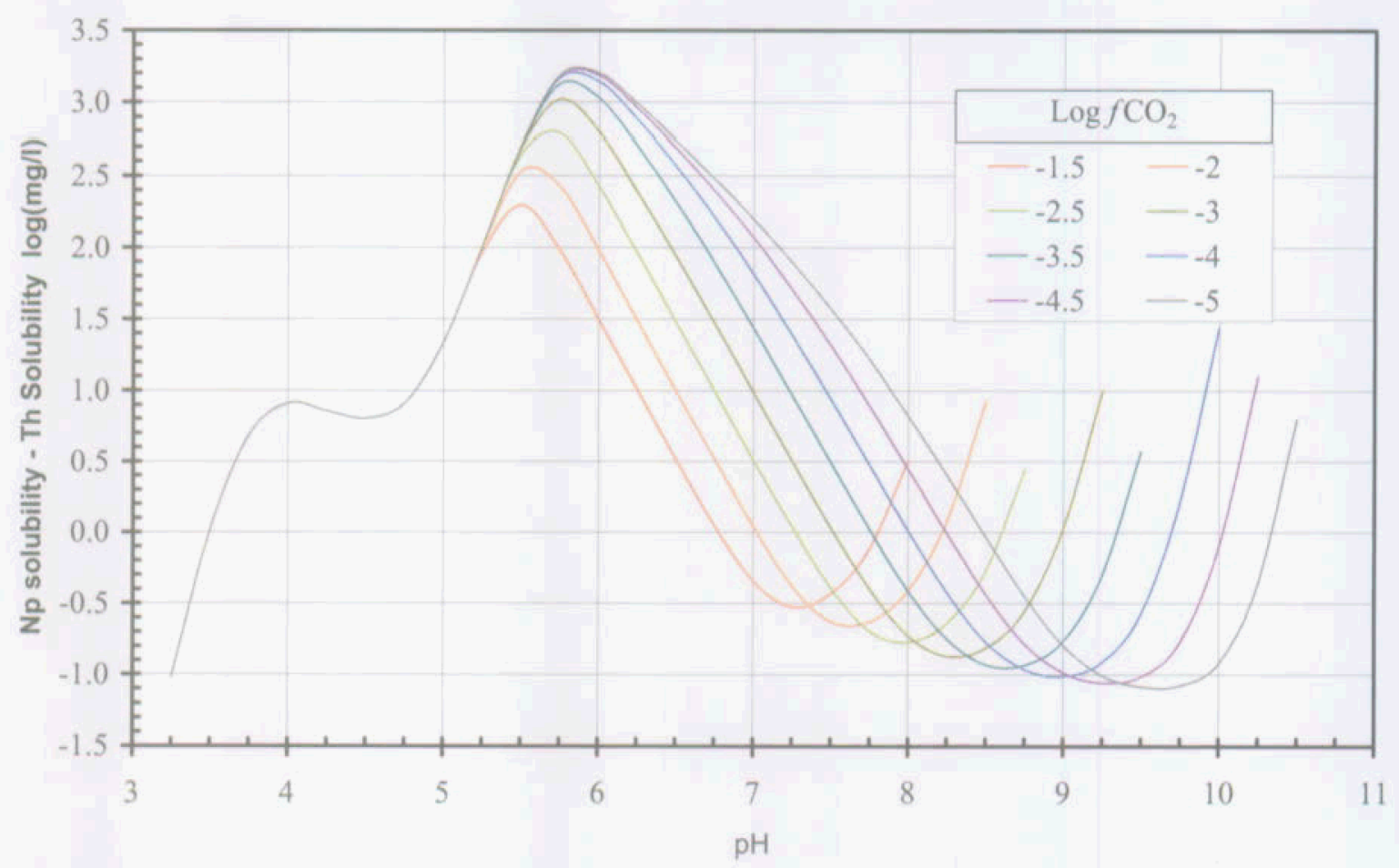

Source: Pa-Np-Th Solubility.xls (Appendix I).

Figure 6.11-2. Differences Between $\mathrm{Np}_{2} \mathrm{O}_{5}$ and $\mathrm{ThO}_{2}(\mathrm{am})$ Solubilities (log $\mathrm{mg} / \mathrm{L}$ ) as Functions of $\mathrm{pH}$ and $\mathrm{fCO}_{2}$

\subsubsection{Alternative Protactinium Solubility Model}

The base-case protactinium model is based on the $\mathrm{Np}_{2} \mathrm{O}_{5}$ model run at atmospheric oxygen. However, Section 6.6.3 presents a new neptunium model based on the lower redox potentials seen at Yucca Mountain (Section 6.5.4.2 for discussions on redox in natural waters). The alternative $\mathrm{Pa}$ model is based on the $\mathrm{Np}_{2} \mathrm{O}_{5}$ model implementing the adjusted Eh. Tables 6.11-5 and 6.11-6 give the protactinium concentrations in $\mathrm{mg} / \mathrm{L}$ and $\log [\mathrm{Pa}] \mathrm{mg} / \mathrm{L}$ respectively. These tables are equivalent to the corresponding tables for $\mathrm{Np}_{2} \mathrm{O}_{5}$.

Because the independent variables of calculated Pa solubility are in log scales and the user of the table may need to interpolate between calculated values, the logarithm of Pa solubility is given in Table 6.11-6. The second table includes the value " 500 " for those ranges of conditions for which no concentrations were given in Table 6.11-5. This value is intended as a flag to indicate that release rates rather than concentration limits for protactinium should be selected for these conditions in the TSPA-LA modeling. For any conditions that fall between a valid solubility and a flag of 500 , the flag should be used. In addition, for any conditions outside of the 3.0 to 11.0 
$\mathrm{pH}$ range, the -1.5 to -5.0 bar $\log f \mathrm{CO}_{2}$ range, or with an ionic strength greater than 1.0 molal, the concentrations calculated according to the dissolution rate of individual waste forms, water volume, and the solubility caps presented in Table 8-5.

Table 6.11-5. Alternative Protactinium Solubility (mg/L)

\begin{tabular}{|c|c|c|c|c|c|c|c|c|}
\hline \multirow[b]{2}{*}{ pH } & \multicolumn{8}{|c|}{$\log f_{\mathrm{CO} 2}$ (bars) } \\
\hline & -1.50 & -2.00 & -2.50 & -3.00 & -3.50 & -4.00 & -4.50 & -5.00 \\
\hline 3.25 & $1.25 E+04$ & $1.25 \mathrm{E}+04$ & $1.25 \mathrm{E}+04$ & $1.25 E+04$ & $1.25 E+04$ & $1.25 \mathrm{E}+04$ & $1.25 \mathrm{E}+04$ & $1.25 \mathrm{E}+04$ \\
\hline 3.50 & $6.65 E+03$ & $6.65 \mathrm{E}+03$ & $6.65 E+03$ & $6.65 E+03$ & $6.65 E+03$ & $6.65 \mathrm{E}+03$ & $6.65 E+03$ & $6.65 E+03$ \\
\hline 3.75 & $3.57 E+03$ & $3.57 E+03$ & $3.57 E+03$ & $3.57 E+03$ & $3.57 E+03$ & $3.57 \mathrm{E}+03$ & $3.57 E+03$ & $3.57 E+03$ \\
\hline 4.00 & $1.94 \mathrm{E}+03$ & $1.94 \mathrm{E}+03$ & $1.94 E+03$ & $1.94 \mathrm{E}+03$ & $1.94 \mathrm{E}+03$ & $1.94 \mathrm{E}+03$ & $1.94 E+03$ & $1.94 \mathrm{E}+03$ \\
\hline 4.25 & $1.07 E+03$ & $1.07 E+03$ & $1.07 \mathrm{E}+03$ & $1.07 E+03$ & $1.07 \mathrm{E}+03$ & $1.07 E+03$ & $1.07 E+03$ & $1.07 \mathrm{E}+03$ \\
\hline 4.50 & $5.90 \mathrm{E}+02$ & $5.90 \mathrm{E}+02$ & $5.90 \mathrm{E}+02$ & $5.90 \mathrm{E}+02$ & $5.90 E+02$ & $5.90 \mathrm{E}+02$ & $5.90 \mathrm{E}+02$ & $5.90 \mathrm{E}+02$ \\
\hline 4.75 & $3.28 \mathrm{E}+02$ & $3.29 E+02$ & $3.29 \mathrm{E}+02$ & $3.29 \mathrm{E}+02$ & $3.29 E+02$ & $3.29 \mathrm{E}+02$ & $3.29 \mathrm{E}+02$ & $3.29 E+02$ \\
\hline 5.00 & $1.84 \mathrm{E}+02$ & $1.84 \mathrm{E}+02$ & $1.84 \mathrm{E}+02$ & $1.84 \mathrm{E}+02$ & $1.84 E+02$ & $1.84 \mathrm{E}+02$ & $1.84 \mathrm{E}+02$ & $1.84 \mathrm{E}+02$ \\
\hline 5.25 & $1.03 E+02$ & $1.03 E+02$ & $1.03 E+02$ & $1.03 E+02$ & $1.03 E+02$ & $1.03 \mathrm{E}+02$ & $1.03 E+02$ & $1.03 \mathrm{E}+02$ \\
\hline 5.50 & $5.77 \mathrm{E}+01$ & $5.77 E+01$ & $5.77 E+01$ & $5.77 \mathrm{E}+01$ & $5.77 \mathrm{E}+01$ & $5.77 \mathrm{E}+01$ & $5.77 E+01$ & $5.77 \mathrm{E}+01$ \\
\hline 5.75 & $3.24 \mathrm{E}+01$ & $3.24 \mathrm{E}+01$ & $3.24 E+01$ & $3.24 \mathrm{E}+01$ & $3.24 \mathrm{E}+01$ & $3.24 E+01$ & $3.24 E+01$ & $3.24 \mathrm{E}+01$ \\
\hline 6.00 & $1.82 \mathrm{E}+01$ & $1.82 E+01$ & $1.82 \mathrm{E}+01$ & $1.82 \mathrm{E}+01$ & $1.82 E+01$ & $1.82 \mathrm{E}+01$ & $1.82 E+01$ & $1.82 \mathrm{E}+01$ \\
\hline 6.25 & $1.03 E+01$ & $1.02 E+01$ & $1.02 E+01$ & $1.02 E+01$ & $1.02 \mathrm{E}+01$ & $1.02 E+01$ & $1.02 E+01$ & $1.02 \mathrm{E}+01$ \\
\hline 6.50 & $5.83 E+00$ & $5.78 \mathrm{E}+00$ & $5.77 \mathrm{E}+00$ & $5.76 \mathrm{E}+00$ & $5.76 \mathrm{E}+00$ & $5.76 \mathrm{E}+00$ & $5.76 \mathrm{E}+00$ & $5.76 \mathrm{E}+00$ \\
\hline 6.75 & $3.43 \mathrm{E}+00$ & $3.29 \mathrm{E}+00$ & $3.25 \mathrm{E}+00$ & $3.24 \mathrm{E}+00$ & $3.24 \mathrm{E}+00$ & $3.24 E+00$ & $3.24 E+00$ & $3.24 \mathrm{E}+00$ \\
\hline 7.00 & $2.22 \mathrm{E}+00$ & $1.92 \mathrm{E}+00$ & $1.85 \mathrm{E}+00$ & $1.83 \mathrm{E}+00$ & $1.82 \mathrm{E}+00$ & $1.82 E+00$ & $1.82 E+00$ & $1.82 \mathrm{E}+00$ \\
\hline 7.25 & $1.74 \mathrm{E}+00$ & $1.23 E+00$ & $1.08 \mathrm{E}+00$ & $1.04 \mathrm{E}+00$ & $1.03 E+00$ & $1.03 E+00$ & $1.02 E+00$ & $1.02 E+00$ \\
\hline 7.50 & $1.89 \mathrm{E}+00$ & 9.56E-01 & 6.87E-01 & $6.11 \mathrm{E}-01$ & 5.87E-01 & 5.79E-01 & 5.77E-01 & 5.76E-01 \\
\hline 7.75 & $2.86 \mathrm{E}+00$ & $1.02 E+00$ & $5.29 \mathrm{E}-01$ & $3.87 \mathrm{E}-01$ & $3.44 \mathrm{E}-01$ & $3.30 \mathrm{E}-01$ & $3.26 \mathrm{E}-01$ & $3.24 \mathrm{E}-01$ \\
\hline 8.00 & - & $1.48 \mathrm{E}+00$ & 5.59E-01 & 2.96E-01 & $2.18 \mathrm{E}-01$ & 1.94E-01 & $1.86 \mathrm{E}-01$ & 1.83E-01 \\
\hline 8.25 & - & $2.81 E+00$ & 7.96E-01 & $3.08 \mathrm{E}-01$ & 1.67E-01 & 1.23E-01 & $1.09 \mathrm{E}-01$ & $1.04 \mathrm{E}-01$ \\
\hline 8.50 & - & $1.01 \mathrm{E}+01$ & $1.40 \mathrm{E}+00$ & $4.35 \mathrm{E}-01$ & $1.72 \mathrm{E}-01$ & $9.39 \mathrm{E}-02$ & $6.91 \mathrm{E}-02$ & $6.13 \mathrm{E}-02$ \\
\hline 8.75 & - & - & $3.45 \mathrm{E}+00$ & 7.41E-01 & $2.40 \mathrm{E}-01$ & $9.70 \mathrm{E}-02$ & $5.29 \mathrm{E}-02$ & $3.89 \mathrm{E}-02$ \\
\hline 9.00 & - & - & - & $1.54 \mathrm{E}+00$ & 4.02E-01 & $1.33 \mathrm{E}-01$ & $5.46 \mathrm{E}-02$ & $2.98 \mathrm{E}-02$ \\
\hline 9.25 & - & - & - & $6.59 \mathrm{E}+00$ & $7.80 \mathrm{E}-01$ & 2.22E-01 & 7.51E-02 & $3.08 \mathrm{E}-02$ \\
\hline 9.50 & - & - & - & - & $2.36 \mathrm{E}+00$ & $4.16 \mathrm{E}-01$ & 1.23E-01 & 4.23E-02 \\
\hline 9.75 & - & - & - & - & - & $1.05 \mathrm{E}+00$ & 2.27E-01 & 6.88E-02 \\
\hline 10.00 & - & - & - & - & - & $9.04 E+00$ & 5.27E-01 & 1.26E-01 \\
\hline 10.25 & - & - & - & - & - & - & $3.34 \mathrm{E}+00$ & $2.80 \mathrm{E}-01$ \\
\hline 10.50 & - & - & - & - & - & - & - & $1.48 \mathrm{E}+00$ \\
\hline
\end{tabular}

Source: Np base case-Ehadjusted.x/s (Appendix I).

NOTE: Some cells have no data because the EQ3NR calculations do not converge.

Runs with ionic strengths $>1.0$ are outside the range of validation, and are not reported. 
Dissolved Concentration Limits of Radioactive Elements

Table 6.11-6. Alternative Protactinium Solubility (log[Pa], mg/L)

\begin{tabular}{|c|c|c|c|c|c|c|c|c|}
\hline \multirow{2}{*}{ pH } & \multicolumn{8}{|c|}{$\log \mathrm{fCO}_{2}$ (bars) } \\
\hline & -1.50 & -2.00 & -2.50 & -3.00 & -3.50 & -4.00 & -4.50 & -5.00 \\
\hline 3.25 & 4.10 & 4.10 & 4.10 & 4.10 & 4.10 & 4.10 & 4.10 & 4.10 \\
\hline 3.50 & 3.82 & 3.82 & 3.82 & 3.82 & 3.82 & 3.82 & 3.82 & 3.82 \\
\hline 3.75 & 3.55 & 3.55 & 3.55 & 3.55 & 3.55 & 3.55 & 3.55 & 3.55 \\
\hline 4.00 & 3.29 & 3.29 & 3.29 & 3.29 & 3.29 & 3.29 & 3.29 & 3.29 \\
\hline 4.25 & 3.03 & 3.03 & 3.03 & 3.03 & 3.03 & 3.03 & 3.03 & 3.03 \\
\hline 4.50 & 2.77 & 2.77 & 2.77 & 2.77 & 2.77 & 2.77 & 2.77 & 2.77 \\
\hline 4.75 & 2.52 & 2.52 & 2.52 & 2.52 & 2.52 & 2.52 & 2.52 & 2.52 \\
\hline 5.00 & 2.26 & 2.26 & 2.26 & 2.26 & 2.26 & 2.26 & 2.26 & 2.26 \\
\hline 5.25 & 2.01 & 2.01 & 2.01 & 2.01 & 2.01 & 2.01 & 2.01 & 2.01 \\
\hline 5.50 & 1.76 & 1.76 & 1.76 & 1.76 & 1.76 & 1.76 & 1.76 & 1.76 \\
\hline 5.75 & 1.51 & 1.51 & 1.51 & 1.51 & 1.51 & 1.51 & 1.51 & 1.51 \\
\hline 6.00 & 1.26 & 1.26 & 1.26 & 1.26 & 1.26 & 1.26 & 1.26 & 1.26 \\
\hline 6.25 & 1.01 & 1.01 & 1.01 & 1.01 & 1.01 & 1.01 & 1.01 & 1.01 \\
\hline 6.50 & 0.77 & 0.76 & 0.76 & 0.76 & 0.76 & 0.76 & 0.76 & 0.76 \\
\hline 6.75 & 0.54 & 0.52 & 0.51 & 0.51 & 0.51 & 0.51 & 0.51 & 0.51 \\
\hline 7.00 & 0.35 & 0.28 & 0.27 & 0.26 & 0.26 & 0.26 & 0.26 & 0.26 \\
\hline 7.25 & 0.24 & 0.09 & 0.04 & 0.02 & 0.01 & 0.01 & 0.01 & 0.01 \\
\hline 7.50 & 0.28 & -0.02 & -0.16 & -0.21 & -0.23 & -0.24 & -0.24 & -0.24 \\
\hline 7.75 & 0.46 & 0.01 & -0.28 & -0.41 & -0.46 & -0.48 & -0.49 & -0.49 \\
\hline 8.00 & 500 & 0.17 & -0.25 & -0.53 & -0.66 & -0.71 & -0.73 & -0.74 \\
\hline 8.25 & 500 & 0.45 & -0.10 & -0.51 & -0.78 & -0.91 & -0.96 & -0.98 \\
\hline 8.50 & 500 & 1.00 & 0.15 & -0.36 & -0.76 & -1.03 & -1.16 & -1.21 \\
\hline 8.75 & 500 & 500 & 0.54 & -0.13 & -0.62 & -1.01 & -1.28 & -1.41 \\
\hline 9.00 & 500 & 500 & 500 & 0.19 & -0.40 & -0.87 & -1.26 & -1.53 \\
\hline 9.25 & 500 & 500 & 500 & 0.82 & -0.11 & -0.65 & -1.12 & -1.51 \\
\hline 9.50 & 500 & 500 & 500 & 500 & 0.37 & -0.38 & -0.91 & -1.37 \\
\hline 9.75 & 500 & 500 & 500 & 500 & 500 & 0.02 & -0.64 & -1.16 \\
\hline 10.00 & 500 & 500 & 500 & 500 & 500 & 0.96 & -0.28 & -0.90 \\
\hline 10.25 & 500 & 500 & 500 & 500 & 500 & 500 & 0.52 & -0.55 \\
\hline 10.50 & 500 & 500 & 500 & 500 & 500 & 500 & 500 & 0.17 \\
\hline
\end{tabular}

Source: Np base case-Ehadjusted.xls (Appendix I).

NOTE: Some cells have no valid data because the EQ3NR calculations do not converge, and those results are reported as 500 . Runs with ionic strengths $>1.0$ are outside the range of validation and are reported as 500. Equivalent to $\mathrm{Np}_{2} \mathrm{O}_{5}$ solubility table.

\subsubsection{Uncertainty}

It is difficult to assign formal uncertainty to the protactinium solubility because the values are based on chemical analogy rather than on thermodynamic data and are supported by only one experimental study made in waters unlike those used for modeling the solubilities of other elements. 
Because protactinium data are so sparse that even the choice of the best analogous element is uncertain, the uncertainty in the protactinium solubility is taken as the difference between the solubilities of the two best analogous elements. That is, the uncertainty is taken as a uniform distribution in $\log [\mathrm{Pa}]$ (in $\mathrm{mg} / \mathrm{L}$ ) ranging from neptunium and thorium solubilities. As Figure 6.11-3 illustrates, these differences range from -0.05 to $-4.42 \mathrm{in} \log \mathrm{mg} / \mathrm{L}$.

The uncertainty in protactinium solubilities due to fluoride contents is also unknown. It is taken as the larger of the corresponding uncertainty of the $\mathrm{Np}_{2} \mathrm{O}_{5}$ or $\mathrm{ThO}_{2}(\mathrm{am})$ solubilities.

The protactinium solubility model is summarized by the following equation:

$$
\log [\mathrm{Pa}]=S\left(p H, \log f \mathrm{CO}_{2}\right)+\varepsilon_{1}+\varepsilon_{2}
$$

The values for the parameters in this equation depend on the waste package type. Parameter $S\left(p H, \log f_{\mathrm{CO}_{2}}\right)$ is the base solubility and is taken from Table 6.11-6. Parameter $\varepsilon_{1}$ is associated with the uncertainties in the $\log \mathrm{K}$ data. Parameter $\varepsilon_{2}$ is associated with the uncertainties in the fluoride concentrations. Table 6.11-7 gives the values for the parameters $\varepsilon_{1}$ and $\varepsilon_{2}$.

The distribution properties of these uncertainty terms are listed in Table 6.11-7.

Table 6.11-7. Alternative Uncertainty Terms of $\log [\mathrm{Pa}]$

\begin{tabular}{|c|c|c|c|c|}
\hline $\begin{array}{c}\text { Uncertainty } \\
\text { Term }\end{array}$ & Associated With & Distribution Type & $\begin{array}{l}\text { Distribution } \\
\text { Parameter }\end{array}$ & Applicability \\
\hline$\varepsilon_{1}$ & Analogs & Uniform & $\begin{array}{l}\text { Over an interval } \\
{[-0.05 \text { to }-4.42]}\end{array}$ & Values in Table 6.11-6 \\
\hline$\varepsilon_{2} \operatorname{CSNF}$ & $\begin{array}{l}\text { Fluoride concentration in } \\
\text { CSNF waste packages }\end{array}$ & Triangular & $\begin{array}{l}a=b=0 \\
c=3.10\end{array}$ & CSNF waste packages \\
\hline$\varepsilon_{2}{ }^{\text {CDSP-water influx }}$ & $\begin{array}{l}\text { Fluoride concentration in } \\
\text { codisposal waste packages } \\
\text { (water influx scenario) }\end{array}$ & Triangular & $\begin{array}{l}a=b=0 \\
c=4.21\end{array}$ & $\begin{array}{l}\text { Codisposal waste } \\
\text { packages and the invert }\end{array}$ \\
\hline$\varepsilon_{2}{ }^{\text {CDSP-vapor influx }}$ & $\begin{array}{l}\text { Fluoride concentration In } \\
\text { CDNR waste package } \\
\text { (vapor influx scenario) }\end{array}$ & Triangular & $\begin{array}{l}a=b=0 \\
c=5.27\end{array}$ & $\begin{array}{l}\text { Codisposal waste } \\
\text { packages and the invert }\end{array}$ \\
\hline
\end{tabular}

Source: $\varepsilon_{1}$ value from Spreadsheet $\mathrm{Pa}-\mathrm{Np}$-Th solubility-new.x/s, $\varepsilon_{2}{ }^{\mathrm{CSNF}}, \varepsilon_{2}{ }^{\text {CDSP-water influx }}, \varepsilon_{2}{ }^{\text {CDSP-vapor influx }}$ values from Table 6.8-6. 


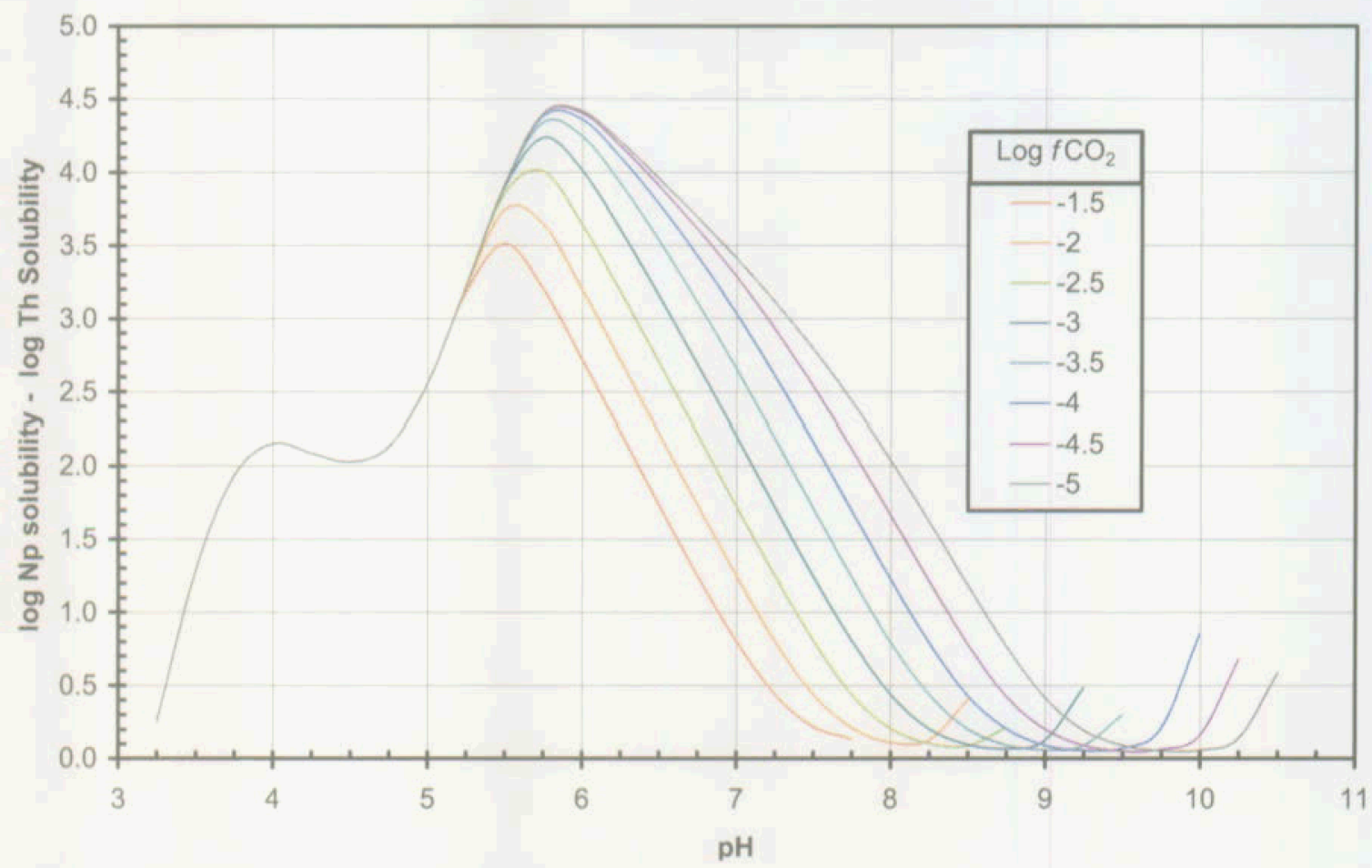

Source: Pa-Np-Th Solubility-new.xls (Appendix I).

Figure 6.11-3. Differences Between $\mathrm{Np}_{2} \mathrm{O}_{5}$ and $\mathrm{ThO}_{2}(\mathrm{am})$ Solubilities (log $\left.\mathrm{mg} / \mathrm{L}\right)$ as Functions of $\mathrm{pH}$ and $\mathrm{fCO}_{2}$

\subsection{RADIUM SOLUBILITY}

Radium solubility has been studied briefly in Pure Phase Solubility Limits - LANL (CRWMS M\&O 2001 [DIRS 154629], Section 6.3.7). EQ3NR runs (EQ3NR output files in $R a$ Eq3 files.zip of Appendix I) at $\log f \mathrm{CO}_{2}=-3.0$ bars indicate that the solubility-controlling phase, if solid solutions with $\mathrm{BaSO}_{4}$ or $\mathrm{SrSO}_{4}$ are not taken into account, is $\mathrm{RaSO}_{4}$. Accordingly, the solubility depends primarily on the concentration of free $\mathrm{SO}_{4}{ }^{2-}$ in the solution (free means not combined with other elements in complexes or ion pairs). The free $\mathrm{SO}_{4}{ }^{2-}$ is expected to vary over a wide range for two reasons. First, acid conditions may arise from the oxidation of sulfur to $\mathrm{SO}_{4}{ }^{2-}$ during the corrosion of steel (Section 6.4.3.5). Such an increase in $\mathrm{SO}_{4}{ }^{2-}$ represses the solubility of $\mathrm{Ra}^{2+}$. Second, under alkaline conditions ion pairs, such as $\mathrm{NaSO}_{4}{ }^{-}$or $\mathrm{CaSO}_{4}(\mathrm{aq})$ should form, thereby limiting the reducing free $\mathrm{SO}_{4}{ }^{2-}$ and enhancing solubility.

For slightly alkaline (J-13 well water) and acidified Yucca Mountain waters, the calculated radium solubility ranges from $9.1 \mathrm{E}-03$ to $1.9 \mathrm{E}-02 \mathrm{mg} / \mathrm{L}$. A constant solubility of $2.0 \mathrm{E}-02 \mathrm{mg} / \mathrm{L}$ is recommended for radium for $\mathrm{pH} 7.75$ or less. Under more alkaline conditions, $\mathrm{pH}$ values from 8.0 to 9.75 , the calculated solubility ranges from $7.1 \mathrm{E}-02$ to $1.2 \mathrm{mg} / \mathrm{L}$. For this $\mathrm{pH}$ range a constant value of $1.2 \mathrm{mg} / \mathrm{L}$ is recommended. These values are recommended for both CSNF and codisposal waste packages.

At $\mathrm{pH}$ at or above 10 , the rate of release of radium from the waste must be used. A higher $\mathrm{pH}$ cannot be achieved at equilibrium with the specified values of $f \mathrm{CO}_{2}$ because any attempt to do so (e.g., adding $\mathrm{NaOH}$ to the solution) simply results in the precipitation of sodium bicarbonate or 
carbonate. Similarly, the addition of any other cation, such as $\mathrm{Ca}^{2+}$, would result in the supersaturation and precipitation of the corresponding carbonate, or an oxide or hydroxide. The EQ3NR runs show that the solution becomes supersaturated in a sodium-calcium carbonate (gaylussite) and several calcium or magnesium carbonates, or both, at $\mathrm{pH} 7.75$.

Field studies have shown that radium concentrations in some natural waters are orders of magnitude below levels corresponding to $\mathrm{RaSO}_{4}$ saturation. Radium concentrations more probably correspond to the solubilities of radium in solid solution in more common sulfate solids, such as $\mathrm{SrSO}_{4}$ or $\mathrm{BaSO}_{4}$ (Langmuir and Riese 1985 [DIRS 106457]). A radium concentration based on pure $\mathrm{RaSO}_{4}$ solubility is, therefore, a conservative value. The recommended radium solubility limits are summarized in Table 6.12-1.

Table 6.12-1. Radium Solubility Values

\begin{tabular}{|c|c|}
\hline pH Range & Radium Solubility (mg/L) \\
\hline 3.0 to 7.75 & $2.0 \mathrm{E}-2$ \\
\hline 7.75 to 9.75 & 1.2 \\
\hline$>9.75$ & 500 (not controlled by solubility) \\
\hline
\end{tabular}

\subsection{LEAD SOLUBILITY}

Lead is one of the least mobile of the heavy metals as it forms a number of sparingly soluble mineral phases and sorbs strongly to many mineral surfaces. The formation of $\mathrm{Pb}_{3}\left(\mathrm{CO}_{3}\right)_{2}(\mathrm{OH})_{2}$ can limit dissolved lead levels to $50 \mathrm{ppb}$ or less under neutral to alkaline conditions (Hem 1985 [DIRS 115670], p. 144). Lead sulfate forms under sulfate-rich, acidic conditions,. Lowsolubility lead-phosphate formation limits dissolved lead levels in some soils. Lead ion $\left(\mathrm{Pb}^{2+}\right)$ forms complexes with carbonate, hydroxyls, and sulfate. It also interacts strongly with a number of organic acids.

Surface waters containing $1 \mathrm{ppb}$ lead are reasonably common. Waters with lead loads greater than $10 \mathrm{ppb}$ are less common and tend to possess lead in particulate, mineral-associated form, as opposed to dissolved lead (Hem 1985 [DIRS 115670], p. 144).

Because in-package fluids are expected to be either low-pH sulfate-rich waters or neutral-toalkaline carbonate-rich waters, or some combination of the two, there is a strong likelihood that dissolved lead levels are limited by either lead sulfate or lead hydroxycarbonate formation. Uptake by corrosion products is also substantial. Because the lead sinks in the waste package environment are similar to a number of those that control lead in the environment, it is reasonable to expect dissolved lead levels to roughly reflect natural distributions (i.e., levels between 1 and $100 \mathrm{ppb}$ ). This corresponds to a range of $4.8 \mathrm{E}-9$ to $4.8 \mathrm{E}-7 \mathrm{M}$. Therefore, it is recommended that TSPA-LA use a log-uniform distribution, with a minimum of $4.8 \mathrm{E}-9 \mathrm{~mol} / \mathrm{L}$ and a maximum of $4.8 \mathrm{E}-7 \mathrm{~mol} / \mathrm{L}$ to constrain lead solubility.

\subsection{TECHNETIUM SOLUBILITY}

Under the repository conditions, no solubility-controlling solid exists for technetium. Therefore, technetium solubility is undefined and flagged by the default value of 500 . In TSPA-LA 
modeling, the release of technetium is controlled by the dissolution rate of waste forms rather than by solubility.

\subsection{CARBON SOLUBILITY}

Although under neutral or high-pH conditions, calcite may control the solubility of carbon; under $\mathrm{pH}$ as low as 3.6, calcite is not stable (Langmuir 1997 [DIRS 100051], Figure 6.6, p. 202). Therefore, carbon solubility is undefined and it is flagged by the default value of 500 . In TSPA-LA modeling, the release of carbon is controlled by the dissolution rate of waste forms rather than by solubility.

\subsection{IODINE SOLUBILITY}

Under the repository conditions, no solubility-controlling solid exists for iodine. Therefore, iodine solubility is undefined and it is flagged by the default value of 500 . In TSPA-LA modeling, the release of iodine is controlled by the dissolution rate of waste forms rather than by solubility.

\subsection{CESIUM SOLUBILITY}

Under the repository conditions, no solubility-controlling solid exists for cesium. Therefore, cesium solubility is undefined and it is flagged by the default value of 500 . In TSPA-LA modeling, the release of cesium is controlled by the dissolution rate of waste forms rather than by solubility.

\subsection{STRONTIUM SOLUBILITY}

Strontium is quite soluble. The most likely solids to precipitate under the repository conditions are carbonate (strontianite, $\mathrm{SrCO}_{3}$ ) or sulfate (celestite, $\mathrm{SrSO}_{4}$ ). It is conservatively assumed that no solubility-controlling solid exists for strontium. Therefore, strontium solubility is undefined and flagged by the default value of 500. In TSPA-LA modeling, the release of strontium is controlled by the dissolution rate of waste forms rather than by solubility. Strontium solubility can be developed using strontianite or celestite as its solubility-controlling solid.

\subsection{CONSIDERATION OF ALTERNATIVE CONCEPTUAL MODELS}

Alternative conceptual models are considered in developing the solubility models reported for many of the elements included in this report. These alternative models were described explicitly or implicitly in the discussions of each element. Some elements are assigned arbitrarily high solubilities so that the control on their concentrations is release rates from the waste form rather than solubility control. No alternative conceptual models are considered for these elements.

The alternative conceptual models considered are summarized in Table 6.19-1. 
Table 6.19-1. Summary of Alternative Conceptual Models

\begin{tabular}{|c|c|c|c|}
\hline Element & $\begin{array}{c}\text { Alternative Conceptual } \\
\text { Model }\end{array}$ & Model Bases & Screening Assessment and Basis \\
\hline \multirow[t]{2}{*}{$\mathrm{Pu}$} & Theoretical $\mathrm{fO}_{2}$ model & $\begin{array}{l}\mathrm{fO}_{2}=0.2 \text { bars } \\
\text { (Section } 5.1 \text { ). }\end{array}$ & $\begin{array}{l}\text { Model results differ significantly from experimental } \\
\text { measurements }\end{array}$ \\
\hline & Empirical Eh model & $E h=1.04-0.0592 \mathrm{pH}$ & Model results are lower than experimental results \\
\hline \multirow[t]{2}{*}{$\mathrm{Np}$} & $\begin{array}{l}\text { Solubility control by } \\
\mathrm{NpO}_{2}\end{array}$ & $\begin{array}{l}\text { Pure-phase solid- } \\
\text { controlling neptunium } \\
\text { concentration is } \mathrm{NpO}_{2} \\
\text { rather than } \mathrm{Np}_{2} \mathrm{O}_{5}\end{array}$ & $\begin{array}{l}\text { Laboratory experiments show neptunium control } \\
\text { by } \mathrm{Np}_{2} \mathrm{O}_{5} \text { formation at } \mathrm{T}<100^{\circ} \mathrm{C} \text { and by } \mathrm{NpO}_{2} \text { at } \\
\text { higher temperatures. More-soluble } \mathrm{Np}_{2} \mathrm{O}_{5} \text { chosen } \\
\text { for conservatism. }\end{array}$ \\
\hline & $\begin{array}{l}\text { Neptunium incorporation } \\
\text { into uranyl secondary } \\
\text { phases }\end{array}$ & $\begin{array}{l}\text { Neptunium concentration } \\
\text { controlled by solid } \\
\text { solution rather than by } \\
\text { pure phases }\end{array}$ & $\begin{array}{l}\text { Experimental studies on whether schoepite, the } \\
\text { critical secondary uranyl phase, can incorporate } \\
\text { sufficient neptunium and immobilize it during } \\
\text { spent fuel corrosion do not provide a solid basis } \\
\text { for recommending this model to be used in the } \\
\text { TSPA-LA model. }\end{array}$ \\
\hline Th & $\begin{array}{l}\text { Solubility control by other } \\
\text { Th phases included in } \\
\text { thermodynamic modeling } \\
\text { database including ThO } \\
\text { (thorianite), } \mathrm{Th}_{0.75} \mathrm{PO}_{4} \\
\mathrm{Th}_{4}\left(\mathrm{SO}_{4}\right)_{2}, \mathrm{ThF}_{4} \\
\mathrm{ThF}_{4} \cdot 2 \mathrm{H}_{2} \mathrm{O}\end{array}$ & $\begin{array}{l}\text { Solubility of } \\
\text { thermodynamically } \\
\text { most-stable phase } \\
\text { controls concentrations }\end{array}$ & $\begin{array}{l}\text { Solubilities calculated with } \mathrm{ThO}_{2}(\mathrm{am}) \text { are most } \\
\text { consistent with measured Th solubility in pure } \\
\text { water. Other phases may be less soluble under } \\
\text { only certain conditions or may be based on } \\
\text { questionable data. More-soluble } \mathrm{ThO}_{2}(\mathrm{am}) \\
\text { chosen for conservatism. }\end{array}$ \\
\hline $\mathrm{Am}$ & $\begin{array}{l}\text { Solubility control by } \\
\text { phase with properties } \\
\text { between } \mathrm{Am}(\mathrm{OH})_{3}(\mathrm{am}) \text { to } \\
\mathrm{Am}(\mathrm{OH})_{3}\end{array}$ & $\begin{array}{l}\text { Initially formed } \\
\text { Am(OH })_{3}(\mathrm{am}) \text { inverts to } \\
\text { more-stable } \mathrm{Am}(\mathrm{OH})_{3} \\
\text { with time. } \mathrm{Am}(\mathrm{OH})_{3} \\
\text { stability decreases with } \\
\text { time from self irradiation. }\end{array}$ & $\begin{array}{l}\text { AmOHCO } \mathrm{CO}_{3} \text { is formed in americium solubility } \\
\text { experiments under Yucca Mountain conditions. } \\
\text { Under some conditions, } \mathrm{Am}(\mathrm{OH})_{3} \text { may be less } \\
\text { soluble, but choosing } \mathrm{AmOHCO}_{3} \text { is, generally, } \\
\text { conservative. }\end{array}$ \\
\hline $\mathrm{AC}$ & N/A (Section 6.10) & N/A (Section 6.10) & $\mathrm{N} / \mathrm{A}($ Section 6.10$)$ \\
\hline $\mathrm{Pa}$ & $\begin{array}{l}\text { Solubility is same as that } \\
\text { of } \mathrm{ThO}_{2}(\mathrm{am})\end{array}$ & $\begin{array}{l}\text { Thorium is also a good } \\
\text { analogue to protactinium } \\
\text { and was modeled in this } \\
\text { report }\end{array}$ & $\begin{array}{l}\text { Solubility of } \mathrm{Np}_{2} \mathrm{O}_{5} \text { was chosen because it is lower } \\
\text { than that of } \mathrm{ThO}_{2} \text { (am) under most conditions } \\
\text { modeled, so its choice is conservative }\end{array}$ \\
\hline $\mathrm{Ra}$ & None & $\mathrm{N} / \mathrm{A}$ & $\begin{array}{l}\text { Chemistry of in-package and invert waters are not } \\
\text { so far outside the normal range of natural waters } \\
\text { to cause different radium solubilities }\end{array}$ \\
\hline $\mathrm{Pb}$ & None & $\mathrm{N} / \mathrm{A}$ & $\begin{array}{l}\text { Chemistry of in-package and invert are not so far } \\
\text { outside the normal range of natural waters to } \\
\text { cause different lead solubilities }\end{array}$ \\
\hline Tc & None & N/A & $\begin{array}{l}\text { No solubility was defined and inventory release } \\
\text { should be in control }\end{array}$ \\
\hline $\mathrm{C}$ & None & $\mathrm{N} / \mathrm{A}$ & $\begin{array}{l}\text { No solubility was defined and inventory release is } \\
\text { in control }\end{array}$ \\
\hline $\mathrm{I}$ & None & $\mathrm{N} / \mathrm{A}$ & $\begin{array}{l}\text { No solubility was defined and inventory release is } \\
\text { in control }\end{array}$ \\
\hline Cs & None & N/A & $\begin{array}{l}\text { No solubility was defined and inventory release is } \\
\text { in control }\end{array}$ \\
\hline $\mathrm{Sr}$ & $\begin{array}{l}\text { Solubility controlled by } \\
\mathrm{SrCO}_{3} \text { or } \mathrm{SrSO}_{4}\end{array}$ & N/A & $\begin{array}{l}\text { No solubility was defined and inventory release is } \\
\text { in control. This is a conservative approach. }\end{array}$ \\
\hline
\end{tabular}




\section{VALIDATION}

The purpose of this report is to develop models to evaluate solubility limits of elements with radioactive isotopes. The models are based on geochemical modeling calculations using geochemical modeling tools, thermodynamic databases, and measurements collected from laboratory experiments and fieldwork.

The scope of this modeling activity is the development of solubility limits as tabulated functions with $\mathrm{pH}$ and $\log f \mathrm{CO}_{2}$ as independent variables, distributions, or constants for elements with radioactive isotopes transported outside breached waste packages identified by Radionuclide Screening (BSC 2002 [DIRS 160059]). Fourteen elements with radioactive isotopes are identified as important to dose for the time period from $10^{2}$ to $2 \times 10^{4}$ years: actinium, americium, carbon, cesium, iodine, lead, neptunium, plutonium, protactinium, radium, strontium, technetium, thorium, and uranium. TSPA-LA uses the results of this report to constrain the release of these elements.

As described in Section 6.3, development of solubility models for use in TSPA-LA has several components including: (1) a thermodynamic database and modeling tool, (2) the environmental conditions of concern, (3) the construction of the conceptual model, and (4) the calculation of solubility limits using a geochemical modeling tool based on the conceptual model. Because the thermodynamic database used in this report and the EQ3/6 code are controlled products and are used within their valid ranges, the first and fourth components need no validation. The second component is represented by inputs to the model and also needs no validation. Therefore, model validation discussed in this report focuses on the third component, the conceptual model (e.g., the solubility-controlling mechanism).

Alternative solubility models described in this document are not recommended for the TSPA-LA base-case analyses. Therefore, they have no impact on the estimate of mean annual dose. According to Appendix B of Scientific Processes Guidelines Manual (BSC 2002 [DIRS 160313], p. B-1), model validation is not required for these models.

\subsection{CONFIDENCE BUILDING DURING MODEL DEVELOPMENT TO ESTABLISH SCIENTIFIC BASIS AND ACCURACY FOR INTENDED USE}

Section 2.2.1 of Technical Work Plan for: Regulatory Integration Modeling and Analysis of the Waste Form and Waste Package (BSC 2004 [DIRS 171583]) specifies that each model contains documentation of decisions and activities implemented during the model development process to build confidence and verify a reasonable, credible, technical approach using scientific and engineering principles. The decisions or activities required for confidence building in all models, regardless of the level of confidence, as specified in AP-SIII.10Q (Section 5.3.2(b)) and AP-2.27Q (Attachment 3), are as follows:

\section{Selection of input parameters and/or input data, and a discussion of how the} selection process builds confidence in the model. (AP-SIII.10Q, Section 5.3.2(b)(1); AP-2.27Q, Attachment 3, Level I (a)).

The selection of the solubility-controlling solid phases, as documented in Section 6, is based on laboratory or field observations and corroborated by Project-specific laboratory results where 
feasible and reasonable ( $\mathrm{Pu}, \mathrm{Np}$, and $\mathrm{Am}$ are somewhat corroborated). Other corroborative information includes natural analog data $(U)$, data published in peer-reviewed literature (U, Th, $\mathrm{Pa}$ ), and demonstration of conservatism $(\mathrm{Pu}, \mathrm{Np}, \mathrm{Pa}, \mathrm{Ra})$. Paucity of data precludes strong validation of americium. Since aqueous concentrations of technetium, carbon, iodine, cesium, and strontium are modeled as being controlled by waste form dissolution rates, no solubility models are developed for these elements, and therefore no validation is required. Lead aqueous concentrations are derived from values in peer-reviewed literature and professional judgment.

2. Description of calibration activities, and/or initial boundary condition runs, and/or run convergences, and a discussion of how the activity or activities build confidence in the model. Inclusion of a discussion of impacts of any nonconvergence runs. Documentation of activities to ensure that simulation conditions are set up to span the range of intended use and avoid inconsistent outputs, (AP-SIII.10Q, Section 5.3.2(b)(2); AP-2.27Q, Attachment 3, Level I (e)).

Discussion of the chemical system (temperature, oxidation potential, $\mathrm{pH}$, fugacity of $\mathrm{CO}_{2}$, water chemistry, etc) used in model runs is described in Section 6.3 and 6.4. Model formulations for dissolved concentrations of elements with radioactive isotopes are discussed in Sections 6.5 through 6.18. The solubilities span the range of intended use conditions for each of the factors that influence the dissolved concentrations of 14 important elements with radioactive isotopes (Sections 6.3 and 6.4). Run nonconvergences are discussed in Section 6.4.

3. Discussion of the impacts of uncertainties to the model results including how the model results represent the range of possible outcomes consistent with important uncertainties. (AP-SIII.10Q, Section 5.3.2(b)(3); AP-2.27Q, Attachment 3, Level 1 (d) and (f)).

The uncertainty associated with the selection of solubility-controlling phases is discussed in Section 6.3.2. Uncertainty in the selection of the solubility-controlling solid for $U$ is discussed in Section 6.7.2. The other uncertainties are listed in Table 8-3 and discussed in Section 6.

4. Formulation of defensible assumptions and simplifications. (AP-2.27Q, Attachment 3, Level I (b)).

Discussion of assumptions and their rationale are provided in Section 5.

5. Consistency with physical principles, such as conservation of mass, energy, and momentum. (AP-2.27Q, Attachment 3 Level I (c)).

Section 6 discusses the choice of solubility controlling phases. All choices are consistent with physical principles.

\subsection{CONFIDENCE-BUILDING AFTER MODEL DEVELOPMENT TO SUPPORT THE SCIENTIFIC BASIS OF THE MODEL}

Post-model development validation is required by AP-2.27. As mentioned in Section 1, Np and $\mathrm{Pu}$ require Level II validation. The rest of the solubility models require Level I validation For confidence building after model development, Table 2-1 of Technical Work Plan for: Regulatory 
Integration Modeling and Analysis of the Waste Form and Waste Package (BSC 2004 [DIRS 171583]) specifies the following validation activities and criteria:

1. Are the solubility controlling phases selected in the model consistent with the experimental or literature data? (VA 1,3)

2. Are the solubilities calculated in the model consistent with experimental or literature data? (VA 1,3)

3. For elements with little or no experimental data, is the model reasonable and acceptable given the level of validation required (low)? (N/A)

Validation metric/criteria for validation activities/criteria 1 through 3 requires that corroborating data must match qualitatively and must be bounded by model predictions

4. The solubility model will be validated by an independent technical review, and the review will answer the following questions: (VA 5)

- Do the treatments of the kinetics and thermodynamic factors adequately capture the behavior of the radionuclides over geologic timeframes?

- Is the value for Eh implemented in the model consistent with conditions expected in the repository over geologic timeframes?

Validation metric/criteria for validation activities/criteria 4 indicates Independent technical review: assessment of the validation activities will be qualitative, and considered successful if deemed defendable by the reviewer.

In Sections 7.2.2 and 7.2.3, the postdevelopment activities for $\mathrm{Pu}$ and $\mathrm{Np}$ (Level II) are described. Sections 7.2.4 through 7.2.11 describe postdevelopment activities for many of the other radionuclides (Level I). Corroborative data used to validate solubility models are summarized in Table 7-1.

Table 2-1 of Technical Work Plan for: Regulatory Integration Modeling and Analysis of the Waste Form and Waste Package (BSC 2004 [DIRS 171583]) also indicates the following validation activity:

Technical review planned in the applicable TWP, by reviewers independent of the development, checking, and review of the model documentation (AP-SIII.10Q, Section 5.3 .2 (c) (5)).

Section 7.2.1 and Appendix III contain the independent technical review of the $\mathrm{Pu}$ and $\mathrm{Np}$ models. The validation of the $\mathrm{Pu}$ - and $\mathrm{Np}$-solubility models introduces additional challenges due to the new analytical approach of Eh-adjustment that is used in the model. Additionally, these models are very important to dose calculations for the TSPA-LA. As a result, the use of an independent technical review by an individual with appropriate expertise was deemed to be the most appropriate method of validation for the $\mathrm{Np}$ and $\mathrm{Pu}$ solubility limits models and does not 
apply to the validation of Level I models. This is a departure from Section 2.2.3.2 of Technical Work Plan for: Regulatory Integration Modeling and Analysis of the Waste Form and Waste Package (BSC 2004 [DIRS 171583]).

Table 7-1. Corroborative Data Used for Model Validation

\begin{tabular}{|c|c|c|}
\hline Model & Source & Note \\
\hline \multirow{7}{*}{ Plutonium Solubility } & $\begin{array}{l}\text { Efurd et al. } 1998 \text { [DIRS 108015], Table 4, } \\
\text { p. } 3,897\end{array}$ & Plutonium solubility measured at $25^{\circ} \mathrm{C}$ \\
\hline & $\begin{array}{l}\text { Nitsche et al. } 1993 \text { [DIRS 155218], Table XVI, } \\
\text { p. } 54\end{array}$ & Plutonium solubility measured at $25^{\circ} \mathrm{C}$ \\
\hline & $\begin{array}{l}\text { Nitsche et al. } 1994 \text { [DIRS 144515], Table XIV, } \\
\text { p.39 }\end{array}$ & Plutonium solubility measured at $25^{\circ} \mathrm{C}$ \\
\hline & Rai 1984 [DIRS 122768], Table 3, p.100 & Plutonium solubility \\
\hline & $\begin{array}{l}\text { Rai et al. } 2001 \text { [DIRS 168392], Tables A. } 1 \text { and } \\
\text { A.2 }\end{array}$ & $\begin{array}{l}\text { Plutonium solubility measure in } 0.408 \\
\mathrm{~m} \mathrm{NaCl} \mathrm{solution} \mathrm{and} 0.403 \mathrm{~m} \mathrm{NaClO} \\
\text { solution at } 106 \text { days }\end{array}$ \\
\hline & $\begin{array}{l}\text { Wilson 1990a [DIRS 100949] } \\
\text { (PNL-Wilson.x/s in Appendix I) }\end{array}$ & $\begin{array}{l}\text { Plutonium concentrations measured at } \\
\text { spent fuel corrosion experiments }\end{array}$ \\
\hline & $\begin{array}{l}\text { Wilson 1990b [DIRS 100793] } \\
\text { (PNL-Wilson.x/s in Appendix I) }\end{array}$ & $\begin{array}{l}\text { Plutonium concentrations measured at } \\
\text { spent fuel corrosion experiments }\end{array}$ \\
\hline \multirow{3}{*}{$\begin{array}{l}\text { Base-Case } \mathrm{Np}_{2} \mathrm{O}_{5} \\
\text { Solubility }\end{array}$} & $\begin{array}{l}\text { Wilson 1990a [DIRS 100949] } \\
\text { (PNL-Wilson.x/s in Appendix I) }\end{array}$ & $\begin{array}{l}\text { Neptunium concentrations measured } \\
\text { at spent fuel corrosion experiments }\end{array}$ \\
\hline & $\begin{array}{l}\text { Wilson 1990b [DIRS 100793] } \\
\text { (PNL-Wilson.x/s in Appendix I) }\end{array}$ & $\begin{array}{l}\text { Neptunium concentrations measured } \\
\text { at spent fuel corrosion experiments }\end{array}$ \\
\hline & $\begin{array}{l}\text { CRWMS M\&O } 2000 \text { [DIRS 131861] and } \\
\text { CRWMS M\&O } 2000 \text { [DIRS 153105] for ANL } \\
\text { high-drip and low-drip tests (ANL6dripData.x/s } \\
\text { in Appendix I) }\end{array}$ & $\begin{array}{l}\text { Neptunium concentrations measured } \\
\text { at spent fuel corrosion experiments }\end{array}$ \\
\hline Uranium Solubility & Pearcy et al. 1994 [DIRS 100486] & $\begin{array}{l}\text { Natural analog corroboration of phases } \\
\text { used to control U solubility }\end{array}$ \\
\hline Thorium Solubility & $\begin{array}{l}\text { Hummel et al. } 2002 \text { [DIRS 161904], } \\
\text { Section } 5.21\end{array}$ & Thorium solubilities \\
\hline Americium Solubility & $\begin{array}{l}\text { Nitsche et al. } 1993 \text { [DIRS 155218] } \\
\text { Nitsche et al. } 1994 \text { [DIRS 144515] }\end{array}$ & Americium measured solubilities \\
\hline \multirow[b]{2}{*}{ Protactinium Solubility } & Berry et al. 1989 [DIRS 144728] & Protactinium solubility \\
\hline & Berner 2002 [DIRS 162000] & $\begin{array}{l}\text { Protactinium solubility - discussion of } \\
\text { data by Yui et al. (1999 } \\
\text { [DIRS 162664]) }\end{array}$ \\
\hline
\end{tabular}

\subsubsection{Pu and Np Independent Technical Review}

A technical review of the solubility models for $\mathrm{Pu}$ and $\mathrm{Np}$ was conducted. Dr. Gregory Choppin, Department of Chemistry and Biogeochemistry of Florida State University, a recognized expert in the field of actinide and lanthanide geochemistry, was selected to review and report on the models for $\mathrm{Np}$ and $\mathrm{Pu}$ developed herein. Dr. Choppin's independent review was conducted in accordance with the requirements of Technical Work Plan for: Regulatory Integration Modeling 
and Analysis of the Waste Form and Waste Package (BSC 2004 [DIRS 171583]) and the results are reported in Appendix III The reviewer, Greg Choppin, who was independent of the development and checking of the document, concluded:

"I agree with your answers to my questions and the changes you made in the document. The new paragraph is a very good response to my concerns and should be adequate to inform the readers of the colloid situation in connection with the truly dissolved concentration."

The independent technical review for the $\mathrm{Pu}$ and $\mathrm{Np}$ models has deemed them defensible. Therefore, the $\mathrm{Pu}$ and $\mathrm{Np}$ dissolved concentrations models have been validated by means of a technical review.

\subsubsection{Validation of the Adjusted-Eh Pu-Solubility Model}

The bases for the adjusted-Eh Pu-solubility model are experimental observations consisting of (1) the solubility-controlling phase $\mathrm{PuO}_{2}$ (hyd,aged), (2) solubility measurements, and (3) Eh measurements of natural waters at Yucca Mountain. The selection of the solubility-controlling phase for this model is consistent with laboratory experiments conducted at LANL (Efurd et al. 1998 [DIRS 108015]) and LBNL (Nitsche et al. 1993 [DIRS 155218]; 1994 [DIRS 144515]). 

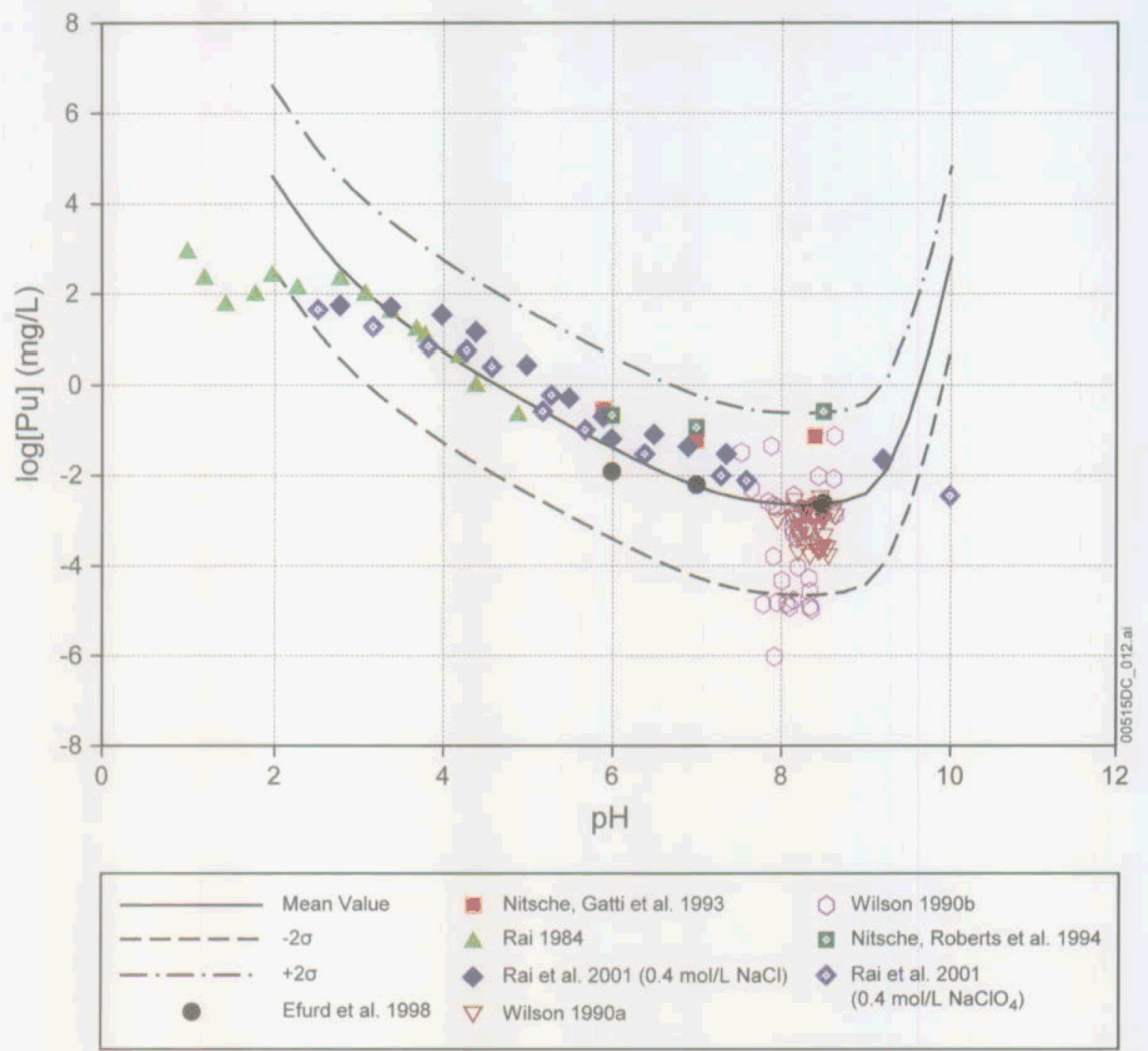

Figure 7-1. Comparison of Experimental Data with the Predictions of Plutonium Solubility Model

Figure 7-1 presents the adjusted-Eh Pu-solubility model for $\log f \mathrm{CO}_{2}=-3.5$ bars. The solid line represents the mean values of $\log [\mathrm{Pu}]$; the dotted and dashed lines represent upper and lower thermodynamic uncertainty ranges at $95 \%$ confidence interval, respectively. Eight sets of experimental data that are used for model validation also plotted in Figure 7-1. These data sets have been discussed in Section 6.5.3.3. Most of the data points from these eight sets of experiments fall within the uncertainty range of the model. More importantly, no data points fall above the upper bound of the model.

The favorable comparison between the model results and experimental results, which were not used in the choice of the solubility-controlling phase, strongly indicates that the proposed plutonium solubility model is representative of literature studies and slightly conservative when compared against the dissolution of commercial spent fuel and, thus, is valid. Therefore, the required level of confidence (Level II) is obtained. 


\subsubsection{Validation of $\mathrm{Np}_{2} \mathrm{O}_{5}-\mathrm{NaNpO}_{2} \mathrm{CO}_{3}$ Solubility Model}

The basis for the Np-solubility model is the use of $\mathrm{Np}_{2} \mathrm{O}_{5}$ for the solubility-controlling phase under low-pH conditions, and $\mathrm{NaNpO}_{2} \mathrm{CO}_{3}$ for the solubility-controlling phase under high-pH conditions. The selection of $\mathrm{Np}_{2} \mathrm{O}_{5}$ (low $\mathrm{pH}$ ) and $\mathrm{NaNpO}_{2} \mathrm{CO}_{3}$ (high $\mathrm{pH}$ ) as the solubilitycontrolling solids is based on Project-specific laboratory observations (Efurd et al. 1998 [DIRS 108015]; Nitsche et al. 1993 [DIRS 155218], p. 37).

Figure 7-2 presents the $\mathrm{Np}_{2} \mathrm{O}_{5}$ solubility at $25^{\circ} \mathrm{C}$ and at $f \mathrm{CO}_{2}$ of $10^{-3.5}$ bars. As all available $\mathrm{Np}_{2} \mathrm{O}_{5}$-solubility data is used to derive inputs for this model, no direct comparison between the modeling results and independent values of measured $\mathrm{Np}_{2} \mathrm{O}_{5}$ solubility is possible. However, Figure 7-2 also presents measured neptunium concentrations in several spent fuel corrosion experiments. These experiments were conducted at PNNL (Wilson 1990a [DIRS 100949]; Wilson 1990b [DIRS 100793]; PNL-Wilson.xls in Appendix I) and at ANL (Finn et al. 1994 [DIRS 100746]; CRWMS M\&O 2000 [DIRS 131861]; CRWMS M\&O 2000 [DIRS 153105]; DTN: LL991001251021.090 [DIRS 129285] $]^{1}$ ). This comparison shows that the $\mathrm{Np}_{2} \mathrm{O}_{5}-$ $\mathrm{NaNpO}_{2} \mathrm{CO}_{3}$ solubility model developed in this report is conservative and, thus, is adequate for TSPA-LA use. The fact that the measured neptunium concentrations in spent fuel corrosion experiments are four to six orders of magnitude lower than the modeled pure neptunium phase solubility indicates that neptunium may be controlled by different mechanism(s) than by pure-phase solubility (Section 6.6).

In summary, post development model validation shows that the $\mathrm{Np}_{2} \mathrm{O}_{5}-\mathrm{NaNpO}_{2} \mathrm{CO}_{3}$ solubility model results are corroborated by Project-specific experimental data, and that the model is conservative and adequate for TSPA-LA use.

\footnotetext{
I The concentration reported in this DTN is, according to the data report (CRWMS M\&O 2000d [DIRS 131861], p. 13), "the ratio of the moles of the element released divided by the liters of injected EJ-13" water. This is the concentration as the injected water leaves the Zircaloy- 4 holder, which can be only calculated. As the report pointed out, the released mass may include dissolved mass and suspended as colloids in solution. Thus, the concentration values reported in this DTN may be higher than the dissolved concentration in solution. However, this fact does not affect the use of these data to validate the neptunium solubility model because (1) colloids are not the major mechanism for neptunium release under oxidation conditions due to the fact that $\mathrm{NpO}_{2}^{+}$has a low $\mathrm{K}_{\mathrm{d}}$ value (Silva and Nitsche 1995 [DIRS 112092], Section 4.4) and "conditions for Np(V) colloid formation in environmental waters would usually not be achieved" (Silva and Nitsche 1995 [DIRS 112092], Section 4.5); and (2) because the data were used to demonstrate that the neptunium solubility model is conservative. The fact that the reported neptunium concentrations may be higher than the dissolved concentration in solution but are still lower than the modeled solubility actually confirms the solubility model is conservative.
} 


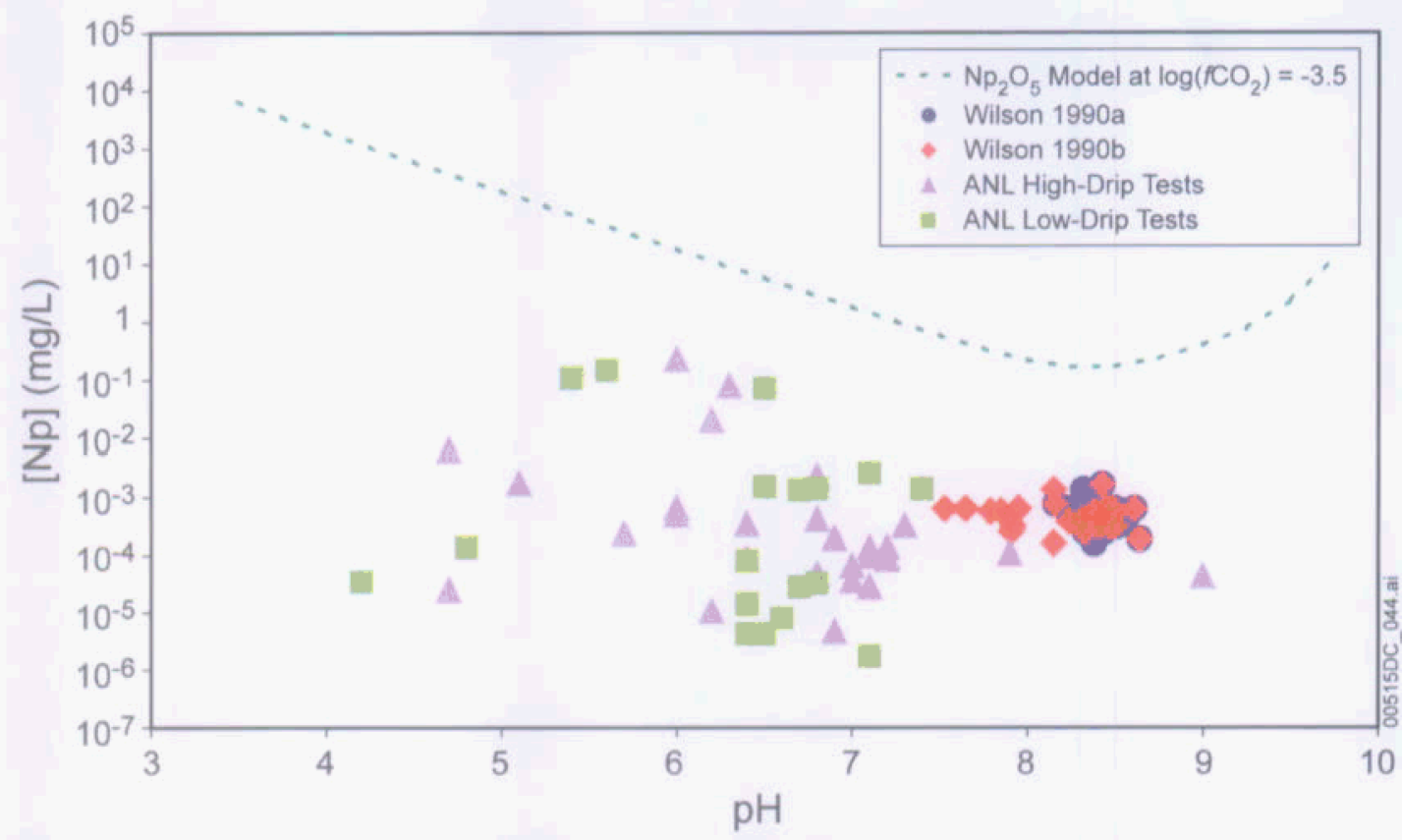

Data Source: Wilson 1990a [DIRS 100949]; Wilson 1990b [DIRS 100793] (PNL-wilson.xis in Appendix I); CRWMS M\&O 2000 [DIRS 131861] and CRWMS M\&O 2000 [DIRS 153105] for ANL high-drip and low-drip tests (ANL6dripData.x/s in Appendix I).

Source: fig72.x/s (Appendix I).

Figure 7-2. Comparison of $\mathrm{Np}_{2} \mathrm{O}_{5}$ Neptunium Solubility Model with PNNL and ANL Measurements

\subsubsection{Validation of Uranium Solubility Model}

The uranium solubility model is based on three U-bearing solubility-controlling phases. These are schoepite $\left(\mathrm{UO}_{3} \cdot 2 \mathrm{H}_{2} \mathrm{O}\right)$, the controlling mineral at low to moderate $\mathrm{pH}$ and $f \mathrm{CO}_{2}$ values; Na-boltwoodite $\left(\mathrm{NaUO}_{2} \mathrm{SiO}_{3} \mathrm{OH} \cdot 1.5 \mathrm{H}_{2} \mathrm{O}\right)$, the controlling solid at moderate to high $\mathrm{pH}$ and $f \mathrm{CO}_{2}$ values; and the solid $\mathrm{Na}_{4} \mathrm{UO}_{2}\left(\mathrm{CO}_{3}\right)_{3}$, the controlling solid at high $\mathrm{pH}$ and $f \mathrm{CO}_{2}$ values. The solubility calculations are carried out for a range of $\mathrm{pH}$ and $f \mathrm{CO}_{2}$ values in water the composition of J-13 well water, modified by the addition of $\mathrm{Na}^{+}$or $\mathrm{SO}_{4}$, as required for solution electroneutrality and with dissolved silica fixed by saturation with the silica phase chalcedony. To validate this model, this section presents evidence from a natural analogue supporting the selection of these U-controlling phases and the silica-controlling phase.

The selection of the solids used to model $U$ concentrations is based on laboratory studies (Wronkiewicz et al. 1996 [DIRS 102047]). The data presented by Pearcy et al. (1994 [DIRS 100486]) are used to corroborate the model. Pearcy et al. (1994 [DIRS 100486]) describe a natural analog study of uraninite alteration in the Nopal I deposit at Peña Blanca, Mexico (an environment similar in most respects to that of Yucca Mountain). The paragenesis of alteration products in the natural analog study is entirely consistent with that of the laboratory study. The differences that are evident are related to the chemistry of the alteration water in the two situations. The U-bearing alteration phases observed in both studies are given in Table 7-2. 
Table 7-2. Comparison of Phases Observed in Natural $\mathrm{UO}_{2}$ Alteration in a Geologic Environment Similar to Yucca Mountain.

\begin{tabular}{|c|c|c|c|}
\hline Mineral & $\begin{array}{c}\text { Phases Formed During } \\
\text { Laboratory Degradation of } \mathrm{UO}_{2} \\
\text { and Composition } \\
\text { (Wronkiewicz et al. } 1996 \\
\text { [DIRS 102047], Table 5) }\end{array}$ & $\begin{array}{c}\text { Principal Natural } \\
\text { Analog Phases and } \\
\text { Composition } \\
\text { (Pearcy et al. 1994 } \\
\text { [DIRS 100486], pp. } 717 \\
\text { to 724) } \\
\end{array}$ & $\begin{array}{c}\text { Composition of Phases } \\
\text { for Available } \\
\text { Thermodynamic Data } \\
\text { (Data0.ymp.R2) }\end{array}$ \\
\hline \multicolumn{4}{|c|}{ Uranyl-Oxide Hydrates } \\
\hline lanthinite & & $\mathrm{U}^{+4}\left(\mathrm{U}^{+6} \mathrm{O}_{2}\right)_{5}(\mathrm{OH})_{14} \cdot 3 \mathrm{H}_{2} \mathrm{O}$ & \\
\hline Dehydrated Schoepite & $\mathrm{UO}_{3} \cdot\left(0.8-1.0 \mathrm{H}_{2} \mathrm{O}\right)$ & & $\mathrm{UO}_{2}(\mathrm{OH})_{2}$ \\
\hline Schoepite & $\mathrm{UO}_{3} \cdot \mathrm{nH}_{2} \mathrm{O}(\mathrm{n}<2)$ & $\mathrm{UO}_{3} \cdot 2 \mathrm{H}_{2} \mathrm{O}$ & $\mathrm{UO}_{3} \cdot 2 \mathrm{H}_{2} \mathrm{O}$ \\
\hline Compreignacite & $\mathrm{K}_{2}\left[\left(\mathrm{UO}_{2}\right)_{6} \mathrm{O}_{4}(\mathrm{OH})_{6}\right] \cdot 8 \mathrm{H}_{2} \mathrm{O}$ & & \\
\hline Becquerelite & $\mathrm{Ca}\left[\left(\mathrm{UO}_{2}\right)_{6} \mathrm{O}_{4}(\mathrm{OH})_{6}\right] \cdot 8 \mathrm{H}_{2} \mathrm{O}$ & & \\
\hline \multicolumn{4}{|c|}{ Uranyl Silicate Hydrate } \\
\hline Soddyite & $\left(\mathrm{UO}_{2}\right)_{2} \mathrm{SiO}_{4} \cdot 2 \mathrm{H}_{2} \mathrm{O}$ & $\left(\mathrm{UO}_{2}\right)_{2} \mathrm{SiO}_{4} \cdot 2 \mathrm{H}_{2} \mathrm{O}$ & $\left(\mathrm{UO}_{2}\right)_{2} \mathrm{SiO}_{4} \cdot 2 \mathrm{H}_{2} \mathrm{O}$ \\
\hline \multicolumn{4}{|c|}{ Alkali and Alkaline Earth Uranyl Silicate Hydrates } \\
\hline Uranophane & $\mathrm{Ca}\left[\left(\mathrm{UO}_{2}\right)\left(\mathrm{SiO}_{3}\right)(\mathrm{OH})\right]_{2} \cdot 5 \mathrm{H}_{2} \mathrm{O}^{\mathrm{a}}$ & $\mathrm{Ca}\left(\mathrm{UO}_{2}\right) \mathrm{Si}_{2} \mathrm{O}_{7} \cdot 6 \mathrm{H}_{2} \mathrm{O}$ & $\mathrm{Ca}\left(\mathrm{UO}_{2} \mathrm{SiO}_{3} \mathrm{OH}\right)_{2} \cdot 5 \mathrm{H}_{2} \mathrm{O}$ \\
\hline Sklodowskite & $\mathrm{Mg}\left(\mathrm{UO}_{2}\right)_{2}\left(\mathrm{SiO}_{4}\right)_{2}\left(\mathrm{H}_{3} \mathrm{O}\right)_{2} \cdot 2 \mathrm{H}_{2} \mathrm{O}$ & & \\
\hline Weeksite & & $\mathrm{K}_{2}\left(\mathrm{UO}_{2}\right)_{2} \mathrm{Si}_{6} \mathrm{O}_{15} \cdot 4 \mathrm{H}_{2} \mathrm{O}$ & \\
\hline Boltwoodite & $\mathrm{K}_{2}\left(\mathrm{UO}_{2}\right)_{2}\left(\mathrm{SiO}_{4}\right)_{2}\left(\mathrm{H}_{3} \mathrm{O}\right)_{2} \cdot 2 \mathrm{H}_{2} \mathrm{O}$ & $\mathrm{HK}\left(\mathrm{UO}_{2}\right) \mathrm{SiO}_{4} \cdot 1.5 \mathrm{H}_{2} \mathrm{O}$ & \\
\hline Na-boltwoodite & $(\mathrm{Na}, \mathrm{K})\left(\mathrm{UO}_{2}\right)\left(\mathrm{SiO}_{4}\right)\left(\mathrm{H}_{3} \mathrm{O}\right) \cdot \mathrm{H}_{2} \mathrm{O}$ & & $\mathrm{NaUO}_{2} \mathrm{SiO}_{3} \mathrm{OH} \cdot 1.5 \mathrm{H}_{2} \mathrm{O}$ \\
\hline
\end{tabular}

NOTE: Comparison of phases observed in natural $\mathrm{UO}_{2}$ alteration in a geologic environment closely similar to Yucca Mountain (Pearcy et al. 1994 [DIRS 100486]) with those found during a 10 -year study of $\mathrm{UO}_{2}$ degradation by dripping water of J-13 well water composition (Wronkiewicz et al. 1996 [DIRS 102047], Table 5). Corresponding phases for which thermodynamic data are available in modeling database Data0.ymp.R2 (DTN: MO0302SPATHDYN.000 [DIRS 161756]) are also shown.

${ }^{a}$ Brackets missing in Wronkiewicz et al. 1996 [DIRS 102047], Table 5.

In summary, the choice of U-controlling phases is corroborated by comparison with phases reported in the reviewed literature from a natural analog site to Yucca Mountain.

\subsubsection{Validation of Thorium Solubility Model}

The basis of the thorium model is the use of $\mathrm{ThO}_{2}(\mathrm{am})$ as the solubility-controlling phase, as described in Section 6.8. This is based on several considerations, including the fact that $\mathrm{ThO}_{2}(\mathrm{am})$ is generally more soluble than thorianite $\left(\mathrm{ThO}_{2}\right)$. The choice of $\mathrm{ThO}_{2}(\mathrm{am})$ is corroborated by the observation that use of $\mathrm{ThO}_{2}(\mathrm{am})$ in solubility calculations leads to dissolved thorium concentrations similar to those commonly measured in solubility studies (Hummel et al. 2002 [DIRS 161904]).

The minimum thorium concentration modeled is $6.36 \times 10^{-4} \mathrm{mg} / \mathrm{L}\left(2.7 \times 10^{-9} \mathrm{~mol} / \mathrm{L}\right)$ at a $f \mathrm{CO}_{2}$ of $10^{-5}$ bars and a $\mathrm{pH}$ of 6.25 . At this $\mathrm{pH}$ and low $f \mathrm{CO}_{2}$ the impact of Th-F-, $\mathrm{SO}_{4}{ }^{2-}$, and $\mathrm{CO}_{3}{ }^{2-}$ complexes is minimal and the hydroxyl complex $\mathrm{Th}(\mathrm{OH})_{4}(\mathrm{aq})$ dominates. This solubility should, therefore, represent the experimental solubility of thorium dioxide in pure water at moderate-tohigh pH values. Hummel et al. (2002 [DIRS 161904], Section 5.21) have developed an internally consistent set of thermodynamic data for thorium. As part of their reported work, they 
summarize the results of a number of studies of thorium solubility in pure water. From these data, they show that at $\mathrm{pH}$ values above 6 , the $\log [\mathrm{Th}]$ is $-8.5 \pm 0.6 \mathrm{~mol} / \mathrm{L}$ (Hummel and Berner 2002 [DIRS 170921], Figure 5.2 and Section 2). The minimum thorium concentration modeled in this report is $6.36 \times 10^{-4} \mathrm{mg} / \mathrm{L}\left(2.7 \times 10^{-9} \mathrm{~mol} / \mathrm{L}\right)$. This is equal to $\log [\mathrm{Th}]=-8.6 \mathrm{~mol} / \mathrm{L}$, close to the mean of Hummel and Berner (2002 [DIRS 170921]) and well within the uncertainty of the measured values.

In summary, it is demonstrated that the thorium solubility model is corroborated by data published in the peer-reviewed literature.

\subsubsection{Validation of Americium Solubility Model}

The basis for the americium solubility model is the solubility-controlling phase $\mathrm{AmOHCO}_{3}$, which is chosen from a number of candidate phases based on arguments described in Sections 6.9.1 and 6.9.2. These arguments reduce the total number of possible phases to three; data reported by Nitsche et al. (1993 [DIRS 155218]; 1994 [DIRS 144515]) corroborated this short list of phases and are used to narrow the list down to the single phase used in the model.

In the Project-specific experimental results presented by Nitsche et al. (1993 [DIRS 155218]; 1994 [DIRS 144515]), $\mathrm{AmOHCO}_{3}$ was identified as forming from solutions similar to the reference water. Because of the paucity of americium solubility data, it is generally necessary to use these sources to corroborate the thought process leading to the short list of candidate solubility-controlling phases, as well as to aid in the final choice of solubility-controlling phase.

\subsubsection{Validation of Actinium Solubility Model}

As indicated in Section 6.10, TSPA-LA calculations do not use actinium in transport models so its solubility is not modeled in this report. Therefore, no validation was conducted.

\subsubsection{Validation of Protactinium Solubility Model}

Since there are no thermodynamic data for protactinium in the database (Data0.ymp.R2), protactinium is treated as an analogue of neptunium due to their similar positions in the periodic table of the elements, as discussed in Section 6.11. The experimental data of Baes and Mesmer (1986 [DIRS 100702], Section 9), Shibutani et al. (1998 [DIRS 161998]), and Yui et al. (1999 [DIRS 162664]) indicate that $\mathrm{Pa}(\mathrm{V})$ solubility should be less than that of $\mathrm{Np}(\mathrm{V})$ (Section 6.11). In the protactinium solubility model, protactinium $\left(\mathrm{Pa}_{2} \mathrm{O}_{5}\right)$ solubility is set equal to the solubility of $\mathrm{Np}_{2} \mathrm{O}_{5}$, which is conservative according to the cited experimental data.

Berner (2002 [DIRS 162000], Section 4.7) discusses protactinium in terms of $\mathrm{Pa}_{2} \mathrm{O}_{5}$ as the solubility-limiting solid and $\mathrm{PaO}(\mathrm{OH})_{3}(\mathrm{aq})$ as the dominant complex in solution. Berner (2002 [DIRS 162000]) notes that a "sensible" estimate obtained from the data of Yui et al. (1999 [DIRS 162664]) could be on the order of $10^{-8} \mathrm{~mol} / \mathrm{L}$ (corresponding to roughly $3 \times 10^{-3} \mathrm{mg} / \mathrm{L}$ ). Table 6.11-2 lists protactinium solubilities (based on $\mathrm{Np}_{2} \mathrm{O}_{5}$ analog) for a range of $\mathrm{pH}$ and $f \mathrm{CO}_{2}$ conditions; every calculated value is higher than Berner's (2002 [DIRS 162000]) estimate, supporting that the calculated values are conservative.

Berry et al. (1989 [DIRS 144728]) describe experiments on protactinium behavior in solutions of several types at a range of $\mathrm{pH}$ values. The protactinium behavior is dominated by sorption, but 
the authors were able to develop a solubility limit of $10^{-10} \mathrm{~mol} / \mathrm{L}\left(2.3 \times 10^{-5} \mathrm{mg} / \mathrm{L}\right)$ at high $\mathrm{pH}$ values in waters typical of those emanating from cements. This is two orders of magnitude lower than the lowest solubility calculated for thorium (Figure 6.8-1) and four orders of magnitude lower than the lowest neptunium solubility (Figure 6.6-1). Although the experiments were carried out for reducing aqueous conditions, the oxidation state of the protactinium was unaffected. The relative solubilities of protactinium and neptunium corroborate the basis of the protactinium solubility model (i.e., $\mathrm{Pa}_{2} \mathrm{O}_{5}$ solubility is lower than the solubility of $\mathrm{Np}_{2} \mathrm{O}_{5}$, and setting $\mathrm{Pa}_{2} \mathrm{O}_{5}$ solubility equal to $\mathrm{Np}_{2} \mathrm{O}_{5}$ solubility is, therefore, conservative).

\subsubsection{Validation of Radium Solubility Model}

The radium solubility model is based on the solubility of pure $\mathrm{RaSO}_{4}$, which is found to control radium solubility in EQ3NR computer runs if solid solutions such as $\mathrm{BaSO}_{4}$ and $\mathrm{SrSO}_{4}$ are not taken into account, as discussed in Section 6.12. Field studies have shown that radium concentrations in some natural waters are orders of magnitude below levels corresponding to $\mathrm{RaSO}_{4}$ saturation. Radium concentrations more probably correspond to the solubilities of radium in solid solutions of more common sulfate solids such as $\mathrm{SrSO}_{4}$ or $\mathrm{BaSO}_{4}$ (Langmuir and Riese 1985 [DIRS 106457]). A radium concentration based on pure $\mathrm{RaSO}_{4}$ solubility is therefore a conservative value and adequate for TSPA-LA use.

\subsubsection{Validation of Lead Solubility Model}

The lead solubility limit recommended in this report (Section 6.13) is based on literature data and professional judgment, and no model calculation is conducted.

\subsubsection{Validation of Technetium, Carbon, Iodine, Cesium, and Strontium Solubility Models}

As described in Sections 6.14 through 6.18, for these elements it is expected that no solubilitycontrolling phases controls their solubilities under repository conditions, and that their release rates are controlled by the dissolution rates of the waste forms. Therefore, since no solubility models are developed for technetium, carbon, iodine, cesium, and strontium, no model validations were conducted.

\subsection{VALIDATION SUMMARY}

The solubility models have been validated by applying acceptance criteria based on an evaluation of the model's relative importance to the potential performance of the repository system. All validation requirements defined in Section 2 of Technical Work Plan for: Regulatory Integration Modeling and Analysis of the Waste Form and Waste Package (BSC 2004 [DIRS 171583]) have been fulfilled, including corroboration of model results with experimental data, publications of refereed journals, and independent technical review. Activities required for confidence building during model development have been satisfied. The model development activities and postdevelopment validation activities described establish the scientific basis for the solubility models. Based on this, the solubility models summarized in Section 8 are considered to be sufficiently accurate and adequate for their intended purpose. The level of confidence required by the model's relative importance to the performance of the repository system has been met. 
INTENTIONALLY LEFT BLANK 


\section{CONCLUSIONS}

The scope of this modeling activity is to predict dissolved concentrations or solubility limits as functions of environmental conditions, distributions, or single values for all elements with radioactive isotopes transported outside breached waste packages that are important to the performance of the repository. Solubility models have been developed based on geochemical modeling calculations using geochemical modeling tools, thermodynamic databases, and measurements made in laboratory experiments and field work for 14 elements with radioactive isotopes, resulting in 14 base-case models (for plutonium, neptunium, uranium, thorium, americium, actinium, protactinium, radium, lead, technetium, carbon, iodine, cesium, and strontium), two alternative conceptual models for neptunium, and one alternative model for protactinium.

The output from this model can be found archived in output DTN: MO0408SPADCLRE.000.

\subsection{MODEL OUTPUT}

The base-case model output is summarized in Table 8-1. Model output for two neptunium alternative conceptual models and one Protactinium alternative conceptual model is summarized in Table 8-2. The output for plutonium, neptunium, uranium, thorium, americium, and protactinium solubilities are tabulated as functions of $\mathrm{pH}$ and $\log f \mathrm{CO}_{2}$. These tables are located in Section 6 and are not repeated in this section. There are two base case uranium solubility models. One is for CSNF waste packages in nominal and seismic scenarios, and the other is for CDSP waste packages in all scenarios and for CSNF packages breached during an igneous intrusion and for the invert. For some very soluble elements, there is no adequate basis to specify a solubility-controlling solid, so they are modeled as highly soluble, and their releases are considered to be controlled by the dissolution rate of waste forms. Elements in this category are technetium, carbon, iodine, cesium, and strontium. 
Table 8-1. Summary of Base-Case Solubility Models

\begin{tabular}{|c|c|c|}
\hline Element & Value & Note \\
\hline $\mathrm{Pu}$ & Table $6.5-1$ (log of solubility in $\mathrm{mg} / \mathrm{L}$ ) & \\
\hline $\mathrm{Np}$ & Table 6.6-3 (log of solubility in $\mathrm{mg} / \mathrm{L})$ & \\
\hline \multirow[b]{2}{*}{$u$} & Table 6.7-3 (log of solubility in $\mathrm{mg} / \mathrm{L}$ ) & $\begin{array}{l}\text { For CSNF waste packages in nominal } \\
\text { and seismic scenarios }\end{array}$ \\
\hline & Table $6.7-5$ and $6.7-6$ (log of solubility in $\mathrm{mg} / \mathrm{L}$ ) & $\begin{array}{l}\text { For CDSP waste packages, for CSNF } \\
\text { waste packages breached during an } \\
\text { igneous intrusion, and for the invert }\end{array}$ \\
\hline Th & Table $6.8-2$ (log of solubility in $\mathrm{mg} / \mathrm{L}$ ) & \\
\hline $\mathrm{Am}$ & Table 6.9-2 (log of solubility in $\mathrm{mg} / \mathrm{L}$ ) & \\
\hline Ac & N/A & \\
\hline $\mathrm{Pa}$ & Table $6.11-3$ ( $\log$ of solubility in $\mathrm{mg} / \mathrm{L}$ ) & \\
\hline $\mathrm{Ra}$ & $\begin{array}{l}8.8 \mathrm{E}-8 \mathrm{~mol} / \mathrm{L}(2.0 \mathrm{E}-2 \mathrm{mg} / \mathrm{L}) \text { for } \mathrm{pH} \text { range of } 3.0 \text { to } 7.75 \\
5.3 \mathrm{E}-6 \mathrm{~mol} / \mathrm{L}(1.2 \mathrm{mg} / \mathrm{L}) \text { for } \mathrm{pH} \text { range of } 7.75 \text { to } 9.75 \\
500 \text { for } \mathrm{pH}>9.75\end{array}$ & Constants for two intervals \\
\hline $\mathrm{Pb}$ & $4.8 \mathrm{E}-9$ to $4.8 \mathrm{E}-7 \mathrm{~mol} / \mathrm{L}(1.0 \mathrm{E}-3$ to $1.0 \mathrm{E}-1 \mathrm{mg} / \mathrm{L})$ & log Uniform Distribution \\
\hline Tc & 500 & Controlled by dissolution rate \\
\hline C & 500 & Controlled by dissolution rate \\
\hline 1 & 500 & Controlled by dissolution rate \\
\hline Cs & 500 & Controlled by dissolution rate \\
\hline $\mathrm{Sr}$ & 500 & Controlled by dissolution rate \\
\hline
\end{tabular}

Table 8-2. Summary of Alternative Solubility Models

\begin{tabular}{|l|l|}
\hline \multicolumn{1}{|c|}{ Model Name } & \multicolumn{1}{|c|}{ Value } \\
\hline $\begin{array}{l}\text { Neptunium Alternative Model I: } \mathrm{NpO}_{2} \\
\text { Solubility }\end{array}$ & Table 6.6-7 $(\log$ of solubility in $\mathrm{mg} / \mathrm{L})$ \\
\hline $\begin{array}{l}\text { Neptunium Alternative Model II: } \\
\text { Secondary-Phase Neptunium Solubility } \\
\text { (Applicable for CSNF waste packages } \\
\text { only) }\end{array}$ & Table 6.6-15 (log of solubility in $\mathrm{mg} / \mathrm{L})$ \\
\hline Alternative Protactinium Solubility Model & Table 6.11-6 (log of solubility in $\mathrm{mg} / \mathrm{L})$ \\
\hline
\end{tabular}

\subsection{OUTPUT UNCERTAINTY}

Uncertainties from various sources are addressed in this report. They consist of (1) uncertainty in selection of the solubility-controlling phase (for uranium solubility model only), (2) uncertainty in $\log \mathrm{K}$ of the solubility-controlling phase, (3) uncertainty associated with temperature variations, (4) uncertainty associated with variations in fluoride concentrations, and (5) additional uncertainty in solubility values in solutions with ionic strengths from 1 to 3 molal. For the secondary phase neptunium solubility model, an additional uncertainty term is given arising from the derivation of the concentrating factor $\left(F_{c}\right)$ from experimental data. 
The output uncertainty for the base-case models is summarized in Table 8-3. For Pu, Np, and $U$, uncertainty is added to the solubilities presented in Tables 6.5-1 (for $\mathrm{Pu}$ ), 6.6-3 (for $\mathrm{Np}$ ), and Tables 6.7-3, 6.7-5, and 6.7-6 (for $\mathrm{U}$ ) by the following equation:

$$
\log [\mathrm{Pu}]=\mathrm{S}\left(\mathrm{pH}, \log f \mathrm{CO}_{2}\right)+\varepsilon_{1}+\left(\varepsilon_{2} \times \mathrm{N}\right)
$$

Uncertainty for $\mathrm{Am}$, Th, and $\mathrm{Pa}$ are added to the solubility values presented in Tables $6.8-2$ (for Th), 6.9-2 (for Am), and 6.11-3 (for Pa) by the following equation:

$$
\log [\mathrm{Pu}]=\mathrm{S}\left(\mathrm{pH}, \log f \mathrm{CO}_{2}\right)+\varepsilon_{1}+\varepsilon_{2}
$$

where:

$S\left(p H, \log f_{\mathrm{CO}_{2}}\right)$ is $\log$ of the modeled actinide concentration as a function of $\mathrm{pH}$ and $\log f_{\mathrm{CO} 2}$

$\varepsilon_{1}$ is the uncertainty term associated with uncertainty in $\log \mathrm{K}$ values. This term has a normal distribution truncated at $2 \sigma$. The value used during a given run is chosen from within this distribution by the TSPA-LA model.

$\varepsilon_{2}$ is the uncertainty term associated with variations in fluoride concentration. The range of fluoride uncertainty for a given TSPA-LA run depends on the type of waste package being considered and the $\mathrm{pH}$. This term has a right-sided triangular distribution with the minimum (indicated by "a"), most probable values (indicated by "b") equal to one another (i.e., $a=b$ ), and the maximum value (indicated by "c") corresponding to the maximum value uncertainty.

$\mathrm{N}$ is the factor by which the maximum fluoride uncertainty $\left(\varepsilon_{2}\right)$ is normalized for $\mathrm{pH}$.

The output uncertainties for the three alternative conceptual models (two for neptunium and one for protactinium) are summarized in Table 8-4, which also indicates alternative uncertainty terms that can be used for americium and thorium.

Equation 8.1 applies to all the uncertainties presented in Table 8-4 except for the neptunium alternative model II: secondary phase neptunium solubility model. The uncertainty for this alternative model is added to the solubility values by the following equations:

$$
\log [N p]=S\left(p H, \log f_{C_{2}}\right)+\varepsilon_{1}+\varepsilon_{2}+\varepsilon_{3}
$$

where

$S\left(p H, \log f_{\mathrm{CO}_{2}}\right)$ is $\log$ of the modeled actinide concentration as a function of $\mathrm{pH}$ and $\log f_{\mathrm{CO} 2}$

$\varepsilon_{1}$ is the uncertainty term associated with uncertainty in $\log \mathrm{K}$ of the uranium solubility when schoepite is the controlling phase

$\varepsilon_{2}$ is the uncertainty term associated with variations in fluoride concentration

$\varepsilon_{3}$ is the uncertainty term in $F_{c}$. 
Table 8-3. Summary of Uncertainty for Base-Case Solubility Models

\begin{tabular}{|c|c|c|c|c|c|}
\hline Element & \multicolumn{2}{|c|}{ Sources of Uncertainty } & $\begin{array}{l}\text { Uncertainty } \\
\text { Distribution }\end{array}$ & Characteristic Values & Notes \\
\hline \multirow{4}{*}{$\begin{array}{l}\text { Plutonium } \\
\text { solubility }\end{array}$} & \multicolumn{2}{|l|}{$\log K$} & $\begin{array}{l}\text { Normal } \\
\text { Truncated at } \pm 2 \sigma\end{array}$ & $\mu=0, \sigma=1.0(1.04)^{\mathrm{a}}$ & \multirow{4}{*}{ Table $6.5-5$} \\
\hline & \multicolumn{2}{|c|}{$\begin{array}{l}\mathrm{F}^{-} \text {(for CSNF waste packages - } \\
\text { Water Influx Scenario) }\end{array}$} & Triangular & $\begin{array}{l}a=b=0, c=0.496(p H \\
\text { dependence of } c \text { indicated in } \\
\text { Table 6.5-4) }\end{array}$ & \\
\hline & \multirow{2}{*}{$\begin{array}{l}\mathrm{F}^{-} \text {(for } \\
\text { codisposal } \\
\text { waste package } \\
\text { and invert) }\end{array}$} & $\begin{array}{l}\text { Water Influx } \\
\text { Scenario }\end{array}$ & Triangular & $\begin{array}{l}a=b=0, c=0.957(p H \\
\text { dependence of } c \text { indicated in } \\
\text { Table 6.5-4) }\end{array}$ & \\
\hline & & $\begin{array}{l}\text { Vapor Influx } \\
\text { Scenario }\end{array}$ & Triangular & $\begin{array}{l}a=b=0, c=1.69(p H \\
\text { dependence of } c \text { indicated in } \\
\text { Table 6.5-4) }\end{array}$ & \\
\hline \multirow{4}{*}{$\begin{array}{l}\text { Neptunium } \\
\text { solubility }\end{array}$} & \multicolumn{2}{|l|}{$\log K$} & $\begin{array}{l}\text { Normal } \\
\text { Truncated at } \pm 2 \sigma\end{array}$ & $\mu=0, \sigma=0.80(0.85)^{a}$ & \multirow{4}{*}{ Table 6.6-5 } \\
\hline & \multicolumn{2}{|c|}{$\begin{array}{l}\mathrm{F}^{-} \text {(for CSNF waste packages - } \\
\text { Water Influx Scenario) }\end{array}$} & Triangular & $\begin{array}{l}a=b=0, c=0.010(p H \\
\text { dependence of } c \text { indicated in } \\
\text { Table } 6.6-6)\end{array}$ & \\
\hline & \multirow{2}{*}{$\begin{array}{l}\mathrm{F}^{-} \text {(for } \\
\text { codisposal } \\
\text { waste package } \\
\& \text { invert) }\end{array}$} & $\begin{array}{l}\text { Water Influx } \\
\text { Scenario }\end{array}$ & Triangular & $\begin{array}{l}a=b=0, c=0.026(p H \\
\text { dependence of } c \text { indicated in } \\
\text { Table 6.6-6) }\end{array}$ & \\
\hline & & $\begin{array}{l}\text { Vapor Influx } \\
\text { Scenario }\end{array}$ & Triangular & $\begin{array}{l}a=b=0, c=0.079(\mathrm{pH} \\
\text { dependence of } c \text { indicated in } \\
\text { Table 6.6-6) }\end{array}$ & \\
\hline \multirow{2}{*}{$\begin{array}{l}\text { Uranium } \\
\text { solubility: } \\
\text { CSNF } \\
\text { packages for } \\
\text { nominal and } \\
\text { seismic } \\
\text { breach } \\
\text { scenarios } \\
\end{array}$} & \multicolumn{2}{|c|}{$\log K$ - schoepite } & $\begin{array}{l}\text { Normal } \\
\text { Truncated at } \pm 2 \sigma\end{array}$ & $\mu=0, \sigma=0.50(0.60)^{\mathrm{a}}$ & \\
\hline & \multicolumn{2}{|c|}{$\begin{array}{l}\mathrm{F}^{-} \text {(for CSNF waste packages - } \\
\text { Water Influx Scenario) }\end{array}$} & Triangular & $\begin{array}{l}a=b=0, c=1.03(p H \\
\text { dependence of } c \text { indicated in } \\
\text { Table 6.7-9) }\end{array}$ & $\begin{array}{l}\text { Section } \\
6.7 .6\end{array}$ \\
\hline \multirow{5}{*}{$\begin{array}{l}\text { Uranium } \\
\text { solubility: } \\
\text { Codisposal } \\
\text { packages, } \\
\text { CSNF } \\
\text { packages } \\
\text { breached } \\
\text { during an } \\
\text { igneous } \\
\text { intrusion, } \\
\text { and invert }\end{array}$} & \multirow{3}{*}{ Schoepite } & $\log K$ & $\begin{array}{l}\text { Normal } \\
\text { Truncated at } \pm 2 \sigma\end{array}$ & $\mu=0, \sigma=0.50(0.60)^{\mathrm{a}}$ & $\begin{array}{l}\text { Section } \\
6.7 .6\end{array}$ \\
\hline & & $\begin{array}{l}\mathrm{F}^{-}-(\text {Water Influx } \\
\text { CDSP and CSNF } \\
\text { packages } \\
\text { breached during } \\
\text { an igneous } \\
\text { intrusion) }\end{array}$ & Triangular & $\begin{array}{l}a=b=0, c=1.65(p H \\
\text { dependence of } c \text { indicated in } \\
\text { Table 6.7-11) }\end{array}$ & \multirow[t]{2}{*}{ Table $6.7-10$} \\
\hline & & $\begin{array}{l}F^{-}-(\text {Vapor Influx } \\
\text { CDSP Waste } \\
\text { Packages and } \\
\text { invert) }\end{array}$ & Triangular & $\begin{array}{l}a=b=0, c=2.40(p H \\
\text { dependence of } c \text { indicated in } \\
\text { Table 6.7-11) }\end{array}$ & \\
\hline & \multirow[b]{2}{*}{ Na-boltwoodite } & $\log K$ & $\begin{array}{l}\text { Normal } \\
\text { Truncated at } \pm 2 \sigma\end{array}$ & $\mu=0, \sigma=0.50(0.60)^{a}$ & $\begin{array}{l}\text { Section } \\
6.7 .6 \\
\end{array}$ \\
\hline & & $\begin{array}{l}\mathrm{F}^{-}-\text {(Water Influx } \\
\text { CDSP and CSNF } \\
\text { packages } \\
\text { breached during } \\
\text { an igneous } \\
\text { intrusion) }\end{array}$ & Triangular & $\begin{array}{l}a=b=0, c=0.368(p H \\
\text { dependence of } c \text { indicated in } \\
\text { Table 6.7-11) }\end{array}$ & Table $6.7-10$ \\
\hline
\end{tabular}


Table 8-3. Summary of Uncertainty for Base-Case Solubility Models (Continued)

\begin{tabular}{|c|c|c|c|c|c|}
\hline \multirow[t]{4}{*}{ Element } & \multicolumn{2}{|c|}{ Sources of Uncertainty } & $\begin{array}{l}\text { Uncertainty } \\
\text { Distribution }\end{array}$ & Characteristic Values & Notes \\
\hline & & $\begin{array}{l}F^{-}-(\text {Vapor Influx } \\
\text { CDSP Waste } \\
\text { Packages and } \\
\text { invert) }\end{array}$ & Triangular & $\begin{array}{l}a=b=0, c=1.17(\mathrm{pH} \\
\text { dependence of } \mathrm{c} \text { indicated in } \\
\text { Table } 6.7-11)\end{array}$ & \\
\hline & \multirow[b]{2}{*}{$\mathrm{Na}_{4} \mathrm{UO}_{2}\left(\mathrm{CO}_{3}\right)_{3}$} & $\log K$ & $\begin{array}{l}\text { Normal } \\
\text { Truncated at } \pm 2 \sigma\end{array}$ & $\mu=0, \sigma=0.6^{b}$ & $\begin{array}{l}\text { Section } \\
6.7 .6 \\
\end{array}$ \\
\hline & & $\begin{array}{l}\mathrm{F}^{-}-(\mathrm{CDSP} \text { and } \\
\text { CSNF packages } \\
\text { breached during } \\
\text { an igneous } \\
\text { intrusion, and } \\
\text { invert) }\end{array}$ & Triangular & $a=b=0, c=0$ & Table $6.7-10$ \\
\hline \multirow{3}{*}{$\begin{array}{l}\text { Thorium } \\
\text { solubility }\end{array}$} & \multicolumn{2}{|l|}{$\log K$} & \begin{tabular}{|l|} 
Normal \\
Truncated at $\pm 2 \sigma$ \\
\end{tabular} & $\mu=0, \sigma=0.7(0.76)^{a}$ & \multirow{3}{*}{ Table $6.8-4$} \\
\hline & \multicolumn{2}{|c|}{$\begin{array}{l}\mathrm{F}^{-} \text {(for CSNF waste packages - } \\
\text { Water Influx Scenario) }\end{array}$} & Triangular & $a=b=0, c=3.10$ & \\
\hline & \multicolumn{2}{|c|}{$\begin{array}{l}\mathrm{F}^{-} \text {(for codisposal waste package } \\
\text { and invert) }\end{array}$} & Triangular & $a=b=0, c=5.72$ & \\
\hline \multirow{3}{*}{$\begin{array}{l}\text { Americium } \\
\text { solubility }\end{array}$} & \multicolumn{2}{|l|}{$\log K$} & $\begin{array}{l}\text { Normal } \\
\text { Truncated at } \pm 2 \sigma\end{array}$ & $\mu=0, \sigma=1.0(1.04)^{\mathrm{a}}$ & \multirow{3}{*}{ Table 6.9-4 } \\
\hline & \multicolumn{2}{|c|}{$\begin{array}{l}\mathrm{F}^{-} \text {(for CSNF waste packages - } \\
\text { Water Influx Scenario) }\end{array}$} & Triangular & $a=b=0, c=5.91 E-2$ & \\
\hline & \multicolumn{2}{|c|}{$\begin{array}{l}F^{-} \text {(for codisposal waste package } \\
\text { and invert) }\end{array}$} & Triangular & $a=b=0, c=1.46$ & \\
\hline \multirow{3}{*}{$\begin{array}{l}\text { Protactinium } \\
\text { solubility }\end{array}$} & \multicolumn{2}{|l|}{ Analogs } & Uniform & $\begin{array}{l}\text { Over an interval of [-1.02, } \\
3.04]\end{array}$ & \multirow{3}{*}{ Table 6.11-4 } \\
\hline & \multicolumn{2}{|c|}{$\begin{array}{l}F^{-} \text {(for CSNF waste packages - } \\
\text { Water Influx Scenario) }\end{array}$} & Triangular & $a=b=0, c=3.10$ & \\
\hline & \multicolumn{2}{|c|}{$\begin{array}{l}F^{-} \text {(for codisposal waste package } \\
\text { and invert) }\end{array}$} & Triangular & $a=b=0, c=5.79$ & \\
\hline $\begin{array}{l}\text { Radium } \\
\text { solubility }\end{array}$ & \multicolumn{2}{|l|}{ N/A } & N/A & Distribution & $\mathrm{N} / \mathrm{A}$ \\
\hline $\begin{array}{l}\text { Lead } \\
\text { solubility }\end{array}$ & \multicolumn{2}{|l|}{ N/A } & N/A & Distribution & N/A \\
\hline $\begin{array}{l}\text { Technetium } \\
\text { solubility }\end{array}$ & \multicolumn{2}{|l|}{$\mathrm{N} / \mathrm{A}$} & N/A & Constant & $\mathrm{N} / \mathrm{A}$ \\
\hline $\begin{array}{l}\text { Carbon } \\
\text { solubility }\end{array}$ & \multicolumn{2}{|l|}{ N/A } & N/A & Constant & N/A \\
\hline $\begin{array}{l}\text { lodine } \\
\text { solubility }\end{array}$ & \multicolumn{2}{|l|}{ N/A } & N/A & Constant & N/A \\
\hline $\begin{array}{l}\text { Cesium } \\
\text { solubility }\end{array}$ & \multicolumn{2}{|l|}{ N/A } & N/A & Constant & N/A \\
\hline $\begin{array}{l}\text { Strontium } \\
\text { Solubility }\end{array}$ & \multicolumn{2}{|l|}{ N/A } & N/A & Constant & N/A \\
\hline
\end{tabular}

NOTES: ${ }^{a}$ When used with solutions having an ionic strength from 1 to 3 molal, $\log \mathrm{K}$ uncertainty is the number indicated in parentheses.

${ }^{b}$ EQ3NR runs show that when $\mathrm{Na}_{4} \mathrm{UO}_{2}\left(\mathrm{CO}_{3}\right)_{3}$ is the dominant $\mathrm{U}$ phase, ionic strength of solutions are usually above 1 . Therefore, the log $\mathrm{K}$ uncertainty term already accounts for the square root of the mean addition of the \pm 0.3 value to the uncertainty term. 
Table 8-4. Summary of Alternative Solubility Model Uncertainties and Alternative Uncertainties for Base-Case Models

\begin{tabular}{|c|c|c|c|c|c|}
\hline Element & \multicolumn{2}{|c|}{ Sources of Uncertainty } & $\begin{array}{l}\text { Uncertainty } \\
\text { Distribution }\end{array}$ & Characteristic Values & Notes \\
\hline \multirow{3}{*}{$\begin{array}{l}\text { Neptunium Alternative } \\
\text { Model I: } \mathrm{NpO}_{2} \\
\text { Solubility }\end{array}$} & \multicolumn{2}{|l|}{$\log K$} & $\begin{array}{l}\text { Normal } \\
\text { Truncated at } \pm 2 \sigma\end{array}$ & $\mu=0, \sigma=0.6(0.67)^{\mathrm{a}}$ & \multirow{3}{*}{ Table 6.6-9 } \\
\hline & \multicolumn{2}{|c|}{$\begin{array}{l}F^{-} \text {(for CSNF waste packages } \\
\text { - Water Influx Scenario) }\end{array}$} & Triangular & $\begin{array}{l}a=b=0, c=0.043(p H \\
\text { dependence of } c \\
\text { indicated in Table 6.6- } \\
10)\end{array}$ & \\
\hline & \multicolumn{2}{|c|}{$\begin{array}{l}\mathrm{F}^{--} \text {(for codisposal waste } \\
\text { package and invert) }\end{array}$} & Triangular & $\begin{array}{l}a=b=0, c=0.887(p H \\
\text { dependence of } c \\
\text { indicated in Table 6.6- } \\
10)\end{array}$ & \\
\hline \multirow{3}{*}{$\begin{array}{l}\text { Neptunium Alternative } \\
\text { Model II: Secondary } \\
\text { Phase Neptunium } \\
\text { Solubility } \\
\text { (applicable for CSNF } \\
\text { Waste Packages only) }\end{array}$} & \multicolumn{2}{|l|}{$\log K$} & Normal & $\mu=0, \sigma=0.5(0.60)^{a}$ & \multirow{3}{*}{ Table 6.6-16 } \\
\hline & \multicolumn{2}{|c|}{$\begin{array}{l}\mathrm{F}^{-} \text {(for CSNF waste packages } \\
- \text { Water Influx Scenario) }\end{array}$} & Triangular & $a=b=0, c=1.03$ & \\
\hline & \multicolumn{2}{|l|}{$F_{c}$} & Normal & $\mu=0, \sigma=0.5$ & \\
\hline \multirow{4}{*}{$\begin{array}{l}\text { Alternative } \\
\text { Protactinium solubility } \\
\text { Model }\end{array}$} & \multicolumn{2}{|l|}{ Analogs } & Uniform & $\begin{array}{l}\text { Over an interval of [- } \\
0.05,-4.42]\end{array}$ & \multirow{4}{*}{ Table $6.11-7$} \\
\hline & \multicolumn{2}{|c|}{$\begin{array}{l}\mathrm{F}^{-} \text {(for CSNF waste packages } \\
- \text { Water Influx Scenario) }\end{array}$} & Triangular & $a=b=0, c=3.10$ & \\
\hline & \multirow{2}{*}{$\begin{array}{l}\mathrm{F}^{-} \text {(for } \\
\text { codisposal } \\
\text { waste package } \\
\text { and invert) }\end{array}$} & $\begin{array}{l}\text { Water Influx } \\
\text { Scenario }\end{array}$ & Triangular & $a=b=0, c=4.21$ & \\
\hline & & $\begin{array}{l}\text { Vapor Influx } \\
\text { Scenario }\end{array}$ & Triangular & $a=b=0, c=5.27$ & \\
\hline \multirow{4}{*}{$\begin{array}{l}\text { Alternative } \\
\text { Uncertainty values for } \\
\text { Thorium solubility }\end{array}$} & \multicolumn{2}{|l|}{$\log K$} & $\begin{array}{l}\text { Normal } \\
\text { Truncated at } \pm 2 \sigma\end{array}$ & $\mu=0, \sigma=0.7(0.76)^{a, b}$ & \multirow{4}{*}{ Table 6.8-6 } \\
\hline & \multicolumn{2}{|c|}{$\begin{array}{l}F^{-} \text {(for CSNF waste packages } \\
- \text { Water Influx Scenario) }\end{array}$} & Triangular & $\begin{array}{l}\mathrm{a}=\mathrm{b}=0, \mathrm{c}=3.10^{\mathrm{c}}(\mathrm{pH} \\
\text { dependence of } \mathrm{c} \\
\text { indicated in Table 6.8-7 }\end{array}$ & \\
\hline & \multirow{2}{*}{$\begin{array}{l}F^{-} \text {(for } \\
\text { codisposal } \\
\text { waste package } \\
\text { and invert) }\end{array}$} & $\begin{array}{l}\text { Water Influx } \\
\text { Scenario }\end{array}$ & Triangular & $\begin{array}{l}\mathrm{a}=\mathrm{b}=0, \mathrm{c}=4.21(\mathrm{pH} \\
\text { dependence of } \mathrm{c} \\
\text { indicated in Table 6.8-7) }\end{array}$ & \\
\hline & & $\begin{array}{l}\text { Vapor Influx } \\
\text { Scenario }\end{array}$ & Triangular & $\begin{array}{l}a=b=0, c=5.27(p H \\
\text { dependence of } c \\
\text { indicated in Table 6.8-7) }\end{array}$ & \\
\hline \multirow{4}{*}{$\begin{array}{l}\text { Alternative } \\
\text { Uncertainty values for } \\
\text { Americium solubility }\end{array}$} & \multicolumn{2}{|l|}{$\log K$} & $\begin{array}{l}\text { Normal } \\
\text { Truncated at } \pm 2 \sigma\end{array}$ & $\mu=0, \sigma=1.0(1.04)^{a_{1} b}$ & \multirow{4}{*}{ Table 6.9-6 } \\
\hline & \multicolumn{2}{|c|}{$\begin{array}{l}F^{-} \text {(for CSNF waste packages } \\
\text { - Water Influx Scenario) }\end{array}$} & Triangular & $\begin{array}{l}a=b=0, c=5.91 E-2^{c} \\
\text { (pH dependence of } c \\
\text { indicated in Table 6.9-7) }\end{array}$ & \\
\hline & \multirow{2}{*}{$\begin{array}{l}\mathrm{F}^{-} \text {(for } \\
\text { codisposal } \\
\text { waste package } \\
\text { and invert) }\end{array}$} & $\begin{array}{l}\text { Water Influx } \\
\text { Scenario }\end{array}$ & Triangular & $\begin{array}{l}a=b=0, c=0.40(p H \\
\text { dependence of } c \\
\text { indicated in Table 6.8-7) }\end{array}$ & \\
\hline & & $\begin{array}{l}\text { Vapor Influx } \\
\text { Scenario }\end{array}$ & Triangular & $\begin{array}{l}a=b=0, c=0.99(p H \\
\text { dependence of } c \\
\text { indicated in Table 6.8-7) }\end{array}$ & \\
\hline
\end{tabular}

NOTES: ${ }^{a}$ When used with solutions having an ionic strength from 1 to 3 molal, log $\mathrm{K}$ uncertainty is the number indicated in parentheses.

bame as base-case value.

c Uncertainty term used in base case without $\mathrm{pH}$ dependence. 
The look-up tables for radionuclide solubilities (summarized in Tables 8-1 and 8-2) include a flag of 500, which indicates no solubility can be calculated within the valid range of the model. Constraining the dissolved concentrations is necessary for use in TSPA-LA calculations for cases in which solubility is undefined, such as when "500" flags are indicated or conditions are outside of the range of validity of the dissolved concentrations model (example, ionic strength above 3 ). As an example, because of the instantaneous release rate attributed to DSNF, it is possible to release the entire inventory in one TSPA time step. Setting caps on the solubilities will prevent unconstrained concentrations of actinides entering solution.

The densities located in Table 8-5 are to be applied in TSPA-LA under the following conditions.

- When a 500 flag is indicated in the solubility look up tables.

- When conditions are outside of the range of validity for the dissolved concentrations model (see Table 8-6 for range of applicable conditions)

Table 8-5. Density of Actinides at $25^{\circ} \mathrm{C}$

\begin{tabular}{|l|c|c|c|c|c|c|c|}
\hline & Pu & Np & U & Th & Am & Ac & Pa \\
\hline Density (g/cm $\mathbf{3})$ & 19.7 & 20.2 & 19.1 & 11.7 & $13.65^{\mathrm{a}}$ & 10 & 15.4 \\
\hline Density (mg/L) & $1.97 \mathrm{E}+07$ & $2.02 \mathrm{E}+07$ & $1.91 \mathrm{E}+07$ & $1.17 \mathrm{E}+07$ & $1.36 \mathrm{E}+07$ & $1.00 \mathrm{E}+07$ & $1.54 \mathrm{E}+07$ \\
\hline
\end{tabular}

NOTE: a TSPA-LA currently implements the Am cap as indicated in MO0408SPADCLRE.000. However, this value is incorrectly pulled from spreadsheet Lide 2002 ([DIRS 160832] p. 4-40) (actual value is $12 \mathrm{~g} / \mathrm{cm}^{3}$ ).

\subsection{YUCCA MOUNTAIN REVIEW PLAN ACCEPTANCE CRITERIA}

Yucca Mountain Review Plan, Final Report (NRC 2003 [DIRS 163274]) contains Acceptance Criteria that are intended to establish the basis for the review of the material contained in the License Application. As this report serves, in part, as the basis for the License Application, it is important to show how the information contained herein addresses each of the applicable Acceptance Criteria.

The Acceptance Criteria that are applicable to this report are identified in Technical Work Plan for: Regulatory Integration Modeling and Analysis of the Waste Form and Waste Package (BSC 2004 [DIRS 171583], Table 3-1). For each applicable criterion, the criterion is quoted in italics, followed by pointers to where within the report the information addressing the criterion can be found. In some cases, the criterion is only partially addressed in this report. A demonstration of full compliance requires a review of multiple reports.

Radionuclide Release Rates and Solubility Limits (NRC 2003 [DIRS 163274], Section 2.2.1.3.4.3)

\section{Acceptance Criterion 1-System Description and Model Integration Are Adequate.}

(1) Total system performance assessment adequately incorporates important design features, physical phenomena, and couplings, and uses consistent and appropriate assumptions throughout the radionuclide release rates and solubility limits abstraction process. 
Sections 6.3 and 6.4 addresses the chemical conditions expected in the repository. Assumptions are listed in Section 5.

(2) The abstraction of radionuclide release rates and solubility limits uses assumptions, technical bases, data, and models that are appropriate and consistent with other related U.S. Department of Energy abstractions. For example, the assumptions used for this model abstraction are consistent with the abstractions of "Degradation of Engineered Barriers" (Section 2.2.1.3.1); "Mechanical Disruption of Waste Packages" (Section 2.2.1.3.2); "Quantity and Chemistry of Water Contacting Waste Packages and Waste Forms" (Section 2.2.1.3.3); "Climate and Infiltration" (Section 2.2.1.3.5); and "Flow Paths in the Unsaturated Zone" (Section 2.2.1.3.6). The descriptions and technical bases provide transparent and traceable support for the abstraction of radionuclide release rates and solubility limits;

The range of chemical conditions expected in the repository (Sections 6.3 and 6.4) and the assumptions (Section 5) are consistent with other models, such as In-Package Chemistry Abstraction (BSC 2004 [DIRS 167621]) and Engineered Barrier System: Physical and Chemical Environment (BSC 2004 [DIRS 169054].

(3) The abstraction of radionuclide release rates and solubility limits provides sufficient, consistent design information on waste packages and engineered barrier systems. For example, inventory calculations and selected radionuclides are based on the detailed information provided on the distribution (both spatially and by compositional phase) of the radionuclide inventory, within the various types of high-level radioactive waste;

Section 1 indicates that the radionuclides selected to be included in this report are based on the radiation dose that a person located near the repository might receive.

(4) The U.S. Department of Energy reasonably accounts for the range of environmental conditions expected inside breached waste packages and in the engineered barrier environment surrounding the waste package. For example, the U.S. Department of Energy should provide a description and sufficient technical bases for its abstraction of changes in hydrologic properties in the near field, caused by coupled thermal-hydrologic-mechanical-chemical processes;

The solubility models account for the range of environmental conditions ( $\mathrm{pH}$, temperature, and carbonate) expected, as described in Sections 6.3 and 6.4.

(5) The description of process-level conceptual and mathematical models is sufficiently complete, with respect to thermal-hydrologic processes affecting radionuclide release from the emplacement drifts. For example, if the U.S. Department of Energy uncouples coupled processes, the demonstration that uncoupled model results bound predictions of fully coupled results is adequate;

The influence of temperature on the solubilities is discussed in Section 6.3.3.3. 
(6) Technical bases for inclusion of any thermal-hydrologic-mechanical-chemical couplings and features, events, and processes in the radionuclide release rates and solubility limits model abstraction are adequate. For example, technical bases may include activities, such as independent modeling, laboratory or field data, or sensitivity studies;

As discussed in Section 6, the selections of the solubility-controlling solid phases were based on laboratory or field observations and corroborated by Project-specific laboratory results.

(7)...

Not Applicable (applies to criticality).

(8) Guidance in NUREG-1297 and NUREG-1298 or other acceptable approaches for peer reviews and data qualification is followed.

Section 4.1 addresses data inputs to the model and qualification of data.

\section{Acceptance Criterion 2-Data Are Sufficient for Model Justification}

(1) Geological, hydrological, and geochemical values used in the license application are adequately justified. Adequate description of how the data were used, interpreted, and appropriately synthesized into the parameters is provided;

The thermodynamic database and other inputs are discussed in Section 4.1. As discussed in Section 6, the selections of the solubility-controlling solid phases were based on laboratory or field observations and corroborated by Project-specific laboratory results.

(2) Sufficient data have been collected on the characteristics of the natural system and engineered materials to establish initial and boundary conditions for conceptual models and simulations of thermal-hydrologic-chemical coupled processes. For example, sufficient data should be provided on design features, such as the type, quantity, and reactivity of materials, that may affect radionuclide release for this abstraction;

Experimental data used to establish controlling phase and uncertainties are listed in Sections 4.1, 6, and 6.1. Chemistry of the water is discussed in Section 6.4.

(3) Where the U.S. Department of Energy uses data supplemented by models to support abstraction of solubility limits, the anticipated range of proportions and compositions of phases under the various physicochemical conditions expected are supported by experimental data;

Laboratory experiments and observations of natural systems that support the choice of solubilitycontrolling solids are discussed in Sections 6, 6.3.2, and 7.

(4) The corrosion and radionuclide release testing program for high-level radioactive waste forms intended for disposal provides consistent, sufficient, and 
suitable data for the in-package and in-drift chemistry used in the abstraction of radionuclide release rates and solubility limits. For expected environmental conditions, the U.S. Department of Energy provides sufficient justification for the use of test results, not specifically collected from the Yucca Mountain site, for engineered barrier components, such as high-level radioactive waste forms, drip shield, and backfill.

Results from testing that were used to validate the solubility models are discussed in Section 7.

\section{Acceptance Criterion 3-Data Uncertainty Is Characterized and Propagated Through the Model Abstraction.}

(1) Models use parameter values, assumed ranges, probability distributions, and bounding assumptions that are technically defensible, reasonably account for uncertainties and variabilities, and do not result in an under-representation of the risk estimate;

Uncertainty is discussed in Sections 6.3.3, 6.5 through 6.11, and 8.2.

(2) Parameter values, assumed ranges, probability distributions, and bounding assumptions used in the abstractions of radionuclide release rates and solubility limits in the total system performance assessment are technically defensible and reasonable based on data from the Yucca Mountain region, laboratory tests, and natural analogs. For example, parameter values, assumed ranges, probability distributions, and bounding assumptions adequately reflect the range of environmental conditions expected inside breached waste packages;

Parameter values and uncertainty are discussed in Sections 4.1, 6.3, and 6.4.

(3)...

Not applicable (applies to release, rather than solubility).

(4) Uncertainty is adequately represented in parameter development for conceptual models, process models, and alternative conceptual models considered in developing the abstraction of radionuclide release rates and solubility limits, either through sensitivity analyses or use of bounding analyses;

Uncertainty is addressed throughout the document, such as Sections 6.3.3, 6.5 through 6.11, and 8.2 .

$(5-6) \ldots$

Not Applicable (applies to water flow and criticality).

(7) The U.S. Department of Energy uses as appropriate range of time-history of temperature, humidity, and dripping to constrain the probability for microbial effects, such as production of organic by-products that act as complexing ligands 
for actinides and microbially enhanced dissolution of the high-level radioactive waste glass form;

The complexing ligands that are important to solubility are discussed in Section 6.4.1. Organic complexing ligands are not expected to be present in significant concentrations in the repository (BSC 2004 [DIRS 163116], Section 6.2.26, pp. 94 to 95).

(8) The U.S. Department of Energy adequately considers the uncertainties, in the characteristics of the natural system and engineered materials, such as the type, quantity, and reactivity of material, in establishing initial and boundary conditions for conceptual models and simulations of thermal-hydrologic-chemical coupled processes that affect radionuclide release; and

Uncertainty is addressed throughout the document, such as Sections 6.3.3, 6.5 through 6.11, and 8.2.

(9)...

Not Applicable (applies only when insufficient data exists).

\section{Acceptance Criterion 4 - Model Uncertainty Is Characterized and Propagated Through the Model Abstraction.}

(1) Alternative modeling approaches of features, events, and processes are considered and are consistent with available data and current scientific understanding, and the results and limitations are appropriately considered in the abstraction;

Alternative modeling approaches are discussed in Sections 6.19 and 8.1.

(2) In considering alternative conceptual models for radionuclide release rates and solubility limits, the U.S. Department of Energy uses appropriate models, tests, and analyses that are sensitive to the processes modeled for both natural and engineering systems. Conceptual model uncertainties are adequately defined and documented, and effects on conclusions regarding performance are properly assessed. For example, in modeling flow and radionuclide release from the drifts, the U.S. Department of Energy represents significant discrete features, such as fault zones, separately, or demonstrates that their inclusion in the equivalent continuum model produces a conservative effect on calculated performance; and

Alternative models and their effects on solubility are discussed in Section 6.19.

(3) Consideration of conceptual model uncertainty is consistent with available site characterization data, laboratory experiments, field measurements, natural analog information and process-level modeling studies; and the treatment of conceptual model uncertainty does not result in an under-representation of the risk estimate; and 
Alternative models and their effects on solubility are discussed in Section 6.19.

(4) $\ldots$

Not applicable (refers to radionuclide release rather than solubility).

\section{Acceptance Criterion 5 Model Abstraction Output Is Supported by Objective} Comparisons.

(1) The models implemented in this total system performance assessment abstraction provide results consistent with output from detailed process-level models and/or empirical observations (laboratory and field testing and/or natural analogs);

As discussed in Section 6, the selections of the solubility-controlling solid phases were based on laboratory or field observations and corroborated by Project-specific laboratory results.

(2) $\ldots$

Not Applicable (applies to thermal hydrologic models).

(3) $\ldots$

Not applicable (applies to radionuclide release rather than solubility).

(4)...

Not Applicable (applies to the performance confirmation program).

\subsection{RESTRICTIONS}

As discussed in Section 6.4, the solubility models developed in this report are valid for broad ranges of water composition, as listed in Table 8-6. They may be applied inside and outside waste packages. 
Table 8-6. Valid Range of the Solubility Models Reported in This Report

\begin{tabular}{|c|c|}
\hline Variable & Value or Range \\
\hline $\mathrm{pH}$ & 3.0 to 11.0 \\
\hline $\log \mathrm{fCO}_{2}$ & -5.0 to -1.5 bars \\
\hline Temperature & $25^{\circ} \mathrm{C}$ to $100^{\circ} \mathrm{C}$ \\
\hline $\mathrm{F}^{-}$concentration & $\begin{array}{l}\text { For Th, Am, and Pa } 1 \text { to } 10 \text { times the base-case value for } \\
\text { CSNF waste packages; } 1 \text { to } 200 \text { times the base-case value for } \\
\text { codisposal waste packages; and } 1 \text { to } 200 \text { times the base-case } \\
\text { value for the invert. For } \mathrm{Pu}, \mathrm{Np} \text {, and } \mathrm{U}: 1 \text { to } 10 \text { times the base- } \\
\text { case value for CSNF packages for nominal and seismic } \\
\text { breach scenarios: } 1 \text { to } 27 \text { times the base-case value for water } \\
\text { influx codisposal packages and CSNF packages breached } \\
\text { during an igneous intrusion: } 1 \text { to } 96 \text { times the base-case value } \\
\text { for vapor influx codisposal packages and invert }\end{array}$ \\
\hline \multirow[t]{2}{*}{ Ionic Strength } & $\begin{array}{l}\text { Less than } 1 \text { molal: With } \sigma \text { values for log } \mathrm{K} \text { uncertainties given } \\
\text { in Table 8-3 for all controlling solids. }\end{array}$ \\
\hline & $\begin{array}{l}\text { From } 1 \text { to } 3 \text { molal: With } \sigma \text { values for log } \mathrm{K} \text { uncertainties equal } \\
\text { to }\left(\sigma^{2}+0.3^{2}\right)^{1 / 2} \text { where } \sigma \text { is the log } \mathrm{K} \text { uncertainty value given in } \\
\text { Table } 8-3 \text { for all controlling solids except } \mathrm{Na}_{4} \cup \mathrm{O}_{2}\left(\mathrm{CO}_{3}\right)_{3} \text {. For } \\
\mathrm{Na}_{4} \mathrm{UO}_{2}\left(\mathrm{CO}_{3}\right)_{3} \text { as controlling solid use log } \mathrm{K} \text { uncertainty value } \\
\text { given in Table 8-3. }\end{array}$ \\
\hline
\end{tabular}


INTENTIONALLY LEFT BLANK 


\section{INPUTS AND REFERENCES}

\subsection{DOCUMENTS CITED}

134303 Atkins, P.W. 1994. Physical Chemistry. 5th Edition. New York, New York: W.H. Freeman and Company. TIC: 246986.

168371 Baas Becking, L.G.M.; Kaplan, I.R.; and Moore, D. 1960. "Limits of the Natural Environment in Terms of $\mathrm{pH}$ and Oxidation-Reduction Potentials." Journal of Geology, 68, (3), 243-284. [Chicago, Illinois: University of Chicago Press]. TIC: 255394.

100702 Baes, C.F., Jr. and Mesmer, R.E. 1986. The Hydrolysis of Cations. Malabar, Florida: Krieger Publishing Company. TIC: 223481.

162000 Berner, U. 2002. Project Opalinus Clay: Radionuclide Concentration Limits in the Near-Field of a Repository for Spent Fuel and Vitrified High-Level Waste. PSI Bericht 02-22. Villigen, Switzerland: Paul Scherrer Institut. TIC: 253856.

144728 Berry, J.A.; Hobley, J.; Lane, S.A.; Littleboy, A.K.; Nash, M.J.; Oliver, P.; SmithBriggs, J.L.; and Williams, S.J. 1989. "Solubility and Sorption of Protactinium in the Near-Field and Far-Field Environments of a Radioactive Waste Repository." Analyst, 114, 339-347. Cambridge, England: Royal Society of Chemistry. TIC: 247004.

146304 Bevington, P.R. 1969. Data Reduction and Error Analysis for the Physical Sciences. New York, New York: McGraw-Hill. TIC: 244912.

111794 Bruno, J.; Cera, E.; de Pablo, J.; Duro, L.; Jordana, S.; and Savage, D. 1997. Determination of Radionuclide Solubility Limits to be Used in SR 97 - Uncertainties Associated to Calculated Solubilities. SKB TR-97-33. Stockholm, Sweden: Svensk Kärnbränsleförsörjning A.B. TIC: 239307. [DIRS 111794]

101565 Bruno, J.; Cera, E.; Eklund, U.B.; Eriksen, T.E.; and Grive, M. 1998. Some Preliminary Modeling Results of Long Term Radiolytic Mass Balance Experiments. Presentation at the Spent Fuel Workshop 1998, Las Vegas, Nevada, May 18-20, 1998. Barcelona, Spain: Quantisci. TIC: 240716. [DIRS 101565]

153909 BSC (Bechtel SAIC Company) 2001. Waste Package Radionuclide Inventory Approximations for TSPA-SR. CAL-WIS-MD-000004 REV 00 ICN 01. Las Vegas, Nevada: Bechtel SAIC Company. ACC: MOL.20010227.0015. [DIRS 153909]

154841 BSC 2001. Inventory Abstraction. ANL-WIS-MD-000006 REV 00 ICN 02. Las Vegas, Nevada: Bechtel SAIC Company. ACC: MOL.20010416.0088.

154844 BSC 2001. Secondary Uranium-Phase Paragenesis and Incorporation of Radionuclides into Secondary Phases. ANL-EBS-MD-000019 REV 00 ICN 01. Las Vegas, Nevada: Bechtel SAIC Company. ACC: MOL.20010625.0306. 
160059 BSC 2002. Radionuclide Screening. ANL-WIS-MD-000006 REV 01. Las Vegas, Nevada: Bechtel SAIC Company. ACC: MOL.20020923.0177.

160313 BSC 2002. Scientific Processes Guidelines Manual. MIS-WIS-MD-000001 REV 01. Las Vegas, Nevada: Bechtel SAIC Company. ACC: MOL.20020923.0176.

166845 BSC 2003. Waste Form and In-Drift Colloids-Associated Radionuclide Concentrations: Abstraction and Summary. MDL-EBS-PA-000004 REV 00 ICN 01. Las Vegas, Nevada: Bechtel SAIC Company. ACC: DOC.20031222.0012.

168361 BSC 2004. Q-List. 000-30R-MGR0-00500-000-000 REV 00. Las Vegas, Nevada: Bechtel SAIC Company. ACC: ENG.20040721.0007.

171583 BSC 2004. Technical Work Plan for: Regulatory Integration Modeling and Analysis of the Waste Form and Waste Package. TWP-WIS-MD-000009 REV 00 ICN 01. Las Vegas, Nevada: Bechtel SAIC Company. ACC:DOC.20040910.0001.

169054 BSC 2004. Engineered Barrier System: Physical and Chemical Environment. ANLEBS-MD-000033 REV 02, with 1 errata. Las Vegas, Nevada: Bechtel SAIC Company. ACC: DOC.20040212.0004; DOC.20040426.0003.

167621 BSC (Bechtel SAIC Company) 2004. In-Package Chemistry Abstraction. ANL-EBSMD-000037, Rev. 03. Las Vegas, Nevada: Bechtel SAIC Company.

168960 BSC 2004. Igneous Intrusion Impacts on Waste Packages and Waste Forms. MDLEBS-GS-000002 REV 01. Las Vegas, Nevada: Bechtel SAIC Company. ACC: DOC.20040421.0002.

170020 BSC 2004. Waste-Form Features, Events, and Processes. ANL-WIS-MD-000009 REV 02. Las Vegas, Nevada: Bechtel SAIC Company. ACC: DOC.20041028.0006.

167461 BSC 2004. Engineered Barrier System: Physical and Chemical Environment Model. ANL-EBS-MD-000033 REV 02. Las Vegas, Nevada: Bechtel SAIC Company. ACC: DOC.2004021.0004.

170025 BSC 2004. Waste Form and In-Drift Colloids-Associated Radionuclide Concentrations: Abstraction and Summary. MDL-EBS-PA-000004 REV 01. Las Vegas, Nevada: Bechtel SAIC Company. ACC: DOC.20041028.0007.

100388 Buck, E.C.; Finch, R.J.; Finn, P.A.; and Bates, J.K. 1998. "Retention of Neptunium in Uranyl Alteration Phases Formed During Spent Fuel Corrosion." Scientific Basis for Nuclear Waste Management XXI, Symposium held September 28-October 3, 1997, Davos, Switzerland. McKinley, I.G. and McCombie, C., eds. 506, 87-94.

Warrendale, Pennsylvania: Materials Research Society. TIC: 240702.

100389 Burns, P.C.; Ewing, R.C.; and Miller, M.L. 1997. "Incorporation Mechanisms of Actinide Elements into the Structures of $\mathrm{U}^{6+}$ Phases Formed During the Oxidation of 
Spent Nuclear Fuel." Journal of Nuclear Materials, 245, (1), 1-9. Amsterdam, The Netherlands: North-Holland. TIC: 235501.

171442 Burns, P.C.; Deely, K.M.; and Skanthakumar, S. 2004. "Neptunium Incorporation into Uranyl Compounds that Form as Alteration Products of Spent Nuclear Fuel: Implications for Geologic Repository Performance." Radiochimica Acta, 92, 151-159. München, Germany: Oldenbourg Wissenschaftsverlag. TIC: 256456.

166275 Canori, G.F. and Leitner, M.M. 2003. Project Requirements Document. TER-MGR-MD-000001 REV 02. Las Vegas, Nevada: Bechtel SAIC Company. ACC: DOC.20031222.0006.

161997 Chen, Y. 2001. “An Empirical Np Solubility Model Based on Spent Fuel Dissolution Experiments." Back to the Future - Managing the Back End of the Nuclear Fuel Cycle to Create a More Secure Energy Future," Proceedings of the 9th International High-Level Radioactive Waste Management Conference (IHLRWM), Las Vegas, Nevada, April 29-May 3, 2001. La Grange Park, Illinois: American Nuclear Society. TIC: 247873.

162709 Chen, Y. 2003. "Using Reactive Transport Modeling to Evaluate the Source Term at Yucca Mountain." Computers \& Geosciences, 29, (3), 385-397. New York, New York: Pergamon. TIC: 254363.

161996 Chen, Y.; Loch, A.R.; Wolery, T.J.; Steinborn, T.L.; Brady, P.V.; and Stockman, C.T. 2002. "Solubility Evaluation for Yucca Mountain TSPA-SR." Scientific Basis for Nuclear Waste Management XXV, Symposium held November 26-29, 2001, Boston, Massachusetts. McGrail, B.P. and Cragnolino, G.A., eds. 713, 775-782. Warrendale, Pennsylvania: Materials Research Society. TIC: 248663.

145441 Chen, Y.; Siegmann, E.; Mattie, P.; NcNeish, J.; Sevougian, S.D.; and Andrews, R. 1999. "A Mechanistic Model of Spent Fuel Dissolution, Secondary Mineral Precipitation, and Np Release." Scientific Basis for Nuclear Waste Management XXII, Symposium held November 30-December 4, 1998, Boston, Massachusetts, U.S.A. Wronkiewicz, D.J. and Lee, J.H., eds. 556, 471-478. Warrendale, Pennsylvania: Materials Research Society. TIC: 246426.

168308 Choppin, G.R. 2003. “Actinide Speciation in the Environment.” Radiochimica Acta, 91, (11), 645-649. München, Germany: Oldenbourg Wissenschaftsverlag. TIC: 255776.

168379 Choppin, G.R. and Stout, B.E. 1989. "Actinide Behavior in Natural Waters." Science of the Total Environmental, 83, ([3]), 203-216. Amsterdam, The Netherlands: Elsevier. TIC: 255706.

168377 Choppin, G.R.; Roberts, R.A.; and Morse, J.W. 1986. "Effects of Humic Substances on Plutonium Speciation in Marine Systems." Organic Marine Geochemistry. Sohn, M.L., ed. ACS Symposium Series 305. Pages 382-388. Washington, D.C.: American Chemical Society. TIC: 255705. 
168395 Choppin, G. 1983, Aspects of Plutonium Solution Chemistry, in Plutonium Chemistry, by Carnall, William T.;Choppin, G.R. (eds.). TIC :219103.

100222 CRWMS M\&O (Civilian Radioactive Waste Management System Management and Operations) 1997. Degraded Mode Criticality Analysis of Immobilized Plutonium Waste Forms in a Geologic Repository. Predecisional Document. A0000000001717-5705-00014 REV 01. Las Vegas, Nevada: CRWMS M\&O. ACC: MOL.19980422.0911.

100348 CRWMS M\&O 1998. Constraints on Solubility-Limited Neptunium Concentrations for Use in Performance Assessment Analyses. B00000000-01717-2200-00191 REV 00. Las Vegas, Nevada: CRWMS M\&O. ACC: MOL.19980213.0484.

100362 CRWMS M\&O 1998. "Waste Form Degradation, Radionuclide Mobilization, and Transport Through the Engineered Barrier System." Chapter 6 of Total System Performance Assessment-Viability Assessment (TSPA-VA) Analyses Technical Basis Document. B00000000-01717-4301-00006 REV 01. Las Vegas, Nevada: CRWMS M\&O. ACC: MOL.19981008.0006.

152507 CRWMS M\&O 2000. Data Qualification Report: Composition of J-13 Well Water for Use on the Yucca Mountain Project, Revision 0. TDR-NBS-HS-000003 REV 00. Las Vegas, Nevada: CRWMS M\&O. ACC: MOL.20000724.0463.

131861 CRWMS M\&O 2000. Commercial Spent Nuclear Fuel Degradation in Unsaturated Drip Tests. Input Transmittal WP-WP-99432.T. Las Vegas, Nevada: CRWMS M\&O. ACC: MOL.20000107.0209.

153105 CRWMS M\&O 2000. Measured Solubilities, Argonne National Lab High Drip Rate Tests. Input Transmittal 00333.T. Las Vegas, Nevada: CRWMS M\&O. ACC: MOL.20000919.0019.

135790 CRWMS M\&O 2000. In-Drift Accumulation of Fissile Material from Waste Packages Containing Plutonium Disposition Waste Forms. CAL-EDC-GS-000001 REV 00. Las Vegas, Nevada: CRWMS M\&O. ACC: MOL.20001016.0008.

154629 CRWMS M\&O 2001. Pure Phase Solubility Limits - LANL. ANL-EBS-MD-000017 REV 00 ICN 01. Las Vegas, Nevada: CRWMS M\&O. ACC:

MOL.20010126.0005.

155943 DOE 2002. Yucca Mountain Science and Engineering Report. DOE/RW-0539, Rev. 1. Washington, D.C.: U.S. Department of Energy, Office of Civilian Radioactive Waste Management. ACC: MOL.20020404.0042.

108015 Efurd, D.W.; Runde, W.; Banar, J.C.; Janecky, D.R.; Kaszuba, J.P.; Palmer, P.D.; Roensch, F.R.; and Tait, C.D. 1998. "Neptunium and Plutonium Solubilities in a Yucca Mountain Groundwater." Environmental Science \& Technology, 32, (24), 3893-3900. Easton, Pennsylvania: American Chemical Society. TIC: 243857. 
161979 Finch, R.J.; Fortner, J.A.; Buck, E.C.; and Wolf, S.F. 2002. "Neptunium Incorporation into Uranium(VI) Compounds Formed During Aqueous Corrosion of Neptunium-Bearing Uranium Oxides." Scientific Basis for Nuclear Waste Management XXV, Symposium held November 26-29, 2001, Boston, Massachusetts. McGrail, B.P. and Cragnolino, G.A., eds. 713, 647-654. Warrendale, Pennsylvania: Materials Research Society. TIC: 248663.

113056 Finch, R.J.; Suksi, J.; Rasilainen, K.; and Ewing, R.C. 1996. "Uranium Series Ages of Secondary Uranium Minerals, with Applications to the Long-Term Storage of Spent Nuclear Fuel." Scientific Basis for Nuclear Waste Management XIX, Symposium held November 27-December 1, 1995, Boston, Massachusetts. Murphy, W.M. and Knecht, D.A., eds. 412, 823-830. Pittsburgh, Pennsylvania: Materials Research Society. TIC: 233877.

100746 Finn, P.A.; Buck, E.C.; Gong, M.; Hoh, J.C.; Emery, J.W.; Hafenrichter, L.D.; and Bates, J.K. 1994. "Colloidal Products and Actinide Species in Leachate from Spent Nuclear Fuel." Radiochimica Acta, 66/67, 197-203. München, Germany: R. Oldenbourg Verlag. TIC: 238493.

124142 Finn, P.A.; Hoh, J.C.; Wolf, S.F.; Surchik, M.T.; Buck, E.C.; and Bates, J.K. 1997. "Spent Fuel Reaction: The Behavior of the Epsilon-Phase Over 3.1 Years." Scientific Basis for Nuclear Waste Management XX, Symposium held December 2-6, 1996, Boston, Massachusetts. Gray, W.J. and Triay, I.R., eds. 465, 527-534. Pittsburgh, Pennsylvania: Materials Research Society. TIC: 238884.

144877 Garrels, R.M. and Christ, C.L. 1990. Solutions, Minerals, and Equilibria. Boston, Massachusetts: Jones and Bartlett Publishers. TIC: 223483.

161964 Grenthe, I. 1991. "Thermodynamics in Migration Chemistry." Radiochimica Acta, 52/53, (Part II), 425-432. München, Germany: R. Oldenbourg Verlag. TIC: 250613.

101671 Grenthe, I.; Fuger, J.; Konings, R.J.M.; Lemire, R.J.; Muller, A.B.; Nguyen-Trung, C.; and Wanner, H. 1992. Chemical Thermodynamics of Uranium. Volume 1 of Chemical Thermodynamics. Wanner, H. and Forest, I., eds. Amsterdam, The Netherlands: North-Holland Publishing Company. TIC: 224074.

109205 Guenther, R.J.; Blahnik, D.E.; Campbell, T.K.; Jenquin, U.P.; Mendel, J.E.; Thomas, L.E.; and Thornhill, C.K. 1988. Characterization of Spent Fuel Approved Testing Material ATM-103. PNL-5109-103. Richland, Washington: Pacific Northwest Laboratory. ACC: NNA.19911017.0104.

109206 Guenther, R.J.; Blahnik, D.E.; Campbell, T.K.; Jenquin, U.P.; Mendel, J.E.; and Thornhill, C.K. 1988. Characterization of Spent Fuel Approved Testing MaterialATM-106. PNL-5109-106. Richland, Washington: Pacific Northwest Laboratory. ACC: NNA.19911017.0105. 
168382 Guillaumont, Robert, Fänghanel, Thomas, Fuger, Jean, Grenthe, Ingmar, Neck, Volker, Palmer, Donald A. and Rand, Malcolm H. 2003. Update on the Chemical Thermodynamics of Uranium, Neptunium, Americium and Technetium. Volume 5 of Chemical Thermodynamics. Amsterdam. Elsevier. TIC: 255230.

100814 Harrar, J.E.; Carley, J.F.; Isherwood, W.F.; and Raber, E. 1990. Report of the Committee to Review the Use of J-13 Well Water in Nevada Nuclear Waste Storage Investigations. UCID-21867. Livermore, California: Lawrence Livermore National Laboratory. ACC: NNA.19910131.0274.

162001 Haschke, J.M. and Allen, T.H. 2002. "Equilibrium and Thermodynamic Properties of the $\mathrm{PuO}_{2+\mathrm{x}}$ Solid Solution." Journal of Alloys and Compounds, 336, (1-2), 124-131. New York, New York: Elsevier. TIC: 253947.

162699 Haschke, J.M. and Bassett, R.L. 2002. "Control of Plutonium Dioxide Solubility by Amorphous Tetrahydroxide: A Critical Review of the Model." Radiochimica Acta, 90, (9-11), 505-509. München, Germany: Oldenbourg Verlag. TIC: 252601.

161911 Haschke, J.M. and Oversby, V.M. 2002. "Plutonium Chemistry: A Synthesis of Experimental Data and a Quantitative Model for Plutonium Oxide Solubility." Journal of Nuclear Materials, 305, (2-3), 187-201. New York, New York: Elsevier. TIC: 253028.

150367 Haschke, J.M.; Allen, T.H.; and Morales, L.A. 2000. "Reaction of Plutonium Dioxide with Water: Formation and Properties of $\mathrm{PuO}_{2+\mathrm{x}}$." Science, 287, 285-287. Washington, D.C: American Association for the Advancement of Science. TIC: 248119.

115670 Hem, J.D. 1985. Study and Interpretation of the Chemical Characteristics of Natural Water. 3rd Edition. U.S. Geological Survey Water-Supply Paper 2254. 3rd Edition. Washington, D.C.: U.S. Government Printing Office. ACC: NNA.19940427.0181.

161904 Hummel, W.; Berner, U.; Curti, E.; Pearson, F.J.; and Thoenen, T. 2002. Nagra/PSI Chemical Thermodynamic Data Base 01/01. Parkland, Florida: Universal Publishers. TIC: 253421.

170921 Hummel, W. and Berner, U. 2002. Application of the Nagra/PSI TDB 01/01: Solubility of $T h, U, N p$, and $P u$. Nagra Technical Report 02-12. Wettingen, Switzerland: National Cooperative for the Disposal of Radioactive Waste. TIC: 256305.

151237 Kielland, J. 1937. "Individual Activity Coefficients of Ions in Aqueous Solutions." Journal of the American Chemical Society, 59, (9), 1675-1678. Easton, Pennsylvania: The American Chemical Society. TIC: 248309.

122387 Kim J.I. and Kanellakopulos B. 1989. "Solubility Products of Plutonium(IV) Oxide and Hydroxide." Radiochimica Acta, 48, 145-150. Munich, Germany: R. Oldenbourg Verlag. TIC: 246360. 
101702 Krauskopf, K.B. and Bird, D.K. 1995. Introduction to Geochemistry. 3rd Edition. New York, New York: McGraw-Hill. TIC: 239316.

100051 Langmuir, D. 1997. Aqueous Environmental Geochemistry. Upper Saddle River, New Jersey: Prentice Hall. TIC: 237107.

106457 Langmuir, D. and Riese, A.C. 1985. "The Thermodynamic Properties of Radium." Geochimica et Cosmochimica Acta, 49, 1593-1601. New York, New York: Pergamon Press. TIC: 241035.

159027 Lemire, R.J. 2001. Chemical Thermodynamics of Neptunium and Plutonium. Volume 4 of Chemical Thermodynamics. New York, New York: Elsevier. TIC: 209037.

101876 Lide, D.R., ed. 1995. CRC Handbook of Chemistry and Physics. 76th Edition. Boca Raton, Florida: CRC Press. TIC: 216194.

160832 Lide, D.R., ed. 2002. CRC Handbook of Chemistry and Physics. 83rd Edition. Boca Raton, Florida: CRC Press. TIC: 253582.

101731 Murphy, W.M. 1997. "Retrograde Solubilities of Source Term Phases." Scientific Basis for Nuclear Waste Management XX, Symposium held December 2-6, 1996, Boston, Massachusetts. Gray, W.J. and Triay, I.R., eds. 465, 713-720. Pittsburgh, Pennsylvania: Materials Research Society. TIC: 238884.

168433 Murphy, W.M. and Shock, E.L. 1999. "Environmental Aqueous Geochemistry of Actinides." Chapter 5 of Uranium: Mineralogy, Geochemistry and the Environment. Burns, P.C. and Finch, R.J., eds. Reviews in Mineralogy Volume 38. Washington, D.C.: Mineralogical Society of America. TIC: 247121.

168258 Neck, V. and Kim, J.I. 2001. "Solubility and Hydrolysis of Tetravalent Actinides." Radiochimica Acta, 89, (1), 1-16. München, Germany: Oldenbourg Wissenschaftsverlag. TIC: 250728.

170922 NAGRA 2002. Project Opalinus Clay: Safety Report: Demonstration of Disposal Feasibility for Spent Fuel, Vitrified High-Level Waste and Long-Lived IntermediateLevel Waste. NAGRA NTB 02-05. Wettingen, Switzerland: NAGRA. TIC: 254437.

155218 Nitsche, H.; Gatti, R.C.; Standifer, E.M.; Lee, S.C.; Müller, A.; Prussin, T.; Deinhammer, R.S.; Maurer, H.; Becraft, K.; Leung, S.; and Carpenter, S.A. 1993. Measured Solubilities and Speciations of Neptunium, Plutonium, and Americium in a Typical Groundwater (J-13) from the Yucca Mountain Region.LA-12562-MS. Los Alamos, New Mexico: Los Alamos National Laboratory. ACC: NNA.19930507.0136.

144515 Nitsche, H.; Roberts, K.; Prussin, T.; Muller, A.; Becraft, K.; Keeney, D.; Carpenter, S.A.; and Gatti, R.C. 1994. Measured Solubilities and Speciations from Oversaturation Experiments of Neptunium, Plutonium, and Americium in UE-25P \#1 Well Water from the Yucca Mountain Region Milestone Report 3329- 
WBS1 2.3.4.1.3.1.LA-12563-MS. Los Alamos, New Mexico: Los Alamos National Laboratory. TIC: 210589.

153965 Nordstrom, D. K. and Munoz, J. L. 1986. Geochemical Thermodynamics. Palo Alto, CA. Blackwell Scientific. TIC: 208228.

163274 NRC (U.S. Nuclear Regulatory Commission) 2003. Yucca Mountain Review Plan, Final Report. NUREG-1804, Rev. 2. Washington, D.C.: U.S. Nuclear Regulatory Commission, Office of Nuclear Material Safety and Safeguards. TIC: 254568.

159511 Parkhurst, D.L. and Appelo, C.A.J. 1999. User's Guide to PHREEQC (Version 2)A Computer Program for Speciation, Batch-Reaction, One-Dimensional Transport, and Inverse Geochemical Calculations. Water-Resources Investigations Report 994259. Denver, Colorado: U.S. Geological Survey. TIC: 253046.

100486 Pearcy, E.C.; Prikryl, J.D.; Murphy, W.M.; and Leslie, B.W. 1994. "Alteration of Uraninite from the Nopal I Deposit, Pena Blanca District, Chihuahua, Mexico, Compared to Degradation of Spent Nuclear Fuel in the Proposed U.S. High-Level Nuclear Waste Repository at Yucca Mountain, Nevada." Applied Geochemistry, 9, 713-732. New York, New York: Elsevier. TIC: 236934.

161925 Quinones, J.; Grambow, B.; Loida, A.; and Geckeis, H. 1996. "Coprecipitation Phenomena During Spent Fuel Dissolution. Part 1: Experimental Procedure and Initial Results on Trivalent Ion Behaviour." Journal of Nuclear Materials, 238, (1), 38-43. Amsterdam, The Netherlands: Elsevier. TIC: 252663.

144599 Rai, D. and Swanson, J.L. 1981. "Properties of Plutonium(IV) Polymer of Environmental Importance.” Nuclear Technology, 54, (1), 107-112. La Grange Park, Illinois: American Nuclear Society. TIC: 221390.

112060 Rai, D. and Ryan, J.L. 1982. "Crystallinity and Solubility of Pu(IV) Oxide and Hydrous Oxide in Aged Aqueous Suspensions." Radiochimica Acta, 30, 213-216. München, Germany: R. Oldenbourg Verlag. TIC: 219107.

122768 Rai, D 1984. "Solubility Product of Pu(IV) Hydrous Oxide and Equilibrium Constatnts of $\mathrm{Pu}(\mathrm{IV}) / \mathrm{Pu}(\mathrm{V}), \mathrm{Pu}(\mathrm{IV}) / \mathrm{Pu}(\mathrm{VI})$, and $\mathrm{Pu}(\mathrm{V}) / \mathrm{Pu}(\mathrm{VI})$ Couples." Radiochimica Acta, 35, 97-106. Munchen, German: Oldenbourg Verlag. TIC: 219109.

168392 Rai, D.; Moore, D.A.; Felmy, A.R.; Choppin, G.R.; and Moore, R.C. 2001. "Thermodynamics of the $\mathrm{PuO}_{2}{ }^{+}-\mathrm{Na}^{+}-\mathrm{OH}^{-} \mathrm{Cl}^{-} \mathrm{ClO}_{4}{ }^{-}-\mathrm{H}_{2} \mathrm{O}$ System: Use of $\mathrm{NpO}_{2}{ }^{+}$Pitzer Parameters for $\mathrm{PuO}_{2}{ }^{+}$." Radiochimica Acta, 89, ([8]), 491-498. München, Germany: Oldenbourg Wissenschaftsverlag. TIC: 255398.

162536 Roberts, K.E.; Wolery, T.J.; Atkins-Duffin, C.E.; Prussin, T.G.; Allen, P.G.; Bucher, J.J.; Shuh, D.K.; Finch, R.J.; and Prussin, S.G. 2003. "Precipitation of Crystalline Neptunium Dioxide from Near-Neutral Aqueous Solution." Radiochimica Acta, 91, (2), 87-92. München, Germany: Oldenbourg Wissenschaftsverlag. TIC: 254035. 
108567 Robinson, R. A. and Stokes, R. H. 1965. Electrolyte solutions, the measurement and interpretation of conductance, chemical potential and diffusion in solutions of simple electrolytes. 2nd edition (revised). London, England. Butterworths \& Co. TIC: 242575.

168432 Runde, W.; Conradson, S.D.; Efurd, D.W.; Lu, N.P.; VanPelt, C.E.; and Tait, C.D. 2002. "Solubility and Sorption of Redox-Sensitive Radionuclides ( Np, Pu) in J-13 Water from the Yucca Mountain Site: Comparison between Experiment and Theory." Applied Geochemistry, 17, (6), 837-853. New York, New York: Pergamon. TIC: 254046.

153587 Shannon, R.D. 1976. "Revised Effective Ionic Radii and Systematic Studies of Interatomic Distances in Halides and Chalcogenides." Acta Crystallographica, A32, (5), 751-767. Copenhagen, Denmark: Munksgaard International Publishers. TIC: 240561 .

161998 Shibutani, T.; Shibutani, S.; and Yui, M. 1998. Database Development of Chemical Thermodynamics of Protactinium for Performance Assessment of HLW Geological Disposal System. Tokyo, Japan: Tokai Works, Power Reactor and Nuclear Fuel Development Corporation. TIC: 251126.

112092 Silva, R.J. and Nitsche, H. 1995. “Actinide Environmental Chemistry." Radiochimica Acta, 70/71, 377-396. München, Germany: R. Oldenbourg Verlag. TIC: 243223.

102087 Silva, R.J.; Bidoglio, G.; Rand, M.H.; Robouch, P.B.; Wanner, H.; and Puigdomenech, I. 1995. Chemical Thermodynamics of Americium. Volume 2 of Chemical Thermodynamics. Amsterdam, The Netherlands: Elsevier. TIC: 237106.

161956 Steinborn, T.L.; Wolery, T.J.; Alcorn, S.R.; Arthur, S.E.; Bernot, P.A.; Brady, P.V.; Chen, Y.; Domski, P.S.; Jolley, D.M.; Metcalf, R.C.; and Thomas, E. 2003. Data Qualification: Update and Revision of the Geochemical Thermodynamic Database, Data0.ymp. TDR-EBS-MD-000022 REV 00. Las Vegas, Nevada: Bechtel SAIC Company. ACC: DOC.20030331.0003.

125332 Stumm, W. and Morgan, J.J. 1996. Aquatic Chemistry, Chemical Equilibria and Rates in Natural Waters. 3rd Edition. New York, New York: John Wiley \& Sons. TIC: 246296.

168394 Toth, L.M.; Friedman, H.A.; and Osborne, M.M. 1983. "Aspects of Plutonium(IV) Hydrous Polymer Chemistry." Chapter 15 of Plutonium Chemistry. Carnall, W.T. and Choppin, G.R., eds. ACS Symposium Series 216. Washington, D.C.: American Chemical Society. TIC: 219103.

170136 Truesdell, A.H. and Jones, B.F. 1974. "WATEQ, A Computer Program for Calculating Chemical Equilibria of Natural Waters." Journal of Research of the U.S. Geological Survey, Vol. 2, (No. 2), 233-248. Denver, CO: U.S. Geological Survey. TIC: 224163. 
159216 Wagman, D.D.; Evans, W.H.; Parker, V.B.; Schumm, R.H.; Halow, I.; Bailey, S.M.; Churney, K.L.; and Nuttall, R.L. 1982. "The NBS Tables of Chemical Thermodynamic Properties, Selected Values for Inorganic and $\mathrm{C}_{1}$ and $\mathrm{C}_{2}$ Organic Substances in SI Units." Journal of Physical and Chemical Reference Data, 11, (Supplement No. 2), Pages 2-276 and 2-282. Washington, D.C.: American Chemical Society. TIC: 239715.

113466 Werme, L.O. and Spahiu, K. 1998. "Direct Disposal of Spent Nuclear Fuel: Comparison Between Experimental and Modelled Actinide Solubilities in Natural Waters." Journal of Alloys and Compounds, 271-273, 194-200. Lausanne, Switzerland: Elsevier. TIC: 243085.

100949 Wilson, C.N. 1990a. Results from NNWSI Series 2 Bare Fuel Dissolution Tests. PNL-7169. Richland, Washington: Pacific Northwest Laboratory. ACC: NNA.19900814.0048.

100793 Wilson, C.N. 1990b. Results from NNWSI Series 3 Spent Fuel Dissolution Tests. PNL-7170. Richland, Washington: Pacific Northwest Laboratory. ACC: NNA.19900329.0142.

100836 Wolery, T.J. 1992. EQ3NR, A Computer Program for Geochemical Aqueous Speciation-Solubility Calculations: Theoretical Manual, User's Guide, and Related Documentation (Version 7.0). UCRL-MA-110662 PT III. Livermore, California: Lawrence Livermore National Laboratory. ACC: MOL.19980717.0626.

100493 Wronkiewicz, D.J.; Bates, J.K.; Gerding, T.J.; Veleckis, E.; and Tani, B.S. 1992. "Uranium Release and Secondary Phase Formation During Unsaturated Testing of $\mathrm{UO}_{2}$ at $90^{\circ} \mathrm{C}$." Journal of Nuclear Materials, 190, 107-127. Amsterdam, The Netherlands: North-Holland Publishing Company. TIC: 236558.

102047 Wronkiewicz, D.J.; Bates, J.K.; Wolf, S.F.; and Buck, E.C. 1996. "Ten-Year Results from Unsaturated Drip Tests with $\mathrm{UO}_{2}$ at $90^{\circ} \mathrm{C}$ : Implications for the Corrosion of Spent Nuclear Fuel." Journal of Nuclear Materials, 238, (1), 78-95. Amsterdam, The Netherlands: North-Holland Publishing Company. TIC: 243361.

162664 Yui, M.; Azuma, J.; and Shibata, M. 1999. JNC Thermodynamic Database for Performance Assessment of High-Level Radioactive Waste Disposal System. JNC TN8400 99-070. Tokyo, Japan: Tokai Works, Japan Nuclear Cycle Development Institute. TIC: 251129.

\subsection{CODES, STANDARDS, REGULATIONS, AND PROCEDURES}

15660510 CFR 63. Energy: Disposal of High-Level Radioactive Wastes in a Geologic Repository at Yucca Mountain, Nevada. Readily available.

AP-2.12Q, Rev. 0, ICN 4. Peer Review. Washington, D.C.: U.S. Department of Energy, Office of Civilian Radioactive Waste Management. ACC:

MOL.20020619.0084. 
AP-2.22Q, Rev. 1. Classification Criteria and Maintenance of the Monitored Geologic Repository Q-List. Washington, D.C.: U.S. Department of Energy, Office of Civilian Radioactive Waste Management. ACC: DOC.20030807.0002.

AP-2.27Q, Rev. 1, ICN 4. Planning for Science Activities. Washington, D.C.: U.S. Department of Energy, Office of Civilian Radioactive Waste Management. ACC: DOC.20040610.0006.

LP-SI.11Q-BSC REV.000. Software Management. Washington, D.C.: U.S. Department of Energy, Office of Civilian Radioactive Waste Management. ACC: DOC.20040225.0007

AP-SIII.10Q, Rev. 2, ICN 5. Models. Washington, D.C.: U.S. Department of Energy, Office of Civilian Radioactive Waste Management. ACC: DOC.20040615.0003.

105725 ASTM C 1174-97. 1998. Standard Practice for Prediction of the Long-Term Behavior of Materials, Including Waste Forms, Used in Engineered Barrier Systems (EBS) for Geological Disposal of High-Level Radioactive Waste. West

Conshohocken, Pennsylvania: American Society for Testing and Materials. TIC: 246015.

\subsection{SOURCE AND CORROBORATIVE DATA, LISTED BY DATA TRACKING NUMBER}

160899 GS020408312272.003. Collection and Analysis of Pore Water Samples for the Period from April 2001 to February 2002. Submittal date: 04/24/2002.

149202 LA0004AM831234.001. Flow-Through Cell Measurements for NC-EWDP-01S, 22Feb-99 and 23-Feb-99. Submittal date: 04/17/2000.

149213 LA0004AM831234.002. Downhole Probe Measurements for NC-EWDP-03S, 23Feb-99. Submittal date: 04/17/2000.

160051 LA0206AM831234.001. Eh-pH Field Measurements on Nye County EWDP Wells. Submittal date: 06/21/2002.

149196 LA9907AM831234.003. Downhole Eh and pH Measurements for NC-EWDP-01D, 11-Jan-99. Submittal date: 01/27/2000.

149209 LA9907AM831234.009. Flow-through Cell Measurements for NC-EWDP-01S, NCEWDP-03S, NC-EWDP-09SX, 5/17/99, 5/18/99, 5/19/99, 5/20/99. Submittal date: $01 / 27 / 2000$

149210 LA9907AM831234.010. Flow-Through Cell Measurements for SD6-ST1, 2-Jun-99 and 8-Jun-99. Submittal date: 01/27/2000.

168347 LAAM831311AQ98.003. Downhole Eh and pH Measurements for UE-25 WT\#17. Submittal date: 09/14/1998. 
168346 LAAM831311AQ98.004. Downhole Eh and pH Measurements for UE-25 WT\#3. Submittal date: 09/14/1998.

149181 LAAM831311AQ98.005. Geochemical Field Measurements for UE-25 WT\#17, 27Jan-98. Submittal date: 09/14/1998.

149520 LAAM831311AQ98.007. Flow-Thru Cell and Static Measurements at UE-25 WT\#3, 22-Jun-98. Submittal date: 09/14/1998.

149521 LAAM831311AQ98.008. Analysis of Bailed Sample for UE-25 WT\#17, 04 Jun 98. Submittal date: 09/14/1998.

168348 LAAM831311AQ98.009. Flow through Cell Measurements for UE-25 WT\#17, 01Jul-98. Submittal date: 09/14/1998.

129285 LL991001251021.090. Draft - CSNF Waste Form Degradation: Unsaturated Drip Tests - G2020 Analysis and Modeling Report. Submittal date: 10/04/1999.

151029 MO0006J13WTRCM.000. Recommended Mean Values of Major Constituents in J13 Well Water. Submittal date: 06/07/2000.

169187 MO0404SPAIPCHM.005. Abstractions of In-Package Chemistry for TSPA-LA. Submittal date: 04/29/2004.

161756 MO0302SPATHDYN.000. Thermodynamic Data Input Files - Data0.YMP.R2. Submittal date: $02 / 05 / 2003$.

170760 MO0407SEPFEPLA.000. LA FEP List. Submittal date: 07/20/2004.

152993 SN0011T0810599.023. Final Waste Package Radionuclide Inventory Approximations for Total System Performance Assessment-Site Recommendation (TSPA-SR). Submittal date: 11/01/2000.

\subsection{OUTPUT DATA, LISTED BY DATA TRACKING NUMBER}

MO0408SPADCLRE.000. Dissolved Concentration Limits of 14 Radioactive Elements for LA. Submittal Date: 08/27/2004.

\subsection{SOFTWARE CODES}

161900 Software Code: GetEQData. V1.0.1. PC w/Windows 2000. 10809-1.0.1-0.

153964 Software Code: EQ3/6. V7.2b. UCRL-MA-110662 (LSCR198).

155520 Software Routine: BUILDEQ3.BAS. V1.0. PC, Windows NT 4.0. 10365-1.00-00.

159731 Software Code: EQ6, Version 7.2bLV. PC. 10075-7.2bLV-00. Windows NT, 2000. 


\section{APPENDIX I}

\section{CD-ROM}




\section{INTENTIONALLY LEFT BLANK}


APPENDIX II

LIST OF COMPUTER FILES 
INTENTIONALLY LEFT BLANK 


\section{LIST OF COMPUTER FILES}

This appendix contains the name and size of the zip file placed on the electronic media (Appendix I). Winzip 8.1 was used to compress the files.

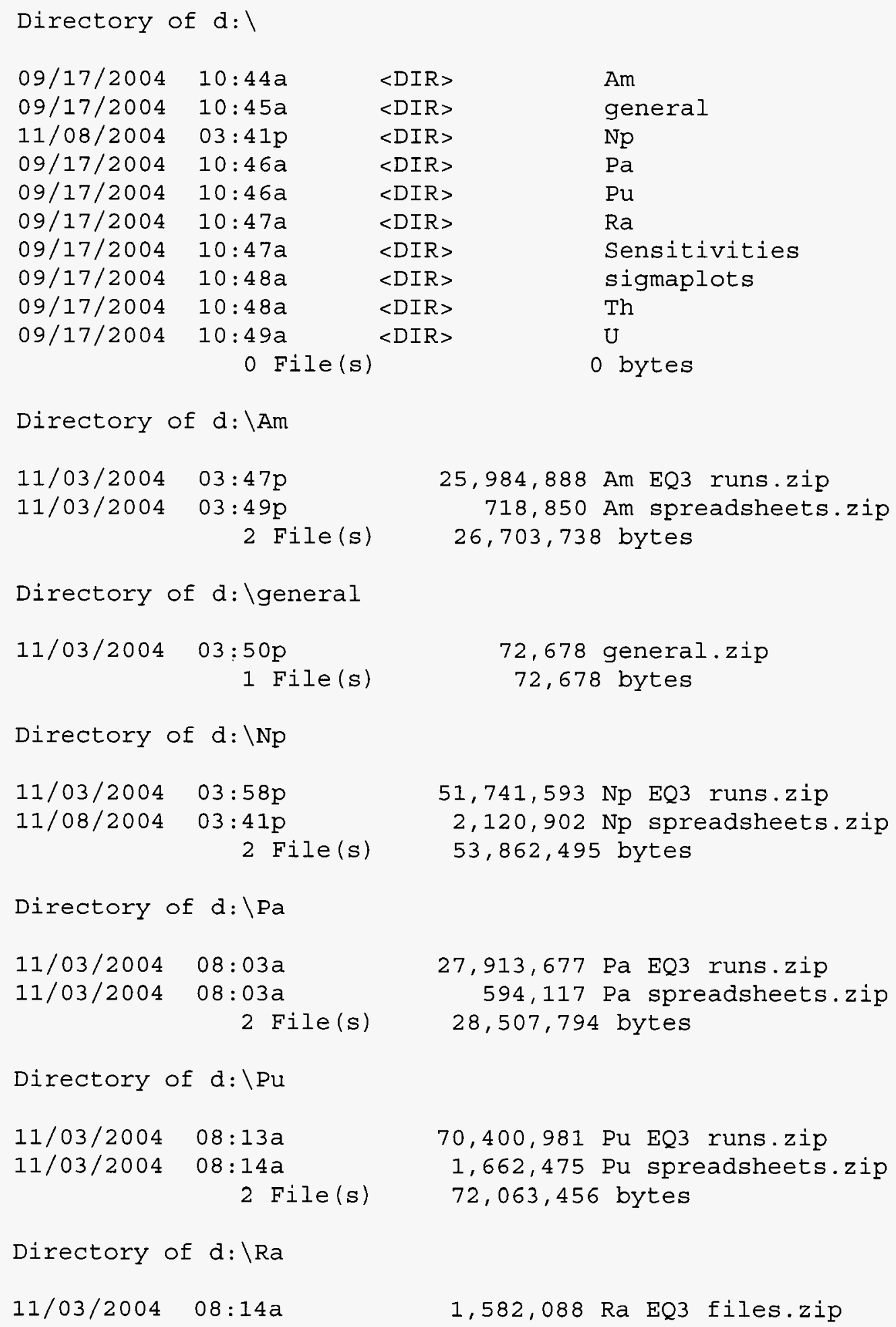

Directory of $d: \backslash P u$ 


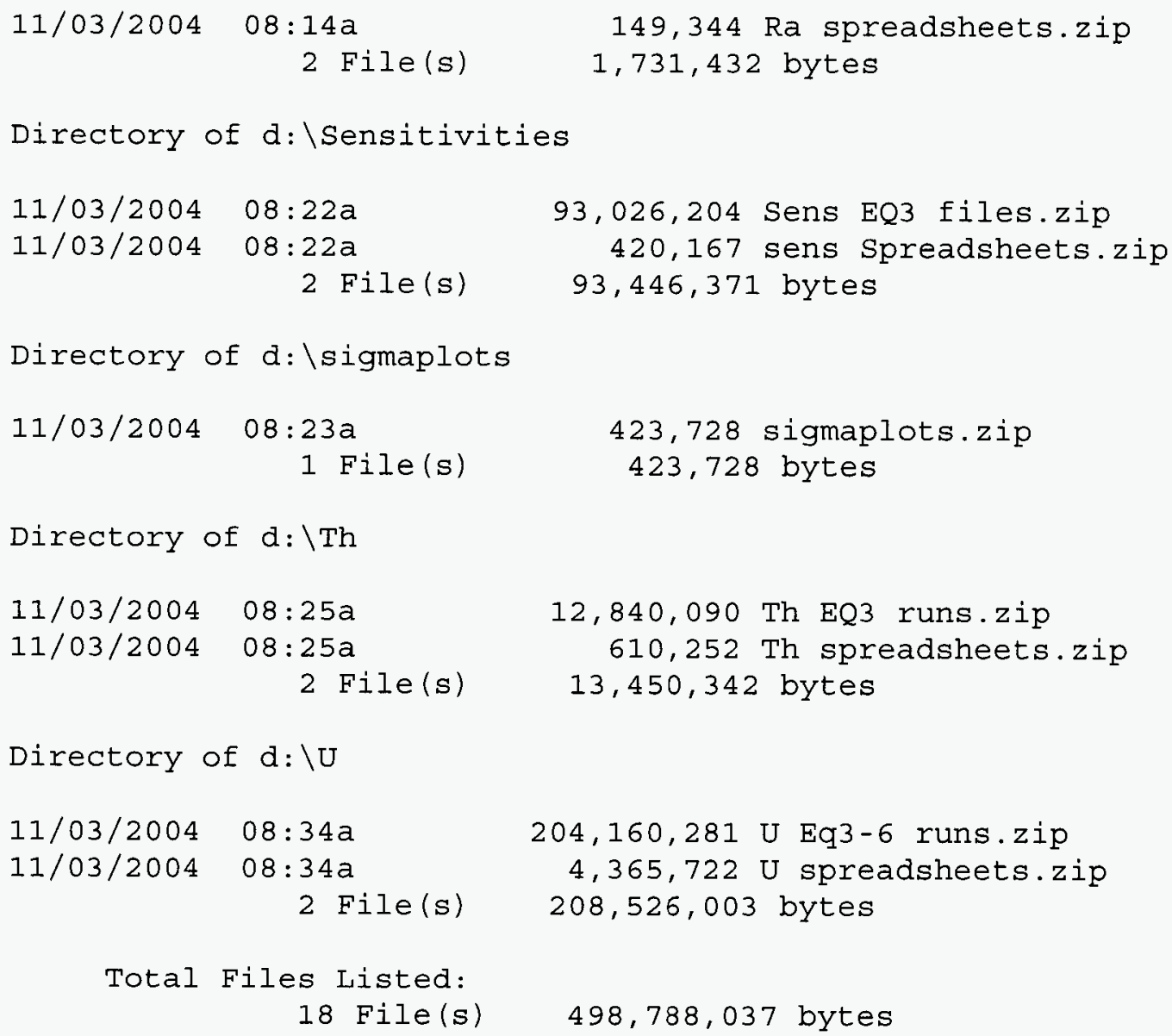

The zip files contain files of various types:

Excel files (extensions $=$ xls $)$

EQ3 input files (extension $=3 \mathrm{i}$ )

EQ6 input files $($ extension $=6 \mathrm{i})$

ASCII text file: provides input parameters for EQ3

EQ3 output files $($ extension $=30)$

EQ6 output files $($ extension $=60)$

ASCII text file: provides detailed information about the system at each print point, which is specified by the user in the input file

EQ3/6 text data files used for the calculations, Data0.ymp.R2 and Data0.yc3.R1

Winzip files (extension $=$ zip). 


\section{APPENDIX III \\ EVALUATION OF DISSOLVED CONCENTRATION LIMITS OF NEPTUNIUM AND PLUTUTONIUM}


INTENTIONALLY LEFT BLANK 


\section{EVALUATION OF DISSOLVED CONCENTRATION LIMITS OF NEPTUNIUM AND PLUTUTONIUM}

The following evaluation was performed by Greg Choppin (GC) on 8/20/2004 under direction from Technical Work Plan for: Regulatory Integration Modeling and Analysis of the Waste Form and Waste Package (BSC 2004 [DIRS 171583]). The evaluation raised several questions that were answered by Patricia A. Bernot $(\mathrm{PAB})$ below:

This is a review of Sections 6.5 (Plutonium Solubility) and 6.6 (Neptunium Solubility).

To answer the two principle questions:

1. Do the treatments of the kinetic and thermodynamic factors adequately capture the behavior of the radionuclides over geologic timeframes?

- (GC) The treatment of the thermodynamic and with kinetic factors is somewhat brief, especially if geologic times are considered. The text associated for Sections 6.5 and 6.6 speak of the effects of $\mathrm{CO}_{3}{ }^{2-}, \mathrm{OH}^{-}, \mathrm{F}^{-}$complexation but do not cite the stability constants and the ionic strength associated with these, in the modeling. Earlier, I had reviewed some of the reports and publications used in some of the model calculations for $\mathrm{Pu}$ but did not have time today to check these. To allow validation of these reports for the $\mathrm{NRC}$, some better documentation of the values used in modeling seems necessary. Also, in this report there is no evaluation of the effect of ionic strength or temperature on these modeling parameters - both in the thermodynamics and the kinetics. If the evaluation is to be for time spans of millennia, this seems very necessary. The treatment of the thermodynamic modeling for solubility and speciation is probably acceptable for $298^{\circ} \mathrm{C}$ (where most complexation constants have been measured) but questionable if YMT is a "hot repository." Similarly, the kinetics of solubility, redox, complexation, etc. are very temperature dependent. Whenever kinetics are discussed for speciation or solubility modeling, or both, the temperature must be cited and the effects of temperature change over time should be included in the calculations.

- (PAB) It is recognized that actinide solubility is very complex and depends upon temperature, $\mathrm{pH}$, fugacity of $\mathrm{CO}_{2}$ and $\mathrm{O}_{2}$, etc. The effects of these parameters on solubility limits of elements with radioactive isotopes are only given a brief overview in Chapters 6.5 and 6.6 since they are covered elsewhere in the report. Sections 6.3 and 6.4 provide discussions on the effects that different conditions have on solubilities. These include temperature, oxidation potential, $\mathrm{pH}, \mathrm{CO}_{2}$ fugacity, and water composition. Fugacity of $\mathrm{CO}_{2}$ and $\mathrm{pH}$ are already taken into account in model outputs, which present solubility limits as a function of $\mathrm{pH}$ and $\mathrm{CO}_{2}$ fugacity. Justification for solubility modeling at atmospheric oxygen levels and ambient temperatures are outlined in Sections 6.4.2.1 and 6.4.2.2, respectively. The effects of water chemistry are studied in depth in a sensitivity analysis presented in Section 6.4.2.5. Any ions (such as fluoride) shown to have a large effect on solubilities are included as an uncertainty term in the model as indicated in Section 6.4.3.6. Time also plays a crucial factor in determining solubility limits. It 
is impossible to know for what time periods a kinetic system will dominate over a thermodynamically stable system in a repository over geologic time scales. For this reason, modeling uses conservative bases to choose solubility controlling phases and aqueous species.

2. Is the value for Eh implemented in the model consistent with conditions expected in the repository over geologic timeframes?

- (GC) Evaluation of $E_{h}$ effects is difficult. In natural systems, the measured $E_{h}$ for the aquatic media is often irrelevant for modeling of the behavior of metal ion systems due to localized conditions. Sorbed materials (e.g., humic material, biota etc.) can induce redox behaviors not related to the gross $E_{h}$ of the solution. As a result, it is difficult to predict redox behavior in environmental systems. This would become more of a problem over time as the repository ages and conditions change. The $E_{h}$ effect in homogenous true solutions (no colloids or suspended material) is usually predictable but the abnormal redox occurs on surfaces of colloids etc.. Since, in a repository, colloids and suspended material is most likely, calculations of speciation, etc. based on $E_{h}$ values for true solutions is to be treated with caution. If $E_{h}$ is accepted in the YMT systems, the calculations in Sections 6.5 and 6.6 seem well done. Nevertheless, the reliability of such calculations in this case should be discussed.

- (PAB) As indicated in Section 6.4.2.1, the repository is designed so the waste is under atmospheric conditions except in isolated local situations. Thus, oxidizing conditions are assumed as indicated in Section 5.1. Additionally, solubility limits of elements with radioactive isotopes are known to be less soluble in reduced conditions than in fully oxidized systems. Therefore, the treatment of solubilities in a fully oxidized system is conservative and is indicated as such in the report.

At a later time, Dr. Choppin also brought up a concern related to the clarity of what the report defines as colloidal and dissolved Pu. This was answered by addition of text to the second paragraph of Section 6.5.1.

Concurrence with the text changes and answers to concerns is located in Section 7.2.1. 

$G A: Q A$

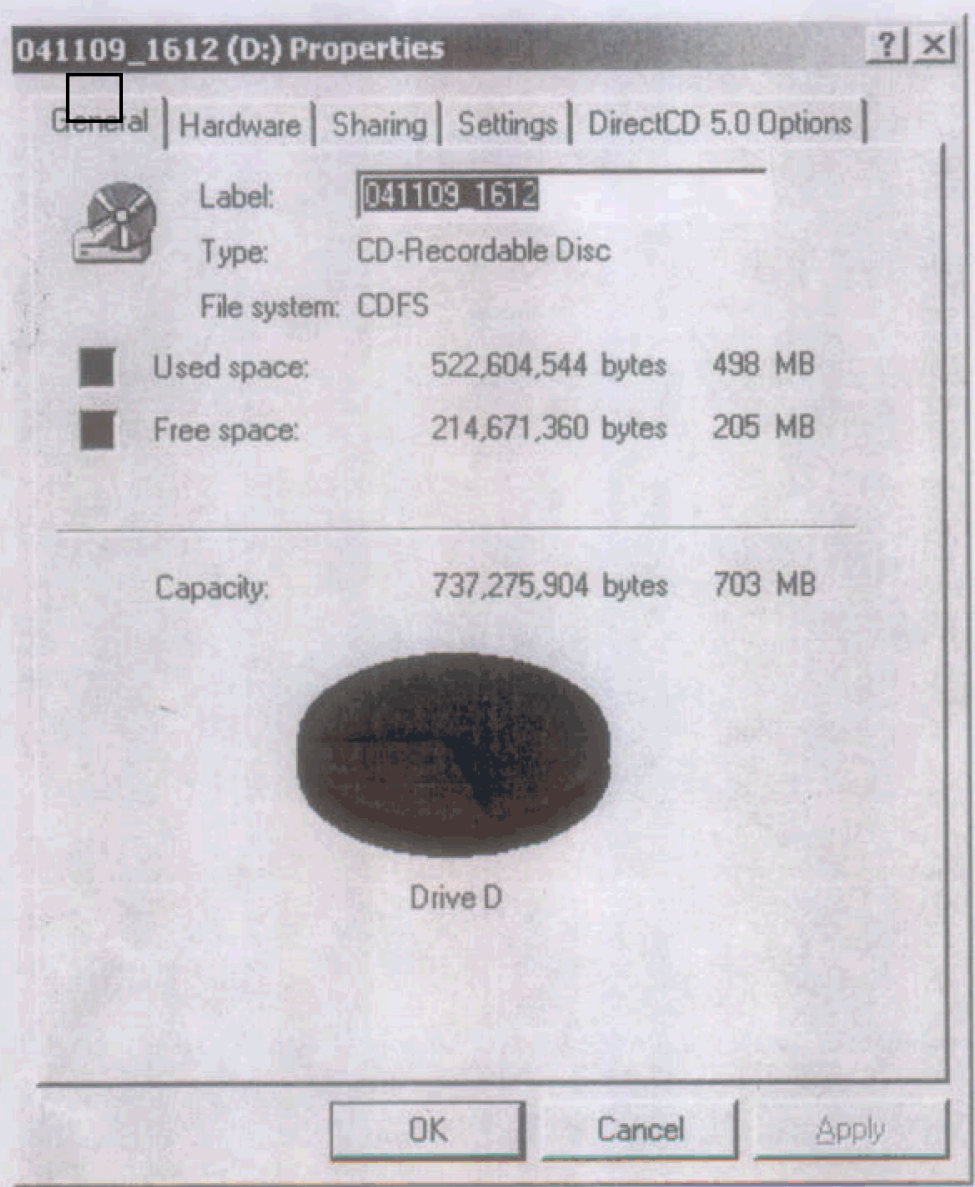

\section{9_1612 (D:) Properties}

General| Hardware Sharing |Settings | DirectCD 5.00ptions |

$\infty$

You can share this folder among other users on your network. To enable sharing for this folder, click Share this foldet.

Do not share this folder

c. Share this folder

Share name: D

Comment:

User limit:

$$
\begin{aligned}
& \text { C Maximum allowed } \\
& \text { Allow }
\end{aligned}
$$

To set permissions for how users access this folder over the network, click Permissions.

Permissions

To configure settings for Offline access to this shared folder, click Caching.

Caching

New Share
041109_1612 (Di) Properties

General Hardware |Sharing | Settings | DirectCD 5.0 Options |

All disk dives:

\begin{tabular}{|l|l|}
\hline Name & Type \\
\hline WDCWD4008B-75CA40 & Disk dives \\
\hline Floppy disk drive & Floppy disk... \\
3)HL-DT-ST RW/DVD GCC-4240N & DVD/CD-A...
\end{tabular}

- Device Properties

Manufacturer: [Standard disk drives]

Hardware Revision: Not available

Location: Location $0(0)$

Device Status: This device is working properly.

Iroubleshoot... Ploperties

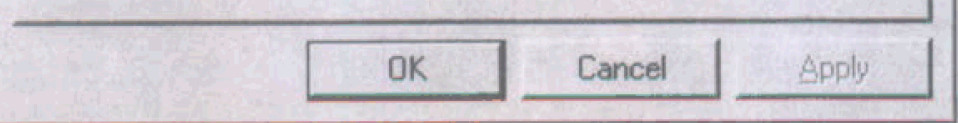

\section{9_1612 (D) Properties}

General | Hardware | Sharing Seltings | DirectCD 5.00ptions |

- Device: Unlocked

Name: HL-DT-ST RW/DVD GCC-4240N

Type: CD-RW drive Firmware revision: D110

Target ID: 0

Logical unit number: 0

\section{- Media Type:}

None. with read-only files/folders. This disc can be converted for read and write access.

$\begin{aligned} \text { Device Access Speed: } & \\ \text { Current Pead Speed: } & 24 \times \text { Max } \\ \text { Current Write Speed: } & 24 \times \text { Max }\end{aligned}$

\section{OK} Cancel Apply 


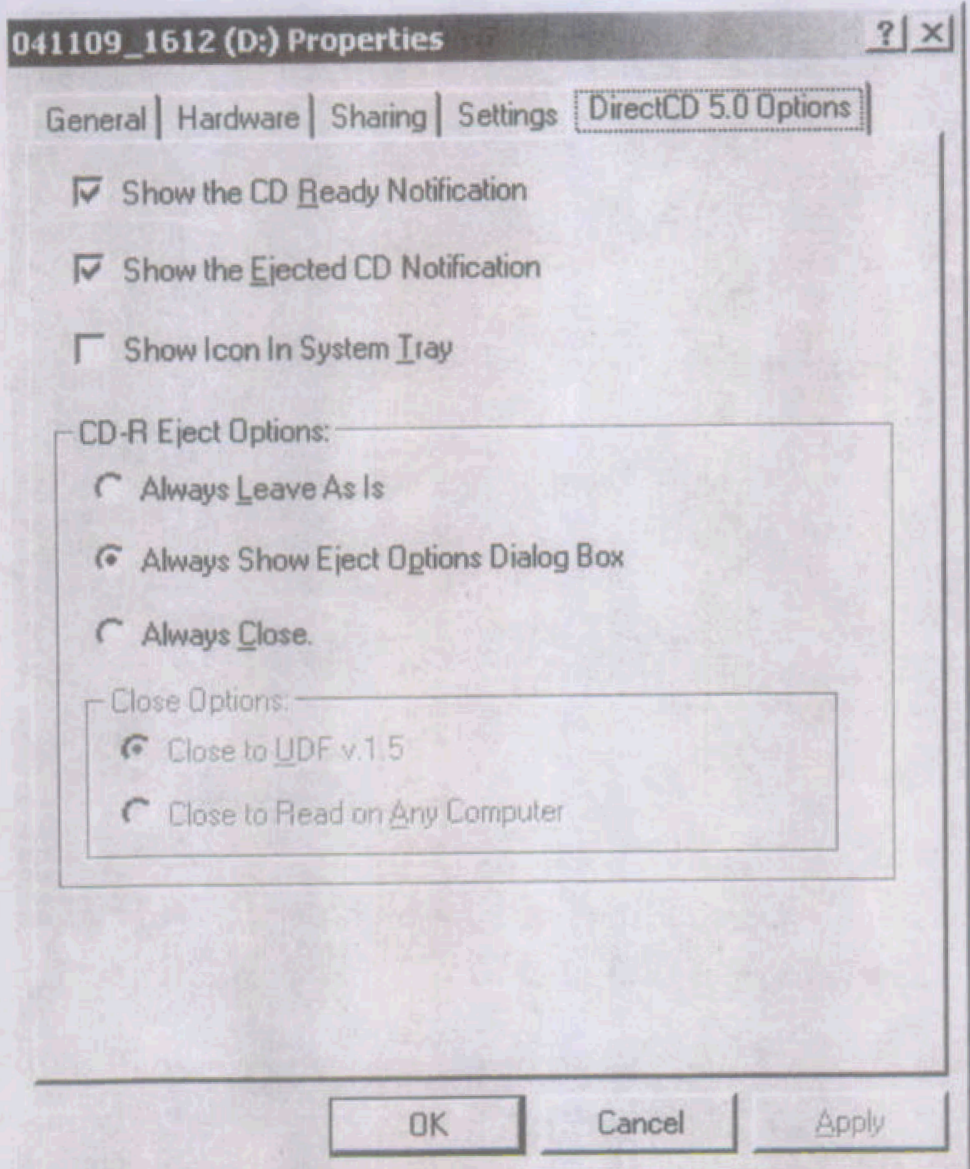

\section{U,...Properties}

General |

18 Files, 10 Folders

Type: $\quad$ All of type File Folder

Location: All in D:!

Size: $\quad 475$ MB $(498,788,037$ bytes $)$

Size on disk: $\quad 475$ MB ( $498,802,688$ bytes)

$\begin{array}{ll}\text { Attributes } & \nabla \nabla \text { Read-only } \\ & \Gamma \text { Hidden } \\ & \Gamma \text { Archive }\end{array}$

OK

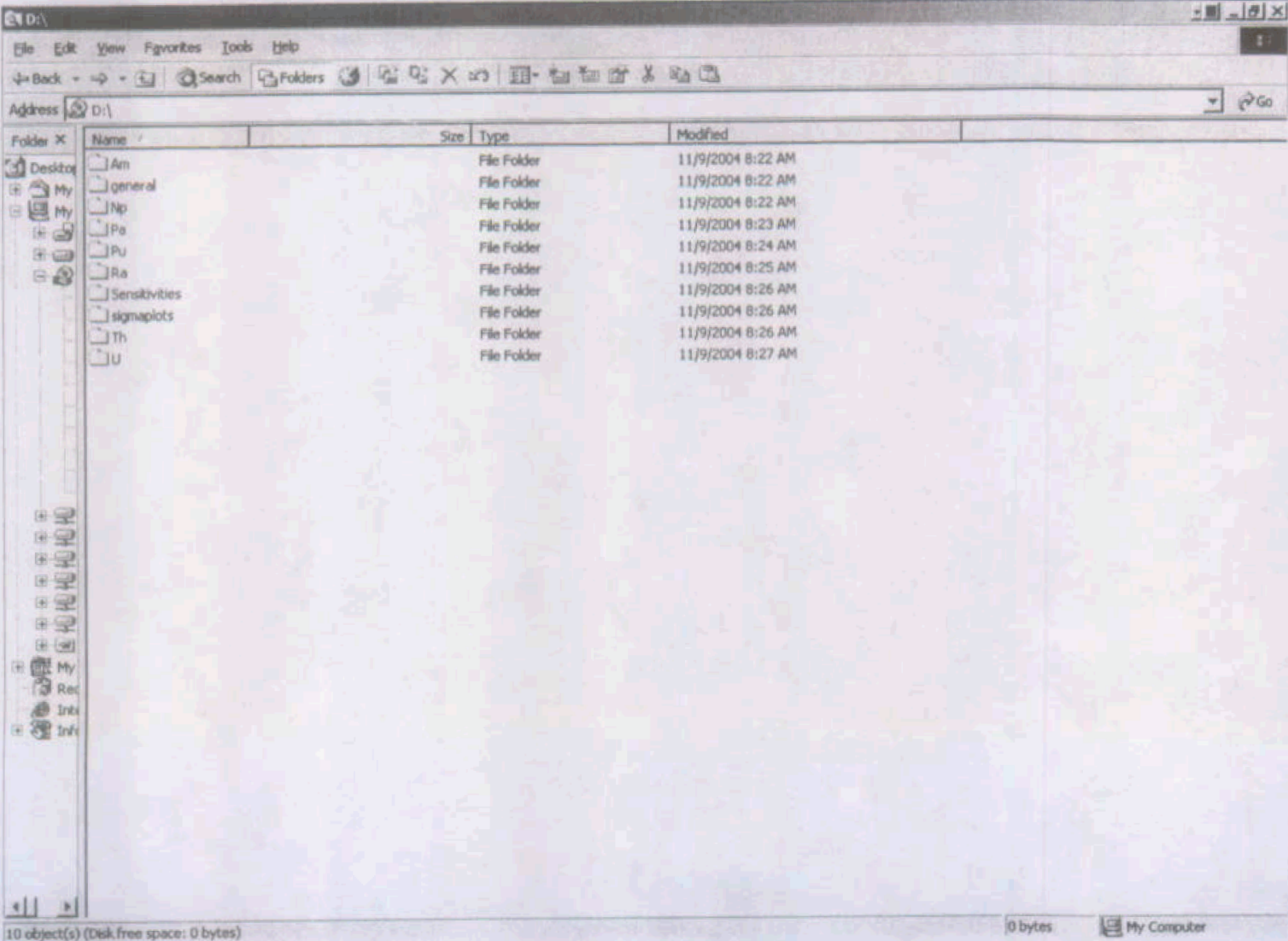




\section{LIST OF COMPUTER FILES}

This appendix contains the name and size of the zip file placed on the electronic media (Appendix I). Winzip 8.1 was used to compress the files.

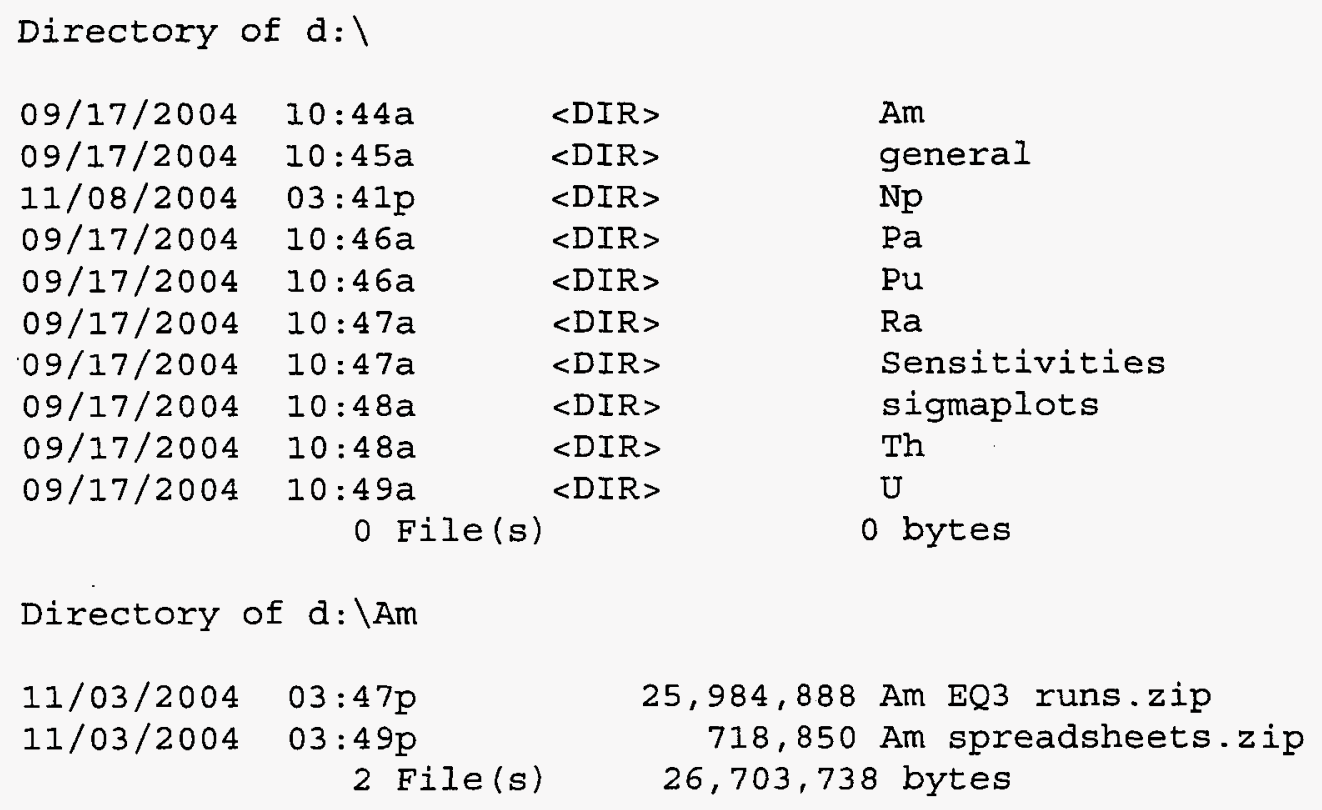

$<\mathrm{DIR}>$$$
<\mathrm{DIR}>
$$$$
<\mathrm{DIR}>
$$$$
<\mathrm{DIR}>
$$$$
<\text { DIR }>
$$

<DIR>

$<D I R>$

$<\mathrm{DIR}>$

$<D I R>$ $\langle\mathrm{DIR}>$

0 bytes

Directory of $d: \backslash A m$
$11 / 03 / 2004 \quad 03: 47 \mathrm{p}$
$11 / 03 / 2004 \quad 03: 49 p$
2 File (s)

Directory of $\mathrm{d}$ : Igeneral
11/03/2004 03:50p
1 File (s)

Directory of $d: \backslash N p$

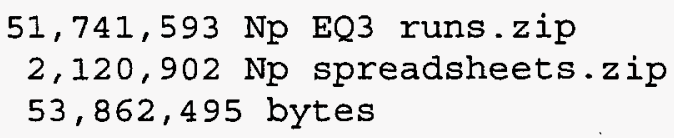

Directory of $\mathrm{d}: \backslash \mathrm{Pa}$

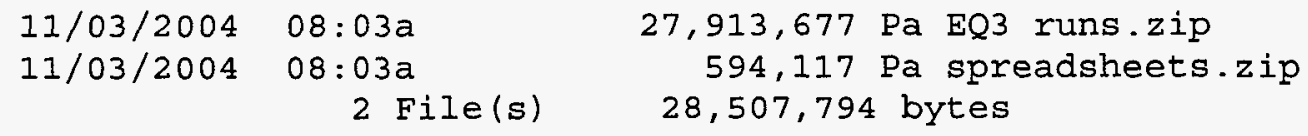

Directory of $d: \backslash R a$
$11 / 03 / 2004 \quad 08: 14 a$
1,582,088 Ra EQ3 files.zip 


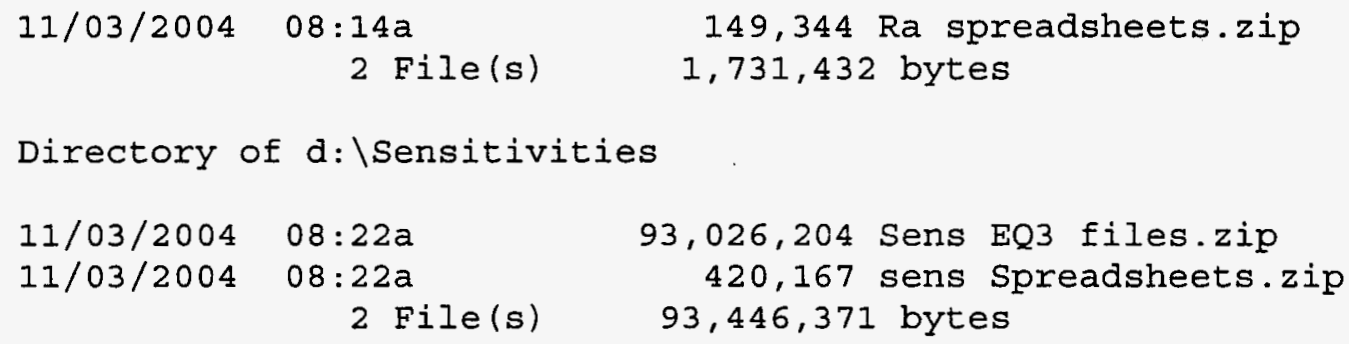

Directory of d: Isigmaplots
$11 / 03 / 2004$
$08: 23 a$
1 File (s)
423,728 sigmaplots.zip
423,728 bytes

Directory of $d: \backslash T h$

$11 / 03 / 2004 \quad 08: 25 a$

$11 / 03 / 2004 \quad 08: 25 a$

2 File(s)

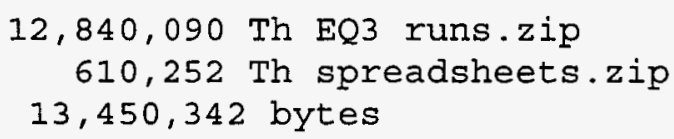

Directory of $d: \backslash U$
$11 / 03 / 2004$
$08: 34 a$
$11 / 03 / 2004$
$08: 34 a$
2 File(s)
Total Files Listed:

$$
18 \text { File(s) } \quad 498,788,037 \text { bytes }
$$

The zip files contain files of various types:

Excel files $($ extensions $=\mathrm{xls})$

EQ3 input files (extension $=3 \mathrm{i})$

EQ6 input files $($ extension $=6 \mathrm{i})$

ASCII text file: provides input parameters for EQ3

EQ3 output files (extension $=30)$

EQ6 output files $($ extension $=60)$

ASCII text file: provides detailed information about the system at each print point, which is specified by the user in the input file

EQ3/6 text data files used for the calculations, Data0.ymp.R2 and Data0.yc3.R1

Winzip files (extension $=$ zip) . 